THIAGO DOS SANTOS GARCIA

\title{
AVALIAÇÃO DO CONFORTO TÉRMICO DOS APARTAMENTOS DO BNH DA CIDADE DE SANTOS.
}

São Paulo 


\section{THIAGO DOS SANTOS GARCIA}

\section{AVALIAÇÃO DE CONFORTO TÉRMICO DOS APARTAMENTOS DO BNH DA CIDADE DE SANTOS.}

Dissertação apresentada à Escola

Politécnica da Universidade de São

Paulo para obtenção do título de mestre.

São Paulo

2015 


\section{THIAGO DOS SANTOS GARCIA}

\section{AVALIAÇÃO DE CONFORTO TÉRMICO DOS APARTAMENTOS DO BNH DA CIDADE DE SANTOS.}

Dissertação apresentada à Escola

Politécnica da Universidade de São Paulo.

Área de Concentração: Engenharia da Construção Civil e Urbana

Orientador: Professor Associado

Racine Tadeu Araujo Prado

São Paulo 
Este exemplar foi revisado e corrigido em relação à versão original, sob responsabilidade única do autor e com a anuência de seu orientador.

São Paulo, 03 de Julho de 2015

Assinatura do autor:

Assinatura do orientador:

GARCIA, Thiago dos Santos

AVALIAÇÃO DO CONFORTO TÉRMICO DOS APARTAMENTOS DO BNH DA CIDADE DE SANTOS. / T. S. GARCIA -- versão corr. -- São Paulo, 2015. $162 \mathrm{p}$.

Dissertação (Mestrado) - Escola Politécnica da Universidade de São Paulo. Departamento de Engenharia de Construção Civil.

1.Conforto Térmico 2. Habitação de Interesse Social 3.BNH Santos-SP 4.Conforto Ambiental no Ambiente Construído 5.Simulação de Conforto Térmico I.Universidade de São Paulo. Escola Politécnica. Departamento de Engenharia de Construção Civil II.t. 


\section{RESUMO}

Boas alternativas nas escolhas de materiais construtivos em um projeto arquitetônico possibilitam de forma mais assertiva os aspectos de conforto térmico em habitações de interesse social. A existência de normas que determinem alguns parâmetros de conforto térmico não significa que a unidade habitacional esteja dentro dos parâmetros ideais, já que dependem de bons projetos, correta execução da obra e estarem adequadas às restrições econômicas dos usuários. Esta pesquisa teve como motivação revelar as reclamações dos usuários referentes ao conforto térmico no interior das unidades habitacionais do BNH de Santos, construído em 1969 , identificando quais eram os principais problemas térmicos ocorridos nestas unidades habitacionais. $O$ objetivo desta pesquisa é verificar se os usuários encontram-se dentro dos padrões de conforto térmico estabelecidos por normas existentes e recomendar possíveis soluções que colaborem para que os apartamentos estejam dentro dos parâmetros de conforto térmico adequados. Através de relatos dos usuários, foi proposta uma medição no local cuja finalidade era identificar se havia compatibilidade entre os resultados obtidos na APO aplicada com os resultados medidos e identificar se estas compatibilidades aplicavam-se as normas de conforto térmico existentes. Simulações no software energyplus foram realizadas com a finalidade de propor melhorias projetuais nos apartamentos que estivessem em desconforto térmico. Os resultados mostram que a maioria dos usuários entende que, ao longo do ano, os apartamentos possuem temperaturas elevadas, gerando desconforto térmico. Estes desconfortos ocorrem possivelmente à ocupação de cada apartamento, além da influência da radiação solar direta que cada apartamento recebe ao longo do dia.

Palavras-Chave: Conforto Térmico; Conforto Ambiental, Simulação de conforto térmico; Habitação de Interesse Social. 


\begin{abstract}
The current wide range of alternatives in building materials makes it possible for architects to have greater control over aspects affecting thermal comfort in their designs for social dwelling. The existence of rules governing thermal comfort parameters does not mean that dwelling units are always constructed within the optimal parameters, as this depends on the quality of projects, the correct execution of construction work, and the economic constraints of users. This study was motivated by user complaints relating to thermal comfort inside the BNH Santos dwelling units, which were built in 1969. These complaints identify the main thermal problems occurring in the dwellings units. The objective of this research is to verify whether users live within the existing standards for thermal comfort, and to recommend possible solutions so that the apartments can all be within proper thermal comfort parameters. Based on reports from users, measurements were taken on site to determine whether there was compatibility between the results obtained in the POE and the measured results, and to identify whether any compatibilities applied to existing standards of thermal comfort. Energyplus software simulations were carried out, in order to determine proposed improvements to apartments whose inhabitants were experiencing thermal discomfort. The results show that most users understand that, during the year, the apartments have high temperatures that generate thermal discomfort. This discomfort may occur as a result of the occupation of each apartment, and may go beyond the influence of the direct sunlight that each apartment receives throughout the day.
\end{abstract}

Keywords: Thermal comfort, environmental comfort, thermal comfort simulation, social dwelling. 


\section{DEDICATÓRIA}

Dedico este trabalho a Deus, aos meus pais, a minha filha Sofia e a minha esposa Mariana, pela paciência e confiança ao longo destes anos de crescimento acadêmico. 


\section{AGRADECIMENTOS}

Agradeço ao meu orientador, professor Racine T. A. Prado, pelo acolhimento, confiança, ensinamentos e incentivo à realização deste trabalho.

À Escola Politécnica da Universidade de São Paulo pela oportunidade.

Aos moradores do Conjunto Habitacional Castelo Branco, que permitiram minha "invasão" em suas residências e sempre me receberam com todo respeito, sem vocês, esta pesquisa não teria acontecido.

Às colegas da sala Asteroide, Débora Cavalheiro e Lidiane Oliveira pelas informações extras a pesquisa.

Às colegas do Laboratório de Sistemas Prediais, Débora Costa e Elaine Gonçalves, pelas trocas de informações e pelas trocas de ensinamentos técnicos.

Aos professores Alberto Hernandez Neto e Arlindo Tribess por toda a ajuda na bibliografia deste trabalho.

À Coordenação de Aperfeiçoamento de Pessoal de Nível Superior (CAPES), pela bolsa concedida à pesquisa.

À minha esposa, Mariana Pereira Melzi, pelos três anos de ajuda, em todas as esferas da minha vida, que muito além de minha mecenas, foi minha grande incentivadora, amiga e companheira, registro aqui o meu muito obrigado.

Às professoras Maria Akutsu e Lucila Labaki por todas as contribuições posteriores a defesa, que foram de grande valia para o fechamento desta pesquisa.

A todos que de alguma forma contribuíram para que este trabalho pudesse ser realizado. 
"Feliz aquele que transfere o que sabe e aprende o que ensina".

Cora Coralina. 


\section{LISTA DE ILUSTRAÇÕES}

Figura 1: BNH de Santos. Fonte: Arquivo pessoal. 36

Figura 2: Conjunto do Rincão, Vila Matilde - São Paulo. Fonte: BONDUKI, 2014 ...37 Figura 3: Implantação do projeto original do BNH de Santos. Fonte: Revista Acrópole $n^{\circ} 350,1968$. 39

Figura 4: Proposta original dos espaços comuns do BNH de Santos. Fonte: Revista Acrópole $n^{\circ} 350,1968$.

Figura 5: Tipologia do projeto original do BNH de Santos. Fonte: Revista Acrópole ${ }^{\circ}$ $350,1968$.

Figura 6: Layout das unidades do projeto original do BNH de Santos. Fonte: Revista Acrópole $n^{\circ} 350,1968$. 41

Figura 7: Morfologia do entorno da área do BNH de Santos. 41

Figura 8: Relação entre PMV e PPD. (Adaptado da ISO 7730, 2005). 43

Figura 9: Faixas de temperaturas operativas aceitáveis para conforto em ambientes ventilados naturalmente (adaptado de ASHRAE 55, 2010). .45

Figura 10: Valores de velocidade do ar mínima exigida dentro da zona de conforto ocupada. Fonte: Cândido et al 2011.

Figura 11: Percentual de pessoas insatisfeitas devido à assimetria da radiação (TRIBESS, 2008 apud ASHRAE 2010).

Figura 12: Correntes de ar para 15\% de insatisfeitos em atividade sedentária (TRIBESS, 2008 apud ASHRAE 2005).

Figura 13: Percentual de pessoas insatisfeitas com a diferença vertical de temperatura do ar entre os pés e a cabeça (TRIBESS, 2008 apud ASHRAE 2010).51

Figura 14: Zonas Bioclimática 5. Fonte: NBR 15.220-3/2005. .53

Figura 15: Carta bioclimática apresentando as normais climatológicas de cidades desta zona, destacando a cidade de Santos,SP. Fonte: NBR Fonte: NBR 15.2203/2005. .54

Figura 16: Modelo de questionário aplicado aos moradores para levantamento da APO. .58

Figura 17: Modelo de questionário aplicado aos moradores para levantamento dos equipamentos elétricos e eletrônicos. 
Figura 18: Localização do Complexo BNH de Santos-SP. Fonte: Google Earth.......61 Figura 19: Vista aérea (implantação atual) do Complexo BNH de Santos-SP. Fonte: Google Earth.

Figura 20: Limite superior do intervalo de confiança para 95\% de confiabilidade.....64 Figura 21: Monitor de análises climáticas Delta Ohm 32.1 (confortímetro). 67

Figura 22: HP3217 - Sonda combinada de temperatura e umidade. Fonte: Manual HD 32.1. 69

Figura 23: AP3203 - Sonda a fio quente multidirecional para velocidade do ar. Fonte: Manual HD 32.1. .70

Figura 24: TP3275 - Sensor de temperatura com globo negro. Fonte: Manual HD 32.1

Figura 25: HP3217 - Sonda bulbo úmido a ventilação natural. Fonte: Manual HD 32.1. .71

Figura 26: Faixa Etária dos entrevistados. ......................................................

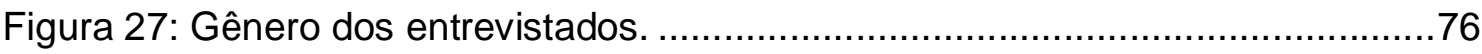

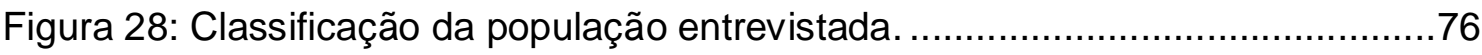

Figura 29: Resumo dos resultados dos moradores referentes ao conforto térmico nos apartamentos. 78

Figura 30: Comparação dos resultados entre APO e Métodos para conforto térmico adaptativo. .79

Figura 31: Medição térmica realizada no quarto do apartamento $A$. .80

Figura 32: Média das temperaturas nas cidades de Santos entre os meses de Julho de 2013 e Junho de 2014. Fonte: CllAGRO

Figura 33: Comparação entre Temperatura Operativa x Temperatura Externa - salas dos apartamentos do último pavimento. 82

Figura 34: Comparação entre Temperatura Operativa x Temperatura Externa - salas dos apartamentos de pavimento intermediário 83

Figura 35: Temperaturas radiantes das salas dos apartamentos de cobertura no verão. .84

Figura 36: Temperaturas radiantes das salas dos apartamentos intermediários no verão. 85

Figura 37: Medição de 24 horas da Temperatura Operativa entre verão e inverno do apartamento $\mathrm{E}$. 86 
Figura 38: Medição de 24 horas da Temperatura Operativa entre outono e primavera do apartamento $\mathrm{E}$.

Figura 39: Localização do apartamento E. Pouca (quase nula) incidência solar. .....88 Figura 40: Medição de 24 horas da Temperatura Operativa entre verão e inverno do apartamento $\mathrm{F}$. 88

Figura 41: Medição de 24 horas da Temperatura Operativa entre outono e primavera do apartamento $\mathrm{F}$. 89

Figura 42: Medição de 24 horas da Temperatura Operativa entre verão e inverno do apartamento $\mathrm{G}$.

.90

Figura 43: Medição de 24 horas da Temperatura Operativa entre outono e primavera do apartamento $\mathrm{G}$.

Figura 44: Medição de 24 horas da Temperatura Operativa entre verão e inverno do apartamento $\mathrm{H}$. 92

Figura 45: Medição de 24 horas da Temperatura Operativa entre outono e primavera do apartamento $\mathrm{H}$. .93

Figura 46: Simulação das temperaturas operativas do apartamento $\mathrm{F}$ com proposta de melhorias. .94

Figura 47: Simulação das temperaturas operativas do apartamento F com proposta de melhorias. .95

Figura 48: Simulação das temperaturas operativas do apartamento F com proposta de melhorias. .96

Figura 49: Planta baixa referente ao Apartamento A 105

Figura 50: Sensação térmica segundo modelo adaptativo da ASHRAE (Quarto apartamento $\mathrm{A}$ ). 105

Figura 51: Sensação térmica segundo modelo adaptativo da ASHRAE (Sala apartamento A) 106

Figura 52: Planta baixa referente ao Apartamento B. 106

Figura 53: Sensação térmica segundo modelo adaptativo da ASHRAE (Quarto apartamento $\mathrm{B})$.

Figura 54: Sensação térmica segundo modelo adaptativo da ASHRAE (Sala apartamento $\mathrm{B}$ ) 107

Figura 55: Planta baixa referente ao Apartamento C. 108

Figura 56: Sensação térmica segundo modelo adaptativo da ASHRAE (Quarto apartamento C). 
Figura 57: Sensação térmica segundo modelo adaptativo da ASHRAE (Sala -

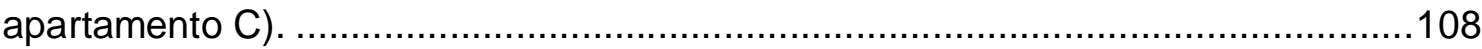

Figura 58: Planta baixa referente ao Apartamento D. ........................................109

Figura 59: Sensação térmica segundo modelo adaptativo da ASHRAE (Quarto apartamento D).

Figura 60: Sensação térmica segundo modelo adaptativo da ASHRAE (Sala apartamento D).

Figura 61: Planta baixa referente ao Apartamento $\mathrm{E}$ 110

Figura 62: Sensação térmica segundo modelo adaptativo da ASHRAE (Quarto apartamento E).

Figura 63: Sensação térmica segundo modelo adaptativo da ASHRAE (Sala apartamento E).

Figura 64: Planta baixa referente ao Apartamento $F$

Figura 65: Sensação térmica segundo modelo adaptativo da ASHRAE (Quarto apartamento F).

Figura 66: Sensação térmica segundo modelo adaptativo da ASHRAE (Sala apartamento F)

Figura 67: Planta baixa referente ao Apartamento G. 113

Figura 68: Sensação térmica segundo modelo adaptativo da ASHRAE (Quarto apartamento G)

Figura 69: Sensação térmica segundo modelo adaptativo da ASHRAE (Sala apartamento G)

Figura 70: Planta baixa referente ao Apartamento $\mathrm{H}$. 114

Figura 71: Sensação térmica segundo modelo adaptativo da ASHRAE (Quarto apartamento $\mathrm{H}$ ).

Figura 72: Sensação térmica segundo modelo adaptativo da ASHRAE (Sala apartamento $\mathrm{H}$ ). 


\section{LISTA DE TABELAS}

Tabela 1: Valores das constantes em relação à velocidade do vento........................46

Tabela 2: Equações para cálculo de conforto da temperatura neutra.......................47

Tabela 3: Dados Climáticos Santos-SP. Média entre os anos 2004 e 2013 .............53

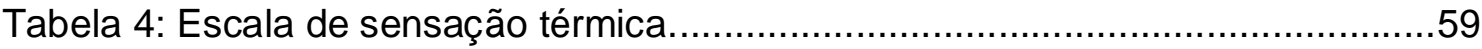

Tabela 5 - Especificação dos sensores utilizados na pesquisa (Programa A) . .........68

Tabela 6: Características dos instrumentos de medição ...........................................69

Tabela 7: Características dos materiais componentes das paredes externas, piso e laje.

.73

Tabela 8: Satisfação dos usuários quanto à temperatura e ventilação dentro dos

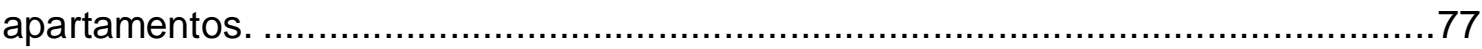

Tabela 9: Características do apartamento A ……………................................105

Tabela 10: Características do apartamento B …………...............................106

Tabela 11: Características do apartamento $\mathrm{C}$...................................................107

Tabela 12: Características do apartamento D .................................................109

Tabela 13: Características do apartamento E ....................................................110

Tabela 14: Características do apartamento $F$...................................................111

Tabela 15: Características do apartamento G................................................113

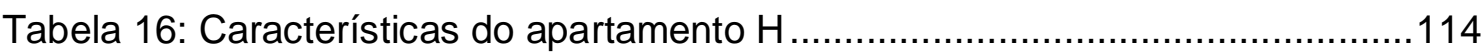

Tabela 17: Resultados coletados in loco no quarto do Apartamento A no mês de

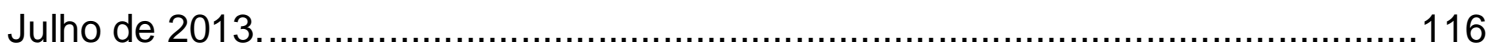

Tabela 18: Resultados coletados in loco no quarto do Apartamento A no mês de

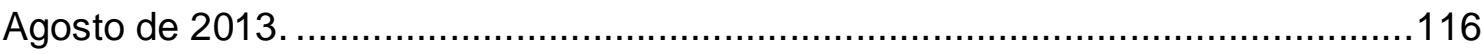

Tabela 19: Resultados coletados in loco no quarto do Apartamento A no mês de

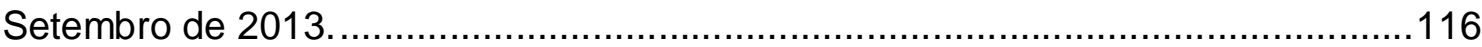

Tabela 20: Resultados coletados in loco no quarto do Apartamento A no mês de Outubro de 2013. 116

Tabela 21: Resultados coletados in loco no quarto do Apartamento A no mês de Novembro de 2013.

Tabela 22: Resultados coletados in loco no quarto do Apartamento A no mês de Dezembro de 2013. 
Tabela 23: Resultados coletados in loco no quarto do Apartamento A no mês de Janeiro de 2014 ......

Tabela 24: Resultados coletados in loco no quarto do Apartamento A no mês de Fevereiro de 2014.

Tabela 25: Resultados coletados in loco no quarto do Apartamento A no mês de Março de 2014. 118

Tabela 26: Resultados coletados in loco no quarto do Apartamento A no mês de Abril de 2014. 118

Tabela 27: Resultados coletados in loco no quarto do Apartamento A no mês de Maio de 2014 118

Tabela 28: Resultados coletados in loco no quarto do Apartamento A no mês de Junho de 2014 118

Tabela 29: Resultados coletados in loco na sala do Apartamento A no mês de Julho de 2013

Tabela 30: Resultados coletados in loco na sala do Apartamento A no mês de Agosto de 2013

Tabela 31: Resultados coletados in loco na sala do Apartamento A no mês de Setembro de 2013. 119

Tabela 32: Resultados coletados in loco na sala do Apartamento A no mês de Outubro de 2013.

Tabela 33: Resultados coletados in loco na sala do Apartamento A no mês de Novembro de 2013.

Tabela 34: Resultados coletados in loco na sala do Apartamento A no mês de Dezembro de 2013. 120

Tabela 35: Resultados coletados in loco na sala do Apartamento A no mês de Janeiro de 2014 120

Tabela 36: Resultados coletados in loco na sala do Apartamento A no mês de Fevereiro de 2014. 120

Tabela 37: Resultados coletados in loco na sala do Apartamento A no mês de Março de 2014.

Tabela 38: Resultados coletados in loco na sala do Apartamento A no mês de Abril de 2014

Tabela 39: Resultados coletados in loco na sala do Apartamento A no mês de Maio de 2014 
Tabela 40: Resultados coletados in loco na sala do Apartamento A no mês de Junho de 2014.

Tabela 41: Resultados coletados in loco no quarto do Apartamento B no mês de Julho de 2013.

Tabela 42: Resultados coletados in loco no quarto do Apartamento B no mês de Agosto de 2013.

Tabela 43: Resultados coletados in loco no quarto do Apartamento B no mês de Setembro de 2013. 122

Tabela 44: Resultados coletados in loco no quarto do Apartamento B no mês de Outubro de 2013. 122

Tabela 45: Resultados coletados in loco no quarto do Apartamento B no mês de Novembro de 2013. 122

Tabela 46: Resultados coletados in loco no quarto do Apartamento B no mês de Dezembro de 2013. 123

Tabela 47: Resultados coletados in loco no quarto do Apartamento B no mês de Janeiro de 2014. 123

Tabela 48: Resultados coletados in loco no quarto do Apartamento B no mês de Fevereiro de 2014. 123

Tabela 49: Resultados coletados in loco no quarto do Apartamento B no mês de Março de 2014. 123

Tabela 50: Resultados coletados in loco no quarto do Apartamento B no mês de Abril de 2014. 124

Tabela 51: Resultados coletados in loco no quarto do Apartamento B no mês de Maio de 2014 124

Tabela 52: Resultados coletados in loco no quarto do Apartamento B no mês de Junho de 2014 124

Tabela 53: Resultados coletados in loco na sala do Apartamento B no mês de Julho de 2013. 124

Tabela 54: Resultados coletados in loco na sala do Apartamento B no mês de Agosto de 2013. 125

Tabela 55: Resultados coletados in loco na sala do Apartamento B no mês de Setembro de 2013. 125

Tabela 56: Resultados coletados in loco na sala do Apartamento B no mês de Outubro de 2013. 
Tabela 57: Resultados coletados in loco na sala do Apartamento B no mês de Novembro de 2013.

Tabela 58: Resultados coletados in loco na sala do Apartamento B no mês de Dezembro de 2013. 126

Tabela 59: Resultados coletados in loco na sala do Apartamento B no mês de Janeiro de 2014 126

Tabela 60: Resultados coletados in loco na sala do Apartamento B no mês de Fevereiro de 2014. 126

Tabela 61: Resultados coletados in loco na sala do Apartamento B no mês de Março de 2014 126

Tabela 62: Resultados coletados in loco na sala do Apartamento B no mês de Abril de 2014.

Tabela 63: Resultados coletados in loco na sala do Apartamento B no mês de Maio de 2014

Tabela 64: Resultados coletados in loco na sala do Apartamento B no mês de Junho de 2014 127

Tabela 65: Resultados coletados in loco no quarto do Apartamento C no mês de Julho de 2013. 127

Tabela 66: Resultados coletados in loco no quarto do Apartamento $C$ no mês de Agosto de 2013. 128

Tabela 67: Resultados coletados in loco no quarto do Apartamento $C$ no mês de Setembro de 2013. 128

Tabela 68: Resultados coletados in loco no quarto do Apartamento C no mês de Outubro de 2013. 128

Tabela 69: Resultados coletados in loco no quarto do Apartamento C no mês de Novembro de 2013. 128

Tabela 70: Resultados coletados in loco no quarto do Apartamento C no mês de Dezembro de 2013. 129

Tabela 71: Resultados coletados in loco no quarto do Apartamento $C$ no mês de Janeiro de 2014

Tabela 72: Resultados coletados in loco no quarto do Apartamento C no mês de Fevereiro de 2014. 129

Tabela 73: Resultados coletados in loco no quarto do Apartamento $C$ no mês de Março de 2014 
Tabela 74: Resultados coletados in loco no quarto do Apartamento $C$ no mês de Abril de 2014.

130

Tabela 75: Resultados coletados in loco no quarto do Apartamento C no mês de Maio de 2014 130

Tabela 76: Resultados coletados in loco no quarto do Apartamento $C$ no mês de Junho de 2014 130

Tabela 77: Resultados coletados in loco na sala do Apartamento C no mês de Julho de 2013. 130

Tabela 78: Resultados coletados in loco na sala do Apartamento C no mês de Agosto de 2013.

Tabela 79: Resultados coletados in loco na sala do Apartamento C no mês de Setembro de 2013.

Tabela 80: Resultados coletados in loco na sala do Apartamento C no mês de Outubro de 2013.

Tabela 81: Resultados coletados in loco na sala do Apartamento C no mês de Novembro de 2013. 131

Tabela 82: Resultados coletados in loco na sala do Apartamento C no mês de Dezembro de 2013. 132

Tabela 83: Resultados coletados in loco na sala do Apartamento C no mês de Janeiro de 2014

132

Tabela 84: Resultados coletados in loco na sala do Apartamento C no mês de Fevereiro de 2014. 132

Tabela 85: Resultados coletados in loco na sala do Apartamento C no mês de Março de 2014 132

Tabela 86: Resultados coletados in loco na sala do Apartamento $C$ no mês de Abril de 2014 . 133

Tabela 87: Resultados coletados in loco na sala do Apartamento C no mês de Maio de 2014 133

Tabela 88: Resultados coletados in loco na sala do Apartamento C no mês de Maio de 2014.

Tabela 89: Resultados coletados in loco na sala do Apartamento C no mês de Maio de 2014

Tabela 90: Resultados coletados in loco no quarto do Apartamento D no mês de Agosto de 2013 
Tabela 91: Resultados coletados in loco no quarto do Apartamento D no mês de Setembro de 2013

Tabela 92: Resultados coletados in loco no quarto do Apartamento D no mês de Outubro de 2013. 134

Tabela 93: Resultados coletados in loco no quarto do Apartamento D no mês de Novembro de 2013. 134

Tabela 94: Resultados coletados in loco no quarto do Apartamento D no mês de Dezembro de 2013. 135

Tabela 95: Resultados coletados in loco no quarto do Apartamento D no mês de Janeiro de 2014 135

Tabela 96: Resultados coletados in loco no quarto do Apartamento D no mês de Fevereiro de 2014. 135

Tabela 97: Resultados coletados in loco no quarto do Apartamento D no mês de Março de 2014 135

Tabela 98: Resultados coletados in loco no quarto do Apartamento D no mês de Abril de 2014. 136

Tabela 99: Resultados coletados in loco no quarto do Apartamento $D$ no mês de Maio de 2014 136

Tabela 100: Resultados coletados in loco no quarto do Apartamento D no mês de Junho de 2014 136

Tabela 101: Resultados coletados in loco na sala do Apartamento D no mês de Julho de 2013. 136

Tabela 102: Resultados coletados in loco na sala do Apartamento D no mês de Agosto de 2013.

Tabela 103: Resultados coletados in loco na sala do Apartamento D no mês de Setembro de 2013. 137

Tabela 104: Resultados coletados in loco na sala do Apartamento D no mês de Outubro de 2013.

Tabela 105: Resultados coletados in loco na sala do Apartamento D no mês de Novembro de 2013.

Tabela 106: Resultados coletados in loco na sala do Apartamento D no mês de Dezembro de 2013. 138

Tabela 107: Resultados coletados in loco na sala do Apartamento D no mês de Janeiro de 2014 
Tabela 108: Resultados coletados in loco na sala do Apartamento $D$ no mês de Fevereiro de 2014.

138

Tabela 109: Resultados coletados in loco na sala do Apartamento $D$ no mês de Março de 2014

Tabela 110: Resultados coletados in loco na sala do Apartamento $D$ no mês de Abril de 2014. 139

Tabela 111: Resultados coletados in loco na sala do Apartamento $D$ no mês de Maio de 2014. 139

Tabela 112: Resultados coletados in loco na sala do Apartamento $D$ no mês de Junho de 2014 139

Tabela 113: Resultados coletados in loco no quarto do Apartamento E no mês de Julho de 2013. 139

Tabela 114: Resultados coletados in loco no quarto do Apartamento E no mês de Agosto de 2013. 140

Tabela 115: Resultados coletados in loco no quarto do Apartamento E no mês de Setembro de 2013. 140

Tabela 116: Resultados coletados in loco no quarto do Apartamento E no mês de Outubro de 2013. 140

Tabela 117: Resultados coletados in loco no quarto do Apartamento E no mês de Novembro de 2013.

Tabela 118: Resultados coletados in loco no quarto do Apartamento E no mês de Dezembro de 2013. 141

Tabela 119: Resultados coletados in loco no quarto do Apartamento E no mês de Janeiro de 2014 141

Tabela 120: Resultados coletados in loco no quarto do Apartamento E no mês de Fevereiro de 2014. 141

Tabela 121: Resultados coletados in loco no quarto do Apartamento E no mês de Março de 2014.

Tabela 122: Resultados coletados in loco no quarto do Apartamento E no mês de Abril de 2014.

Tabela 123:Resultados coletados in loco no quarto do Apartamento E no mês de Maio de 2014 142

Tabela 124Resultados coletados in loco no quarto do Apartamento E no mês de Junho de 2014 
Tabela 125: Resultados coletados in loco na sala do Apartamento E no mês de Julho de 2013.

Tabela 126: Resultados coletados in loco na sala do Apartamento E no mês de Agosto de 2013.

Tabela 127: Resultados coletados in loco na sala do Apartamento E no mês de Setembro de 2013. 143

Tabela 128: Resultados coletados in loco na sala do Apartamento E no mês de Outubro de 2013. 143

Tabela 129: Resultados coletados in loco na sala do Apartamento E no mês de Novembro de 2013. 143

Tabela 130: Resultados coletados in loco na sala do Apartamento E no mês de Dezembro de 2013.

Tabela 131: Resultados coletados in loco na sala do Apartamento E no mês de Janeiro de 2014 144

Tabela 132: Resultados coletados in loco na sala do Apartamento E no mês de Fevereiro de 2014. 144

Tabela 133: Resultados coletados in loco na sala do Apartamento E no mês de Março de 2014. 144

Tabela 134: Resultados coletados in loco na sala do Apartamento E no mês de Abril de 2014.

Tabela 135: Resultados coletados in loco na sala do Apartamento E no mês de Maio de 2014. 145

Tabela 136: Resultados coletados in loco na sala do Apartamento E no mês de Junho de 2014 145

Tabela 137: Resultados coletados in loco no quarto do Apartamento $\mathrm{F}$ no mês de Julho de 2013. 145

Tabela 138: Resultados coletados in loco no quarto do Apartamento $F$ no mês de Agosto de 2013. 146

Tabela 139: Resultados coletados in loco no quarto do Apartamento $F$ no mês de Setembro de 2013. 146

Tabela 140: Resultados coletados in loco no quarto do Apartamento F no mês de Outubro de 2013. 146

Tabela 141: Resultados coletados in loco no quarto do Apartamento $\mathrm{F}$ no mês de Novembro de 2013. 146 
Tabela 142: Resultados coletados in loco no quarto do Apartamento $F$ no mês de Dezembro de 2013.

Tabela 143: Resultados coletados in loco no quarto do Apartamento $F$ no mês de Janeiro de 2014

Tabela 144: Resultados coletados in loco no quarto do Apartamento $\mathrm{F}$ no mês de Fevereiro de 2014.

Tabela 145: Resultados coletados in loco no quarto do Apartamento $\mathrm{F}$ no mês de Março de 2014.

Tabela 146: Resultados coletados in loco no quarto do Apartamento $F$ no mês de Abril de 2014 148

Tabela 147: Resultados coletados in loco no quarto do Apartamento $F$ no mês de Maio de 2014

Tabela 148: Resultados coletados in loco no quarto do Apartamento $\mathrm{F}$ no mês de Junho de 2014 148

Tabela 149: Resultados coletados in loco na sala do Apartamento F no mês de Julho de 2013. 148

Tabela 150: Resultados coletados in loco na sala do Apartamento $\mathrm{F}$ no mês de Agosto de 2013 149

Tabela 151: Resultados coletados in loco na sala do Apartamento $F$ no mês de Setembro de 2013. 149

Tabela 152: Resultados coletados in loco na sala do Apartamento $F$ no mês de Outubro de 2013. 149

Tabela 153: Resultados coletados in loco na sala do Apartamento $F$ no mês de Novembro de 2013. 149

Tabela 154: Resultados coletados in loco na sala do Apartamento $\mathrm{F}$ no mês de Dezembro de 2013. 150

Tabela 155: Resultados coletados in loco na sala do Apartamento F no mês de Janeiro de 2014 150

Tabela 156: Resultados coletados in loco na sala do Apartamento $\mathrm{F}$ no mês de Fevereiro de 2014. 150

Tabela 157: Resultados coletados in loco na sala do Apartamento $\mathrm{F}$ no mês de Março de 2014.

Tabela 158: Resultados coletados in loco na sala do Apartamento $F$ no mês de Abril de 2014 
Tabela 159: Resultados coletados in loco na sala do Apartamento F no mês de Maio de 2014.

Tabela 160: Resultados coletados in loco na sala do Apartamento F no mês de Junho de 2014

Tabela 161: Resultados coletados in loco no quarto do Apartamento G no mês de Julho de 2013.

Tabela 162: Resultados coletados in loco no quarto do Apartamento $G$ no mês de Agosto de 2013. 152

Tabela 163: Resultados coletados in loco no quarto do Apartamento $G$ no mês de Setembro de 2013. 152

Tabela 164: Resultados coletados in loco no quarto do Apartamento $G$ no mês de Outubro de 2013. 152

Tabela 165: Resultados coletados in loco no quarto do Apartamento $G$ no mês de Novembro de 2013. 152

Tabela 166: Resultados coletados in loco no quarto do Apartamento $G$ no mês de Novembro de 2013. 153

Tabela 167: Resultados coletados in loco no quarto do Apartamento G no mês de Janeiro de 2014 153

Tabela 168: Resultados coletados in loco no quarto do Apartamento G no mês de Fevereiro de 2014. 153

Tabela 169: Resultados coletados in loco no quarto do Apartamento $G$ no mês de Março de 2014. 153

Tabela 170: Resultados coletados in loco no quarto do Apartamento G no mês de Abril de 2014 154

Tabela 171: Resultados coletados in loco no quarto do Apartamento G no mês de Maio de 2014 154

Tabela 172: Resultados coletados in loco no quarto do Apartamento G no mês de Junho de 2014 154

Tabela 173: Resultados coletados in loco na sala do Apartamento $G$ no mês de Julho de 2013. 154

Tabela 174: Resultados coletados in loco na sala do Apartamento $G$ no mês de Agosto de 2013. 155

Tabela 175: Resultados coletados in loco na sala do Apartamento G no mês de Setembro de 2013. 
Tabela 176: Resultados coletados in loco na sala do Apartamento $G$ no mês de Outubro de 2013.

Tabela 177: Resultados coletados in loco na sala do Apartamento $G$ no mês de Novembro de 2013. 155

Tabela 178: Resultados coletados in loco na sala do Apartamento G no mês de Dezembro de 2013. 155

Tabela 179: Resultados coletados in loco na sala do Apartamento G no mês de Janeiro de 2014 156

Tabela 180: Resultados coletados in loco na sala do Apartamento G no mês de Fevereiro de 2014. 156

Tabela 181: Resultados coletados in loco na sala do Apartamento $G$ no mês de Março de 2014. 156

Tabela 182: Resultados coletados in loco na sala do Apartamento $G$ no mês de Abril de 2014. 156

Tabela 183: Resultados coletados in loco na sala do Apartamento $G$ no mês de Maio de 2014 156

Tabela 184: Resultados coletados in loco na sala do Apartamento G no mês de Junho de 2014 157

Tabela 185: Resultados coletados in loco no quarto do Apartamento H no mês de Julho de 2013.

Tabela 186: Resultados coletados in loco no quarto do Apartamento $\mathrm{H}$ no mês de Agosto de 2013. 157

Tabela 187: Resultados coletados in loco no quarto do Apartamento $\mathrm{H}$ no mês de Setembro de 2013.

Tabela 188: Resultados coletados in loco no quarto do Apartamento H no mês de Outubro de 2013. 158

Tabela 189: Resultados coletados in loco no quarto do Apartamento $\mathrm{H}$ no mês de Novembro de 2013. 158

Tabela 190: Resultados coletados in loco no quarto do Apartamento H no mês de Dezembro de 2013. 158

Tabela 191: Resultados coletados in loco no quarto do Apartamento $\mathrm{H}$ no mês de Janeiro de 2014 158

Tabela 192: Resultados coletados in loco no quarto do Apartamento $\mathrm{H}$ no mês de Fevereiro de 2014. 
Tabela 193: Resultados coletados in loco no quarto do Apartamento H no mês de Março de 2014.

Tabela 194: Resultados coletados in loco no quarto do Apartamento H no mês de Abril de 2014. 159

Tabela 195: Resultados coletados in loco no quarto do Apartamento H no mês de Maio de 2014 159

Tabela 196: Resultados coletados in loco no quarto do Apartamento $\mathrm{H}$ no mês de Junho de 2014 . 160

Tabela 197: Resultados coletados in loco na sala do Apartamento H no mês de Julho de 2013. 160

Tabela 198: Resultados coletados in loco na sala do Apartamento $\mathrm{H}$ no mês de Agosto de 2013. 160

Tabela 199: Resultados coletados in loco na sala do Apartamento $\mathrm{H}$ no mês de Setembro de 2013. 160

Tabela 200: Resultados coletados in loco na sala do Apartamento $\mathrm{H}$ no mês de Outubro de 2013. 160

Tabela 201: Resultados coletados in loco na sala do Apartamento H no mês de Novembro de 2013. 161

Tabela 202: Resultados coletados in loco na sala do Apartamento $\mathrm{H}$ no mês de Dezembro de 2013.

161

Tabela 203: Resultados coletados in loco na sala do Apartamento $\mathrm{H}$ no mês de Janeiro de 2014

Tabela 204: Resultados coletados in loco na sala do Apartamento $\mathrm{H}$ no mês de Fevereiro de 2014. 161

Tabela 205: Resultados coletados in loco na sala do Apartamento $\mathrm{H}$ no mês de Março de 2014 162

Tabela 206: Resultados coletados in loco na sala do Apartamento H no mês de Abril de 2014. 162

Tabela 207: Resultados coletados in loco na sala do Apartamento H no mês de Maio de 2014. 162

Tabela 208: Resultados coletados in loco na sala do Apartamento $\mathrm{H}$ no mês de Junho de 2014 162 


\section{SUMÁRIO}

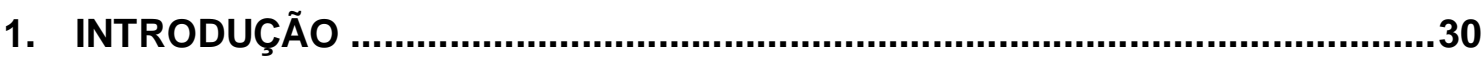

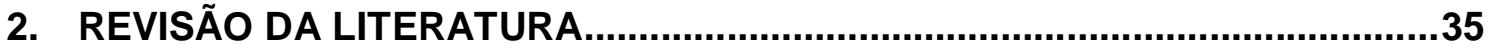

2.1. ORIGENS DA HABITAÇÃO SOCIAL NO BRASIL ……...............................

2.2. CONJUNTO HABITACIONAL "MARECHAL HUMBERTO DE ALENCAR

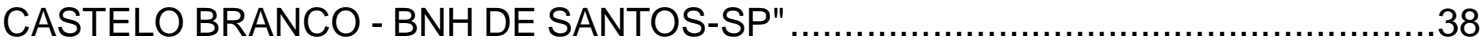

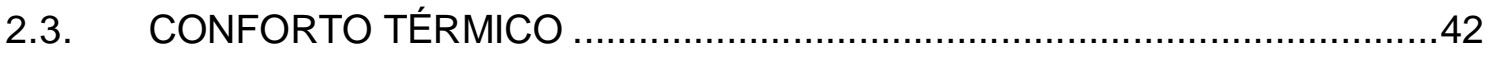

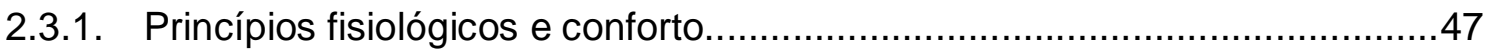

2.3.2. Balanço de calor do corpo humano e condições de conforto térmico............48

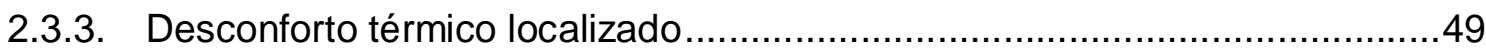

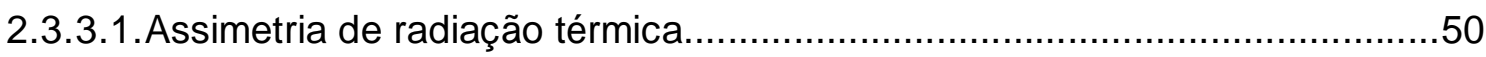

2.3.3.2. Correntes de Ar (Draught rate - DR) ....................................................50

2.3.3.3. Diferença na temperatura do ar (sentido vertical) ......................................51

2.3.3.4. Desempenho térmico da edificação.........................................................52

2.4. ZONEAMENTO BIOCLIMÁTICO E DADOS CLIMATOLÓGICOS DA CIDADE

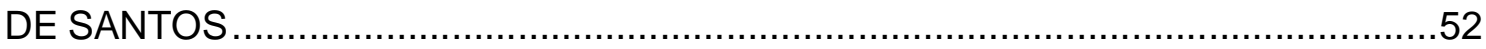

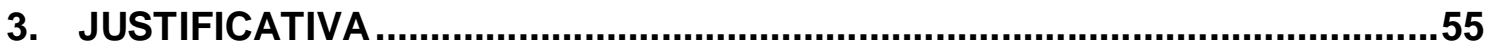

4. OBJETIVO

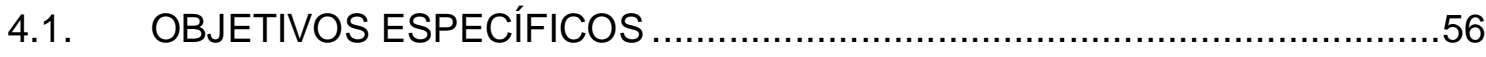

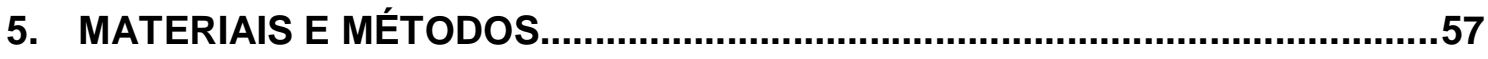

5.1. AVALIAÇÃO PÓS-OCUPAÇÃO E LEVANTAMENTO IN LOCO...................57

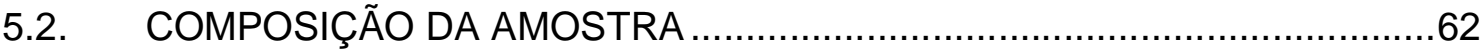

5.2.1. Conceituação de estatísticas e amostragens ..........................................62

5.2.1.1. Amostra não probabilística: amostras por conveniências ...............................63

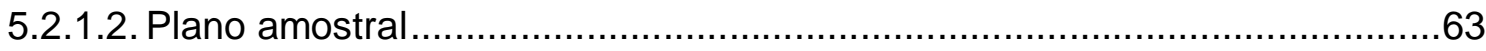

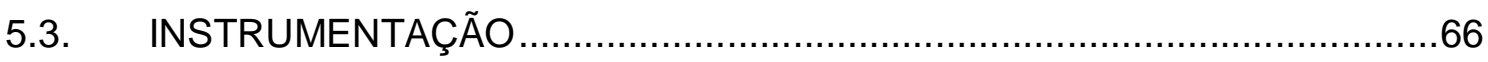




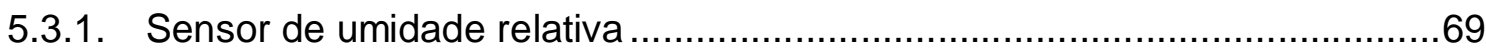

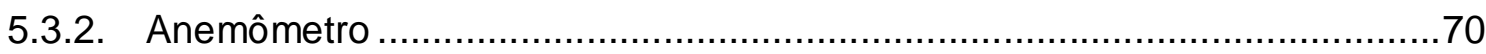

5.3.3. Sensor de temperatura de globo negro …................................................

5.3.4. Sensor de bulbo úmido e ventilação natural..............................................71

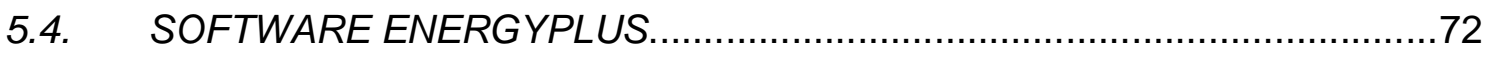

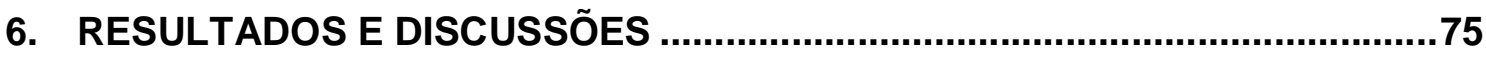

6.1. RESULTADOS DA APO E ENTREVISTAS ……....................................

6.2. COMPARAÇÃO DOS MÉTODOS DE CONFORTO TÉRMICO ADAPTATIVO 78

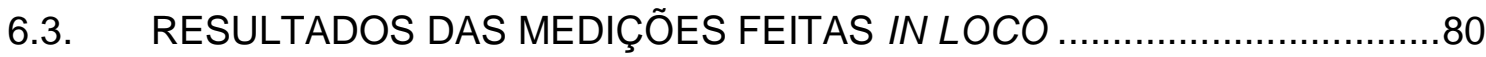

6.3.1. Avaliação das temperaturas operativas dos apartamentos .........................81

6.3.2. Avaliação das temperaturas radiantes internas dos apartamentos avaliados 84

6.3.3. Avaliação das temperaturas entre os apartamentos em períodos de 24 horas 85

6.3.4. Resultados das simulações das propostas de melhorias nos apartamentos

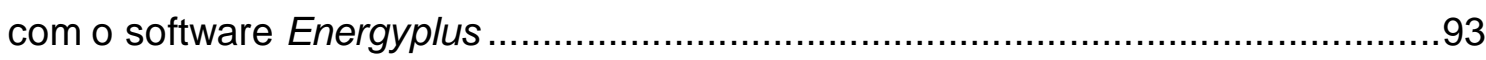

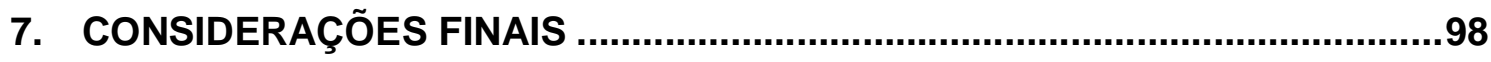

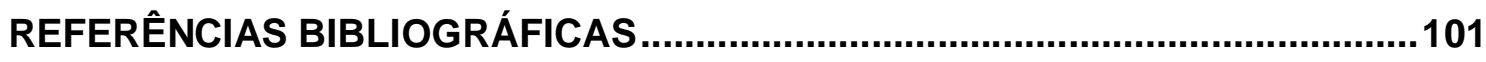
APÊNDICE A - Características Espaciais e Térmicas dos Apartamentos Avaliados 105

APÊNDICE B - Dados Obtidos nas medições in loco dos apartamentos avaliados 


\title{
LISTA DE ABREVIATURAS E SIGLAS
}

\author{
ABNT Associação Brasileira de Normas Técnicas \\ APO Avaliação Pós-Ocupação \\ ASHRAE American Society of Heating and Air Conditioning Engineers \\ BNH Banco Nacional de Habitação \\ CDHU Companhia de Desenvolvimento Habitacional e Urbano \\ CIIAGRO Centro Integrado de Informações Agrometeorológicas \\ DIN Deutsches Institut für Normung \\ DR Draught Rate \\ FCP Fundação Casa Popular \\ HIS Habitação de Interesse Social \\ INOCOOP Instituto de Orientação às Cooperativas \\ IAPs Institutos de Aposentadoria e Pensões da Casa Popular \\ ISO International Standard Organization \\ NBR Norma Brasileira \\ OMS Organização Mundial da Saúde \\ PMCMV Programa Minha Casa Minha Vida \\ PMV Predicted Mean Votes \\ PPD Predicted Percent of Dissatisfied
}

SERFHAU Serviço Federal de Habitação e Urbanismo

USP Universidade de São Paulo 


\section{LISTA DE SÍMBOLOS}

Top

a

$\mathrm{Ta}$

$\overline{T_{r}}$

$\mathrm{Tn}$

$\mathrm{M}$

W

Qsk

Qres

$C+R$

Esk

Cres

Eres

$\mathrm{N}$

$\mathrm{Za}$

s

e

eo

$\sigma$

$\mathrm{n}$
Temperatura Operativa do ambiente

Variável constante em relação a velocidade do vento

Temperatura do ar

Temperatura Radiante média

Temperatura neutra

Taxa metabólica de produção de calor $\left(\mathrm{W} / \mathrm{m}^{2}\right)$

Trabalho mecânico desenvolvido pelo corpo $\left(\mathrm{W} / \mathrm{m}^{2}\right)$

Taxa total de perda de calor pela pele $\left(\mathrm{W} / \mathrm{m}^{2}\right)$

Taxa total de perda de calor pela respiração $\left(\mathrm{W} / \mathrm{m}^{2}\right)$

Perda de calor latente pela pele por evaporação $\left(\mathrm{W} / \mathrm{m}^{2}\right)$

Perda de calor pela pele por evaporação $\left(\mathrm{W} / \mathrm{m}^{2}\right)$

Perda de calor sensível pela respiração por convecção $\left(\mathrm{W} / \mathrm{m}^{2}\right)$

Perda de calor latente pela respiração por evaporação $\left(\mathrm{W} / \mathrm{m}^{2}\right)$

Tamanho do universo de população

1,96 (probabilidade de 95\% de confiabilidade)

Limite superior (desvio padrão)

Limite de erro (intervalo de confiança)

Intervalo de confiança

Desvio padrão

Tamanho da amostra 
Tnw Temperatura do bulbo úmido a ventilação natural

Tg Temperatura de globo

$\operatorname{Pr} \quad$ Pressão atmosférica

Rh Umidade relativa do ar

Va Velocidade do ar

WBGT Wet Bulb Globe Temperature

Tbu Temperatura de bulbo úmido $\left({ }^{\circ} \mathrm{C}\right)$ 


\section{INTRODUÇÃO}

A questão habitacional no Brasil, sempre foi um problema complexo ao desenvolvimento do país. O déficit habitacional acumulado ao longo da história obrigou os governos a proporem políticas públicas destinadas à produção de moradias. Esta produção significou envolver a indústria da construção civil, tornando-a um importante segmento para as ações públicas orientadas para o emprego e renda.

Desde o século passado, as cidades brasileiras se expandem de forma desigual. $\mathrm{O}$ quadro de deficiências em infraestrutura e a oferta insuficiente de moradias levavam a um crescimento urbano que mais se assemelhava a um aglomerado de pessoas concentradas em determinadas áreas, longe, portanto de uma expansão legítima dos espaços urbanizados.

Os primeiros organismos que se dedicaram à construção de casas populares em maior escala foram os diversos institutos de aposentadoria e pensão (industriários, comerciários, bancários, etc.), criados a partir de 1930. Entretanto, essas entidades operavam normalmente de maneira fragmentária, sendo sua atividade, nesse campo, considerada secundária e atingindo um pequeno número de associados. (AZEVEDO, 1988).

Nesse sentido, pode-se afirmar que é somente com a criação da Fundação da Casa Popular (FCP), em 1946, que se institucionaliza a primeira agência de nível nacional voltada exclusivamente para a construção de casas populares para as classes de baixa renda (AZEVEDO, 1988).

Após a chegada do governo militar em 1964 ao poder, a Fundação da Casa Popular passou a ser considerada pelas autoridades como uma instituição irrecuperável, em virtude de sua ligação visceral com 0 antigo regime (AZEVEDO, 1988).

A criação do BNH (Banco Nacional de Habitação), além de colaborar na legitimação da nova ordem política, previa inúmeros efeitos positivos na esfera econômica: estímulo à população; absorção pelo mercado de trabalho, de um maior contingente de mão de obra não qualificada; desenvolvimento da indústria de material de construção; fortalecimento, expansão e diversificação das empresas de construção civil e das atividades associadas (empresas de 
incorporações, escritórios de arquitetura, agências imobiliárias, etc.) (AZEVEDO, 1988).

Com o fim do programa habitacional do $\mathrm{BNH}$, em 1986, novas propostas de modelos de conjuntos habitacionais de interesse social foram surgindo, inclusive nas esferas regionais. No estado de São Paulo, por exemplo, os programas com maiores destaques foram $\mathrm{COHAB}$ e $\mathrm{CDHU}$. Atualmente o programa de habitação de interesse social de maior destaque é o do Governo Federal, o programa "Minha Casa Minha Vida", criado pelo Ministério das cidades em 2003.

O Conjunto Habitacional (BNH) Humberto de Alencar Castelo Branco possui uma população próxima de 40 mil habitantes. Localizado no bairro Aparecida no município de Santos, contempla 3.280 apartamentos que foram entregues no ano de $1969^{1}$.

Para este trabalho foram avaliados apartamentos multifamiliares instalados no Conjunto BNH de Santos, por apresentarem características criticas de ocupação no interior dos apartamentos.

Dadas às restrições econômicas dos usuários, entende-se que, em Habitações de Interesse Social (HIS), deva haver uma preocupação com a qualidade e o conforto do ambiente para que haja relevância para a satisfação dos usuários, já que as possibilidades de adaptação dos moradores desta tipologia habitacional são limitadas ou nulas em alguns casos. Em busca dos limites físicos e individuais, para que atinjam níveis satisfatórios de conforto do ser humano em seu meio, diversas pesquisas na área de conforto ambiental trabalham com índices de modelos preditivos e adaptativos, que relacionam variáveis para prever, com maior precisão, as condições que os usuários estariam confortáveis em determinados ambientes. O conforto térmico é influenciado por uma série de fatores ambientais e subjetivos. Os critérios ambientais são compostos pela temperatura do ar, temperatura das superfícies, movimento do ar, umidade relativa do ar e taxa de troca da ventilação natural. O conforto térmico dependerá também da atividade exercida e das roupas utilizadas pelo usuário, quantidade de pessoas no ambiente, equipamentos eletrônicos ligados dentro de um ambiente, além da idade, estado de saúde, sexo

\footnotetext{
${ }^{1}$ Em http://www.novomilenio.inf.br/. Acesso em: 15 de Março de 2013.
} 
e adaptação ao ambiente local e clima. Outros fatores como ambientes aglomerados e subocupação também podem influenciar os aspectos de conforto interno.

Independente da tipologia a ser construída, seja ela de um edifício comercial, industrial ou habitacional, o processo de construção do edifício deve passar por inúmeras etapas de execução, que envolvem centenas de pessoas e conhecimentos diferentes, desde o projeto até a sua construção e acabamento, se estendendo à sua operação e manutenção.

Desde que se confirmou a crise no cenário energético mundial, a arquitetura passou a desempenhar um papel ainda mais importante, pois pode através da correta utilização de recursos naturais, oferecer aos seus usuários não somente um edifício mais confortável e saudável, como também eficiente energeticamente. Assim, o uso de estratégias passivas de resfriamento deveria ser o ponto de partida quando se visa projetos adequados a climas quentes como é o caso do Brasil (MORAIS \& LABAKI, 2014).

Assim como a forma de projetar e construir as edificações tem revelado uma grande influência das características climáticas, imprimindo uma identidade própria, como parte da cultura de cada povo, os métodos de avaliação do desempenho térmico de edificações também não fogem à realidade determinada por esta influência (AKUTSU, 1998).

Tem sido demonstrado que o clima exerce uma forte influência no comportamento de uma pessoa exposta a um ambiente térmico, portanto, as condições climáticas interferem nas variáveis térmicas de cada indivíduo (vestuário, posição e taxa metabólica) e o uso do edifício controlado (BRAVO; GONZÁLEZ, 2013).

O clima de uma dada região é determinado pelos padrões de variações de vários elementos e suas combinações. Os principais elementos climáticos, quando o conforto humano e projeto de construção estão sendo consideradas, são a radiação solar, temperatura do ar, umidade, vento e precipitação (GIVONI, 1976).

Além das variáveis climáticas naturais que podem interferir no conforto e desempenho térmico das edificações, ressalta-se a existência de ilhas de calor que surgem por adensamento de construções na envoltória de determinado local. 
O fenômeno das ilhas de calor está se tornando cada vez mais intenso nas áreas urbanas, modificando o microclima dessas áreas, agravando os fenômenos climáticos e causando todos os tipos de danos. A redução dos efeitos desejáveis das ilhas de calor pode ser alcançada através da alteração dos materiais utilizados nos edifícios, os quais, por sua vez, podem levar a efeitos benéficos diretos e indiretos para o homem e para o ambiente. Os efeitos diretos positivos são a redução da temperatura do ar em áreas urbanas, a redução da demanda de energia para sistemas de ar condicionado e a redução da poluição atmosférica. O efeito indireto positivo é a redução da demanda de geração de energia. O microclima em torno de um edifício é causado pela radiação solar incidente sobre a envolvente do edifício. A radiação térmica ou de onda longa proveniente de construção de superfícies contribui para o desenvolvimento de características climáticas locais específicas, tais como temperatura do ar, umidade relativa e velocidade do vento. A redução dos materiais de superfície de temperatura contribui diretamente para a mitigação dos efeitos negativos das ilhas de calor (PRADO \& FERREIRA, 2005).

Segundo Akutsu (1998), no Brasil predominam as situações onde o conforto térmico deve ser equacionado para as condições de verão. Neste caso, não basta adotar o mesmo procedimento utilizado para as condições de inverno, baseado no parâmetro "resistência térmica" ou no "coeficiente global de transmissão de calor", simplesmente invertendo-se o sentido do fluxo de energia, ou seja, supondo que o objetivo seja apenas reduzir os ganhos de energia por condução proveniente do ambiente externo. É necessário considerar, ao mesmo tempo, as demais trocas térmicas que ocorrem nos ambientes, como as possibilidades de perda de energia pelo ambiente, seja pela ventilação, sejam até por condução/convecção de alguns elementos da edificação, por meio de uma abordagem dinâmica, buscando, portanto, equacionar o equilíbrio entre as perdas e ganhos de energia que ocorrem simultaneamente e que variam significativamente ao longo de um dia. Desta forma, a capacidade térmica da edificação não pode ser desprezada e, portanto, as resistências térmicas dos elementos e componentes não são suficientes para caracterizar o comportamento térmico da edificação.

Devem-se atentar às soluções de estratégia de projeto, já que uma mesma solução pode ser percebida de forma diferente quando relacionadas à percepção 
fisiológica dos usuários, como por exemplo, casos de insuflamento de ar, que podem ser considerados uma corrente de ar incômoda em dias frios ou uma excelente brisa em dias quentes.

Segundo a Organização Mundial da Saúde (OMS), estes fatores podem variar de acordo com cada indivíduo em determinados ambientes ao longo dos dias, e a temperatura do ar interna em uma residência deve ser o foco principal no desenvolvimento do projeto, com o intuito de proteger a saúde do usuário (ORMANDY \& EZRATTY, 2012).

Ondas de calor de verão ${ }^{2}$ ocorrem durante todo o mundo e tendem a ser mais frequentes e intensas no futuro (MEEHL \& TEBALDI, 2004 apud HARLAN et al 2006).

Idosos, crianças e pessoas com doenças respiratórias e cardiovasculares crônicas são mais suscetíveis aos perigos da exposição prolongada ao calor excessivo do que jovens e adultos saudáveis (MCGEEHIN \& MIRABELLI, 2001 apud HARLAN et al 2006). Os casos de mortes relacionados ao calor dos ambientes são mais frequentes em lugares com climas temperados. No caso de climas quentes e úmidos, as maiores causas de reclamações feitas pelos usuários são a de desconforto térmico e em alguns casos o surgimento de doenças.

A orientação da OMS para a temperatura do ar em habitações é dirigida para a proteção da saúde, em particular a saúde daqueles mais suscetíveis ao calor e/ou frio. A orientação basea-se em testes e tem sido apoiada por pesquisas recentes que determinam que para que haja uma proteção à saúde onde os usuários permaneçam entre 15 a $25{ }^{\circ} \mathrm{C}$, distintos dos valores de referência da década de 80 que estipulava valores entre 18 a $24^{\circ} \mathrm{C}$.

Para a avaliação do conforto térmico existem normas que estabelecem faixas de conforto térmico. No Brasil a principal referência é a NBR 16401 (2008). As normas internacionais as referências mais utilizadas são a ISO 7730 (2005) e a ASHRAE (2010).

\footnotetext{
${ }^{2}$ Períodos esporádicos de temperaturas elevadas, fora da faixa normal de variabilidade climática.
} 


\section{REVISÃO DA LITERATURA}

\subsection{ORIGENS DA HABITAÇÃO SOCIAL NO BRASIL}

O período de Vargas marca o surgimento da habitação social no Brasil. Com a revolução de 1930, ocorre uma profunda transformação no Estado brasileiro, que abandona o liberalismo e passa a interferir em todos os aspectos da vida econômica do país. Até 1964, com o golpe militar, a questão habitacional foi tratada de maneira fragmentada por inúmeros órgãos promotores voltados para o atendimento de sua própria clientela, sem que existisse uma estratégia governamental estruturada para enfrentar de maneira universal e abrangente o problema. Os principais órgãos foram os IAPs, que não tinham como finalidade básica realizar um atendimento habitacional, enquanto a Fundação da Casa Popular (FCP), esvaziada logo no nascedouro, nunca teve fundos específicos e orçamento para, minimamente, enfrentar o problema.

Pouco após o golpe militar, a Fundação da Casa Popular foi transformada no Serviço Federal de Habitação e Urbanismo (SERFHAU), voltado para a formulação da política urbana e habitacional, além de difundir uma mentalidade de planejamento urbano nas administrações municipais. Em agosto de 1964, foi criado o Banco Nacional de Habitação (BNH), ideia que desde o segundo governo Vargas estava sendo estudada pelo Estado (BONDUKI, 2014).

Em agosto de 1964, foi criado o Banco Nacional de Habitação. Com estas iniciativas, começou a se estruturar uma política nacional de habitação, baseada em um novo Sistema Financeiro da Habitação. O novo quadro político imposto pelos militares em 1964, com o apoio das elites conservadoras do país e do governo americano, particularmente interessado em bloquear os governos progressistas na América Latina, representou um ponto de inflexão muito importante na ação do Estado brasileiro na questão da habitação. No novo governo, que interrompeu a ordem institucional, antigas medidas que Vargas queria implementar ainda em 1945, como a extinção dos $\operatorname{IAPs}^{3}$ e a unificação da previdência, objetivando universalizar

\footnotetext{
${ }^{3}$ IAPs: Institutos de Aposentadoria e Pensões da Casa Popular, primeiros órgãos federais que atuaram no setor da habitação social no Brasil (BONDUKI, 2011).
} 
a previdência social e ampliar o atendimento habitacional, puderam se viabilizar (BONDUKI, 2014).

Os estudos que analisam os conjuntos habitacionais financiados pelo Banco Nacional de Habitação são muito críticos em relação à sua qualidade arquitetônica e urbanística. A partir dos anos de 1970, tornou-se quase consensual, no meio acadêmico e técnico e na própria opinião pública, uma avaliação negativa sobre a política habitacional realizada no período e, em especial, em relação à sua produção. Essa visão foi reforçada pela forte associação entre o BNH e a ditadura militar, de modo que essa crítica foi se aprofundando à medida que cresceu a oposição política ao regime (BONDUKI, 2014).

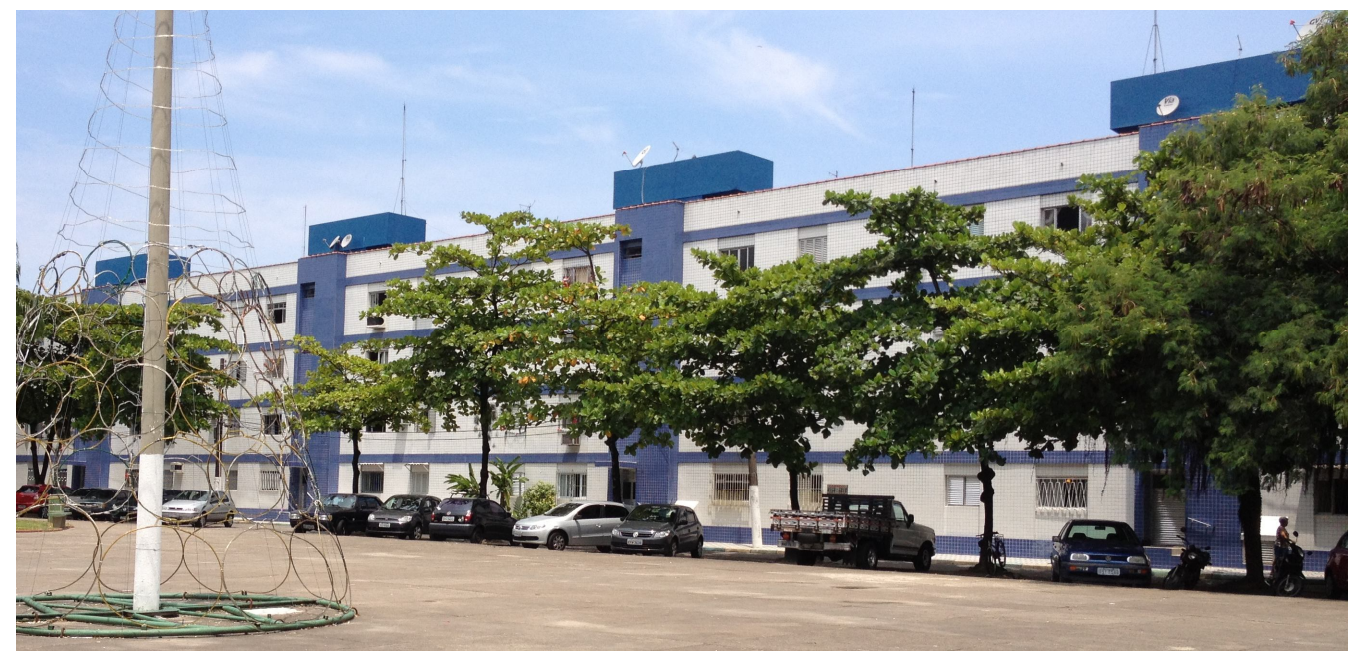

Figura 1: BNH de Santos. Fonte: Arquivo pessoal.

No início dos anos 1980, a crise econômica, marcada pelo desemprego, arrocho salarial e elevação incontrolada da inflação, agravou a situação dos mutuários do Sistema Financeiro da Habitação, que passaram a ter grandes dificuldades para pagar suas prestações, reajustadas pela correção monetária (associada à inflação) e juros. Em consequência, a inadimplência explodiu, dando origem a uma forte mobilização de mutuários, que lutaram para mudar as regras dos financiamentos. No curso desse movimento, consolidou-se a imagem de que se pagava muito para se receber uma moradia de baixa qualidade, elemento que desgastou ainda mais 0 regime militar (BONDUKI, 2014). 
Entre a forte crise econômica e política do início dos anos 1980, que afetou fortemente o Serviço Federal de Habitação e Urbanismo e o BNH, e a criação do Ministério das cidades, em 2003, quando uma nova política habitacional foi estruturada, o Brasil percorreu um dos mais interessantes e emocionantes processos de transição de uma ditadura para o regime democrático.

As décadas de 1980 e 1990 se caracterizaram pelo fortalecimento dos movimentos de moradia, que promoveram inúmeras ações mobilizadoras, como ocupações de terras e de imóveis ociosos, exigindo iniciativas concretas de poder público, o que acabou por promover a consolidação de propostas alternativas com o fim do BNH em 1986. Com a redemocratização, eleições livres e avanço da mobilização popular, municípios e estados foram forçados a implementar, de forma criativa e com recursos próprios, ações habitacionais baseadas em novos pressupostos.

Empossados em 1983, governadores eleitos pela oposição, como Franco Montoro, em São Paulo, e Leonel Brizola, no Rio de Janeiro, iniciaram programas habitacionais alternativos ao modelo convencional do BNH. Em São Paulo a antiga empresa habitacional do governo do estado foi redefinida e remodelada - passou a chamar Companhia de Desenvolvimento Habitacional e Urbano (CDHU) -, e foi criado um programa descentralizado, baseado em recursos orçamentários, parceria com municípios e organizações comunitárias, procurando produzir moradias a baixo custo em sistema de mutirão gerido pelo poder público.

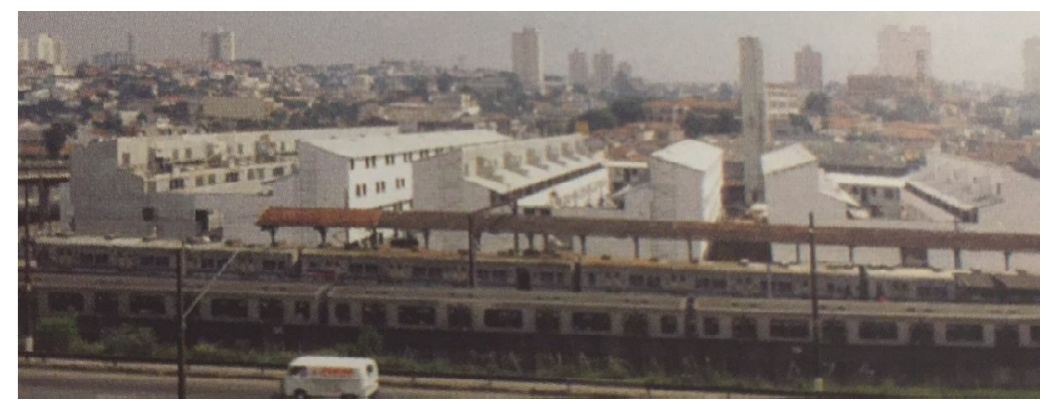

Figura 2: Conjunto do Rincão, Vila Matilde - São Paulo. Fonte: BONDUKI, 2014.

Empossados em 1983, governadores eleitos pela oposição, como Franco Montoro, em São Paulo, e Leonel Brizola, no Rio de Janeiro, iniciaram programas 
habitacionais alternativos ao modelo convencional do BNH. Em São Paulo a antiga empresa habitacional do governo do estado foi redefinida e remodelada - passou a chamar Companhia de Desenvolvimento Habitacional e Urbano (CDHU) -, e foi criado um programa descentralizado, baseado em recursos orçamentários, parceria com municípios e organizações comunitárias, procurando produzir moradias a baixo custo em sistema de mutirão gerido pelo poder público.

Atualmente, o Programa Minha Casa Minha Vida (PMCMV), criado em março de 2009, engloba a maior parte da habitação produzida para as classes média e média baixa no Brasil, sendo o responsável pelo aquecimento do mercado imobiliário. Entretanto, a questão que se coloca é qual o nível de qualidade desses novos empreendimentos, pois acima de metas quantitativas, deveria ser priorizada a qualidade arquitetônica e urbanística das moradias (BATISTA et al. 2014).

\subsection{CONJUNTO HABITACIONAL "MARECHAL HUMBERTO DE ALENCAR CASTELO BRANCO - BNH DE SANTOS-SP"}

Em 1968, o Engenheiro-Arquiteto Oswaldo Corrêa Gonçalves venceu o concurso promovido para a construção a ser financiada pelo $\mathrm{BNH}$ e orientada pelo Instituto de Orientação às Cooperativas INOCOOP, na cidade de Santos. O programa exigia um total de 2.800 apartamentos atendendo aproximadamente 10.000 habitantes, com área construída em torno de $150.000 \mathrm{~m}^{2}$ em um terreno de $81.424 \mathrm{~m}^{2}$ (SCAPUCCIN, 2005).

Segundo matéria publicada na Revista Acrópole (1968), o partido tomado era formado por blocos longos com unidades ligadas, em números pares com as seguintes características:

- Orientação: As fachadas com predominância de insolação do lado leste possuem azimute de $49^{\circ}$ enquanto que as fachadas com predominância de insolação oeste possuem azimute de $248^{\circ}$ para cada unidade. Estas têm dois lados preponderantes: social e de serviço. O primeiro está sempre voltado para o lado de maior espaço possível deixado entre blocos (9 metros). O outro lado recebe insolação razoável, inclusive para o último dormitório. A 
solução de blocos alongados no sentido Nordeste - Sudoeste foi preferido porque permitiria um fluxo contínuo de ventos oriundos do mar, evitando a criação de "zonas mortas" que fatalmente existiriam se fosse adotada a orientação Leste-Oeste para os blocos alongados.

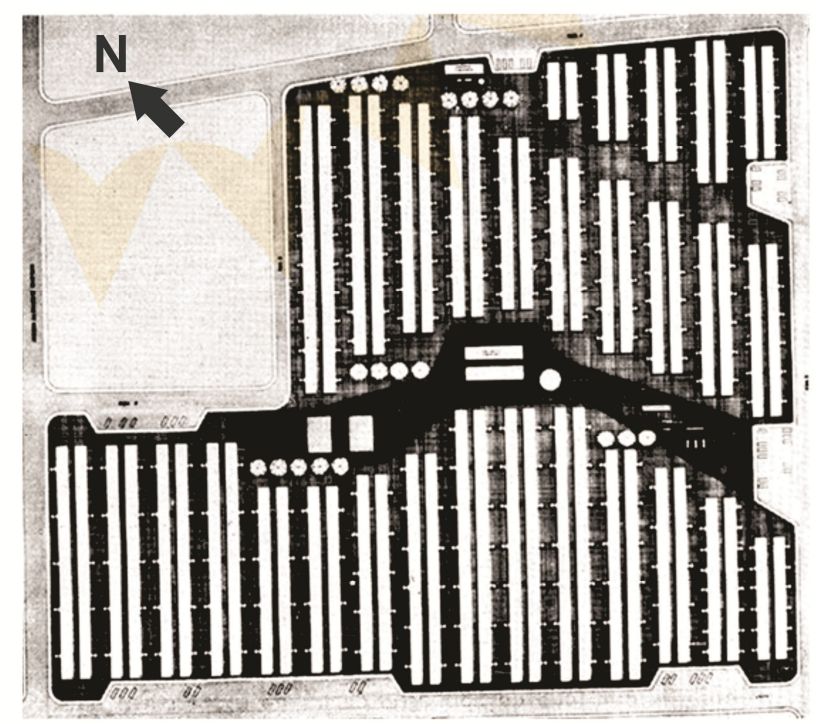

Figura 3: Implantação do projeto original do BNH de Santos. Fonte: Revista Acrópole n 350, 1968.

- Circulação: Foi considerado de máxima importância que se evitasse o trânsito de veículos na área, devido ao grande número de usuários que habitariam o projeto. A solução adotada para o sistema viário é periférica, por ruas existentes que contornam a área e uma rua nova proposta no lado Sul da gleba completando o anel.

- Espaços verdes: A presença do espaço verde também foi preocupação do projeto. As escadas externas aos blocos e a justaposição das unidades em blocos alongadas permitiram a criação de uma área livre no meio da gleba de tamanho suficiente para a implantação de um parque onde funcionasse um sistema de recreio aos habitantes do conjunto residencial. 


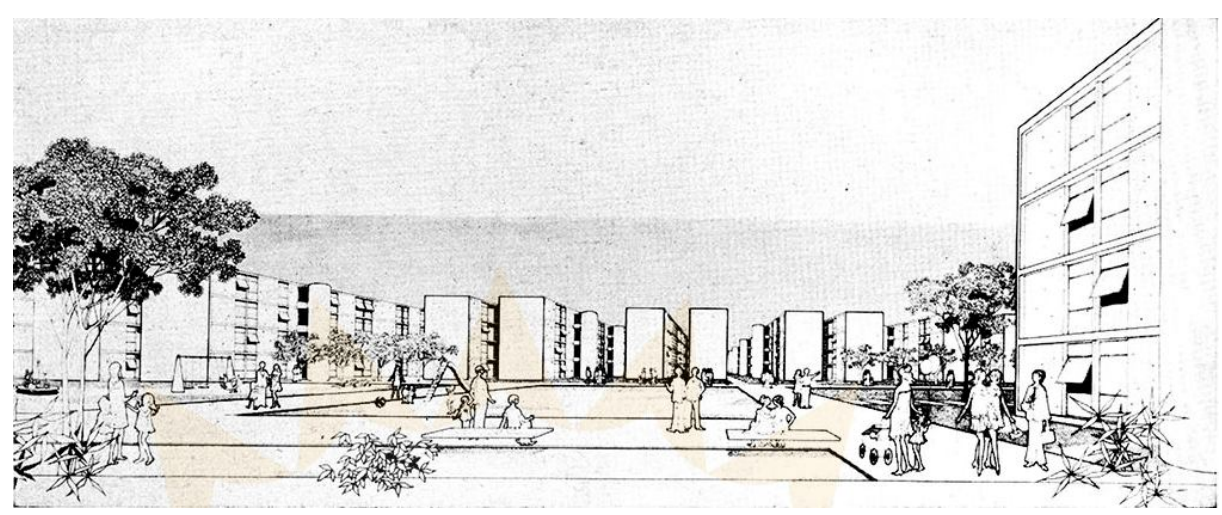

Figura 4: Proposta original dos espaços comuns do BNH de Santos. Fonte: Revista Acrópole n 350, 1968.

- Unidade de Habitação: Adotou-se como acesso uma escada para cada duas unidades por pavimento, reduzindo-se ao mínimo a área comum com a supressão de corredores. A colocação das escadas externas aos blocos permitiu redução substancial ao comprimento do bloco e em consequência o aumento da área verde. Também facilita a solução estrutural dos apartamentos. A justaposição de unidades diminui o número e seus revestimentos relativamente ao caso de unidades isoladas.

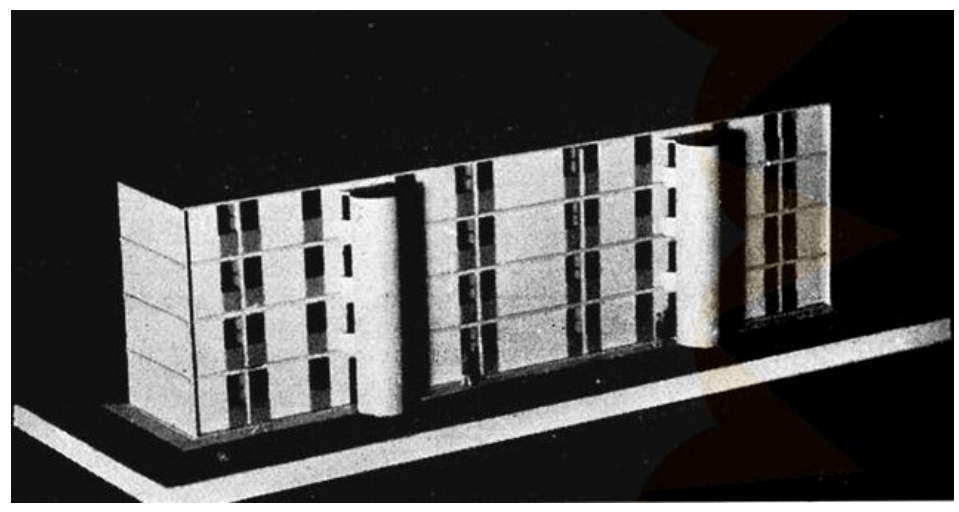

Figura 5: Tipologia do projeto original do BNH de Santos. Fonte: Revista Acrópole n 350, 1968.

Cada unidade teria como área útil, para cada tipo de apartamento, sendo as

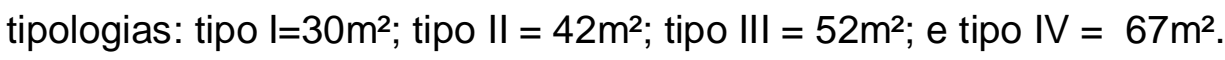




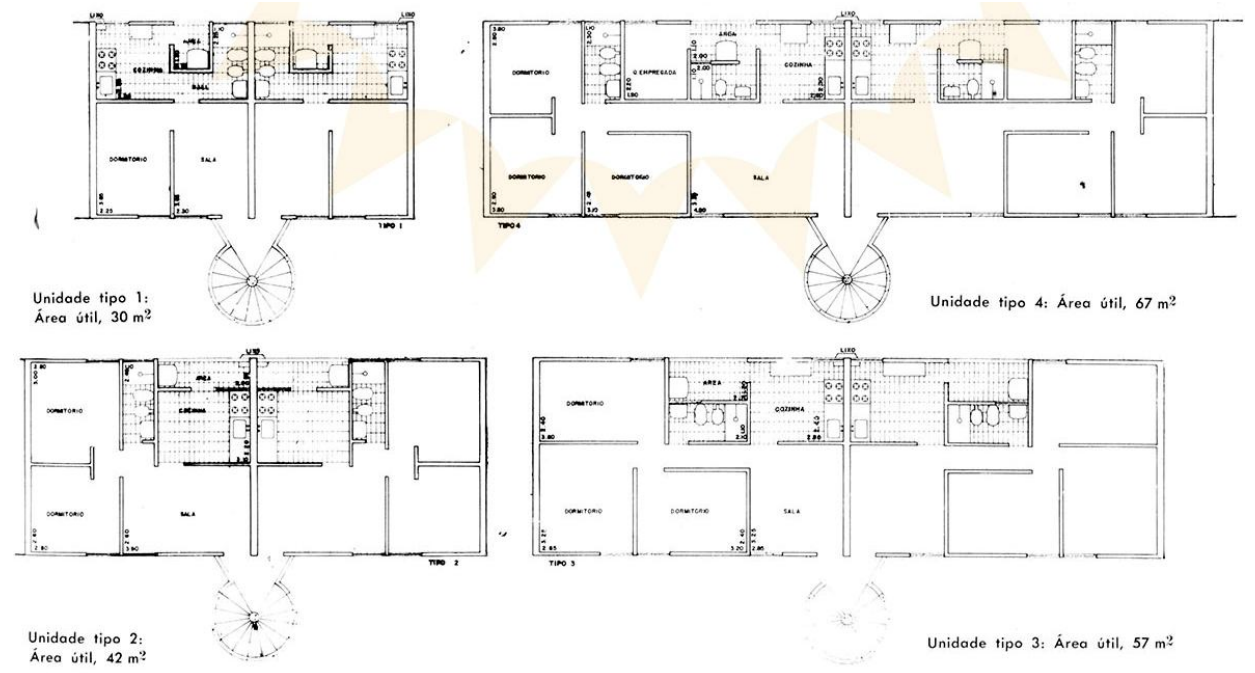

Figura 6: Layout das unidades do projeto original do BNH de Santos. Fonte: Revista Acrópole n 350, 1968.

A figura 7 mostra a morfologia urbana do entorno que envolve a atual área do BNH de Santos. Observa-se que houve uma significativa mudança na paisagem nesta região da cidade, resultante da verticalização urbana proposta pela cidade de Santos.

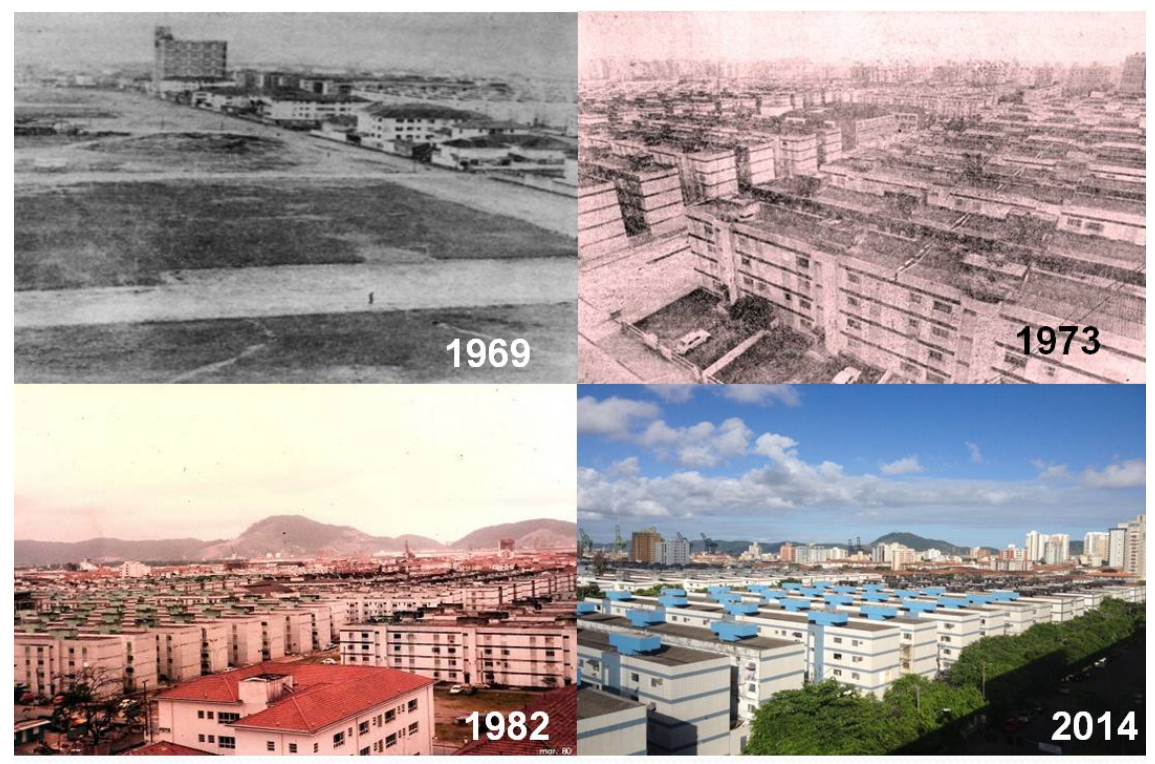

Figura 7: Morfologia do entorno da área do BNH de Santos. 


\subsection{CONFORTO TÉRMICO}

A conservação do equilíbrio térmico entre o corpo humano e seu ambiente é um dos principais requisitos para a saúde, bem-estar e conforto (GIVONI, 1976).

O conforto térmico pode ser obtido através de diferentes combinações no ambiente construído, como: nível de atividade (calor gerado pelo corpo), roupas adequadas para determinados climas e ambientes, temperatura do ar, temperatura radiante média, velocidade do ar e umidade relativa do ar. Para que o ambiente esteja proporcionando conforto térmico, vários sistemas podem ser aplicados, como a escolha correta dos materiais, adequação da edificação ao clima, estratégias corretas de projeto e aplicação de um sistema de ar condicionado.

A norma ASHRAE 55 (2010) define o conforto térmico como "um estado de espírito que expressa satisfação com o ambiente térmico que envolve a pessoa". Esta definição não esclarece o que significa estado de espírito e satisfação, mas enfatiza corretamente que o julgamento do conforto é um processo cognitivo, que envolve muitos dados de entrada influenciados por processos físicos, fisiológicos, psicológicos, entre outros (ASHRAE, 2005 apud TRIBESS, 2008).

O conforto térmico ocorre quando são mantidas as temperaturas do corpo em uma faixa estreita de variação, onde a evaporação de suor é pequena e o esforço fisiológico de regulação é minimizado.

Quando as condições térmicas tornam-se distintas para uma pessoa que esta em conforto, o organismo provoca reações desencadeadas pelo sistema termorregulador, que age no sentido de manter constante a temperatura interna do corpo frente a variações térmicas internas e externas. Esta ação mais intensa do sistema termorregulador causa sensação de desconforto.

Fanger estabelece três condições básicas para uma situação de conforto térmico:

A. A existência de equilíbrio através da troca de calor: O sistema termorregulador do corpo humano deve controlar a troca com o meio dentro de amplos limites de variação das condições ambientais, sem a qual o conforto não é estabelecido;

B. A temperatura média da pele; 
C. O calor eliminado por evaporação do suor na zona de regulação contra o calor. (TRIBESS, 2012).

De acordo com a ISO 7730 (2005), conforto térmico é um conceito que é influenciado por parâmetros que podem ser percebidos de forma distinta por todos os indivíduos. No entanto, tentativas de se desenvolver uma relação empírica que relacione à percepção humana as respostas fisiológicas ao conforto térmico estão sendo avaliadas. O modelo mais utilizado é o sugerido por Fanger (1972), conhecido como Predicted Mean Vote (PMV), que procura expressar quantitativamente o conforto térmico e a sensação térmica associada ao Predicted Percent of Dissatisfied (PPD), modelo este adotado pela ISO 7730 e aplicado a ambientes condicionados. O modelo desenvolvido por Fanger (1972) foi objeto de estudo realizado por estudantes em idade universitária, em condição ambiental não variável e climatizada, denominada de câmara climática. Estes estudos foram realizados na Universidade Técnica da Dinamarca e na Universidade de Kansas, nos Estados Unidos. Os parâmetros considerados foram a temperatura, a velocidade e umidade do ar e a temperatura radiante média, enquanto que os parâmetros pessoais foram o metabolismo e a resistência térmica que ocorre no corpo, além da pele, quando há vestimentas.

$O$ índice de PPD estipulado por Fanger estima o número de pessoas termicamente insatisfeitas entre um grande número de pessoas. A figura 8 apresenta a relação entre PMV e PPD.

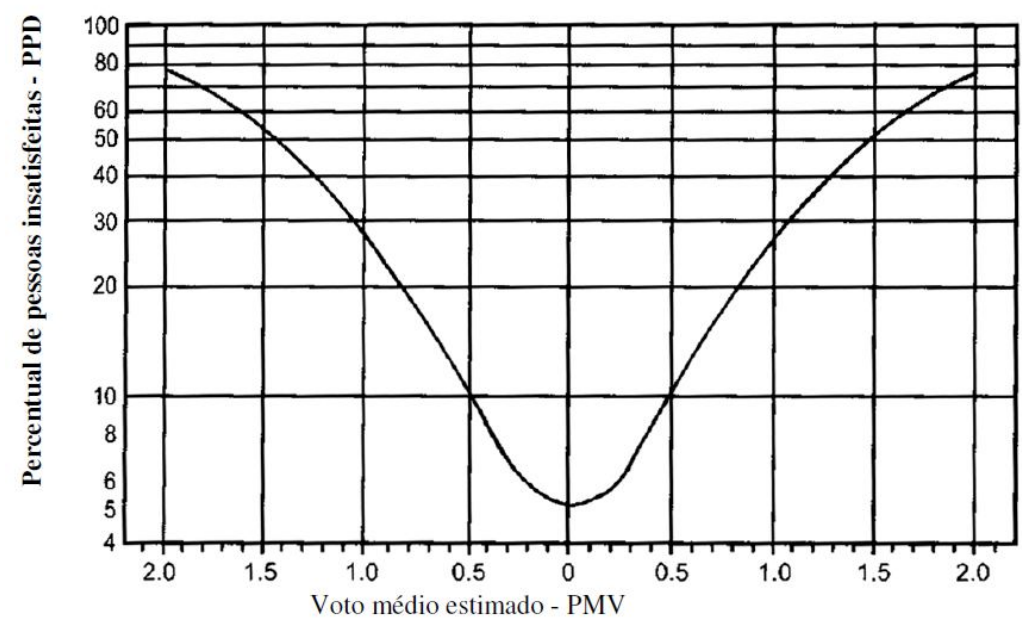

Figura 8: Relação entre PMV e PPD. (Adaptado da ISO 7730, 2005). 
Segundo Nicol (2004), existe um problema com relação à predição do conforto térmico ao utilizar a ISO 7730 em regiões de clima quente, já que existem limitações relacionadas à aplicabilidade do PMV. As temperaturas do ar acima de $30^{\circ} \mathrm{C}$ e velocidade do ar acima de $1 \mathrm{~m} / \mathrm{s}$ não são incomuns em edifícios de países tropicais. Existem muitos estudos de campo em climas quentes que revelam que os usuários em determinadas situações podem estar em conforto térmico com temperaturas de $30{ }^{\circ} \mathrm{C}$ ou superior, principalmente se utilizarem ventiladores.

Segundo Dear \& Brager (2002), ao compararem-se edifícios com sistema de ar condicionado e ventilação natural, os resultados sugerem que ocupantes em edificações climatizadas por sistemas de ar condicionado adaptam-se às condições térmicas mais homogêneas, enquanto ocupantes de edifícios ventilados naturalmente adaptam-se a uma gama maior de valores de sensações térmicas, mais próximos dos valores climáticos da temperatura externa.

Em edifícios climatizados artificialmente, o PMV torna-se uma ferramenta eficiente para identificar os valores de conforto térmico aos usuários, pois demonstra adaptações comportamentais em função das variáveis climáticas internas, como velocidade do ar e vestimentas dos usuários. Nos edifícios naturalmente ventilados existe uma diferença em relação aos parâmetros determinados pelo PMV e o modelo adaptativo, já que neste caso, as variáveis térmicas internas dependem diretamente da mudança de temperatura externa.

Conforme Pereira e Assis (2009) o PMV não é capaz de estimar a real sensação térmica de conforto térmico de indivíduos aclimatados a climas tropicais, condição predominante no território brasileiro, prevendo sensação de desconforto térmico mais severo do que os usuários realmente percebem.

Como alternativa ao uso do PMV, alguns autores brasileiros têm adotado diferentes índices adaptativos. Esses índices caracterizam-se por sua simplicidade: de modo geral, apresentam apenas uma temperatura de conforto térmico em função da temperatura média mensal registrada. Por esse motivo, servem como modelo exploratório nas etapas iniciais do projeto arquitetônico, nas quais o projetista possui poucos dados e necessita de informações objetivas para direcionar as estratégias que adotará. Contudo, não existe consenso sobre qual 
índice adaptativo usar, visto que existem vários modelos desenvolvidos no mundo, mas nenhum modelo desenvolvido ou validado para o país (PEREIRA \& ASSIS, 2009).

De acordo com a ASHRAE 55 (2010), para pessoas que vivem em ambientes naturalmente ventilados e estão aclimatadas a este tipo de ambiente, sugere-se um método para avaliação de conforto, denominado conforto adaptativo, onde os ocupantes têm a possibilidade de atuar sobre as aberturas (janelas) e sua vestimenta. Para que esta zona de conforto exista é necessário que a temperatura média mensal externa esteja em uma faixa de $10^{\circ} \mathrm{C}$ a $33,5^{\circ} \mathrm{C}$. Existe ainda um intervalo de tolerância para a temperatura operativa ${ }^{4}$ ideal, que considera as condições de conforto térmico em um ambiente para $80 \%$ ou $90 \%$ de satisfação dos ocupantes, conforme demonstrado na figura 9.

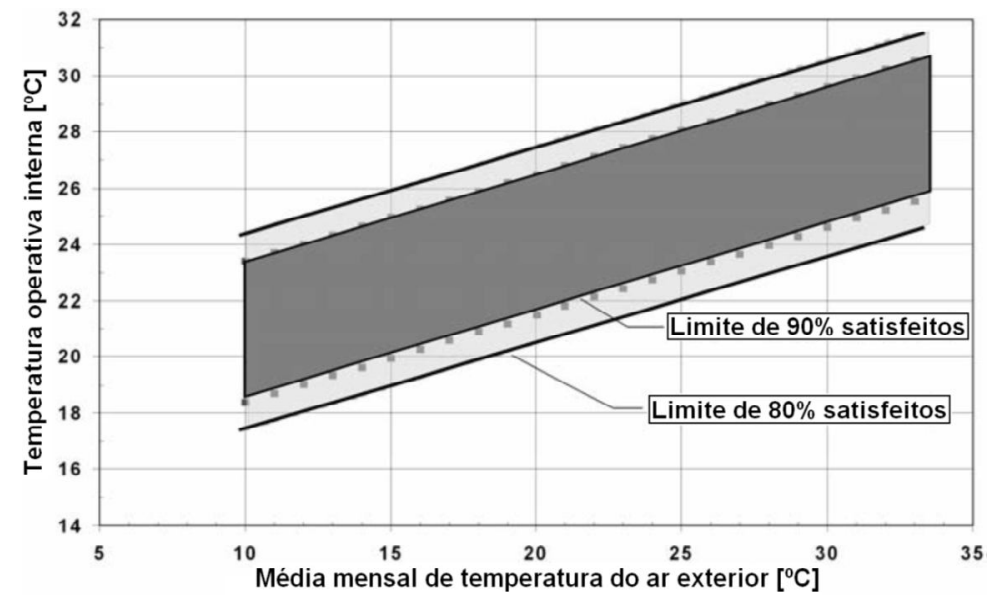

Figura 9: Faixas de temperaturas operativas aceitáveis para conforto em ambientes ventilados naturalmente (adaptado de ASHRAE 55, 2010).

De forma alternativa, considera-se que, a Temperatura Operativa no ambiente, $T_{o p}$ pode ser obtida pela equação:

\footnotetext{
${ }^{4}$ Temperatura Operativa é a temperatura uniforme de um ambiente com comportamento de corpo negro imaginário, no qual o ocupante poderia trocar a mesma quantidade de calor por radiação e convecção que no ambiente não uniforme (NBR 15.220-1/2005).
} 


$$
T_{o p}=a \cdot T_{a}+(1-a) \cdot \overline{T_{r}}
$$

Onde:

Top = Temperatura Operativa do ambiente;

a = Constantes em relação a velocidade do vento;

$\mathrm{Ta}=$ Temperatura do ar;

$\overline{T_{r}}=$ Temperatura Radiante média .

\begin{tabular}{|c|c|c|c|}
\hline $\mathrm{Va}(\mathrm{m} / \mathrm{s})$ & $0-0,2$ & $0,2-0,6$ & $0,6-1,0$ \\
\hline$\alpha$ & 0,5 & 0,6 & 0,7 \\
\hline
\end{tabular}

A velocidade do ar é considerada um parâmetro importante para o conforto térmico dos ocupantes em determinados ambientes, principalmente em períodos quentes, elemento essencial para a contribuição de retirada de carga térmica dos ambientes.

Segundo Cândido et al. (2011), foram propostas revisões aos limites de velocidades do ar levando em consideração a possibilidade de ajustes e controles da velocidade do ar realizado pelos ocupantes em determinados ambientes e para determinadas atividades, incluindo habitações e ambientes de trabalho. Esta aceitabilidade da velocidade do ar deve estar nos limites de $80 \%$ e $90 \%$, conforme mostra a figura 10 . 


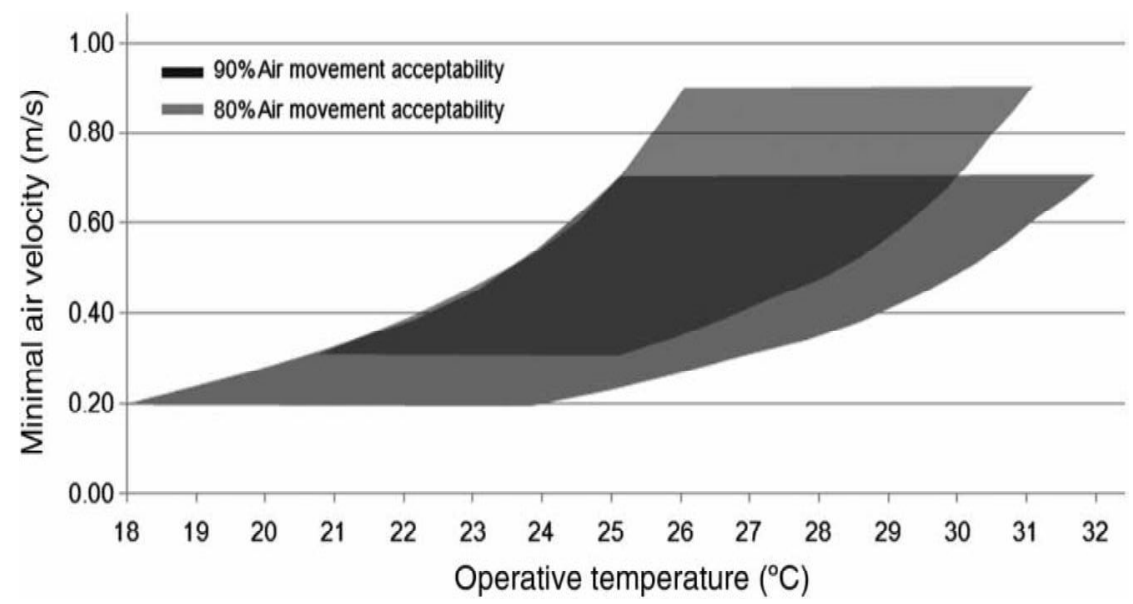

Figura 10: Valores de velocidade do ar mínima exigida dentro da zona de conforto ocupada. Fonte: Cândido et al 2011.

De acordo com Pereira e Assis (2009), os índices adaptativos buscam reproduzir as condições reais, nas quais o indivíduo também é agente nas condições térmicas do ambiente, ao interagir com o meio. A tabela 1 demonstra equações que determinam a temperatura de neutralidade desenvolvida por autores que buscam reproduzir condições reais dos índices adaptativos.

Tabela 2: Equações para cálculo de conforto da temperatura neutra.

\begin{tabular}{lll}
\hline \multicolumn{1}{c}{ Autores } & \multicolumn{1}{c}{ Equação } & \multicolumn{1}{c}{ Faixa de Conforto } \\
\hline Aluciems (1981) & $\mathrm{Tn}=0,314 . \mathrm{T}+17,6^{\circ} \mathrm{C}$ & $\begin{array}{l}\text { Sem definição } \\
\mathrm{Tn}+/-2 \text { a } 3^{\circ} \mathrm{C} \text { e em condições de umidade relativa } \\
\text { do ar elevada, } \mathrm{Tn}+/-1^{\circ} \mathrm{C} .\end{array}$ \\
$\begin{array}{lll}\text { Nicol e Humpheys } \\
\text { (2002) }\end{array}$ & $\mathrm{Tn}=0,540 . \mathrm{T}+13,5^{\circ} \mathrm{C}$ & $\begin{array}{l}\mathrm{Tn}+/-2^{\circ} \mathrm{C} \text { em situações onde não há } \\
\text { possibilidades de mudanças de vestimenta, nível } \\
\text { de atividade ou taxa de ventilação. }\end{array}$ \\
$\begin{array}{l}\text { De Dear e Brager } \\
\text { (2002) }\end{array}$ & $\mathrm{Tn}=0,310 . \mathrm{T}+17,8^{\circ} \mathrm{C}$ & $\begin{array}{l}\mathrm{Tn}+/-2,5^{\circ} \mathrm{C}(90 \% \text { de aceitabilidade }) \text { e } \mathrm{Tn}+/- \\
3,5^{\circ} \mathrm{C}(80 \% \text { de aceitabilidade }) .\end{array}$ \\
\hline
\end{tabular}

Fonte: Pereira e Assis (2009)

\subsubsection{Princípios fisiológicos e conforto}

O corpo humano dispõe de um mecanismo termorregulador, o qual controla as variações térmicas do organismo, e como o ser humano possui um organismo homotérmico, onde sua temperatura deva permanecer praticamente constante, esse mecanismo termorregulador cria condições para que isso ocorra. 
As pessoas podem apresentar zonas de respostas fisiológicas e comportamentais, de acordo com as condições a que estiverem submetidas e de acordo com a atividade que estiverem desempenhando. Segundo Lamberts e Xavier (2002), na maioria dos estudos de conforto térmico, as atividades desempenhadas são do tipo sedentárias, o fator humano de influência sobre a determinação da zona de conforto, é a vestimenta utilizada pelas pessoas. Podese então apresentar duas zonas de conforto, para pessoas vestidas e pessoas nuas, em função da temperatura do ar:

- Para pessoas nuas: Zona de conforto para que se mantenha o equilíbrio térmico situado entre $29^{\circ} \mathrm{C}$ e $31^{\circ} \mathrm{C}$;

- Para pessoas com vestimentas normais de trabalho (isolamento =0,5 clo): Zona de conforto para que se mantenha o equilíbrio térmico situa-se entre $23^{\circ} \mathrm{C}$ e $27^{\circ} \mathrm{C}$.

Fanger (1970) define que: "Neutralidade térmica é a condição na qual uma pessoa não prefira nem mais calor nem mais frio no ambiente a seu redor".

Cada indivíduo possui uma temperatura corporal neutra, isto é, que esteja em neutralidade térmica e nem necessite do seu mecanismo termorregulador.

\subsubsection{Balanço de calor do corpo humano e condições de conforto térmico}

O ganho de calor no corpo humano se dá através de produção de calor pelo metabolismo, e as perdas de calor se sucedem através da respiração e pela pele. As perdas de calor, de maneira sensível e latente, pela pele e pela respiração, são expressas em termos de fatores ambientais. As expressões também levam em conta a resistência térmica e a permeabilidade das roupas. A expressão do balanço de energia entre o corpo e o ambiente, é definida como (TRIBESS, 2008):

$$
M-W=Q_{S K}+Q_{R E S}
$$

As perdas de calor pela pele $\left(\boldsymbol{Q}_{\boldsymbol{S} K}\right)$ e respiração $\left(\boldsymbol{Q}_{\boldsymbol{R} E \boldsymbol{S}}\right)$, também são expressas em forma de mecanismo de perda de calor, como convecção, radiação 
e evaporação, e assim atingem-se a expressão dupla que representa o balanço de calor para o corpo em estado de repouso:

$$
M-W=Q_{S K}+Q_{R E S}=\left(C+R+E_{S K}\right)+\left(C_{R E S}+E_{R E S}\right)
$$

Onde:

$\mathrm{M}=$ Taxa metabólica de produção de calor $\left(\mathrm{W} / \mathrm{m}^{2}\right)$;

$\mathrm{W}=$ Trabalho mecânico desenvolvido pelo corpo $\left(\mathrm{W} / \mathrm{m}^{2}\right)$.

$\boldsymbol{Q}_{\boldsymbol{S} \boldsymbol{K}}=$ Taxa total de perda de calor pela pele $\left(\mathrm{W} / \mathrm{m}^{2}\right)$. Igual a perda de calor pela evaporação pela pele mais a condução de calor da pele até a superfície externa das roupas, podendo ser escrita como: $\boldsymbol{Q}_{S K}=\boldsymbol{E}_{S K}+\boldsymbol{E}_{C L}$;

$\boldsymbol{Q}_{\boldsymbol{R} E S}=$ Taxa total de perda de calor pela respiração $\left(\mathrm{W} / \mathrm{m}^{2}\right)$;

$\mathrm{C}+\mathrm{R}=$ Perda de calor latente pela pele, através da evaporação $\left(\mathrm{W} / \mathrm{m}^{2}\right)$;

$\boldsymbol{E}_{\boldsymbol{S}}=$ Perda de calor pela pele, através da evaporação $\left(\mathrm{W} / \mathrm{m}^{2}\right)$;

$\boldsymbol{C}_{\boldsymbol{R} E \boldsymbol{S}}=$ Perda de calor sensível pela respiração, por convecção $\left(\mathrm{W} / \mathrm{m}^{2}\right)$;

$\boldsymbol{E}_{\boldsymbol{R} E \boldsymbol{S}}=$ Perda de calor latente pela respiração, por evaporação $\left(\mathrm{W} / \mathrm{m}^{2}\right)$;

Desta forma, a expressão do balanço térmico pode ser reescrita da seguinte forma:

$$
(M-W)-C_{R E S}-E_{S K}-E_{R E S}=K_{C L}=C+R
$$

\subsubsection{Desconforto térmico localizado}

Vários fatores podem causar desconforto localizado em indivíduos, estejam eles desempenhando qualquer atividade. Estes fatores não atingem o corpo como um todo, e embora uma pessoa possa estar satisfeita com a temperatura do corpo como um todo, normalmente pode ficar incomodada e sair do seu estado de conforto. Entre os principais fatores que podem causar esse desconforto, podemos citar os mais comuns: 


\subsubsection{Assimetria de radiação térmica}

A radiação térmica em torno do ocupante pode não ser uniforme, devido tanto a superfícies frias ou quentes quanto à radiação solar direta. Esta assimetria pode causar desconforto local e reduzir a aceitabilidade térmica do ambiente. Em geral, as pessoas são mais sensíveis à radiação assimétrica causada por teto quente do que aquelas por superfícies verticais frias ou quentes (TRIBESS, 2008).

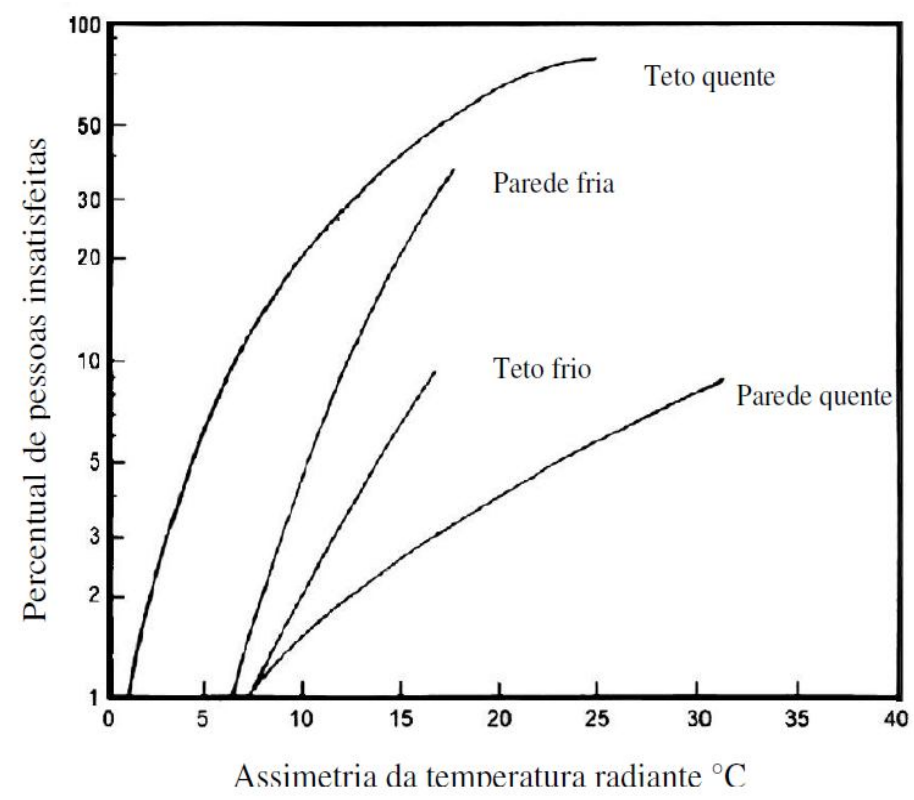

Figura 11: Percentual de pessoas insatisfeitas devido à assimetria da radiação (TRIBESS, 2008 apud ASHRAE 2010).

\subsubsection{Correntes de Ar (Draught rate-DR).}

Quando ocorre um resfriamento localizado e indesejado no corpo, devido ao movimento do ar, há uma sensação de corrente de ar, que depende da velocidade do ar, da temperatura do ar, da intensidade de turbulência, da atividade e da vestimenta das pessoas. A sensibilidade a corrente de ar é maior em partes do corpo descobertas, especialmente na região da cabeça, pescoço e ombros e na região dos pés, tornozelos e pernas (TRIBESS, 2008). 


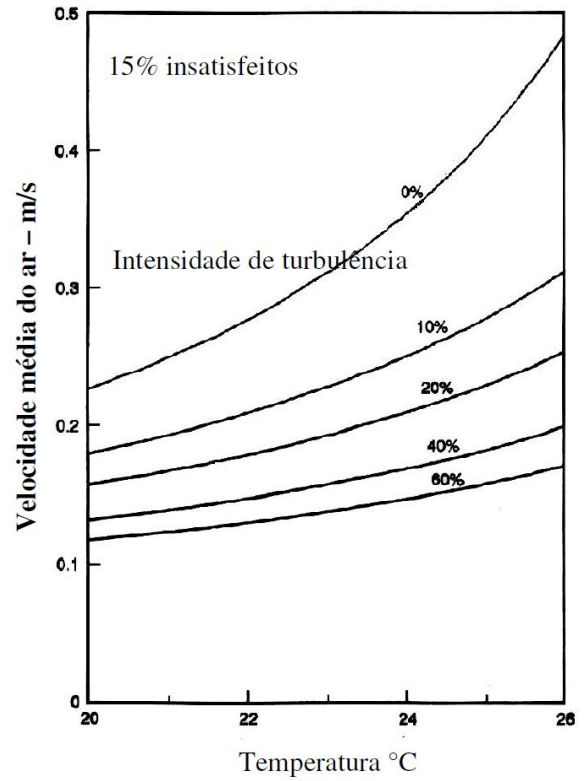

Figura 12: Correntes de ar para 15\% de insatisfeitos em atividade sedentária (TRIBESS, 2008 apud ASHRAE 2005).

\subsubsection{Diferença na temperatura do ar (sentido vertical)}

Na maioria dos ambientes das edificações, a temperatura do ar normalmente aumenta com a altura em relação ao piso. Se a gradiente de temperatura é suficientemente grande entre a temperatura ao nível da cabeça e a temperatura do tornozelo, ocorre desconforto por calor na altura da cabeça ou um desconforto por frio ao nível dos pés, estando o corpo como um todo em neutralidade térmica (LAMBERTS; XAVIER, 2002).

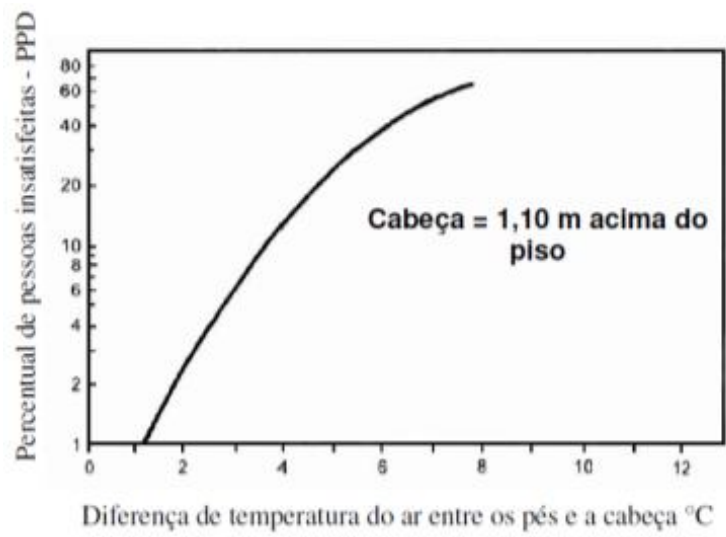

Figura 13: Percentual de pessoas insatisfeitas com a diferença vertical de temperatura do ar entre os pés e a cabeça (TRIBESS, 2008 apud ASHRAE 2010). 


\subsubsection{Desempenho térmico da edificação}

Para a avaliação do desempenho térmico, é necessário saber como variam a temperatura do ar, a umidade relativa do ar, a direção e a velocidade do vento e a radiação solar. Os valores horários dos parâmetros climáticos, necessários para a avaliação do desempenho térmico de edificações, são agrupados nos chamados dias típicos de projeto, para períodos de verão e de inverno (AKUTSU, 1998).

$\mathrm{O}$ desempenho térmico de uma edificação corresponde à resposta de um determinado abrigo, em termos de parâmetros climáticos interiores ao clima da área onde se encontra. A envoltória do edifício, que separa o ambiente interior do exterior, é determinante no desempenho térmico da edificação. As características termo físicas dos materiais e arquitetônicas influenciam significativamente nos fluxos energéticos.

\subsection{ZONEAMENTO BIOCLIMÁTICO E DADOS CLIMATOLÓGICOS DA CIDADE DE SANTOS}

O clima predominante no Brasil é o tropical. A influência da continentalidade, marítimidade, latitude, relevo e massas de ar faz com que, no Brasil, existam vários subtipos de clima tropical (continental, altitude e semiárido), subtropical e equatorial. Mesmo dentro de uma região geográfica do país ou dentro de um estado, há uma diversidade climática.

Segundo Abreu (2005) apud Monteiro (1975), é feita uma combinação na classificação de feições climáticas e fatores geográficos e humanos que estabelece uma graduação na classificação, da escala regional à local.

A área de estudo deste trabalho esta localizada na região litoral e Planalto Atlântico Sul, sendo esta a área de maior variação da pluviosidade devido ao afastamento da Serra de Paranapiacaba, com maior índice de penetração de massas polares e passagens frontais. Devido à topografia, há grande multiplicidade de climas locais, sendo o trecho litorâneo mais exposto a abaixamentos de temperatura. $O$ índice de precipitação polar no verão é o mais elevado do Estado. É também a área de maior pluviosidade do Estado de São Paulo e até mesmo do país, com índices pluviométricos anuais superiores a 
4.500mm. A proximidade da serra oferece acentuada influência da altitude no clima (ABREU, 2005).

O zoneamento bioclimático brasileiro é dividido em oito zonas bioclimáticas. Para este trabalho esta sendo utilizada a zona bioclimática 5 , que abrange 0 município de Santos, no estado de São Paulo, e para esta zona bioclimática, a NBR 15.220-3/2005 determina que as diretrizes construtivas para habitações unifamiliares de interesse social a serem seguidas nas decisões de projetos de edificações habitacionais são:

- Abertura para ventilação: Médias;

- Sombreamento das aberturas.

Estratégias de condicionamento térmico passivo para a Zona Bioclimática 5:

- No verão: Ventilação cruzada;

- No inverno: Vedações internas pesadas (inércia térmica).

Tabela 3: Dados Climáticos Santos-SP. Média entre os anos 2004 e 2013.

\begin{tabular}{lccccccccccccc}
\hline \multicolumn{1}{c}{ Meses } & Jan. & Fev & Mar & Abr & Mai & Jun & Jul & Ago & Set & Out & Nov & Dez \\
\hline Temp. Máx. Média $\left({ }^{\circ} \mathrm{C}\right)$ & 29 & 30,1 & 28,3 & 26,6 & 24,6 & 22,6 & 23,1 & 22,6 & 22,6 & 23,9 & 26,3 & 27,4 \\
Temp. Mín. Média $\left({ }^{\circ} \mathrm{C}\right)$ & 23,3 & 23,8 & 22,8 & 21,2 & 19,1 & 17,2 & 17,1 & 17,6 & 18,5 & 19,8 & 21,2 & 22,3 \\
Umidade relativa do ar $(\%)$ & 81 & 80 & 83 & 81 & 80 & 79 & 80 & 80 & 83 & 83 & 80 & 82 \\
Número de dias com chuva & 17 & 11 & 13 & 13 & 10 & 9 & 7 & 9 & 11 & 12 & 12 & 16 \\
\hline Precipitação mensal total $(\mathrm{mm})$ & 204 & 196 & 167 & 154 & 104 & 64 & 65 & 33 & 85 & 86 & 106 & 171 \\
\hline
\end{tabular}

Fonte: INMET, 2013.

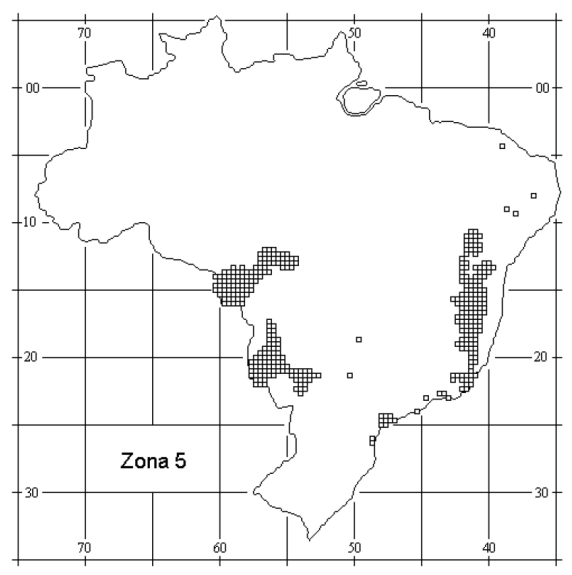

Figura 14: Zonas Bioclimática 5. Fonte: NBR 15.220-3/2005. 
A carta bioclimática brasileira basea-se nas considerações de Givoni, onde explica que o clima interno em edifícios não condicionados reage mais largamente à variação do clima externo e à experiência de uso dos habitantes, ou seja, a carta bioclimática proposta por Givoni permite identificar a partir da análise climática local, os parâmetros para o desenvolvimento dos projetos das edificações.

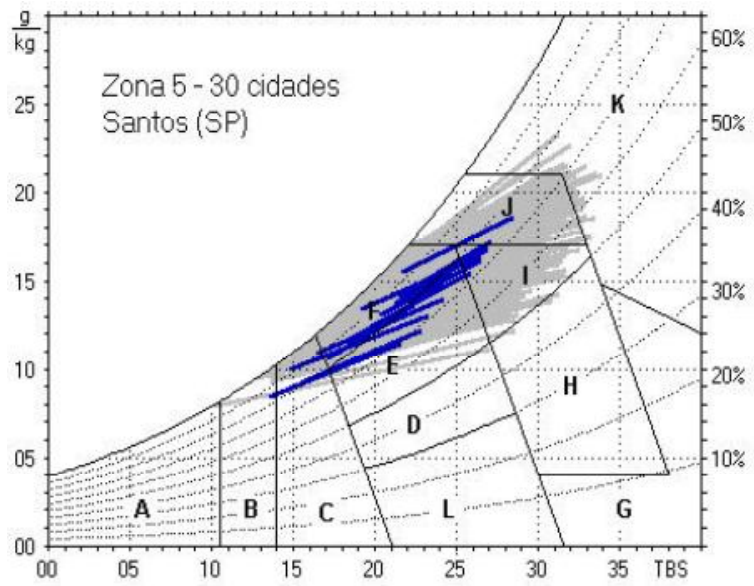

Figura 15: Carta bioclimática apresentando as normais climatológicas de cidades desta zona, destacando a cidade de Santos,SP. Fonte: NBR Fonte: NBR 15.220-3/2005. 


\section{JUSTIFICATIVA}

Esta pesquisa teve como motivação as manifestações dos usuários que alegaram, através de uma entrevista, que o que mais os incomodavam eram os aspectos de desconforto térmico, principalmente no período de verão, pelo fato de as temperaturas do ar dentro das unidades habitacionais permanecerem elevadas, uma vez que a cidade de Santos encontra-se em uma Zona Bioclimática com características de temperaturas elevadas no verão e alta umidade do transcorrer do ano. Pelos motivos citados, esta pesquisa buscou aprofundar quais eram os níveis de satisfação dos usuários ocorridos no interior dos apartamentos do BNH de Santos. 


\section{OBJETIVO}

O objetivo desta pesquisa é verificar se os usuários dos apartamentos do conjunto BNH de Santos encontram-se dentro dos padrões de conforto térmico estabelecidos por normas brasileiras e internacionais. Quando identificados apartamentos fora dos padrões estabelecidos, recomendar possíveis melhorias que contribuam com o conforto térmico interno dos apartamentos analisados.

\subsection{OBJETIVOS ESPECÍFICOS}

- Comparar as temperaturas operativas monitoradas no local em períodos de 24 horas, com a finalidade de avaliar o desempenho do conforto térmico interno dos apartamentos;

- Simular, através do software Energyplus, um modelo de apartamento representativo das habitações do $\mathrm{BNH}$, com dados climáticos e características construtivas semelhantes ao local de estudo, cujo objetivo é propor soluções que melhorem o conforto térmico dos apartamentos quando necessários.

- Utilizar a Norma ASHRAE 55 (2010), como base para as medições que estabelecem parâmetros de conforto térmico para os usuários e identificar se os apartamentos estão dentro das faixas de conforto estabelecidas por esta norma; 


\section{MATERIAIS E MÉTODOS}

Nos próximos itens serão discutidos os critérios de escolha e número de apartamentos da amostra, e descrição da instrumentação, dos procedimentos de medição e da análise de dados.

- Avaliar as respostas referentes à APO demonstrando os resultados através de gráficos e tabelas, identificando os problemas definidos pelos próprios moradores;

- Cotejar os resultados de medições realizadas in loco de parâmetros de conforto com as prescrições de normas nacionais e internacionais de conforto térmico;

- Comparar os resultados das entrevistas feitas com os moradores do conjunto quanto ao conforto térmico com os dados levantados com confortímetro e as faixas de conforto térmico determinadas pela ASHRAE 55 (2010);

\subsection{AVALIAÇÃO PÓS-OCUPAÇÃO E LEVANTAMENTO IN LOCO}

Segundo Romero e Ornstein (2003) A Avaliação Pós-Ocupação (APO) é um processo sistematizado e rigoroso de avaliação de edifícios, passado algum tempo de sua construção e ocupação, tendo como objeto de análises os seus ocupantes e as suas necessidades, elaborando levantamentos a partir dos quais se formam conclusões acerca das consequências das decisões de projeto no desempenho da edificação, sendo um instrumento útil na implementação de melhorias na criação de edifícios futuros e para se criar um banco de dados que colabore na prevenção e manutenção dos mesmos.

A APO, portanto, diz respeito a uma série de métodos e técnicas que diagnosticam fatores positivos e negativos do ambiente durante sua utilização, a partir da análise de fatores socioeconômicos, de infraestrutura e superestrutura urbanas dos sistemas construtivos, conforto ambiental, conservação de energia, 
fatores estéticos, funcionais e comportamentais, levando em consideração o ponto de vista dos próprios avaliadores, projetistas e usuários.

A abordagem da APO para esta pesquisa foi direcionada à avaliação do conforto térmico nos ambientes definidos em cada apartamento, procurando identificar as queixas definidas pelos próprios usuários.

A figura 16 demonstra a primeira parte do modelo do questionário aplicado, onde foram avaliadas as sensações de conforto térmico e ventilação natural descrita pelos usuários.

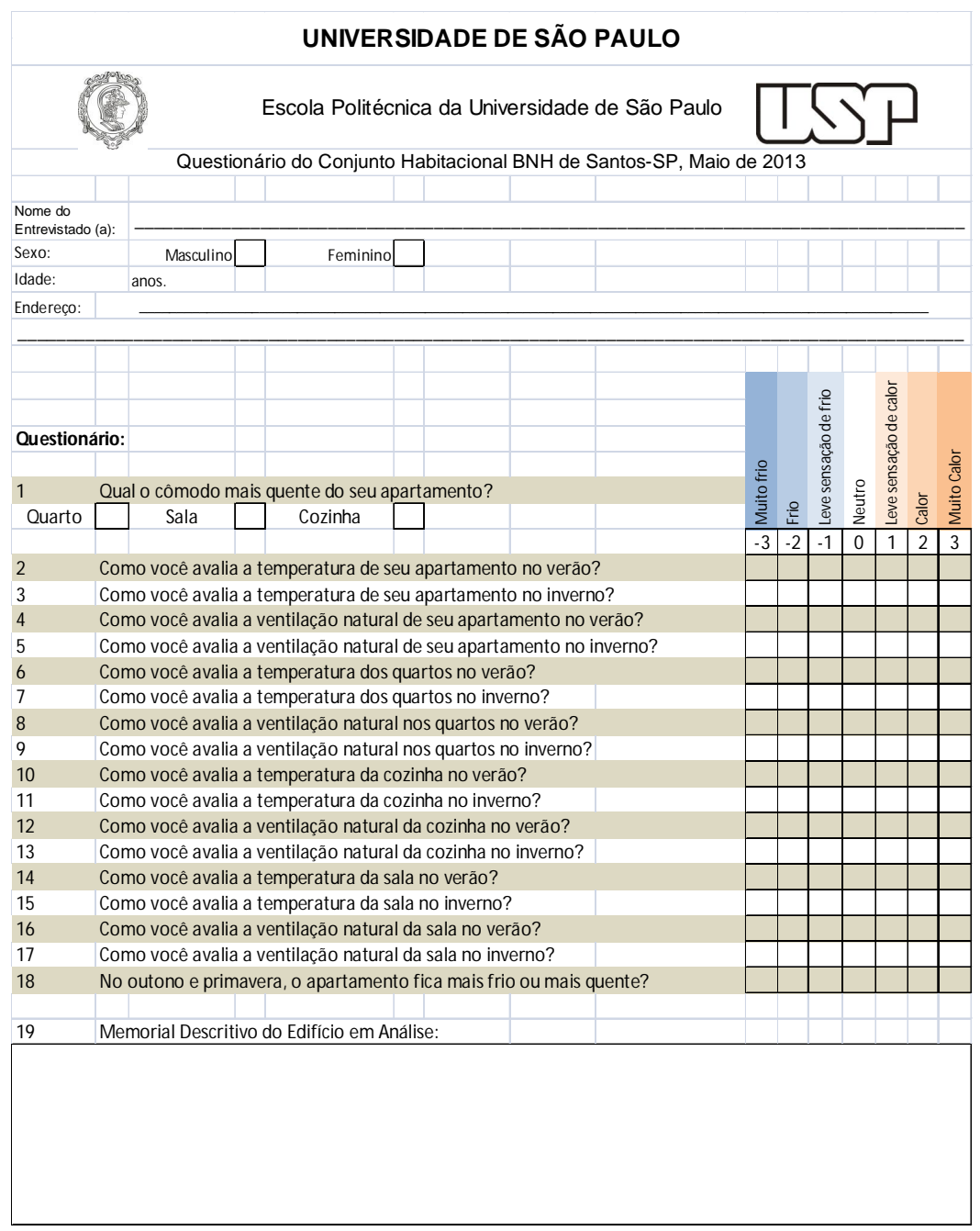

Figura 16: Modelo de questionário aplicado aos moradores para levantamento da APO. 
Inicialmente foi realizada uma avaliação de satisfação por parte dos usuários, por meio de um questionário com 18 questões referentes ao conforto térmico no interior dos apartamentos. Posterior às avaliações nas entrevistas, estabeleceu-se critérios específicos de conforto térmico para as unidades habitacionais avaliadas, além de um levantamento das características da envoltória do local. As respostas dos usuários foram inseridas às escalas de valores da ISO 7730 (2005), conforme a Tabela 4:

Tabela 4: Escala de sensação térmica.

\begin{tabular}{cc}
\hline Escala & Sensação \\
\hline+3 & Muito quente \\
+2 & Quente \\
+1 & Leve sensação de calor \\
0 & Neutro \\
-1 & Leve sensação de frio \\
-2 & Frio \\
-3 & Muito frio \\
\hline Fonte: ISO $7730,2005$.
\end{tabular}

A segunda etapa do questionário identificou os equipamentos utilizados nos ambientes onde seriam feitas as análises de conforto térmico de cada apartamento, conforme modelo demonstrado na figura 17. 


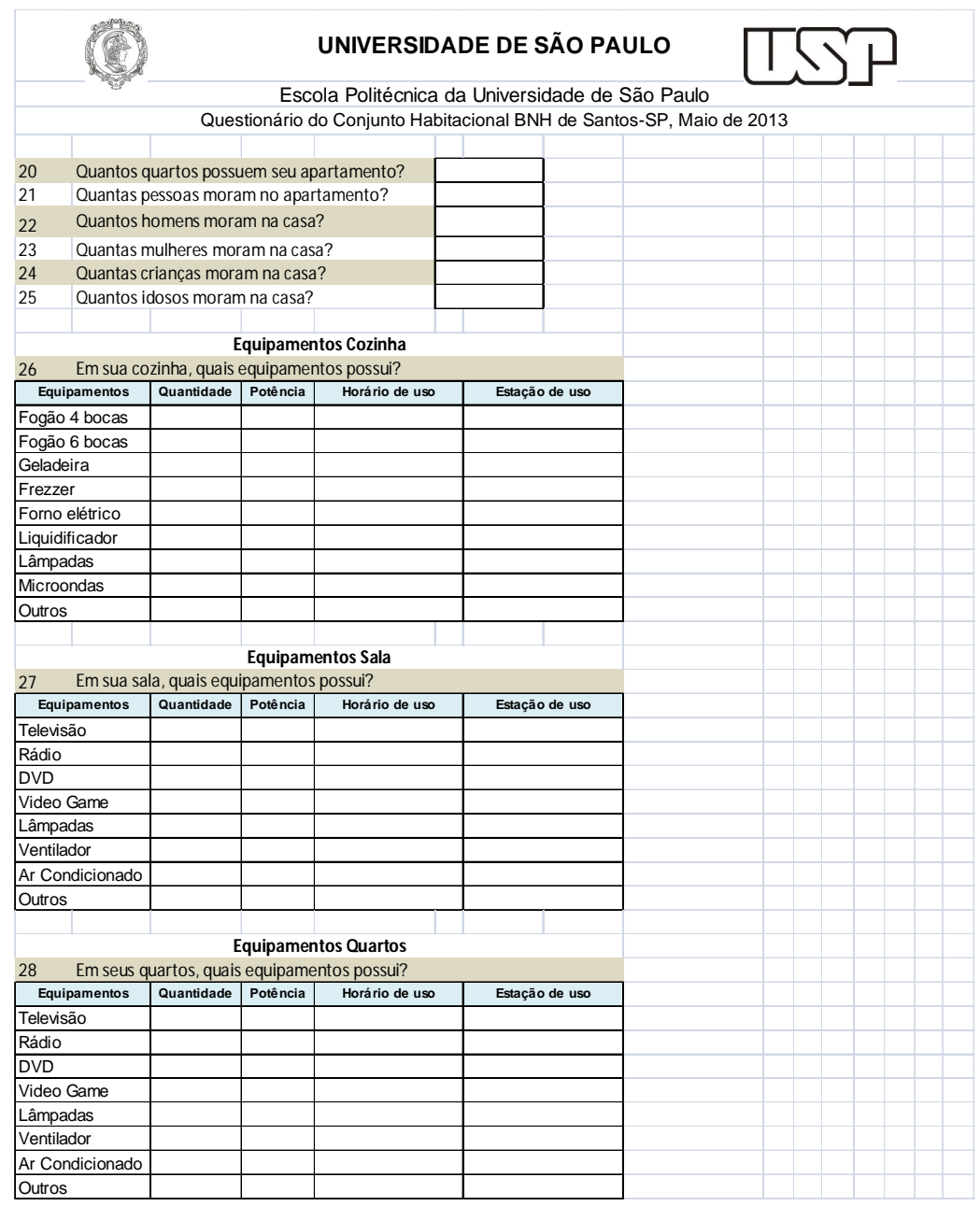

Figura 17: Modelo de questionário aplicado aos moradores para levantamento dos equipamentos elétricos e eletrônicos.

Além da APO, foram medidas as áreas e pé direito dos cômodos onde seriam feitas as coletas dos dados térmicos, com a finalidade de identificar os tamanhos dos apartamentos, em metros quadrados, relacionados ao número de pessoas que ali habitavam. Para a coleta de dados utilizou-se um confortímetro. O passo seguinte foi avaliar o posicionamento das fachadas a serem estudadas, através de bússolas e imagens aéreas, identificando assim o norte verdadeiro para as análises.

A construção do Shopping influenciou diretamente no bloqueio da ventilação natural, que vem do mar (ventos predominantes sudoeste), localizado em frente do Shopping, sendo a falta de ventilação natural local uma das mais significativas queixas dos moradores do $\mathrm{BNH}$, demonstrado na figura 18. 


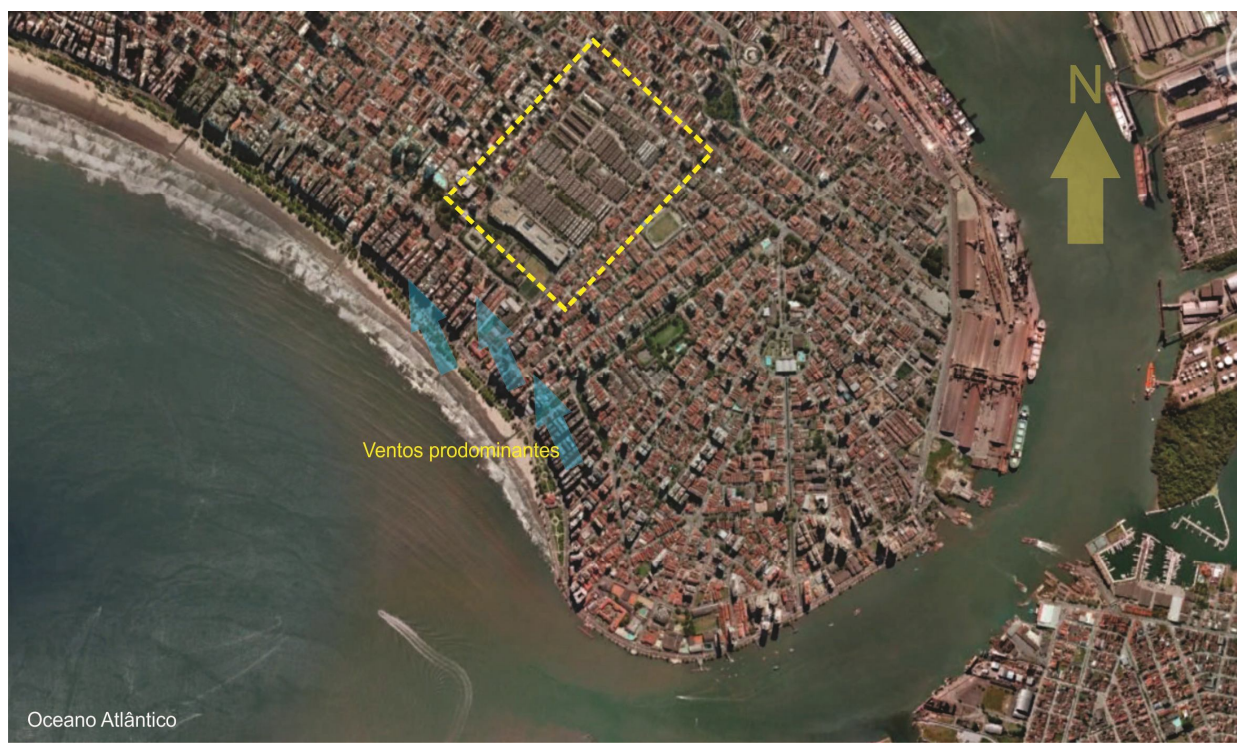

Figura 18: Localização do Complexo BNH de Santos-SP. Fonte: Google Earth.

A figura 19 mostra a localização do complexo com seus respectivos conjuntos e, indicando a localização de um Shopping Center construído há aproximadamente uma década.

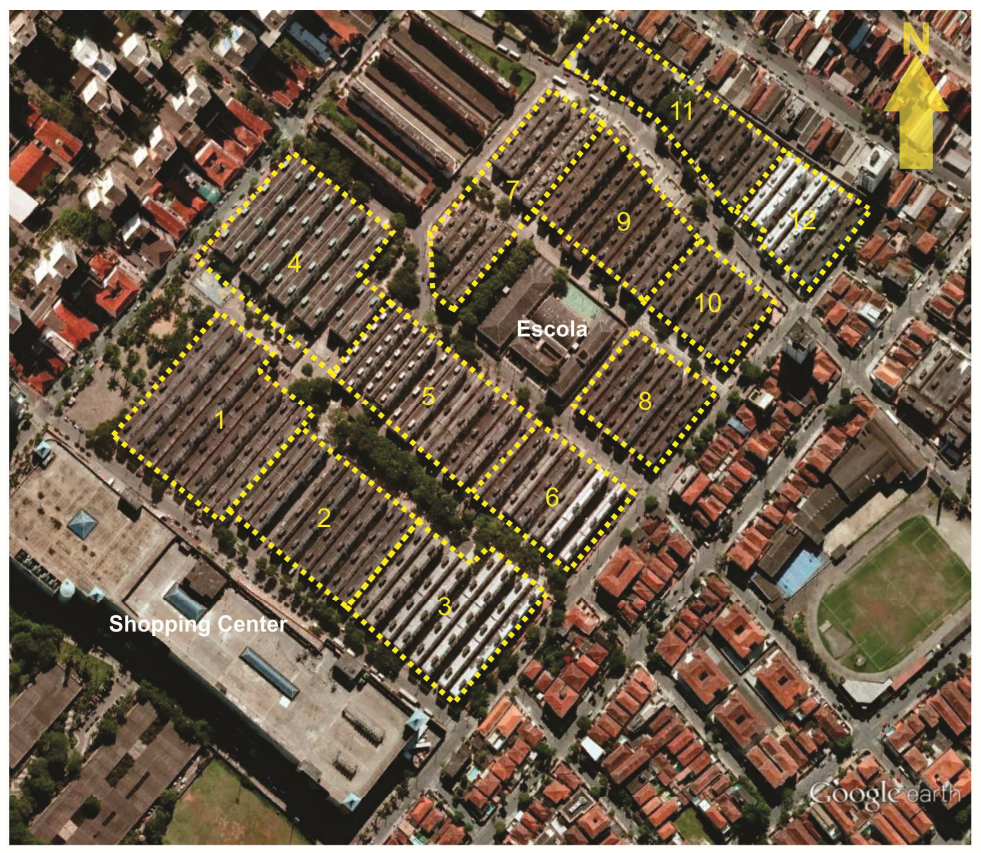
1- Conjunto Argentina
2- Conjunto Bolívia;
6- Conjunto Guiana Francesa;
11- Conjunto Uruguai;
3- Conjunto Chile;
7- Conjunto Guiana Inglesa;
12- Conjunto Venezuela.
4- Conjunto Colombia;
8- Conjunto Paragua ;
9- Conjunto Peru;
10- Conjunto Suriname

Figura 19: Vista aérea (implantação atual) do Complexo BNH de Santos-SP. Fonte: Google Earth. 
Sabe-se que para a análise da ventilação natural nos edifícios, a distribuição da pressão do vento sobre a superfície de uma construção depende da forma do edifício, da velocidade do vento e a direção em relação à edificação, além da localização do edifício e seu entorno.

O BNH de Santos está inserido dentro de uma malha urbana adensada por edificações verticais maiores, ocorrendo desta forma uma queda na velocidade média do vento proveniente da praia, principalmente em função da obstrução ocorrida pela existência de um Shopping.

\subsection{COMPOSIÇÃO DA AMOSTRA}

Posteriormente às escolhas e identificações dos objetos de estudos, houve a necessidade de um levantamento in loco, buscando diagnosticar os problemas existentes referentes ao desconforto térmico, porém antes de apresentar as conclusões relacionadas à composição da amostra, foi necessário estabelecer algumas considerações sobre os fundamentos estatísticos para a elaboração desta dissertação.

\subsubsection{Conceituação de estatísticas e amostragens}

Podemos considerar a Estatística como ciência que se preocupa com a organização, descrição, análise e interpretação dos dados experimentais (COSTA NETO, 1978).

Sendo a Estatística uma ciência que busca tirar conclusões probabilísticas sobre determinada população, esta por sua vez busca resultados verificados em amostras que são retiradas destas populações de análises. As maneiras pelas quais, a partir dessas amostras, tiram-se conclusões aproximadas de diversos aspectos das populações estudadas.

É preciso garantir que a amostra ou amostras utilizadas sejam obtidas por processos adequados. Se erros grosseiros forem cometidos no momento de 
selecionar os elementos da amostra, o trabalho todo ficará comprometido e os resultados finais estarão provavelmente incorretos.

\subsubsection{Amostra não probabilística: amostras por conveniências}

A amostra não probabilística é obtida a partir de algum tipo de critério, e nem todos os elementos da população têm a mesma chance de ser selecionado, o que torna os resultados não generalizáveis. Guardando suas limitações, esse tipo de amostra pode ser conveniente quando os respondentes são pessoas difíceis de identificar ou grupos específicos ou, ainda, quando existe restrição no orçamento da pesquisa (FREITAS et al, 2000 apud FINK, 1995).

Segundo Freitas et al. (2000), na amostra por conveniência, os participantes são escolhidos por estarem disponíveis, logo, foram entrevistadas apenas pessoas que estavam a disposição nas ruas do $\mathrm{BNH}$, os moradores não foram acionados em suas respectivas moradias.

\subsubsection{Plano amostral}

Todo o universo do BNH de Santos-SP é formado por todos os apartamentos existentes no conjunto, considerando todos os pavimentos. Os apartamentos possuem as seguintes tipologias: 01 quarto, 02 quartos e 03 quartos, podendo estar nas fachadas noroeste ou sudeste em relação à rua.

A população objeto desta pesquisa foi formada através dos resultados obtidos nas entrevistas. Para o dimensionamento estatístico da amostra, foram necessárias realizar algumas medições pilotos a fim de obter dados suficientes para determinar um número mínimo de amostras, através de um valor estimado de uma variável, associando ao índice de confiança esperado e relativa margem de erro.

Para identificar o tamanho da amostra, foi utilizada a expressão a seguir: 


$$
n=\frac{Z a^{2} \cdot s^{2} \cdot N}{(N-1) \cdot e^{2}+s^{2} \cdot Z a^{2}}
$$

Onde:

$\mathrm{N}=$ Tamanho do universo (População);

Z $\alpha=1,96$ (Probabilidade de 95\% de confiabilidade);

s = Limite superior (desvio padrão);

$\mathrm{e}=$ Limite de erro (Intervalo de confiança).

O gráfico a seguir, nos fornece um nível de confiança de 95\%, ou seja, o nível de significância ( $\alpha$ ) é a probabilidade de errar a estimativa, e se $\alpha$ corresponder $5 \%$, teremos $2,5 \%(\alpha / 2)$ à esquerda do limite inferior do intervalo e $2,5 \%$ à direita do limite superior, ou seja, estas serão as probabilidades da estimativa estar fora do intervalo especificado. Assim teremos uma área de $47,5 \%$ entre a média amostral e o limite superior do intervalo, o que nos fornece uma área total (nível de confiança) de $95 \%$ conforme demonstrado na figura 20 :

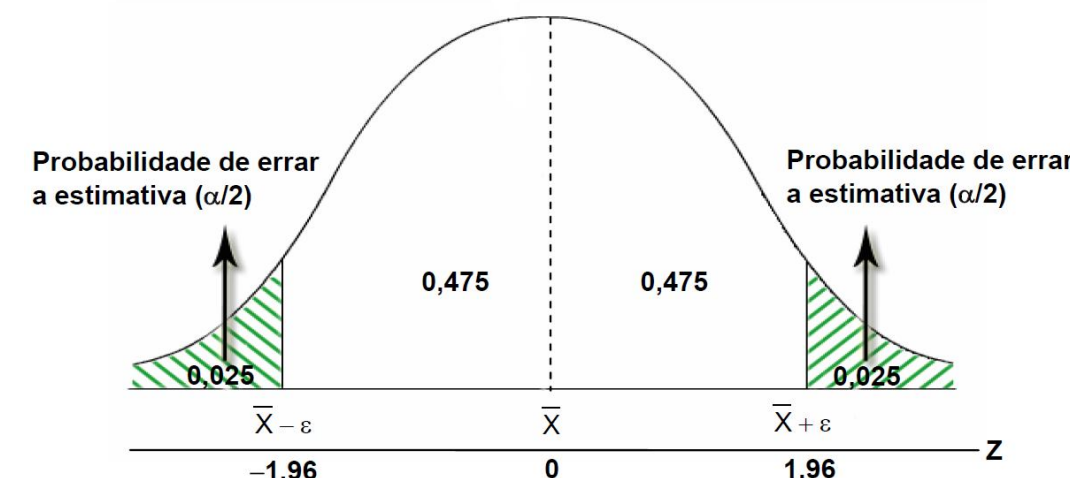

Figura 20: Limite superior do intervalo de confiança para 95\% de confiabilidade.

Procurando na tabela da distribuição Normal Padrão a área de 0,475, encontramos exatamente este valor, correspondente a uma abscissa de 1,96, valor de intervalo de confiança utilizado para esta pesquisa. 
Uma vez fixados a e $n$, pode-se determinar e (amplitude do intervalo de confiança) através da equação a seguir:

$$
e_{0=Z_{\alpha}} \frac{\sigma}{\sqrt{n}}
$$

Onde:

e 0 = Intervalo de confiança;

$Z \alpha=1,96$ (Probabilidade de 95\% de confiabilidade);

$\sigma=$ Desvio padrão;

$\mathrm{n}=$ tamanho da amostra

Portanto, tirando as médias e os desvios padrões do levantamento piloto das variáveis de temperatura ambiente, de cinco apartamentos, calcula-se:

$$
\begin{aligned}
& e_{0=1.96 \frac{0,74}{\sqrt{5}}} \\
& e_{0=+/-0,65}
\end{aligned}
$$

Sendo a Média das temperaturas ambiente dos apartamentos medidos de $22,4^{\circ} \mathrm{C}$, o intervalo de confiança para o cálculo da amostragem será entre $21,75^{\circ} \mathrm{C}$ e $23,05^{\circ} \mathrm{C}$ (Valores adotados no início da pesquisa, sendo a estação o inverno). Aplicando o valor do intervalo de confiança na fórmula a seguir, teremos:

$$
\begin{gathered}
n=\frac{Z a^{2} \cdot S^{2} \cdot N}{(N-1) \cdot e^{2}+s^{2} \cdot Z a^{2}} \\
n=\frac{1,96^{2} \cdot 0,74^{2} \cdot 3280}{(3280-1) \cdot 0,65^{2}+0,74^{2} \cdot 1,96^{2}}
\end{gathered}
$$

$$
n=5 \text { Apartamentos }
$$


Apesar de a amostra ter como resultado 5 apartamentos, foram escolhidos 8 apartamentos como garantia de que o valor mínimo fosse preservado.

\subsection{INSTRUMENTAÇÃO}

Para o levantamento quantitativo da análise das condições ambientais dos apartamentos do $\mathrm{BNH}$, utilizou-se um confortímetro. O confortímetro é constituído por um tripé, hastes para apoio das sondas, cabos, sondas para medição dos parâmetros ambientais e de desconforto local, além de um datalogger para armazenamento de dados, conforme demonstrado na figura 21. Esse equipamento possui dois sistemas operacionais: Programa "A" (análise de microclima) e Programa "B" (desconforto térmico). Para esta pesquisa foi utilizado apenas o Programa "A".

Para a medição das condições ambientais de cada apartamento, o confortímetro obtém os seguintes dados de saída:

Tnw: temperatura do bulbo úmido a ventilação natural;

Tg: temperatura de globo;

Ta: temperatura ambiente;

Pr; pressão atmosférica

Rh: umidade relativa do ar;

Va: velocidade do ar;

To: Temperatura operativa.

Além das medições diretas efetuadas com as sondas conectadas, 0 instrumento é também capaz de calcular e visualizar diretamente os seguintes dados:

- Índice WBGT (Wet Bulb Globe Temperature) ou IBUTG: índice de temperatura de bulbo úmido e de globo. É um dos índices utilizados para a determinação do estresse térmico em ambientes quentes onde o 
usuário possa estar. Representa o valor, em relação ao metabolismo associado a uma atividade particular de trabalho, que quando superado, leva o individuo a uma situação de estresse térmico. O IBUTG combina a medição de temperatura do bulbo úmido a ventilação natural, Tnw, com a temperatura do globo, $\mathrm{Tg}$, e, em algumas situações, com a temperatura do ar, Ta.

- $\operatorname{Tr}$ (Temperatura Radiante Média): A temperatura Radiante Média é a temperatura uniforme de um ambiente imaginário onde a troca de calor por radiação do corpo humano é igual à troca de calor por radiação em um ambiente real não uniforme.

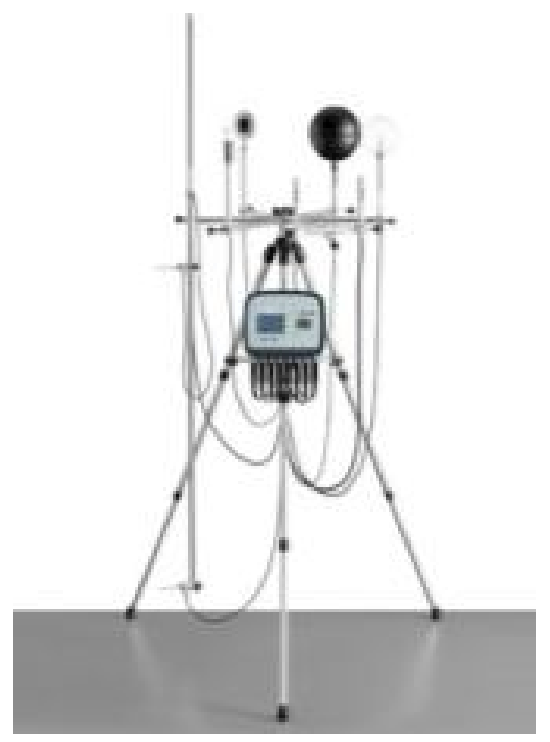

Figura 21: Monitor de análises climáticas Delta Ohm 32.1 (confortímetro).

A tabela 5 apresenta os tipos de sensores e respectivos intervalos e incertezas de medição de acordo com o manual de uso dos equipamentos, utilizados no Programa $A$, onde os modelos especificados são:

- AP3203 - Anemômetro de fio quente para medir velocidade do ar;

- HP3201 - Sonda combinada a bulbo úmido e ventilação natural;

- HP3217 - Sonda combinada de temperatura e umidade relativa do ar.

- TP3275 - Sonda globotermômetro, utilizada para a medição da Temperatura Média Radiante e WBGT; 
Tabela 5 - Especificação dos sensores utilizados na pesquisa (Programa A).

\begin{tabular}{|c|c|c|c|}
\hline Modelo & Tipo de sensor & $\begin{array}{l}\text { Intervalo de } \\
\text { medição }\end{array}$ & Incerteza de medição \\
\hline AP3203 & $\begin{array}{l}\text { Anemômetro (NTC } \\
\text { 10Kohm) }\end{array}$ & $\begin{array}{l}0^{\circ} \mathrm{C} \text { a } 80^{\circ} \mathrm{Ce} \\
0 \mathrm{~m} / \mathrm{s} \text { a } 5 \mathrm{~m} / \mathrm{s}\end{array}$ & $\begin{array}{l} \pm 0.02 \mathrm{~m} / \mathrm{s}(0 \text { a } 1 \mathrm{~m} / \mathrm{s}) \\
\pm 0.1 \mathrm{~m} / \mathrm{s}(1 \text { a } 5 \mathrm{~m} / \mathrm{s})\end{array}$ \\
\hline HP3201 & Pt100 (TBU) & $4^{\circ} \mathrm{C}$ a $80^{\circ} \mathrm{C}$ & Classe A \\
\hline HP3217 & $\begin{array}{l}\text { Pt100 + sensor } \\
\text { capacitivo }\end{array}$ & $\begin{array}{l}-10^{\circ} \mathrm{C} \text { a } 80^{\circ} \mathrm{C} \\
5 \% \text { a } 98 \%\end{array}$ & Classe $1 / 3$ DIN $\pm 2,5 \%$ \\
\hline TP3275 & Pt100 & $-10^{\circ} \mathrm{C}$ a $100^{\circ} \mathrm{C}$ & Classe 1/3 DIN \\
\hline
\end{tabular}

Fonte: Manual do sistema de microclimas do confortímetro HD 32.1

A incerteza de medição específica às classes conforme normas europeias:

Classe $1 / 3$ DIN $=1 / 3 \times(0,3+0,005 \times \mathrm{Ta})$

Classe $A= \pm(0,15+0,002 \times \mathrm{Tbu})$

Onde:

Ta $=$ temperatura de bulbo seco $\left({ }^{\circ} \mathrm{C}\right)$;

Tbu = temperatura de bulbo úmido $\left({ }^{\circ} \mathrm{C}\right)$.

As incertezas de medição, especificadas pelas normas europeias, dependem das variáveis medidas in loco. Quanto maior a temperatura, maior a incerteza. Por exemplo, para uma temperatura de bulbo seco de $21^{\circ} \mathrm{C}$, o erro para a classe $1 / 3$ DIN seria de $\pm 0,135^{\circ} \mathrm{C}$. Já para $27^{\circ} \mathrm{C}$, a incerteza de medição seria de \pm $0,145^{\circ} \mathrm{C} \pm 2,5 \%$, o que corresponderia a uma variação de temperatura de aproximadamente $26,85^{\circ} \mathrm{C}$ a $27,15^{\circ} \mathrm{C}$ (SUZUKI, 2010).

A ISO 7726 (1998) especifica as seguintes características para os instrumentos de medição para conforto térmico: 
Tabela 6: Características dos instrumentos de medição

\begin{tabular}{l|ll}
\hline Parâmetro & $\begin{array}{l}\text { Intervalo de } \\
\text { medição }\end{array}$ & Incerteza de medição \\
\hline $\begin{array}{l}\text { Temperatura do ar } \\
\text { Temperatura radiante }\end{array}$ & $10^{\circ} \mathrm{C}$ a $40^{\circ} \mathrm{C}$ & $\begin{array}{l}\text { Solicitada: } \pm 0,5^{\circ} \mathrm{C} \\
\text { Desejada: } \pm 0,2^{\circ} \mathrm{C} \\
\text { média }\end{array}$ \\
$\begin{array}{ll}\text { Solicitada: } \pm 2^{\circ} \mathrm{C} \\
\text { Desejada: } \pm 0,2^{\circ} \mathrm{C}\end{array}$ \\
Velocidade do ar $40^{\circ} \mathrm{C}$ & $\begin{array}{l}\text { Solicitada: } \pm(0,05+0,05 . \mathrm{Va}) \mathrm{m} / \mathrm{s} \\
\text { Desejada: } \pm(0,02+0,07 . \mathrm{Va}) \mathrm{m} / \mathrm{s} \\
\pm 0,15 \mathrm{kPa}\end{array}$ \\
\hline
\end{tabular}

Não somente os dados de intervalos de medição, quanto às incertezas dos equipamentos normalmente utilizados, estão de acordo com os intervalos e valores estipulados pela norma ISO 7726 (1998) de instrumentação para a medição de quantidades físicas.

\subsubsection{Sensor de umidade relativa}

Para a medição da umidade, utilizou-se um sensor do tipo capacitivo, no qual a medição da umidade relativa é fornecida pela variação da capacidade elétrica do sensor, de acordo com as solicitações da ISO 7726, 1998. A figura 22 mostra uma sonda combinada de temperatura e umidade do equipamento, que foi utilizada para medição.
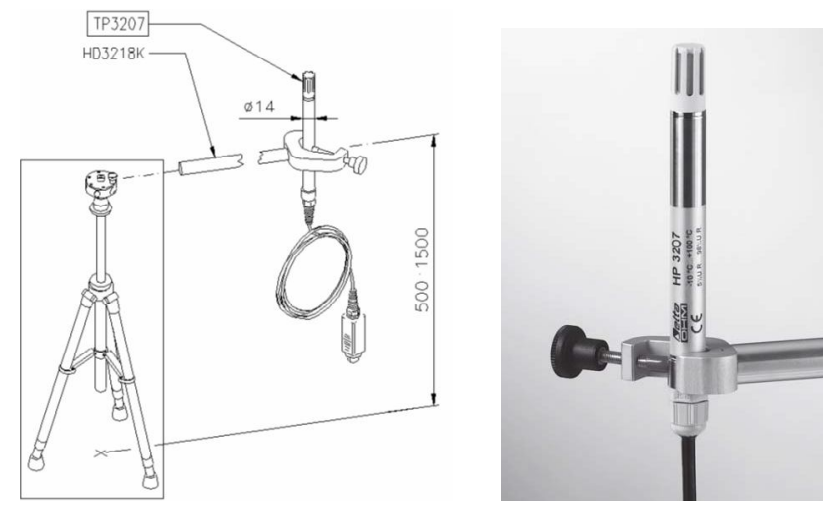

Figura 22: HP3217 - Sonda combinada de temperatura e umidade. Fonte: Manual HD 32.1. 


\subsubsection{Anemômetro}

Foi utilizado para a medição da velocidade do ar um anemômetro térmico (fio quente), que consiste em uma termorresistência aquecida junto com um sensor termistor inserido na ponta de uma sonda. Com o movimento do ar, o sensor, que fica eletricamente aquecido, esfria proporcionalmente à velocidade do fluxo de ar. A figura 23 demonstra o modelo utilizado nas medições deste trabalho:
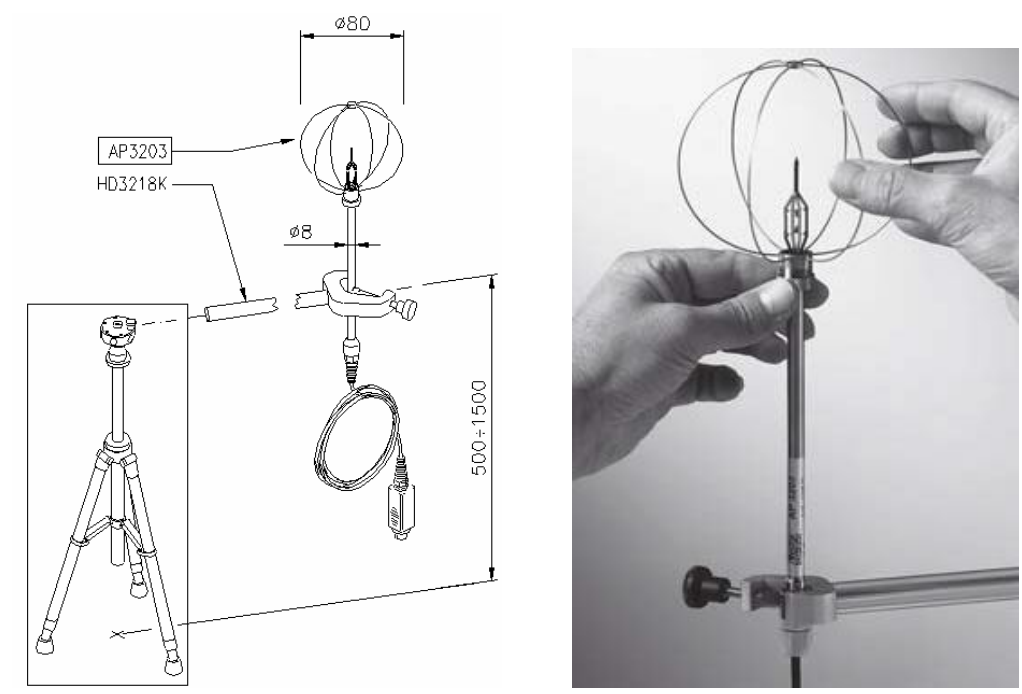

Figura 23: AP3203 - Sonda a fio quente multidirecional para velocidade do ar. Fonte: Manual HD 32.1.

\subsubsection{Sensor de temperatura de globo negro}

Consiste em um sensor de temperatura Pt100 que é inserido dentro de um globo negro, geralmente com diâmetro de $150 \mathrm{~mm}$. É usado para obter um valor aproximado de temperatura radiante média por meio dos valores simultâneos de temperatura de globo $(T g)$, temperatura ambiente $(T a)$ e velocidade do ar ( $V a)$ em volta do globo, de acordo com a ASHRAE (2010). O formato esférico do sensor de globo pode fornecer uma aproximação razoável do formato do corpo de uma pessoa sentada (ISO 7726, 1998). 

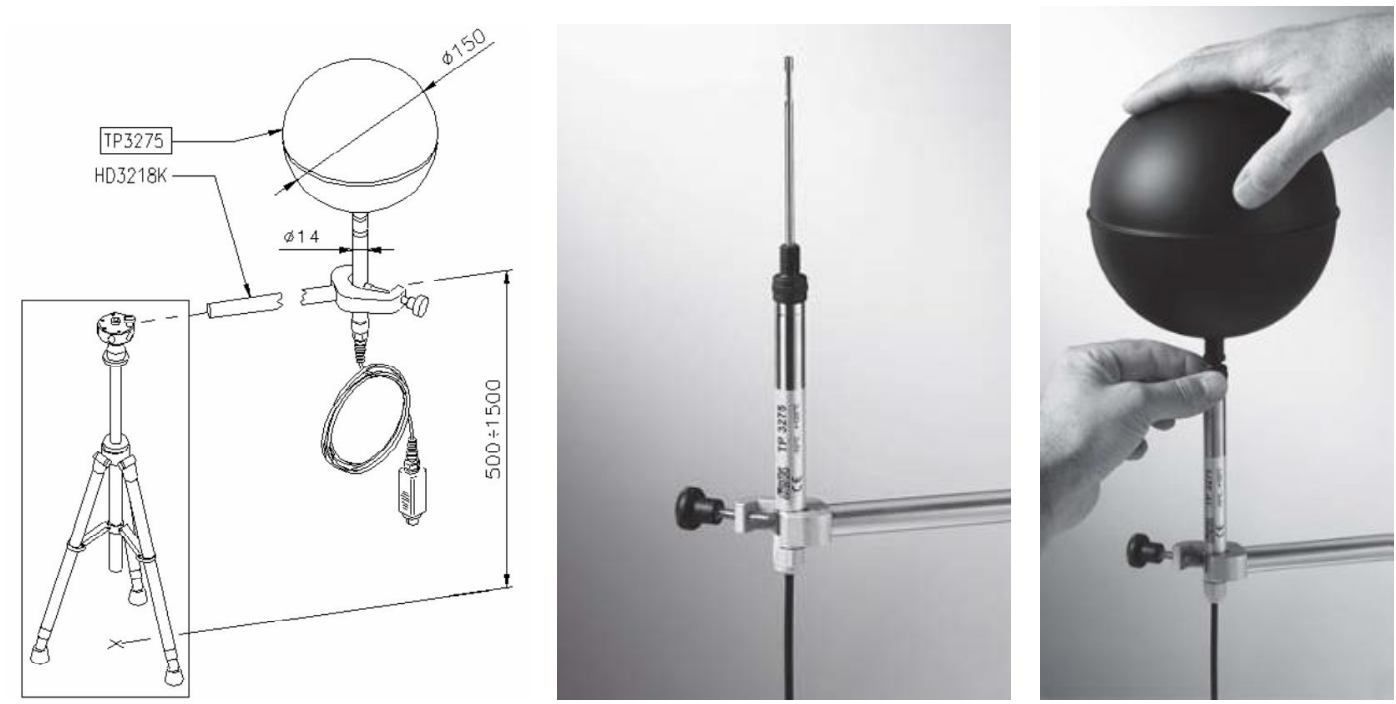

Figura 24: TP3275 - Sensor de temperatura com globo negro. Fonte: Manual HD 32.1.

\subsubsection{Sensor de bulbo úmido e ventilação natural}

Consiste em uma sonda a bulbo úmido e a ventilação natural, possuindo um sensor do tipo Pt100 mm. Para utilização, no recipiente necessita ser inserida água destilada, para que se possa medir a máxima quantidade de vapor $d$ água no ar em relação à máxima quantidade que pode ser mantida, em uma dada temperatura.

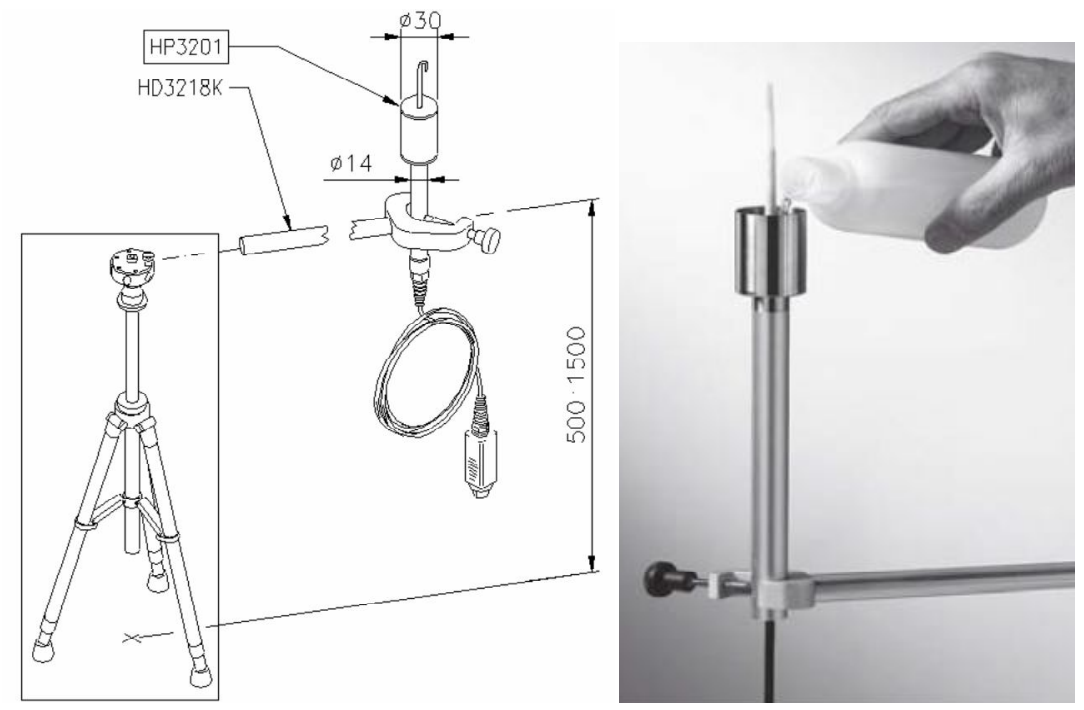

Figura 25: HP3217 - Sonda bulbo úmido a ventilação natural. Fonte: Manual HD 32.1. 
As temperaturas internas do ambiente foram registradas com o confortímetro, localizado no centro do quarto, nos horários entre 11:50 horas e 14:50 horas. Os segundos registros eram efetivados no centro da sala nos horários entre 15:00 horas e 17:00 horas. Tal instrumento serviu para registrar os valores da temperatura do ar, temperatura de globo, umidade e velocidade do ar dos ambientes. Durante as medições, o controle de janelas e portas foi realizado livremente pelos usuários, sem nenhuma interferência do pesquisador, ficando proibido apenas à utilização de aparelhos de ar condicionado e ventiladores durante o horário das medições.

Para a análise de desempenho térmico, utilizou-se um termômetro de fluxo de laser, dispositivo utilizado para medir a temperatura das superfícies. As temperaturas foram medidas nas paredes voltadas pra rua, paredes internas e teto do apartamento.

\subsection{SOFTWARE ENERGYPLUS}

Para que se realizasse uma análise comparativa entre os registros das variáveis ambientais e as temperaturas das superfícies do ambiente medidas pelo confortímetro e o termômetro, respectivamente, utilizou-se o software Energyplus versão 8.1, software de análise energética e de simulação de carga térmica.

Segundo Neto et al (2008), para que os dados apresentem resultados mais precisos, os dados de entrada devem se basear em um banco de dados próximos da realidade, quando disponíveis.

Para a simulação de um dia, o usuário deve fornecer um conjunto de parâmetros, tais como temperatura máxima e mínima de bulbo seco, temperatura de bulbo úmido, velocidade e direção do vento, etc., todas estas informações para um único dia. O software fornecerá para esse dia a mesma saída de informações de uma simulação anual (NETO et al, 2008).

O modelo utilizado para a simulação fundamentou-se em princípios de balanço energético, os mesmos dados coletados na medição in loco com o confortímetro foram adaptados ao software com o objetivo de fazer uma análise comparativa de desempenho entre o software e os resultados determinados pelo aparelho. A partir desta análise foram inseridos no software os dados climáticos de 
entrada da cidade de Iguape $^{5}$ com o propósito de deixar os dados de entrada próximos à realidade do local.

O sistema construtivo adotado no projeto padrão basea-se em uma tecnologia convencional aplicada principalmente em Habitações de Interesse Social e em outros setores da construção no Brasil. Todos os apartamentos do BNH foram construídos com alvenaria de tijolo cerâmico furado, argamassa de cimento, janelas com vidro simples, venezianas de alumínio e lajes de concreto comum. Inicialmente os apartamentos foram executados com piso de madeira, mas a maioria dos usuários optou por trocar os pisos por material cerâmico, como é o caso da unidade em estudo.

As características construtivas do $\mathrm{BNH}$, demonstradas na tabela 7 , os dados climáticos da cidade de Santos e os resultados identificados nas medições in loco pelo confortímetro ${ }^{6}$, foram inseridas no Banco de Dados no software Energyplus, para que as simulações feitas no mesmo período anual pudessem ser comparadas com maior precisão.

Tabela 7: Características dos materiais componentes das paredes externas, piso e laje.

\begin{tabular}{lcccc}
\hline \multicolumn{1}{c}{ Descrição } & $\mathrm{e}(\mathrm{m})$ & $\lambda((\mathrm{W} /(\mathrm{m} \cdot \mathrm{K}))$ & $\begin{array}{c}\mathrm{d} \\
\left(\mathrm{Kg} / \mathrm{m}^{3}\right)\end{array}$ & $\begin{array}{c}\mathrm{C} \\
\left(\mathrm{J} / \mathrm{Kg}^{\circ} \mathrm{C}\right)\end{array}$ \\
\hline Concreto Comum & 0.20 & 1,28 & 2000 & 1005 \\
Piso cerâmico & 0.005 & 0,46 & Variável & 837 \\
Argamassa de cal e cimento (ou de & 0.015 & 0,85 & 1800 & 754 \\
cimento) & 0,004 & 0,8 & 2200 & 667 \\
Vidro simples & 0,01 & 0,65 & 1600 & 1005 \\
Telha de fibrocimento & 0,15 & 0,7 & 1300 & 920 \\
Tijolo cerâmico furado & 0,001 & 230 & 2700 & 900 \\
Alumínio & & & &
\end{tabular}

Fonte: adaptada da NBR 15.220-3/2005.

Através do software livre da Google, o Sketchup, foram modelados dois edifícios do BNH que representasse o objeto de estudo desta pesquisa.

Para a modelagem, utilizou-se um recurso conhecido como plugin chamado Open Studio. As características dos materiais construtivos foram inseridas nos

\footnotetext{
${ }^{5}$ Como não existem arquivos climáticos para a cidade de Santos, optou-se por utilizar arquivos climáticos da cidade de Iguape, localizada a aproximadamente $140 \mathrm{~km}$ da cidade de Santos e com características semelhantes, como a estratégia bioclimática recomendada pela NBR 15.220-3/2005 para a Zona Bioclimática 5.

${ }^{6}$ Os resultados compatibilizados de todos os apartamentos avaliados encontram-se no Apêndice B desta dissertação.
} 
dados de entrada do Energyplus, possibilitando que o software simulasse a temperatura operativa do apartamento com características semelhantes aos dados obtidos pelo confortímetro. 


\section{RESULTADOS E DISCUSSÕES}

\subsection{RESULTADOS DA APO E ENTREVISTAS}

A análise dos resultados foi dividida em três partes. Primeiramente foram analisados os resultados das entrevistas, em seguida foram avaliados os resultados das medições e por último foram realizadas as simulações.

Com o resultado das entrevistas entre as famílias, que contemplaram 40 pessoas no total, pois apenas um representante de cada família participou das entrevistas, foram identificados que $32 \%$ destes entrevistados eram moradores do primeiro pavimento, $25 \%$ do segundo pavimento, $15 \%$ do terceiro pavimento e $28 \%$ do quarto pavimento.

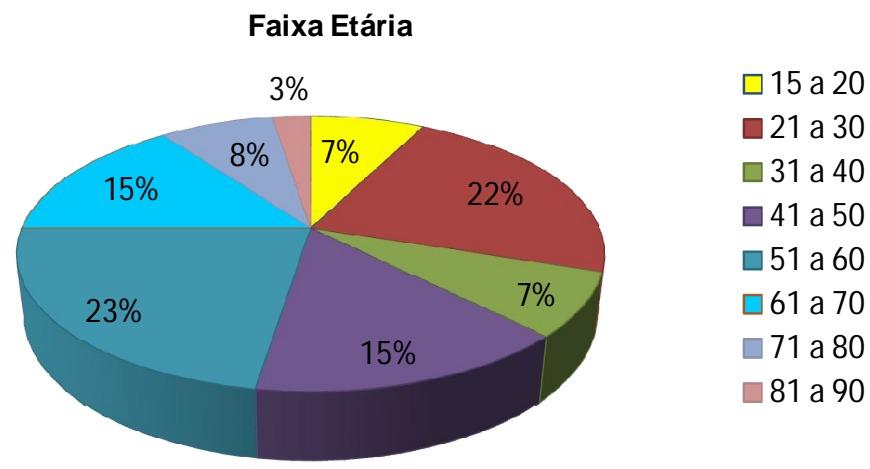

Figura 26: Faixa Etária dos entrevistados.

A idade dos moradores variou entre 15 e 90 anos com predominância de adultos entre 50 e 61 anos e de gênero predominantemente feminino, com $60 \%$ das entrevistadas. Estes resultados estão demonstrados nas figuras 26 e 27 . 
Gênero dos entrevistados

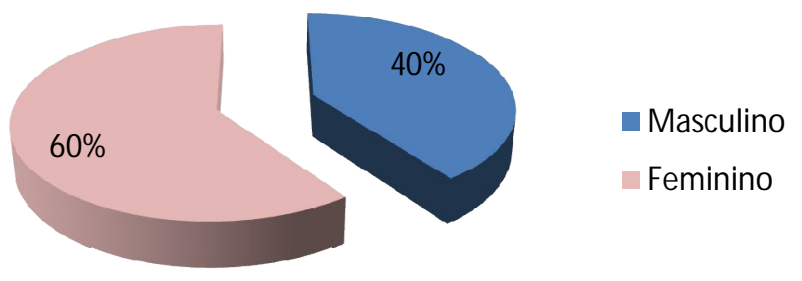

Figura 27: Gênero dos entrevistados.

A figura 28 representa a classificação da população entrevistada, cuja predominância foi de mulheres adultas.

\section{Classificação da população entrevistada}

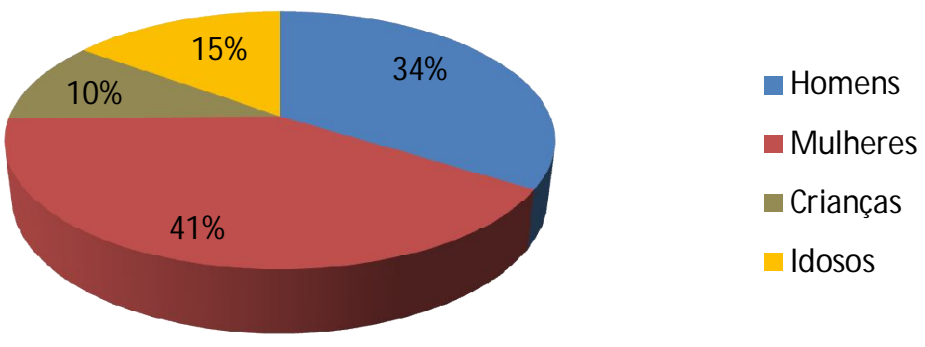

Figura 28: Classificação da população entrevistada.

Para a análise dos resultados da APO, as respostas dos usuários foram adaptadas de acordo com a escala da ISO 7730, 2005. Os resultados mostram que $82,5 \%$ dos usuários consideram os cômodos com fachadas voltadas para a rua (quarto e sala) os mais quentes dos apartamentos, deste total, $75,7 \%$ consideram o quarto o cômodo mais quente. 
A tabela 8 mostra as respostas da APO aplicada aos usuários quanto à sensação de conforto térmico no interior dos apartamentos ao longo das estações do ano.

Tabela 8: Satisfação dos usuários quanto à temperatura e ventilação dentro dos apartamentos.

\begin{tabular}{|c|c|c|c|c|c|c|c|c|c|}
\hline \multicolumn{2}{|r|}{$\begin{array}{c}\text { Perguntas referentes ao conforto térmico } \\
\text { nos apartamentos do BNH }\end{array}$} & \multicolumn{8}{|c|}{ Respostas dos usuários } \\
\hline & & -3 & -2 & -1 & 0 & 1 & 2 & 3 & Total \\
\hline 2 & $\begin{array}{l}\text { Avaliação da temperatura de } \\
\text { seu apartamento no verão? }\end{array}$ & $2,5 \%$ & $0,0 \%$ & $0,0 \%$ & $5,0 \%$ & $7,5 \%$ & $27,5 \%$ & $57,5 \%$ & $100 \%$ \\
\hline 3 & $\begin{array}{l}\text { Avaliação da temperatura de } \\
\text { seu apartamento no inverno? }\end{array}$ & $5,0 \%$ & $27,5 \%$ & $30,0 \%$ & $27,5 \%$ & $7,5 \%$ & $2,5 \%$ & $0,0 \%$ & $100 \%$ \\
\hline 4 & $\begin{array}{l}\text { Avaliação da ventilação natural de } \\
\text { seu apartamento no verão? }\end{array}$ & $0,0 \%$ & $0,0 \%$ & $5,0 \%$ & $5,0 \%$ & $10,0 \%$ & $35,0 \%$ & $45,0 \%$ & $100 \%$ \\
\hline 5 & $\begin{array}{l}\text { Avaliação da ventilação natural de } \\
\text { seu apartamento no inverno? }\end{array}$ & $20,0 \%$ & $37,5 \%$ & $22,5 \%$ & $12,5 \%$ & $7,5 \%$ & $0,0 \%$ & $0,0 \%$ & $100 \%$ \\
\hline 6 & $\begin{array}{l}\text { Avaliação da temperatura dos } \\
\text { quartos no verão? }\end{array}$ & $0,0 \%$ & $0,0 \%$ & $0,0 \%$ & $0,0 \%$ & $2,5 \%$ & $15,0 \%$ & $82,5 \%$ & $100 \%$ \\
\hline 7 & $\begin{array}{l}\text { Avaliação da temperatura dos } \\
\text { quartos no inverno? }\end{array}$ & $10,0 \%$ & $22,5 \%$ & $32,5 \%$ & $20,0 \%$ & $7,5 \%$ & $7,5 \%$ & $0,0 \%$ & $100 \%$ \\
\hline 8 & $\begin{array}{l}\text { Avaliação da ventilação natural } \\
\text { nos quartos no verão? }\end{array}$ & $0,0 \%$ & $0,0 \%$ & $2,5 \%$ & $2,5 \%$ & $2,5 \%$ & $35,0 \%$ & $57,5 \%$ & $100 \%$ \\
\hline 9 & $\begin{array}{l}\text { Avaliação da ventilação natural } \\
\text { nos quartos no inverno? }\end{array}$ & $15,0 \%$ & $20,0 \%$ & $32,5 \%$ & $25,0 \%$ & $5,0 \%$ & $2,5 \%$ & $0,0 \%$ & $100 \%$ \\
\hline 10 & $\begin{array}{l}\text { Avaliação da temperatura da } \\
\text { cozinha no verão? }\end{array}$ & $0,0 \%$ & $0,0 \%$ & $0,0 \%$ & $10,0 \%$ & $5,0 \%$ & $20,0 \%$ & $65,0 \%$ & $100 \%$ \\
\hline 11 & $\begin{array}{l}\text { Avaliação da temperatura da } \\
\text { cozinha no inverno? }\end{array}$ & $0,0 \%$ & $20,0 \%$ & $17,5 \%$ & $45,0 \%$ & $10,0 \%$ & $5,0 \%$ & $2,5 \%$ & $100 \%$ \\
\hline 12 & $\begin{array}{l}\text { Avaliação da ventilação natural } \\
\text { da cozinha no verão? }\end{array}$ & $0,0 \%$ & $0,0 \%$ & $2,5 \%$ & $10,0 \%$ & $7,5 \%$ & $42,5 \%$ & $37,5 \%$ & $100 \%$ \\
\hline 13 & $\begin{array}{l}\text { Avaliação da ventilação natural } \\
\text { da cozinha no inverno? } \\
\text { Avaliação da }\end{array}$ & $10,0 \%$ & $25,0 \%$ & $22,5 \%$ & $25,0 \%$ & $5,0 \%$ & $12,5 \%$ & $0,0 \%$ & $100 \%$ \\
\hline 14 & $\begin{array}{l}\text { temperatura da sala } \\
\text { no verão? } \\
\text { Avaliação da }\end{array}$ & $0,0 \%$ & $0,0 \%$ & $2,5 \%$ & $0,0 \%$ & $10,0 \%$ & $20,0 \%$ & $67,5 \%$ & $100 \%$ \\
\hline 15 & $\begin{array}{l}\text { temperatura da sala } \\
\text { no inverno? }\end{array}$ & $12,5 \%$ & $17,5 \%$ & $27,5 \%$ & $32,5 \%$ & $10,0 \%$ & $0,0 \%$ & $0,0 \%$ & $100 \%$ \\
\hline 16 & $\begin{array}{l}\text { Avaliação da ventilação natural } \\
\text { da sala no verão? }\end{array}$ & $0,0 \%$ & $0,0 \%$ & $2,5 \%$ & $10,0 \%$ & $12,5 \%$ & $22,5 \%$ & $52,5 \%$ & $100 \%$ \\
\hline 17 & $\begin{array}{l}\text { Avaliação da ventilação natural } \\
\text { da sala no inverno? } \\
\text { No outono e primavera, o }\end{array}$ & $17,5 \%$ & $25,0 \%$ & $27,5 \%$ & $25,0 \%$ & $5,0 \%$ & $0,0 \%$ & $0,0 \%$ & $100 \%$ \\
\hline 18 & $\begin{array}{l}\text { apartamento fica mais frio ou mais } \\
\text { quente? }\end{array}$ & $0,0 \%$ & $7,5 \%$ & $37,5 \%$ & $32,5 \%$ & $20,0 \%$ & $2,0 \%$ & $0,0 \%$ & $100 \%$ \\
\hline
\end{tabular}

Entre os resultados mais críticos definidos pelos usuários, existe uma tendência à sensação térmica definida dos apartamentos, em geral, serem mais quentes, onde $52,8 \%$ dos usuários definem os apartamentos com sensação térmica quente, $17 \%$ definem que existe neutralidade térmica e 30,2\% definem que os apartamentos tendem a ser mais frios ao longo do ano, conforme mostrado na figura 29. 


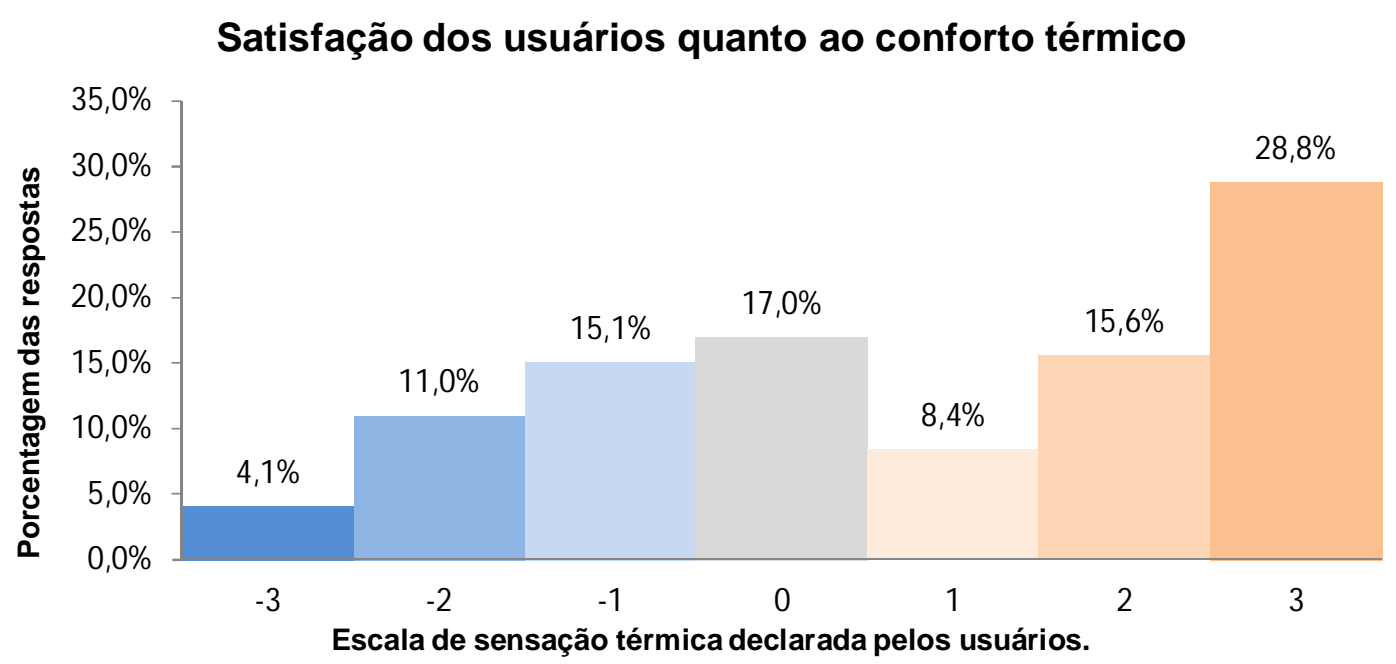

Figura 29: Resumo dos resultados dos moradores referentes ao conforto térmico nos apartamentos.

Se analisarmos somente a APO, estes resultados podem não ser conclusivos, pois alguns apartamentos possuem insolação matinal (fachada sudeste) e outros com insolação vespertina (fachada noroeste), sendo os horários de insolação distintos de acordo com o pavimento, em função do sombreamento gerado entre eles.

\subsection{COMPARAÇÃO DOS MÉTODOS DE CONFORTO TÉRMICO ADAPTATIVO}

Foram comparados neste trabalho quatro métodos de análise para conforto adaptativo que melhor se adaptassem as características locais deste projeto, sendo eles: ASHRAE 55 (2010); NBR 15.220-3/2005 que estabelece diretrizes de projeto e basea-se pelo método de Givoni; o método determinado por De Dear e Brager (2002) e por fim o método estabelecido por Cândido et al. (2011).

Entre os quatro métodos avaliados foram observados que os resultados do método ASHRAE 55 (2010) aderem melhor aos resultados da APO. As comparações foram realizadas através dos resultados das temperaturas operativas dentro das faixas de conforto térmico determinadas por cada metodologia, onde, estes resultados, foram comparados às percepções dos usuários, através da APO realizada, ou seja, a quantidade de respostas que estiveram dentro da faixa de conforto térmico de cada método foi compatibilizada ao número de respostas de satisfação de conforto térmico da APO. 
A figura 30 representa os resultados das comparações das metodologias que se apresentaram com maior compatibilidade aos resultados da APO. Com 66\% de compatibilidade entre as respostas, a ASHRAE 55 (2010) foi a metodologia com maior destaque; a NBR 15.220- (2005), com 64\% de compatibilidade entre as respostas; o método determinado por De Dear e Brager (2002) com 60\% de compatibilidade das respostas e por fim a metodologia proposta por Cândido et al. (2011), com 25\% de compatibilidade, este último caso deve-se ressaltar que, para este método, o ambiente depende de no mínimo $0,2 \mathrm{~m} / \mathrm{s}$ de ventilação para que a temperatura operativa atinja o mínimo de conforto térmico, valores de ventilação nunca registrados no $\mathrm{BNH}$, já que o valor máximo registrado foi de $0,1 \mathrm{~m} / \mathrm{s}$.

\section{Compatibilidade entre respostas da APO X Resultados dos métodos de conforto adaptativo}

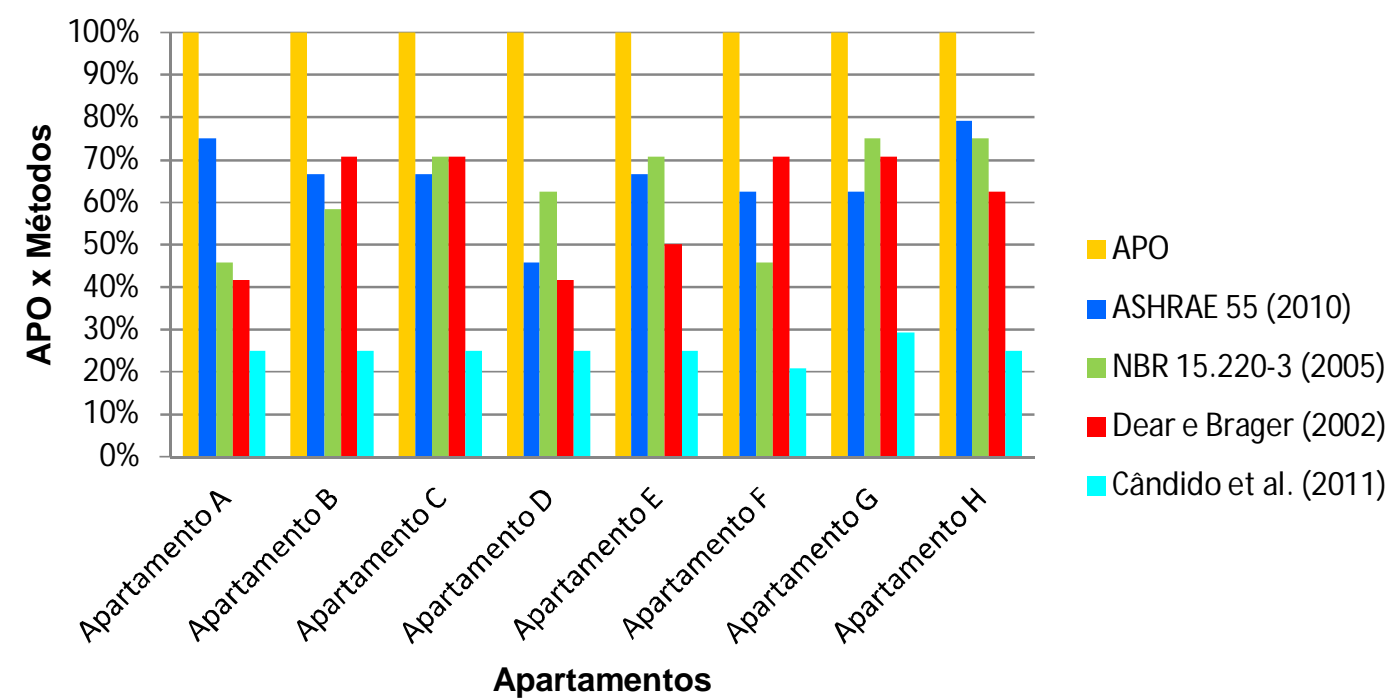

Figura 30: Comparação dos resultados entre APO e Métodos para conforto térmico adaptativo.

Em função destes resultados, elegeu-se por trabalhar com a metodologia ASHRAE 55 (2010), para garantir maior confiabilidade nos resultados desta pesquisa de conforto térmico adaptativo. 


\subsection{RESULTADOS DAS MEDIÇÕES FEITAS IN LOCO}

Foram realizadas medições de campo nos cômodos que mais se destacaram à sensação de desconforto térmico relatados pelos usuários do $\mathrm{BNH}$, os quartos $\mathrm{e}$ as salas.

Para esta etapa foram realizadas medições através do confortímetro ao longo de um ano, entre os meses de Julho de 2013 a Junho de 2014. As medições, em todos os apartamentos foram realizadas nos horários entre 11:50 hs e 14:50 hs (12:50 hs e 15:50 no horário de verão) para os quartos e entre 15:00 hs e 17:00 hs (16:00 hs e 18:00 hs no horário de verão) para as salas, ambos com orientação voltada para a rua. Mensalmente era escolhido um dia aleatório para executar as medições. Estes dias foram agendados de acordo com as disponibilidades dos moradores de cada apartamento.

Os apartamentos analisados foram nomeados, para efeito de comparação dos resultados, por letras de "A" a "H". Foram divididos entre apartamentos intermediários, os quais estão inseridos nas edificações como apartamentos que ficam entre os pavimentos térreos e terceiro, e apartamentos de cobertura, que estão localizados no último pavimento. Os apartamentos $A, B, F$ e $G$ estão localizados nas coberturas enquanto que os apartamentos $C, D, E$ e $H$ são apartamentos que estão entre os pavimentos térreo e terceiro, denominados neste pesquisa de intermediários.

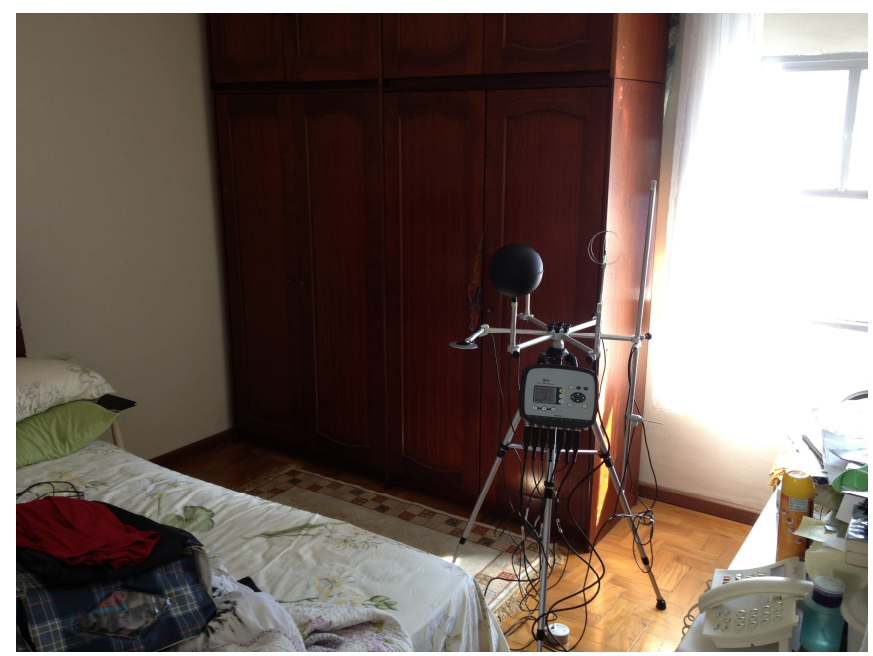

Figura 31: Medição térmica realizada no quarto do apartamento $A$. 
Serão demonstrados nesta etapa do trabalho os resultados com maiores destaques relacionados ao desconforto térmico apresentados em alguns apartamentos.

Para estas análises relacionadas à temperatura operativa dos apartamentos, deve ser analisado o comportamento climático da temperatura externa da região ao longo do ano, conforme demonstrado na figura 32.

Temperatura média de Santos entre Julho de 2013 e Junho de 2014

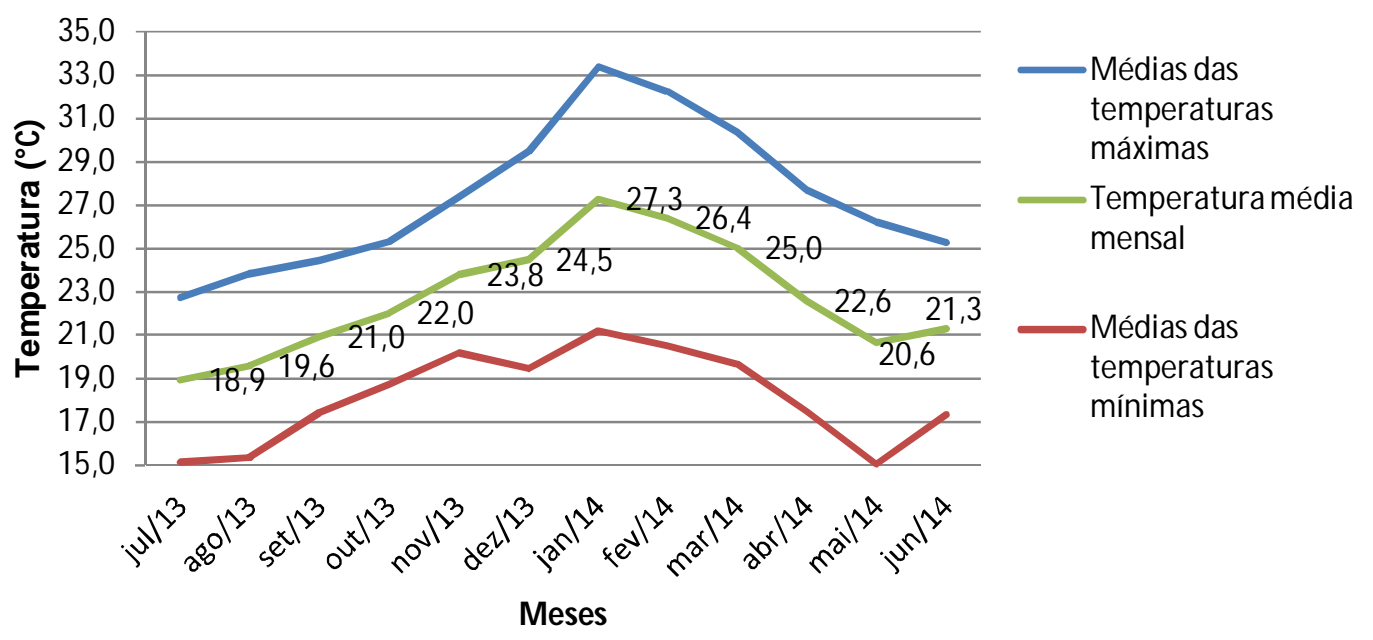

Figura 32: Média das temperaturas nas cidades de Santos entre os meses de Julho de 2013 e Junho de 2014. Fonte: CIIAGRO.

Foi observada, que durante o ano, o comportamento climático na cidade de Santos apresentou curvas das médias das temperaturas com características da região, com as estações do ano bem definas, com temperaturas frias de inverno e quente de verão e equinócios com temperaturas equilibradas.

\subsubsection{Avaliação das temperaturas operativas dos apartamentos}

A figura 33 mostra a comparação das temperaturas operativas ${ }^{7}$ das salas dos apartamentos localizados no último pavimento, com o telhado exposto a radiação solar direta. Observou-se que as temperaturas operativas estão sempre com valores superiores à temperatura externa. Os apartamentos com amplitudes

\footnotetext{
${ }^{7}$ Os resultados das Temperaturas Operativas foram fornecidos por meio dos dados de saída do confortímetro.
} 
térmicas mais elevadas foram os apartamentos A e B. Observou-se também que o apartamento $B$ tem predominância de altas temperaturas, este aumento pode estar relacionado ao número de morados e também por ser um apartamento de esquina com fachadas norte e nordeste, colaborando com o aumento da temperatura em função da radiação solar direta. Apesar do apartamento $G$ ter as mesmas características do apartamento $\mathrm{B}$, em alguns dias as medições ocorreram em dias nublados, apresentando resultados menores de temperaturas.

\section{Comparações das Temperaturas Operativas das salas dos apartamentos do último pavimento}
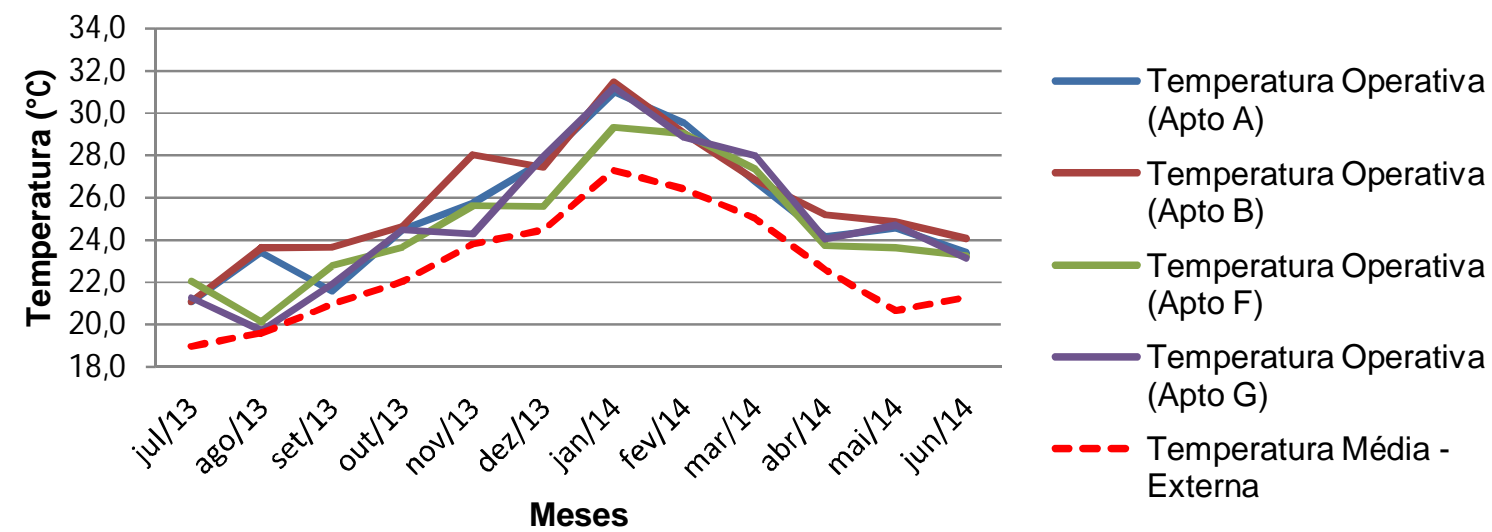

Figura 33: Comparação entre Temperatura Operativa x Temperatura Externa - salas dos apartamentos do último pavimento.

O apartamento $\mathrm{F}$ apresentou amplitudes térmicas menores em relação aos demais apartamentos, este resultado pode ter ocorrido em função da quantidade de morados, apenas dois e que não permaneceram nos apartamentos durante os dias avaliados, além da fachada da sala ter orientação sudeste, recebendo menos radiação solar direta e por menos tempo.

As temperaturas operativas registradas na pesquisa mostraram que no período em que as medições foram realizadas nas salas, as amplitudes térmicas registradas foram maiores que as amplitudes térmicas registradas nos quartos. Estes aumentos das temperaturas nas salas ocorrem em função da orientação solar, pois nos horários em que eram realizadas as medições nas salas, a irradiância solar total era mais intensa, além da contribuição da permanência dos usuários e de equipamento eletrônicos ligados nestes horários. As características 
espaciais dos apartamentos e os resultados das temperaturas operativas realizados para este trabalho encontram-se no Apêndice A.

A figura 34 mostra os resultados das temperaturas operativas das salas dos apartamentos intermediários. As curvas mostram que, assim como ocorreu com as salas dos apartamentos dos últimos pavimentos, as temperaturas operativas possuem desvios superiores à temperatura externa. As maiores amplitudes térmicas registradas ocorreram nos apartamentos $\mathrm{C}$ e $\mathrm{H}$, ocorrências maiores registradas no verão, e nos demais meses há um destaque do apartamento $\mathrm{E}$.

O apartamento $D$ foi o que apresentou menores temperaturas, com exceção do mês de Maio, estes registros podem ter ocorridos em função deste apartamento, junto com o apartamento $E$, serem localizados no térreo, recebendo pouca incidência solar, a diferença é que o apartamento $E$ possui nove moradores, enquanto que o apartamento $D$ apenas, contribuindo desta forma com menos ganhos de calor no interior do apartamento.

Comparações das Temperaturas Operativas das salas dos apartamentos intermediários
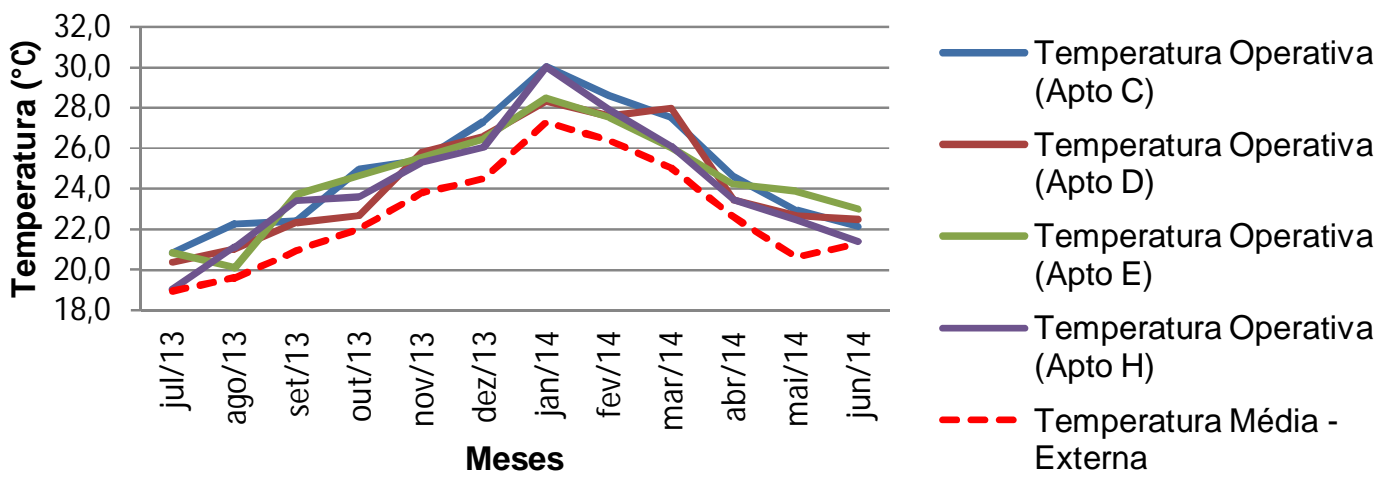

Figura 34: Comparação entre Temperatura Operativa x Temperatura Externa - salas dos apartamentos de pavimento intermediário.

Observou-se também que em todas as medições realizadas, as temperaturas internas permaneceram acima da temperatura externa do ar, tanto para os apartamentos do último pavimento quanto para os apartamentos intermediários. 


\subsubsection{Avaliação das temperaturas radiantes internas dos apartamentos avaliados}

Uma das variáveis para o cálculo da temperatura operativa, segundo a metodologia da ASHRAE 55 (2010), são as temperaturas radiantes do ambiente interno. Os dados a seguir representam as médias das temperaturas radiantes medidas durante os meses de verão.

A figura 35 representa a comparação das médias das temperaturas radiantes ${ }^{8}$ internas das salas nos apartamentos dos últimos pavimentos. Os resultados demonstram que os apartamentos A e $G$ destacam-se com temperaturas superiores, mesmo sendo os apartamentos menos populosos nestes horários, mas deve-se ressaltar que durante as medições realizadas para estes apartamentos, as temperaturas externas nos dias das medições, atingiram valores superiores as demais avaliações, contribuindo desta forma para que as temperaturas radiantes internas, influenciadas pela transmitância das alvenarias externas, contribuíssem com o aumento das temperaturas radiantes nestes apartamentos.

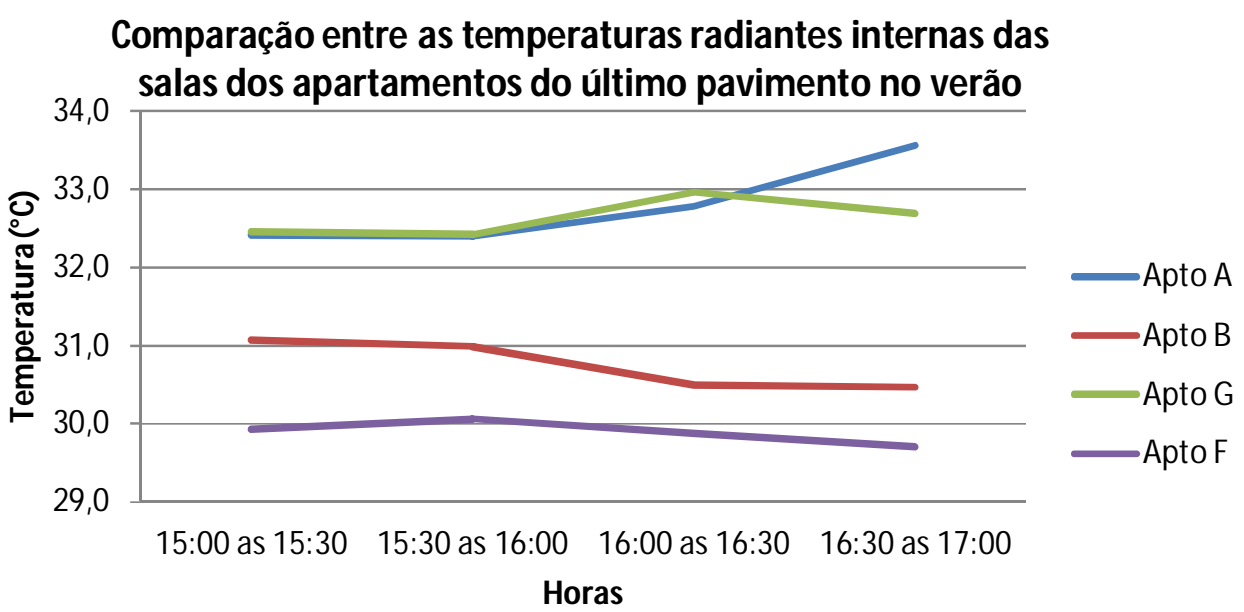

Figura 35: Temperaturas radiantes das salas dos apartamentos de cobertura no verão.

A figura 36 representa a comparação das médias das temperaturas radiantes internas das salas nos apartamentos intermediários. Os resultados demonstram que os apartamentos $\mathrm{C}$ e $\mathrm{H}$, apresentaram temperaturas radiantes superiores

\footnotetext{
${ }^{8}$ Dados coletados por um termômetro de fluxo laser da marca Raytek Raynger ST.
} 
quando comparados com os apartamentos D e E, apresentando como possível causa o fato destes apartamentos receberem maior incidência solar, já que estão localizados em andares superiores, porém com fachadas opostas.

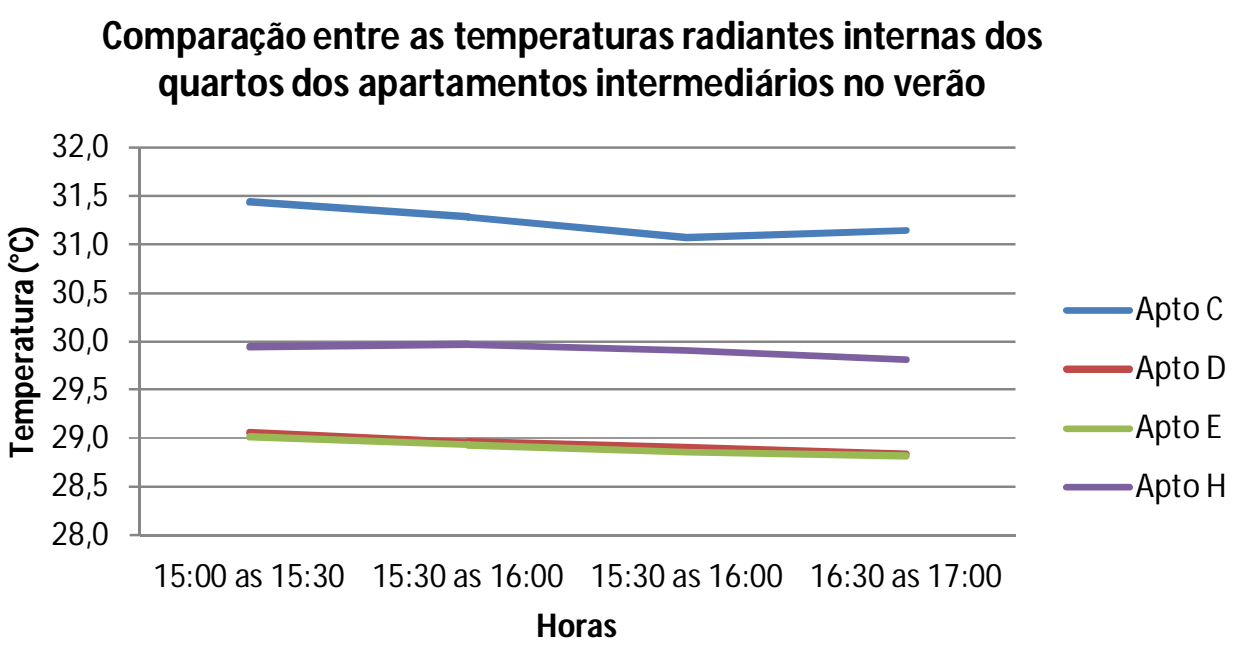

Figura 36: Temperaturas radiantes das salas dos apartamentos intermediários no verão.

Os apartamentos D e E, são apartamentos térreos, que quase não recebem incidência solar durante o dia, onde no verão, as temperaturas radiantes destes apartamentos registraram valores tênues, muito em função das temperaturas externas se apresentarem elevadas, mas durante o resto do ano, as temperaturas radiantes do apartamento $E$ foram superiores ao do apartamento $D$.

\subsubsection{Avaliação das temperaturas entre os apartamentos em períodos de 24 horas}

Ao longo de um ano, foram realizadas medições de 24 horas de duração nos apartamentos E, F, G e H. Novamente, era agendando um dia no mês, de acordo com a disponibilidade dos moradores e, neste dia, eram realizadas as medições. Estas medições foram realizadas para comparar o desempenho da temperatura operativa no interior dos apartamentos e as temperaturas externas nos dias das medições, para desta forma identificar se os apartamentos avaliados estariam em conforto térmico conforme os parâmetros da ASHRAE 55 (2010). 
O gráfico da figura 37 representa a comparação entre as temperaturas operativas médias e as temperaturas externas dos dias avaliados no inverno e no verão.

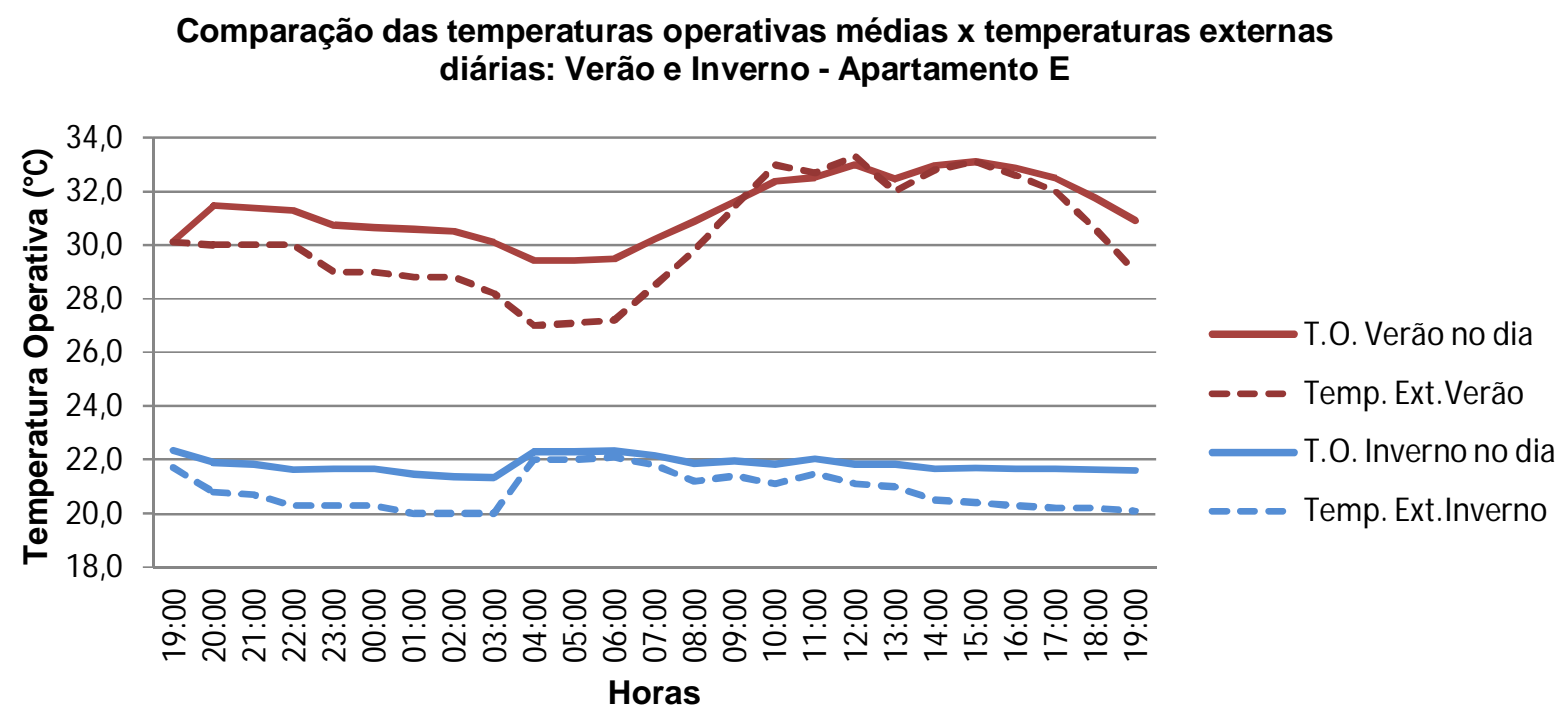

Figura 37: Medição de 24 horas da Temperatura Operativa entre verão e inverno do apartamento E.

Observa-se que as curvas das temperaturas operativas e externas possuem curvas similares no verão e no inverno, com a temperatura operativa apresentando valores superiores na maior parte das medições, ou seja, independente da estação do ano as temperaturas monitoradas nos apartamentos são, na maior parte do tempo, superiores as temperaturas externas, no caso do apartamento $E$, esta diferença pode ocorrer em função do número excessivo de usuários dentro do apartamento e a quantidade de equipamentos e iluminação, somados a pouca ventilação natural local e pé direito baixo, que contribui para o acréscimo de calor interno, pois quanto menor o pé direito, maior a probabilidade de desconforto térmico devido ao calor interno, isto pode ocorrer porque em ambientes com o pé direito menor, pode implicar em um volume menor de ar para o calor se dissipar, proveniente das cargas térmicas internas, aumentando a temperatura no ambiente. No verão, o maior desvio entre as curvas da temperatura externa e a temperatura operativa interna foi de $2,3^{\circ} \mathrm{C}$ enquanto no inverno foi de $1,5^{\circ} \mathrm{C}$, onde a amplitude térmica da temperatura externa foi de $6,3^{\circ} \mathrm{C}$ enquanto que a amplitude térmica da temperatura operativa interna foi de $3,9^{\circ} \mathrm{C}$. Os resultados mostram que 0 apartamento $\mathrm{E}$, de acordo com a 
metodologia da ASHRAE 55, durante o verão constitui temperatura operativa em zona de conforto durante as 19:00 hs e entre 04:00 hs e 06:00 hs. Durante o inverno a temperatura operativa permaneceu estável na zona de conforto durante todo o período avaliado.

A figura 38 representa a comparação das temperaturas operativas médias em relação a temperaturas externas dos dias avaliados no outono e na primavera.

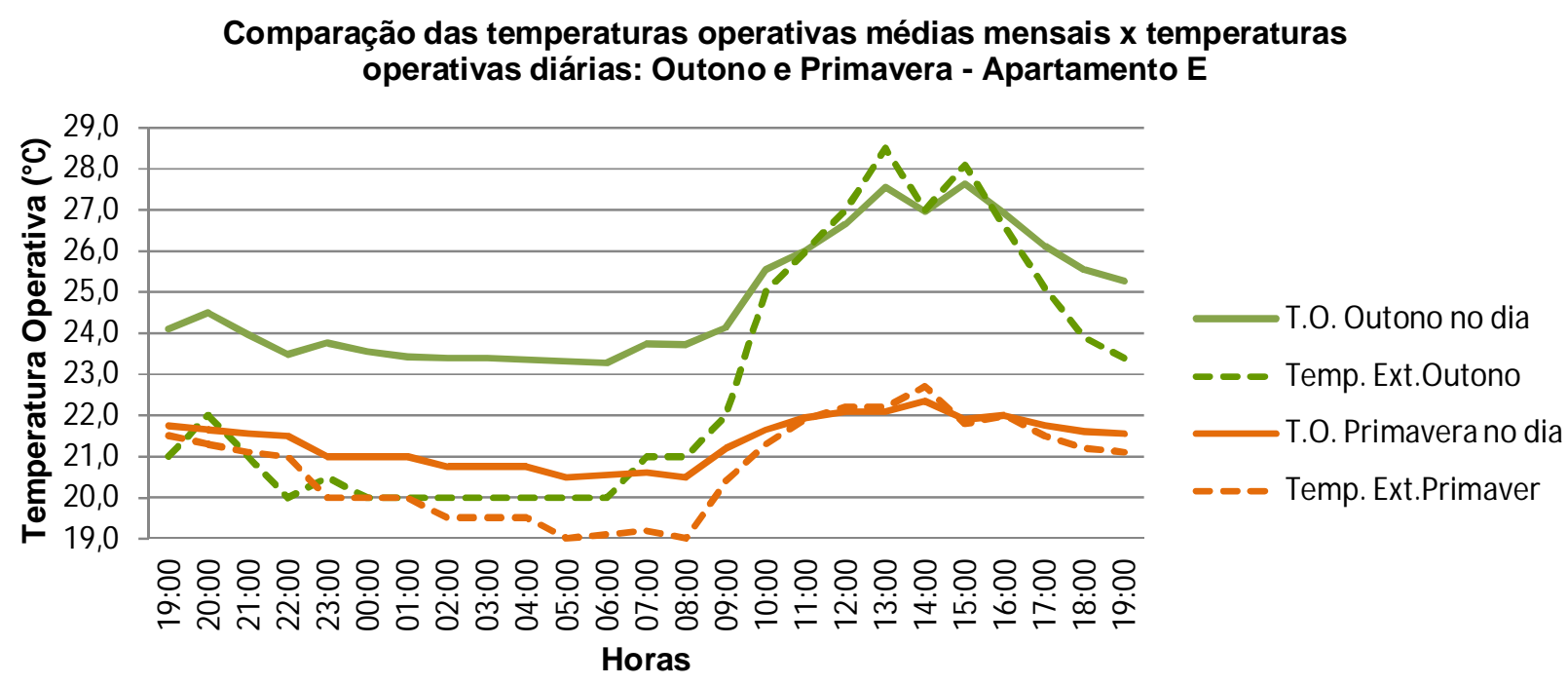

Figura 38: Medição de 24 horas da Temperatura Operativa entre outono e primavera do apartamento E.

Apesar da similaridade das curvas entre as temperaturas externas e operativas na figura 36 , no outono o desvio máximo das temperaturas foi de a $3,4^{\circ} \mathrm{C}$, enquanto que na primavera, este desvio foi de $1,5^{\circ} \mathrm{C}$. A amplitude térmica no outono foi de $8,5^{\circ} \mathrm{C}$ enquanto que na primavera este amplitude chegou a $3,7^{\circ} \mathrm{C}$. Comparando as medições das figuras 37 e 38, observa-se que, entre 06:00 hs e 18:00 hs, existem justaposições e aumento das temperaturas, que podem estar relacionados aos períodos em que todos os moradores permaneçam no apartamento, já que este apartamento recebe muito pouco incidência solar, conforme mostrado na figura 39. 


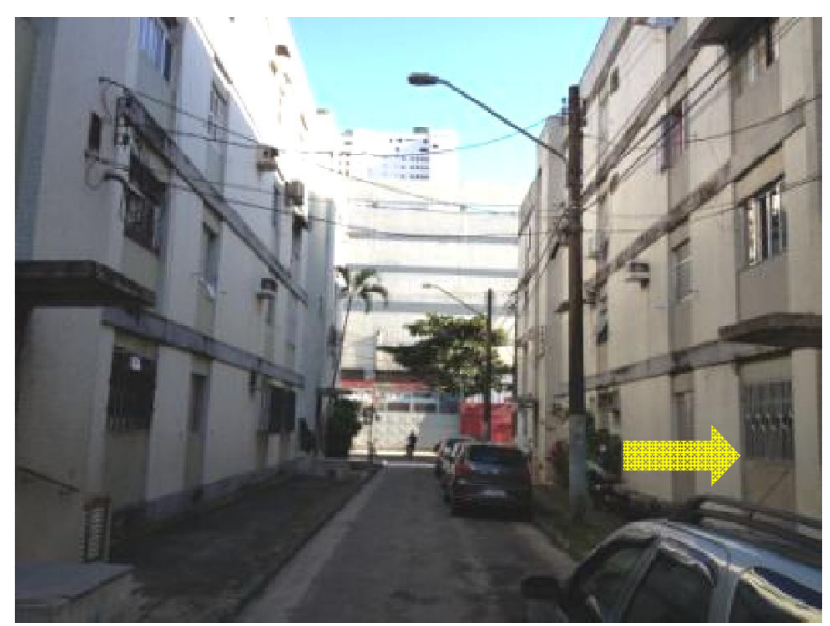

Figura 39: Localização do apartamento E. Pouca (quase nula) incidência solar.

A figura 40 mostra os resultados do apartamento $\mathrm{F}$. O resultado da medição realizada no verão mostra que existe uma justaposição das temperaturas externa e operativa entre 07:00 hs e 14:00 hs. Os resultados mostram que durante o verão, a faixa de desconforto térmico ocorre no período entre 09:00 hs e 18:00 hs, ocorrendo um desvio entre as curvas de temperaturas externa e operativa, cujo maior desvio chega a $3,1^{\circ} \mathrm{C}$ no verão e $1,7^{\circ} \mathrm{C}$ no inverno.

\section{Comparação das temperaturas operativas médias $\mathrm{x}$ temperaturas externas diárias: Verão e Inverno - Apartamento $F$}

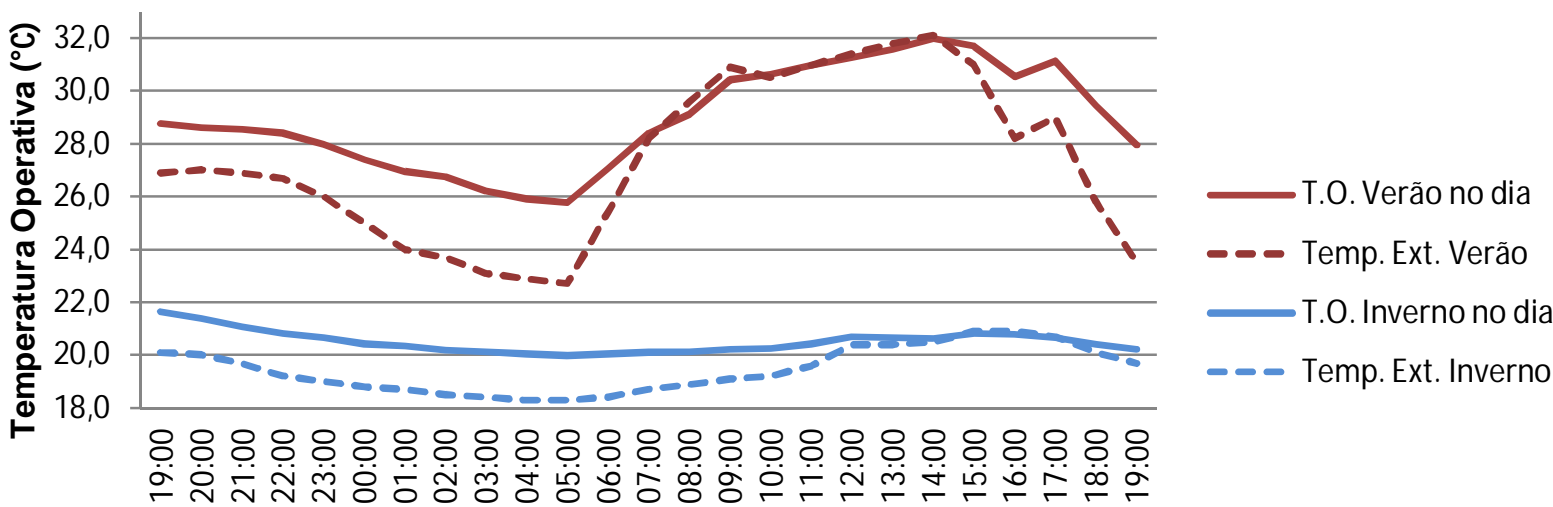
Horas

Figura 40: Medição de 24 horas da Temperatura Operativa entre verão e inverno do apartamento F.

A amplitude térmica da temperatura externa durante o verão é de $9,4^{\circ} \mathrm{C}$ enquanto que a amplitude térmica da temperatura operativa no verão foi de $5,2^{\circ} \mathrm{C}$. Durante o inverno, as amplitudes térmicas permaneceram mais estáveis, sendo a 
amplitude térmica externa de $1,8^{\circ} \mathrm{C}$ enquanto que a amplitude térmica da temperatura operativa foi de $1,4^{\circ} \mathrm{C}$, permitindo que a temperatura interna do apartamento tivesse um comportamento térmico de conforto.

Comparação das temperaturas operativas médias mensais $\mathrm{x}$ temperaturas externas diárias: Outono e Primavera - Apartamento F

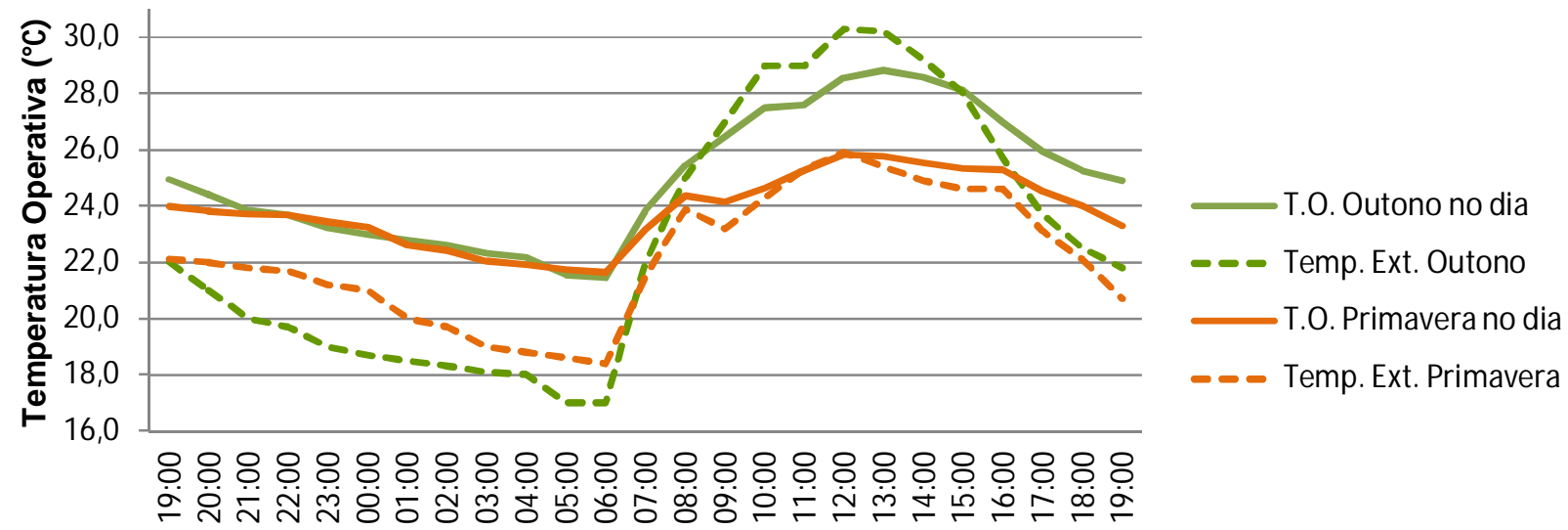

Horas

Figura 41: Medição de 24 horas da Temperatura Operativa entre outono e primavera do apartamento F.

A figura 41 representa a comparação das temperaturas operativas médias em relação a temperaturas externas dos dias avaliados no outono e na primavera. Apesar da similaridade das curvas entre as temperaturas externas e operativas, no outono o desvio máximo das temperaturas foi de a $4,6^{\circ} \mathrm{C}$, enquanto que na primavera, este desvio foi de $3,2^{\circ} \mathrm{C}$. A amplitude térmica no outono foi de $13,3^{\circ} \mathrm{C}$ enquanto que na primavera este amplitude chegou a $7,5^{\circ} \mathrm{C}$. Os resultados deste apartamento, em ambas as estações do ano, outono como na primavera, apresentaram justaposições pontuais, diferente do que ocorreu nos resultados do verão e do inverno. De acordo com os moradores, na medição do outono, o apartamento permaneceu vazio entre 07:00 hs e 17:00 hs e sem equipamentos eletrônicos ou qualquer iluminação ligada neste período, e como este é um apartamento com insolação sudeste, estes fatores podem ter colaborado para que a temperatura operativa estivesse abaixo da temperatura externa entre os horários 08:00 hs e 15:00 hs. Durante a primavera, as medições ocorreram com os dois morados instalados no apartamento durante as 24 horas, prevalecendo 
desta forma uma temperatura operativa sempre com curva sempre superior a temperatura externa. Apesar da existência de desvios nas curvas dos resultados, em ambas as medições, outono e primavera, registrou-se conforto térmico no interior do apartamento, de acordo com o método da ASHRAE 55.

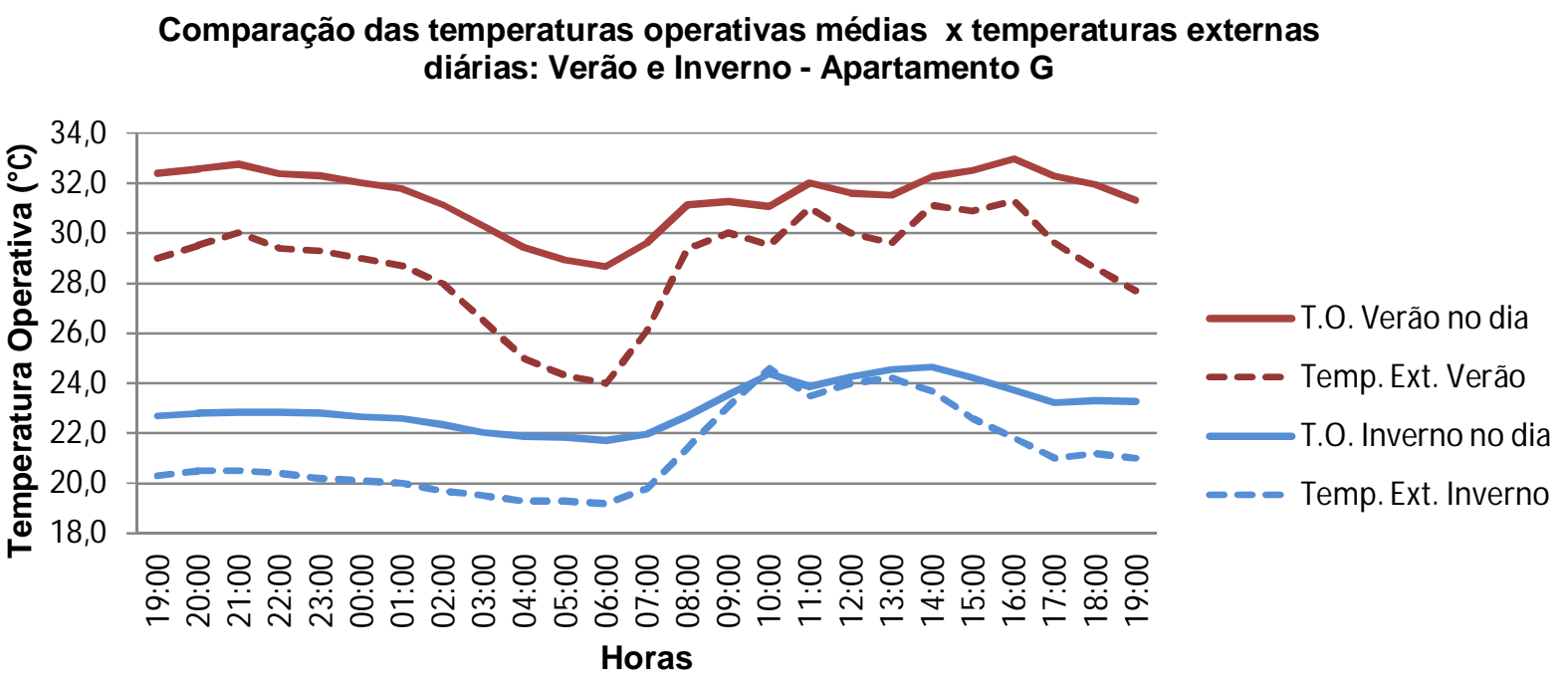

Figura 42: Medição de 24 horas da Temperatura Operativa entre verão e inverno do apartamento G.

A figura 42 mostra os resultados do apartamento G. Foi observado que, durante o verão, a faixa de conforto térmico ocorre no período entre 06:00 hs e 07:00 hs, permanecendo o restante do dia em zona de desconforto térmico. Durante o verão o desvio máximo entre as curvas de temperatura externa e temperatura operativa foi de $4,7^{\circ} \mathrm{C}$ com amplitude térmica de $4,3^{\circ} \mathrm{C}$. Durante o inverno, o desvio máximo entre as curvas foi de $2,5^{\circ} \mathrm{C}$ e a amplitude térmica da temperatura externa foi de $2,4^{\circ} \mathrm{C}$. Durante a medição de inverno, a temperatura operativa permaneceu sempre dentro da zona de conforto térmico. 
Comparação das temperaturas operativas médias mensais $\mathrm{x}$ temperaturas operativas diárias: Outono e Primavera - Apartamento G

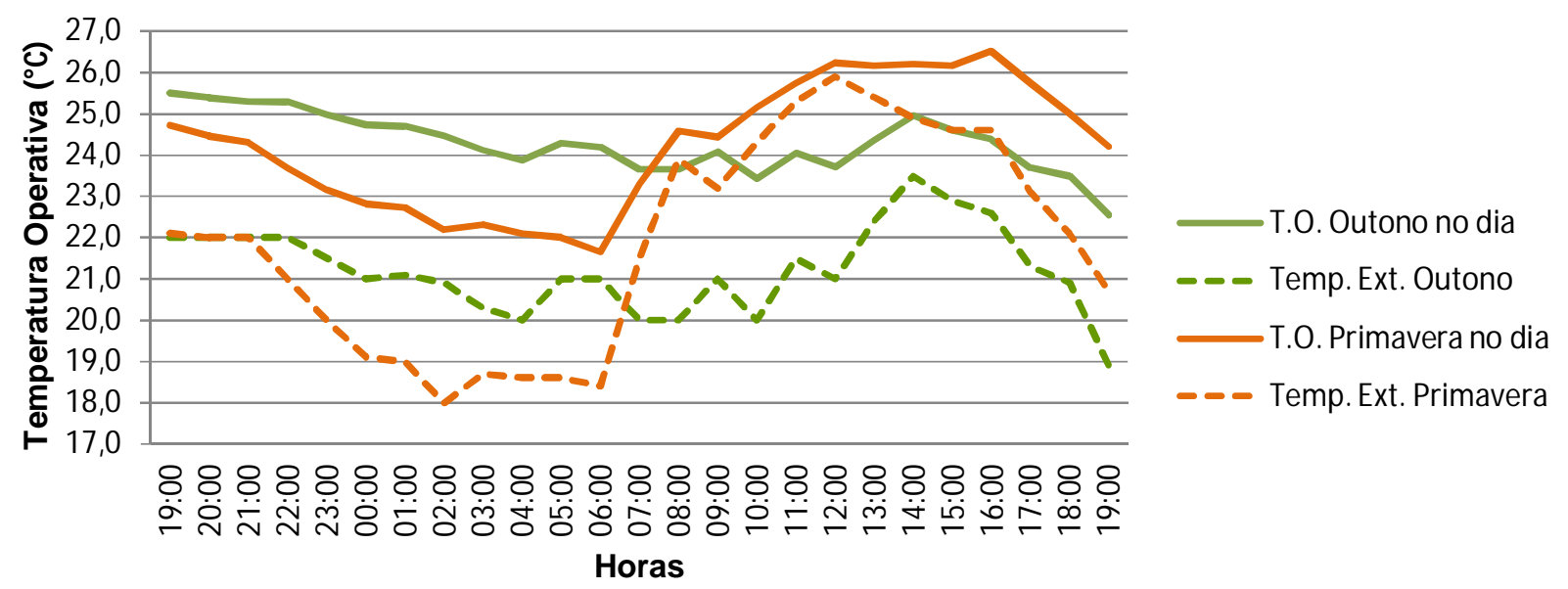

Figura 43: Medição de 24 horas da Temperatura Operativa entre outono e primavera do apartamento G.

A figura 43 representa a comparação das temperaturas operativas médias em relação a temperaturas externas dos dias avaliados no outono e na primavera. No outono o desvio máximo das temperaturas foi de a $3,9^{\circ} \mathrm{C}$, enquanto que na primavera, este desvio foi de $4,2^{\circ} \mathrm{C}$. A amplitude térmica no outono foi de $4,6^{\circ} \mathrm{C}$ enquanto que na primavera este amplitude chegou a $7,9^{\circ} \mathrm{C}$. Em ambas as medições, outono e primavera, as temperaturas operativas no interior do apartamento permaneceram dentro da zona de conforto térmico estabelecida pela ASHRAE 55. 


\section{Comparação das temperaturas operativas médias $\mathrm{x}$ temperaturas externas diárias: Verão e Inverno - Apartamento H}

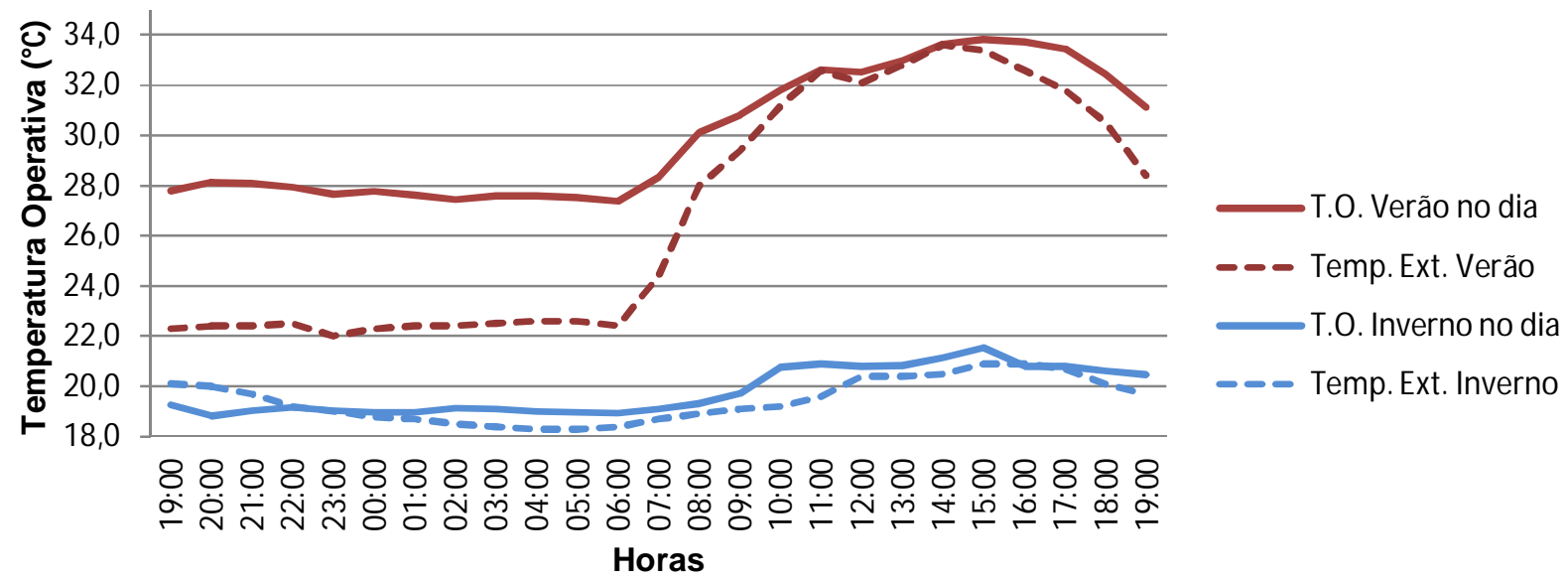

Figura 44: Medição de 24 horas da Temperatura Operativa entre verão e inverno do apartamento H.

A figura 44 mostra os resultados do apartamento $H$. Foi observado que, durante o verão, a faixa de desconforto térmico ocorre no período entre 09:00 hs e 19:00 hs do dia posterior. Durante o verão o desvio máximo entre as curvas de temperatura externa e temperatura operativa foi de $5,7^{\circ} \mathrm{C}$ com amplitude térmica da temperatura externa de $11,6^{\circ} \mathrm{C}$. Durante o inverno, o desvio máximo entre as curvas foi de $1,6^{\circ} \mathrm{C}$ e a amplitude térmica da temperatura externa foi de $1,9^{\circ} \mathrm{C}$. Durante a medição de inverno foi registrada temperatura operativa em desconforto térmico predisposta ao frio entre 19:00 hs e 09:00 hs. 
Comparação das temperaturas operativas médias mensais $\mathrm{x}$ temperaturas operativas diárias: Outono e Primavera - Apartamento $\mathrm{H}$

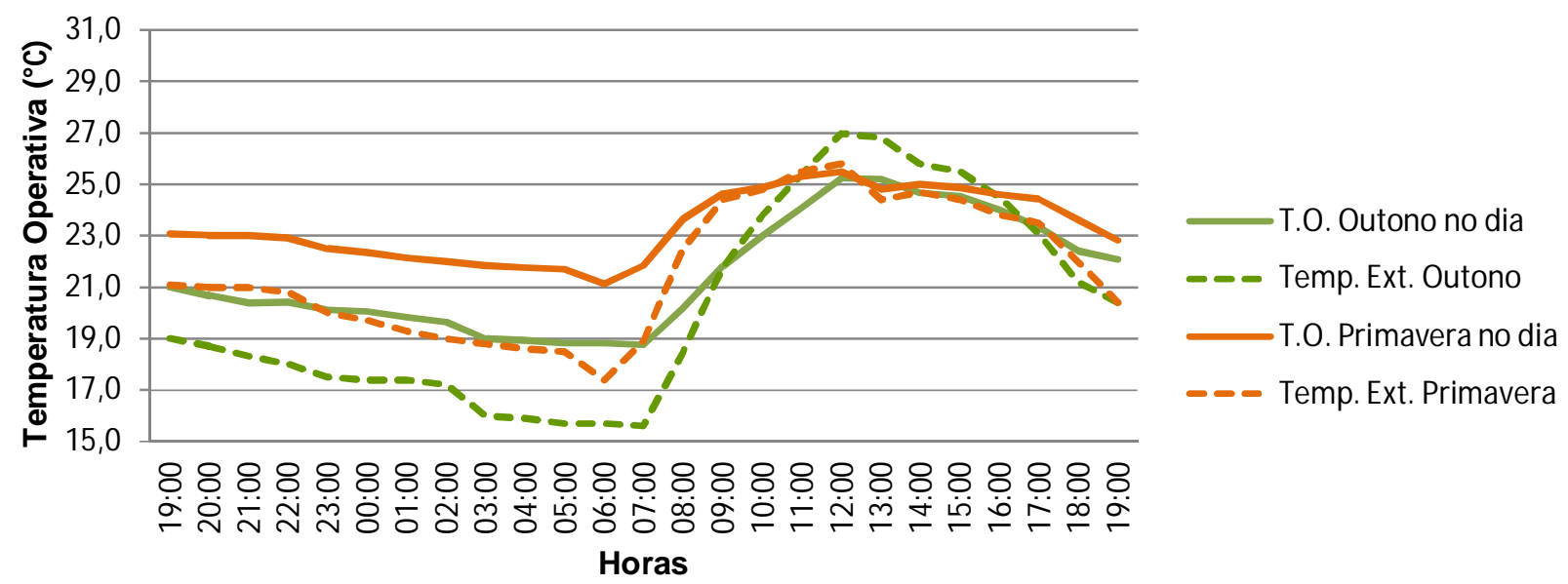

Figura 45: Medição de 24 horas da Temperatura Operativa entre outono e primavera do apartamento $\mathrm{H}$.

A figura 45 mostra os resultados do apartamento $F$ realizados nas estações do outono e primavera. No outono o desvio máximo das temperaturas foi de a $3,7^{\circ} \mathrm{C}$, enquanto que na primavera, este desvio foi de $3,3^{\circ} \mathrm{C}$. A amplitude térmica no outono foi de $11,4^{\circ} \mathrm{C}$ enquanto que na primavera este amplitude chegou a $8,4^{\circ} \mathrm{C}$. Em ambas as medições, outono e primavera, as temperaturas operativas no interior do apartamento permaneceram dentro da zona de conforto térmico estabelecida pela ASHRAE 55, apesar das baixas temperaturas externas ocorridas durante as medições no outono.

\subsubsection{Resultados das simulações das propostas de melhorias nos apartamentos com o software Energyplus}

Foram simulados dois apartamentos do último pavimento (cobertura) do BNH de Santos, os Apartamentos F e G, de fachadas opostas. Os resultados gerados propõem duas soluções que possam melhorar o conforto térmico no interior dos apartamentos. A primeira solução é a troca das atuais telhas de fibrocimento por telhas cerâmicas pintadas de branco e a segunda, a instalação de brises de 70 $\mathrm{cm}$ nas janelas. 
As simulações das temperaturas dos apartamentos foram realizadas com as temperaturas operativas do mesmo dia das temperaturas operativas medidas in loco, entre as 19:00 hs do dia 20 de Janeiro de 2014 e as 19:00 hs do dia 21 de Janeiro de 2014 para o apartamento F, e 19:00 hs do dia 25 de Janeiro de 2014 até as 19:00 hs do dia 26 de Janeiro para o apartamento G. As simulações foram realizadas para as mesmas datas das medições locais, para que o arquivo climático do energyplus pudesse utilizar a mesma radiação solar do dia medido, possibilitando que os resultados aderissem melhor os parâmetros entre os resultados medidos in loco e os resultados simulados pelo software.

A figura 46 mostra os resultados entre as temperaturas operativas medidas in loco e as temperaturas simuladas para o apartamento F. Primeiramente observase que, existe um desvio maior entre as curvas da temperatura operativa real e a temperatura simulada entre os horários das 07:00 hs e 17:00 hs.

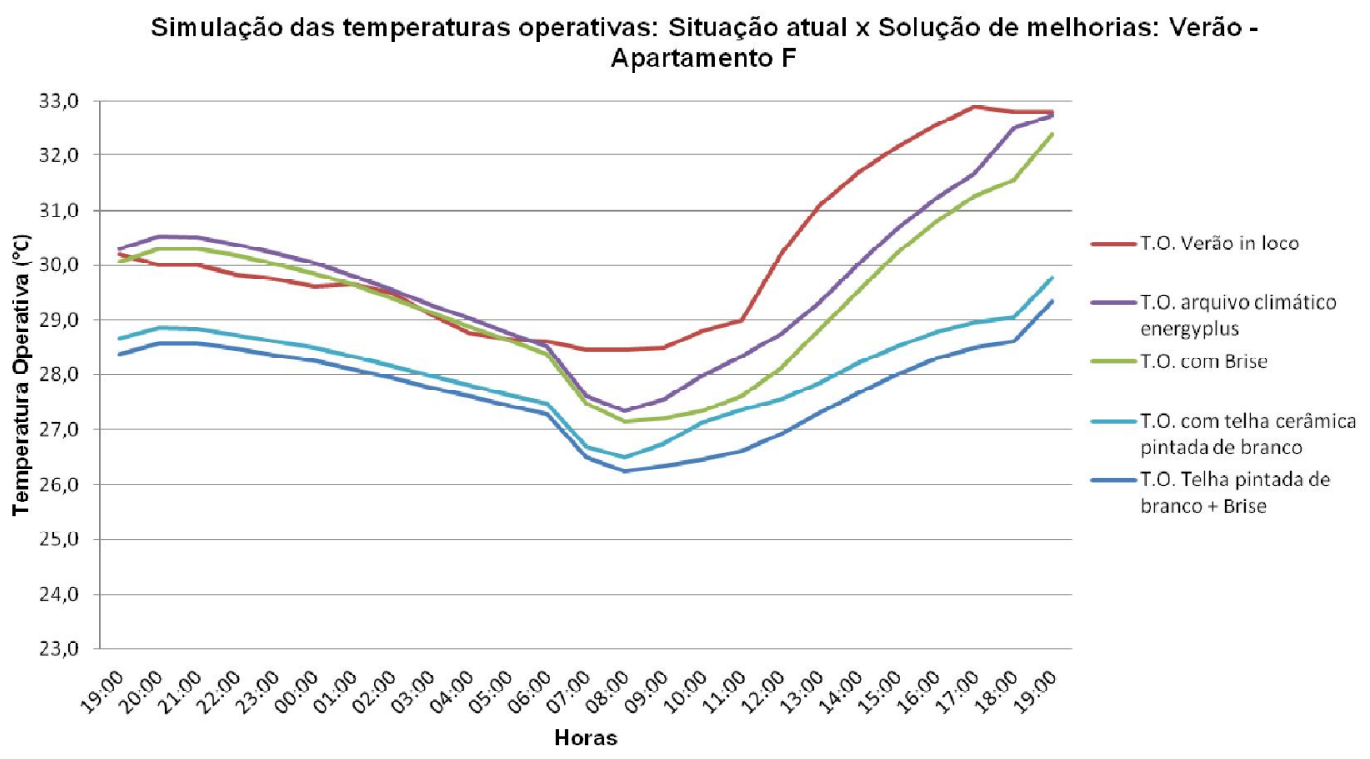

Figura 46: Simulação das temperaturas operativas do apartamento F com proposta de melhorias.

Partindo da validação da temperatura operativa gerada pelo arquivo climático, quando são inseridas as duas propostas de melhorias, brises e telhas cerâmicas pintadas de branco, observa-se uma queda nas temperaturas operativas. Com a implantação somente dos brises, observa-se uma diferença menor entre as 
temperaturas simuladas, com uma variação média de $0,3^{\circ} \mathrm{C}$; e com a implantação somente das telhas cerâmicas pintadas de branco a diferença aumenta para uma variação média de $1,6^{\circ} \mathrm{C}$ podendo reduzir a temperatura pontualmente em até $3,4^{\circ} \mathrm{C}$. Quando são simuladas as duas soluções juntas à variação média da diferença entre as temperaturas caem em $2,0^{\circ} \mathrm{C}$, com desvio entre as curvas atingindo $3,9^{\circ} \mathrm{C}$.

A figura 47 mostra os resultados entre as temperaturas operativas medidas in loco e as temperaturas simuladas para o apartamento G. Primeiramente observase que, existe um desvio maior entre as curvas da temperatura operativa real e a temperatura simulada entre os horários das 08:00 hs e 12:00 hs.

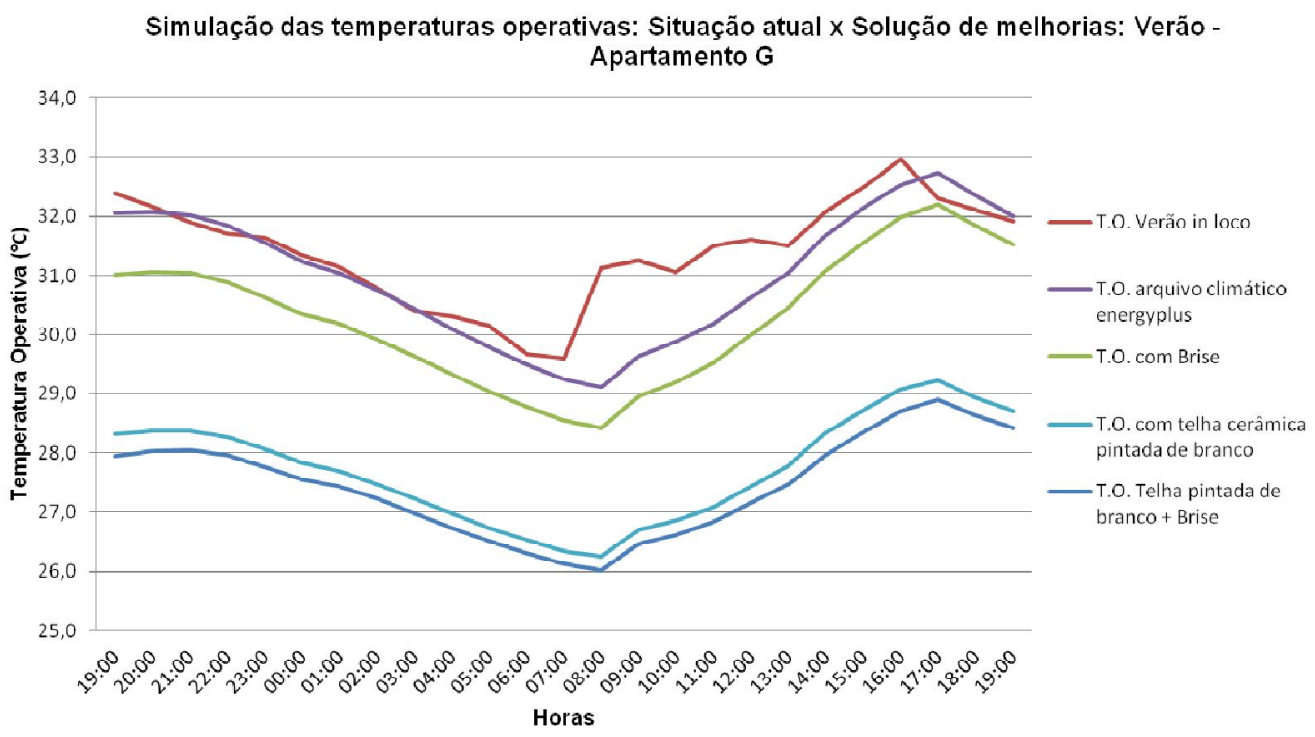

Figura 47: Simulação das temperaturas operativas do apartamento F com proposta de melhorias.

Com a implantação somente dos brises, observa-se uma diferença menor entre as temperaturas simuladas, com uma variação média de $0,7^{\circ} \mathrm{C}$; e com a implantação somente das telhas cerâmicas pintadas de branco a diferença aumenta para uma variação média de $3,3^{\circ} \mathrm{C}$ podendo reduzir a temperatura pontualmente em até $3,7^{\circ} \mathrm{C}$. Quando são simuladas as duas soluções juntas à variação média da diferença entre as temperaturas caem em $3,6^{\circ} \mathrm{C}$, com desvio entre as curvas atingindo $4,1^{\circ} \mathrm{C}$. 
Um dos fatores que possivelmente colaboraram com a atenuação das temperaturas operativas nos apartamentos, ao substituir as telhas de fibrocimento por telhas cerâmicas pintadas de branco, é que a telha cerâmica possui melhor desempenho com relação à absortância solar ( $\alpha$ ). Enquanto a absortância da telha de fibrocimento varia entre 0,85 e 0,95, a das telhas cerâmicas pintadas de branco varia entre 0,2 e 0,3, permitindo que a fração de radiação absorvida seja menor em relação ao material fibrocimento. Estas diferenças de valores de propriedades termofísicas dos materiais alteram diretamente o desempenho térmico, contribuindo para que o desconforto térmico seja mais presente no interior dos apartamentos.

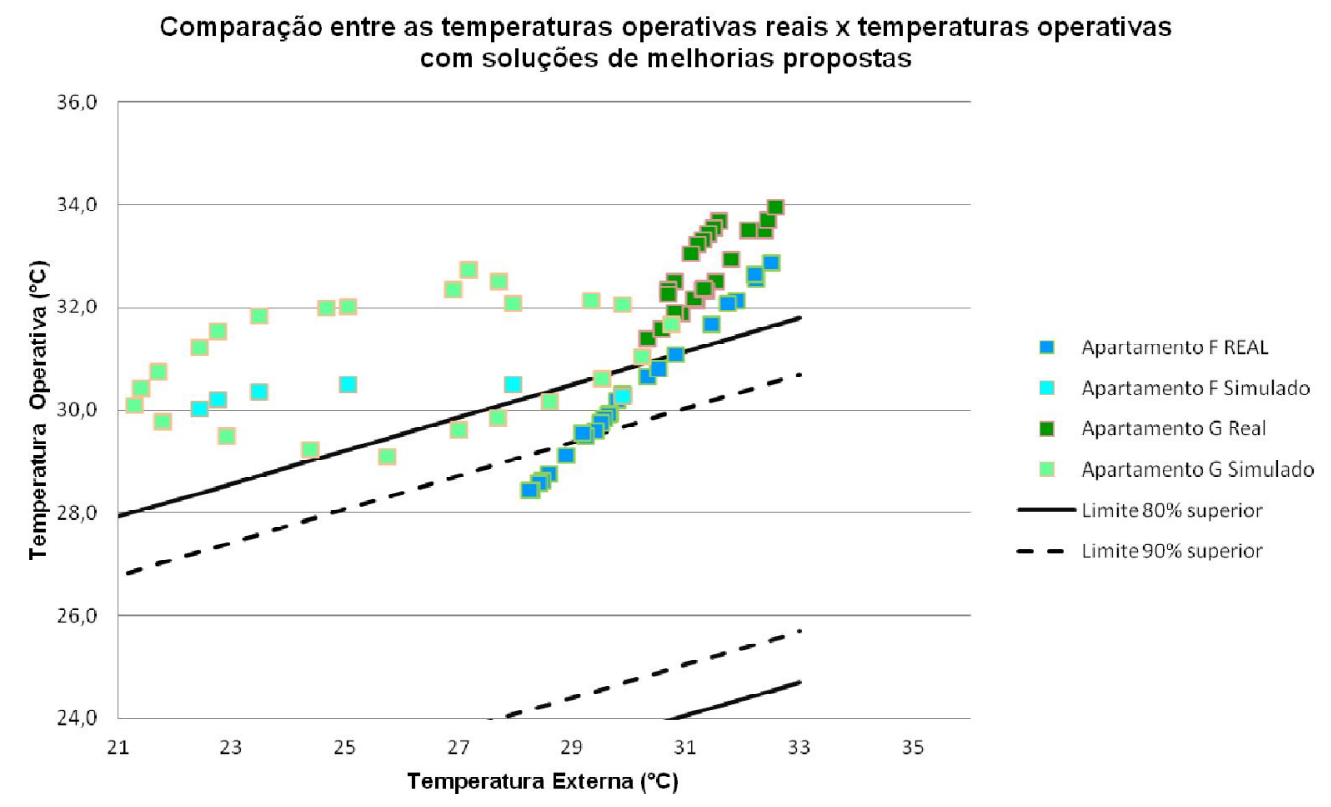

Figura 48: Simulação das temperaturas operativas do apartamento F com proposta de melhorias.

A figura 48 mostra os resultados das temperaturas operativas medidas in loco e as temperaturas operativas simuladas com os novos materiais. Observa-se, em ambos os apartamentos, que ocorre uma queda nas temperaturas operativas internas, porém, apenas em alguns períodos do dia avaliado os apartamentos estarão dentro da faixa de conforto térmico.

Provavelmente, estas soluções propostas amenizariam o desconforto térmico relacionado ao calor, contribuindo para o conforto térmico dos moradores. 
No caso dos apartamentos intermediários, embora não tenham sido simulados, em grande parte do dia são obstruídos em relação à incidência solar, por este motivo, recomenda-se que, quando possível, tenham um número reduzido de moradores e melhorem as aberturas de ventilação natural. 


\section{CONSIDERAÇÕES FINAIS}

Procurou-se, nesta pesquisa, identificar quais eram os aspectos de conforto térmico para usuários de uma Habitação de Interesse Social, neste caso, o BNH (Conjunto Castelo Branco) da cidade de Santos. Foi possível observar os critérios de diferentes normas que seriam utilizadas como base para pesquisa, contribuindo desta forma para que este trabalho utilizasse a metodologia que melhor se aplicasse ao local.

Analisando os resultados da pesquisa de APO, os usuários manifestaram-se com queixas em relação ao calor no interior dos apartamentos, principalmente nos meses que compreendem a estação do verão, e em alguns casos mais pontuais houveram reclamações a respeito do frio nos apartamentos em alguns períodos do inverno.

Foi observado, que no processo de escolha das metodologias, as que abrangeram maior compatibilidade entre as respostas da APO, foram a ASHRAE 55 (2010) e a NBR 15.220-3 (2005). Já a metodologia sugerida por De Dear e Brager (2002) apresentou resultados mais dispersos quanto às respostas dos usuários. No caso da metodologia sugerida por Cândido et al. (2011), exige-se que, para países tropicais, o ambiente construído tenha pelo menos $0,2 \mathrm{~m} / \mathrm{s}$ de ventilação natural, valores estes não observados no caso do BNH de Santos, pois durante o período das medições o valor máximo não ultrapassou $0,1 \mathrm{~m} / \mathrm{s}$.

Após a análise das respostas dos usuários, o passo seguinte foi adotar uma metodologia que estivesse compatível com as respostas dos moradores. Optouse pela metodologia ASHRAE 55 (2010) por ter obtido resultados mais semelhantes ao diagnóstico da APO.

Ao comparar os resultados do conforto térmico no interior dos apartamentos, foram registrados estados de desconforto térmico durante os dias frios e dias quentes. Os apartamentos $\mathrm{A}, \mathrm{B}, \mathrm{F}$ e $\mathrm{G}$, por serem apartamentos do último pavimento, com o telhado exposto a radiação solar, em todas as medições apresentaram-se nos meses de verão com temperaturas operativas elevadas, proporcionando desconforto térmico (quente) durante este período. No caso dos apartamentos B e G, uma possível contribuição do acréscimo da temperatura pode estar associada ao maior número de moradores e equipamento eletroeletrônicos ligados durante os horários das medições. 
Nos meses frios em que foram medidas as temperaturas operativas, alguns apartamentos apresentaram resultados fora da faixa de conforto estabelecidos pela metodologia da ASHRAE 55 (2010), sendo os apartamentos E, F, G e H, os que apresentaram respostas ao desconforto térmico (frio), principalmente nos meses de Julho e Agosto.

Observou-se nos apartamentos que são do último pavimento uma grande incidência de radiação solar. Estes apartamentos possuem alvenarias com pequenas espessuras e aberturas pequenas, tornando os ambientes pouco isolados, o que permite que temperaturas baixas e elevadas sejam transmitidas para o seu interior, além disso, possuem aberturas de janelas insuficientes, ocorrendo assim pouca circulação de ar, comprometendo a troca térmica dos apartamentos em dias quentes.

As medições de 24 horas apontaram certos caminhos que, os apartamentos geralmente permanecem em estado de conforto térmico durante o ano, ocorrendo pequenos desconfortos pontuais, com exceção do período de verão, quando os apartamentos avaliados permanecem em estado de desconforto térmico praticamente durante todo o período avaliado. Uma possível hipótese seria o pédireito mais baixo $(2,32 \mathrm{~m})$, as aberturas insuficientes e em alguns casos, 0 número excessivo de pessoas nos apartamentos, além dos materiais aplicados, por possuírem elevada transmitância térmica. Recomenda-se para trabalhos futuros, que a alteração destes projetos sejam melhorados.

Foram avaliados, através das simulações pelo software Energyplus, as temperaturas operativas dos apartamentos utilizando-se de duas soluções de materiais. Primeiramente, foi necessário gerar uma simulação que representasse uma comparação entre as temperaturas que foram medidas in loco e as temperaturas operativas geradas pelo arquivo climático do software.

Observou-se que, em alguns horários, as curvas de desvio dos resultados superam os limites de incertezas, estes desvios podem ser atribuídas ao fato de o arquivo climático ser da cidade de lguape, cidade esta com urbanização menos adensada, diferente de Santos, onde o processo de verticalização no entorno do BNH contribui com a formação de ilhas de calor, podendo alterar as temperaturas locais.

Considerando a existência destas diferenças e tomando como parâmetros o resultado da simulação, foi sugerida a aplicação de novos materiais, trocando as telhas de fibrocimento por telhas cerâmicas pintadas de branco e a inserção de 
brises de 0,70 cm nas aberturas. Em ambos os apartamentos, com apenas a instalação dos brises a variação média das temperaturas cai menos que a aplicação das telhas cerâmicas pintadas de branco, concluindo-se que a solução da instalação das telhas cerâmicas brancas seja mais eficiente que os brises, possivelmente por causa da emissividade proporcionada pelo material.

Outro item que colabora com o melhor desempenho das telhas cerâmicas pintadas de branco é a absortância solar, pois a fração de radiação absorvida é menor que o material fibrocimento, contribuindo para que o desconforto térmico seja menos presente no interior dos apartamentos.

De forma geral, pode-se afirmar que a percepção do usuário representa uma fração significativa de confiabilidade para os resultados. É importante ressaltar que, se os apartamentos possuíssem pé-direito maior, aberturas adequadas, alvenarias com maior capacidade de isolamento térmico e número de moradores adequado à área de cada apartamento, possivelmente as temperaturas operativas estariam mais adequadas aos padrões de conforto térmico. 


\section{REFERÊNCIAS BIBLIOGRÁFICAS}

ABREU, F.L. Parâmetros climáticos para a arquitetura: Definição de zoneamento climático para o Estado de São Paulo a partir do estudo de condicionantes relevantes para inverno e verão. Dissertação de mestrado apresentada à Universidade de São Paulo, volume 1. Faculdade de Arquitetura e Urbanismo. São Paulo, SP. 2005.

AKUTSU, M. Método para avaliação do desempenho térmico de edificações no Brasil. São Paulo: Universidade de São Paulo, Faculdade de Arquitetura e Urbanismo. Tese de Doutorado. 1998.

AKUTSU, M. VITTORINO, F. The use of simulation Software to Evaluate the Thermal Performance of Buildings in Brazil. Institute for Technological Research of São Paulo of State (Instituto de Pesquisas Tecnológicas do estado de São Paulo. 1999.

ANSI/ASHRAE 55. Thermal Environmental Conditions for Human Occupancy, American Socitey of Heating, refrigerating and Air Conditioning Engenieers, Inc. Atlanta, 1974, 1981, 1995, 2004, 2010.

ASSOCIAÇÃO BRASILEIRA DE NORMAS TÉCNICAS. NBR 15.220-3: Desempenho térmico de edificações Parte 3: Zoneamento bioclimático brasileiro e diretrizes construtivas para habitações unifamiliares de interesse social. Rio de Janeiro, 2013.

ASSOCIAÇÃO BRASILEIRA DE NORMAS TÉCNICAS. NBR 15.575: Edificações Habitacionais - Desempenho. Rio de Janeiro, 2013.

AZEVEDO, S. Vinte e dois anos de política de habitação popular (1964-86): criação, trajetória e extinção do BNH. Revista de Administração Pública, Vol 22, n.4. Rio de Janeiro-RJ. 1988.

BATISTA, J. O. PEIXOTO, I. M. L. CAVALCANTE, K. E. L. LIMA, I. M. Desempenho térmico de Habitação multifamiliar do programa Minha Casa Minha Vida em Maceió - AL. Maceió-Al. ENTAC 2014. 
BONDUKI, N. Os pioneiros da habitação social - cem anos de política pública no Brasil. Editora UNESP. São Paulo-SP. 2014.

BONDUKI, N. Origens da habitação social no Brasil - arquitetura Moderna, Lei do Inquilinato e Difusão da Casa Própria. Ed. Estação Liberdade. São Paulo-SP. 2011.

BRAGER, S. G. DEAR, R.J. Thermal comfort in naturally ventilated buildings: revisions to ASHRAE 55. Energy and Building. ELSEVIER. USA. 2002.

BRAVO, G. GONZÁLEZ, E. Thermal comfort in naturally ventiladed spaces and under indirect evaporative passive cooling condiditions in hot-humid climate. Energy and Buildings, ELSEVIER. Universidad del Zulia, Venezuela. 2013.

CÂNDIDO, C. DEAR, R. LAMBERTS, R. Combined thermal acceptability and air movement assessments in a hot humid climate. ELSEVIER, Building and Environment, 46. P. 379-385. Federal University of Santa Catarina. Department of Civil Engineering, Brazil. 2011.

CÂNDIDO, C. LAMBERTS, R. DEAR, R. BITTENCOURT, L. VECCHI, R. Towards a Brazilian standard for naturally ventilated building: guidelines for thermal and air movement acceptability. Routledge Taylor \& Francis Group. Building Research \& Information. University of Sydney, Sydney, Australia. 2011.

CÂNDIDO, C. LAMBERTS, R. BITTENCOURT, L. DEAR, R. Aplicabilidade dos limites da velocidade do ar para efeito de conforto térmico em climas quentes e úmidos. Ambiente Construído. Porto Alegre, RS. 2010.

COSTA NETO, P.L.O. Estatística. São Paulo: Ed.Edgar Blücher, 2002.

DEAR, R.J. GAIL. S.B. Thermal comfort in naturally ventilated buildings: revisions to ASHRAE Standard 55. Energy and Buildings. N. 34, p. 549-561. 2002.

FANGER, P. O. Thermal Comfort, Analysis and Application in Environmental Engineering. McGraw-Hill, New York, U.S.A. 1972.

FREITAS, H. OLIVEIRA, M. SACCOL, A.Z. MOSCAROLA, J. O método de pesquisa survey. Revista de Administração, volume 35. São Paulo-SP. 2000.

GIVONI, B. Man, Climate and Architecture. Applied Science Publishers LTD, second edition. London, UK. 1976. 
HARLAN, S. L. BRAZEL, A.J. PRASHAD, L. STEFANOV, W.L. LARSEN, L. Neighborhood microclimates and vulnerability to heat stress. Social Science \& Medicine. ELSEVIER. University of Michigan, MI, USA. 2006.

ISO 7726. Ergonomics of thermal environment - Instruments for measuring physical quantities. International Organization for Standardization, Geneva, 1985, 1996.

ISO 7730. Moderate Thermal Environments - Determination of the PMV and PPD Indices and Specification of the Conditions of thermal comfort. International Organization for Standardization, Geneva, 1994, 2005.

LAMBERTZ, R. XAVIER, A. A. GOULART, S. DE VECCHI, R. Conforto e stress térmico. Laboratório de Eficiência Energética em edificações. Universidade Federal de Santa Catarina, SC.2011.

MORAIS, J.M.C. LABAKI, L.C. Projetos de edifícios multifamiliares do "Minha Casa Minha Vida": Análise do ponto de vista da ventilação natural. XV Encontro NAcional de Tecnologia do Ambiente Construído - ENTAC. Maceió-AL. 2014.

NETO, A. H. BIM e seu impacto em edificações climatizadas - Building Information Modeling e seu conceito aplicado. E/A Engenharia e Arquitetura Disponível em: http://www.engenhariaearquitetura.com.br/noticias/283/BIM-e-seuimpacto-em-edificacoes-climatizadas.aspx > Acesso em: 12 jul, 2013.

NETO, A. H. FIORELLI, F.A.S. Comparison between detailed model simulation and artificial neural network for forecasting building consumption. Energy and Buildings, ELSEVIER. Universidade de São Paulo, 2008.

NICOL, F. Adaptive thermal comfort standars in the hot - humid tropics. Energy and Building. ELSEVIER. Oxford Brookes University. Oxford, UK. 2004.

ORMANDY, D. EZRATTY, V. Health and thermal comfort: From WHO guidance to housing strategies. Energy Policy ELSEVIER. University of Warwick, Coventry, UK. 2012.

PEREIRA, I.M. ASSIS, E.S. Avaliação de modelos de índices adaptativos para uso no projeto arquitetônico bioclimático. Ambiente Construído. Porto Alegre, RS. 2009. 
PRADO, R.T.A. FERREIRA, F.L. Measurement of Albedo and analysis of its influence the surface temperature of buildings roof materials. ELSEVIER. Energy and Building. Escola Politécnica da Escola de São Paulo. São Paulo-SP. 2004.

Revista Acrópole. Núcleo Habitacional Ponta da Praia. Vol. 30, n 350, páginas 28-29. 1968.

ROMERO, M. A. ORNSTEIN, S. W. Avaliação Pós Ocupação, Métodos e Técnicas Aplicados à Habitação de Interesse Social. 1a. Ed. Porto Alegre: Coleção Habitare/FINEP/ANTAC. 2003.

SCAPUCCIN, L. M. Requalificação do Conjunto Habitacional "Marechal Humberto de Alencar Castelo Branco", BNH da Aparecida. Monografia apresentada ao Departamento de Arquitetura e Urbanismo da Universidade Católica de Santos. Santos-SP. 2005.

SUZUKI, E. H. Avaliação do conforto térmico e do nível de $\mathrm{CO}_{2}$ em Edifícios de escritório com climatização artificial na cidade de São Paulo. 147p. Escola Politécnica da Universidade de São Paulo. Dissertação de Mestrado. São Paulo, SP. 2010.

TRIBESS, A. Análise do conforto térmico em ambientes climatizados. 2008, 130p. Escola Politécnica da Universidade de São Paulo. Tese (Livre Docência). São Paulo,SP. 2008.

TRIBESS, A. Ventilação, qualidade do ar e conforto térmico. São Paulo: Departamento de Engenharia Mecânica da Escola Politécnica da Universidade de São Paulo, 2012. Notas de aula. 


\section{APÊNDICE A - Características Espaciais e Térmicas dos Apartamentos Avaliados}

Tabela 9: Características do apartamento A

\begin{tabular}{cccccccccc}
\hline $\begin{array}{c}\text { Apartamento } \\
\text { A }\end{array}$ & Conjunto & Prédio & Porta Número do & $\begin{array}{c}\text { Quantidade } \\
\text { de } \\
\text { apartamento } \\
\text { moradores }\end{array}$ & $\begin{array}{c}\text { Quantidade } \\
\text { de quartos }\end{array}$ & $\begin{array}{c}\text { Área total do } \\
\text { apartamento } \\
\left(\mathrm{m}^{2}\right)\end{array}$ & $\begin{array}{c}\text { Área do } \\
\text { quarto } \\
\text { analisado } \\
\left(\mathrm{m}^{2}\right)\end{array}$ & $\begin{array}{c}\text { Área da } \\
\text { sala } \\
\text { analisada } \\
\left(\mathrm{m}^{2}\right)\end{array}$ \\
\hline $\begin{array}{c}\text { Último } \\
\text { pavimento }\end{array}$ & Argentina & 335 & 5 & 409 & 3 & 3 & 54,7 & 9,75 & 14,5 \\
\hline
\end{tabular}

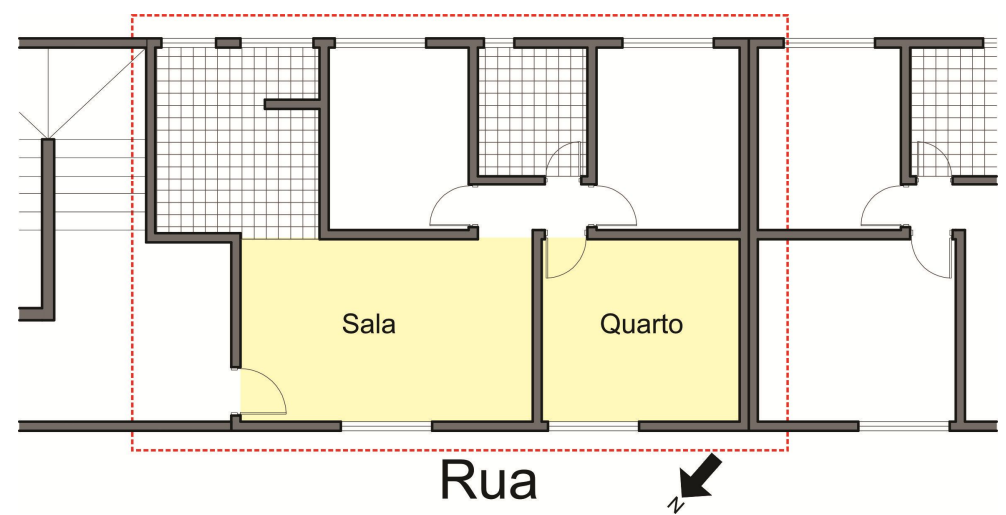

Figura 49: Planta baixa referente ao Apartamento A.

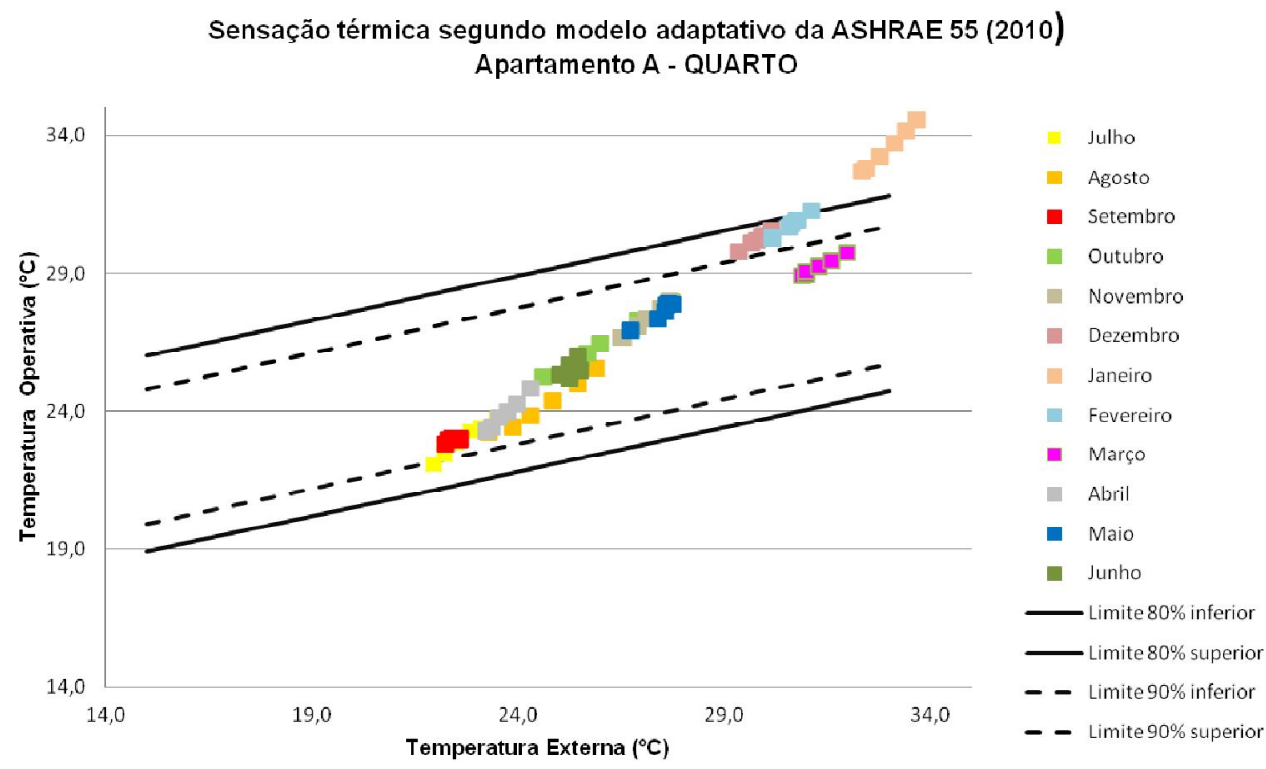

Figura 50: Sensação térmica segundo modelo adaptativo da ASHRAE (Quarto - apartamento A). 


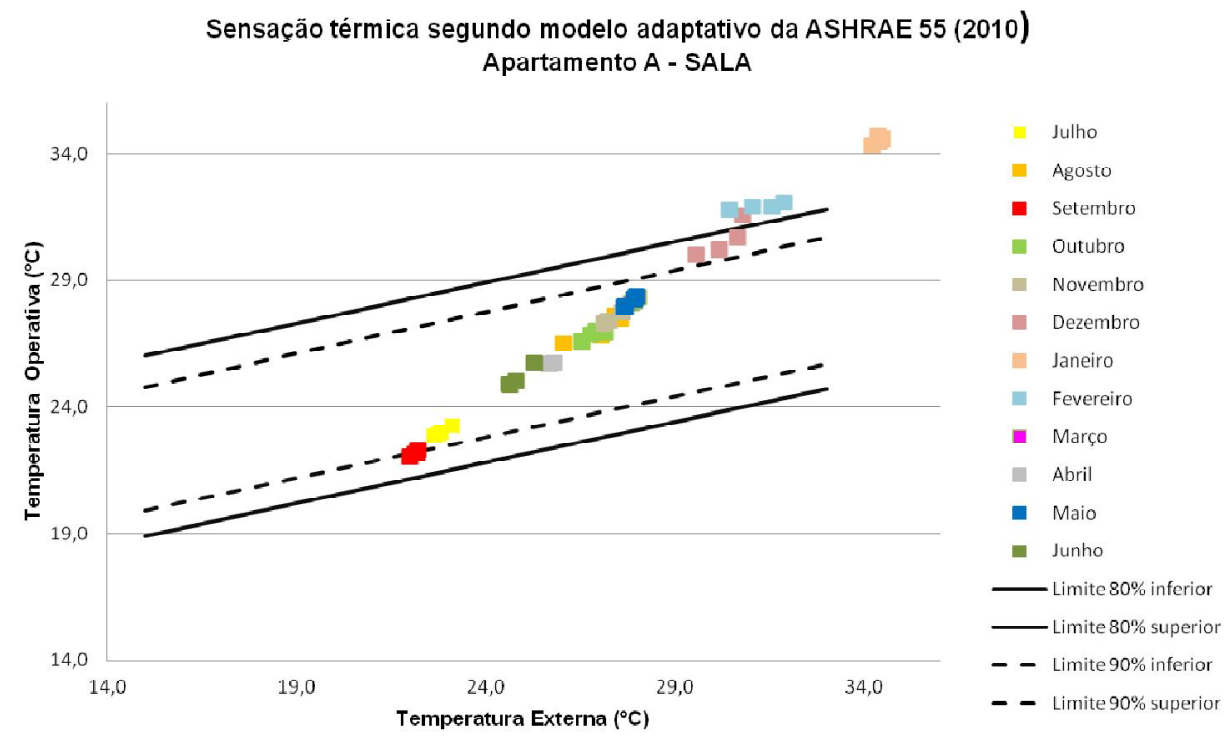

Figura 51: Sensação térmica segundo modelo adaptativo da ASHRAE (Sala - apartamento A).

Tabela 10: Características do apartamento B

\begin{tabular}{cccccccccc}
\hline $\begin{array}{c}\text { Apartamento } \\
\text { B }\end{array}$ & Conjunto & Prédio Porta & $\begin{array}{c}\text { Número do } \\
\text { apartamento }\end{array}$ & $\begin{array}{c}\text { Quantidade } \\
\text { de } \\
\text { moradores }\end{array}$ & $\begin{array}{c}\text { Quantidade } \\
\text { de quartos }\end{array}$ & $\begin{array}{c}\text { Área total } \\
\text { do } \\
\text { apartamento } \\
\left(\mathrm{m}^{2}\right)\end{array}$ & $\begin{array}{c}\text { Área do } \\
\text { quarto } \\
\text { analisado } \\
\left(\mathrm{m}^{2}\right)\end{array}$ & $\begin{array}{c}\text { Área da } \\
\text { sala } \\
\text { analisada } \\
\left(\mathrm{m}^{2}\right)\end{array}$ \\
\hline $\begin{array}{c}\text { Último } \\
\text { pavimento }\end{array}$ & Argentina & 331 & 5 & 412 & 5 & 3 & 54,7 & 9,75 & 14,5 \\
\hline
\end{tabular}

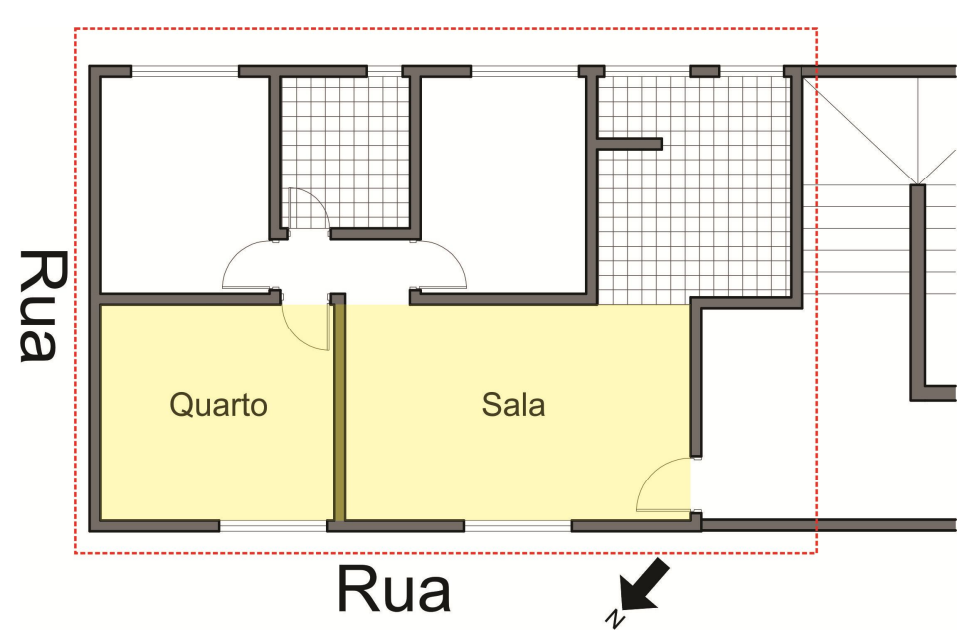

Figura 52: Planta baixa referente ao Apartamento B. 


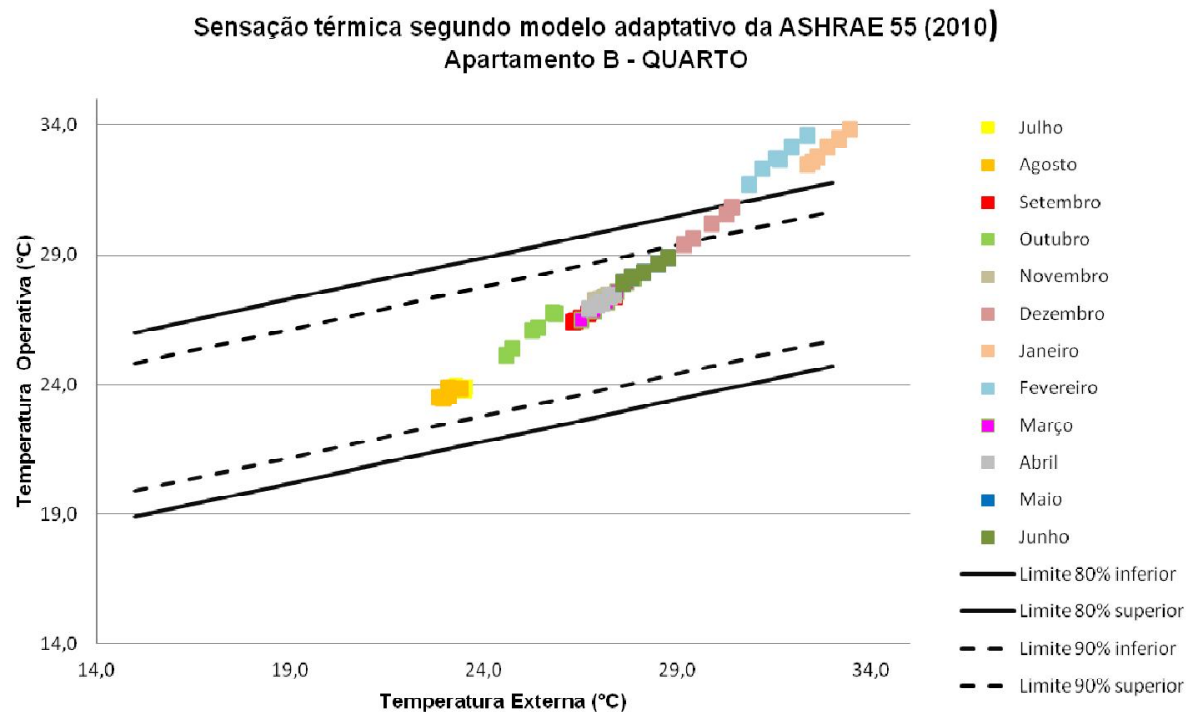

Figura 53: Sensação térmica segundo modelo adaptativo da ASHRAE (Quarto - apartamento B).

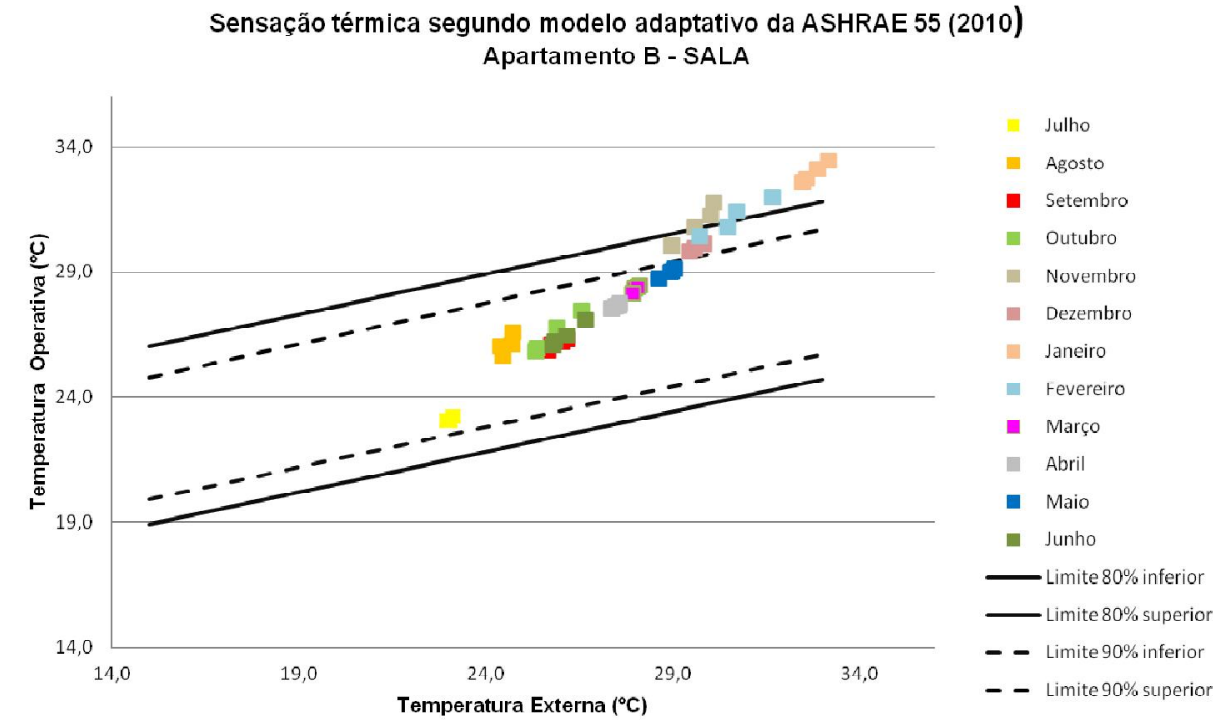

Figura 54: Sensação térmica segundo modelo adaptativo da ASHRAE (Sala - apartamento B).

Tabela 11: Características do apartamento C

\begin{tabular}{ccccccccccc}
\hline $\begin{array}{c}\text { Apartamento } \\
\text { C }\end{array}$ & Conjunto & Prédio Porta & $\begin{array}{c}\text { Número do } \\
\text { apartamento }\end{array}$ & $\begin{array}{c}\text { Quantidade } \\
\text { de } \\
\text { moradores }\end{array}$ & $\begin{array}{c}\text { Quantidade } \\
\text { de quartos }\end{array}$ & $\begin{array}{c}\text { Área total do } \\
\text { apartamento } \\
\left(\mathrm{m}^{2}\right)\end{array}$ & $\begin{array}{c}\text { Área do } \\
\text { quarto } \\
\text { analisado } \\
\left(\mathrm{m}^{2}\right)\end{array}$ & $\begin{array}{c}\text { Área da } \\
\text { sala } \\
\text { analisada } \\
\left(\mathrm{m}^{2}\right)\end{array}$ \\
\hline $\begin{array}{c}\text { Terceiro } \\
\text { pavimento }\end{array}$ & Bolívia & 361 & 2 & 304 & 5 & 3 & 54,7 & 9,75 & 14,5 \\
\hline
\end{tabular}




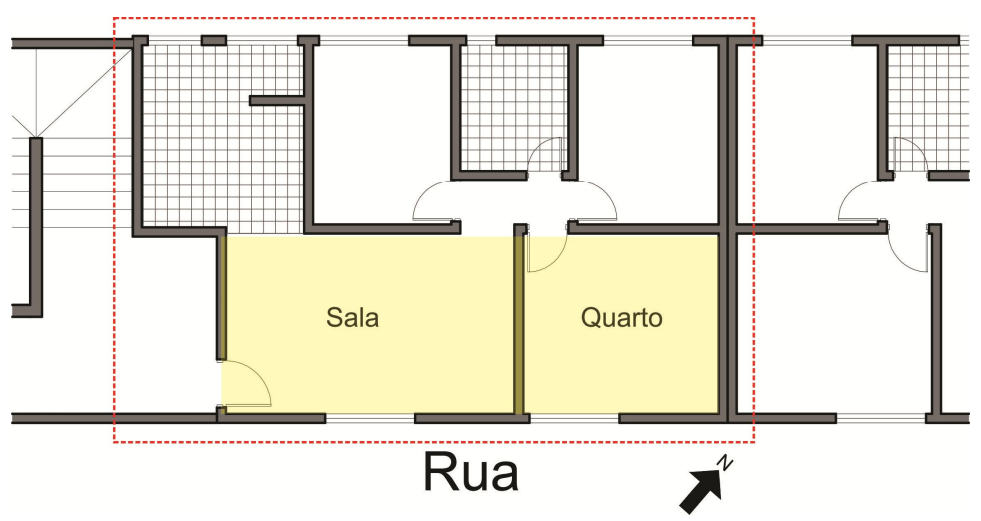

Figura 55: Planta baixa referente ao Apartamento C.

Sensação térmica segundo modelo adaptativo da ASHRAE 55 (2010) Apartamento C - QUARTO

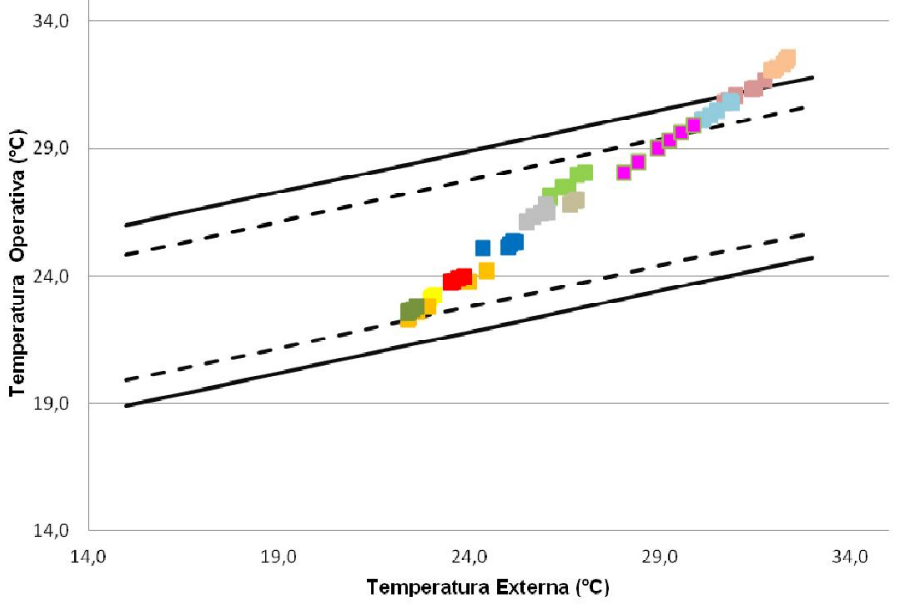

III Julho

1. Agasto

- Setembro

11. Dutubro

Movemhrn

- Dezembro

11. Janeiro

1. Fevereirn

- Marro

III Abril

- Maio

- Iınho

- limite 80\% inferior

Limite $80 \%$ superio

- - Limite $90 \%$ inferior

- - limite $90 \%$ supperio

Figura 56: Sensação térmica segundo modelo adaptativo da ASHRAE (Quarto - apartamento C).

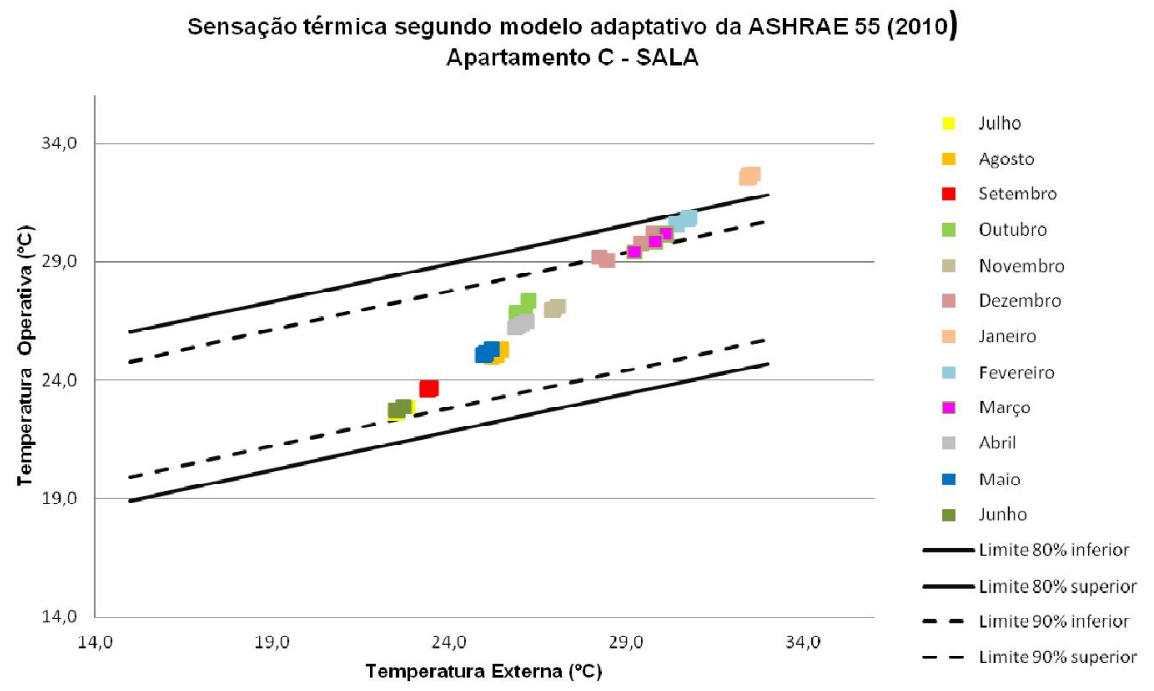

Figura 57: Sensação térmica segundo modelo adaptativo da ASHRAE (Sala - apartamento C). 
Tabela 12: Características do apartamento D

\begin{tabular}{cccccccccc}
\hline $\begin{array}{c}\text { Apartamento } \\
\text { D }\end{array}$ & Conjunto & Prédio & Porta $\begin{array}{c}\text { Número do } \\
\text { apartamento }\end{array}$ & $\begin{array}{c}\text { Quantidade } \\
\text { de } \\
\text { moradores }\end{array}$ & $\begin{array}{c}\text { Quantidade } \\
\text { de quartos }\end{array}$ & $\begin{array}{c}\text { Área total do } \\
\text { apartamento } \\
\left(\mathrm{m}^{2}\right)\end{array}$ & $\begin{array}{c}\text { Área do } \\
\text { quarto } \\
\text { analisado } \\
\left(\mathrm{m}^{2}\right)\end{array}$ & $\begin{array}{c}\text { Área da } \\
\text { sala } \\
\text { analisada } \\
\left(\mathrm{m}^{2}\right)\end{array}$ \\
\hline $\begin{array}{c}\text { Pavimento } \\
\text { Térreo }\end{array}$ & Bolívia & 345 & 3 & 106 & 2 & 2 & 54,4 & 9,75 & 14,4 \\
\hline
\end{tabular}

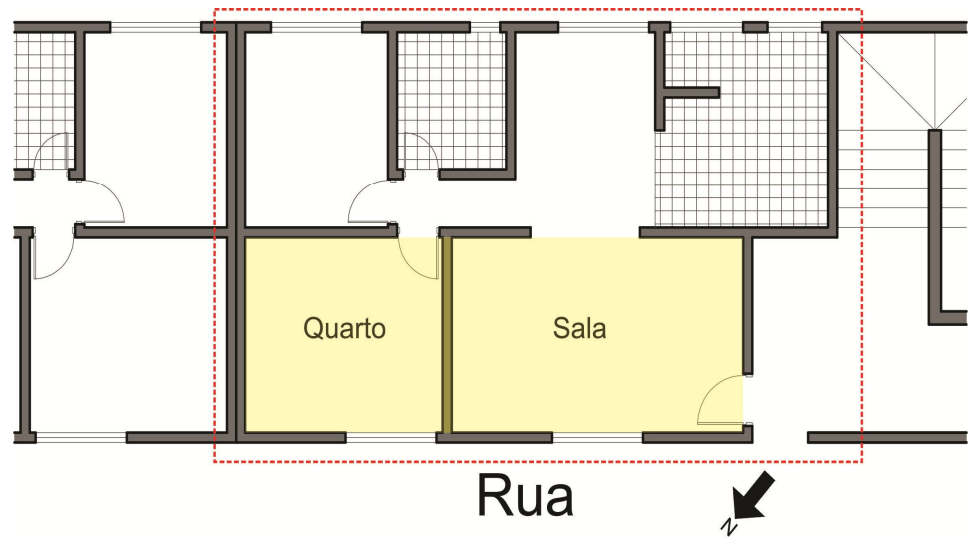

Figura 58: Planta baixa referente ao Apartamento D.

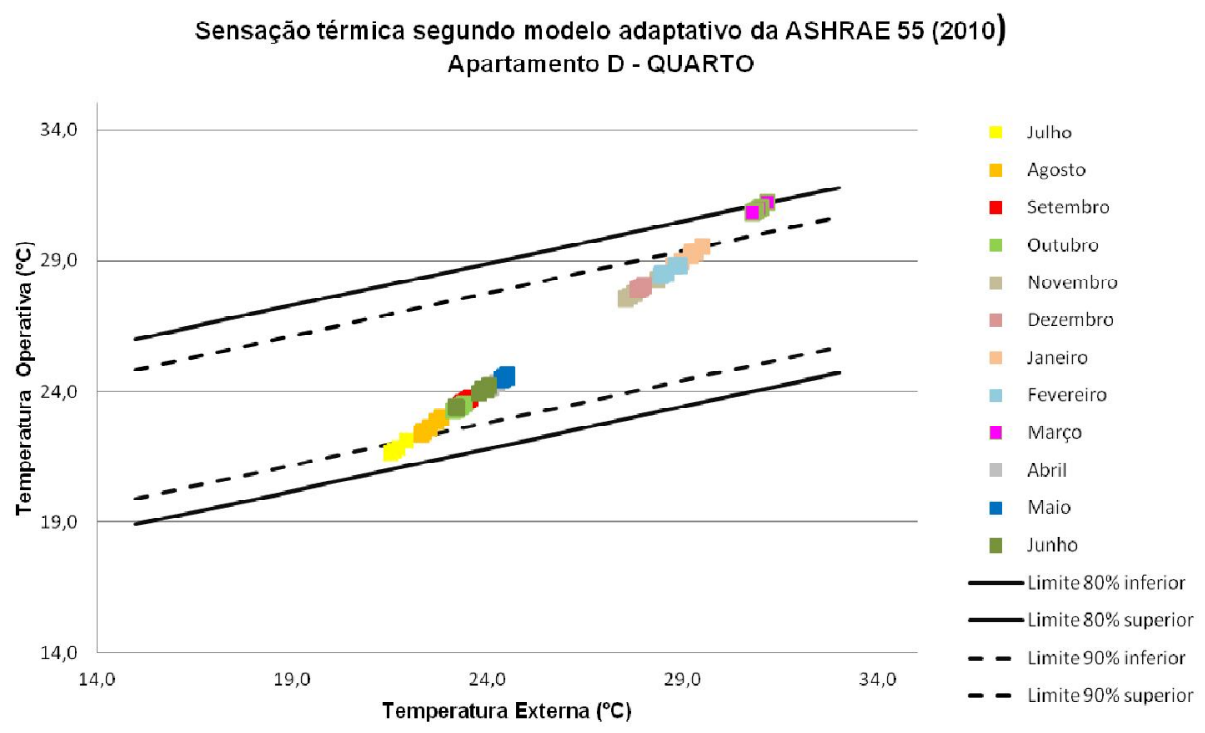

Figura 59: Sensação térmica segundo modelo adaptativo da ASHRAE (Quarto - apartamento D). 
Sensação térmica segundo modelo adaptativo da ASHRAE 55 (2010) Apartamento D - SALA

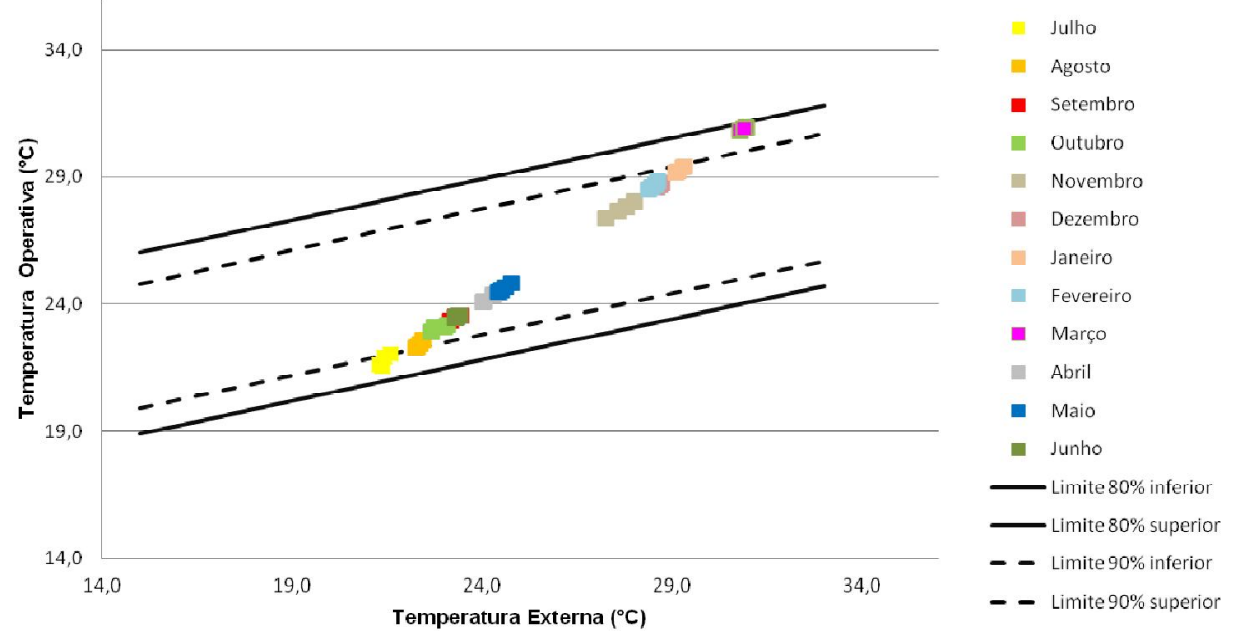

Figura 60: Sensação térmica segundo modelo adaptativo da ASHRAE (Sala - apartamento D).

Tabela 13: Características do apartamento E

\begin{tabular}{cccccccccc}
\hline $\begin{array}{c}\text { Apartamento } \\
\text { E }\end{array}$ & Conjunto & Prédio & Porta & $\begin{array}{c}\text { Número do } \\
\text { apartamento }\end{array}$ & $\begin{array}{c}\text { Quantidade } \\
\text { de } \\
\text { moradores }\end{array}$ & $\begin{array}{c}\text { Quantidade } \\
\text { de quartos }\end{array}$ & $\begin{array}{c}\text { Área total do } \\
\text { apartamento } \\
\left(\mathrm{m}^{2}\right)\end{array}$ & $\begin{array}{c}\text { Área do } \\
\text { quarto } \\
\text { analisado } \\
\left(\mathrm{m}^{2}\right)\end{array}$ & $\begin{array}{c}\text { Área da } \\
\text { sala } \\
\text { analisada } \\
\left(\mathrm{m}^{2}\right)\end{array}$ \\
\hline $\begin{array}{c}\text { Pavimento } \\
\text { Térreo }\end{array}$ & Chile & 371 & 2 & 103 & 9 & 3 & 50,7 & 9,9 & 14,4 \\
\hline
\end{tabular}

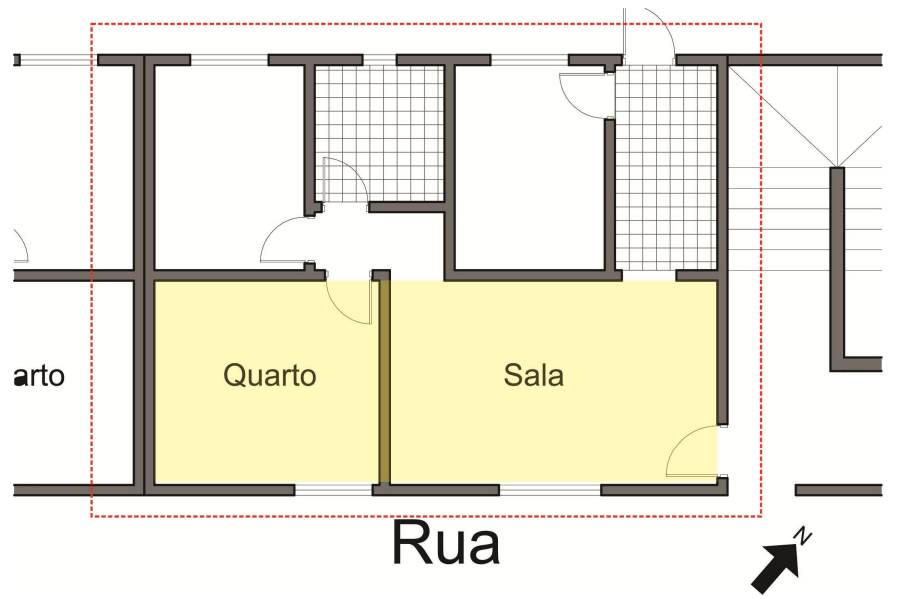

Figura 61: Planta baixa referente ao Apartamento E. 
Sensação térmica segundo modelo adaptativo da ASHRAE 55 (2010) Apartamento E - QUARTO

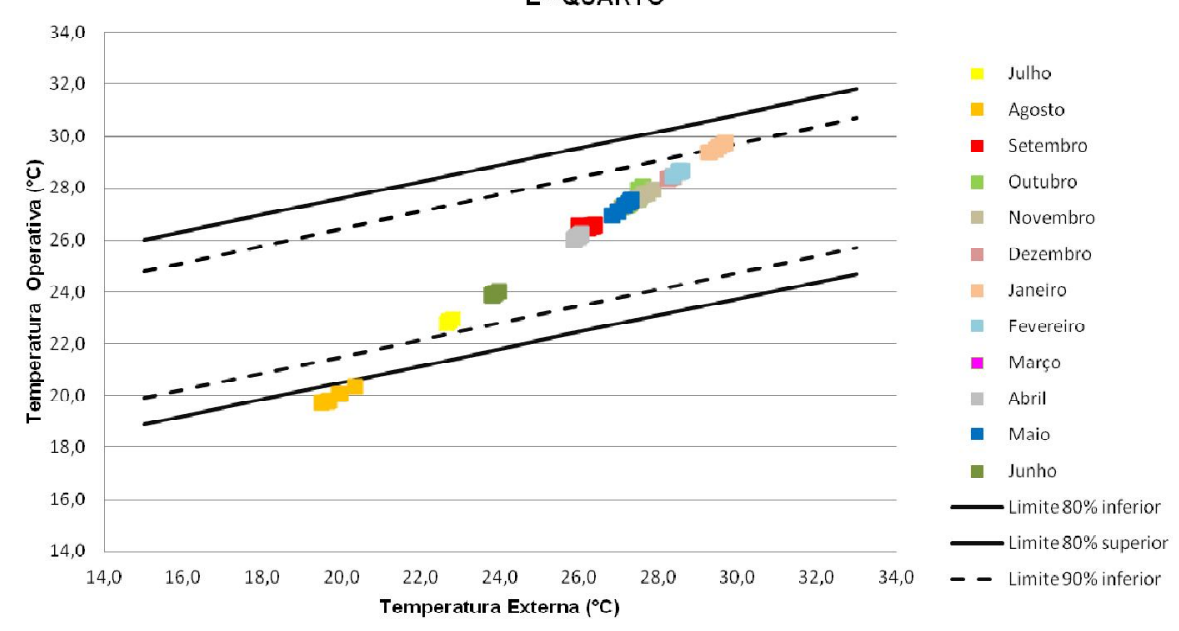

Figura 62: Sensação térmica segundo modelo adaptativo da ASHRAE (Quarto - apartamento E).

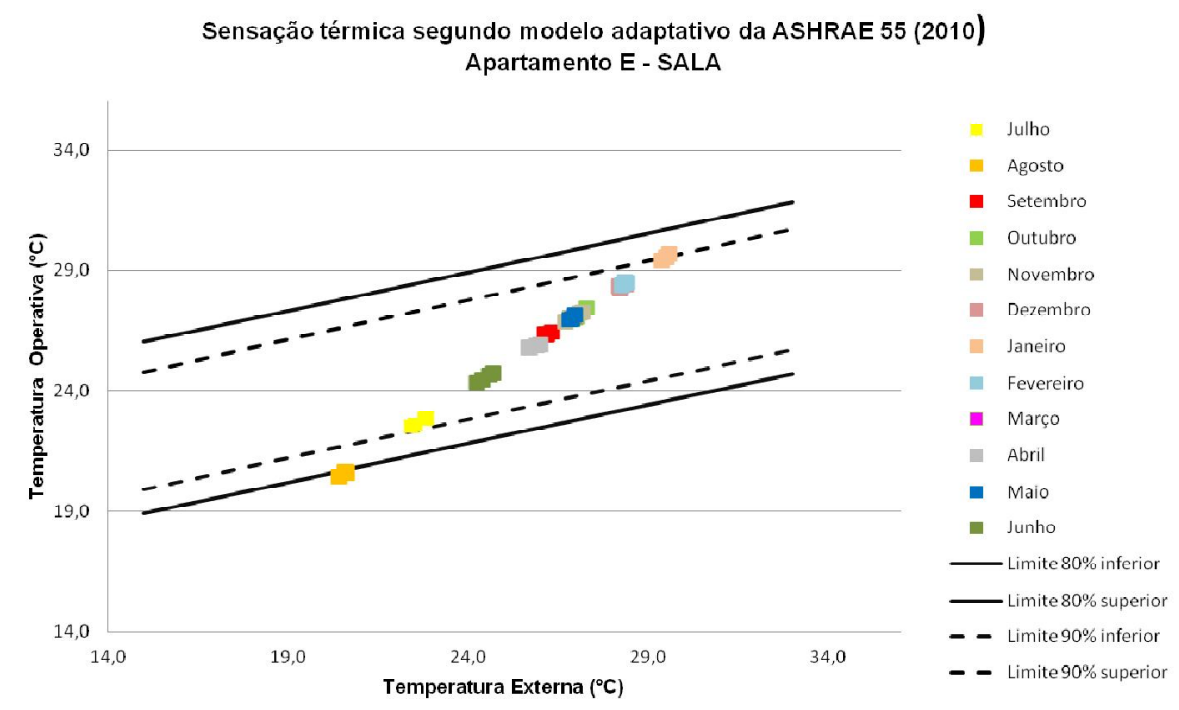

Figura 63: Sensação térmica segundo modelo adaptativo da ASHRAE (Sala - apartamento E).

Tabela 14: Características do apartamento $\mathrm{F}$

\begin{tabular}{cccccccccc}
\hline $\begin{array}{c}\text { Apartamento } \\
\mathrm{F}\end{array}$ & Conjunto Prédio & Porta $\begin{array}{c}\text { Número do } \\
\text { apartamento }\end{array}$ & $\begin{array}{c}\text { Quantidade } \\
\text { de } \\
\text { moradores }\end{array}$ & $\begin{array}{c}\text { Quantidade } \\
\text { de quartos }\end{array}$ & $\begin{array}{c}\text { Área total do } \\
\text { apartamento } \\
\left(\mathrm{m}^{2}\right)\end{array}$ & $\begin{array}{c}\text { Área do } \\
\text { quarto } \\
\text { analisado } \\
\left(\mathrm{m}^{2}\right)\end{array}$ & $\begin{array}{c}\text { Área da } \\
\text { sala } \\
\text { analisada } \\
\left(\mathrm{m}^{2}\right)\end{array}$ \\
\hline $\begin{array}{c}\text { Último } \\
\text { pavimento }\end{array}$ & $\begin{array}{c}\text { Guiana } \\
\text { Inglesa }\end{array}$ & 232 & 2 & 404 & 2 & 2 & 37 & 9,3 & 8,8 \\
\hline
\end{tabular}




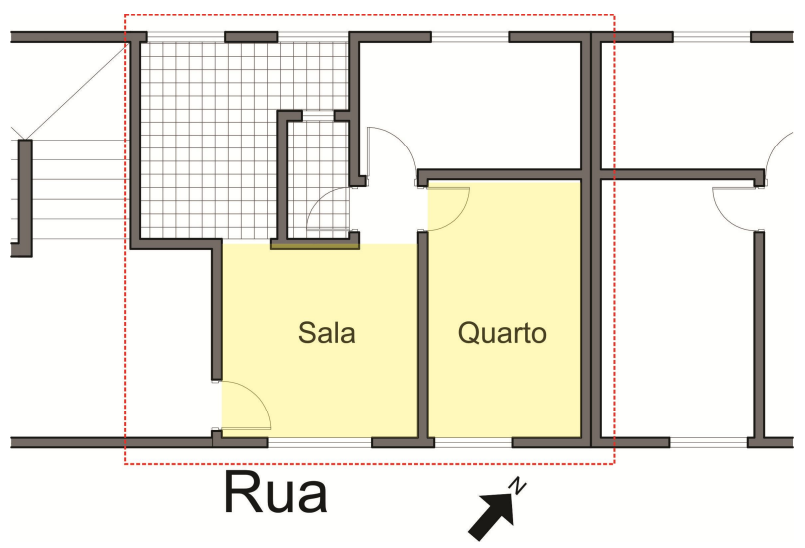

Figura 64: Planta baixa referente ao Apartamento F.

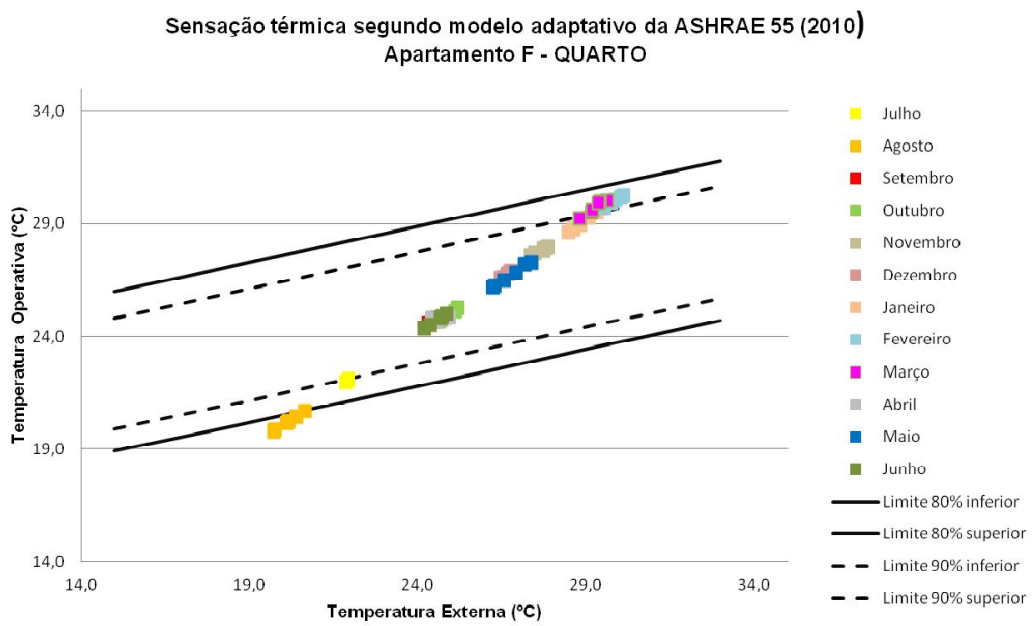

Figura 65: Sensação térmica segundo modelo adaptativo da ASHRAE (Quarto - apartamento F).

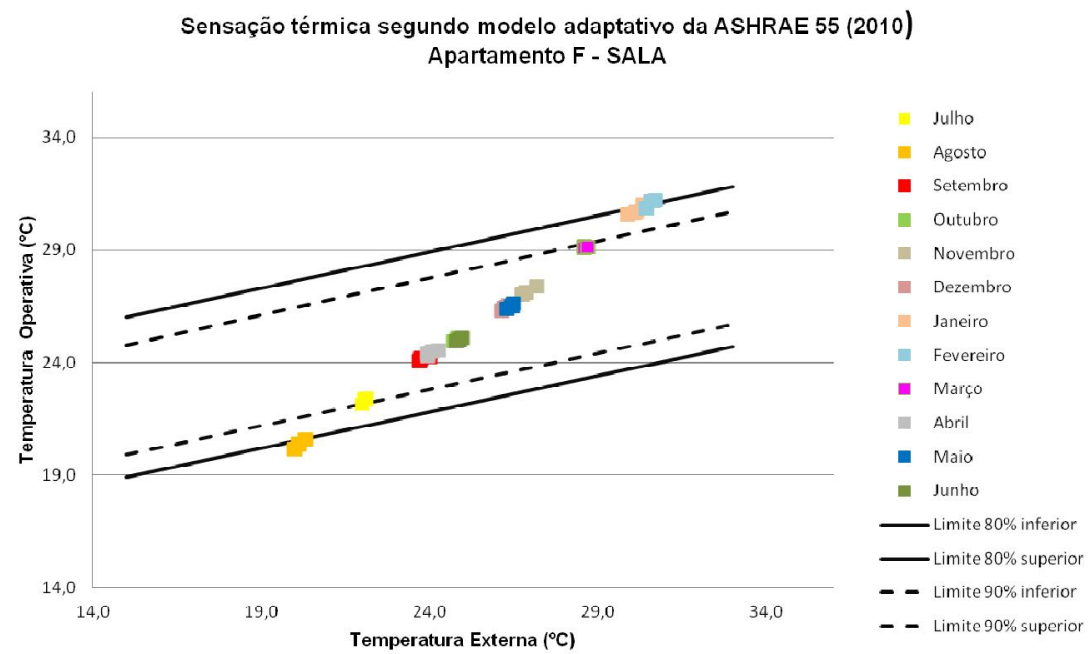

Figura 66: Sensação térmica segundo modelo adaptativo da ASHRAE (Sala - apartamento F). 
Tabela 15: Características do apartamento G

\begin{tabular}{ccccccccc}
\hline $\begin{array}{c}\text { Apartamento } \\
\mathrm{G}\end{array}$ & Conjunto Prédio Porta & $\begin{array}{c}\text { Número do } \\
\text { apartamento }\end{array}$ & $\begin{array}{c}\text { Quantidade } \\
\text { de } \\
\text { moradores }\end{array}$ & $\begin{array}{c}\text { Quantidade } \\
\text { de quartos }\end{array}$ & $\begin{array}{c}\text { Área total do } \\
\text { apartamento } \\
\left(\mathrm{m}^{2}\right)\end{array}$ & $\begin{array}{c}\text { Área do } \\
\text { quarto } \\
\text { analisado } \\
\left(\mathrm{m}^{2}\right)\end{array}$ & $\begin{array}{c}\text { Área da } \\
\text { sala } \\
\text { analisada } \\
\left(\mathrm{m}^{2}\right)\end{array}$ \\
\hline $\begin{array}{c}\text { Último } \\
\text { pavimento }\end{array}$ & $\begin{array}{c}\text { Guiana } \\
\text { Francesa }\end{array}$ & 151 & 4 & 401 & 4 & 3 & 59,2 & 10,8 \\
\hline
\end{tabular}

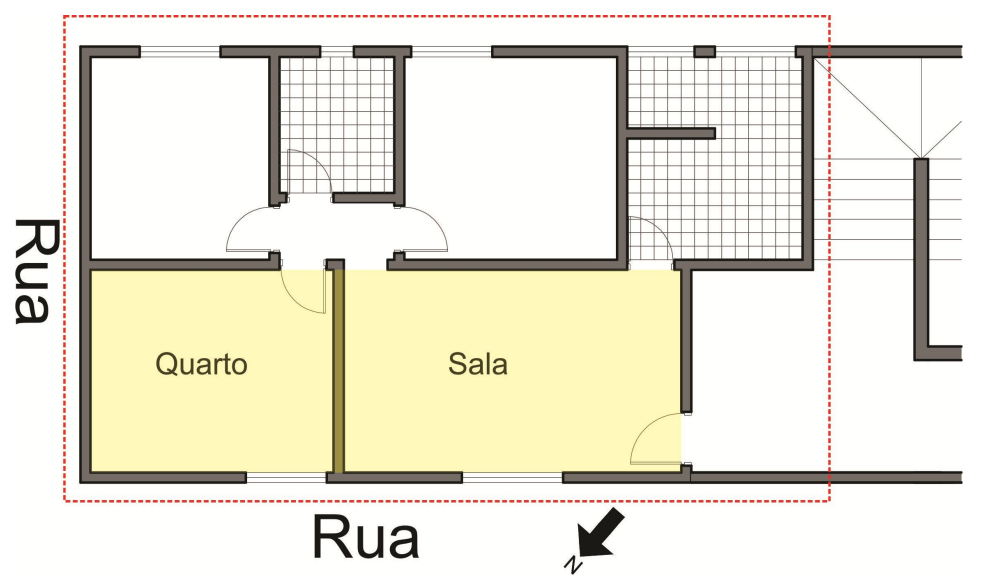

Figura 67: Planta baixa referente ao Apartamento G.

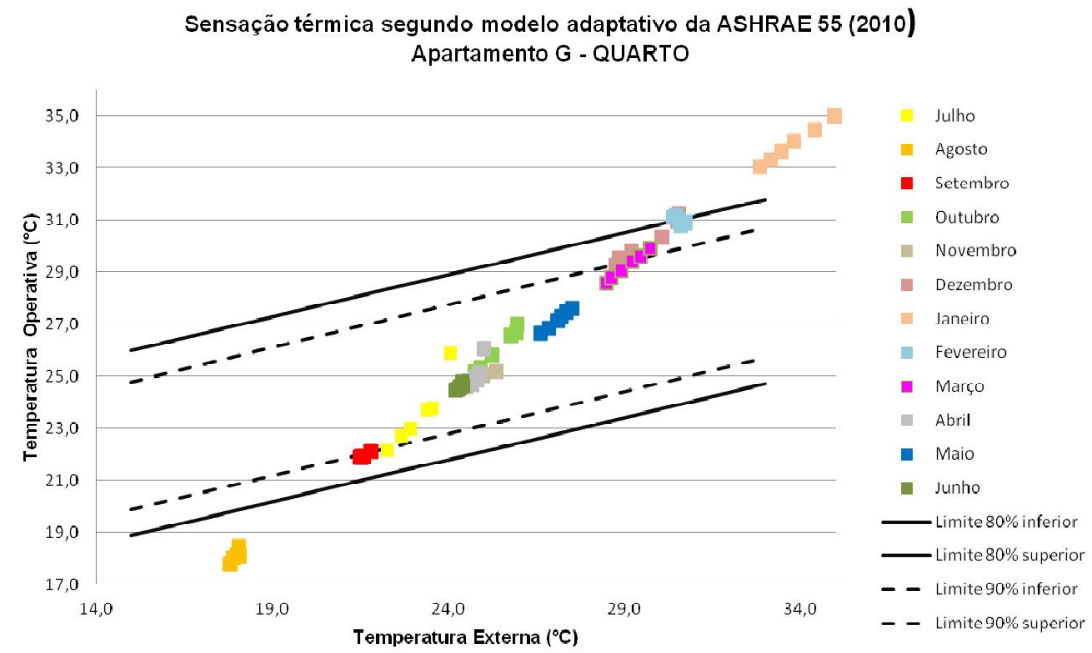

Figura 68: Sensação térmica segundo modelo adaptativo da ASHRAE (Quarto - apartamento G). 


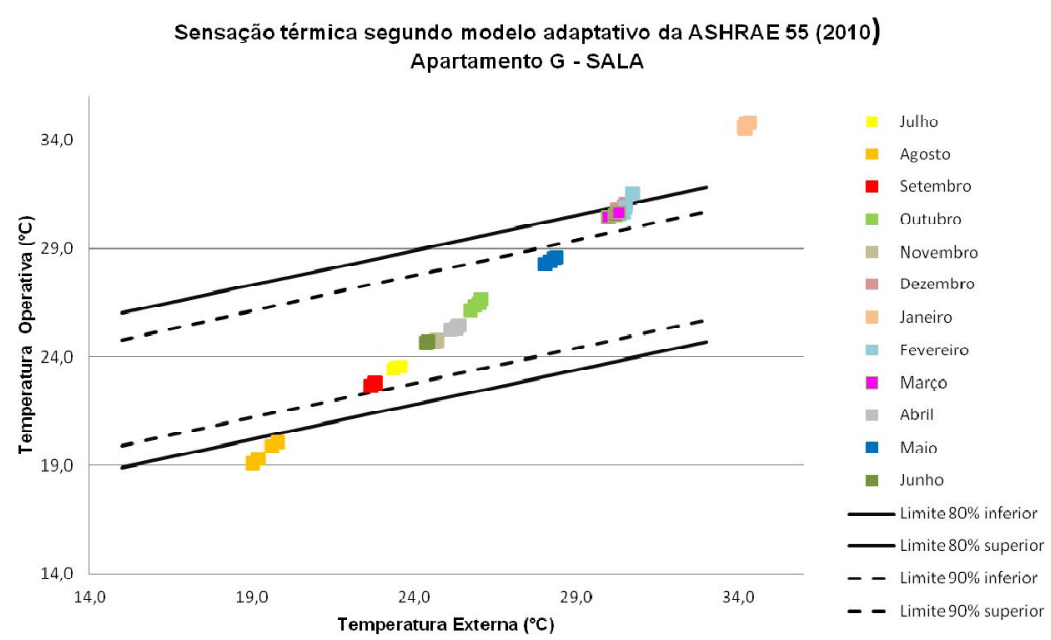

Figura 69: Sensação térmica segundo modelo adaptativo da ASHRAE (Sala - apartamento G).

Tabela 16: Características do apartamento $\mathrm{H}$

\begin{tabular}{cccccccccc}
\hline $\begin{array}{c}\text { Apartamento } \\
\mathrm{H}\end{array}$ & Conjunto & Prédio & Porta $\begin{array}{c}\text { Número do } \\
\text { apartamento }\end{array}$ & $\begin{array}{c}\text { Quantidade } \\
\text { de } \\
\text { moradores }\end{array}$ & $\begin{array}{c}\text { Quantidade } \\
\text { de quartos }\end{array}$ & $\begin{array}{c}\text { Área total do } \\
\text { apartamento } \\
\left(\mathrm{m}^{2}\right)\end{array}$ & $\begin{array}{c}\text { Área do } \\
\text { quarto } \\
\text { analisado } \\
\left(\mathrm{m}^{2}\right)\end{array}$ & $\begin{array}{c}\text { Área da } \\
\text { sala } \\
\text { analisada } \\
\left(\mathrm{m}^{2}\right)\end{array}$ \\
\hline $\begin{array}{c}\text { Segundo } \\
\text { pavimento }\end{array}$ & Peru & 398 & 3 & 206 & 1 & 2 & 37 & 9,3 & 8,8 \\
\hline
\end{tabular}

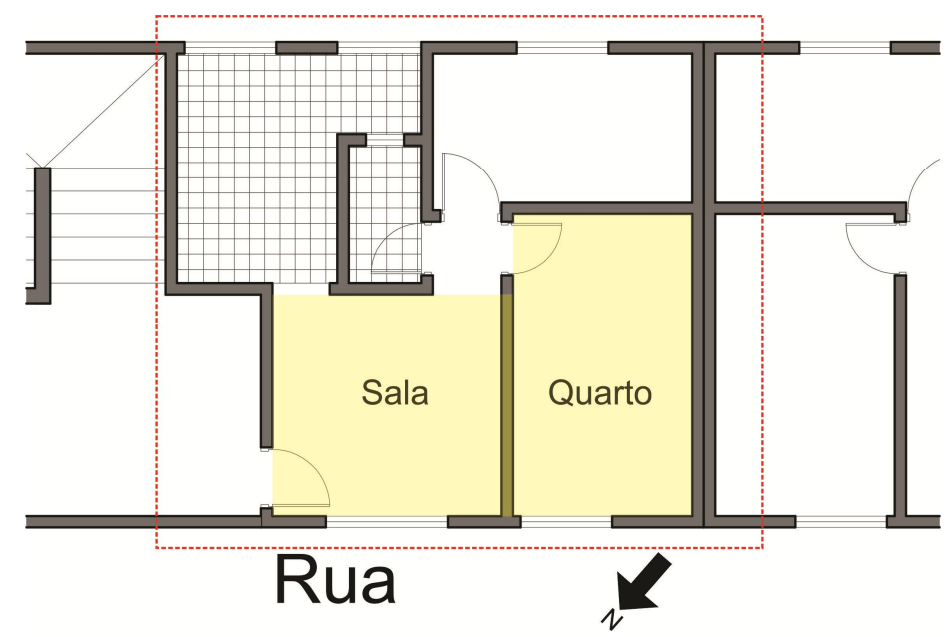

Figura 70: Planta baixa referente ao Apartamento $\mathrm{H}$. 


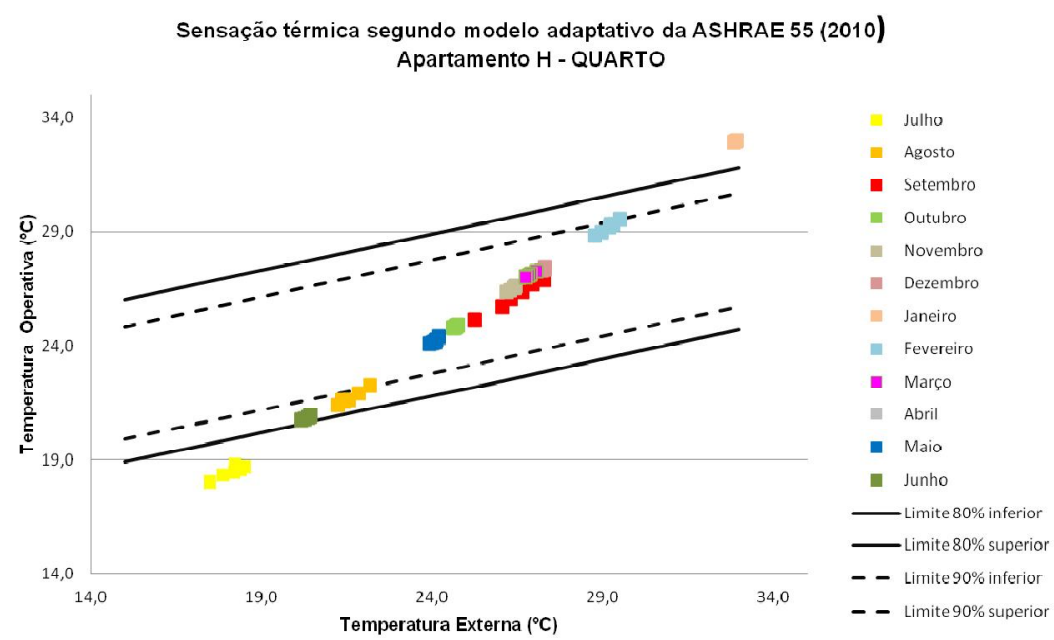

Figura 71: Sensação térmica segundo modelo adaptativo da ASHRAE (Quarto - apartamento H).

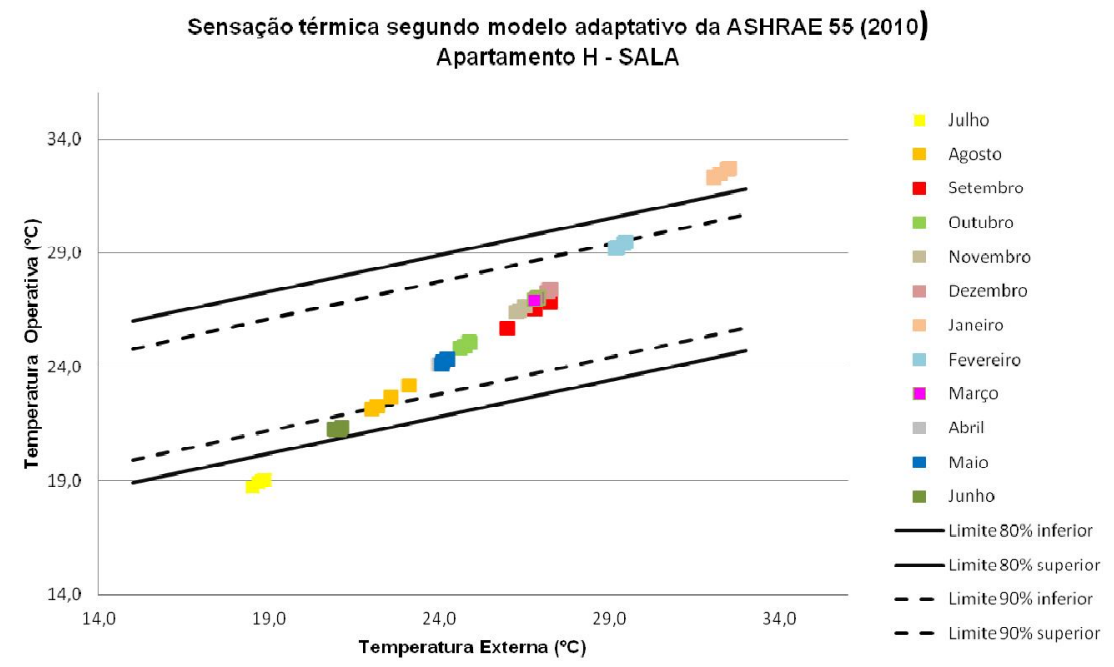

Figura 72: Sensação térmica segundo modelo adaptativo da ASHRAE (Sala - apartamento H). 


\section{APÊNDICE B - Dados Obtidos nas medições in loco dos apartamentos avaliados}

\begin{tabular}{|c|c|c|c|c|c|c|c|c|}
\hline \multicolumn{2}{|l|}{ Apartamento A } & \multicolumn{4}{|c|}{ Dados coletados CONFORTÍMETRO Julho 2013 - QUARTO } & \multicolumn{3}{|c|}{ céu claro } \\
\hline Intervalo & $\begin{array}{l}\text { Temperatura de } \\
\text { bulbo úmido }\left({ }^{\circ} \mathrm{C}\right)\end{array}$ & $\begin{array}{c}\text { Temperatura de } \\
\text { globo }\left({ }^{\circ} \mathrm{C}\right)\end{array}$ & $\begin{array}{l}\text { Temperatura do ar } \\
\left({ }^{\circ} \mathrm{C}\right)\end{array}$ & $\begin{array}{c}\text { Pressão } \\
\text { Atmosférica (atm) }\end{array}$ & $\begin{array}{l}\text { Umidade relativa } \\
\text { do ar (\%) }\end{array}$ & $\begin{array}{l}\text { Velocidade do ar } \\
\qquad(\mathrm{m} / \mathrm{s})\end{array}$ & $\begin{array}{l}\text { Temperatura } \\
\text { radiante }\left({ }^{\circ} \mathrm{C}\right)\end{array}$ & $\begin{array}{l}\text { Temperatura } \\
\text { Operativa }\left({ }^{\circ} \mathrm{C}\right)\end{array}$ \\
\hline $11: 50$ as $12: 20$ & 19,7 & 22,2 & 22,0 & 1021,3 & 75,5 & 0,0 & 22,3 & 22,1 \\
\hline $12: 20$ as $12: 50$ & 19,9 & 22,5 & 22,2 & 1020,7 & 74,8 & 0,0 & 22,7 & 22,5 \\
\hline $12: 50$ as $13: 20$ & 20,1 & 22,9 & 22,5 & 1020,2 & 74,1 & 0,0 & 23,2 & 22,9 \\
\hline $13: 20$ as $13: 50$ & 20,2 & 23,4 & 22,9 & 1019,9 & 72,5 & 0,0 & 23,7 & 23,3 \\
\hline $13: 50$ as $14: 20$ & 20,4 & 23,6 & 23,1 & 1019,7 & 71,0 & 0,0 & 23,7 & 23,4 \\
\hline $14: 20$ as $14: 50$ & 20,4 & 23,8 & 23,5 & 1019,5 & 69,6 & 0,0 & 23,9 & 23,7 \\
\hline Desvio Padrão & 0,26 & 0,60 & 0,54 & 0,62 & 2,15 & 0,03 & 0,63 & 1,63 \\
\hline Média & 20,1 & 23,0 & 22,7 & 1020,2 & 72,9 & 0,0 & 23,2 & 23,0 \\
\hline \multicolumn{9}{|c|}{ Dados coletados Termômetro de fluxo de laser } \\
\hline Horário/Quarto & $\begin{array}{l}\text { Temp. Externa do ar } \\
\qquad\left({ }^{\circ} \mathrm{C}\right)\end{array}$ & $\begin{array}{l}\text { Temp. Paredes } \\
\text { externas }\left({ }^{\circ} \mathrm{C}\right)\end{array}$ & $\begin{array}{c}\text { Temp. Paredes } \\
\text { voltada para a rua } \\
\left({ }^{\circ} \mathrm{C}\right)\end{array}$ & \multicolumn{3}{|c|}{ Temp. Média das paredes $\left({ }^{\circ} \mathrm{C}\right)$} & Temp. Teto $\left({ }^{\circ} \mathrm{C}\right)$ & \\
\hline 11:50 & 21 & 20,5 & 21,7 & \multicolumn{3}{|c|}{21} & 22,5 & \\
\hline $15: 00$ & 22 & 22 & 23,5 & \multicolumn{3}{|c|}{23} & 23,7 & \\
\hline
\end{tabular}

Tabela 17: Resultados coletados in loco no quarto do Apartamento A no mês de Julho de 2013.

\begin{tabular}{|c|c|c|c|c|c|c|c|c|}
\hline \multicolumn{6}{|c|}{ Dados coletados CONFORTÍM ETRO Ago sto 2013 - QUARTO } & \multicolumn{3}{|c|}{ céu claro } \\
\hline Intervalo & $\begin{array}{l}\text { Temperatura de } \\
\text { bulbo úmido }\left({ }^{\circ} \mathrm{C}\right)\end{array}$ & $\begin{array}{c}\text { Temperatura de } \\
\text { globo }\left({ }^{\circ} \mathrm{C}\right)\end{array}$ & $\begin{array}{c}\text { Temperatura do ar } \\
\left({ }^{\circ} \mathrm{C}\right)\end{array}$ & $\begin{array}{c}\text { Pressão } \\
\text { Atmosférica (atm) }\end{array}$ & $\begin{array}{c}\text { Umidade relativa } \\
\text { do } \operatorname{ar}(\%)\end{array}$ & $\begin{array}{c}\text { Velocidade do ar } \\
(\mathrm{m} / \mathrm{s})\end{array}$ & $\begin{array}{l}\text { Temperatura } \\
\text { radiante }\left({ }^{\circ} \mathrm{C}\right)\end{array}$ & $\begin{array}{l}\text { Temperatura } \\
\text { Operativa }\left({ }^{\circ} \mathrm{C}\right)\end{array}$ \\
\hline $11: 50$ as $12: 20$ & 19,9 & 23,2 & 23,3 & 1011,5 & 66,6 & 0,0 & 23,2 & 23,2 \\
\hline $12: 20$ as $12: 50$ & 19,2 & 23,5 & 23,9 & 1011,7 & 58,6 & 0,1 & 23,0 & 23,4 \\
\hline $12: 50$ as $13: 50$ & 19,2 & 23,9 & 24,3 & 1011,7 & 56,0 & 0,1 & 23,4 & 23,8 \\
\hline $13: 50$ as $14: 20$ & 19,3 & 24,4 & 24,9 & 1011,2 & 53,5 & 0,1 & 23,9 & 24,4 \\
\hline $14: 20$ as $14: 50$ & 19,34 & 25,02 & 25,46 & 1010,47 & 50,6 & 0,08 & 24,55 & 25,0 \\
\hline Desvio Padrão & 0,3 & 0,6 & 0,7 & 0,4 & 5,5 & 0,1 & 0,6 & 1,6 \\
\hline Média & 19,4 & 24,1 & 24,4 & 1011,3 & 56,6 & 0,1 & 23,6 & 23,6 \\
\hline \multicolumn{8}{|c|}{ Dados coletados Termômetro de fluxo de laser } & \\
\hline Horário/Quarto & $\begin{array}{l}\text { Temp. Externa do ar } \\
\left({ }^{\circ} \mathrm{C}\right)\end{array}$ & $\begin{array}{c}\text { Temp. Paredes } \\
\text { externas }\left({ }^{\circ} \mathrm{C}\right)\end{array}$ & $\begin{array}{c}\text { Temp.Paredes } \\
\text { voltada para a rua } \\
\left({ }^{\circ} \mathrm{C}\right)\end{array}$ & \multicolumn{3}{|c|}{ Temp. Média das paredes $\left({ }^{\circ} \mathrm{C}\right)$} & Temp. Teto $\left({ }^{\circ} \mathrm{C}\right)$ & \\
\hline $11: 50$ & 21,8 & 22,8 & 22,5 & \multicolumn{3}{|c|}{23} & 23,4 & \\
\hline $15: 00$ & 26,1 & 27,5 & 26,5 & \multicolumn{3}{|c|}{26,6} & 25,5 & \\
\hline
\end{tabular}

Tabela 18: Resultados coletados in loco no quarto do Apartamento A no mês de Agosto de 2013.

\begin{tabular}{|c|c|c|c|c|c|c|c|c|}
\hline \multicolumn{2}{|l|}{ Apartamento $\mathrm{A}$} & \multicolumn{4}{|c|}{ Dados coletados CONFORTIMMETRO Setembro 2013 - QUARTO } & \multicolumn{3}{|c|}{ Nublado } \\
\hline Intervalo & $\begin{array}{l}\text { Temperatura de } \\
\text { bulbo úmido }\left({ }^{\circ} \mathrm{C}\right)\end{array}$ & $\begin{array}{c}\text { Temperatura de } \\
\text { globo }\left({ }^{\circ} \mathrm{C}\right)\end{array}$ & $\begin{array}{c}\text { Temperatura do ar } \\
\left({ }^{\circ} \mathrm{C}\right)\end{array}$ & $\begin{array}{c}\text { Pressão } \\
\text { Atmosférica (atm) }\end{array}$ & $\begin{array}{c}\text { Umidade relativa } \\
\text { do ar (\%) }\end{array}$ & $\begin{array}{l}\text { Velocidade do ar } \\
\qquad(\mathrm{m} / \mathrm{s})\end{array}$ & $\begin{array}{l}\text { Temperatura } \\
\text { radiante }\left({ }^{\circ} \mathrm{C}\right)\end{array}$ & $\begin{array}{l}\text { Temperatura } \\
\text { Operativa }\left({ }^{\circ} \mathrm{C}\right)\end{array}$ \\
\hline $11: 50$ as $12: 20$ & 19,4 & 23,0 & 22,6 & 1013,6 & 74,1 & 0,1 & 23,3 & 23,0 \\
\hline $12: 20$ as $12: 50$ & 19,4 & 23,0 & 22,6 & 1013,2 & 74,1 & 0,1 & 23,4 & 23,0 \\
\hline $12: 50$ as $13: 50$ & 19,2 & 22,9 & 22,4 & 1013,0 & 74,2 & 0,1 & 23,5 & 23,0 \\
\hline $13: 50$ as $14: 20$ & 19,2 & 22,8 & 22,3 & 1013,0 & 74,5 & 0,1 & 23,6 & 23,0 \\
\hline $13: 50$ as $14: 20$ & 19,3 & 22,7 & 22,3 & 1013,0 & 76,2 & 0,1 & 23,4 & 22,8 \\
\hline Desvio Padrão & 0,1 & 0,2 & 0,2 & 0,2 & 0,9 & 0,1 & 0,4 & 1,6 \\
\hline Média & 19,3 & 22,9 & 22,4 & 1013,1 & 74,6 & 0,1 & 23,5 & 23,6 \\
\hline \multicolumn{8}{|c|}{ Dados coletados Termômetro de fluxo de laser } & \\
\hline Horário/Quarto & $\begin{array}{l}\text { Temp. Externa do ar } \\
\qquad\left({ }^{\circ} \mathrm{C}\right)\end{array}$ & $\begin{array}{l}\text { Temp. Paredes } \\
\text { externas }\left({ }^{\circ} \mathrm{C}\right)\end{array}$ & $\begin{array}{c}\text { Temp. Paredes } \\
\text { voltada para a rua } \\
\left({ }^{\circ} \mathrm{C}\right)\end{array}$ & \multicolumn{3}{|c|}{ Temp. Média das paredes $\left({ }^{\circ} \mathrm{C}\right)$} & Temp. Teto $\left({ }^{\circ} \mathrm{C}\right)$ & \\
\hline 11:50 & 22 & 21,3 & 21,3 & \multicolumn{3}{|c|}{22,8} & 22,3 & \\
\hline $15: 00$ & 21,2 & 20,9 & 21,7 & \multicolumn{3}{|c|}{22,7} & 22,9 & \\
\hline
\end{tabular}

Tabela 19: Resultados coletados in loco no quarto do Apartamento A no mês de Setembro de 2013.

\begin{tabular}{|c|c|c|c|c|c|c|c|c|}
\hline \multicolumn{2}{|l|}{ Apartamento A } & \multicolumn{4}{|c|}{ Dados coletados CONFORTÍMETRO Outubro 2013 - QUARTO } & \multicolumn{3}{|c|}{ Nublado } \\
\hline Intervalo & $\begin{array}{l}\text { Temperatura de } \\
\text { bulbo úmido }\left({ }^{\circ} \mathrm{C}\right)\end{array}$ & $\begin{array}{c}\text { Temperatura de } \\
\text { globo }\left({ }^{\circ} \mathrm{C}\right)\end{array}$ & $\begin{array}{c}\text { Temperatura do ar } \\
\left({ }^{\circ} \mathrm{C}\right)\end{array}$ & $\begin{array}{c}\text { Pressão } \\
\text { Atmosférica (atm) }\end{array}$ & $\begin{array}{c}\text { Umidade relativa } \\
\text { do } \operatorname{ar}(\%)\end{array}$ & $\begin{array}{l}\text { Velocidade do ar } \\
(\mathrm{m} / \mathrm{s})\end{array}$ & $\begin{array}{l}\text { Temperatura } \\
\text { radiante }\left({ }^{\circ} \mathrm{C}\right)\end{array}$ & $\begin{array}{l}\text { Temperatura } \\
\text { Operativa }\left({ }^{\circ} \mathrm{C}\right)\end{array}$ \\
\hline $11: 50$ AS 12:20 & 21,8 & 25,5 & 24,6 & 1009,5 & 71,6 & 0,0 & 25,9 & 25,3 \\
\hline $12: 20$ as $12: 50$ & 21,9 & 26,0 & 25,5 & 1008,9 & 67,3 & 0,0 & 26,2 & 25,9 \\
\hline $12: 50$ as $13: 20$ & 22,0 & 26,2 & 25,7 & 1008,6 & 66,2 & 0,0 & 26,5 & 26,1 \\
\hline $13: 20$ as $13: 50$ & 22,0 & 26,6 & 26,0 & 1008,5 & 65,0 & 0,0 & 27,0 & 26,5 \\
\hline $13: 50$ as $14: 20$ & 22,0 & 27,4 & 26,9 & 1008,3 & 59,9 & 0,0 & 27,7 & 27,3 \\
\hline $14: 20$ as $14: 50$ & 22,2 & 28,1 & 27,7 & 1007,9 & 57,1 & 0,0 & 28,2 & 28,0 \\
\hline Desvio Padrão & 0,16 & 0,92 & 1,09 & 0,59 & 5,27 & 0,0 & 0,86 & 1,63 \\
\hline Média & 22,0 & 26,4 & 25,8 & 1008,8 & 66,1 & 0,0 & 26,7 & 26,2 \\
\hline \multicolumn{8}{|c|}{ Dados coletados Termômetro de fluxo de laser } & \\
\hline Horário/Quarto & $\begin{array}{l}\text { Temp. Externa do ar } \\
\left({ }^{\circ} \mathrm{C}\right)\end{array}$ & $\begin{array}{l}\text { Temp. Paredes } \\
\text { externas }\left({ }^{\circ} \mathrm{C}\right)\end{array}$ & $\begin{array}{c}\text { Temp.Paredes } \\
\text { voltada para a rua } \\
\left({ }^{\circ} \mathrm{C}\right)\end{array}$ & \multicolumn{3}{|c|}{ Temp. Média das paredes $\left({ }^{\circ} \mathrm{C}\right)$} & Temp. Teto $\left({ }^{\circ} \mathrm{C}\right)$ & \\
\hline $11: 50$ & 24,7 & 24,6 & 24,5 & \multicolumn{3}{|c|}{24,1} & 23,6 & \\
\hline $15: 00$ & 30,7 & 27,1 & 24 & \multicolumn{3}{|c|}{25,3} & 29,6 & \\
\hline
\end{tabular}

Tabela 20: Resultados coletados in loco no quarto do Apartamento A no mês de Outubro de 2013. 


\begin{tabular}{|c|c|c|c|c|c|c|c|c|}
\hline \multicolumn{2}{|l|}{ Apartamento $\mathrm{A}$} & \multicolumn{4}{|c|}{ Dados coletados CONFORTÍMETRO Novembro 2013 - QUARTO } & \multicolumn{3}{|c|}{ Nublado } \\
\hline Intervalo & $\begin{array}{l}\text { Temperatura de } \\
\text { bulbo úmido }\left({ }^{\circ} \mathrm{C}\right)\end{array}$ & $\begin{array}{c}\text { Temperatura de } \\
\text { globo }\left({ }^{\circ} \mathrm{C}\right)\end{array}$ & $\begin{array}{c}\text { Temperatura do ar } \\
\left({ }^{\circ} \mathrm{C}\right)\end{array}$ & $\begin{array}{c}\text { Pressão } \\
\text { Atmosférica (atm) }\end{array}$ & $\begin{array}{c}\text { Umidade relativa } \\
\text { do ar (\%) }\end{array}$ & $\begin{array}{l}\text { Velo cidade do ar } \\
\qquad(\mathrm{m} / \mathrm{s})\end{array}$ & $\begin{array}{l}\text { Temperatura } \\
\text { radiante }\left({ }^{\circ} \mathrm{C}\right)\end{array}$ & $\begin{array}{l}\text { Temperatura } \\
\text { Operativa }\left({ }^{\circ} \mathrm{C}\right)\end{array}$ \\
\hline $12: 50$ as $13: 20$ & 23,1 & 26,6 & 26,5 & 1004,5 & 70,2 & 0,1 & 26,8 & 26,7 \\
\hline $13: 20$ as $13: 50$ & 23,1 & 26,7 & 26,6 & 1004,2 & 69,3 & 0,1 & 26,8 & 26,7 \\
\hline $13: 50$ as $14: 20$ & 22,9 & 27,1 & 26,9 & 1004,0 & 65,9 & 0,1 & 27,3 & 27,1 \\
\hline $14: 20$ as $14: 50$ & 22,9 & 27,3 & 27,1 & 1003,7 & 64,7 & 0,1 & 27,6 & 27,4 \\
\hline $14: 50$ as $15: 20$ & 23,1 & 27,7 & 27,5 & 1003,5 & 63,7 & 0,1 & 28,0 & 27,7 \\
\hline $14: 50$ as $15: 20$ & 23,3 & 28,0 & 27,7 & 1003,4 & 63,8 & 0,1 & 28,4 & 28,0 \\
\hline Desvio Padrão & 0,16 & 0,52 & 0,45 & 0,45 & 2,79 & 0,1 & 0,62 & 1,63 \\
\hline Média & 23,1 & 27,2 & 27,0 & 1003,9 & 66,6 & 0,1 & 27,4 & 27,2 \\
\hline \multicolumn{9}{|c|}{ Dados coletados Termômetro de fluxo de laser } \\
\hline Horário/Quarto & $\begin{array}{l}\text { Temp. Externa do ar } \\
\left({ }^{\circ} \mathrm{C}\right)\end{array}$ & $\begin{array}{l}\text { Temp. Paredes } \\
\text { externas }\left({ }^{\circ} \mathrm{C}\right)\end{array}$ & $\begin{array}{c}\text { Temp. Paredes } \\
\text { voltada para a rua } \\
\left({ }^{\circ} \mathrm{C}\right)\end{array}$ & \multicolumn{3}{|c|}{ Temp. Média das paredes $\left({ }^{\circ} \mathrm{C}\right)$} & Temp. Teto $\left({ }^{\circ} \mathrm{C}\right)$ & \\
\hline 11:50 & 28 & 28,5 & 25,8 & \multicolumn{3}{|c|}{25,9} & 26,4 & \\
\hline $15: 00$ & 31,6 & 34,9 & 28,2 & \multicolumn{3}{|c|}{26,7} & 31,1 & \\
\hline
\end{tabular}

Tabela 21: Resultados coletados in loco no quarto do Apartamento A no mês de Novembro de 2013.

\begin{tabular}{|c|c|c|c|c|c|c|c|c|}
\hline \multicolumn{2}{|l|}{ Apartamento A } & \multicolumn{4}{|c|}{ Dados coletados CONFORTíM ETRO Dezembro 2013 - QUARTO } & \multicolumn{3}{|c|}{ Céu claro } \\
\hline Intervalo & $\begin{array}{l}\text { Temperatura de } \\
\text { bulbo úmido }\left({ }^{\circ} \mathrm{C}\right)\end{array}$ & $\begin{array}{c}\text { Temperatura de } \\
\text { globo }\left({ }^{\circ} \mathrm{C}\right)\end{array}$ & $\begin{array}{c}\text { Temperatura do ar } \\
\left({ }^{\circ} \mathrm{C}\right)\end{array}$ & $\begin{array}{c}\text { Pressão } \\
\text { Atmosférica (atm) }\end{array}$ & $\begin{array}{c}\text { Umidade relativa } \\
\text { do } \operatorname{ar}(\%)\end{array}$ & $\begin{array}{l}\text { Velocidade do ar } \\
\qquad(\mathrm{m} / \mathrm{s})\end{array}$ & $\begin{array}{l}\text { Temperatura } \\
\text { radiante }\left({ }^{\circ} \mathrm{C}\right)\end{array}$ & $\begin{array}{l}\text { Temperatura } \\
\text { Operativa }\left({ }^{\circ} \mathrm{C}\right)\end{array}$ \\
\hline $12: 50$ as $13: 20$ & 24,8 & 29,9 & 29,4 & 1007,7 & 62,5 & 0,0 & 30,2 & 29,8 \\
\hline $13: 20$ as $13: 50$ & 25,0 & 30,2 & 29,7 & 1007,4 & 61,6 & 0,0 & 30,5 & 30,1 \\
\hline $13: 50$ as $14: 20$ & 24,9 & 30,3 & 29,8 & 1007,2 & 59,7 & 0,0 & 30,6 & 30,2 \\
\hline $14: 20$ as $14: 50$ & 25,1 & 30,5 & 29,9 & 1007,0 & 60,4 & 0,0 & 30,8 & 30,3 \\
\hline $14: 50$ as $15: 20$ & 25,1 & 30,5 & 30,0 & 1006,7 & 60,1 & 0,0 & 30,8 & 30,4 \\
\hline $15: 20$ as $15: 50$ & 24,6 & 30,7 & 30,2 & 1006,3 & 56,2 & 0,0 & 30,9 & 30,5 \\
\hline Desvio Padrão & 0,22 & 0,29 & 0,28 & 0,46 & 2,22 & 0,03 & 0,30 & 1,63 \\
\hline Média & 24,9 & 30,3 & 29,8 & 1007,1 & 60,3 & 0,0 & 30,6 & 30,2 \\
\hline \multicolumn{9}{|c|}{ Dados coletados Termômetro de fluxo de laser } \\
\hline Horário/Quarto & $\begin{array}{l}\text { Temp. Externa do ar } \\
\left({ }^{\circ} \mathrm{C}\right)\end{array}$ & $\begin{array}{l}\text { Temp. Paredes } \\
\text { externas }\left({ }^{\circ} \mathrm{C}\right)\end{array}$ & $\begin{array}{c}\text { Temp. Paredes } \\
\text { voltada para a rua } \\
\left({ }^{\circ} \mathrm{C}\right)\end{array}$ & \multicolumn{3}{|c|}{ Temp. Média das paredes $\left({ }^{\circ} \mathrm{C}\right)$} & Temp. Teto $\left({ }^{\circ} \mathrm{C}\right)$ & \\
\hline $11: 50$ & 29 & 31,5 & 30,1 & \multicolumn{3}{|c|}{29,8} & 33,2 & \\
\hline $15: 00$ & 29,3 & 32,8 & 31,4 & \multicolumn{3}{|c|}{30,5} & 36,2 & \\
\hline
\end{tabular}

Tabela 22: Resultados coletados in loco no quarto do Apartamento A no mês de Dezembro de 2013.

\begin{tabular}{|c|c|c|c|c|c|c|c|c|}
\hline \multicolumn{2}{|l|}{ Apartamento A } & \multicolumn{4}{|c|}{ Dados coletados CONFORTÍM ETRO Janeiro 2014 - QUARTO } & \multicolumn{3}{|c|}{ Céu claro } \\
\hline Intervalo & $\begin{array}{l}\text { Temperatura de } \\
\text { bulbo úmido }\left({ }^{\circ} \mathrm{C}\right)\end{array}$ & $\begin{array}{c}\text { Temperatura de } \\
\text { globo }\left({ }^{\circ} \mathrm{C}\right)\end{array}$ & $\begin{array}{c}\text { Temperatura do ar } \\
\left({ }^{\circ} \mathrm{C}\right)\end{array}$ & $\begin{array}{c}\text { Pressão } \\
\text { Atmosférica (atm) }\end{array}$ & $\begin{array}{c}\text { Umidade relativa } \\
\text { do } \operatorname{ar}(\%)\end{array}$ & $\begin{array}{l}\text { Velocidade do ar } \\
(\mathrm{m} / \mathrm{s})\end{array}$ & $\begin{array}{l}\text { Temperatura } \\
\text { radiante }\left({ }^{\circ} \mathrm{C}\right)\end{array}$ & $\begin{array}{c}\text { Temperatura } \\
\text { Operativa }\left({ }^{\circ} \mathrm{C}\right)\end{array}$ \\
\hline $12: 50$ as $13: 20$ & 27,0 & 32,7 & 32,4 & 1012,2 & 61,4 & 0,1 & 33,0 & 32,7 \\
\hline $13: 20$ as $13: 50$ & 27,4 & 32,9 & 32,5 & 1012,1 & 62,2 & 0,1 & 33,2 & 32,8 \\
\hline $13: 50$ as $14: 20$ & 27,6 & 33,3 & 32,8 & 1011,9 & 61,8 & 0,1 & 33,7 & 33,2 \\
\hline $14: 20$ as $14: 50$ & 27,7 & 33,8 & 33,1 & 1011,8 & 60,8 & 0,1 & 34,3 & 33,7 \\
\hline $14: 50$ as $15: 20$ & 27,9 & 34,3 & 33,4 & 1011,8 & 60,5 & 0,1 & 35,0 & 34,2 \\
\hline $15: 20$ as $15: 50$ & 28,1 & 34,6 & 33,7 & 1011,5 & 60,2 & 0,1 & 35,5 & 34,6 \\
\hline Desvio Padrão & 0,38 & 0,70 & 0,49 & 0,24 & 0,79 & 0,11 & 1,03 & 1,63 \\
\hline Média & 27,6 & 33,6 & 33,0 & 1011,9 & 61,2 & 0,1 & 34,1 & 33,5 \\
\hline \multicolumn{8}{|c|}{ Dados coletados Termômetro de fluxo de laser } & \\
\hline Horário/Quarto & $\begin{array}{l}\text { Temp. Externa do ar } \\
\left({ }^{\circ} \mathrm{C}\right)\end{array}$ & $\begin{array}{l}\text { Temp. Paredes } \\
\text { externas }\left({ }^{\circ} \mathrm{C}\right)\end{array}$ & $\begin{array}{c}\text { Temp.Paredes } \\
\text { voltada para a rua } \\
\left({ }^{\circ} \mathrm{C}\right)\end{array}$ & \multicolumn{3}{|c|}{ Temp. Média das paredes $\left({ }^{\circ} \mathrm{C}\right)$} & Temp. Teto $\left({ }^{\circ} \mathrm{C}\right)$ & \\
\hline $11: 50$ & 31 & 33,6 & 31,8 & \multirow{2}{*}{\multicolumn{3}{|c|}{33,1}} & 34,5 & \\
\hline $15: 00$ & 40 & 39,6 & 33,4 & & & & 39,6 & \\
\hline
\end{tabular}

Tabela 23: Resultados coletados in loco no quarto do Apartamento A no mês de Janeiro de 2014.

\begin{tabular}{|c|c|c|c|c|c|c|c|c|}
\hline \multicolumn{2}{|l|}{ Apartamento A } & \multicolumn{4}{|c|}{ Dados coletados CONFORTÍM ETRO Fevereiro 2014 - QUARTO } & \multicolumn{3}{|c|}{$\begin{array}{l}\text { Parcialmente } \\
\text { aberto }\end{array}$} \\
\hline Intervalo & $\begin{array}{l}\text { Temperatura de } \\
\text { bulbo úmido }\left({ }^{\circ} \mathrm{C}\right)\end{array}$ & $\begin{array}{c}\text { Temperatura de } \\
\text { globo }\left({ }^{\circ} \mathrm{C}\right)\end{array}$ & $\begin{array}{c}\text { Temperatura do ar } \\
\left({ }^{\circ} \mathrm{C}\right)\end{array}$ & $\begin{array}{c}\text { Pressão } \\
\text { Atmosférica (atm) }\end{array}$ & $\begin{array}{c}\text { Umidade relativa } \\
\text { do ar (\%) }\end{array}$ & $\begin{array}{l}\text { Velocidade do ar } \\
(\mathrm{m} / \mathrm{s})\end{array}$ & $\begin{array}{l}\text { Temperatura } \\
\text { radiante }\left({ }^{\circ} \mathrm{C}\right)\end{array}$ & $\begin{array}{c}\text { Temperatura } \\
\text { Operativa }\left({ }^{\circ} \mathrm{C}\right)\end{array}$ \\
\hline $11: 50$ as $12: 20$ & 25,9 & 30,3 & 30,2 & 1008,9 & 64,8 & 0,0 & 30,4 & 30,3 \\
\hline $12: 20$ as $12: 50$ & 26,3 & 30,7 & 30,6 & 1008,5 & 64,9 & 0,0 & 30,7 & 30,7 \\
\hline $12: 50$ as $13: 20$ & 26,4 & 30,8 & 30,6 & 1008,4 & 65,5 & 0,0 & 30,9 & 30,8 \\
\hline $13: 20$ as $13: 50$ & 26,6 & 31,0 & 30,8 & 1008,4 & 65,2 & 0,0 & 31,1 & 30,9 \\
\hline $13: 50$ as $14: 20$ & 26,2 & 31,0 & 30,8 & 1008,4 & 62,9 & 0,0 & 31,1 & 30,9 \\
\hline $14: 20$ as $14: 50$ & 26,4 & 31,4 & 31,1 & 1008,1 & 62,4 & 0,0 & 31,5 & 31,3 \\
\hline Desvio Padrão & 0,25 & 0,38 & 0,33 & 0,33 & 1,26 & 0,0 & 0,39 & 1,63 \\
\hline Média & 26,2 & 30,8 & 30,6 & 1008,5 & 64,4 & 0,0 & 30,8 & 30,7 \\
\hline \multicolumn{8}{|c|}{ Dados coletados Termômetro de fluxo de laser } & \\
\hline Horário/Quarto & $\begin{array}{l}\text { Temp. Externa do ar } \\
\left({ }^{\circ} \mathrm{C}\right)\end{array}$ & $\begin{array}{l}\text { Temp. Paredes } \\
\text { externas }\left({ }^{\circ} \mathrm{C}\right)\end{array}$ & $\begin{array}{c}\text { Temp.Paredes } \\
\text { voltada para a rua } \\
\left({ }^{\circ} \mathrm{C}\right)\end{array}$ & \multicolumn{3}{|c|}{ Temp. Média das paredes $\left({ }^{\circ} \mathrm{C}\right)$} & Temp. Teto $\left({ }^{\circ} \mathrm{C}\right)$ & \\
\hline $11: 50$ & 30,3 & 31,8 & 29,2 & \multicolumn{3}{|c|}{29,7} & 32,3 & \\
\hline $14: 50$ & 29 & 38 & 32 & \multicolumn{3}{|c|}{31,9} & 37,2 & \\
\hline
\end{tabular}

Tabela 24: Resultados coletados in loco no quarto do Apartamento A no mês de Fevereiro de 2014. 


\begin{tabular}{|c|c|c|c|c|c|c|c|c|}
\hline \multicolumn{2}{|l|}{ Apartamento A } & \multicolumn{4}{|c|}{ Dados coletados CONFORTÍMETRO Março 2014 - QUARTO } & \multicolumn{3}{|c|}{$\begin{array}{l}\text { Parcialmente } \\
\text { aberto }\end{array}$} \\
\hline Intervalo & $\begin{array}{l}\text { Temperatura de } \\
\text { bulbo úmido }\left({ }^{\circ} \mathrm{C}\right)\end{array}$ & $\begin{array}{c}\text { Temperatura de } \\
\text { globo }\left({ }^{\circ} \mathrm{C}\right)\end{array}$ & $\begin{array}{c}\text { Temperatura do ar } \\
\left({ }^{\circ} \mathrm{C}\right)\end{array}$ & $\begin{array}{c}\text { Pressão } \\
\text { Atmosférica (atm) }\end{array}$ & $\begin{array}{c}\text { Umidade relativa } \\
\text { do } \operatorname{ar}(\%)\end{array}$ & $\begin{array}{l}\text { Velocidade do ar } \\
(\mathrm{m} / \mathrm{s})\end{array}$ & $\begin{array}{l}\text { Temperatura } \\
\text { radiante }\left({ }^{\circ} \mathrm{C}\right)\end{array}$ & $\begin{array}{l}\text { Temperatura } \\
\text { Operativa }\left({ }^{\circ} \mathrm{C}\right)\end{array}$ \\
\hline $12: 20$ as $12: 50$ & 22,0 & 26,9 & 26,8 & 1016,5 & 59,7 & 0,0 & 26,9 & 26,8 \\
\hline $12: 50$ as $13: 20$ & 22,3 & 27,1 & 26,9 & 1016,3 & 60,0 & 0,0 & 27,1 & 27,0 \\
\hline $13: 20$ as $13: 50$ & 22,5 & 27,2 & 27,0 & 1016,1 & 61,4 & 0,0 & 27,2 & 27,1 \\
\hline $13: 50$ as $14: 20$ & 22,6 & 27,2 & 27,1 & 1016,0 & 62,0 & 0,0 & 27,3 & 27,2 \\
\hline $13: 50$ as $14: 20$ & 22,7 & 27,4 & 27,2 & 1016,0 & 61,7 & 0,0 & 27,5 & 27,4 \\
\hline Desvio Padrão & 0,28 & 0,21 & 0,20 & 0,27 & 0,95 & 0,0 & 0,23 & 1,6 \\
\hline Média & 22,4 & 27,1 & 26,9 & 1016,3 & 60,9 & 0,0 & 27,2 & 23,6 \\
\hline \multicolumn{9}{|c|}{ Dados coletados Termômetro de fluxo de laser } \\
\hline Horário/Quarto & $\begin{array}{l}\text { Temp. Externa do ar } \\
\left({ }^{\circ} \mathrm{C}\right)\end{array}$ & $\begin{array}{l}\text { Temp. Paredes } \\
\text { externas }\left({ }^{\circ} \mathrm{C}\right)\end{array}$ & $\begin{array}{c}\text { Temp.Paredes } \\
\text { voltada para a rua } \\
\left({ }^{\circ} \mathrm{C}\right)\end{array}$ & \multicolumn{3}{|c|}{ Temp. Média das paredes $\left({ }^{\circ} \mathrm{C}\right)$} & Temp. Teto $\left({ }^{\circ} \mathrm{C}\right)$ & \\
\hline $11: 50$ & 30,9 & 28,7 & 25,5 & \multicolumn{3}{|c|}{25,9} & 27,8 & \\
\hline $14: 50$ & 32 & 31,6 & 25,8 & \multicolumn{3}{|c|}{26,9} & 29,7 & \\
\hline
\end{tabular}

Tabela 25: Resultados coletados in loco no quarto do Apartamento A no mês de Março de 2014.

\begin{tabular}{|c|c|c|c|c|c|c|c|c|}
\hline \multicolumn{2}{|l|}{ Apartamento A } & \multicolumn{4}{|c|}{ Dados coletados CONFORTÍM ETRO Abril 2014 - QUARTO } & \multicolumn{3}{|c|}{$\begin{array}{l}\text { Parcialmente } \\
\text { aberto }\end{array}$} \\
\hline Intervalo & $\begin{array}{l}\text { Temperatura de } \\
\text { bulbo úmido }\left({ }^{\circ} \mathrm{C}\right)\end{array}$ & $\begin{array}{c}\text { Temperatura de } \\
\text { globo }\left({ }^{\circ} \mathrm{C}\right)\end{array}$ & $\begin{array}{c}\text { Temperatura do ar } \\
\left({ }^{\circ} \mathrm{C}\right)\end{array}$ & $\begin{array}{c}\text { Pressão } \\
\text { Atmosférica (atm) }\end{array}$ & $\begin{array}{l}\text { Umidade relativa } \\
\text { do ar (\%) }\end{array}$ & $\begin{array}{l}\text { Velocidade do ar } \\
\qquad(\mathrm{m} / \mathrm{s})\end{array}$ & $\begin{array}{l}\text { Temperatura } \\
\text { radiante }\left({ }^{\circ} \mathrm{C}\right)\end{array}$ & $\begin{array}{l}\text { Temperatura } \\
\text { Operativa }\left({ }^{\circ} \mathrm{C}\right)\end{array}$ \\
\hline $11: 50$ as $12: 20$ & 18,1 & 23,3 & 23,2 & 1013,5 & 52,2 & 0,0 & 23,3 & 23,3 \\
\hline $12: 20$ as $12: 50$ & 18,3 & 23,5 & 23,4 & 1013,0 & 52,3 & 0,0 & 23,5 & 23,4 \\
\hline $12: 50$ as $13: 20$ & 18,3 & 23,8 & 23,6 & 1012,1 & 51,5 & 0,0 & 24,0 & 23,8 \\
\hline $13: 20$ as $13: 50$ & 18,6 & 24,0 & 23,8 & 1011,7 & 52,0 & 0,1 & 24,2 & 24,0 \\
\hline $13: 50$ as $14: 20$ & 19,0 & 24,2 & 24,0 & 1011,2 & 53,7 & 0,1 & 24,5 & 24,3 \\
\hline $14: 20$ as $14: 50$ & 19,2 & 24,7 & 24,3 & 1010,8 & 53,7 & 0,2 & 25,3 & 24,8 \\
\hline Desvio Padrão & 0,43 & 0,49 & 0,38 & 0,97 & 1,05 & 0,1 & 0,72 & 1,63 \\
\hline Média & 18,6 & 23,9 & 23,7 & 1012,1 & 52,6 & 0,1 & 24,1 & 23,9 \\
\hline \multicolumn{9}{|c|}{ Dados coletados Termômetro de fluxo de laser } \\
\hline Horário/Quarto & $\begin{array}{l}\text { Temp. Externa do ar } \\
\left({ }^{\circ} \mathrm{C}\right)\end{array}$ & $\begin{array}{l}\text { Temp. Paredes } \\
\text { externas }\left({ }^{\circ} \mathrm{C}\right)\end{array}$ & $\begin{array}{c}\text { Temp. Paredes } \\
\text { voltada para a rua } \\
\left({ }^{\circ} \mathrm{C}\right)\end{array}$ & \multicolumn{3}{|c|}{ Temp. Média das paredes $\left({ }^{\circ} \mathrm{C}\right)$} & Temp. Teto $\left({ }^{\circ} \mathrm{C}\right)$ & \\
\hline $11: 50$ & 24,3 & 24,3 & 21,8 & \multicolumn{3}{|c|}{23,8} & 22,1 & \\
\hline $14: 50$ & 24,7 & 29,3 & 23,5 & \multicolumn{3}{|c|}{23,9} & 26,1 & \\
\hline
\end{tabular}

Tabela 26: Resultados coletados in loco no quarto do Apartamento A no mês de Abril de 2014.

\begin{tabular}{|c|c|c|c|c|c|c|c|c|}
\hline \multicolumn{2}{|l|}{ Apartamento A } & \multicolumn{4}{|c|}{ Dados coletados CONFORTÍM ETRO M aio 2014 - QUARTO } & \multicolumn{3}{|c|}{ Céu claro } \\
\hline Intervalo & $\begin{array}{l}\text { Temperatura de } \\
\text { bulbo úmido }\left({ }^{\circ} \mathrm{C}\right)\end{array}$ & $\begin{array}{l}\text { Temperatura de } \\
\text { globo }\left({ }^{\circ} \mathrm{C}\right)\end{array}$ & $\begin{array}{c}\text { Temperatura do ar } \\
\left({ }^{\circ} \mathrm{C}\right)\end{array}$ & $\begin{array}{c}\text { Pressão } \\
\text { Atmosférica (atm) }\end{array}$ & $\begin{array}{c}\text { Umidade relativa } \\
\text { do ar (\%) }\end{array}$ & $\begin{array}{l}\text { Velocidade do ar } \\
\qquad(\mathrm{m} / \mathrm{s})\end{array}$ & $\begin{array}{l}\text { Temperatura } \\
\text { radiante }\left({ }^{\circ} \mathrm{C}\right)\end{array}$ & $\begin{array}{l}\text { Temperatura } \\
\text { Operativa }\left({ }^{\circ} \mathrm{C}\right)\end{array}$ \\
\hline $11: 50$ as $12: 20$ & 22,9 & 27,0 & 26,7 & 1017,4 & 64,7 & 0,1 & 27,1 & 26,9 \\
\hline $12: 20$ as $12: 50$ & 23,2 & 27,4 & 27,4 & 1016,9 & 62,8 & 0,1 & 27,3 & 27,4 \\
\hline $12: 50$ as $13: 20$ & 23,5 & 27,6 & 27,6 & 1016,5 & 62,9 & 0,0 & 27,7 & 27,6 \\
\hline $13: 20$ as $13: 50$ & 23,7 & 27,9 & 27,8 & 1016,1 & 62,5 & 0,1 & 28,0 & 27,9 \\
\hline $13: 50$ as $14: 20$ & 23,5 & 27,9 & 27,6 & 1015,8 & 62,6 & 0,1 & 28,1 & 27,9 \\
\hline $14: 20$ as $14: 50$ & 23,7 & 28,0 & 27,7 & 1015,6 & 63,4 & 0,1 & 28,2 & 27,9 \\
\hline Desvio Padrão & 0,32 & 0,38 & 0,37 & 0,63 & 0,90 & 0,08 & 0,44 & 1,63 \\
\hline Média & 23,4 & 27,6 & 27,5 & 1016,4 & 63,1 & 0,1 & 27,7 & 27,6 \\
\hline \multicolumn{9}{|c|}{ Dados coletados Termômetro de fluxo de laser } \\
\hline Horário/Quarto & $\begin{array}{l}\text { Temp. Externa do ar } \\
\left({ }^{\circ} \mathrm{C}\right)\end{array}$ & $\begin{array}{l}\text { Temp. Paredes } \\
\text { externas }\left({ }^{\circ} \mathrm{C}\right)\end{array}$ & $\begin{array}{c}\text { Temp. Paredes } \\
\text { voltada para a rua } \\
\left({ }^{\circ} \mathrm{C}\right)\end{array}$ & \multicolumn{3}{|c|}{ Temp. Média das paredes $\left({ }^{\circ} \mathrm{C}\right)$} & Temp. Teto $\left({ }^{\circ} \mathrm{C}\right)$ & \\
\hline $11: 50$ & 26,3 & 26,6 & 25,4 & \multicolumn{3}{|c|}{27,3} & 28,1 & \\
\hline $14: 50$ & 33,2 & 33 & 26,4 & \multicolumn{3}{|c|}{27,2} & 30 & \\
\hline
\end{tabular}

Tabela 27: Resultados coletados in loco no quarto do Apartamento A no mês de Maio de 2014.

\begin{tabular}{|c|c|c|c|c|c|c|c|c|}
\hline \multicolumn{2}{|l|}{ Apartamento $\mathrm{A}$} & \multicolumn{4}{|c|}{ Dados coletados CONFORTÍMETRO Junho 2014 - QUARTO } & \multicolumn{3}{|c|}{ Céu claro } \\
\hline Intervalo & $\begin{array}{l}\text { Temperatura de } \\
\text { bulbo úmido }\left({ }^{\circ} \mathrm{C}\right)\end{array}$ & $\begin{array}{c}\text { Temperatura de } \\
\text { globo }\left({ }^{\circ} \mathrm{C}\right)\end{array}$ & $\begin{array}{c}\text { Temperatura do ar } \\
\left({ }^{\circ} \mathrm{C}\right)\end{array}$ & $\begin{array}{c}\text { Pressão } \\
\text { Atmosférica (atm) }\end{array}$ & $\begin{array}{c}\text { Umidade relativa } \\
\text { do ar (\%) }\end{array}$ & $\begin{array}{l}\text { Velocidade do ar } \\
\qquad(\mathrm{m} / \mathrm{s})\end{array}$ & $\begin{array}{l}\text { Temperatura } \\
\text { radiante }\left({ }^{\circ} \mathrm{C}\right)\end{array}$ & $\begin{array}{c}\text { Temperatura } \\
\text { Operativa }\left({ }^{\circ} \mathrm{C}\right)\end{array}$ \\
\hline $11: 50$ as $12: 20$ & 17,3 & 25,2 & 25,3 & 1010,9 & 35,8 & 0,1 & 25,1 & 25,2 \\
\hline $12: 20$ as $12: 50$ & 17,9 & 25,5 & 25,5 & 1010,5 & 36,7 & 0,1 & 25,5 & 25,5 \\
\hline $12: 50$ as $13: 20$ & 19,0 & 25,5 & 25,3 & 1010,4 & 46,6 & 0,0 & 25,6 & 25,4 \\
\hline $13: 20$ as $13: 50$ & 20,0 & 25,4 & 25,0 & 1010,1 & 54,3 & 0,0 & 25,7 & 25,3 \\
\hline $13: 50$ as $14: 20$ & 20,0 & 25,8 & 25,3 & 1010,0 & 53,2 & 0,0 & 26,1 & 25,7 \\
\hline $14: 20$ as $14: 50$ & 20,6 & 26,2 & 25,5 & 1009,7 & 52,7 & 0,0 & 26,6 & 26,0 \\
\hline Desvio Padrão & 1,23 & 0,33 & 0,20 & 0,40 & 8,07 & 0,09 & 0,52 & 1,63 \\
\hline Média & 19,1 & 25,6 & 25,3 & 1010,3 & 46,5 & 0,0 & 25,7 & 25,5 \\
\hline \multicolumn{9}{|c|}{ Dados coletados Termômetro de fluxo de laser } \\
\hline Horário/Quarto & $\begin{array}{l}\text { Temp. Externa do ar } \\
\qquad\left({ }^{\circ} \mathrm{C}\right)\end{array}$ & $\begin{array}{l}\text { Temp. Paredes } \\
\text { externas }\left({ }^{\circ} \mathrm{C}\right)\end{array}$ & $\begin{array}{c}\text { Temp. Paredes } \\
\text { voltada para a rua } \\
\left({ }^{\circ} \mathrm{C}\right)\end{array}$ & \multicolumn{3}{|c|}{ Temp. Média das paredes $\left({ }^{\circ} \mathrm{C}\right)$} & Temp. Teto $\left({ }^{\circ} \mathrm{C}\right)$ & \\
\hline $11: 50$ & 24,8 & 25,3 & 23,1 & \multicolumn{3}{|c|}{24,5} & 23,5 & \\
\hline $14: 50$ & 29,1 & 32,9 & 24,8 & \multicolumn{3}{|c|}{24,4} & 26,3 & \\
\hline
\end{tabular}

Tabela 28: Resultados coletados in loco no quarto do Apartamento A no mês de Junho de 2014. 


\begin{tabular}{|c|c|c|c|c|c|c|c|c|}
\hline \multicolumn{2}{|l|}{ Apartamento $\mathrm{A}$} & \multicolumn{4}{|c|}{ Dados coletados CONFORTÍMETRO Julho 2013 - SALA } & \multicolumn{3}{|c|}{ céu claro } \\
\hline Intervalo & $\begin{array}{l}\text { Temperatura de } \\
\text { bulbo úmido }\left({ }^{\circ} \mathrm{C}\right)\end{array}$ & $\begin{array}{c}\text { Temperatura de } \\
\text { globo }\left({ }^{\circ} \mathrm{C}\right)\end{array}$ & $\begin{array}{c}\text { Temperatura do ar } \\
\left({ }^{\circ} \mathrm{C}\right)\end{array}$ & $\begin{array}{c}\text { Pressão Atmosférica } \\
\text { (atm) }\end{array}$ & $\begin{array}{c}\text { Umidade relativa } \\
\text { do ar (\%) }\end{array}$ & $\begin{array}{l}\text { Velocidade do ar } \\
(\mathrm{m} / \mathrm{s})\end{array}$ & $\begin{array}{l}\text { Temperatura } \\
\text { radiante }\left({ }^{\circ} \mathrm{C}\right)\end{array}$ & $\begin{array}{l}\text { Temperatura } \\
\text { Operativa }\left({ }^{\circ} \mathrm{C}\right)\end{array}$ \\
\hline $15: 00$ as $15: 30$ & 20,4 & 23,4 & 23,1 & 1019,4 & 71,2 & 0,0 & 23,4 & 23,3 \\
\hline $15: 30$ as $16: 00$ & 20,3 & 23,1 & 22,8 & 1019,4 & 72,1 & 0,0 & 23,2 & 23,0 \\
\hline $15: 30$ as $16: 00$ & 20,3 & 23,1 & 22,7 & 1019,6 & 72,6 & 0,0 & 23,2 & 23,0 \\
\hline $16: 30$ as $17: 00$ & 20,4 & 23,0 & 22,6 & 1019,8 & 74,0 & 0,0 & 23,1 & 22,9 \\
\hline Desvio Padrão & 0,07 & 0,146 & 0,211 & 0,161 & 1,140 & 0,0 & 0,130 & 1,1 \\
\hline Média & 20,4 & 23,1 & 22,8 & 1019,5 & 72,4 & 0,0 & 23,2 & 23,0 \\
\hline \multicolumn{8}{|c|}{ Dados coletados Termômetro de fluxo de laser } & \\
\hline Horário/Quarto & $\begin{array}{c}\text { Temp. Externa do ar } \\
\left({ }^{\circ} \mathrm{C}\right)\end{array}$ & $\begin{array}{l}\text { Temp. Paredes } \\
\text { externas }\left({ }^{\circ} \mathrm{C}\right)\end{array}$ & $\begin{array}{c}\text { Temp.Paredes } \\
\text { voltada para a rua } \\
\left({ }^{\circ} \mathrm{C}\right)\end{array}$ & \multicolumn{3}{|c|}{ Temp. Média das paredes $\left({ }^{\circ} \mathrm{C}\right)$} & Temp. Teto $\left({ }^{\circ} \mathrm{C}\right)$ & \\
\hline 15:00 & 22 & 23,9 & 23,5 & \multicolumn{3}{|c|}{23,5} & 24,1 & \\
\hline $17: 00$ & 21 & 23 & 22,7 & \multicolumn{3}{|c|}{22,7} & 24 & \\
\hline
\end{tabular}

Tabela 29: Resultados coletados in loco na sala do Apartamento A no mês de Julho de 2013.

\begin{tabular}{|c|c|c|c|c|c|c|c|c|}
\hline \multicolumn{2}{|l|}{ Apartamento $\mathrm{A}$} & \multicolumn{4}{|c|}{ Dados coletados CONFORTÍMETRO Agosto 2013 - SALA } & \multicolumn{3}{|c|}{ céu claro } \\
\hline Intervalo & $\begin{array}{l}\text { Temperatura de } \\
\text { bulbo úmido }\left({ }^{\circ} \mathrm{C}\right)\end{array}$ & $\begin{array}{c}\text { Temperatura de } \\
\text { globo }\left({ }^{\circ} \mathrm{C}\right)\end{array}$ & $\begin{array}{c}\text { Temperatura do ar } \\
\left({ }^{\circ} \mathrm{C}\right)\end{array}$ & $\begin{array}{c}\text { Pressão Atmosférica } \\
\text { (atm) }\end{array}$ & $\begin{array}{c}\text { Umidade relativa } \\
\text { do ar (\%) }\end{array}$ & $\begin{array}{l}\text { Velocidade do ar } \\
(\mathrm{m} / \mathrm{s})\end{array}$ & $\begin{array}{l}\text { Temperatura } \\
\text { radiante }\left({ }^{\circ} \mathrm{C}\right)\end{array}$ & $\begin{array}{l}\text { Temperatura } \\
\text { Operativa }\left({ }^{\circ} \mathrm{C}\right)\end{array}$ \\
\hline $15: 00$ as $15: 30$ & 19,9 & 26,9 & 27,0 & 1009,9 & 45,6 & 0,1 & 26,6 & 26,8 \\
\hline $15: 30$ as $16: 00$ & 20,3 & 27,5 & 27,6 & 1009,4 & 44,7 & 0,1 & 27,5 & 27,5 \\
\hline $16: 00$ as $16: 30$ & 20,9 & 27,7 & 27,4 & 1009,3 & 48,3 & 0,0 & 27,9 & 27,6 \\
\hline $16: 30$ as $17: 00$ & 21,9 & 26,7 & 26,1 & 1009,7 & 60,9 & 0,0 & 27,0 & 26,5 \\
\hline Desvio Padrão & 0,81 & 0,50 & 0,63 & 0,29 & 6,92 & 0,06 & 0,58 & 0,6 \\
\hline Média & 20,7 & 27,2 & 27,0 & 1009,6 & 49,6 & 0,1 & 27,2 & 27,1 \\
\hline \multicolumn{8}{|c|}{ Dados coletados Termômetro de fluxo de laser } & \\
\hline Horário/Sala & $\begin{array}{l}\text { Temp. Externa do ar } \\
\left({ }^{\circ} \mathrm{C}\right)\end{array}$ & $\begin{array}{l}\text { Temp. Paredes } \\
\text { externas }\left({ }^{\circ} \mathrm{C}\right)\end{array}$ & $\begin{array}{c}\text { Temp.Paredes } \\
\text { voltada para a rua } \\
\left({ }^{\circ} \mathrm{C}\right)\end{array}$ & \multicolumn{3}{|c|}{ Temp. Média das paredes $\left({ }^{\circ} \mathrm{C}\right)$} & Temp. Teto $\left({ }^{\circ} \mathrm{C}\right)$ & \\
\hline 15:00 & 26,1 & 27 & 26,7 & \multicolumn{3}{|c|}{26} & 27 & \\
\hline $17: 00$ & 25 & 26 & 25,2 & \multicolumn{3}{|c|}{25,5} & 25,6 & \\
\hline
\end{tabular}

Tabela 30: Resultados coletados in loco na sala do Apartamento A no mês de Agosto de 2013.

\begin{tabular}{|c|c|c|c|c|c|c|c|c|}
\hline \multicolumn{2}{|l|}{ Apartamento A } & \multicolumn{4}{|c|}{ Dados coletados CONFORTÍMETRO Setembro 2013 - SALA } & \multicolumn{3}{|c|}{ Nublado } \\
\hline Intervalo & $\begin{array}{l}\text { Temperatura de } \\
\text { bulbo úmido }\left({ }^{\circ} \mathrm{C}\right)\end{array}$ & $\begin{array}{c}\text { Temperatura de } \\
\text { globo }\left({ }^{\circ} \mathrm{C}\right)\end{array}$ & $\begin{array}{c}\text { Temperatura do ar } \\
\left({ }^{\circ} \mathrm{C}\right)\end{array}$ & $\begin{array}{c}\text { Pressão Atmosférica } \\
\text { (atm) }\end{array}$ & $\begin{array}{c}\text { Umidade relativa } \\
\text { do ar (\%) }\end{array}$ & $\begin{array}{l}\text { Velocidade do ar } \\
\qquad(\mathrm{m} / \mathrm{s})\end{array}$ & $\begin{array}{l}\text { Temperatura } \\
\text { radiante }\left({ }^{\circ} \mathrm{C}\right)\end{array}$ & $\begin{array}{l}\text { Temperatura } \\
\text { Operativa }\left({ }^{\circ} \mathrm{C}\right)\end{array}$ \\
\hline $15: 00$ as $15: 30$ & 19,5 & 22,4 & 22,2 & 1012,8 & 78,0 & 0,0 & 22,4 & 22,3 \\
\hline $15: 30$ as $16: 00$ & 19,5 & 22,2 & 22,1 & 1012,6 & 78,2 & 0,0 & 22,2 & 22,2 \\
\hline $16: 00$ as $16: 30$ & 19,4 & 22,1 & 22,0 & 1012,4 & 78,4 & 0,0 & 22,1 & 22,1 \\
\hline $16: 30$ as $17: 00$ & 19,5 & 22,2 & 22,2 & 1012,2 & 78,3 & 0,0 & 22,2 & 22,2 \\
\hline Desvio Padrão & 0,10 & 0,16 & 0,11 & 0,26 & 0,26 & 0,01 & 0,19 & 0,2 \\
\hline Média & 19,5 & 22,2 & 22,1 & 1012,5 & 78,2 & 0,0 & 22,2 & 22,2 \\
\hline \multicolumn{8}{|c|}{ Dados coletados Termômetro de fluxo de laser } & \\
\hline Horário/Sala & $\begin{array}{l}\text { Temp. Externa do ar } \\
\left({ }^{\circ} \mathrm{C}\right)\end{array}$ & $\begin{array}{l}\text { Temp. Paredes } \\
\text { externas }\left({ }^{\circ} \mathrm{C}\right)\end{array}$ & $\begin{array}{c}\text { Temp.Paredes } \\
\text { voltada para a rua } \\
\left({ }^{\circ} \mathrm{C}\right)\end{array}$ & \multicolumn{3}{|c|}{ Temp. Média das paredes $\left({ }^{\circ} \mathrm{C}\right)$} & Temp. Teto $\left({ }^{\circ} \mathrm{C}\right)$ & \\
\hline 15:00 & 21,2 & 20,9 & 21,4 & \multicolumn{3}{|c|}{22} & 21,8 & \\
\hline $17: 00$ & 20 & 19,7 & 21,6 & \multicolumn{3}{|c|}{22,2} & 21,7 & \\
\hline
\end{tabular}

Tabela 31: Resultados coletados in loco na sala do Apartamento A no mês de Setembro de 2013.

\begin{tabular}{|c|c|c|c|c|c|c|c|c|}
\hline \multicolumn{2}{|l|}{ Apartamento $\mathrm{A}$} & \multicolumn{4}{|c|}{ Dados coletados CONFORTÍM ETRO Outubro 2013 - SALA } & \multicolumn{3}{|c|}{ céu limpo } \\
\hline Intervalo & $\begin{array}{l}\text { Temperatura de } \\
\text { bulbo úmido }\left({ }^{\circ} \mathrm{C}\right)\end{array}$ & $\begin{array}{c}\text { Temperatura de } \\
\text { globo }\left({ }^{\circ} \mathrm{C}\right)\end{array}$ & $\begin{array}{c}\text { Temperatura do ar } \\
\left({ }^{\circ} \mathrm{C}\right)\end{array}$ & $\begin{array}{c}\text { Pressão Atmosférica } \\
\text { (atm) }\end{array}$ & $\begin{array}{c}\text { Umidade relativa } \\
\text { do ar (\%) }\end{array}$ & $\begin{array}{l}\text { Velocidade do ar } \\
(\mathrm{m} / \mathrm{s})\end{array}$ & $\begin{array}{l}\text { Temperatura } \\
\text { radiante }\left({ }^{\circ} \mathrm{C}\right)\end{array}$ & $\begin{array}{l}\text { Temperatura } \\
\text { Operativa }\left({ }^{\circ} \mathrm{C}\right)\end{array}$ \\
\hline $15: 00$ as $15: 30$ & 22,3 & 26,9 & 27,2 & 1007,6 & 61,8 & 0,1 & 26,8 & 27,0 \\
\hline $15: 30$ as $16: 00$ & 22,3 & 26,6 & 26,6 & 1007,5 & 64,2 & 0,1 & 26,7 & 26,6 \\
\hline $16: 00$ as $16: 30$ & 22,5 & 26,9 & 26,8 & 1007,5 & 64,3 & 0,1 & 27,0 & 26,9 \\
\hline $16: 30$ as $17: 00$ & 22,3 & 27,0 & 26,9 & 1007,5 & 61,8 & 0,1 & 27,2 & 27,0 \\
\hline Desvio Padrão & 0,16 & 0,28 & 0,37 & 0,08 & 1,83 & 0,05 & 0,29 & 0,3 \\
\hline Média & 22,4 & 26,9 & 26,8 & 1007,5 & 63,1 & 0,1 & 26,9 & 26,9 \\
\hline \multicolumn{8}{|c|}{ Dados coletados Termômetro de fluxo de laser } & \\
\hline Horário/Sala & $\begin{array}{l}\text { Temp. Externa do ar } \\
\left({ }^{\circ} \mathrm{C}\right)\end{array}$ & $\begin{array}{l}\text { Temp. Paredes } \\
\text { externas }\left({ }^{\circ} \mathrm{C}\right)\end{array}$ & $\begin{array}{c}\text { Temp.Paredes } \\
\text { voltada para a rua } \\
\left({ }^{\circ} \mathrm{C}\right)\end{array}$ & \multicolumn{3}{|c|}{ Temp. Média das paredes $\left({ }^{\circ} \mathrm{C}\right)$} & Temp. Teto $\left({ }^{\circ} \mathrm{C}\right)$ & \\
\hline 15:00 & 30,7 & 26,9 & 23 & \multicolumn{3}{|c|}{24} & 25,4 & \\
\hline $17: 00$ & 29,5 & 36,2 & 30,1 & \multicolumn{3}{|c|}{26,1} & 29,1 & \\
\hline
\end{tabular}

Tabela 32: Resultados coletados in loco na sala do Apartamento A no mês de Outubro de 2013.

\begin{tabular}{|c|c|c|c|c|c|c|c|c|}
\hline \multicolumn{2}{|l|}{ Apartamento A } & \multicolumn{4}{|c|}{ Dados coletados CONFORTIMETRO Novembro 2013 - SALA } & \multicolumn{3}{|c|}{ céu limpo } \\
\hline Intervalo & $\begin{array}{l}\text { Temperatura de } \\
\text { bulbo úmido }\left({ }^{\circ} \mathrm{C}\right)\end{array}$ & $\begin{array}{l}\text { Temperatura de } \\
\text { globo }\left({ }^{\circ} \mathrm{C}\right)\end{array}$ & $\begin{array}{c}\text { Temperatura do ar } \\
\left({ }^{\circ} \mathrm{C}\right)\end{array}$ & $\begin{array}{c}\text { Pressão Atmosférica } \\
\text { (atm) }\end{array}$ & $\begin{array}{c}\text { Umidade relativa } \\
\text { do ar (\%) }\end{array}$ & $\begin{array}{l}\text { Velocidade do ar } \\
(\mathrm{m} / \mathrm{s})\end{array}$ & $\begin{array}{l}\text { Temperatura } \\
\text { radiante }\left({ }^{\circ} \mathrm{C}\right)\end{array}$ & $\begin{array}{c}\text { Temperatura } \\
\text { Operativa }\left({ }^{\circ} \mathrm{C}\right)\end{array}$ \\
\hline $16: 00$ as $16: 30$ & 23,5 & 27,5 & 27,3 & 1003,0 & 66,2 & 0,0 & 27,6 & 27,4 \\
\hline $16: 30$ as $17: 00$ & 23,8 & 27,4 & 27,1 & 1002,9 & 68,3 & 0,0 & 27,5 & 27,3 \\
\hline $17: 00$ as $17: 30$ & 23,7 & 27,5 & 27,2 & 1002,8 & 67,6 & 0,0 & 27,7 & 27,4 \\
\hline $17: 30$ as $18: 00$ & 23,5 & 27,7 & 27,6 & 1002,8 & 66,8 & 0,3 & 27,9 & 27,8 \\
\hline Desvio Padrão & 0,21 & 0,14 & 0,19 & 0,12 & 1,04 & 0,15 & 0,22 & 0,2 \\
\hline Média & 23,6 & 27,5 & 27,3 & 1002,9 & 67,2 & 0,1 & 27,7 & 27,5 \\
\hline \multicolumn{8}{|c|}{ Dados coletados Termômetro de fluxo de laser } & \\
\hline Horário/Sala & $\begin{array}{l}\text { Temp. Externa do ar } \\
\left({ }^{\circ} \mathrm{C}\right)\end{array}$ & $\begin{array}{c}\text { Temp. Paredes } \\
\text { externas }\left({ }^{\circ} \mathrm{C}\right)\end{array}$ & $\begin{array}{c}\text { Temp.Paredes } \\
\text { voltada para a rua } \\
\left({ }^{\circ} \mathrm{C}\right)\end{array}$ & \multicolumn{3}{|c|}{ Temp. Média das paredes $\left({ }^{\circ} \mathrm{C}\right)$} & Temp. Teto $\left({ }^{\circ} \mathrm{C}\right)$ & \\
\hline $11: 50$ & 28 & 28,5 & 25,8 & \multicolumn{3}{|c|}{25,9} & 26,4 & \\
\hline $15: 00$ & 31,6 & 34,9 & 28,2 & \multicolumn{3}{|c|}{26,7} & 31,1 & \\
\hline
\end{tabular}

Tabela 33: Resultados coletados in loco na sala do Apartamento A no mês de Novembro de 2013. 


\begin{tabular}{|c|c|c|c|c|c|c|c|c|}
\hline \multicolumn{2}{|l|}{ Apartamento $\mathrm{A}$} & \multicolumn{4}{|c|}{ Dados coletados CONFORTíM ETRO Dezembro 2013 - SALA } & \multicolumn{3}{|c|}{ céu limpo } \\
\hline Intervalo & $\begin{array}{l}\text { Temperatura de } \\
\text { bulbo úmido }\left({ }^{\circ} \mathrm{C}\right)\end{array}$ & $\begin{array}{c}\text { Temperatura de } \\
\text { globo }\left({ }^{\circ} \mathrm{C}\right)\end{array}$ & $\begin{array}{c}\text { Temperatura do ar } \\
\left({ }^{\circ} \mathrm{C}\right)\end{array}$ & $\begin{array}{c}\text { Pressão Atmosférica } \\
\text { (atm) }\end{array}$ & $\begin{array}{c}\text { Umidade relativa } \\
\text { do ar (\%) }\end{array}$ & $\begin{array}{l}\text { Velocidade do ar } \\
(\mathrm{m} / \mathrm{s})\end{array}$ & $\begin{array}{l}\text { Temperatura } \\
\text { radiante }\left({ }^{\circ} \mathrm{C}\right)\end{array}$ & $\begin{array}{c}\text { Temperatura } \\
\text { Operativa }\left({ }^{\circ} \mathrm{C}\right)\end{array}$ \\
\hline $16: 00$ as $16: 30$ & 23,8 & 29,9 & 29,6 & 1006,0 & 57,8 & 0,2 & 30,5 & 30,0 \\
\hline $16: 30$ as $17: 00$ & 23,7 & 30,2 & 30,2 & 1005,8 & 53,8 & 0,1 & 30,3 & 30,2 \\
\hline $17: 00$ as $17: 30$ & 23,5 & 30,7 & 30,7 & 1005,5 & 50,3 & 0,1 & 30,7 & 30,7 \\
\hline $17: 30$ as $18: 00$ & 23,5 & 31,6 & 30,8 & 1005,2 & 50,0 & 0,1 & 32,4 & 31,6 \\
\hline Desvio Padrão & 0,21 & 0,74 & 0,52 & 0,29 & 3,43 & 0,11 & 1,12 & 0,8 \\
\hline Média & 23,6 & 30,6 & 30,3 & 1005,6 & 53,0 & 0,1 & 31,0 & 30,6 \\
\hline \multicolumn{8}{|c|}{ Dados coletados Termômetro de fluxo de laser } & \\
\hline Horário/Sala & $\begin{array}{l}\text { Temp. Externa do ar } \\
\left({ }^{\circ} \mathrm{C}\right)\end{array}$ & $\begin{array}{c}\text { Temp. Paredes } \\
\text { externas }\left({ }^{\circ} \mathrm{C}\right)\end{array}$ & $\begin{array}{c}\text { Temp.Paredes } \\
\text { voltada para a rua } \\
\left({ }^{\circ} \mathrm{C}\right)\end{array}$ & \multicolumn{3}{|c|}{ Temp. Média das paredes $\left({ }^{\circ} \mathrm{C}\right)$} & Temp. Teto $\left({ }^{\circ} \mathrm{C}\right)$ & \\
\hline 15:00 & 29,3 & 32,2 & 29,6 & \multicolumn{3}{|c|}{29,7} & 34,4 & \\
\hline $17: 00$ & 30,7 & 34,7 & 31,6 & \multicolumn{3}{|c|}{31,5} & 35,1 & \\
\hline
\end{tabular}

Tabela 34: Resultados coletados in loco na sala do Apartamento A no mês de Dezembro de 2013.

\begin{tabular}{|c|c|c|c|c|c|c|c|c|}
\hline \multicolumn{2}{|l|}{ Apartamento $\mathrm{A}$} & \multicolumn{4}{|c|}{ Dados coletados CONFORTÍM ETRO Janeiro 2014 - SALA } & \multicolumn{3}{|c|}{ céu limpo } \\
\hline Intervalo & $\begin{array}{l}\text { Temperatura de } \\
\text { bulbo úmido }\left({ }^{\circ} \mathrm{C}\right)\end{array}$ & $\begin{array}{c}\text { Temperatura de } \\
\text { globo }\left({ }^{\circ} \mathrm{C}\right)\end{array}$ & $\begin{array}{c}\text { Temperatura do ar } \\
\left({ }^{\circ} \mathrm{C}\right)\end{array}$ & $\begin{array}{c}\text { Pressão Atmosférica } \\
\text { (atm) }\end{array}$ & $\begin{array}{c}\text { Umidade relativa } \\
\text { do } \operatorname{ar}(\%)\end{array}$ & $\begin{array}{l}\text { Velocidade do ar } \\
(\mathrm{m} / \mathrm{s})\end{array}$ & $\begin{array}{l}\text { Temperatura } \\
\text { radiante }\left({ }^{\circ} \mathrm{C}\right)\end{array}$ & $\begin{array}{l}\text { Temperatura } \\
\text { Operativa }\left({ }^{\circ} \mathrm{C}\right)\end{array}$ \\
\hline $16: 00$ as $16: 30$ & 28,4 & 34,3 & 34,2 & 1011,0 & 59,4 & 0,1 & 34,5 & 34,3 \\
\hline $16: 30$ as $17: 00$ & 28,4 & 34,5 & 34,4 & 1010,8 & 58,7 & 0,1 & 34,6 & 34,5 \\
\hline $17: 00$ as $17: 30$ & 28,4 & 34,6 & 34,5 & 1010,6 & 58,5 & 0,1 & 34,8 & 34,6 \\
\hline $17: 30$ as $18: 00$ & 28,2 & 34,6 & 34,4 & 1010,6 & 58,8 & 0,2 & 35,1 & 34,7 \\
\hline Desvio Padrão & 0,09 & 0,15 & 0,13 & 0,19 & 0,42 & 0,1 & 0,29 & 0,2 \\
\hline Média & 28,3 & 34,5 & 34,4 & 1010,8 & 58,9 & 0,1 & 34,7 & 34,5 \\
\hline \multicolumn{8}{|c|}{ Dados coletados Termômetro de fluxo de laser } & \\
\hline Horário/Sala & $\begin{array}{l}\text { Temp. Externa do ar } \\
\left({ }^{\circ} \mathrm{C}\right)\end{array}$ & $\begin{array}{c}\text { Temp. Paredes } \\
\text { externas }\left({ }^{\circ} \mathrm{C}\right)\end{array}$ & $\begin{array}{c}\text { Temp.Paredes } \\
\text { voltada para a rua } \\
\left({ }^{\circ} \mathrm{C}\right)\end{array}$ & \multicolumn{3}{|c|}{ Temp. Média das paredes $\left({ }^{\circ} \mathrm{C}\right)$} & Temp. Teto $\left({ }^{\circ} \mathrm{C}\right)$ & \\
\hline $11: 50$ & 31 & 33,6 & 31,8 & \multicolumn{3}{|c|}{33,1} & 34,5 & \\
\hline $15: 00$ & 40 & 39,6 & 33,4 & \multicolumn{3}{|c|}{33,2} & 39,6 & \\
\hline
\end{tabular}

Tabela 35: Resultados coletados in loco na sala do Apartamento A no mês de Janeiro de 2014.

\begin{tabular}{|c|c|c|c|c|c|c|c|c|}
\hline \multicolumn{2}{|l|}{ Apartamento A } & \multicolumn{4}{|c|}{ Dados coletados CONFORTÍM ETRO Fevereiro 2014 - SALA } & \multicolumn{3}{|c|}{$\begin{array}{c}\text { Parcialmente } \\
\text { aberto }\end{array}$} \\
\hline Intervalo & $\begin{array}{l}\text { Temperatura de } \\
\text { bulbo úmido }\left({ }^{\circ} \mathrm{C}\right)\end{array}$ & $\begin{array}{c}\text { Temperatura de } \\
\text { globo }\left({ }^{\circ} \mathrm{C}\right)\end{array}$ & $\begin{array}{c}\text { Temperatura do ar } \\
\left({ }^{\circ} \mathrm{C}\right)\end{array}$ & $\begin{array}{c}\text { Pressão Atmosférica } \\
\text { (atm) }\end{array}$ & $\begin{array}{c}\text { Umidade relativa } \\
\text { do ar (\%) }\end{array}$ & $\begin{array}{l}\text { Velocidade do ar } \\
\qquad(\mathrm{m} / \mathrm{s})\end{array}$ & $\begin{array}{l}\text { Temperatura } \\
\text { radiante }\left({ }^{\circ} \mathrm{C}\right)\end{array}$ & $\begin{array}{l}\text { Temperatura } \\
\text { Operativa }\left({ }^{\circ} \mathrm{C}\right)\end{array}$ \\
\hline $15: 00$ as $15: 30$ & 25,8 & 32,0 & 31,9 & 1007,9 & 58,4 & 0,3 & 32,3 & 32,1 \\
\hline $15: 30$ as $16: 00$ & 25,7 & 31,8 & 31,6 & 1008,1 & 59,2 & 0,2 & 32,3 & 32,0 \\
\hline $16: 00$ as $16: 30$ & 26,2 & 31,6 & 31,1 & 1008,0 & 64,3 & 0,3 & 32,9 & 32,0 \\
\hline $16: 30$ as $17: 00$ & 26,2 & 31,3 & 30,5 & 1008,1 & 67,4 & 0,3 & 33,2 & 31,8 \\
\hline Desvio Padrão & 0,29 & 0,30 & 0,56 & 0,19 & 3,80 & 0,1 & 0,52 & 0,5 \\
\hline Média & 26,0 & 31,7 & 31,3 & 1008,0 & 62,1 & 0,3 & 32,7 & 32,0 \\
\hline \multicolumn{8}{|c|}{ Dados coletados Termômetro de fluxo de laser } & \\
\hline Horário/Sala & $\begin{array}{l}\text { Temp. Externa do ar } \\
\left({ }^{\circ} \mathrm{C}\right)\end{array}$ & $\begin{array}{c}\text { Temp. Paredes } \\
\text { externas }\left({ }^{\circ} \mathrm{C}\right)\end{array}$ & $\begin{array}{c}\text { Temp.Paredes } \\
\text { voltada para a rua } \\
\left({ }^{\circ} \mathrm{C}\right)\end{array}$ & \multicolumn{3}{|c|}{ Temp. Média das paredes $\left({ }^{\circ} \mathrm{C}\right)$} & Temp. Teto $\left({ }^{\circ} \mathrm{C}\right)$ & \\
\hline $11: 50$ & 30,3 & 31,8 & 29,2 & \multicolumn{3}{|c|}{29,7} & 32,3 & \\
\hline $14: 50$ & 29 & 38 & 32 & \multicolumn{3}{|c|}{31,9} & 37,2 & \\
\hline
\end{tabular}

Tabela 36: Resultados coletados in loco na sala do Apartamento A no mês de Fevereiro de 2014.

\begin{tabular}{|c|c|c|c|c|c|c|c|c|}
\hline \multicolumn{2}{|l|}{ Apartamento A } & \multicolumn{4}{|c|}{ Dados coletados CONFORTÍM ETRO Março 2014 - SALA } & \multicolumn{3}{|c|}{$\begin{array}{l}\text { Parcialmente } \\
\text { nublado }\end{array}$} \\
\hline Intervalo & $\begin{array}{l}\text { Temperatura de } \\
\text { bulbo úmido }\left({ }^{\circ} \mathrm{C}\right)\end{array}$ & $\begin{array}{c}\text { Temperatura de } \\
\text { globo }\left({ }^{\circ} \mathrm{C}\right)\end{array}$ & $\begin{array}{c}\text { Temperatura do ar } \\
\left({ }^{\circ} \mathrm{C}\right)\end{array}$ & $\begin{array}{c}\text { Pressão Atmosférica } \\
\text { (atm) }\end{array}$ & $\begin{array}{c}\text { Umidade relativa } \\
\text { do ar (\%) }\end{array}$ & $\begin{array}{l}\text { Velocidade do ar } \\
(\mathrm{m} / \mathrm{s})\end{array}$ & $\begin{array}{l}\text { Temperatura } \\
\text { radiante }\left({ }^{\circ} \mathrm{C}\right)\end{array}$ & $\begin{array}{l}\text { Temperatura } \\
\text { Operativa }\left({ }^{\circ} \mathrm{C}\right)\end{array}$ \\
\hline $15: 00$ as $15: 30$ & 23,1 & 28,3 & 27,9 & 1015,9 & 59,5 & 0,0 & 28,4 & 28,1 \\
\hline $15: 30$ as $16: 00$ & 23,0 & 28,5 & 28,0 & 1015,9 & 57,9 & 0,0 & 28,6 & 28,3 \\
\hline $16: 00$ as $16: 30$ & 22,9 & 28,3 & 27,9 & 1016,0 & 57,4 & 0,0 & 28,4 & 28,2 \\
\hline $16: 30$ as $17: 00$ & 22,9 & 28,5 & 28,1 & 1016,2 & 56,4 & 0,0 & 28,6 & 28,3 \\
\hline Desvio Padrão & 0,12 & 0,12 & 0,09 & 0,15 & 1,22 & 0,0 & 0,13 & 0,1 \\
\hline Média & 23,0 & 28,4 & 28,0 & 1016,0 & 57,8 & 0,0 & 28,5 & 28,2 \\
\hline \multicolumn{8}{|c|}{ Dados coletados Termômetro de fluxo de laser } & \\
\hline Horário/Sala & $\begin{array}{l}\text { Temp. Externa do ar } \\
\left({ }^{\circ} \mathrm{C}\right)\end{array}$ & $\begin{array}{c}\text { Temp. Paredes } \\
\text { externas }\left({ }^{\circ} \mathrm{C}\right)\end{array}$ & $\begin{array}{c}\text { Temp.Paredes } \\
\text { voltada para a rua } \\
\left({ }^{\circ} \mathrm{C}\right)\end{array}$ & \multicolumn{3}{|c|}{ Temp. Média das paredes $\left({ }^{\circ} \mathrm{C}\right)$} & Temp. Teto $\left({ }^{\circ} \mathrm{C}\right)$ & \\
\hline 15:00 & 32 & 30,9 & 27,8 & \multicolumn{3}{|c|}{26,7} & 28,2 & \\
\hline $17: 00$ & 31 & 30,8 & 31,1 & \multicolumn{3}{|c|}{27,9} & 29,7 & \\
\hline
\end{tabular}

Tabela 37: Resultados coletados in loco na sala do Apartamento A no mês de Março de 2014. 


\begin{tabular}{|c|c|c|c|c|c|c|c|c|}
\hline \multicolumn{2}{|l|}{ Apartamento A } & \multicolumn{5}{|c|}{ Dados coletados CONFORTíM ETRO Abril 2014 - SALA } & \multicolumn{2}{|l|}{ Parcialmente claro } \\
\hline Intervalo & $\begin{array}{l}\text { Temperatura de } \\
\text { bulbo úmido }\left({ }^{\circ} \mathrm{C}\right)\end{array}$ & $\begin{array}{c}\text { Temperatura de } \\
\text { globo }\left({ }^{\circ} \mathrm{C}\right)\end{array}$ & $\begin{array}{c}\text { Temperatura do ar } \\
\left({ }^{\circ} \mathrm{C}\right)\end{array}$ & $\begin{array}{c}\text { Pressão Atmosférica } \\
\text { (atm) }\end{array}$ & $\begin{array}{c}\text { Umidade relativa } \\
\text { do ar (\%) }\end{array}$ & $\begin{array}{l}\text { Velocidade do ar } \\
\qquad(\mathrm{m} / \mathrm{s})\end{array}$ & $\begin{array}{l}\text { Temperatura } \\
\text { radiante }\left({ }^{\circ} \mathrm{C}\right)\end{array}$ & $\begin{array}{l}\text { Temperatura } \\
\text { Operativa }\left({ }^{\circ} \mathrm{C}\right)\end{array}$ \\
\hline $15: 00$ as $15: 30$ & 20,5 & 25,7 & 25,7 & 1007,9 & 54,2 & 0,38 & 25,7 & 25,7 \\
\hline $15: 30$ as $16: 00$ & 20,5 & 25,7 & 25,7 & 1007,9 & 54,2 & 0,38 & 25,7 & 25,7 \\
\hline $16: 00$ as $16: 30$ & 20,6 & 25,7 & 25,8 & 1007,9 & 54,1 & 0,22 & 25,7 & 25,8 \\
\hline $16: 30$ as $17: 00$ & 20,6 & 25,7 & 25,8 & 1007,9 & 54,1 & 0,22 & 25,7 & 25,8 \\
\hline Desvio Padrão & 0,06 & 0,00 & 0,06 & 0,0 & 0,06 & 0,1 & 0,00 & 0,0 \\
\hline Média & 20,6 & 25,7 & 25,8 & 1007,9 & 54,2 & 0,3 & 25,7 & 25,7 \\
\hline \multicolumn{9}{|c|}{ Dados coletados Termômetro de fluxo de laser } \\
\hline Horário/Sala & $\begin{array}{l}\text { Temp. Externa do ar } \\
\left({ }^{\circ} \mathrm{C}\right)\end{array}$ & $\begin{array}{c}\text { Temp. Paredes } \\
\text { externas }\left({ }^{\circ} \mathrm{C}\right)\end{array}$ & $\begin{array}{c}\text { Temp.Paredes } \\
\text { voltada para a rua } \\
\left({ }^{\circ} \mathrm{C}\right)\end{array}$ & \multicolumn{3}{|c|}{ Temp. Média das paredes $\left({ }^{\circ} \mathrm{C}\right)$} & Temp. Teto $\left({ }^{\circ} \mathrm{C}\right)$ & \\
\hline $15: 00$ & 24,7 & 28,2 & 23,6 & \multicolumn{3}{|c|}{23,8} & 24,2 & \\
\hline $17: 00$ & 28,5 & 33,6 & 24 & \multicolumn{3}{|c|}{25,1} & 26 & \\
\hline
\end{tabular}

Tabela 38: Resultados coletados in loco na sala do Apartamento A no mês de Abril de 2014.

\begin{tabular}{|c|c|c|c|c|c|c|c|c|}
\hline \multicolumn{2}{|l|}{ Apartamento A } & \multicolumn{4}{|c|}{ Dados coletados CONFORTíMETRO M aio 2014 - SALA } & \multicolumn{3}{|c|}{ Céu claro } \\
\hline Intervalo & $\begin{array}{l}\text { Temperatura de } \\
\text { bulbo úmido }\left({ }^{\circ} \mathrm{C}\right)\end{array}$ & $\begin{array}{c}\text { Temperatura de } \\
\text { globo }\left({ }^{\circ} \mathrm{C}\right)\end{array}$ & $\begin{array}{c}\text { Temperatura do ar } \\
\left({ }^{\circ} \mathrm{C}\right)\end{array}$ & $\begin{array}{c}\text { Pressão Atmosférica } \\
\text { (atm) }\end{array}$ & $\begin{array}{c}\text { Umidade relativa } \\
\text { do } \operatorname{ar}(\%)\end{array}$ & $\begin{array}{l}\text { Velocidade do ar } \\
(\mathrm{m} / \mathrm{s})\end{array}$ & $\begin{array}{l}\text { Temperatura } \\
\text { radiante }\left({ }^{\circ} \mathrm{C}\right)\end{array}$ & $\begin{array}{l}\text { Temperatura } \\
\text { Operativa }\left({ }^{\circ} \mathrm{C}\right)\end{array}$ \\
\hline $15: 00$ as $15: 30$ & 23,8 & 28,4 & 28,0 & 1015,5 & 64,2 & 0,1 & 28,8 & 28,4 \\
\hline $15: 30$ as $16: 00$ & 23,8 & 28,2 & 27,9 & 1015,4 & 64,4 & 0,1 & 28,6 & 28,3 \\
\hline $16: 00$ as $16: 30$ & 23,7 & 28,0 & 27,7 & 1015,4 & 65,1 & 0,1 & 28,3 & 28,0 \\
\hline $16: 30$ as $17: 00$ & 23,9 & 27,9 & 27,7 & 1015,6 & 66,1 & 0,1 & 28,2 & 27,9 \\
\hline Desvio Padrão & 0,08 & 0,19 & 0,15 & 0,11 & 0,77 & 0,04 & 0,26 & 0,2 \\
\hline Média & 23,8 & 28,1 & 27,8 & 1015,4 & 65,0 & 0,1 & 28,5 & 28,1 \\
\hline \multicolumn{8}{|c|}{ Dados coletados Termômetro de fluxo de laser } & \\
\hline Horário/Sala & $\begin{array}{l}\text { Temp. Externa do ar } \\
\left({ }^{\circ} \mathrm{C}\right)\end{array}$ & $\begin{array}{l}\text { Temp. Paredes } \\
\text { externas }\left({ }^{\circ} \mathrm{C}\right)\end{array}$ & $\begin{array}{c}\text { Temp.Paredes } \\
\text { voltada para a rua } \\
\left({ }^{\circ} \mathrm{C}\right)\end{array}$ & \multicolumn{3}{|c|}{ Temp. Média das paredes $\left({ }^{\circ} \mathrm{C}\right)$} & Temp. Teto $\left({ }^{\circ} \mathrm{C}\right)$ & \\
\hline $15: 00$ & 33,2 & 36,5 & 27 & \multicolumn{3}{|c|}{26,8} & 27,8 & \\
\hline $17: 00$ & 30,5 & 30,3 & 30,4 & \multicolumn{3}{|c|}{27,7} & 28,1 & \\
\hline
\end{tabular}

Tabela 39: Resultados coletados in loco na sala do Apartamento A no mês de Maio de 2014.

\begin{tabular}{|c|c|c|c|c|c|c|c|c|}
\hline \multicolumn{2}{|l|}{ Apartamento $\mathrm{A}$} & \multicolumn{4}{|c|}{ Dados coletados CONFORTíMETRO Junho 2014 - SALA } & \multicolumn{3}{|c|}{ Céu claro } \\
\hline Intervalo & $\begin{array}{l}\text { Temperatura de } \\
\text { bulbo úmido }\left({ }^{\circ} \mathrm{C}\right)\end{array}$ & $\begin{array}{c}\text { Temperatura de } \\
\text { globo }\left({ }^{\circ} \mathrm{C}\right)\end{array}$ & $\begin{array}{c}\text { Temperatura do ar } \\
\left({ }^{\circ} \mathrm{C}\right)\end{array}$ & $\begin{array}{c}\text { Pressão Atmosférica } \\
\text { (atm) }\end{array}$ & $\begin{array}{c}\text { Umidade relativa } \\
\text { do ar (\%) }\end{array}$ & $\begin{array}{l}\text { Velocidade do ar } \\
\qquad(\mathrm{m} / \mathrm{s})\end{array}$ & $\begin{array}{l}\text { Temperatura } \\
\text { radiante }\left({ }^{\circ} \mathrm{C}\right)\end{array}$ & $\begin{array}{l}\text { Temperatura } \\
\text { Operativa }\left({ }^{\circ} \mathrm{C}\right)\end{array}$ \\
\hline $15: 00$ as $15: 30$ & 20,0 & 25,8 & 25,3 & 1009,7 & 52,9 & 0,1 & 26,3 & 25,8 \\
\hline $15: 30$ as $16: 00$ & 19,6 & 25,1 & 24,8 & 1009,8 & 52,5 & 0,0 & 25,3 & 25,0 \\
\hline $16: 00$ as $16: 30$ & 19,6 & 25,0 & 24,6 & 1009,9 & 53,4 & 0,0 & 25,1 & 24,9 \\
\hline $16: 30$ as $17: 00$ & 19,9 & 25,0 & 24,6 & 1010,1 & 54,8 & 0,0 & 25,2 & 24,9 \\
\hline Desvio Padrão & 0,24 & 0,39 & 0,30 & 0,18 & 1,14 & 0,03 & 0,54 & 0,4 \\
\hline Média & 19,8 & 25,2 & 24,9 & 1009,9 & 53,4 & 0,0 & 25,5 & 25,2 \\
\hline \multicolumn{8}{|c|}{ Dados coletados Termômetro de fluxo de laser } & \\
\hline Horário/Sala & $\begin{array}{l}\text { Temp. Externa do ar } \\
\left({ }^{\circ} \mathrm{C}\right)\end{array}$ & $\begin{array}{l}\text { Temp. Paredes } \\
\text { externas }\left({ }^{\circ} \mathrm{C}\right)\end{array}$ & $\begin{array}{c}\text { Temp.Paredes } \\
\text { voltada para a rua } \\
\left({ }^{\circ} \mathrm{C}\right)\end{array}$ & \multicolumn{3}{|c|}{ Temp. Média das paredes $\left({ }^{\circ} \mathrm{C}\right)$} & Temp. Teto $\left({ }^{\circ} \mathrm{C}\right)$ & \\
\hline $15: 00$ & 29,1 & 32,8 & 25,1 & \multicolumn{3}{|c|}{23,7} & 26,1 & \\
\hline 17:00 & 28,3 & 24,6 & 25,6 & \multicolumn{3}{|c|}{26,6} & 25,6 & \\
\hline
\end{tabular}

Tabela 40: Resultados coletados in loco na sala do Apartamento A no mês de Junho de 2014.

\begin{tabular}{|c|c|c|c|c|c|c|c|c|}
\hline \multicolumn{2}{|l|}{ Apartamento B } & \multicolumn{4}{|c|}{ Dados coletados CONFORTÍMETRO Julho 2013 - QUARTO } & \multicolumn{3}{|c|}{ céu claro } \\
\hline Intervalo & $\begin{array}{l}\text { Temperatura de } \\
\text { bulbo úmido }\left({ }^{\circ} \mathrm{C}\right)\end{array}$ & $\begin{array}{c}\text { Temperatura de } \\
\text { globo }\left({ }^{\circ} \mathrm{C}\right)\end{array}$ & $\begin{array}{c}\text { Temperatura do ar } \\
\left({ }^{\circ} \mathrm{C}\right)\end{array}$ & $\begin{array}{c}\text { Pressão } \\
\text { Atmosférica (atm) }\end{array}$ & $\begin{array}{c}\text { Umidade relativa } \\
\text { do ar (\%) }\end{array}$ & $\begin{array}{c}\text { Velocidade do ar } \\
(\mathrm{m} / \mathrm{s})\end{array}$ & $\begin{array}{l}\text { Temperatura } \\
\text { radiante }\left({ }^{\circ} \mathrm{C}\right)\end{array}$ & $\begin{array}{l}\text { Temperatura } \\
\text { Operativa }\left({ }^{\circ} \mathrm{C}\right)\end{array}$ \\
\hline $11: 50$ as $12: 20$ & 21,0 & 23,8 & 23,2 & 1021,2 & 76,9 & 0,1 & 24,5 & 23,9 \\
\hline $12: 20$ as $12: 50$ & 21,1 & 23,7 & 23,4 & 1021,1 & 77,1 & 0,1 & 24,1 & 23,7 \\
\hline $12: 50$ as $13: 20$ & 21,1 & 23,9 & 23,5 & 1021,0 & 75,7 & 0,1 & 24,3 & 23,9 \\
\hline $13: 20$ as $13: 50$ & 21,1 & 23,8 & 23,5 & 1020,9 & 75,5 & 0,1 & 24,1 & 23,8 \\
\hline $13: 50$ as $14: 20$ & 21,1 & 23,8 & 23,5 & 1020,8 & 75,6 & 0,1 & 24,0 & 23,8 \\
\hline $14: 20$ as $14: 50$ & 21,1 & 23,9 & 23,3 & 1020,7 & 76,8 & 0,1 & 24,7 & 24,0 \\
\hline Desvio Padrão & 0,14 & 0,14 & 0,17 & 0,19 & 0,93 & 0,09 & 0,45 & 1,63 \\
\hline Média & 21,1 & 23,8 & 23,4 & 1020,9 & 76,3 & 0,1 & 24,3 & 23,8 \\
\hline \multicolumn{9}{|c|}{ Dados coletados Termômetro de fluxo de laser } \\
\hline Horário/Quarto & $\begin{array}{l}\text { Temp. Externa do ar } \\
\left({ }^{\circ} \mathrm{C}\right)\end{array}$ & $\begin{array}{c}\text { Temp. Paredes } \\
\text { externas }\left({ }^{\circ} \mathrm{C}\right)\end{array}$ & $\begin{array}{c}\text { Temp.Paredes } \\
\text { voltada para a rua } \\
\left({ }^{\circ} \mathrm{C}\right)\end{array}$ & \multicolumn{3}{|c|}{ Temp. Média das paredes $\left({ }^{\circ} \mathrm{C}\right)$} & Temp. Teto $\left({ }^{\circ} \mathrm{C}\right)$ & \\
\hline $11: 50$ & 21 & 23 & 22,5 & \multicolumn{3}{|c|}{22,5} & 22,5 & \\
\hline $15: 00$ & 20,7 & 23 & 22,7 & \multicolumn{3}{|c|}{21,7} & 22,7 & \\
\hline
\end{tabular}

Tabela 41: Resultados coletados in loco no quarto do Apartamento B no mês de Julho de 2013. 


\begin{tabular}{|c|c|c|c|c|c|c|c|c|}
\hline \multicolumn{2}{|l|}{ Apartamento B } & \multicolumn{4}{|c|}{ Dados coletados CONFORTÍM ETRO Agosto 2013 - QUARTO } & \multicolumn{3}{|c|}{ céu claro } \\
\hline Intervalo & $\begin{array}{l}\text { Temperatura de } \\
\text { bulbo úmido }\left({ }^{\circ} \mathrm{C}\right)\end{array}$ & $\begin{array}{c}\text { Temperatura de } \\
\text { globo }\left({ }^{\circ} \mathrm{C}\right)\end{array}$ & $\begin{array}{c}\text { Temperatura do ar } \\
\left({ }^{\circ} \mathrm{C}\right)\end{array}$ & $\begin{array}{c}\text { Pressão } \\
\text { Atmosférica (atm) }\end{array}$ & $\begin{array}{c}\text { Umidade relativa } \\
\text { do ar (\%) }\end{array}$ & $\begin{array}{l}\text { Velocidade do ar } \\
(\mathrm{m} / \mathrm{s})\end{array}$ & $\begin{array}{l}\text { Temperatura } \\
\text { radiante }\left({ }^{\circ} \mathrm{C}\right)\end{array}$ & $\begin{array}{l}\text { Temperatura } \\
\text { Operativa }\left({ }^{\circ} \mathrm{C}\right)\end{array}$ \\
\hline $11: 50$ as $12: 20$ & 20,0 & 23,7 & 23,1 & 1013,2 & 71,7 & 0,1 & 24,7 & 23,9 \\
\hline $12: 20$ as $12: 50$ & 19,9 & 23,4 & 22,8 & 1013,5 & 72,4 & 0,1 & 24,1 & 23,5 \\
\hline $12: 50$ as $13: 20$ & 20,0 & 23,4 & 23,0 & 1014,0 & 71,9 & 0,1 & 23,9 & 23,5 \\
\hline $13: 20$ as $13: 50$ & 20,0 & 23,4 & 22,9 & 1014,0 & 72,3 & 0,1 & 24,0 & 23,4 \\
\hline $13: 50$ as $14: 20$ & 20,1 & 23,5 & 23,1 & 1014,0 & 71,9 & 0,1 & 24,0 & 23,5 \\
\hline $14: 20$ as $14: 50$ & 20,3 & 23,8 & 23,4 & 1013,9 & 71,0 & 0,1 & 24,2 & 23,8 \\
\hline Desvio Padrão & 0,16 & 0,21 & 0,21 & 0,31 & 0,59 & 0,06 & 0,39 & 1,63 \\
\hline Média & 20,0 & 23,5 & 23,0 & 1013,7 & 71,9 & 0,1 & 24,1 & 23,6 \\
\hline \multicolumn{9}{|c|}{ Dados coletados Termômetro de fluxo de laser } \\
\hline Horário/Quarto & $\begin{array}{l}\text { Temp. Externa do ar } \\
\left({ }^{\circ} \mathrm{C}\right)\end{array}$ & $\begin{array}{c}\text { Temp. Paredes } \\
\text { externas }\left({ }^{\circ} \mathrm{C}\right)\end{array}$ & $\begin{array}{c}\text { Temp.Paredes } \\
\text { voltada para a rua } \\
\left({ }^{\circ} \mathrm{C}\right)\end{array}$ & \multicolumn{3}{|c|}{ Temp. M édia das paredes $\left({ }^{\circ} \mathrm{C}\right)$} & Temp. Teto $\left({ }^{\circ} \mathrm{C}\right)$ & \\
\hline $11: 50$ & 22,1 & 23,2 & 23,4 & \multicolumn{3}{|c|}{23,4} & 23,4 & \\
\hline $15: 00$ & 24,6 & 26,2 & 25,6 & \multicolumn{3}{|c|}{26,3} & 25,6 & \\
\hline
\end{tabular}

Tabela 42: Resultados coletados in loco no quarto do Apartamento B no mês de Agosto de 2013.

\begin{tabular}{|c|c|c|c|c|c|c|c|c|}
\hline \multicolumn{2}{|l|}{ Apartamento B } & \multicolumn{4}{|c|}{ Dados coletados CONFORTÍMETRO Setembro 2013 - QUARTO } & \multicolumn{3}{|c|}{ Nublado } \\
\hline Intervalo & $\begin{array}{l}\text { Temperatura de } \\
\text { bulbo úmido }\left({ }^{\circ} \mathrm{C}\right)\end{array}$ & $\begin{array}{c}\text { Temperatura de } \\
\text { globo }\left({ }^{\circ} \mathrm{C}\right)\end{array}$ & $\begin{array}{l}\text { Temperatura do ar } \\
\left({ }^{\circ} \mathrm{C}\right)\end{array}$ & $\begin{array}{c}\text { Pressão } \\
\text { Atmosférica (atm) }\end{array}$ & $\begin{array}{l}\text { Umidade relativa } \\
\text { do ar (\%) }\end{array}$ & $\begin{array}{l}\text { Velocidade do ar } \\
\qquad(\mathrm{m} / \mathrm{s})\end{array}$ & $\begin{array}{l}\text { Temperatura } \\
\text { radiante }\left({ }^{\circ} \mathrm{C}\right)\end{array}$ & $\begin{array}{l}\text { Temperatura } \\
\text { Operativa }\left({ }^{\circ} \mathrm{C}\right)\end{array}$ \\
\hline $11: 50$ as $12: 20$ & 20,4 & 27,3 & 27,4 & 1008,8 & 43,9 & 0,0 & 27,3 & 27,3 \\
\hline $12: 20$ as $12: 50$ & 20,7 & 26,8 & 26,7 & 1008,8 & 48,5 & 0,0 & 26,8 & 26,8 \\
\hline $12: 50$ as $13: 20$ & 20,9 & 26,8 & 26,7 & 1008,9 & 50,5 & 0,0 & 26,8 & 26,7 \\
\hline $13: 20$ as $13: 50$ & 21,3 & 26,6 & 26,5 & 1009,1 & 53,8 & 0,0 & 26,6 & 26,6 \\
\hline $13: 50$ as $14: 20$ & 21,5 & 26,5 & 26,4 & 1009,2 & 55,9 & 0,0 & 26,5 & 26,4 \\
\hline $14: 20$ as $14: 50$ & 21,5 & 26,4 & 26,3 & 1009,4 & 56,4 & 0,0 & 26,5 & 26,4 \\
\hline Desvio Padrão & 0,43 & 0,34 & 0,40 & 0,21 & 4,52 & 0,04 & 0,31 & 1,63 \\
\hline Média & 21,0 & 26,7 & 26,7 & 1009,0 & 51,4 & 0,0 & 26,8 & 26,7 \\
\hline \multicolumn{9}{|c|}{ Dados coletados Termômetro de fluxo de laser } \\
\hline Horário/Quarto & $\begin{array}{l}\text { Temp. Externa do ar } \\
\left({ }^{\circ} \mathrm{C}\right)\end{array}$ & $\begin{array}{l}\text { Temp. Paredes } \\
\text { externas }\left({ }^{\circ} \mathrm{C}\right)\end{array}$ & $\begin{array}{c}\text { Temp. Paredes } \\
\text { voltada para a rua } \\
\left({ }^{\circ} \mathrm{C}\right)\end{array}$ & \multicolumn{3}{|c|}{ Temp. Média das paredes $\left({ }^{\circ} \mathrm{C}\right)$} & Temp. Teto $\left({ }^{\circ} \mathrm{C}\right)$ & \\
\hline $11: 50$ & 28,3 & 29,7 & 28,1 & \multicolumn{3}{|c|}{26,7} & 27 & \\
\hline $15: 00$ & 27 & 27 & 27,6 & \multicolumn{3}{|c|}{26,1} & 27 & \\
\hline
\end{tabular}

Tabela 43: Resultados coletados in loco no quarto do Apartamento B no mês de Setembro de 2013.

\begin{tabular}{|c|c|c|c|c|c|c|c|c|}
\hline \multicolumn{2}{|l|}{ Apartamento B } & \multicolumn{4}{|c|}{ Dados coletados CONFORTÍMETRO Outubro 2013 - QUARTO } & \multicolumn{3}{|c|}{$\begin{array}{l}\text { Parcialmente } \\
\text { Nublado }\end{array}$} \\
\hline Intervalo & $\begin{array}{l}\text { Temperatura de } \\
\text { bulbo úmido }\left({ }^{\circ} \mathrm{C}\right)\end{array}$ & $\begin{array}{c}\text { Temperatura de } \\
\text { globo }\left({ }^{\circ} \mathrm{C}\right)\end{array}$ & $\begin{array}{c}\text { Temperatura do ar } \\
\left({ }^{\circ} \mathrm{C}\right)\end{array}$ & $\begin{array}{c}\text { Pressão } \\
\text { Atmosférica (atm) }\end{array}$ & $\begin{array}{c}\text { Umidade relativa } \\
\text { do ar (\%) }\end{array}$ & $\begin{array}{l}\text { Velocidade do ar } \\
(\mathrm{m} / \mathrm{s})\end{array}$ & $\begin{array}{l}\text { Temperatura } \\
\text { radiante }\left({ }^{\circ} \mathrm{C}\right)\end{array}$ & $\begin{array}{l}\text { Temperatura } \\
\text { Operativa }\left({ }^{\circ} \mathrm{C}\right)\end{array}$ \\
\hline $11: 50$ as $12: 20$ & 20,2 & 25,3 & 24,6 & 1013,0 & 60,8 & 0,1 & 25,6 & 25,1 \\
\hline $12: 20$ as $12: 50$ & 19,9 & 25,7 & 24,7 & 1012,9 & 57,9 & 0,0 & 26,0 & 25,4 \\
\hline $12: 50$ as $13: 20$ & 20,1 & 26,4 & 25,2 & 1012,8 & 56,7 & 0,0 & 26,9 & 26,1 \\
\hline $13: 20$ as $13: 50$ & 20,3 & 26,5 & 25,4 & 1012,7 & 57,0 & 0,2 & 27,0 & 26,2 \\
\hline $13: 50$ as $14: 20$ & 20,8 & 27,1 & 25,9 & 1012,4 & 56,6 & 0,1 & 27,6 & 26,7 \\
\hline $14: 20$ as $14: 50$ & 20,7 & 27,2 & 25,8 & 1012,0 & 56,7 & 0,1 & 27,7 & 26,8 \\
\hline Desvio Padrão & 0,41 & 0,69 & 0,50 & 0,34 & 1,63 & 0,12 & 0,78 & 1,63 \\
\hline Média & 20,3 & 26,4 & 25,3 & 1012,6 & 57,7 & 0,1 & 26,8 & 26,0 \\
\hline \multicolumn{9}{|c|}{ Dados coletados Termômetro de fluxo de laser } \\
\hline Horário/Quarto & $\begin{array}{l}\text { Temp. Externa do ar } \\
\qquad\left({ }^{\circ} \mathrm{C}\right)\end{array}$ & $\begin{array}{l}\text { Temp. Paredes } \\
\text { externas }\left({ }^{\circ} \mathrm{C}\right)\end{array}$ & $\begin{array}{c}\text { Temp. Paredes } \\
\text { voltada para a rua } \\
\left({ }^{\circ} \mathrm{C}\right)\end{array}$ & \multicolumn{3}{|c|}{ Temp. Média das paredes $\left({ }^{\circ} \mathrm{C}\right)$} & Temp. Teto $\left({ }^{\circ} \mathrm{C}\right)$ & \\
\hline $11: 50$ & 25,4 & 24,9 & 23,9 & \multicolumn{3}{|c|}{23,9} & 24,8 & \\
\hline $15: 00$ & 29 & 35,2 & 27,2 & \multicolumn{3}{|c|}{24,6} & 27,3 & \\
\hline
\end{tabular}

Tabela 44: Resultados coletados in loco no quarto do Apartamento B no mês de Outubro de 2013.

\begin{tabular}{|c|c|c|c|c|c|c|c|c|}
\hline \multicolumn{2}{|l|}{ Apartamento B } & \multicolumn{4}{|c|}{ Dados coletados CONFORTÍM ETRO Novembro 2013 - QUARTO } & \multicolumn{3}{|c|}{$\begin{array}{l}\text { Parcialmente } \\
\text { Nublado }\end{array}$} \\
\hline Intervalo & $\begin{array}{l}\text { Temperatura de } \\
\text { bulbo úmido }\left({ }^{\circ} \mathrm{C}\right)\end{array}$ & $\begin{array}{l}\text { Temperatura de } \\
\text { globo }\left({ }^{\circ} \mathrm{C}\right)\end{array}$ & $\begin{array}{l}\text { Temperatura do ar } \\
\left({ }^{\circ} \mathrm{C}\right)\end{array}$ & $\begin{array}{c}\text { Pressão } \\
\text { Atmosférica (atm) }\end{array}$ & $\begin{array}{c}\text { Umidade relativa } \\
\text { do ar (\%) }\end{array}$ & $\begin{array}{l}\text { Velocidade do ar } \\
\qquad(\mathrm{m} / \mathrm{s})\end{array}$ & $\begin{array}{l}\text { Temperatura } \\
\text { radiante }\left({ }^{\circ} \mathrm{C}\right)\end{array}$ & $\begin{array}{l}\text { Temperatura } \\
\text { Operativa }\left({ }^{\circ} \mathrm{C}\right)\end{array}$ \\
\hline $12: 50$ as $13: 20$ & 23,6 & 27,3 & 26,9 & 1011,2 & 73,6 & 0,0 & 27,6 & 27,2 \\
\hline $13: 20$ as $13: 50$ & 23,7 & 27,4 & 27,0 & 1010,9 & 73,2 & 0,0 & 27,5 & 27,3 \\
\hline $13: 50$ as $14: 20$ & 23,7 & 27,3 & 27,0 & 1010,7 & 73,6 & 0,0 & 27,5 & 27,2 \\
\hline $14: 20$ as $14: 50$ & 23,7 & 27,4 & 27,1 & 1010,5 & 73,0 & 0,0 & 27,5 & 27,3 \\
\hline $14: 50$ as $15: 20$ & 23,7 & 27,4 & 27,1 & 1010,5 & 72,6 & 0,0 & 27,6 & 27,4 \\
\hline $15: 20$ as $15: 50$ & 23,6 & 27,5 & 27,2 & 1010,5 & 71,9 & 0,0 & 27,7 & 27,4 \\
\hline Desvio Padrão & 0,11 & 0,18 & 0,14 & 0,24 & 0,63 & 0,02 & 0,24 & 1,63 \\
\hline Média & 23,7 & 27,4 & 27,0 & 1010,9 & 73,3 & 0,0 & 27,6 & 27,3 \\
\hline \multicolumn{9}{|c|}{ Dados coletados Termômetro de fluxo de laser } \\
\hline Horário/Quarto & $\begin{array}{l}\text { Temp. Externa do ar } \\
\left({ }^{\circ} \mathrm{C}\right)\end{array}$ & $\begin{array}{l}\text { Temp. Paredes } \\
\text { externas }\left({ }^{\circ} \mathrm{C}\right)\end{array}$ & $\begin{array}{c}\text { Temp. Paredes } \\
\text { voltada para a rua } \\
\left({ }^{\circ} \mathrm{C}\right)\end{array}$ & \multicolumn{3}{|c|}{ Temp. Média das paredes $\left({ }^{\circ} \mathrm{C}\right)$} & Temp. Teto $\left({ }^{\circ} \mathrm{C}\right)$ & \\
\hline $12: 50$ & 26,2 & 28,7 & 27,1 & \multicolumn{3}{|c|}{27,8} & 28,1 & \\
\hline $16: 00$ & 31,6 & 28,9 & 27,8 & \multicolumn{3}{|c|}{26,4} & 29,3 & \\
\hline
\end{tabular}

Tabela 45: Resultados coletados in loco no quarto do Apartamento B no mês de Novembro de 2013. 


\begin{tabular}{|c|c|c|c|c|c|c|c|c|}
\hline \multicolumn{2}{|l|}{ Apartamento B } & \multicolumn{4}{|c|}{ Dados coletados CONFORTÍM ETRO Dezembro 2013 - QUARTO } & \multicolumn{3}{|c|}{ Céu claro } \\
\hline Intervalo & $\begin{array}{l}\text { Temperatura de } \\
\text { bulbo úmido }\left({ }^{\circ} \mathrm{C}\right)\end{array}$ & $\begin{array}{l}\text { Temperatura de } \\
\text { globo }\left({ }^{\circ} \mathrm{C}\right)\end{array}$ & $\begin{array}{l}\text { Temperatura do ar } \\
\left({ }^{\circ} \mathrm{C}\right)\end{array}$ & $\begin{array}{c}\text { Pressão } \\
\text { Atmosférica (atm) }\end{array}$ & $\begin{array}{c}\text { Umidade relativa } \\
\text { do ar (\%) }\end{array}$ & $\begin{array}{l}\text { Velocidade do ar } \\
\qquad(\mathrm{m} / \mathrm{s})\end{array}$ & $\begin{array}{l}\text { Temperatura } \\
\text { radiante }\left({ }^{\circ} \mathrm{C}\right)\end{array}$ & $\begin{array}{l}\text { Temperatura } \\
\text { Operativa }\left({ }^{\circ} \mathrm{C}\right)\end{array}$ \\
\hline $12: 50$ as $13: 20$ & 24,8 & 29,4 & 29,2 & 1010,3 & 66,8 & 0,1 & 29,6 & 29,4 \\
\hline $13: 20$ as $13: 50$ & 24,9 & 29,6 & 29,4 & 1010,1 & 66,0 & 0,1 & 29,8 & 29,6 \\
\hline $13: 50$ as $14: 20$ & 25,0 & 30,2 & 29,9 & 1010,0 & 64,1 & 0,1 & 30,5 & 30,2 \\
\hline $14: 20$ as $14: 50$ & 25,2 & 30,6 & 30,3 & 1009,8 & 63,0 & 0,1 & 30,8 & 30,5 \\
\hline $14: 50$ as $15: 20$ & 25,4 & 30,9 & 30,4 & 1009,5 & 62,7 & 0,1 & 31,3 & 30,8 \\
\hline $15: 20$ as $15: 50$ & 25,4 & 30,9 & 30,4 & 1009,5 & 61,7 & 0,1 & 31,3 & 30,8 \\
\hline Desvio Padrão & 0,27 & 0,57 & 0,49 & 0,30 & 1,85 & 0,0 & 0,66 & 1,63 \\
\hline Média & 25,1 & 30,3 & 29,9 & 1009,9 & 64,0 & 0,1 & 30,6 & 30,3 \\
\hline \multicolumn{9}{|c|}{ Dados coletados Termômetro de fluxo de laser } \\
\hline Horário/Quarto & $\begin{array}{l}\text { Temp. Externa do ar } \\
\left({ }^{\circ} \mathrm{C}\right)\end{array}$ & $\begin{array}{l}\text { Temp. Paredes } \\
\text { externas }\left({ }^{\circ} \mathrm{C}\right)\end{array}$ & $\begin{array}{c}\text { Temp. Paredes } \\
\text { voltada para a rua } \\
\left({ }^{\circ} \mathrm{C}\right)\end{array}$ & \multicolumn{3}{|c|}{ Temp. Média das paredes $\left({ }^{\circ} \mathrm{C}\right)$} & Temp. Teto $\left({ }^{\circ} \mathrm{C}\right)$ & \\
\hline $12: 50$ & 28,6 & 32,7 & 28,6 & \multicolumn{3}{|c|}{28,4} & 30,1 & \\
\hline $16: 00$ & 32,5 & 36,1 & 30,1 & \multicolumn{3}{|c|}{28,8} & 33,1 & \\
\hline
\end{tabular}

Tabela 46: Resultados coletados in loco no quarto do Apartamento B no mês de Dezembro de 2013.

\begin{tabular}{|c|c|c|c|c|c|c|c|c|}
\hline \multicolumn{2}{|l|}{ Apartamento B } & \multicolumn{4}{|c|}{ Dados coletados CONFORTÍM ETRO Janeiro 2014 - QUARTO } & \multicolumn{3}{|c|}{ Céu claro } \\
\hline Intervalo & $\begin{array}{l}\text { Temperatura de } \\
\text { bulbo úmido }\left({ }^{\circ} \mathrm{C}\right)\end{array}$ & $\begin{array}{c}\text { Temperatura de } \\
\text { globo }\left({ }^{\circ} \mathrm{C}\right)\end{array}$ & $\begin{array}{l}\text { Temperatura do ar } \\
\left({ }^{\circ} \mathrm{C}\right)\end{array}$ & $\begin{array}{c}\text { Pressão } \\
\text { Atmosférica (atm) }\end{array}$ & $\begin{array}{l}\text { Umidade relativa } \\
\text { do ar (\%) }\end{array}$ & $\begin{array}{l}\text { Velocidade do ar } \\
\qquad(\mathrm{m} / \mathrm{s})\end{array}$ & $\begin{array}{l}\text { Temperatura } \\
\text { radiante }\left({ }^{\circ} \mathrm{C}\right)\end{array}$ & $\begin{array}{l}\text { Temperatura } \\
\text { Operativa }\left({ }^{\circ} \mathrm{C}\right)\end{array}$ \\
\hline $12: 50$ as $13: 20$ & 26,7 & 32,5 & 32,4 & 1009,2 & 59,0 & 0,1 & 32,6 & 32,5 \\
\hline $13: 20$ as $13: 50$ & 26,7 & 32,6 & 32,5 & 1008,8 & 58,0 & 0,0 & 32,7 & 32,6 \\
\hline $13: 50$ as $14: 20$ & 26,6 & 32,8 & 32,6 & 1008,6 & 57,1 & 0,1 & 32,9 & 32,8 \\
\hline $14: 20$ as $14: 50$ & 27,0 & 33,1 & 32,9 & 1008,4 & 57,9 & 0,1 & 33,4 & 33,1 \\
\hline $14: 50$ as $15: 20$ & 27,6 & 33,5 & 33,2 & 1008,3 & 59,6 & 0,1 & 33,7 & 33,4 \\
\hline $15: 20$ as $15: 50$ & 27,5 & 33,9 & 33,5 & 1008,4 & 57,7 & 0,1 & 34,2 & 33,8 \\
\hline Desvio Padrão & 0,43 & 0,52 & 0,41 & 0,35 & 1,13 & 0,1 & 0,62 & 1,63 \\
\hline Média & 27,0 & 33,0 & 32,8 & 1008,7 & 58,3 & 0,1 & 33,2 & 33,0 \\
\hline \multicolumn{9}{|c|}{ Dados coletados Termômetro de fluxo de laser } \\
\hline Horário/Quarto & $\begin{array}{l}\text { Temp. Externa do ar } \\
\left({ }^{\circ} \mathrm{C}\right)\end{array}$ & $\begin{array}{l}\text { Temp. Paredes } \\
\text { externas }\left({ }^{\circ} \mathrm{C}\right)\end{array}$ & $\begin{array}{c}\text { Temp. Paredes } \\
\text { voltada para a rua } \\
\left({ }^{\circ} \mathrm{C}\right)\end{array}$ & \multicolumn{3}{|c|}{ Temp. Média das paredes $\left({ }^{\circ} \mathrm{C}\right)$} & Temp. Teto $\left({ }^{\circ} \mathrm{C}\right)$ & \\
\hline $12: 50$ & 36 & 36,6 & 32,1 & \multicolumn{3}{|c|}{32,7} & 34,3 & \\
\hline $16: 00$ & 38,5 & 43,2 & 36,3 & \multicolumn{3}{|c|}{34,2} & 40 & \\
\hline
\end{tabular}

Tabela 47: Resultados coletados in loco no quarto do Apartamento B no mês de Janeiro de 2014.

\begin{tabular}{|c|c|c|c|c|c|c|c|c|}
\hline \multicolumn{2}{|l|}{ Apartamento B } & \multicolumn{4}{|c|}{ Dados coletados CONFORTÍM ETRO Fevereiro 2014 - QUARTO } & \multicolumn{3}{|c|}{$\begin{array}{l}\text { Parcialmente } \\
\text { claro }\end{array}$} \\
\hline Intervalo & $\begin{array}{l}\text { Temperatura de } \\
\text { bulbo úmido }\left({ }^{\circ} \mathrm{C}\right)\end{array}$ & $\begin{array}{l}\text { Temperatura de } \\
\text { globo }\left({ }^{\circ} \mathrm{C}\right)\end{array}$ & $\begin{array}{c}\text { Temperatura do ar } \\
\left({ }^{\circ} \mathrm{C}\right)\end{array}$ & $\begin{array}{c}\text { Pressão } \\
\text { Atmosférica (atm) }\end{array}$ & $\begin{array}{l}\text { Umidade relativa } \\
\text { do ar (\%) }\end{array}$ & $\begin{array}{l}\text { Velocidade do ar } \\
(\mathrm{m} / \mathrm{s})\end{array}$ & $\begin{array}{l}\text { Temperatura } \\
\text { radiante }\left({ }^{\circ} \mathrm{C}\right)\end{array}$ & $\begin{array}{l}\text { Temperatura } \\
\text { Operativa }\left({ }^{\circ} \mathrm{C}\right)\end{array}$ \\
\hline $11: 50$ as $12: 20$ & 26,2 & 31,5 & 30,8 & 1010,6 & 65,7 & 0,2 & 32,6 & 31,7 \\
\hline $12: 20$ as $12: 50$ & 26,5 & 32,0 & 31,2 & 1010,4 & 65,6 & 0,2 & 33,5 & 32,3 \\
\hline $12: 50$ as $13: 20$ & 26,7 & 32,5 & 31,5 & 1010,0 & 63,6 & 0,1 & 33,9 & 32,7 \\
\hline $13: 20$ as $13: 50$ & 26,2 & 32,2 & 31,6 & 1009,5 & 61,4 & 0,5 & 33,7 & 32,7 \\
\hline $13: 50$ as $14: 20$ & 26,4 & 32,8 & 32,0 & 1009,6 & 59,8 & 0,2 & 34,3 & 33,1 \\
\hline $14: 20$ as $14: 50$ & 26,1 & 33,4 & 32,3 & 1009,7 & 55,2 & 0,1 & 34,8 & 33,6 \\
\hline Desvio Padrão & 0,29 & 0,65 & 0,52 & 0,45 & 3,86 & 0,19 & 1,02 & 1,63 \\
\hline Média & 26,4 & 32,4 & 31,6 & 1010,0 & 62,1 & 0,2 & 33,7 & 32,6 \\
\hline \multicolumn{9}{|c|}{ Dados coletados Termômetro de fluxo de laser } \\
\hline Horário/Quarto & $\begin{array}{l}\text { Temp. Externa do ar } \\
\qquad\left({ }^{\circ} \mathrm{C}\right)\end{array}$ & $\begin{array}{l}\text { Temp. Paredes } \\
\text { externas }\left({ }^{\circ} \mathrm{C}\right)\end{array}$ & $\begin{array}{c}\text { Temp.Paredes } \\
\text { voltada para a rua } \\
\left({ }^{\circ} \mathrm{C}\right)\end{array}$ & \multicolumn{3}{|c|}{ Temp. Média das paredes $\left({ }^{\circ} \mathrm{C}\right)$} & Temp. Teto $\left({ }^{\circ} \mathrm{C}\right)$ & \\
\hline $11: 50$ & 30,8 & 34,4 & 30,4 & \multicolumn{3}{|c|}{30,8} & 31,8 & \\
\hline $14: 50$ & 36,2 & 38,8 & 33,2 & \multicolumn{3}{|c|}{30,7} & 34,1 & \\
\hline
\end{tabular}

Tabela 48: Resultados coletados in loco no quarto do Apartamento B no mês de Fevereiro de 2014.

\begin{tabular}{|c|c|c|c|c|c|c|c|c|}
\hline \multicolumn{2}{|l|}{ Apartamento B } & \multicolumn{4}{|c|}{ Dados coletados CONFORTÍMETRO Março 2014 - QUARTO } & \multicolumn{3}{|c|}{$\begin{array}{c}\text { Parcialmente } \\
\text { nublado }\end{array}$} \\
\hline Intervalo & $\begin{array}{l}\text { Temperatura de } \\
\text { bulbo úmido }\left({ }^{\circ} \mathrm{C}\right)\end{array}$ & $\begin{array}{l}\text { Temperatura de } \\
\text { globo }\left({ }^{\circ} \mathrm{C}\right)\end{array}$ & $\begin{array}{c}\text { Temperatura do ar } \\
\left({ }^{\circ} \mathrm{C}\right)\end{array}$ & $\begin{array}{c}\text { Pressão } \\
\text { Atmosférica (atm) }\end{array}$ & $\begin{array}{l}\text { Umidade relativa } \\
\text { do ar (\%) }\end{array}$ & $\begin{array}{l}\text { Velocidade do ar } \\
\qquad(\mathrm{m} / \mathrm{s})\end{array}$ & $\begin{array}{l}\text { Temperatura } \\
\text { radiante }\left({ }^{\circ} \mathrm{C}\right)\end{array}$ & $\begin{array}{l}\text { Temperatura } \\
\text { Operativa }\left({ }^{\circ} \mathrm{C}\right)\end{array}$ \\
\hline $11: 50$ as $12: 20$ & 23,5 & 26,5 & 26,5 & 1014,6 & 72,8 & 0,0 & 26,5 & 26,5 \\
\hline $12: 20$ as $12: 50$ & 23,8 & 26,8 & 26,8 & 1014,2 & 72,7 & 0,0 & 26,8 & 26,8 \\
\hline $12: 50$ as $13: 20$ & 23,9 & 27,2 & 27,2 & 1013,9 & 71,6 & 0,0 & 27,2 & 27,2 \\
\hline $13: 20$ as $13: 50$ & 24,1 & 27,6 & 27,4 & 1013,6 & 70,8 & 0,1 & 27,7 & 27,5 \\
\hline $13: 50$ as $14: 20$ & 24,3 & 27,9 & 27,7 & 1013,3 & 70,9 & 0,1 & 28,2 & 27,9 \\
\hline $14: 20$ as $14: 50$ & 24,4 & 28,1 & 27,9 & 1013,1 & 70,7 & 0,1 & 28,3 & 28,1 \\
\hline Desvio Padrão & 0,35 & 0,62 & 0,52 & 0,58 & 1,10 & 0,06 & 0,73 & 1,63 \\
\hline Média & 23,9 & 27,2 & 27,1 & 1013,9 & 71,8 & 0,0 & 27,3 & 27,2 \\
\hline \multicolumn{9}{|c|}{ Dados coletados Termômetro de fluxo de laser } \\
\hline Horário/Quarto & $\begin{array}{l}\text { Temp. Externa do ar } \\
\left({ }^{\circ} \mathrm{C}\right)\end{array}$ & $\begin{array}{l}\text { Temp. Paredes } \\
\text { externas }\left({ }^{\circ} \mathrm{C}\right)\end{array}$ & $\begin{array}{c}\text { Temp.Paredes } \\
\text { voltada para a rua } \\
\left({ }^{\circ} \mathrm{C}\right)\end{array}$ & \multicolumn{3}{|c|}{ Temp. Média das paredes $\left({ }^{\circ} \mathrm{C}\right)$} & Temp. Teto $\left({ }^{\circ} \mathrm{C}\right)$ & \\
\hline $11: 50$ & 27,5 & 28,5 & 25,5 & \multicolumn{3}{|c|}{26,3} & 26,3 & \\
\hline $14: 50$ & 30,3 & 36,4 & 30,1 & \multicolumn{3}{|c|}{27,7} & 29,3 & \\
\hline
\end{tabular}

Tabela 49: Resultados coletados in loco no quarto do Apartamento B no mês de Março de 2014. 


\begin{tabular}{|c|c|c|c|c|c|c|c|c|}
\hline \multicolumn{2}{|l|}{ Apartamento B } & \multicolumn{4}{|c|}{ Dados coletados CONFORTÍMETRO Abril 2014 - QUARTO } & \multicolumn{3}{|c|}{$\begin{array}{l}\text { Parcialmente } \\
\text { aberto }\end{array}$} \\
\hline Intervalo & $\begin{array}{l}\text { Temperatura de } \\
\text { bulbo úmido }\left({ }^{\circ} \mathrm{C}\right)\end{array}$ & $\begin{array}{c}\text { Temperatura de } \\
\text { globo }\left({ }^{\circ} \mathrm{C}\right)\end{array}$ & $\begin{array}{c}\text { Temperatura do ar } \\
\left({ }^{\circ} \mathrm{C}\right)\end{array}$ & $\begin{array}{c}\text { Pressão } \\
\text { Atmosférica (atm) }\end{array}$ & $\begin{array}{c}\text { Umidade relativa } \\
\text { do } \operatorname{ar}(\%)\end{array}$ & $\begin{array}{l}\text { Velocidade do ar } \\
(\mathrm{m} / \mathrm{s})\end{array}$ & $\begin{array}{l}\text { Temperatura } \\
\text { radiante }\left({ }^{\circ} \mathrm{C}\right)\end{array}$ & $\begin{array}{l}\text { Temperatura } \\
\text { Operativa }\left({ }^{\circ} \mathrm{C}\right)\end{array}$ \\
\hline $11: 50$ as $12: 20$ & 23,7 & 27,2 & 27,0 & 1010,8 & 68,4 & 0,0 & 27,2 & 27,1 \\
\hline $12: 20$ as $12: 50$ & 23,6 & 27,1 & 26,9 & 1010,5 & 68,6 & 0,0 & 27,2 & 27,0 \\
\hline $12: 50$ as $13: 20$ & 23,9 & 26,9 & 26,7 & 1010,3 & 71,8 & 0,0 & 27,0 & 26,9 \\
\hline $13: 20$ as $13: 50$ & 24,1 & 27,2 & 27,0 & 1010,0 & 71,5 & 0,0 & 27,3 & 27,1 \\
\hline $13: 50$ as $14: 20$ & 24,3 & 27,4 & 27,3 & 1009,9 & 71,8 & 0,0 & 27,5 & 27,4 \\
\hline $14: 20$ as $14: 50$ & 24,4 & 27,5 & 27,4 & 1009,8 & 71,4 & 0,0 & 27,5 & 27,4 \\
\hline Desvio Padrão & 0,31 & 0,21 & 0,23 & 0,34 & 1,61 & 0,04 & 0,18 & 1,63 \\
\hline Média & 24,0 & 27,2 & 27,0 & 1010,2 & 70,7 & 0,0 & 27,3 & 27,2 \\
\hline \multicolumn{9}{|c|}{ Dados coletados Termômetro de fluxo de laser } \\
\hline Horário/Quarto & $\begin{array}{l}\text { Temp. Externa do ar } \\
\left({ }^{\circ} \mathrm{C}\right)\end{array}$ & $\begin{array}{l}\text { Temp. Paredes } \\
\text { externas }\left({ }^{\circ} \mathrm{C}\right)\end{array}$ & $\begin{array}{c}\text { Temp. Paredes } \\
\text { voltada para a rua } \\
\left({ }^{\circ} \mathrm{C}\right)\end{array}$ & \multicolumn{3}{|c|}{ Temp. Média das paredes $\left({ }^{\circ} \mathrm{C}\right)$} & Temp. Teto $\left({ }^{\circ} \mathrm{C}\right)$ & \\
\hline $11: 50$ & 28 & 28,8 & 26,4 & \multicolumn{3}{|c|}{27,1} & 27,6 & \\
\hline $14: 50$ & 29 & 28,6 & 27,7 & \multicolumn{3}{|c|}{27,8} & 29,1 & \\
\hline
\end{tabular}

Tabela 50: Resultados coletados in loco no quarto do Apartamento B no mês de Abril de 2014.

\begin{tabular}{|c|c|c|c|c|c|c|c|c|}
\hline \multicolumn{2}{|l|}{ Apartamento B } & \multicolumn{4}{|c|}{ Dados coletados CONFORTÍMETRO M aio 2014 - QUARTO } & \multicolumn{3}{|c|}{ Céu claro } \\
\hline Intervalo & $\begin{array}{l}\text { Temperatura de } \\
\text { bulbo úmido }\left({ }^{\circ} \mathrm{C}\right)\end{array}$ & $\begin{array}{c}\text { Temperatura de } \\
\text { globo }\left({ }^{\circ} \mathrm{C}\right)\end{array}$ & $\begin{array}{l}\text { Temperatura do ar } \\
\left({ }^{\circ} \mathrm{C}\right)\end{array}$ & $\begin{array}{c}\text { Pressão } \\
\text { Atmosférica (atm) }\end{array}$ & $\begin{array}{l}\text { Umidade relativa } \\
\text { do ar (\%) }\end{array}$ & $\begin{array}{l}\text { Velocidade do ar } \\
\qquad(\mathrm{m} / \mathrm{s})\end{array}$ & $\begin{array}{l}\text { Temperatura } \\
\text { radiante }\left({ }^{\circ} \mathrm{C}\right)\end{array}$ & $\begin{array}{l}\text { Temperatura } \\
\text { Operativa }\left({ }^{\circ} \mathrm{C}\right)\end{array}$ \\
\hline $11: 50$ as $12: 20$ & 23,9 & 27,9 & 27,6 & 1011,6 & 70,0 & 0,1 & 28,2 & 27,9 \\
\hline $12: 20$ as $12: 50$ & 23,9 & 27,9 & 27,6 & 1011,1 & 70,1 & 0,1 & 28,2 & 27,9 \\
\hline $12: 50$ as $13: 20$ & 23,8 & 28,1 & 27,8 & 1010,5 & 68,2 & 0,1 & 28,4 & 28,1 \\
\hline $13: 20$ as $13: 50$ & 24,1 & 28,3 & 28,1 & 1010,0 & 67,3 & 0,1 & 28,5 & 28,3 \\
\hline $13: 50$ as $14: 20$ & 24,6 & 28,7 & 28,5 & 1009,7 & 67,5 & 0,0 & 28,8 & 28,7 \\
\hline $14: 20$ as $14: 50$ & 24,8 & 28,9 & 28,8 & 1009,4 & 67,0 & 0,0 & 29,0 & 28,9 \\
\hline Desvio Padrão & 0,43 & 0,42 & 0,46 & 0,76 & 1,34 & 0,07 & 0,33 & 1,63 \\
\hline Média & 24,2 & 28,3 & 28,1 & 1010,4 & 68,3 & 0,1 & 28,5 & 28,3 \\
\hline \multicolumn{9}{|c|}{ Dados coletados Termômetro de fluxo de laser } \\
\hline Horário/Quarto & $\begin{array}{l}\text { Temp. Externa do ar } \\
\left({ }^{\circ} \mathrm{C}\right)\end{array}$ & $\begin{array}{l}\text { Temp. Paredes } \\
\text { externas }\left({ }^{\circ} \mathrm{C}\right)\end{array}$ & $\begin{array}{c}\text { Temp.Paredes } \\
\text { voltada para a rua } \\
\left({ }^{\circ} \mathrm{C}\right)\end{array}$ & \multicolumn{3}{|c|}{ Temp. Média das paredes $\left({ }^{\circ} \mathrm{C}\right)$} & Temp. Teto $\left({ }^{\circ} \mathrm{C}\right)$ & \\
\hline 11:50 & 28,3 & 30,7 & 27,3 & \multicolumn{3}{|c|}{27,7} & 29 & \\
\hline $14: 50$ & 28,5 & 31,7 & 30,9 & \multicolumn{3}{|c|}{29,1} & 30,6 & \\
\hline
\end{tabular}

Tabela 51: Resultados coletados in loco no quarto do Apartamento B no mês de Maio de 2014.

\begin{tabular}{|c|c|c|c|c|c|c|c|c|}
\hline \multicolumn{2}{|l|}{ Apartamento B } & \multicolumn{4}{|c|}{ Dados coletados CONFORTÍMETRO Junho 2014 - QUARTO } & \multicolumn{3}{|c|}{ Céu claro } \\
\hline Intervalo & $\begin{array}{l}\text { Temperatura de } \\
\text { bulbo úmido }\left({ }^{\circ} \mathrm{C}\right)\end{array}$ & $\begin{array}{l}\text { Temperatura de } \\
\text { globo }\left({ }^{\circ} \mathrm{C}\right)\end{array}$ & $\begin{array}{l}\text { Temperatura do ar } \\
\left({ }^{\circ} \mathrm{C}\right)\end{array}$ & $\begin{array}{c}\text { Pressão } \\
\text { Atmosférica (atm) }\end{array}$ & $\begin{array}{c}\text { Umidade relativa } \\
\text { do ar (\%) }\end{array}$ & $\begin{array}{l}\text { Velocidade do ar } \\
\qquad(\mathrm{m} / \mathrm{s})\end{array}$ & $\begin{array}{l}\text { Temperatura } \\
\text { radiante }\left({ }^{\circ} \mathrm{C}\right)\end{array}$ & $\begin{array}{l}\text { Temperatura } \\
\text { Operativa }\left({ }^{\circ} \mathrm{C}\right)\end{array}$ \\
\hline $11: 50$ as $12: 20$ & 23,9 & 27,9 & 27,6 & 1011,6 & 70,0 & 0,1 & 28,2 & 27,9 \\
\hline $12: 20$ as $12: 50$ & 23,9 & 27,9 & 27,6 & 1011,1 & 70,1 & 0,1 & 28,2 & 27,9 \\
\hline $12: 50$ as $13: 20$ & 23,8 & 28,1 & 27,8 & 1010,5 & 68,2 & 0,1 & 28,4 & 28,1 \\
\hline $13: 20$ as $13: 50$ & 24,1 & 28,3 & 28,1 & 1010,0 & 67,3 & 0,1 & 28,5 & 28,3 \\
\hline $13: 50$ as $14: 20$ & 24,6 & 28,7 & 28,5 & 1009,7 & 67,5 & 0,0 & 28,8 & 28,7 \\
\hline $14: 20$ as $14: 50$ & 24,8 & 28,9 & 28,8 & 1009,4 & 67,0 & 0,0 & 29,0 & 28,9 \\
\hline Desvio Padrão & 0,43 & 0,42 & 0,46 & 0,76 & 1,34 & 0,07 & 0,33 & 1,63 \\
\hline Média & 24,2 & 28,3 & 28,1 & 1010,4 & 68,3 & 0,1 & 28,5 & 28,3 \\
\hline \multicolumn{9}{|c|}{ Dados coletados Termômetro de fluxo de laser } \\
\hline Horário/Quarto & $\begin{array}{l}\text { Temp. Externa do ar } \\
\left({ }^{\circ} \mathrm{C}\right)\end{array}$ & $\begin{array}{l}\text { Temp. Paredes } \\
\text { externas }\left({ }^{\circ} \mathrm{C}\right)\end{array}$ & $\begin{array}{c}\text { Temp. Paredes } \\
\text { voltada para a rua } \\
\left({ }^{\circ} \mathrm{C}\right)\end{array}$ & \multicolumn{3}{|c|}{ Temp. Média das paredes $\left({ }^{\circ} \mathrm{C}\right)$} & Temp. Teto $\left({ }^{\circ} \mathrm{C}\right)$ & \\
\hline $11: 50$ & 28,3 & 30,7 & 27,3 & \multicolumn{3}{|c|}{27,7} & 29 & \\
\hline $14: 50$ & 28,5 & 31,7 & 30,9 & \multicolumn{3}{|c|}{29,1} & 30,6 & \\
\hline
\end{tabular}

Tabela 52: Resultados coletados in loco no quarto do Apartamento B no mês de Junho de 2014.

\begin{tabular}{|c|c|c|c|c|c|c|c|c|}
\hline \multicolumn{2}{|l|}{ Apartamento B } & \multicolumn{4}{|c|}{ Dados coletados CONFORTíM ETRO Julho 2013 - SALA } & \multicolumn{3}{|c|}{ Chuva } \\
\hline Intervalo & $\begin{array}{l}\text { Temperatura de } \\
\text { bulbo úmido }\left({ }^{\circ} \mathrm{C}\right)\end{array}$ & $\begin{array}{c}\text { Temperatura de } \\
\text { globo }\left({ }^{\circ} \mathrm{C}\right)\end{array}$ & $\begin{array}{c}\text { Temperatura do ar } \\
\left({ }^{\circ} \mathrm{C}\right)\end{array}$ & $\begin{array}{c}\text { Pressão } \\
\text { Atmosférica }\end{array}$ & $\begin{array}{l}\text { Umidade relativa } \\
\text { do ar (\%) }\end{array}$ & $\begin{array}{l}\text { Velocidade do ar } \\
\qquad(\mathrm{m} / \mathrm{s})\end{array}$ & $\begin{array}{l}\text { Temperatura } \\
\text { radiante }\left({ }^{\circ} \mathrm{C}\right)\end{array}$ & $\begin{array}{l}\text { Temperatura } \\
\text { Operativa }\left({ }^{\circ} \mathrm{C}\right)\end{array}$ \\
\hline $15: 00$ as $15: 30$ & 20,9 & 23,3 & 23,1 & 1020,8 & 75,7 & 0,0 & 23,4 & 23,3 \\
\hline $15: 30$ as $16: 00$ & 20,8 & 23,1 & 23,0 & 1020,9 & 75,8 & 0,0 & 23,2 & 23,1 \\
\hline $15: 30$ as $16: 00$ & 20,6 & 23,1 & 23,0 & 1021,0 & 74,7 & 0,0 & 23,2 & 23,1 \\
\hline $16: 30$ as $17: 00$ & 20,6 & 23,1 & 23,1 & 1021,3 & 74,4 & 0,0 & 23,1 & 23,1 \\
\hline Desvio Padrão & 0,15 & 0,12 & 0,10 & 0,20 & 0,81 & 0,02 & 0,15 & 0,1 \\
\hline Média & 20,7 & 23,2 & 23,0 & 1021,0 & 75,1 & 0,0 & 23,2 & 23,1 \\
\hline \multicolumn{9}{|c|}{ Dados coletados Termômetro de fluxo de laser } \\
\hline Horário/Quarto & $\begin{array}{l}\text { Temp. Externa do ar } \\
\left({ }^{\circ} \mathrm{C}\right)\end{array}$ & $\begin{array}{l}\text { Temp. Paredes } \\
\text { externas }\left({ }^{\circ} \mathrm{C}\right)\end{array}$ & $\begin{array}{c}\text { Temp. Paredes } \\
\text { voltada para a rua } \\
\left({ }^{\circ} \mathrm{C}\right)\end{array}$ & \multicolumn{3}{|c|}{ Temp. Média das paredes $\left({ }^{\circ} \mathrm{C}\right)$} & Temp. Teto $\left({ }^{\circ} \mathrm{C}\right)$ & \\
\hline 15:00 & 20,7 & 23 & 22,9 & \multicolumn{3}{|c|}{22,5} & 23 & \\
\hline $17: 00$ & 21 & 23,2 & 22,8 & \multicolumn{3}{|c|}{22,7} & 23,8 & \\
\hline
\end{tabular}

Tabela 53: Resultados coletados in loco na sala do Apartamento B no mês de Julho de 2013. 


\begin{tabular}{|c|c|c|c|c|c|c|c|c|}
\hline \multicolumn{2}{|l|}{ Apartamento B } & \multicolumn{4}{|c|}{ Dados coletados CONFORTÍMETRO Agosto 2013 - SALA } & \multicolumn{3}{|c|}{ céu claro } \\
\hline Intervalo & $\begin{array}{l}\text { Temperatura de } \\
\text { bulbo úmido }\left({ }^{\circ} \mathrm{C}\right)\end{array}$ & $\begin{array}{c}\text { Temperatura de } \\
\text { globo }\left({ }^{\circ} \mathrm{C}\right)\end{array}$ & $\begin{array}{c}\text { Temperatura do ar } \\
\left({ }^{\circ} \mathrm{C}\right)\end{array}$ & $\begin{array}{c}\text { Pressão } \\
\text { Atmosférica } \\
\text { (atm) }\end{array}$ & $\begin{array}{c}\text { Umidade relativa } \\
\text { do ar (\%) }\end{array}$ & $\begin{array}{l}\text { Velocidade do ar } \\
\qquad(\mathrm{m} / \mathrm{s})\end{array}$ & $\begin{array}{l}\text { Temperatura } \\
\text { radiante }\left({ }^{\circ} \mathrm{C}\right)\end{array}$ & $\begin{array}{l}\text { Temperatura } \\
\text { Operativa }\left({ }^{\circ} \mathrm{C}\right)\end{array}$ \\
\hline $15: 00$ as $15: 30$ & 20,8 & 25,4 & 24,5 & 1013,8 & 67,7 & 0,2 & 26,9 & 25,7 \\
\hline $15: 30$ as $16: 00$ & 20,8 & 25,6 & 24,4 & 1013,7 & 68,0 & 0,2 & 27,7 & 26,0 \\
\hline $15: 30$ as $16: 00$ & 21,0 & 25,9 & 24,7 & 1013,5 & 67,1 & 0,3 & 28,5 & 26,6 \\
\hline $16: 30$ as $17: 00$ & 21,2 & 25,6 & 24,7 & 1013,3 & 68,0 & 0,3 & 27,5 & 26,1 \\
\hline Desvio Padrão & 0,18 & 0,30 & 0,18 & 0,19 & 0,57 & 0,23 & 1,36 & 0,8 \\
\hline Média & 21,0 & 25,6 & 24,6 & 1013,6 & 67,7 & 0,2 & 27,7 & 26,1 \\
\hline \multicolumn{9}{|c|}{ Dados coletados Termômetro de fluxo de laser } \\
\hline Horário/Quarto & $\begin{array}{c}\text { Temp. Externa do ar } \\
\left({ }^{\circ} \mathrm{C}\right)\end{array}$ & $\begin{array}{c}\text { Temp. Paredes } \\
\text { externas }\left({ }^{\circ} \mathrm{C}\right)\end{array}$ & $\begin{array}{c}\text { Temp.Paredes } \\
\text { voltada para a rua } \\
\left({ }^{\circ} \mathrm{C}\right)\end{array}$ & \multicolumn{3}{|c|}{ Temp. Média das paredes $\left({ }^{\circ} \mathrm{C}\right)$} & Temp. Teto $\left({ }^{\circ} \mathrm{C}\right)$ & \\
\hline $15: 00$ & 24,6 & 26,3 & 25,6 & \multicolumn{3}{|c|}{25,3} & 25,1 & \\
\hline $17: 00$ & 24,7 & 25,8 & 26,3 & \multicolumn{3}{|c|}{26,1} & 26,3 & \\
\hline
\end{tabular}

Tabela 54: Resultados coletados in loco na sala do Apartamento B no mês de Agosto de 2013.

\begin{tabular}{|c|c|c|c|c|c|c|c|c|}
\hline \multicolumn{2}{|l|}{ Apartamento B } & \multicolumn{4}{|c|}{ Dados coletados CONFORTÍM ETRO Setembro 2013 - SALA } & \multicolumn{3}{|c|}{ Nublado } \\
\hline Intervalo & $\begin{array}{l}\text { Temperatura de } \\
\text { bulbo úmido }\left({ }^{\circ} \mathrm{C}\right)\end{array}$ & $\begin{array}{c}\text { Temperatura de } \\
\text { globo }\left({ }^{\circ} \mathrm{C}\right)\end{array}$ & $\begin{array}{c}\text { Temperatura do ar } \\
\left({ }^{\circ} \mathrm{C}\right)\end{array}$ & $\begin{array}{l}\text { Pressão } \\
\text { Atmosférica } \\
\text { (atm) }\end{array}$ & $\begin{array}{l}\text { Umidade relativa } \\
\text { do ar (\%) }\end{array}$ & $\begin{array}{l}\text { Velocidade do ar } \\
\qquad(\mathrm{m} / \mathrm{s})\end{array}$ & $\begin{array}{l}\text { Temperatura } \\
\text { radiante }\left({ }^{\circ} \mathrm{C}\right)\end{array}$ & $\begin{array}{l}\text { Temperatura } \\
\text { Operativa }\left({ }^{\circ} \mathrm{C}\right)\end{array}$ \\
\hline $15: 00$ as $15: 30$ & 21,3 & 26,4 & 26,2 & 1009,3 & 57,3 & 0,0 & 26,5 & 26,3 \\
\hline $15: 30$ as $16: 00$ & 21,3 & 26,3 & 26,0 & 1009,2 & 57,7 & 0,0 & 26,3 & 26,2 \\
\hline $15: 30$ as $16: 00$ & 21,0 & 26,1 & 25,8 & 1009,0 & 58,8 & 0,1 & 26,5 & 26,1 \\
\hline $16: 30$ as $17: 00$ & 21,2 & 25,9 & 25,7 & 1008,5 & 59,5 & 0,0 & 26,1 & 25,9 \\
\hline Desvio Padrão & 0,31 & 0,19 & 0,24 & 0,32 & 0,86 & 0,12 & 0,29 & 0,3 \\
\hline Média & 21,1 & 26,1 & 25,9 & 1009,0 & 58,4 & 0,0 & 26,3 & 26,1 \\
\hline \multicolumn{8}{|c|}{ Dados coletados Termômetro de fluxo de laser } & \\
\hline Horário/Quarto & $\begin{array}{l}\text { Temp. Externa do ar } \\
\left({ }^{\circ} \mathrm{C}\right)\end{array}$ & $\begin{array}{c}\text { Temp. Paredes } \\
\text { externas }\left({ }^{\circ} \mathrm{C}\right)\end{array}$ & $\begin{array}{c}\text { Temp. Paredes } \\
\text { voltada para a rua } \\
\left({ }^{\circ} \mathrm{C}\right)\end{array}$ & \multicolumn{3}{|c|}{ Temp. Média das paredes $\left({ }^{\circ} \mathrm{C}\right)$} & Temp. Teto $\left({ }^{\circ} \mathrm{C}\right)$ & \\
\hline 15:00 & 27 & 28,6 & 26,7 & \multicolumn{3}{|c|}{26} & 27 & \\
\hline $17: 00$ & 26,5 & 25,2 & 26,9 & \multicolumn{3}{|c|}{25,8} & 26,4 & \\
\hline
\end{tabular}

Tabela 55: Resultados coletados in loco na sala do Apartamento B no mês de Setembro de 2013.

\begin{tabular}{|c|c|c|c|c|c|c|c|c|}
\hline \multicolumn{2}{|l|}{ Apartamento B } & \multicolumn{4}{|c|}{ Dados coletados CONFORTÍMETRO Outubro 2013 - SALA } & \multicolumn{3}{|c|}{$\begin{array}{l}\text { Parcialmente } \\
\text { Nublado }\end{array}$} \\
\hline Intervalo & $\begin{array}{l}\text { Temperatura de } \\
\text { bulbo úmido }\left({ }^{\circ} \mathrm{C}\right)\end{array}$ & $\begin{array}{l}\text { Temperatura de } \\
\text { globo }\left({ }^{\circ} \mathrm{C}\right)\end{array}$ & $\begin{array}{c}\text { Temperatura do ar } \\
\left({ }^{\circ} \mathrm{C}\right)\end{array}$ & $\begin{array}{l}\text { Pressão } \\
\text { Atmosférica } \\
\text { (atm) }\end{array}$ & $\begin{array}{l}\text { Umidade relativa } \\
\text { do ar (\%) }\end{array}$ & $\begin{array}{l}\text { Velocidade do ar } \\
\qquad(\mathrm{m} / \mathrm{s})\end{array}$ & $\begin{array}{l}\text { Temperatura } \\
\text { radiante }\left({ }^{\circ} \mathrm{C}\right)\end{array}$ & $\begin{array}{l}\text { Temperatura } \\
\text { Operativa }\left({ }^{\circ} \mathrm{C}\right)\end{array}$ \\
\hline $16: 00$ as $16: 30$ & 21,0 & 27,5 & 26,6 & 1011,9 & 54,7 & 0,1 & 28,4 & 27,5 \\
\hline $16: 30$ as $17: 00$ & 20,6 & 26,7 & 25,9 & 1011,8 & 56,9 & 0,1 & 27,7 & 26,8 \\
\hline $17: 00$ as $17: 30$ & 20,4 & 25,9 & 25,4 & 1012,0 & 58,0 & 0,1 & 26,5 & 26,0 \\
\hline $17: 30$ as $18: 00$ & 20,8 & 25,8 & 25,3 & 1012,1 & 60,0 & 0,1 & 26,3 & 25,8 \\
\hline Desvio Padrão & 0,31 & 0,71 & 0,53 & 0,13 & 2,06 & 0,08 & 0,97 & 0,7 \\
\hline Média & 20,7 & 26,5 & 25,8 & 1011,9 & 57,4 & 0,1 & 27,2 & 26,5 \\
\hline \multicolumn{9}{|c|}{ Dados coletados Termômetro de fluxo de laser } \\
\hline Horário/Quarto & $\begin{array}{l}\text { Temp. Externa do ar } \\
\left({ }^{\circ} \mathrm{C}\right)\end{array}$ & $\begin{array}{l}\text { Temp. Paredes } \\
\text { externas }\left({ }^{\circ} \mathrm{C}\right)\end{array}$ & $\begin{array}{c}\text { Temp. Paredes } \\
\text { voltada para a rua } \\
\left({ }^{\circ} \mathrm{C}\right)\end{array}$ & \multicolumn{3}{|c|}{ Temp. Média das paredes $\left({ }^{\circ} \mathrm{C}\right)$} & Temp. Teto $\left({ }^{\circ} \mathrm{C}\right)$ & \\
\hline $16: 00$ & 29 & 36,8 & 26,3 & \multicolumn{3}{|c|}{25,2} & 27,2 & \\
\hline 18:00 & 24,7 & 28,6 & 27,1 & \multicolumn{3}{|c|}{25,6} & 28,1 & \\
\hline
\end{tabular}

Tabela 56: Resultados coletados in loco na sala do Apartamento B no mês de Outubro de 2013.

\begin{tabular}{|c|c|c|c|c|c|c|c|c|}
\hline \multicolumn{2}{|l|}{ Apartamento B } & \multicolumn{4}{|c|}{ Dados coletados CONFORTímETRO Novembro 2013 - SALA } & \multicolumn{3}{|c|}{ céu claro } \\
\hline Intervalo & $\begin{array}{l}\text { Temperatura de } \\
\text { bulbo úmido }\left({ }^{\circ} \mathrm{C}\right)\end{array}$ & $\begin{array}{l}\text { Temperatura de } \\
\text { globo }\left({ }^{\circ} \mathrm{C}\right)\end{array}$ & $\begin{array}{c}\text { Temperatura do ar } \\
\left({ }^{\circ} \mathrm{C}\right)\end{array}$ & $\begin{array}{c}\text { Pressão } \\
\text { Atmosférica } \\
\text { (atm) }\end{array}$ & $\begin{array}{l}\text { Umidade relativa } \\
\text { do ar (\%) }\end{array}$ & $\begin{array}{l}\text { Velocidade do ar } \\
\qquad(\mathrm{m} / \mathrm{s})\end{array}$ & $\begin{array}{l}\text { Temperatura } \\
\text { radiante }\left({ }^{\circ} \mathrm{C}\right)\end{array}$ & $\begin{array}{l}\text { Temperatura } \\
\text { Operativa }\left({ }^{\circ} \mathrm{C}\right)\end{array}$ \\
\hline $16: 00$ as $16: 30$ & 24,8 & 30,1 & 29,0 & 1009,5 & 66,4 & 0,1 & 31,2 & 30,1 \\
\hline $16: 30$ as $17: 00$ & 25,1 & 30,7 & 29,6 & 1009,0 & 65,3 & 0,1 & 32,0 & 30,8 \\
\hline $17: 00$ as $17: 30$ & 25,3 & 31,3 & 30,0 & 1008,7 & 64,0 & 0,1 & 32,5 & 31,3 \\
\hline $17: 30$ as $18: 00$ & 25,2 & 31,6 & 30,1 & 1008,5 & 62,8 & 0,1 & 33,5 & 31,8 \\
\hline Desvio Padrão & 0,26 & 0,64 & 0,51 & 0,39 & 1,64 & 0,09 & 1,08 & 0,8 \\
\hline Média & 25,1 & 30,9 & 29,6 & 1008,9 & 64,7 & 0,1 & 32,3 & 31,0 \\
\hline \multicolumn{9}{|c|}{ Dados coletados Termômetro de fluxo de laser } \\
\hline Horário/Quarto & $\begin{array}{c}\text { Temp. Externa do ar } \\
\left({ }^{\circ} \mathrm{C}\right)\end{array}$ & $\begin{array}{l}\text { Temp. Paredes } \\
\text { externas }\left({ }^{\circ} \mathrm{C}\right)\end{array}$ & $\begin{array}{c}\text { Temp.Paredes } \\
\text { voltada para a rua } \\
\left({ }^{\circ} \mathrm{C}\right)\end{array}$ & \multicolumn{3}{|c|}{ Temp. Média das paredes $\left({ }^{\circ} \mathrm{C}\right)$} & Temp. Teto $\left({ }^{\circ} \mathrm{C}\right)$ & \\
\hline $16: 00$ & 31,6 & 30,7 & 26,9 & \multicolumn{3}{|c|}{26,8} & 30 & \\
\hline $18: 00$ & 33 & 38,7 & 31 & \multicolumn{3}{|c|}{27,6} & 31,7 & \\
\hline
\end{tabular}

Tabela 57: Resultados coletados in loco na sala do Apartamento B no mês de Novembro de 2013. 


\begin{tabular}{|c|c|c|c|c|c|c|c|c|}
\hline \multicolumn{2}{|l|}{ Apartamento B } & \multicolumn{4}{|c|}{ Dados coletados CONFORTÍM ETRO Dezembro 2013 - SALA } & \multicolumn{3}{|c|}{ céu claro } \\
\hline Intervalo & $\begin{array}{l}\text { Temperatura de } \\
\text { bulbo úmido }\left({ }^{\circ} \mathrm{C}\right)\end{array}$ & $\begin{array}{c}\text { Temperatura de } \\
\text { globo }\left({ }^{\circ} \mathrm{C}\right)\end{array}$ & $\begin{array}{c}\text { Temperatura do ar } \\
\left({ }^{\circ} \mathrm{C}\right)\end{array}$ & $\begin{array}{l}\text { Pressão } \\
\text { Atmosférica } \\
\text { (atm) }\end{array}$ & $\begin{array}{l}\text { Umidade relativa } \\
\text { do ar (\%) }\end{array}$ & $\begin{array}{l}\text { Velocidade do ar } \\
\qquad(\mathrm{m} / \mathrm{s})\end{array}$ & $\begin{array}{l}\text { Temperatura } \\
\text { radiante }\left({ }^{\circ} \mathrm{C}\right)\end{array}$ & $\begin{array}{l}\text { Temperatura } \\
\text { Operativa }\left({ }^{\circ} \mathrm{C}\right)\end{array}$ \\
\hline $16: 00$ as $16: 30$ & 25,5 & 30,3 & 29,8 & 1009,3 & 63,9 & 0,0 & 30,5 & 30,2 \\
\hline $16: 30$ as $17: 00$ & 25,5 & 30,2 & 29,8 & 1008,9 & 64,9 & 0,0 & 30,5 & 30,1 \\
\hline $17: 00$ as $17: 30$ & 25,6 & 30,0 & 29,6 & 1008,6 & 67,2 & 0,0 & 30,3 & 29,9 \\
\hline $17: 30$ as $18: 00$ & 25,5 & 29,9 & 29,5 & 1008,6 & 66,5 & 0,0 & 30,2 & 29,8 \\
\hline Desvio Padrão & 0,16 & 0,22 & 0,17 & 0,31 & 1,48 & 0,04 & 0,29 & 0,2 \\
\hline Média & 25,5 & 30,2 & 29,7 & 1009,0 & 65,3 & 0,0 & 30,4 & 30,1 \\
\hline \multicolumn{8}{|c|}{ Dados coletados Termômetro de fluxo de laser } & \\
\hline Horário/Quarto & $\begin{array}{l}\text { Temp. Externa do ar } \\
\left({ }^{\circ} \mathrm{C}\right)\end{array}$ & $\begin{array}{c}\text { Temp. Paredes } \\
\text { externas }\left({ }^{\circ} \mathrm{C}\right)\end{array}$ & $\begin{array}{c}\text { Temp. Paredes } \\
\text { voltada para a rua } \\
\left({ }^{\circ} \mathrm{C}\right)\end{array}$ & \multicolumn{3}{|c|}{ Temp. Média das paredes $\left({ }^{\circ} \mathrm{C}\right)$} & Temp. Teto $\left({ }^{\circ} \mathrm{C}\right)$ & \\
\hline $16: 00$ & 32,5 & 36,5 & 29,6 & \multicolumn{3}{|c|}{28,9} & 32,3 & \\
\hline $18: 00$ & 30,3 & 36 & 31,3 & \multicolumn{3}{|c|}{30,9} & 34 & \\
\hline
\end{tabular}

Tabela 58: Resultados coletados in loco na sala do Apartamento B no mês de Dezembro de 2013.

\begin{tabular}{|c|c|c|c|c|c|c|c|c|}
\hline \multicolumn{7}{|c|}{ Dados coletados CONFORTÍM ETRO Janeiro 2014 - SALA } & \multicolumn{2}{|l|}{$\begin{array}{l}\text { Parcialmente } \\
\text { aberto }\end{array}$} \\
\hline Intervalo & $\begin{array}{l}\text { Temperatura de } \\
\text { bulbo úmido }\left({ }^{\circ} \mathrm{C}\right)\end{array}$ & $\begin{array}{c}\text { Temperatura de } \\
\text { globo }\left({ }^{\circ} \mathrm{C}\right)\end{array}$ & $\begin{array}{c}\text { Temperatura do ar } \\
\left({ }^{\circ} \mathrm{C}\right)\end{array}$ & $\begin{array}{l}\text { Pressão } \\
\text { Atmosférica } \\
\text { (atm) }\end{array}$ & $\begin{array}{c}\text { Umidade relativa } \\
\text { do ar (\%) }\end{array}$ & $\begin{array}{l}\text { Velocidade do ar } \\
\qquad(\mathrm{m} / \mathrm{s})\end{array}$ & $\begin{array}{l}\text { Temperatura } \\
\text { radiante }\left({ }^{\circ} \mathrm{C}\right)\end{array}$ & $\begin{array}{l}\text { Temperatura } \\
\text { Operativa }\left({ }^{\circ} \mathrm{C}\right)\end{array}$ \\
\hline $16: 00$ as $16: 30$ & 25,5 & 30,3 & 30,0 & 1009,3 & 63,9 & 0,1 & 30,4 & 30,2 \\
\hline $16: 30$ as $17: 00$ & 25,5 & 30,2 & 30,0 & 1008,9 & 64,9 & 0,1 & 30,4 & 30,2 \\
\hline $17: 00$ as $17: 30$ & 25,6 & 30,0 & 29,6 & 1008,6 & 67,2 & 0,1 & 30,1 & 29,9 \\
\hline $17: 30$ as $18: 00$ & 25,5 & 29,9 & 29,5 & 1008,6 & 66,5 & 0,1 & 30,1 & 29,8 \\
\hline Desvio Padrão & 0,32 & 4,34 & 0,81 & 0,30 & 3,22 & 0,09 & 8,89 & 4,9 \\
\hline Média & 27,5 & 30,1 & 29,8 & 1007,6 & 40,0 & 0,1 & 47,1 & 38,4 \\
\hline \multicolumn{9}{|c|}{ Dados coletados Termômetro de fluxo de laser } \\
\hline Horário/Quarto & $\begin{array}{l}\text { Temp. Externa do ar } \\
\left({ }^{\circ} \mathrm{C}\right)\end{array}$ & $\begin{array}{l}\text { Temp. Paredes } \\
\text { externas }\left({ }^{\circ} \mathrm{C}\right)\end{array}$ & $\begin{array}{c}\text { Temp. Paredes } \\
\text { voltada para a rua } \\
\left({ }^{\circ} \mathrm{C}\right)\end{array}$ & \multicolumn{3}{|c|}{ Temp. Média das paredes $\left({ }^{\circ} \mathrm{C}\right)$} & Temp. Teto $\left({ }^{\circ} \mathrm{C}\right)$ & \\
\hline $16: 00$ & 32,7 & 36,7 & 29,7 & \multicolumn{3}{|c|}{28,9} & 32,3 & \\
\hline $18: 00$ & 30,5 & 36,3 & 31,4 & \multicolumn{3}{|c|}{31,1} & 34,2 & \\
\hline
\end{tabular}

Tabela 59: Resultados coletados in loco na sala do Apartamento B no mês de Janeiro de 2014.

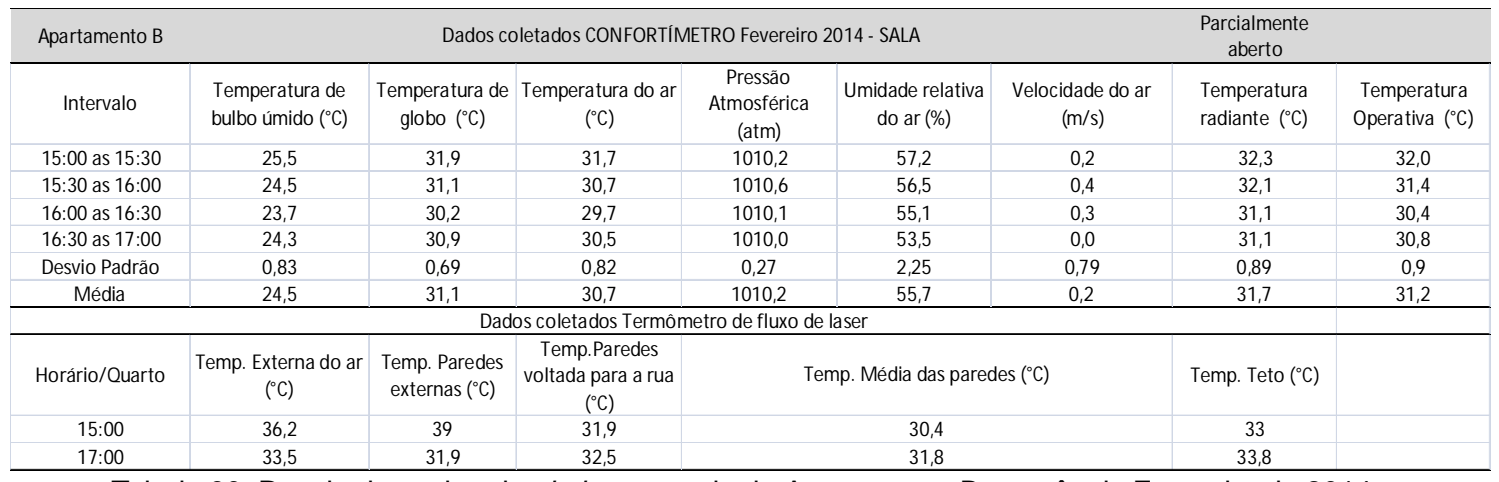

Tabela 60: Resultados coletados in loco na sala do Apartamento B no mês de Fevereiro de 2014.

\begin{tabular}{|c|c|c|c|c|c|c|c|c|}
\hline \multicolumn{2}{|l|}{ Apartamento B } & \multicolumn{4}{|c|}{ Dados coletados CONFORTÍM ETRO M arço 2014 - SALA } & \multicolumn{3}{|c|}{$\begin{array}{l}\text { Parcialmente } \\
\text { aberto }\end{array}$} \\
\hline Intervalo & $\begin{array}{l}\text { Temperatura de } \\
\text { bulbo úmido }\left({ }^{\circ} \mathrm{C}\right)\end{array}$ & $\begin{array}{l}\text { Temperatura de } \\
\text { globo }\left({ }^{\circ} \mathrm{C}\right)\end{array}$ & $\begin{array}{c}\text { Temperatura do ar } \\
\left({ }^{\circ} \mathrm{C}\right)\end{array}$ & $\begin{array}{l}\text { Pressão } \\
\text { Atmosférica } \\
\text { (atm) }\end{array}$ & $\begin{array}{c}\text { Umidade relativa } \\
\text { do ar (\%) }\end{array}$ & $\begin{array}{l}\text { Velocidade do ar } \\
\qquad(\mathrm{m} / \mathrm{s})\end{array}$ & $\begin{array}{l}\text { Temperatura } \\
\text { radiante }\left({ }^{\circ} \mathrm{C}\right)\end{array}$ & $\begin{array}{l}\text { Temperatura } \\
\text { Operativa }\left({ }^{\circ} \mathrm{C}\right)\end{array}$ \\
\hline $15: 00$ as $15: 30$ & 24,4 & 28,3 & 28,0 & 1012,9 & 70,8 & 0,1 & 28,7 & 28,3 \\
\hline $15: 30$ as $16: 00$ & 24,5 & 28,6 & 28,1 & 1012,6 & 69,8 & 0,0 & 28,8 & 28,5 \\
\hline $16: 00$ as $16: 30$ & 24,4 & 28,4 & 28,1 & 1012,6 & 70,1 & 0,0 & 28,7 & 28,4 \\
\hline $16: 30$ as $17: 00$ & 24,5 & 28,2 & 27,9 & 1012,8 & 71,3 & 0,0 & 28,4 & 28,1 \\
\hline Desvio Padrão & 0,09 & 0,20 & 0,12 & 0,16 & 0,80 & 0,05 & 0,28 & 0,2 \\
\hline Média & 24,4 & 28,4 & 28,0 & 1012,7 & 70,5 & 0,0 & 28,6 & 28,3 \\
\hline \multicolumn{9}{|c|}{ Dados coletados Termômetro de fluxo de laser } \\
\hline Horário/Quarto & $\begin{array}{l}\text { Temp. Externa do ar } \\
\left({ }^{\circ} \mathrm{C}\right)\end{array}$ & $\begin{array}{l}\text { Temp. Paredes } \\
\text { externas }\left({ }^{\circ} \mathrm{C}\right)\end{array}$ & $\begin{array}{c}\text { Temp. Paredes } \\
\text { voltada para a rua } \\
\left({ }^{\circ} \mathrm{C}\right)\end{array}$ & \multicolumn{3}{|c|}{ Temp. Média das paredes $\left({ }^{\circ} \mathrm{C}\right)$} & Temp. Teto $\left({ }^{\circ} \mathrm{C}\right)$ & \\
\hline 15:00 & 30,3 & 35,5 & 29,2 & \multicolumn{3}{|c|}{27,4} & 29,8 & \\
\hline $17: 00$ & 28 & 33,5 & 30,6 & \multicolumn{3}{|c|}{28,7} & 30,7 & \\
\hline
\end{tabular}

Tabela 61: Resultados coletados in loco na sala do Apartamento B no mês de Março de 2014. 


\begin{tabular}{|c|c|c|c|c|c|c|c|c|}
\hline Apartamento B & & \multicolumn{4}{|c|}{ Dados coletados CONFORTÍMETRO Abril 2014 - SALA } & \multicolumn{3}{|c|}{$\begin{array}{l}\text { Parcialmente } \\
\text { aberto }\end{array}$} \\
\hline Intervalo & $\begin{array}{l}\text { Temperatura de } \\
\text { bulbo úmido }\left({ }^{\circ} \mathrm{C}\right)\end{array}$ & $\begin{array}{l}\text { Temperatura de } \\
\text { globo }\left({ }^{\circ} \mathrm{C}\right)\end{array}$ & $\begin{array}{c}\text { Temperatura do ar } \\
\left({ }^{\circ} \mathrm{C}\right)\end{array}$ & $\begin{array}{l}\text { Pressão } \\
\text { Atmosférica } \\
\text { (atm) }\end{array}$ & $\begin{array}{l}\text { Umidade relativa } \\
\text { do ar }(\%)\end{array}$ & $\begin{array}{l}\text { Velocidade do ar } \\
\qquad(\mathrm{m} / \mathrm{s})\end{array}$ & $\begin{array}{l}\text { Temperatura } \\
\text { radiante }\left({ }^{\circ} \mathrm{C}\right)\end{array}$ & $\begin{array}{l}\text { Temperatura } \\
\text { Operativa }\left({ }^{\circ} \mathrm{C}\right)\end{array}$ \\
\hline $15: 00$ as $15: 30$ & 24,2 & 27,6 & 27,4 & 1009,9 & 71,0 & 0,0 & 27,7 & 27,6 \\
\hline $15: 30$ as $16: 00$ & 24,1 & 27,7 & 27,5 & 1009,5 & 68,3 & 0,0 & 27,8 & 27,6 \\
\hline $16: 00$ as $16: 30$ & 24,1 & 27,8 & 27,6 & 1009,3 & 67,4 & 0,0 & 27,9 & 27,7 \\
\hline $16: 30$ as $17: 00$ & 24,1 & 27,7 & 27,6 & 1009,3 & 67,9 & 0,0 & 27,8 & 27,7 \\
\hline Desvio Padrão & 0,12 & 0,10 & 0,11 & 0,26 & 1,56 & 0,04 & 0,10 & 0,1 \\
\hline Média & 24,1 & 27,7 & 27,5 & 1009,5 & 68,8 & 0,0 & 27,8 & 27,6 \\
\hline \multicolumn{9}{|c|}{ Dado s coletados Termômetro de fluxo de laser } \\
\hline Horário/Quarto & $\begin{array}{l}\text { Temp. Externa do ar } \\
\left({ }^{\circ} \mathrm{C}\right)\end{array}$ & $\begin{array}{c}\text { Temp. Paredes } \\
\text { externas }\left({ }^{\circ} \mathrm{C}\right)\end{array}$ & $\begin{array}{c}\text { Temp. Paredes } \\
\text { voltada para a rua } \\
\left({ }^{\circ} \mathrm{C}\right)\end{array}$ & \multicolumn{3}{|c|}{ Temp. Média das paredes $\left({ }^{\circ} \mathrm{C}\right)$} & Temp. Teto $\left({ }^{\circ} \mathrm{C}\right)$ & \\
\hline 15:00 & 29 & 28,2 & 27,3 & \multicolumn{3}{|c|}{27,6} & 28,8 & \\
\hline $17: 00$ & 29,6 & 27,8 & 27,9 & \multicolumn{3}{|c|}{27,8} & 29,4 & \\
\hline
\end{tabular}

Tabela 62: Resultados coletados in loco na sala do Apartamento B no mês de Abril de 2014.

\begin{tabular}{|c|c|c|c|c|c|c|c|c|}
\hline \multicolumn{2}{|l|}{ Apartamento B } & \multicolumn{4}{|c|}{ Dados coletados CONFORTíM ETRO M aio 2014 - SALA } & \multicolumn{3}{|c|}{ céu claro } \\
\hline Intervalo & $\begin{array}{l}\text { Temperatura de } \\
\text { bulbo úmido }\left({ }^{\circ} \mathrm{C}\right)\end{array}$ & $\begin{array}{c}\text { Temperatura de } \\
\text { globo }\left({ }^{\circ} \mathrm{C}\right)\end{array}$ & $\begin{array}{c}\text { Temperatura do ar } \\
\left({ }^{\circ} \mathrm{C}\right)\end{array}$ & $\begin{array}{l}\text { Pressão } \\
\text { Atmosférica } \\
\text { (atm) }\end{array}$ & $\begin{array}{c}\text { Umidade relativa } \\
\text { do ar (\%) }\end{array}$ & $\begin{array}{l}\text { Velocidade do ar } \\
\qquad(\mathrm{m} / \mathrm{s})\end{array}$ & $\begin{array}{l}\text { Temperatura } \\
\text { radiante }\left({ }^{\circ} \mathrm{C}\right)\end{array}$ & $\begin{array}{l}\text { Temperatura } \\
\text { Operativa }\left({ }^{\circ} \mathrm{C}\right)\end{array}$ \\
\hline $15: 00$ as $15: 30$ & 24,8 & 29,2 & 29,1 & 1009,2 & 65,2 & 0,0 & 29,3 & 29,2 \\
\hline $15: 30$ as $16: 00$ & 25,0 & 29,1 & 29,0 & 1009,1 & 66,4 & 0,0 & 29,1 & 29,0 \\
\hline $16: 00$ as $16: 30$ & 24,8 & 29,0 & 28,9 & 1008,8 & 67,2 & 0,2 & 29,0 & 29,0 \\
\hline $16: 30$ as $17: 00$ & 25,0 & 28,8 & 28,6 & 1008,8 & 68,4 & 0,0 & 28,8 & 28,7 \\
\hline Desvio Padrão & 0,14 & 0,16 & 0,18 & 0,18 & 1,23 & 0,10 & 0,17 & 0,2 \\
\hline Média & 24,9 & 29,0 & 28,9 & 1009,0 & 66,8 & 0,1 & 29,1 & 29,0 \\
\hline \multicolumn{9}{|c|}{ Dados coletados Termômetro de fluxo de laser } \\
\hline Horário/Quarto & $\begin{array}{l}\text { Temp. Externa do ar } \\
\left({ }^{\circ} \mathrm{C}\right)\end{array}$ & $\begin{array}{c}\text { Temp. Paredes } \\
\text { externas }\left({ }^{\circ} \mathrm{C}\right)\end{array}$ & $\begin{array}{c}\text { Temp. Paredes } \\
\text { voltada para a rua } \\
\left({ }^{\circ} \mathrm{C}\right)\end{array}$ & \multicolumn{3}{|c|}{ Temp. Média das paredes $\left({ }^{\circ} \mathrm{C}\right)$} & Temp. Teto $\left({ }^{\circ} \mathrm{C}\right)$ & \\
\hline 15:00 & 28,5 & 31,7 & 30,9 & \multicolumn{3}{|c|}{29,1} & 30,6 & \\
\hline $17: 00$ & 28,8 & 32,2 & 30,4 & \multicolumn{3}{|c|}{29,7} & 31,4 & \\
\hline
\end{tabular}

Tabela 63: Resultados coletados in loco na sala do Apartamento B no mês de Maio de 2014.

\begin{tabular}{|c|c|c|c|c|c|c|c|c|}
\hline \multirow{2}{*}{$\begin{array}{c}\text { Apartamento B } \\
\text { Intervalo }\end{array}$} & \multicolumn{5}{|c|}{ Dados coletados CONFORTím ETRO J unho 2014 - SALA } & \multicolumn{3}{|c|}{$\begin{array}{l}\text { Parcialmente } \\
\text { aberto }\end{array}$} \\
\hline & $\begin{array}{l}\text { Temperatura de } \\
\text { bulbo úmido }\left({ }^{\circ} \mathrm{C}\right)\end{array}$ & $\begin{array}{l}\text { Temperatura de } \\
\text { globo }\left({ }^{\circ} \mathrm{C}\right)\end{array}$ & $\begin{array}{c}\text { Temperatura do ar } \\
\left({ }^{\circ} \mathrm{C}\right)\end{array}$ & $\begin{array}{l}\text { Pressão } \\
\text { Atmosférica } \\
\text { (atm) }\end{array}$ & $\begin{array}{l}\text { Umidade relativa } \\
\text { do ar (\%) }\end{array}$ & $\begin{array}{l}\text { Velocidade do ar } \\
\qquad(\mathrm{m} / \mathrm{s})\end{array}$ & $\begin{array}{l}\text { Temperatura } \\
\text { radiante }\left({ }^{\circ} \mathrm{C}\right)\end{array}$ & $\begin{array}{l}\text { Temperatura } \\
\text { Operativa }\left({ }^{\circ} \mathrm{C}\right)\end{array}$ \\
\hline $15: 00$ as $15: 30$ & 22,3 & 27,2 & 26,7 & 1010,9 & 61,7 & 0,0 & 27,5 & 27,1 \\
\hline $15: 30$ as $16: 00$ & 22,6 & 26,6 & 26,2 & 1011,2 & 67,7 & 0,0 & 26,8 & 26,5 \\
\hline $16: 00$ as $16: 30$ & 22,6 & 26,3 & 25,9 & 1011,7 & 70,5 & 0,0 & 26,6 & 26,2 \\
\hline $16: 30$ as $17: 00$ & 22,7 & 26,2 & 25,8 & 1011,6 & 71,1 & 0,0 & 26,4 & 26,1 \\
\hline Desvio Padrão & 0,23 & 0,48 & 0,40 & 0,33 & 4,33 & 0,04 & 0,54 & 0,5 \\
\hline Média & 22,5 & 26,6 & 26,2 & 1011,3 & 67,4 & 0,0 & 26,9 & 26,5 \\
\hline \multicolumn{9}{|c|}{ Dados coletados Termômetro de fluxo de laser } \\
\hline Horário/Quarto & $\begin{array}{l}\text { Temp. Externa do ar } \\
\left({ }^{\circ} \mathrm{C}\right)\end{array}$ & $\begin{array}{c}\text { Temp. Paredes } \\
\text { externas }\left({ }^{\circ} \mathrm{C}\right)\end{array}$ & \begin{tabular}{|c|} 
Temp. Paredes \\
voltada para a rua \\
$\left({ }^{\circ} \mathrm{C}\right)$
\end{tabular} & \multicolumn{3}{|c|}{ Temp. Média das paredes $\left({ }^{\circ} \mathrm{C}\right)$} & Temp. Teto $\left({ }^{\circ} \mathrm{C}\right)$ & \\
\hline 15:00 & 28,5 & 34 & 26,8 & \multicolumn{3}{|c|}{26,5} & 28,6 & \\
\hline $17: 00$ & 29 & 27,2 & 27,6 & \multicolumn{3}{|c|}{26,8} & 28,1 & \\
\hline
\end{tabular}

Tabela 64: Resultados coletados in loco na sala do Apartamento B no mês de Junho de 2014.

\begin{tabular}{|c|c|c|c|c|c|c|c|c|}
\hline \multicolumn{2}{|l|}{ Apartamento C } & \multicolumn{4}{|c|}{ Dados coletados CONFORTÍM ETRO Julho 2013 - QUARTO } & \multicolumn{3}{|c|}{ céu claro } \\
\hline Intervalo & $\begin{array}{l}\text { Temperatura de } \\
\text { bulbo úmido }\left({ }^{\circ} \mathrm{C}\right)\end{array}$ & $\begin{array}{l}\text { Temperatura de } \\
\text { globo }\left({ }^{\circ} \mathrm{C}\right)\end{array}$ & Temperatura do ar $\left({ }^{\circ} \mathrm{C}\right)$ & $\begin{array}{c}\text { Pressão Atmosférica } \\
\text { (atm) }\end{array}$ & $\begin{array}{l}\text { Umidade relativa } \\
\text { do ar (\%) }\end{array}$ & $\begin{array}{l}\text { Velocidade do ar } \\
(\mathrm{m} / \mathrm{s})\end{array}$ & $\begin{array}{l}\text { Temperatura } \\
\text { radiante }\left({ }^{\circ} \mathrm{C}\right)\end{array}$ & $\begin{array}{l}\text { Temperatura } \\
\text { Operativa }\left({ }^{\circ} \mathrm{C}\right)\end{array}$ \\
\hline $11: 50$ as $12: 20$ & 20,2 & 23,2 & 23,0 & 1020,7 & 69,5 & 0,0 & 23,3 & 23,1 \\
\hline $12: 20$ as $12: 50$ & 19,8 & 23,1 & 22,9 & 1020,2 & 69,0 & 0,0 & 23,1 & 23,0 \\
\hline $12: 50$ as $13: 20$ & 19,7 & 23,1 & 23,0 & 1019,7 & 68,4 & 0,0 & 23,2 & 23,1 \\
\hline $13: 20$ as $13: 50$ & 19,8 & 23,2 & 23,0 & 1019,2 & 68,9 & 0,0 & 23,3 & 23,2 \\
\hline $13: 50$ as $14: 20$ & 19,9 & 23,3 & 23,1 & 1018,7 & 68,5 & 0,0 & 23,4 & 23,3 \\
\hline $14: 20$ as $14: 50$ & 19,9 & 23,2 & 23,0 & 1018,3 & 68,7 & 0,0 & 23,4 & 23,2 \\
\hline Desvio Padrão & 0,25 & 0,15 & 0,11 & 0,85 & 0,73 & 0,05 & 0,19 & 1,63 \\
\hline Média & 19,9 & 23,2 & 23,0 & 1019,5 & 68,8 & 0,0 & 23,3 & 23,1 \\
\hline \multicolumn{9}{|c|}{ Dados coletados Termômetro de fluxo de laser } \\
\hline Horário/Quarto & $\begin{array}{l}\text { Temp. Externa do ar } \\
\left({ }^{\circ} \mathrm{C}\right)\end{array}$ & $\begin{array}{l}\text { Temp. Paredes } \\
\text { externas }\left({ }^{\circ} \mathrm{C}\right)\end{array}$ & $\begin{array}{c}\text { Temp.Paredes voltada } \\
\text { para a rua }\left({ }^{\circ} \mathrm{C}\right)\end{array}$ & \multicolumn{3}{|c|}{ Temp. Média das paredes $\left({ }^{\circ} \mathrm{C}\right)$} & Temp. Teto $\left({ }^{\circ} \mathrm{C}\right)$ & \\
\hline 11:50 & 22 & 22,2 & 21 & 20,6 & 20,6 & 20,6 & 21,8 & \\
\hline $15: 00$ & 23,5 & 26 & 24 & 25 & 25 & 25 & 28,8 & \\
\hline
\end{tabular}

Tabela 65: Resultados coletados in loco no quarto do Apartamento C no mês de Julho de 2013. 


\begin{tabular}{|c|c|c|c|c|c|c|c|c|}
\hline \multicolumn{2}{|l|}{ Apartamento $\mathrm{C}$} & \multicolumn{4}{|c|}{ Dados coletados CONFORTÍM ETRO Agosto 2013 - QUARTO } & \multicolumn{3}{|c|}{ céu claro } \\
\hline Intervalo & $\begin{array}{l}\text { Temperatura de } \\
\text { bulbo úmido }\left({ }^{\circ} \mathrm{C}\right)\end{array}$ & $\begin{array}{c}\text { Temperatura de } \\
\text { globo }\left({ }^{\circ} \mathrm{C}\right)\end{array}$ & Temperatura do ar $\left({ }^{\circ} \mathrm{C}\right)$ & $\begin{array}{c}\text { Pressão Atmosférica } \\
\text { (atm) }\end{array}$ & $\begin{array}{c}\text { Umidade relativa } \\
\text { do ar (\%) }\end{array}$ & $\begin{array}{l}\text { Velocidade do ar } \\
(\mathrm{m} / \mathrm{s})\end{array}$ & $\begin{array}{l}\text { Temperatura } \\
\text { radiante }\left({ }^{\circ} \mathrm{C}\right)\end{array}$ & $\begin{array}{l}\text { Temperatura } \\
\text { Operativa }\left({ }^{\circ} \mathrm{C}\right)\end{array}$ \\
\hline $11: 50$ as $12: 20$ & 19,6 & 22,6 & 22,6 & 1011,4 & 68,4 & 0,0 & 22,5 & 22,6 \\
\hline $12: 20$ as $12: 50$ & 19,6 & 22,3 & 22,4 & 1011,0 & 70,0 & 0,0 & 22,2 & 22,3 \\
\hline $12: 50$ as $13: 20$ & 19,9 & 22,4 & 22,4 & 1010,4 & 71,9 & 0,0 & 22,3 & 22,4 \\
\hline $13: 20$ as $13: 50$ & 19,8 & 22,7 & 22,9 & 1009,8 & 67,5 & 0,0 & 22,7 & 22,8 \\
\hline $13: 50$ as $14: 20$ & 20,0 & 23,7 & 24,0 & 1009,2 & 62,1 & 0,0 & 23,6 & 23,8 \\
\hline $14: 20$ as $14: 50$ & 19,8 & 24,1 & 24,4 & 1008,5 & 57,8 & 0,0 & 24,0 & 24,2 \\
\hline Desvio Padrão & 0,18 & 0,72 & 0,83 & 1,02 & 5,12 & 0,01 & 0,69 & 1,63 \\
\hline Média & 19,8 & 22,9 & 23,1 & 1010,1 & 66,3 & 0,0 & 22,9 & 23,0 \\
\hline \multicolumn{8}{|c|}{ Dados coletados Termômetro de fluxo de laser } & \\
\hline Horário/Quarto & $\begin{array}{l}\text { Temp. Externa do ar } \\
\left({ }^{\circ} \mathrm{C}\right)\end{array}$ & $\begin{array}{l}\text { Temp. Paredes } \\
\text { externas }\left({ }^{\circ} \mathrm{C}\right)\end{array}$ & $\begin{array}{c}\text { Temp. Paredes voltada } \\
\text { para a rua }\left({ }^{\circ} \mathrm{C}\right)\end{array}$ & \multicolumn{3}{|c|}{ Temp. Média das paredes $\left({ }^{\circ} \mathrm{C}\right)$} & Temp. Teto $\left({ }^{\circ} \mathrm{C}\right)$ & \\
\hline 11:50 & 21,8 & & 20 & \multicolumn{3}{|c|}{20,6} & 21,8 & \\
\hline $15: 00$ & 29,4 & & 26,4 & \multicolumn{3}{|c|}{25,8} & 27,7 & \\
\hline
\end{tabular}

Tabela 66: Resultados coletados in loco no quarto do Apartamento C no mês de Agosto de 2013.

\begin{tabular}{|c|c|c|c|c|c|c|c|c|}
\hline \multicolumn{2}{|l|}{ Apartamento C } & \multicolumn{4}{|c|}{ Dados coletados CONFORTIM ETRO Setembro 2013 - QUARTO } & \multicolumn{3}{|c|}{ céu claro } \\
\hline Intervalo & $\begin{array}{l}\text { Temperatura de } \\
\text { bulbo úmido }\left({ }^{\circ} \mathrm{C}\right)\end{array}$ & $\begin{array}{c}\text { Temperatura de } \\
\text { globo }\left({ }^{\circ} \mathrm{C}\right)\end{array}$ & Temperatura do ar $\left({ }^{\circ} \mathrm{C}\right)$ & $\begin{array}{c}\text { Pressão Atmosférica } \\
\text { (atm) }\end{array}$ & $\begin{array}{c}\text { Umidade relativa } \\
\text { do ar (\%) }\end{array}$ & $\begin{array}{l}\text { Velocidade do ar } \\
(\mathrm{m} / \mathrm{s})\end{array}$ & $\begin{array}{l}\text { Temperatura } \\
\text { radiante }\left({ }^{\circ} \mathrm{C}\right)\end{array}$ & $\begin{array}{l}\text { Temperatura } \\
\text { Operativa }\left({ }^{\circ} \mathrm{C}\right)\end{array}$ \\
\hline $11: 50$ as $12: 20$ & 24,1 & 24,1 & 23,9 & 1018,7 & 65,8 & 0,0 & 24,1 & 24,0 \\
\hline $12: 20$ as $12: 50$ & 23,7 & 23,9 & 23,5 & 1018,5 & 66,0 & 0,0 & 24,1 & 23,8 \\
\hline $12: 50$ as $13: 20$ & 23,8 & 23,9 & 23,5 & 1018,4 & 66,0 & 0,0 & 24,0 & 23,8 \\
\hline $13: 20$ as $13: 50$ & 23,9 & 23,9 & 23,6 & 1018,4 & 65,3 & 0,0 & 24,0 & 23,8 \\
\hline $13: 50$ as $14: 20$ & 23,9 & 23,9 & 23,7 & 1018,4 & 64,5 & 0,0 & 24,1 & 23,9 \\
\hline $14: 20$ as $14: 50$ & 23,6 & 23,9 & 23,5 & 1018,5 & 65,2 & 0,0 & 24,0 & 23,8 \\
\hline Desvio Padrão & 0,27 & 0,11 & 0,20 & 0,17 & 0,52 & 0,02 & 0,12 & 1,63 \\
\hline Média & 23,9 & 24,0 & 23,7 & 1018,6 & 65,6 & 0,0 & 24,1 & 23,9 \\
\hline \multicolumn{8}{|c|}{ Dados coletados Termômetro de fluxo de laser } & \\
\hline Horário/Quarto & $\begin{array}{l}\text { Temp. Externa do ar } \\
\left({ }^{\circ} \mathrm{C}\right)\end{array}$ & $\begin{array}{l}\text { Temp. Paredes } \\
\text { externas }\left({ }^{\circ} \mathrm{C}\right)\end{array}$ & $\begin{array}{c}\text { Temp. Paredes voltada } \\
\text { para a rua }\left({ }^{\circ} \mathrm{C}\right)\end{array}$ & \multicolumn{3}{|c|}{ Temp. Média das paredes $\left({ }^{\circ} \mathrm{C}\right)$} & Temp. Teto $\left({ }^{\circ} \mathrm{C}\right)$ & \\
\hline $11: 50$ & 24,3 & 27,7 & 27,2 & \multicolumn{3}{|c|}{27,2} & 26,9 & \\
\hline $15: 00$ & 26,6 & 27,3 & 26,8 & \multicolumn{3}{|c|}{26,9} & 26,7 & \\
\hline
\end{tabular}

Tabela 67: Resultados coletados in loco no quarto do Apartamento C no mês de Setembro de 2013.

\begin{tabular}{|c|c|c|c|c|c|c|c|c|}
\hline \multicolumn{2}{|l|}{ Apartamento C } & \multicolumn{4}{|c|}{ Dados coletados CONFORTIMETRO Outubro 2013 - QUARTO } & \multicolumn{3}{|c|}{ céu claro } \\
\hline Intervalo & $\begin{array}{l}\text { Temperatura de } \\
\text { bulbo úmido }\left({ }^{\circ} \mathrm{C}\right)\end{array}$ & $\begin{array}{l}\text { Temperatura de } \\
\text { globo }\left({ }^{\circ} \mathrm{C}\right)\end{array}$ & Temperatura do ar $\left({ }^{\circ} \mathrm{C}\right)$ & $\begin{array}{c}\text { Pressão Atmosférica } \\
\text { (atm) }\end{array}$ & $\begin{array}{l}\text { Umidade relativa } \\
\text { do ar (\%) }\end{array}$ & $\begin{array}{l}\text { Velocidade do ar } \\
\qquad(\mathrm{m} / \mathrm{s})\end{array}$ & $\begin{array}{l}\text { Temperatura } \\
\text { radiante }\left({ }^{\circ} \mathrm{C}\right)\end{array}$ & $\begin{array}{l}\text { Temperatura } \\
\text { Operativa }\left({ }^{\circ} \mathrm{C}\right)\end{array}$ \\
\hline $12: 50$ as $13: 20$ & 24,0 & 27,2 & 26,4 & 1013,5 & 77,5 & 0,2 & 28,5 & 27,5 \\
\hline $13: 20$ as $13: 50$ & 24,0 & 27,6 & 26,8 & 1012,9 & 75,9 & 0,3 & 29,2 & 28,0 \\
\hline $13: 50$ as $14: 20$ & 24,0 & 27,7 & 27,0 & 1012,7 & 74,8 & 0,3 & 29,1 & 28,1 \\
\hline $14: 20$ as $14: 50$ & 23,9 & 27,2 & 26,6 & 1012,4 & 76,6 & 0,3 & 28,4 & 27,5 \\
\hline $14: 50$ as $15: 20$ & 23,8 & 26,8 & 26,1 & 1012,2 & 78,4 & 0,2 & 28,0 & 27,1 \\
\hline $15: 20$ as $15: 50$ & 23,9 & 26,8 & 26,1 & 1012,0 & 78,6 & 0,2 & 28,1 & 27,1 \\
\hline Desvio Padrão & 0,15 & 0,39 & 0,45 & 0,58 & 1,77 & 0,15 & 0,71 & 1,63 \\
\hline Média & 23,9 & 27,2 & 26,5 & 1012,9 & 77,1 & 0,2 & 28,5 & 27,5 \\
\hline \multicolumn{8}{|c|}{ Dados coletados Termômetro de fluxo de laser } & \\
\hline Horário/Quarto & $\begin{array}{l}\text { Temp. Externa do ar } \\
\left({ }^{\circ} \mathrm{C}\right)\end{array}$ & $\begin{array}{l}\text { Temp. Paredes } \\
\text { externas }\left({ }^{\circ} \mathrm{C}\right)\end{array}$ & $\begin{array}{c}\text { Temp. Paredes voltada } \\
\text { para a rua }\left({ }^{\circ} \mathrm{C}\right)\end{array}$ & \multicolumn{3}{|c|}{ Temp. Média das paredes $\left({ }^{\circ} \mathrm{C}\right)$} & Temp. Teto $\left({ }^{\circ} \mathrm{C}\right)$ & \\
\hline $12: 50$ & 26,8 & 25,7 & 27,1 & \multicolumn{3}{|c|}{28,2} & 27,7 & \\
\hline $16: 00$ & 28,5 & 27,5 & 26,4 & \multicolumn{3}{|c|}{26,9} & 27 & \\
\hline
\end{tabular}

Tabela 68: Resultados coletados in loco no quarto do Apartamento C no mês de Outubro de 2013.

\begin{tabular}{|c|c|c|c|c|c|c|c|c|}
\hline \multicolumn{2}{|l|}{ Apartamento C } & \multicolumn{4}{|c|}{ Dados coletados CONFORTIM ETRO Novembro 2013 - QUARTO } & \multicolumn{3}{|c|}{ céu claro } \\
\hline Intervalo & $\begin{array}{l}\text { Temperatura de } \\
\text { bulbo úmido }\left({ }^{\circ} \mathrm{C}\right)\end{array}$ & $\begin{array}{c}\text { Temperatura de } \\
\text { globo }\left({ }^{\circ} \mathrm{C}\right)\end{array}$ & Temperatura do ar $\left({ }^{\circ} \mathrm{C}\right)$ & $\begin{array}{c}\text { Pressão Atmosférica } \\
\text { (atm) }\end{array}$ & $\begin{array}{l}\text { Umidade relativa } \\
\text { do ar (\%) }\end{array}$ & $\begin{array}{l}\text { Velocidade do ar } \\
(\mathrm{m} / \mathrm{s})\end{array}$ & $\begin{array}{l}\text { Temperatura } \\
\text { radiante }\left({ }^{\circ} \mathrm{C}\right)\end{array}$ & $\begin{array}{l}\text { Temperatura } \\
\text { Operativa }\left({ }^{\circ} \mathrm{C}\right)\end{array}$ \\
\hline $12: 50$ as $13: 20$ & 23,2 & 26,8 & 26,7 & 1011,6 & 68,9 & 0,0 & 26,9 & 26,8 \\
\hline $13: 20$ as $13: 50$ & 23,2 & 26,8 & 26,6 & 1011,5 & 70,2 & 0,1 & 26,9 & 26,8 \\
\hline $13: 50$ as $14: 20$ & 23,2 & 26,9 & 26,7 & 1011,1 & 68,9 & 0,0 & 26,9 & 26,8 \\
\hline $14: 20$ as $14: 50$ & 23,1 & 27,0 & 26,8 & 1010,8 & 67,8 & 0,1 & 27,1 & 27,0 \\
\hline $14: 50$ as $15: 20$ & 22,6 & 26,9 & 26,8 & 1010,6 & 66,6 & 0,3 & 27,1 & 26,9 \\
\hline $15: 20$ as $15: 50$ & 22,5 & 26,9 & 26,8 & 1010,2 & 65,3 & 0,3 & 27,1 & 27,0 \\
\hline Desvio Padrão & 0,33 & 0,10 & 0,11 & 0,51 & 1,68 & 0,15 & 0,15 & 1,63 \\
\hline Média & 23,0 & 26,9 & 26,7 & 1011,0 & 68,0 & 0,1 & 27,0 & 26,9 \\
\hline \multicolumn{8}{|c|}{ Dados coletados Termômetro de fluxo de laser } & \\
\hline Horário/Quarto & $\begin{array}{l}\text { Temp. Externa do ar } \\
\left({ }^{\circ} \mathrm{C}\right)\end{array}$ & $\begin{array}{l}\text { Temp. Paredes } \\
\text { externas }\left({ }^{\circ} \mathrm{C}\right)\end{array}$ & $\begin{array}{c}\text { Temp.Paredes voltada } \\
\text { para a rua }\left({ }^{\circ} \mathrm{C}\right)\end{array}$ & \multicolumn{3}{|c|}{ Temp. Média das paredes $\left({ }^{\circ} \mathrm{C}\right)$} & Temp. Teto $\left({ }^{\circ} \mathrm{C}\right)$ & \\
\hline $12: 50$ & 28 & 33,3 & 26,4 & \multicolumn{3}{|c|}{26,3} & 26,7 & \\
\hline $16: 00$ & 30,8 & 30,9 & 27,3 & \multicolumn{3}{|c|}{26,5} & 26,8 & \\
\hline
\end{tabular}

Tabela 69: Resultados coletados in loco no quarto do Apartamento C no mês de Novembro de 2013. 


\begin{tabular}{|c|c|c|c|c|c|c|c|c|}
\hline \multicolumn{2}{|l|}{ Apartamento C } & \multicolumn{4}{|c|}{ Dados coletados CONFORTIMMETRO Dezembro 2013 - QUARTO } & \multicolumn{3}{|c|}{ céu claro } \\
\hline Intervalo & $\begin{array}{l}\text { Temperatura de } \\
\text { bulbo úmido }\left({ }^{\circ} \mathrm{C}\right)\end{array}$ & $\begin{array}{c}\text { Temperatura de } \\
\text { globo }\left({ }^{\circ} \mathrm{C}\right)\end{array}$ & Temperatura do ar $\left({ }^{\circ} \mathrm{C}\right)$ & $\begin{array}{c}\text { Pressão Atmosférica } \\
\text { (atm) }\end{array}$ & $\begin{array}{l}\text { Umidade relativa } \\
\text { do ar (\%) }\end{array}$ & $\begin{array}{l}\text { Velocidade do ar } \\
(\mathrm{m} / \mathrm{s})\end{array}$ & $\begin{array}{l}\text { Temperatura } \\
\text { radiante }\left({ }^{\circ} \mathrm{C}\right)\end{array}$ & $\begin{array}{l}\text { Temperatura } \\
\text { Operativa }\left({ }^{\circ} \mathrm{C}\right)\end{array}$ \\
\hline $12: 50$ as $13: 20$ & 24,0 & 30,9 & 30,8 & 1001,5 & 49,1 & 0,0 & 30,9 & 30,9 \\
\hline $13: 20$ as $13: 50$ & 24,5 & 31,3 & 31,4 & 1001,9 & 49,8 & 0,0 & 31,3 & 31,3 \\
\hline $13: 50$ as $14: 20$ & 25,4 & 31,6 & 31,7 & 1002,4 & 53,7 & 0,0 & 31,6 & 31,7 \\
\hline $14: 20$ as $14: 50$ & 25,0 & 31,4 & 31,5 & 1002,8 & 54,5 & 0,1 & 31,3 & 31,4 \\
\hline $14: 50$ as $15: 20$ & 25,9 & 31,0 & 31,0 & 1002,7 & 62,4 & 0,1 & 31,1 & 31,0 \\
\hline $15: 20$ as $15: 50$ & 26,6 & 30,8 & 30,7 & 1002,9 & 67,9 & 0,1 & 30,9 & 30,8 \\
\hline Desvio Padrão & 0,92 & 0,33 & 0,42 & 0,54 & 7,11 & 0,07 & 0,28 & 1,63 \\
\hline Média & 25,2 & 31,2 & 31,2 & 1002,4 & 56,1 & 0,1 & 31,2 & 31,2 \\
\hline \multicolumn{8}{|c|}{ Dados coletados Termômetro de fluxo de laser } & \\
\hline Horário/Quarto & $\begin{array}{l}\text { Temp. Externa do ar } \\
\left({ }^{\circ} \mathrm{C}\right)\end{array}$ & $\begin{array}{l}\text { Temp. Paredes } \\
\text { externas }\left({ }^{\circ} \mathrm{C}\right)\end{array}$ & $\begin{array}{c}\text { Temp.Paredes voltada } \\
\text { para a rua }\left({ }^{\circ} \mathrm{C}\right)\end{array}$ & \multicolumn{3}{|c|}{ Temp. Média das paredes $\left({ }^{\circ} \mathrm{C}\right)$} & Temp. Teto $\left({ }^{\circ} \mathrm{C}\right)$ & \\
\hline $12: 50$ & 39,5 & 39,7 & 32,1 & \multirow{2}{*}{\multicolumn{3}{|c|}{28}} & 29 & \\
\hline $16: 00$ & 30,2 & 27,3 & 31,8 & & & & 31,1 & \\
\hline
\end{tabular}

Tabela 70: Resultados coletados in loco no quarto do Apartamento C no mês de Dezembro de 2013.

\begin{tabular}{|c|c|c|c|c|c|c|c|c|}
\hline \multicolumn{2}{|l|}{ Apartamento C } & \multicolumn{4}{|c|}{ Dados coletados CONFORTIM ETRO Janeiro 2014 - QUARTO } & \multicolumn{3}{|c|}{ céu claro } \\
\hline Intervalo & $\begin{array}{l}\text { Temperatura de } \\
\text { bulbo úmido }\left({ }^{\circ} \mathrm{C}\right)\end{array}$ & $\begin{array}{c}\text { Temperatura de } \\
\text { globo }\left({ }^{\circ} \mathrm{C}\right)\end{array}$ & Temperatura do ar $\left({ }^{\circ} \mathrm{C}\right)$ & $\begin{array}{c}\text { Pressão Atmosférica } \\
\text { (atm) }\end{array}$ & $\begin{array}{c}\text { Umidade relativa } \\
\text { do ar (\%) }\end{array}$ & $\begin{array}{l}\text { Velocidade do ar } \\
(\mathrm{m} / \mathrm{s})\end{array}$ & $\begin{array}{l}\text { Temperatura } \\
\text { radiante }\left({ }^{\circ} \mathrm{C}\right)\end{array}$ & $\begin{array}{l}\text { Temperatura } \\
\text { Operativa }\left({ }^{\circ} \mathrm{C}\right)\end{array}$ \\
\hline $12: 50$ as $13: 20$ & 27,6 & 32,1 & 31,9 & 1009,1 & 67,4 & 0,0 & 32,3 & 32,1 \\
\hline $13: 20$ as $13: 50$ & 27,4 & 32,1 & 32,0 & 1009,2 & 65,2 & 0,0 & 32,2 & 32,1 \\
\hline $13: 50$ as $14: 20$ & 27,2 & 32,2 & 32,1 & 1009,1 & 64,0 & 0,1 & 32,3 & 32,2 \\
\hline $14: 20$ as $14: 50$ & 27,4 & 32,3 & 32,2 & 1008,9 & 64,7 & 0,0 & 32,4 & 32,3 \\
\hline $14: 50$ as $15: 20$ & 27,0 & 32,4 & 32,3 & 1008,6 & 61,2 & 0,0 & 32,5 & 32,4 \\
\hline $15: 20$ as $15: 50$ & 26,6 & 32,6 & 32,4 & 1008,3 & 58,4 & 0,0 & 32,7 & 32,5 \\
\hline Desvio Padrão & 0,40 & 0,20 & 0,19 & 0,38 & 3,25 & 0,04 & 0,23 & 1,63 \\
\hline Média & 27,1 & 32,3 & 32,2 & 1008,8 & 63,0 & 0,0 & 32,4 & 32,3 \\
\hline \multicolumn{8}{|c|}{ Dados coletados Termômetro de fluxo de laser } & \\
\hline Horário/Quarto & $\begin{array}{l}\text { Temp. Externa do ar } \\
\left({ }^{\circ} \mathrm{C}\right)\end{array}$ & $\begin{array}{l}\text { Temp. Paredes } \\
\text { externas }\left({ }^{\circ} \mathrm{C}\right)\end{array}$ & $\begin{array}{c}\text { Temp. Paredes voltada } \\
\text { para a rua }\left({ }^{\circ} \mathrm{C}\right)\end{array}$ & \multicolumn{3}{|c|}{ Temp. Média das paredes $\left({ }^{\circ} \mathrm{C}\right)$} & Temp. Teto $\left({ }^{\circ} \mathrm{C}\right)$ & \\
\hline $12: 50$ & 35 & 37,8 & 31,8 & \multicolumn{3}{|c|}{31,4} & 32,1 & \\
\hline $16: 00$ & 34 & 36,1 & 32,3 & \multicolumn{3}{|c|}{32} & 32,2 & \\
\hline
\end{tabular}

Tabela 71: Resultados coletados in loco no quarto do Apartamento C no mês de Janeiro de 2014.

\begin{tabular}{|c|c|c|c|c|c|c|c|c|}
\hline \multicolumn{2}{|l|}{ Apartamento C } & \multicolumn{4}{|c|}{ Dados coletados CONFORTÍM ETRO Fevereiro 2014 - QUARTO } & \multicolumn{3}{|c|}{ céu claro } \\
\hline Intervalo & $\begin{array}{l}\text { Temperatura de } \\
\text { bulbo úmido }\left({ }^{\circ} \mathrm{C}\right)\end{array}$ & $\begin{array}{l}\text { Temperatura de } \\
\text { globo }\left({ }^{\circ} \mathrm{C}\right)\end{array}$ & Temperatura do ar $\left({ }^{\circ} \mathrm{C}\right)$ & $\begin{array}{c}\text { Pressão Atmosférica } \\
\text { (atm) }\end{array}$ & $\begin{array}{l}\text { Umidade relativa } \\
\text { do ar (\%) }\end{array}$ & $\begin{array}{l}\text { Velocidade do ar } \\
\qquad(\mathrm{m} / \mathrm{s})\end{array}$ & $\begin{array}{l}\text { Temperatura } \\
\text { radiante }\left({ }^{\circ} \mathrm{C}\right)\end{array}$ & $\begin{array}{l}\text { Temperatura } \\
\text { Operativa }\left({ }^{\circ} \mathrm{C}\right)\end{array}$ \\
\hline $11: 50$ as $12: 20$ & 26,0 & 30,1 & 30,1 & 1008,9 & 66,9 & 0,0 & 30,1 & 30,1 \\
\hline $12: 20$ as $12: 50$ & 26,0 & 30,1 & 30,1 & 1008,4 & 66,7 & 0,0 & 30,1 & 30,1 \\
\hline $12: 50$ as $13: 20$ & 25,7 & 30,3 & 30,3 & 1008,0 & 64,0 & 0,0 & 30,3 & 30,3 \\
\hline $13: 20$ as $13: 50$ & 25,8 & 30,5 & 30,5 & 1007,6 & 63,2 & 0,0 & 30,4 & 30,5 \\
\hline $13: 50$ as $14: 20$ & 25,9 & 30,8 & 30,9 & 1007,3 & 62,0 & 0,0 & 30,7 & 30,8 \\
\hline $14: 20$ as $14: 50$ & 25,9 & 30,8 & 30,8 & 1007,2 & 62,6 & 0,1 & 30,8 & 30,8 \\
\hline Desvio Padrão & 0,18 & 0,30 & 0,33 & 0,65 & 2,15 & 0,04 & 0,30 & 1,63 \\
\hline Média & 25,9 & 30,4 & 30,4 & 1008,0 & 64,4 & 0,0 & 30,4 & 30,4 \\
\hline \multicolumn{8}{|c|}{ Dados coletados Termômetro de fluxo de laser } & \\
\hline Horário/Quarto & $\begin{array}{l}\text { Temp. Externa do ar } \\
\left({ }^{\circ} \mathrm{C}\right)\end{array}$ & $\begin{array}{l}\text { Temp. Paredes } \\
\text { externas }\left({ }^{\circ} \mathrm{C}\right)\end{array}$ & $\begin{array}{c}\text { Temp. Paredes voltada } \\
\text { para a rua }\left({ }^{\circ} \mathrm{C}\right)\end{array}$ & \multicolumn{3}{|c|}{ Temp. Média das paredes $\left({ }^{\circ} \mathrm{C}\right)$} & Temp. Teto $\left({ }^{\circ} \mathrm{C}\right)$ & \\
\hline 11:50 & 30,2 & 33,8 & 29,9 & \multicolumn{3}{|c|}{29,8} & 30,4 & \\
\hline $15: 00$ & 32,2 & 33,8 & 31,5 & \multicolumn{3}{|c|}{30,1} & 31,1 & \\
\hline
\end{tabular}

Tabela 72: Resultados coletados in loco no quarto do Apartamento C no mês de Fevereiro de 2014.

\begin{tabular}{|c|c|c|c|c|c|c|c|c|}
\hline \multicolumn{2}{|l|}{ Apartamento C } & \multicolumn{4}{|c|}{ Dados coletados CONFORTÍMETRO Março 2014 - QUARTO } & \multicolumn{3}{|c|}{$\begin{array}{l}\text { Parcialmente } \\
\text { nublado }\end{array}$} \\
\hline Intervalo & $\begin{array}{l}\text { Temperatura de } \\
\text { bulbo úmido }\left({ }^{\circ} \mathrm{C}\right)\end{array}$ & $\begin{array}{c}\text { Temperatura de } \\
\text { globo }\left({ }^{\circ} \mathrm{C}\right)\end{array}$ & Temperatura do ar $\left({ }^{\circ} \mathrm{C}\right)$ & $\begin{array}{c}\text { Pressão Atmosférica } \\
\text { (atm) }\end{array}$ & $\begin{array}{c}\text { Umidade relativa } \\
\text { do ar (\%) }\end{array}$ & $\begin{array}{l}\text { Velocidade do ar } \\
\qquad(\mathrm{m} / \mathrm{s})\end{array}$ & $\begin{array}{l}\text { Temperatura } \\
\text { radiante }\left({ }^{\circ} \mathrm{C}\right)\end{array}$ & $\begin{array}{l}\text { Temperatura } \\
\text { Operativa }\left({ }^{\circ} \mathrm{C}\right)\end{array}$ \\
\hline $11: 50$ as $12: 20$ & 24,7 & 28,1 & 28,0 & 1006,0 & 70,6 & 0,0 & 28,1 & 28,0 \\
\hline $12: 20$ as $12: 50$ & 25,2 & 28,5 & 28,4 & 1005,9 & 71,8 & 0,0 & 28,5 & 28,5 \\
\hline $12: 50$ as $13: 20$ & 25,7 & 29,0 & 28,9 & 1005,8 & 71,9 & 0,0 & 29,0 & 29,0 \\
\hline $13: 20$ as $13: 50$ & 26,1 & 29,4 & 29,2 & 1005,8 & 73,1 & 0,0 & 29,4 & 29,3 \\
\hline $13: 50$ as $14: 20$ & 26,3 & 29,7 & 29,5 & 1005,6 & 72,3 & 0,0 & 29,7 & 29,6 \\
\hline $14: 20$ as $14: 50$ & 26,2 & 30,0 & 29,9 & 1005,6 & 69,8 & 0,0 & 30,0 & 29,9 \\
\hline Desvio Padrão & 0,60 & 0,67 & 0,64 & 0,17 & 1,36 & 0,01 & 0,67 & 1,63 \\
\hline Média & 25,7 & 29,1 & 29,0 & 1005,8 & 71,6 & 0,0 & 29,1 & 29,0 \\
\hline \multicolumn{8}{|c|}{ Dados coletados Termômetro de fluxo de laser } & \\
\hline Horário/Quarto & $\begin{array}{l}\text { Temp. Externa do ar } \\
\left({ }^{\circ} \mathrm{C}\right)\end{array}$ & $\begin{array}{l}\text { Temp. Paredes } \\
\text { externas }\left({ }^{\circ} \mathrm{C}\right)\end{array}$ & $\begin{array}{c}\text { Temp.Paredes voltada } \\
\text { para a rua }\left({ }^{\circ} \mathrm{C}\right)\end{array}$ & \multicolumn{3}{|c|}{ Temp. Média das paredes $\left({ }^{\circ} \mathrm{C}\right)$} & Temp. Teto $\left({ }^{\circ} \mathrm{C}\right)$ & \\
\hline $11: 50$ & 29,7 & 30,1 & 25,8 & \multicolumn{3}{|c|}{25,5} & 27,4 & \\
\hline $15: 00$ & 31,8 & 33,1 & 28,8 & \multicolumn{3}{|c|}{27,9} & 30,2 & \\
\hline
\end{tabular}

Tabela 73: Resultados coletados in loco no quarto do Apartamento C no mês de Março de 2014. 


\begin{tabular}{|c|c|c|c|c|c|c|c|c|}
\hline \multicolumn{2}{|l|}{ Apartamento C } & \multicolumn{4}{|c|}{ Dados coletados CONFORTÍM ETRO Abril 2014 - QUARTO } & \multicolumn{3}{|c|}{$\begin{array}{l}\text { Parcialmente } \\
\text { aberto }\end{array}$} \\
\hline Intervalo & $\begin{array}{l}\text { Temperatura de } \\
\text { bulbo úmido }\left({ }^{\circ} \mathrm{C}\right)\end{array}$ & $\begin{array}{c}\text { Temperatura de } \\
\text { globo }\left({ }^{\circ} \mathrm{C}\right)\end{array}$ & Temperatura do ar $\left({ }^{\circ} \mathrm{C}\right)$ & $\begin{array}{c}\text { Pressão Atmosférica } \\
\text { (atm) }\end{array}$ & $\begin{array}{l}\text { Umidade relativa } \\
\text { do ar (\%) }\end{array}$ & $\begin{array}{l}\text { Velocidade do ar } \\
(\mathrm{m} / \mathrm{s})\end{array}$ & $\begin{array}{l}\text { Temperatura } \\
\text { radiante }\left({ }^{\circ} \mathrm{C}\right)\end{array}$ & $\begin{array}{l}\text { Temperatura } \\
\text { Operativa }\left({ }^{\circ} \mathrm{C}\right)\end{array}$ \\
\hline $11: 50$ as $12: 20$ & 22,8 & 26,4 & 26,0 & 1012,7 & 73,4 & 0,4 & 27,6 & 26,8 \\
\hline $12: 20$ as $12: 50$ & 22,8 & 26,2 & 25,9 & 1012,6 & 73,7 & 0,4 & 27,0 & 26,5 \\
\hline $12: 50$ as $13: 20$ & 22,9 & 26,4 & 26,1 & 1012,4 & 72,8 & 0,2 & 26,9 & 26,5 \\
\hline $13: 20$ as $13: 50$ & 22,8 & 26,4 & 26,1 & 1012,4 & 72,4 & 0,3 & 27,0 & 26,5 \\
\hline $13: 50$ as $14: 20$ & 22,7 & 26,0 & 25,7 & 1012,2 & 74,6 & 0,7 & 27,0 & 26,3 \\
\hline $14: 20$ as $14: 50$ & 22,5 & 25,8 & 25,5 & 1012,1 & 74,1 & 0,8 & 26,7 & 26,1 \\
\hline Desvio Padrão & 0,17 & 0,27 & 0,24 & 0,22 & 0,99 & 0,71 & 0,60 & 1,63 \\
\hline Média & 22,7 & 26,2 & 25,9 & 1012,4 & 73,5 & 0,5 & 27,0 & 26,4 \\
\hline \multicolumn{8}{|c|}{ Dados coletados Termômetro de fluxo de laser } & \\
\hline Horário/Quarto & $\begin{array}{l}\text { Temp. Externa do ar } \\
\left({ }^{\circ} \mathrm{C}\right)\end{array}$ & $\begin{array}{l}\text { Temp. Paredes } \\
\text { externas }\left({ }^{\circ} \mathrm{C}\right)\end{array}$ & $\begin{array}{c}\text { Temp. Paredes voltada } \\
\text { para a rua }\left({ }^{\circ} \mathrm{C}\right)\end{array}$ & \multicolumn{3}{|c|}{ Temp. Média das paredes $\left({ }^{\circ} \mathrm{C}\right)$} & Temp. Teto $\left({ }^{\circ} \mathrm{C}\right)$ & \\
\hline 11:50 & 27,2 & 26,7 & 26,5 & \multicolumn{3}{|c|}{26,8} & 27,2 & \\
\hline $15: 00$ & 28,1 & 26,1 & 26,5 & \multicolumn{3}{|c|}{26,3} & 26,4 & \\
\hline
\end{tabular}

Tabela 74: Resultados coletados in loco no quarto do Apartamento C no mês de Abril de 2014.

\begin{tabular}{|c|c|c|c|c|c|c|c|c|}
\hline \multicolumn{2}{|l|}{ Apartamento C } & \multicolumn{4}{|c|}{ Dados coletados CONFORTIMM ETRO M aio 2014 - QUARTO } & \multicolumn{3}{|c|}{ Céu claro } \\
\hline Intervalo & $\begin{array}{l}\text { Temperatura de } \\
\text { bulbo úmido }\left({ }^{\circ} \mathrm{C}\right)\end{array}$ & $\begin{array}{c}\text { Temperatura de } \\
\text { globo }\left({ }^{\circ} \mathrm{C}\right)\end{array}$ & Temperatura do ar $\left({ }^{\circ} \mathrm{C}\right)$ & $\begin{array}{c}\text { Pressão Atmosférica } \\
\text { (atm) }\end{array}$ & $\begin{array}{c}\text { Umidade relativa } \\
\text { do ar (\%) }\end{array}$ & $\begin{array}{l}\text { Velocidade do ar } \\
(\mathrm{m} / \mathrm{s})\end{array}$ & $\begin{array}{l}\text { Temperatura } \\
\text { radiante }\left({ }^{\circ} \mathrm{C}\right)\end{array}$ & $\begin{array}{l}\text { Temperatura } \\
\text { Operativa }\left({ }^{\circ} \mathrm{C}\right)\end{array}$ \\
\hline $11: 50$ as $12: 20$ & 22,3 & 25,3 & 24,4 & 1015,1 & 75,5 & 0,0 & 25,8 & 25,1 \\
\hline $12: 20$ as $12: 50$ & 22,2 & 25,4 & 25,1 & 1015,0 & 71,8 & 0,0 & 25,6 & 25,3 \\
\hline $12: 50$ as $13: 20$ & 22,3 & 25,3 & 25,2 & 1014,8 & 72,0 & 0,0 & 25,4 & 25,3 \\
\hline $13: 20$ as $13: 50$ & 22,3 & 25,4 & 25,2 & 1014,7 & 72,5 & 0,0 & 25,4 & 25,3 \\
\hline $13: 50$ as $14: 20$ & 22,2 & 25,2 & 25,1 & 1014,5 & 72,7 & 0,0 & 25,4 & 25,2 \\
\hline $14: 20$ as $14: 50$ & 22,3 & 25,2 & 25,0 & 1014,6 & 73,2 & 0,0 & 25,2 & 25,1 \\
\hline Desvio Padrão & 0,10 & 0,11 & 0,16 & 0,18 & 0,77 & 0,04 & 0,16 & 1,63 \\
\hline Média & 22,3 & 25,3 & 25,1 & 1014,7 & 72,5 & 0,0 & 25,4 & 25,3 \\
\hline \multicolumn{8}{|c|}{ Dados coletados Termômetro de fluxo de laser } & \\
\hline Horário/Quarto & $\begin{array}{l}\text { Temp. Externa do ar } \\
\left({ }^{\circ} \mathrm{C}\right)\end{array}$ & $\begin{array}{l}\text { Temp. Paredes } \\
\text { externas }\left({ }^{\circ} \mathrm{C}\right)\end{array}$ & $\begin{array}{c}\text { Temp.Paredes voltada } \\
\text { para a rua }\left({ }^{\circ} \mathrm{C}\right)\end{array}$ & \multicolumn{3}{|c|}{ Temp. Média das paredes $\left({ }^{\circ} \mathrm{C}\right)$} & Temp. Teto $\left({ }^{\circ} \mathrm{C}\right)$ & \\
\hline 11:50 & 25,2 & 26,1 & 24,3 & \multicolumn{3}{|c|}{25,3} & 25,3 & \\
\hline 15:00 & 27,5 & 25,6 & 25,2 & \multicolumn{3}{|c|}{24,9} & 24,7 & \\
\hline
\end{tabular}

Tabela 75: Resultados coletados in loco no quarto do Apartamento C no mês de Maio de 2014.

\begin{tabular}{|c|c|c|c|c|c|c|c|c|}
\hline \multicolumn{2}{|l|}{ Apartamento C } & \multicolumn{4}{|c|}{ Dados coletados CONFORTIM ETRO Junho 2014 - QUARTO } & \multicolumn{3}{|c|}{ Céu claro } \\
\hline Intervalo & $\begin{array}{l}\text { Temperatura de } \\
\text { bulbo úmido }\left({ }^{\circ} \mathrm{C}\right)\end{array}$ & $\begin{array}{l}\text { Temperatura de } \\
\text { globo }\left({ }^{\circ} \mathrm{C}\right)\end{array}$ & Temperatura do ar $\left({ }^{\circ} \mathrm{C}\right)$ & $\begin{array}{c}\text { Pressão Atmosférica } \\
\text { (atm) }\end{array}$ & $\begin{array}{c}\text { Umidade relativa } \\
\text { do } \operatorname{ar}(\%)\end{array}$ & $\begin{array}{l}\text { Velocidade do ar } \\
(\mathrm{m} / \mathrm{s})\end{array}$ & $\begin{array}{l}\text { Temperatura } \\
\text { radiante }\left({ }^{\circ} \mathrm{C}\right)\end{array}$ & $\begin{array}{l}\text { Temperatura } \\
\text { Operativa }\left({ }^{\circ} \mathrm{C}\right)\end{array}$ \\
\hline $11: 50$ as $12: 20$ & 19,6 & 22,7 & 22,4 & 1023,9 & 69,2 & 0,0 & 22,9 & 22,6 \\
\hline $12: 20$ as $12: 50$ & 19,5 & 22,9 & 22,6 & 1023,7 & 67,9 & 0,0 & 22,9 & 22,8 \\
\hline $12: 50$ as $13: 20$ & 19,2 & 22,8 & 22,5 & 1023,3 & 66,5 & 0,0 & 22,9 & 22,7 \\
\hline $13: 20$ as $13: 50$ & 19,1 & 22,7 & 22,4 & 1023,0 & 66,3 & 0,0 & 22,8 & 22,6 \\
\hline $13: 50$ as $14: 20$ & 19,1 & 22,7 & 22,4 & 1022,9 & 66,4 & 0,0 & 22,8 & 22,6 \\
\hline $14: 20$ as $14: 50$ & 19,1 & 22,7 & 22,4 & 1022,9 & 66,2 & 0,0 & 22,8 & 22,6 \\
\hline Desvio Padrão & 0,25 & 0,09 & 0,11 & 0,40 & 1,19 & 0,01 & 0,10 & 1,63 \\
\hline Média & 19,3 & 22,7 & 22,5 & 1023,3 & 67,1 & 0,0 & 22,8 & 22,6 \\
\hline \multicolumn{9}{|c|}{ Dados coletados Termômetro de fluxo de laser } \\
\hline Horário/Quarto & $\begin{array}{l}\text { Temp. Externa do ar } \\
\left({ }^{\circ} \mathrm{C}\right)\end{array}$ & $\begin{array}{l}\text { Temp. Paredes } \\
\text { externas }\left({ }^{\circ} \mathrm{C}\right)\end{array}$ & $\begin{array}{c}\text { Temp.Paredes voltada } \\
\text { para a rua }\left({ }^{\circ} \mathrm{C}\right)\end{array}$ & \multicolumn{3}{|c|}{ Temp. Média das paredes $\left({ }^{\circ} \mathrm{C}\right)$} & Temp. Teto $\left({ }^{\circ} \mathrm{C}\right)$ & \\
\hline 11:50 & 22,8 & 18,1 & 21,6 & \multicolumn{3}{|c|}{23,4} & 23,6 & \\
\hline $15: 00$ & 21,1 & 18,3 & 22,4 & \multicolumn{3}{|c|}{23,6} & 24,6 & \\
\hline
\end{tabular}

Tabela 76: Resultados coletados in loco no quarto do Apartamento C no mês de Junho de 2014.

\begin{tabular}{|c|c|c|c|c|c|c|c|c|}
\hline \multicolumn{2}{|l|}{ Apartamento C } & \multicolumn{4}{|c|}{ Dados coletados CONFORTíM ETRO Julho 2013 - SALA } & \multicolumn{3}{|c|}{ Céu claro } \\
\hline Intervalo & $\begin{array}{l}\text { Temperatura de } \\
\text { bulbo úmido }\left({ }^{\circ} \mathrm{C}\right)\end{array}$ & $\begin{array}{c}\text { Temperatura de } \\
\text { globo }\left({ }^{\circ} \mathrm{C}\right)\end{array}$ & $\begin{array}{c}\text { Temperatura do ar } \\
\left({ }^{\circ} \mathrm{C}\right)\end{array}$ & $\begin{array}{c}\text { Pressão } \\
\text { Atmosférica }\end{array}$ & $\begin{array}{c}\text { Umidade relativa } \\
\text { do ar (\%) }\end{array}$ & $\begin{array}{l}\text { Velocidade do ar } \\
\qquad(\mathrm{m} / \mathrm{s})\end{array}$ & $\begin{array}{l}\text { Temperatura } \\
\text { radiante }\left({ }^{\circ} \mathrm{C}\right)\end{array}$ & $\begin{array}{l}\text { Temperatura } \\
\text { Operativa }\left({ }^{\circ} \mathrm{C}\right)\end{array}$ \\
\hline $15: 00$ as $15: 30$ & 19,6 & 22,9 & 22,9 & 1019,5 & 67,2 & 0,0 & 23,0 & 22,9 \\
\hline $15: 30$ as $16: 00$ & 19,7 & 22,9 & 22,8 & 1019,5 & 68,9 & 0,0 & 22,9 & 22,9 \\
\hline $15: 30$ as $16: 00$ & 19,6 & 22,6 & 22,5 & 1019,7 & 69,4 & 0,0 & 22,6 & 22,6 \\
\hline $16: 30$ as $17: 00$ & 19,6 & 22,6 & 22,5 & 1019,7 & 70,4 & 0,0 & 22,6 & 22,6 \\
\hline Desvio Padrão & 0,13 & 0,20 & 0,19 & 0,10 & 1,62 & 0,03 & 0,21 & 0,2 \\
\hline Média & 19,6 & 22,7 & 22,7 & 1019,6 & 69,2 & 0,0 & 22,8 & 22,7 \\
\hline \multicolumn{9}{|c|}{ Dados coletados Termômetro de fluxo de laser } \\
\hline Horário/Quarto & $\begin{array}{l}\text { Temp. Externa do ar } \\
\left({ }^{\circ} \mathrm{C}\right)\end{array}$ & $\begin{array}{l}\text { Temp. Paredes } \\
\text { externas }\left({ }^{\circ} \mathrm{C}\right)\end{array}$ & $\begin{array}{c}\text { Temp.Paredes } \\
\text { voltada para a rua } \\
\left({ }^{\circ} \mathrm{C}\right)\end{array}$ & \multicolumn{3}{|c|}{ Temp. M édia das paredes $\left({ }^{\circ} \mathrm{C}\right)$} & Temp. Teto $\left({ }^{\circ} \mathrm{C}\right)$ & \\
\hline $15: 00$ & 23 & 26 & 24 & \multicolumn{3}{|c|}{25} & 28,8 & \\
\hline $17: 00$ & 22 & 25 & 22,8 & \multicolumn{3}{|c|}{27,9} & 28,9 & \\
\hline
\end{tabular}

Tabela 77: Resultados coletados in loco na sala do Apartamento C no mês de Julho de 2013. 


\begin{tabular}{|c|c|c|c|c|c|c|c|c|}
\hline \multicolumn{2}{|l|}{ Apartamento C } & \multicolumn{4}{|c|}{ Dados coletados CONFORTíMETRO Agosto 2013 - SALA } & \multicolumn{3}{|c|}{ Céu claro } \\
\hline Intervalo & $\begin{array}{l}\text { Temperatura de } \\
\text { bulbo úmido }\left({ }^{\circ} \mathrm{C}\right)\end{array}$ & $\begin{array}{c}\text { Temperatura de } \\
\text { globo }\left({ }^{\circ} \mathrm{C}\right)\end{array}$ & $\begin{array}{c}\text { Temperatura do ar } \\
\left({ }^{\circ} \mathrm{C}\right)\end{array}$ & $\begin{array}{l}\text { Pressão } \\
\text { Atmosférica } \\
\text { (atm) }\end{array}$ & $\begin{array}{l}\text { Umidade relativa } \\
\text { do ar (\%) }\end{array}$ & $\begin{array}{l}\text { Velocidade do ar } \\
\qquad(\mathrm{m} / \mathrm{s})\end{array}$ & $\begin{array}{l}\text { Temperatura } \\
\text { radiante }\left({ }^{\circ} \mathrm{C}\right)\end{array}$ & $\begin{array}{l}\text { Temperatura } \\
\text { Operativa }\left({ }^{\circ} \mathrm{C}\right)\end{array}$ \\
\hline $15: 00$ as $15: 30$ & 19,8 & 24,9 & 25,3 & 1008,1 & 52,7 & 0,0 & 24,8 & 25,1 \\
\hline $15: 30$ as $16: 00$ & 19,8 & 24,9 & 25,2 & 1007,8 & 53,1 & 0,0 & 24,8 & 25,0 \\
\hline $15: 30$ as $16: 00$ & 19,9 & 25,2 & 25,5 & 1007,7 & 52,7 & 0,0 & 25,1 & 25,3 \\
\hline $16: 30$ as $17: 00$ & 20,1 & 25,2 & 25,5 & 1007,6 & 53,6 & 0,0 & 25,1 & 25,3 \\
\hline Desvio Padrão & 0,19 & 0,18 & 0,16 & 0,20 & 0,91 & 0,02 & 0,19 & 0,2 \\
\hline Média & 19,9 & 25,1 & 25,4 & 1007,8 & 53,0 & 0,0 & 24,9 & 25,2 \\
\hline \multicolumn{9}{|c|}{ Dados coletados Termômetro de fluxo de laser } \\
\hline Horário/Quarto & $\begin{array}{c}\text { Temp. Externa do ar } \\
\left({ }^{\circ} \mathrm{C}\right)\end{array}$ & $\begin{array}{l}\text { Temp. Paredes } \\
\text { externas }\left({ }^{\circ} \mathrm{C}\right)\end{array}$ & $\begin{array}{c}\text { Temp. Paredes } \\
\text { voltada para a rua } \\
\left({ }^{\circ} \mathrm{C}\right)\end{array}$ & \multicolumn{3}{|c|}{ Temp. M édia das paredes $\left({ }^{\circ} \mathrm{C}\right)$} & Temp. Teto $\left({ }^{\circ} \mathrm{C}\right)$ & \\
\hline 15:00 & 29,4 & 30 & 26,6 & \multicolumn{3}{|c|}{25,9} & 27,7 & \\
\hline $17: 00$ & 29,6 & 27 & 28,5 & \multicolumn{3}{|c|}{27,9} & 27,7 & \\
\hline
\end{tabular}

Tabela 78: Resultados coletados in loco na sala do Apartamento C no mês de Agosto de 2013.

\begin{tabular}{|c|c|c|c|c|c|c|c|c|}
\hline \multicolumn{2}{|l|}{ Apartamento C } & \multicolumn{4}{|c|}{ Dados coletados CONFORTÍM ETRO Setembro 2013 - SALA } & \multicolumn{3}{|c|}{ Chuva } \\
\hline Intervalo & $\begin{array}{l}\text { Temperatura de } \\
\text { bulbo úmido }\left({ }^{\circ} \mathrm{C}\right)\end{array}$ & $\begin{array}{l}\text { Temperatura de } \\
\text { globo }\left({ }^{\circ} \mathrm{C}\right)\end{array}$ & $\begin{array}{c}\text { Temperatura do ar } \\
\left({ }^{\circ} \mathrm{C}\right)\end{array}$ & $\begin{array}{l}\text { Pressão } \\
\text { Atmosférica } \\
\text { (atm) }\end{array}$ & $\begin{array}{l}\text { Umidade relativa } \\
\text { do ar (\%) }\end{array}$ & $\begin{array}{l}\text { Velocidade do ar } \\
\qquad(\mathrm{m} / \mathrm{s})\end{array}$ & $\begin{array}{l}\text { Temperatura } \\
\text { radiante }\left({ }^{\circ} \mathrm{C}\right)\end{array}$ & $\begin{array}{l}\text { Temperatura } \\
\text { Operativa }\left({ }^{\circ} \mathrm{C}\right)\end{array}$ \\
\hline $15: 00$ as $15: 30$ & 23,5 & 23,6 & 23,4 & 1017,6 & 66,6 & 0,1 & 24,0 & 23,7 \\
\hline $15: 30$ as $16: 00$ & 23,5 & 23,7 & 23,5 & 1017,6 & 66,2 & 0,0 & 23,9 & 23,7 \\
\hline $15: 30$ as $16: 00$ & 23,6 & 23,8 & 23,5 & 1017,8 & 65,5 & 0,0 & 23,9 & 23,7 \\
\hline $16: 30$ as $17: 00$ & 23,5 & 23,7 & 23,4 & 1018,0 & 66,4 & 0,0 & 23,8 & 23,6 \\
\hline Desvio Padrão & 0,14 & 0,09 & 0,09 & 0,19 & 0,68 & 0,06 & 0,11 & 0,1 \\
\hline Média & 23,5 & 23,7 & 23,4 & 1017,7 & 66,2 & 0,0 & 23,9 & 23,7 \\
\hline \multicolumn{8}{|c|}{ Dados coletados Termômetro de fluxo de laser } & \\
\hline Horário/Quarto & $\begin{array}{l}\text { Temp. Externa do ar } \\
\left({ }^{\circ} \mathrm{C}\right)\end{array}$ & $\begin{array}{l}\text { Temp. Paredes } \\
\text { externas }\left({ }^{\circ} \mathrm{C}\right)\end{array}$ & $\begin{array}{c}\text { Temp. Paredes } \\
\text { voltada para a rua } \\
\left({ }^{\circ} \mathrm{C}\right)\end{array}$ & \multicolumn{3}{|c|}{ Temp. M édia das paredes $\left({ }^{\circ} \mathrm{C}\right)$} & Temp. Teto $\left({ }^{\circ} \mathrm{C}\right)$ & \\
\hline $15: 00$ & 21,7 & 18,9 & 23,4 & \multicolumn{3}{|c|}{25,2} & 24 & \\
\hline $17: 00$ & 20,9 & 19,5 & 23 & \multicolumn{3}{|c|}{23,6} & 23,9 & \\
\hline
\end{tabular}

Tabela 79: Resultados coletados in loco na sala do Apartamento C no mês de Setembro de 2013.

\begin{tabular}{|c|c|c|c|c|c|c|c|c|}
\hline \multicolumn{2}{|l|}{ Apartamento $\mathrm{C}$} & \multicolumn{4}{|c|}{ Dados coletados CONFORTÍMETRO Outubro 2013 - SALA } & \multicolumn{3}{|c|}{ Céu limpo } \\
\hline Intervalo & $\begin{array}{l}\text { Temperatura de } \\
\text { bulbo úmido }\left({ }^{\circ} \mathrm{C}\right)\end{array}$ & $\begin{array}{l}\text { Temperatura de } \\
\text { globo }\left({ }^{\circ} \mathrm{C}\right)\end{array}$ & $\begin{array}{l}\text { Temperatura do ar } \\
\left({ }^{\circ} \mathrm{C}\right)\end{array}$ & $\begin{array}{l}\text { Pressão } \\
\text { Atmosférica } \\
\text { (atm) }\end{array}$ & $\begin{array}{l}\text { Umidade relativa } \\
\text { do ar (\%) }\end{array}$ & $\begin{array}{l}\text { Velocidade do ar } \\
\qquad(\mathrm{m} / \mathrm{s})\end{array}$ & $\begin{array}{l}\text { Temperatura } \\
\text { radiante }\left({ }^{\circ} \mathrm{C}\right)\end{array}$ & $\begin{array}{l}\text { Temperatura } \\
\text { Operativa }\left({ }^{\circ} \mathrm{C}\right)\end{array}$ \\
\hline $16: 00$ as $16: 30$ & 24,0 & 26,9 & 26,3 & 1012,1 & 78,4 & 0,3 & 28,4 & 27,3 \\
\hline $16: 30$ as $17: 00$ & 23,9 & 26,7 & 26,1 & 1011,9 & 78,5 & 0,1 & 27,6 & 26,9 \\
\hline $17: 00$ as $17: 30$ & 24,0 & 26,7 & 25,9 & 1012,0 & 79,5 & 0,1 & 27,7 & 26,8 \\
\hline $17: 30$ as $18: 00$ & 24,1 & 26,8 & 25,9 & 1012,4 & 80,5 & 0,1 & 27,8 & 26,9 \\
\hline Desvio Padrão & 0,14 & 0,18 & 0,29 & 0,20 & 1,25 & 0,12 & 0,64 & 0,5 \\
\hline Média & 24,0 & 26,8 & 26,1 & 1012,1 & 79,2 & 0,2 & 27,9 & 27,0 \\
\hline \multicolumn{8}{|c|}{ Dados coletados Termômetro de fluxo de laser } & \\
\hline Horário/Quarto & $\begin{array}{c}\text { Temp. Externa do ar } \\
\left({ }^{\circ} \mathrm{C}\right)\end{array}$ & $\begin{array}{l}\text { Temp. Paredes } \\
\text { externas }\left({ }^{\circ} \mathrm{C}\right)\end{array}$ & $\begin{array}{c}\text { Temp. Paredes } \\
\text { voltada para a rua } \\
\left({ }^{\circ} \mathrm{C}\right)\end{array}$ & \multicolumn{3}{|c|}{ Temp. M édia das paredes $\left({ }^{\circ} \mathrm{C}\right)$} & Temp. Teto $\left({ }^{\circ} \mathrm{C}\right)$ & \\
\hline 16:00 & 28,5 & 27,6 & 26,6 & \multicolumn{3}{|c|}{27,1} & 27,1 & \\
\hline $18: 00$ & 27,3 & 25,8 & 26,9 & \multicolumn{3}{|c|}{27,2} & 27,2 & \\
\hline
\end{tabular}

Tabela 80: Resultados coletados in loco na sala do Apartamento C no mês de Outubro de 2013.

\begin{tabular}{|c|c|c|c|c|c|c|c|c|}
\hline \multicolumn{2}{|l|}{ Apartamento C } & \multicolumn{4}{|c|}{ Dados coletados CONFORTIMETRO Novembro 2013 - SALA } & \multicolumn{3}{|c|}{ Céu limpo } \\
\hline Intervalo & $\begin{array}{l}\text { Temperatura de } \\
\text { bulbo úmido }\left({ }^{\circ} \mathrm{C}\right)\end{array}$ & $\begin{array}{l}\text { Temperatura de } \\
\text { globo }\left({ }^{\circ} \mathrm{C}\right)\end{array}$ & $\begin{array}{c}\text { Temperatura do ar } \\
\left({ }^{\circ} \mathrm{C}\right)\end{array}$ & $\begin{array}{l}\text { Pressão } \\
\text { Atmosférica } \\
\text { (atm) }\end{array}$ & $\begin{array}{l}\text { Umidade relativa } \\
\text { do ar (\%) }\end{array}$ & $\begin{array}{l}\text { Velocidade do ar } \\
\qquad(\mathrm{m} / \mathrm{s})\end{array}$ & $\begin{array}{l}\text { Temperatura } \\
\text { radiante }\left({ }^{\circ} \mathrm{C}\right)\end{array}$ & $\begin{array}{l}\text { Temperatura } \\
\text { Operativa }\left({ }^{\circ} \mathrm{C}\right)\end{array}$ \\
\hline $16: 00$ as $16: 30$ & 22,5 & 26,9 & 26,9 & 1009,7 & 64,0 & 0,1 & 26,9 & 26,9 \\
\hline $16: 30$ as $17: 00$ & 23,1 & 26,9 & 26,8 & 1009,5 & 67,2 & 0,0 & 27,0 & 26,9 \\
\hline $17: 00$ as $17: 30$ & 23,3 & 27,0 & 26,8 & 1009,3 & 68,7 & 0,0 & 27,1 & 26,9 \\
\hline $17: 30$ as $18: 00$ & 23,0 & 27,1 & 27,0 & 1009,4 & 66,3 & 0,1 & 27,2 & 27,1 \\
\hline Desvio Padrão & 0,37 & 0,09 & 0,12 & 0,17 & 2,19 & 0,04 & 0,12 & 0,1 \\
\hline Média & 22,9 & 27,0 & 26,9 & 1009,5 & 66,4 & 0,1 & 27,0 & 27,0 \\
\hline \multicolumn{9}{|c|}{ Dados coletados Termômetro de fluxo de laser } \\
\hline Horário/Quarto & $\begin{array}{l}\text { Temp. Externa do ar } \\
\left({ }^{\circ} \mathrm{C}\right)\end{array}$ & $\begin{array}{l}\text { Temp. Paredes } \\
\text { externas }\left({ }^{\circ} \mathrm{C}\right)\end{array}$ & $\begin{array}{c}\text { Temp.Paredes } \\
\text { voltada para a rua } \\
\left({ }^{\circ} \mathrm{C}\right)\end{array}$ & \multicolumn{3}{|c|}{ Temp. M édia das paredes $\left({ }^{\circ} \mathrm{C}\right)$} & Temp. Teto $\left({ }^{\circ} \mathrm{C}\right)$ & \\
\hline $16: 00$ & 30,8 & 30,7 & 26,7 & \multicolumn{3}{|c|}{25,2} & 26,4 & \\
\hline 18:00 & 28,6 & 28,7 & 27,3 & \multicolumn{3}{|c|}{27,1} & 26,8 & \\
\hline
\end{tabular}

Tabela 81: Resultados coletados in loco na sala do Apartamento C no mês de Novembro de 2013. 


\begin{tabular}{|c|c|c|c|c|c|c|c|c|}
\hline \multicolumn{2}{|l|}{ Apartamento C } & \multicolumn{4}{|c|}{ Dados coletados CONFORTÍMETRO Dezembro 2013 - SALA } & \multicolumn{3}{|c|}{ Chuva } \\
\hline Intervalo & $\begin{array}{l}\text { Temperatura de } \\
\text { bulbo úmido }\left({ }^{\circ} \mathrm{C}\right)\end{array}$ & $\begin{array}{c}\text { Temperatura de } \\
\text { globo }\left({ }^{\circ} \mathrm{C}\right)\end{array}$ & $\begin{array}{c}\text { Temperatura do ar } \\
\left({ }^{\circ} \mathrm{C}\right)\end{array}$ & $\begin{array}{l}\text { Pressão } \\
\text { Atmosférica } \\
\text { (atm) }\end{array}$ & $\begin{array}{l}\text { Umidade relativa } \\
\text { do ar (\%) }\end{array}$ & $\begin{array}{l}\text { Velocidade do ar } \\
\qquad(\mathrm{m} / \mathrm{s})\end{array}$ & $\begin{array}{l}\text { Temperatura } \\
\text { radiante }\left({ }^{\circ} \mathrm{C}\right)\end{array}$ & $\begin{array}{l}\text { Temperatura } \\
\text { Operativa }\left({ }^{\circ} \mathrm{C}\right)\end{array}$ \\
\hline $16: 00$ as $16: 30$ & 25,7 & 30,1 & 29,8 & 1007,2 & 67,4 & 0,1 & 30,6 & 30,2 \\
\hline $16: 30$ as $17: 00$ & 23,9 & 29,0 & 28,3 & 1009,3 & 64,3 & 0,2 & 30,2 & 29,2 \\
\hline $17: 00$ as $17: 30$ & 24,3 & 29,0 & 28,5 & 1010,4 & 65,7 & 0,1 & 29,7 & 29,1 \\
\hline $17: 30$ as $18: 00$ & 24,6 & 29,7 & 29,4 & 1011,2 & 62,1 & 0,1 & 30,1 & 29,8 \\
\hline Desvio Padrão & 0,74 & 0,61 & 0,78 & 1,58 & 2,48 & 0,06 & 0,52 & 0,6 \\
\hline Média & 24,6 & 29,5 & 29,0 & 1009,5 & 64,9 & 0,1 & 30,2 & 29,6 \\
\hline \multicolumn{9}{|c|}{ Dados coletados Termômetro de fluxo de laser } \\
\hline Horário/Quarto & $\begin{array}{l}\text { Temp. Externa do ar } \\
\left({ }^{\circ} \mathrm{C}\right)\end{array}$ & $\begin{array}{l}\text { Temp. Paredes } \\
\text { externas }\left({ }^{\circ} \mathrm{C}\right)\end{array}$ & $\begin{array}{c}\text { Temp. Paredes } \\
\text { voltada para a rua } \\
\left({ }^{\circ} \mathrm{C}\right)\end{array}$ & \multicolumn{3}{|c|}{ Temp. M édia das paredes $\left({ }^{\circ} \mathrm{C}\right)$} & Temp. Teto $\left({ }^{\circ} \mathrm{C}\right)$ & \\
\hline $16: 00$ & 30,2 & 27,6 & 31,6 & \multicolumn{3}{|c|}{30} & 31,2 & \\
\hline $18: 00$ & 26,3 & 24,6 & 30,8 & \multicolumn{3}{|c|}{30,3} & 31,2 & \\
\hline
\end{tabular}

Tabela 82: Resultados coletados in loco na sala do Apartamento C no mês de Dezembro de 2013.

\begin{tabular}{|c|c|c|c|c|c|c|c|c|}
\hline \multicolumn{2}{|l|}{ Apartamento C } & \multicolumn{4}{|c|}{ Dados coletados CONFORTÍM ETRO Janeiro 2014 - SALA } & \multicolumn{3}{|c|}{ Céu limpo } \\
\hline $16: 00$ as $16: 30$ & 26,7 & 32,7 & 32,5 & 1008,1 & 58,4 & 0,0 & 32,9 & 32,7 \\
\hline $17: 00$ as $17: 30$ & 26,6 & 32,7 & 32,6 & 1007,7 & 56,9 & 0,0 & 32,8 & 32,7 \\
\hline $17: 30$ as $18: 00$ & 26,3 & 32,6 & 32,4 & 1007,7 & 55,6 & 0,0 & 32,6 & 32,5 \\
\hline Desvio Padrão & 0,33 & 0,08 & 0,09 & 0,24 & 1,97 & 0,04 & 0,13 & 0,1 \\
\hline Horário/Quarto & $\begin{array}{l}\text { Temp. Externa do ar } \\
\left({ }^{\circ} \mathrm{C}\right)\end{array}$ & $\begin{array}{l}\text { Temp. Paredes } \\
\text { externas }\left({ }^{\circ} \mathrm{C}\right)\end{array}$ & $\begin{array}{c}\text { Temp. Paredes } \\
\text { voltada para a rua } \\
\left({ }^{\circ} \mathrm{C}\right)\end{array}$ & \multicolumn{3}{|c|}{ Temp. M édia das paredes $\left({ }^{\circ} \mathrm{C}\right)$} & Temp. Teto $\left({ }^{\circ} \mathrm{C}\right)$ & \\
\hline $16: 00$ & 34 & 36,1 & 32 & \multicolumn{3}{|c|}{32,1} & 32,3 & \\
\hline $18: 00$ & 33,5 & 36 & 33,6 & \multicolumn{3}{|c|}{32} & 32,2 & \\
\hline
\end{tabular}

Tabela 83: Resultados coletados in loco na sala do Apartamento C no mês de Janeiro de 2014.

\begin{tabular}{|c|c|c|c|c|c|c|c|c|}
\hline \multicolumn{2}{|l|}{ Apartamento C } & \multicolumn{4}{|c|}{ Dados coletados CONFORTÍMETRO Fevereiro 2014 - SALA } & \multicolumn{3}{|c|}{ Céu limpo } \\
\hline Intervalo & $\begin{array}{l}\text { Temperatura de } \\
\text { bulbo úmido }\left({ }^{\circ} \mathrm{C}\right)\end{array}$ & $\begin{array}{c}\text { Temperatura de } \\
\text { globo }\left({ }^{\circ} \mathrm{C}\right)\end{array}$ & $\begin{array}{c}\text { Temperatura do ar } \\
\left({ }^{\circ} \mathrm{C}\right)\end{array}$ & $\begin{array}{c}\text { Pressão } \\
\text { Atmosférica } \\
\text { (atm) }\end{array}$ & $\begin{array}{c}\text { Umidade relativa } \\
\text { do ar (\%) }\end{array}$ & $\begin{array}{l}\text { Velocidade do ar } \\
\qquad(\mathrm{m} / \mathrm{s})\end{array}$ & $\begin{array}{l}\text { Temperatura } \\
\text { radiante }\left({ }^{\circ} \mathrm{C}\right)\end{array}$ & $\begin{array}{c}\text { Temperatura } \\
\text { Operativa }\left({ }^{\circ} \mathrm{C}\right)\end{array}$ \\
\hline $15: 00$ as $15: 30$ & 26,0 & 30,8 & 30,7 & 1006,9 & 63,0 & 0,0 & 30,8 & 30,8 \\
\hline $15: 30$ as $16: 00$ & 25,9 & 30,9 & 30,8 & 1006,8 & 62,3 & 0,0 & 31,0 & 30,9 \\
\hline $15: 30$ as $16: 00$ & 25,6 & 30,6 & 30,4 & 1006,6 & 62,0 & 0,1 & 30,7 & 30,6 \\
\hline $16: 30$ as $17: 00$ & 25,1 & 30,6 & 30,4 & 1006,5 & 58,8 & 0,1 & 30,7 & 30,6 \\
\hline Desvio Padrão & 0,40 & 0,16 & 0,20 & 0,17 & 2,09 & 0,08 & 0,16 & 0,2 \\
\hline Média & 25,7 & 30,7 & 30,6 & 1006,7 & 61,6 & 0,1 & 30,8 & 30,7 \\
\hline \multicolumn{9}{|c|}{ Dados coletados Termômetro de fluxo de laser } \\
\hline Horário/Quarto & $\begin{array}{l}\text { Temp. Externa do ar } \\
\left({ }^{\circ} \mathrm{C}\right)\end{array}$ & $\begin{array}{l}\text { Temp. Paredes } \\
\text { externas }\left({ }^{\circ} \mathrm{C}\right)\end{array}$ & $\begin{array}{c}\text { Temp.Paredes } \\
\text { voltada para a rua } \\
\left({ }^{\circ} \mathrm{C}\right)\end{array}$ & \multicolumn{3}{|c|}{ Temp. M édia das paredes $\left({ }^{\circ} \mathrm{C}\right)$} & Temp. Teto $\left({ }^{\circ} \mathrm{C}\right)$ & \\
\hline 15:00 & 32,2 & 30,1 & 33,9 & \multicolumn{3}{|c|}{31,3} & 29,9 & \\
\hline $17: 00$ & 33,4 & 34 & 30,6 & \multicolumn{3}{|c|}{30,2} & 30,4 & \\
\hline
\end{tabular}

Tabela 84: Resultados coletados in loco na sala do Apartamento C no mês de Fevereiro de 2014.

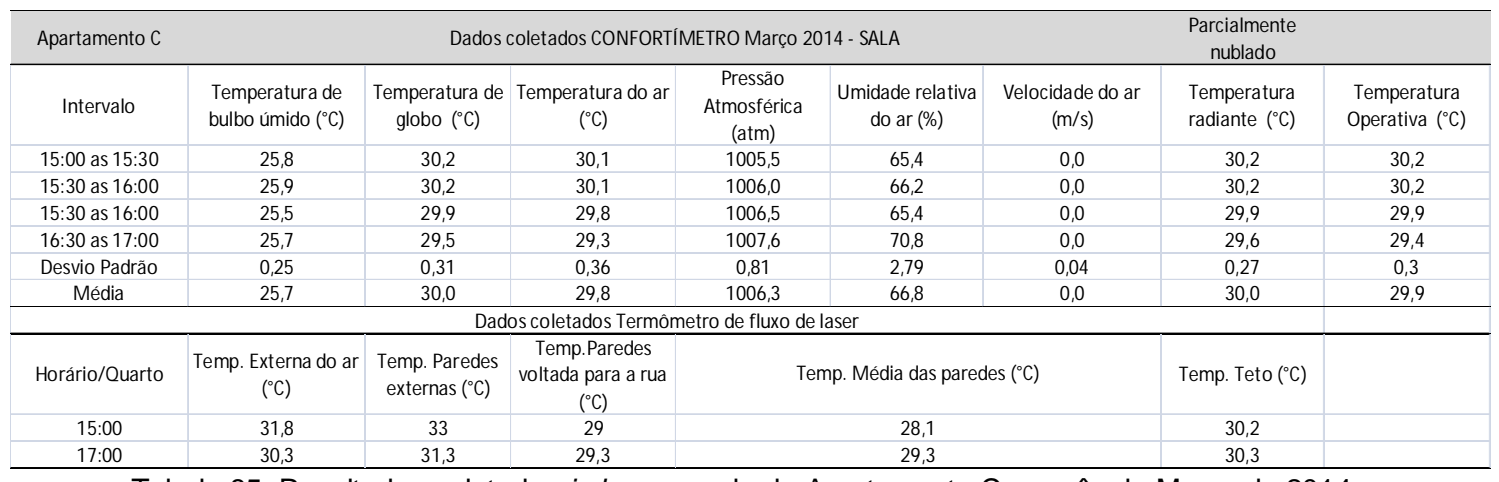

Tabela 85: Resultados coletados in loco na sala do Apartamento C no mês de Março de 2014. 


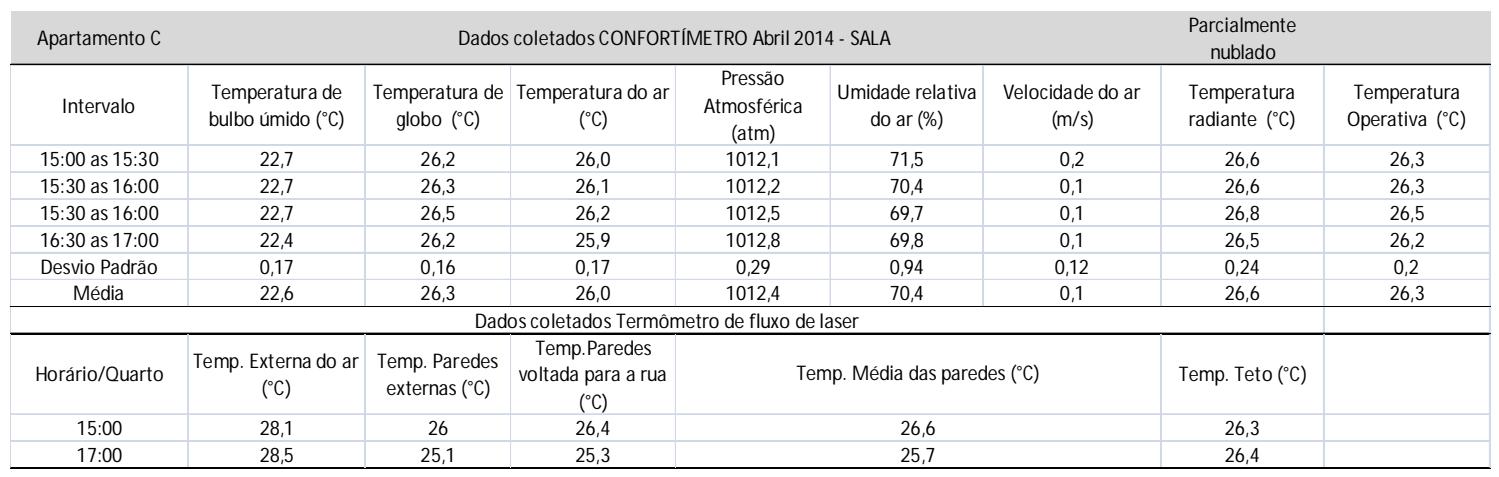

Tabela 86: Resultados coletados in loco na sala do Apartamento C no mês de Abril de 2014.

\begin{tabular}{|c|c|c|c|c|c|c|c|c|}
\hline \multicolumn{2}{|l|}{ Apartamento C } & \multicolumn{4}{|c|}{ Dados coletados CONFORTíM ETRO Maio 2014 - SALA } & \multicolumn{3}{|c|}{ Parcialmente claro } \\
\hline Intervalo & $\begin{array}{l}\text { Temperatura de } \\
\text { bulbo úmido }\left({ }^{\circ} \mathrm{C}\right)\end{array}$ & $\begin{array}{c}\text { Temperatura de } \\
\text { globo }\left({ }^{\circ} \mathrm{C}\right)\end{array}$ & $\begin{array}{c}\text { Temperatura do ar } \\
\left({ }^{\circ} \mathrm{C}\right)\end{array}$ & $\begin{array}{l}\text { Pressão } \\
\text { Atmosférica } \\
\text { (atm) }\end{array}$ & $\begin{array}{l}\text { Umidade relativa } \\
\text { do ar (\%) }\end{array}$ & $\begin{array}{l}\text { Velocidade do ar } \\
\qquad(\mathrm{m} / \mathrm{s})\end{array}$ & $\begin{array}{l}\text { Temperatura } \\
\text { radiante }\left({ }^{\circ} \mathrm{C}\right)\end{array}$ & $\begin{array}{l}\text { Temperatura } \\
\text { Operativa }\left({ }^{\circ} \mathrm{C}\right)\end{array}$ \\
\hline $15: 00$ as $15: 30$ & 22,2 & 25,2 & 25,1 & 1014,5 & 72,5 & 0,0 & 25,3 & 25,2 \\
\hline $15: 30$ as $16: 00$ & 22,1 & 25,1 & 25,0 & 1014,7 & 71,7 & 0,0 & 25,2 & 25,1 \\
\hline $15: 30$ as $16: 00$ & 22,1 & 25,1 & 25,0 & 1014,9 & 71,4 & 0,0 & 25,2 & 25,1 \\
\hline $16: 30$ as $17: 00$ & 22,3 & 25,4 & 25,2 & 1015,1 & 71,6 & 0,0 & 25,4 & 25,3 \\
\hline Desvio Padrão & 0,13 & 0,11 & 0,11 & 0,24 & 0,56 & 0,03 & 0,13 & 0,1 \\
\hline Média & 22,2 & 25,2 & 25,1 & 1014,8 & 71,8 & 0,0 & 25,3 & 25,2 \\
\hline \multicolumn{8}{|c|}{ Dados coletados Termômetro de fluxo de laser } & \\
\hline Horário/Quarto & $\begin{array}{c}\text { Temp. Externa do ar } \\
\left({ }^{\circ} \mathrm{C}\right)\end{array}$ & $\begin{array}{l}\text { Temp. Paredes } \\
\text { externas }\left({ }^{\circ} \mathrm{C}\right)\end{array}$ & $\begin{array}{c}\text { Temp.Paredes } \\
\text { voltada para a rua } \\
\left({ }^{\circ} \mathrm{C}\right)\end{array}$ & \multicolumn{3}{|c|}{ Temp. Média das paredes $\left({ }^{\circ} \mathrm{C}\right)$} & Temp. Teto $\left({ }^{\circ} \mathrm{C}\right)$ & \\
\hline 15:00 & 27,5 & 25,5 & 25 & \multicolumn{3}{|c|}{24,7} & 24,6 & \\
\hline $17: 00$ & 28,2 & 25,1 & 24,6 & \multicolumn{3}{|c|}{25,1} & 25,2 & \\
\hline
\end{tabular}

Tabela 87: Resultados coletados in loco na sala do Apartamento C no mês de Maio de 2014.

\begin{tabular}{|c|c|c|c|c|c|c|c|c|}
\hline \multicolumn{2}{|l|}{ Apartamento $\mathrm{C}$} & \multicolumn{4}{|c|}{ Dados coletados CONFORTÍMETRO Junho 2014 - SALA } & \multicolumn{3}{|c|}{ Chuva } \\
\hline Intervalo & $\begin{array}{l}\text { Temperatura de } \\
\text { bulbo úmido }\left({ }^{\circ} \mathrm{C}\right)\end{array}$ & $\begin{array}{c}\text { Temperatura de } \\
\text { globo }\left({ }^{\circ} \mathrm{C}\right)\end{array}$ & $\begin{array}{l}\text { Temperatura do ar } \\
\left({ }^{\circ} \mathrm{C}\right)\end{array}$ & $\begin{array}{l}\text { Pressão } \\
\text { Atmosférica } \\
\text { (atm) }\end{array}$ & $\begin{array}{l}\text { Umidade relativa } \\
\text { do ar (\%) }\end{array}$ & $\begin{array}{l}\text { Velocidade do ar } \\
\qquad(\mathrm{m} / \mathrm{s})\end{array}$ & $\begin{array}{l}\text { Temperatura } \\
\text { radiante }\left({ }^{\circ} \mathrm{C}\right)\end{array}$ & $\begin{array}{l}\text { Temperatura } \\
\text { Operativa }\left({ }^{\circ} \mathrm{C}\right)\end{array}$ \\
\hline $15: 00$ as $15: 30$ & 19,2 & 22,9 & 22,5 & 1022,7 & 65,2 & 0,0 & 23,0 & 22,8 \\
\hline $15: 30$ as $16: 00$ & 19,1 & 22,9 & 22,5 & 1022,7 & 63,8 & 0,0 & 23,0 & 22,8 \\
\hline $15: 30$ as $16: 00$ & 19,1 & 22,8 & 22,5 & 1022,8 & 64,2 & 0,0 & 22,9 & 22,7 \\
\hline $16: 30$ as $17: 00$ & 19,4 & 23,0 & 22,7 & 1022,8 & 65,2 & 0,0 & 23,0 & 22,9 \\
\hline Desvio Padrão & 0,17 & 0,08 & 0,11 & 0,05 & 1,10 & 0,01 & 0,07 & 0,1 \\
\hline Média & 19,2 & 22,9 & 22,6 & 1022,8 & 64,6 & 0,0 & 23,0 & 22,8 \\
\hline \multicolumn{8}{|c|}{ Dados coletados Termômetro de fluxo de laser } & \\
\hline Horário/Quarto & $\begin{array}{l}\text { Temp. Externa do ar } \\
\left({ }^{\circ} \mathrm{C}\right)\end{array}$ & $\begin{array}{l}\text { Temp. Paredes } \\
\text { externas }\left({ }^{\circ} \mathrm{C}\right)\end{array}$ & $\begin{array}{c}\text { Temp. Paredes } \\
\text { voltada para a rua } \\
\left({ }^{\circ} \mathrm{C}\right)\end{array}$ & \multicolumn{3}{|c|}{ Temp. M édia das paredes $\left({ }^{\circ} \mathrm{C}\right)$} & Temp. Teto $\left({ }^{\circ} \mathrm{C}\right)$ & \\
\hline 15:00 & 21,1 & 18,3 & 22,4 & \multicolumn{3}{|c|}{23,6} & 24,6 & \\
\hline $17: 00$ & 23,4 & 17,2 & 21,8 & \multicolumn{3}{|c|}{22,8} & 23,4 & \\
\hline
\end{tabular}

Tabela 88: Resultados coletados in loco na sala do Apartamento C no mês de Maio de 2014.

\begin{tabular}{|c|c|c|c|c|c|c|c|c|}
\hline \multicolumn{2}{|l|}{ Apartamento D } & \multicolumn{4}{|c|}{ Dados coletados CONFORTÍM ETRO Julho 2013 - QUARTO } & \multicolumn{3}{|c|}{ Nublado } \\
\hline Intervalo & $\begin{array}{l}\text { Temperatura de } \\
\text { bulbo úmido }\left({ }^{\circ} \mathrm{C}\right)\end{array}$ & $\begin{array}{c}\text { Temperatura de } \\
\text { globo }\left({ }^{\circ} \mathrm{C}\right)\end{array}$ & $\begin{array}{l}\text { Temperatura do ar } \\
\left({ }^{\circ} \mathrm{C}\right)\end{array}$ & $\begin{array}{c}\text { Pressão } \\
\text { Atmosférica (atm) }\end{array}$ & $\begin{array}{l}\text { Umidade relativa } \\
\text { do ar (\%) }\end{array}$ & $\begin{array}{l}\text { Velocidade do ar } \\
\qquad(\mathrm{m} / \mathrm{s})\end{array}$ & $\begin{array}{l}\text { Temperatura } \\
\text { radiante }\left({ }^{\circ} \mathrm{C}\right)\end{array}$ & $\begin{array}{l}\text { Temperatura } \\
\text { Operativa }\left({ }^{\circ} \mathrm{C}\right)\end{array}$ \\
\hline $11: 50$ as $12: 20$ & 19,6 & 22,2 & 21,9 & 1018,6 & 71,1 & 0,0 & 22,3 & 22,1 \\
\hline $12: 20$ as $12: 50$ & 19,4 & 21,9 & 21,7 & 1018,3 & 70,3 & 0,0 & 22,0 & 21,8 \\
\hline $12: 50$ as $13: 20$ & 19,0 & 21,8 & 21,6 & 1017,8 & 68,8 & 0,0 & 21,9 & 21,8 \\
\hline $13: 20$ as $13: 50$ & 18,7 & 21,8 & 21,6 & 1017,5 & 66,9 & 0,0 & 21,8 & 21,7 \\
\hline $13: 50$ as $14: 20$ & 18,6 & 21,7 & 21,5 & 1017,2 & 66,4 & 0,0 & 21,8 & 21,7 \\
\hline $14: 20$ as $14: 50$ & 18,5 & 21,7 & 21,5 & 1017,0 & 66,4 & 0,0 & 21,8 & 21,7 \\
\hline Desvio Padrão & 0,43 & 0,19 & 0,16 & 0,59 & 1,94 & 0,01 & 0,20 & 1,63 \\
\hline Média & 19,0 & 21,9 & 21,6 & 1017,7 & 68,3 & 0,0 & 21,9 & 21,8 \\
\hline \multicolumn{9}{|c|}{ Dados coletados Termômetro de fluxo de laser } \\
\hline Horário/ Quarto & $\begin{array}{l}\text { Temp. Externa do ar } \\
\left({ }^{\circ} \mathrm{C}\right)\end{array}$ & $\begin{array}{l}\text { Temp. Paredes } \\
\text { externas }\left({ }^{\circ} \mathrm{C}\right)\end{array}$ & $\begin{array}{c}\text { Temp. Paredes } \\
\text { voltada para a rua } \\
\left({ }^{\circ} \mathrm{C}\right)\end{array}$ & \multicolumn{3}{|c|}{ Temp. Média das paredes $\left({ }^{\circ} \mathrm{C}\right)$} & Temp. Teto $\left({ }^{\circ} \mathrm{C}\right)$ & \\
\hline $11: 50$ & 22 & 20 & 22 & \multicolumn{3}{|c|}{22} & 23 & \\
\hline $15: 00$ & 21 & 21 & 21 & \multicolumn{3}{|c|}{21} & 23 & \\
\hline
\end{tabular}

Tabela 89: Resultados coletados in loco na sala do Apartamento C no mês de Maio de 2014. 


\begin{tabular}{|c|c|c|c|c|c|c|c|c|}
\hline \multicolumn{2}{|l|}{ Apartamento D } & \multicolumn{4}{|c|}{ Dados coletados CONFORTÍMETRO Agosto 2013 - QUARTO } & \multicolumn{3}{|c|}{ Chuva } \\
\hline Intervalo & $\begin{array}{l}\text { Temperatura de } \\
\text { bulbo úmido }\left({ }^{\circ} \mathrm{C}\right)\end{array}$ & $\begin{array}{c}\text { Temperatura de } \\
\text { globo }\left({ }^{\circ} \mathrm{C}\right)\end{array}$ & $\begin{array}{l}\text { Temperatura do ar } \\
\left({ }^{\circ} \mathrm{C}\right)\end{array}$ & $\begin{array}{c}\text { Pressão } \\
\text { Atmosférica (atm) }\end{array}$ & $\begin{array}{l}\text { Umidade relativa } \\
\text { do ar (\%) }\end{array}$ & $\begin{array}{l}\text { Velocidade do ar } \\
\qquad(\mathrm{m} / \mathrm{s})\end{array}$ & $\begin{array}{l}\text { Temperatura } \\
\text { radiante }\left({ }^{\circ} \mathrm{C}\right)\end{array}$ & $\begin{array}{l}\text { Temperatura } \\
\text { Operativa }\left({ }^{\circ} \mathrm{C}\right)\end{array}$ \\
\hline $11: 50$ as $12: 20$ & 20,35 & 23,01 & 22,8 & 1011,15 & 73,58 & 0,03 & 23,1 & 23,0 \\
\hline $12: 20$ as $12: 50$ & 20,27 & 22,88 & 22,7 & 1010,78 & 73,47 & 0,01 & 23,0 & 22,8 \\
\hline $12: 50$ as $13: 20$ & 20,35 & 22,63 & 22,5 & 1010,42 & 75,62 & 0,00 & 22,7 & 22,6 \\
\hline $13: 20$ as $13: 50$ & 20,43 & 22,47 & 22,3 & 1010,22 & 77,27 & 0,00 & 22,5 & 22,4 \\
\hline $13: 50$ as $14: 20$ & 20,57 & 22,40 & 22,3 & 1010,30 & 79,39 & 0,00 & 22,4 & 22,4 \\
\hline $14: 20$ as $14: 50$ & 20,60 & 22,40 & 22,3 & 1010,30 & 79,71 & 0,00 & 22,4 & 22,4 \\
\hline Desvio Padrão & 0,14 & 0,26 & 0,22 & 0,37 & 2,67 & 0,03 & 0,31 & 1,63 \\
\hline Média & 20,4 & 22,7 & 22,5 & 1010,6 & 76,3 & 0,0 & 22,7 & 22,6 \\
\hline \multicolumn{9}{|c|}{ Dados coletados Termômetro de fluxo de laser } \\
\hline Horário/Quarto & $\begin{array}{l}\text { Temp. Externa do ar } \\
\left({ }^{\circ} \mathrm{C}\right)\end{array}$ & $\begin{array}{c}\text { Temp. Paredes } \\
\text { externas }\left({ }^{\circ} \mathrm{C}\right)\end{array}$ & $\begin{array}{c}\text { Temp. Paredes } \\
\text { voltada para a rua } \\
\left({ }^{\circ} \mathrm{C}\right)\end{array}$ & \multicolumn{3}{|c|}{ Temp. Média das paredes $\left({ }^{\circ} \mathrm{C}\right)$} & Temp. Teto $\left({ }^{\circ} \mathrm{C}\right)$ & \\
\hline 11:50 & 22 & 22 & 23 & \multicolumn{3}{|c|}{22} & 24 & \\
\hline $15: 00$ & 22 & 22,2 & 22,5 & \multicolumn{3}{|c|}{22} & 24 & \\
\hline
\end{tabular}

Tabela 90: Resultados coletados in loco no quarto do Apartamento D no mês de Agosto de 2013.

\begin{tabular}{|c|c|c|c|c|c|c|c|c|}
\hline \multicolumn{2}{|l|}{ Apartamento D } & \multicolumn{4}{|c|}{ Dados coletados CONFORTím ETRO Setembro 2013 - QUARTO } & \multicolumn{3}{|c|}{ Chuva } \\
\hline Intervalo & $\begin{array}{l}\text { Temperatura de } \\
\text { bulbo úmido }\left({ }^{\circ} \mathrm{C}\right)\end{array}$ & $\begin{array}{c}\text { Temperatura de } \\
\text { globo }\left({ }^{\circ} \mathrm{C}\right)\end{array}$ & $\begin{array}{c}\text { Temperatura do ar } \\
\left({ }^{\circ} \mathrm{C}\right)\end{array}$ & $\begin{array}{c}\text { Pressão } \\
\text { Atmosférica (atm) }\end{array}$ & $\begin{array}{l}\text { Umidade relativa } \\
\text { do ar (\%) }\end{array}$ & $\begin{array}{l}\text { Velocidade do ar } \\
(\mathrm{m} / \mathrm{s})\end{array}$ & $\begin{array}{l}\text { Temperatura } \\
\text { radiante }\left({ }^{\circ} \mathrm{C}\right)\end{array}$ & $\begin{array}{l}\text { Temperatura } \\
\text { Operativa }\left({ }^{\circ} \mathrm{C}\right)\end{array}$ \\
\hline $11: 50$ as $12: 20$ & 21,7 & 23,8 & 23,5 & 1012,3 & 76,3 & 0,0 & 23,9 & 23,7 \\
\hline $12: 20$ as $12: 50$ & 21,6 & 23,7 & 23,5 & 1012,3 & 75,9 & 0,0 & 23,8 & 23,7 \\
\hline $12: 50$ as $13: 20$ & 21,5 & 23,7 & 23,5 & 1012,1 & 76,0 & 0,0 & 23,8 & 23,6 \\
\hline $13: 20$ as $13: 50$ & 21,4 & 23,7 & 23,3 & 1013,0 & 76,6 & 0,0 & 23,7 & 23,5 \\
\hline $13: 50$ as $14: 20$ & 21,3 & 23,6 & 23,3 & 1012,5 & 76,4 & 0,0 & 23,7 & 23,5 \\
\hline $14: 20$ as $14: 50$ & 21,4 & 23,7 & 23,4 & 1012,0 & 76,5 & 0,0 & 23,7 & 23,6 \\
\hline Desvio Padrão & 0,16 & 0,09 & 0,10 & 0,43 & 0,33 & 0,00 & 0,10 & 1,63 \\
\hline Média & 21,5 & 23,7 & 23,4 & 1012,4 & 76,3 & 0,0 & 23,8 & 23,6 \\
\hline \multicolumn{9}{|c|}{ Dados coletados Termômetro de fluxo de laser } \\
\hline Horário/Quarto & $\begin{array}{l}\text { Temp. Externa do ar } \\
\qquad\left({ }^{\circ} \mathrm{C}\right)\end{array}$ & $\begin{array}{l}\text { Temp. Paredes } \\
\text { externas }\left({ }^{\circ} \mathrm{C}\right)\end{array}$ & $\begin{array}{c}\text { Temp.Paredes } \\
\text { voltada para a rua } \\
\left({ }^{\circ} \mathrm{C}\right)\end{array}$ & \multicolumn{3}{|c|}{ Temp. Média das paredes $\left({ }^{\circ} \mathrm{C}\right)$} & Temp. Teto $\left({ }^{\circ} \mathrm{C}\right)$ & \\
\hline $11: 50$ & 22,3 & 21,3 & 23,7 & \multicolumn{3}{|c|}{24,1} & 24,1 & \\
\hline $15: 00$ & 23 & 22,2 & 23,3 & \multicolumn{3}{|c|}{23,6} & 24,2 & \\
\hline
\end{tabular}

Tabela 91: Resultados coletados in loco no quarto do Apartamento D no mês de Setembro de 2013.

\begin{tabular}{|c|c|c|c|c|c|c|c|c|}
\hline \multicolumn{2}{|l|}{ Apartamento D } & \multicolumn{4}{|c|}{ Dados coletados CONFORTÍMETRO Outubro 2013 - QUARTO } & \multicolumn{3}{|c|}{ Nublado } \\
\hline Intervalo & $\begin{array}{l}\text { Temperatura de } \\
\text { bulbo úmido }\left({ }^{\circ} \mathrm{C}\right)\end{array}$ & $\begin{array}{l}\text { Temperatura de } \\
\text { globo }\left({ }^{\circ} \mathrm{C}\right)\end{array}$ & $\begin{array}{l}\text { Temperatura do ar } \\
\left({ }^{\circ} \mathrm{C}\right)\end{array}$ & $\begin{array}{c}\text { Pressão } \\
\text { Atmosférica (atm) }\end{array}$ & $\begin{array}{l}\text { Umidade relativa } \\
\text { do ar }(\%)\end{array}$ & $\begin{array}{l}\text { Velocidade do ar } \\
\qquad(\mathrm{m} / \mathrm{s})\end{array}$ & $\begin{array}{l}\text { Temperatura } \\
\text { radiante }\left({ }^{\circ} \mathrm{C}\right)\end{array}$ & $\begin{array}{l}\text { Temperatura } \\
\text { Operativa }\left({ }^{\circ} \mathrm{C}\right)\end{array}$ \\
\hline $11: 50$ as $12: 20$ & 21,7 & 23,6 & 23,4 & 1007,1 & 77,7 & 0,0 & 23,6 & 23,5 \\
\hline $12: 20$ as $12: 50$ & 21,5 & 23,5 & 23,3 & 1006,9 & 77,6 & 0,0 & 23,5 & 23,4 \\
\hline $12: 50$ as $13: 20$ & 21,5 & 23,4 & 23,3 & 1006,5 & 77,8 & 0,0 & 23,5 & 23,4 \\
\hline $13: 20$ as $13: 50$ & 21,4 & 23,4 & 23,2 & 1006,2 & 77,0 & 0,0 & 23,4 & 23,3 \\
\hline $13: 50$ as $14: 20$ & 21,3 & 23,4 & 23,2 & 1006,7 & 76,8 & 0,0 & 23,4 & 23,3 \\
\hline $14: 20$ as $14: 50$ & 21,4 & 23,3 & 23,1 & 1006,1 & 78,8 & 0,0 & 23,4 & 23,2 \\
\hline Desvio Padrão & 0,17 & 0,13 & 0,12 & 0,40 & 0,78 & 0,03 & 0,13 & 1,63 \\
\hline Média & 21,5 & 23,4 & 23,3 & 1006,6 & 77,6 & 0,0 & 23,5 & 23,4 \\
\hline \multicolumn{9}{|c|}{ Dados coletados Termômetro de fluxo de laser } \\
\hline Horário/Quarto & $\begin{array}{l}\text { Temp. Externa do ar } \\
\left({ }^{\circ} \mathrm{C}\right)\end{array}$ & $\begin{array}{l}\text { Temp. Paredes } \\
\text { externas }\left({ }^{\circ} \mathrm{C}\right)\end{array}$ & $\begin{array}{c}\text { Temp.Paredes } \\
\text { voltada para a rua } \\
\left({ }^{\circ} \mathrm{C}\right)\end{array}$ & \multicolumn{3}{|c|}{ Temp. Média das paredes $\left({ }^{\circ} \mathrm{C}\right)$} & Temp. Teto $\left({ }^{\circ} \mathrm{C}\right)$ & \\
\hline $11: 50$ & 24,5 & 22,9 & 22,7 & \multicolumn{3}{|c|}{23,4} & 23,4 & \\
\hline $15: 00$ & 18,9 & 21,6 & 23 & \multicolumn{3}{|c|}{23,4} & 23,4 & \\
\hline
\end{tabular}

Tabela 92: Resultados coletados in loco no quarto do Apartamento D no mês de Outubro de 2013.

\begin{tabular}{|c|c|c|c|c|c|c|c|c|}
\hline \multicolumn{2}{|l|}{ Apartamento D } & \multicolumn{4}{|c|}{ Dados coletados CONFORTÍM ETRO Novembro 2013 - QUARTO } & \multicolumn{3}{|c|}{ céu claro } \\
\hline Intervalo & $\begin{array}{l}\text { Temperatura de } \\
\text { bulbo úmido }\left({ }^{\circ} \mathrm{C}\right)\end{array}$ & $\begin{array}{l}\text { Temperatura de } \\
\text { globo }\left({ }^{\circ} \mathrm{C}\right)\end{array}$ & $\begin{array}{l}\text { Temperatura do ar } \\
\left({ }^{\circ} \mathrm{C}\right)\end{array}$ & $\begin{array}{c}\text { Pressão } \\
\text { Atmosférica (atm) }\end{array}$ & $\begin{array}{l}\text { Umidade relativa } \\
\text { do } \operatorname{ar}(\%)\end{array}$ & $\begin{array}{l}\text { Velocidade do ar } \\
\qquad(\mathrm{m} / \mathrm{s})\end{array}$ & $\begin{array}{l}\text { Temperatura } \\
\text { radiante }\left({ }^{\circ} \mathrm{C}\right)\end{array}$ & $\begin{array}{l}\text { Temperatura } \\
\text { Operativa }\left({ }^{\circ} \mathrm{C}\right)\end{array}$ \\
\hline $12: 50$ as $13: 20$ & 24,7 & 28,3 & 28,3 & 1006,8 & 67,3 & 0,0 & 28,2 & 28,3 \\
\hline $13: 20$ as $13: 50$ & 24,7 & 27,7 & 27,8 & 1006,5 & 70,6 & 0,0 & 27,7 & 27,8 \\
\hline $13: 50$ as $14: 20$ & 25,0 & 27,6 & 27,5 & 1007,0 & 74,6 & 0,0 & 27,6 & 27,6 \\
\hline $14: 20$ as $14: 50$ & 25,3 & 27,5 & 27,5 & 1005,9 & 77,8 & 0,0 & 27,5 & 27,5 \\
\hline $14: 50$ as $15: 20$ & 25,7 & 27,6 & 27,6 & 1005,4 & 79,3 & 0,0 & 27,6 & 27,6 \\
\hline $15: 20$ as $15: 50$ & 25,7 & 27,7 & 27,7 & 1004,9 & 78,8 & 0,0 & 27,7 & 27,7 \\
\hline Desvio Padrão & 0,43 & 0,30 & 0,34 & 0,80 & 4,89 & 0,02 & 0,28 & 1,63 \\
\hline Média & 25,1 & 27,8 & 27,8 & 1006,2 & 74,0 & 0,0 & 27,8 & 27,8 \\
\hline \multicolumn{8}{|c|}{ Dados coletados Termômetro de fluxo de laser } & \\
\hline Horário/Quarto & $\begin{array}{l}\text { Temp. Externa do ar } \\
\left({ }^{\circ} \mathrm{C}\right)\end{array}$ & $\begin{array}{l}\text { Temp. Paredes } \\
\text { externas }\left({ }^{\circ} \mathrm{C}\right)\end{array}$ & $\begin{array}{c}\text { Temp.Paredes } \\
\text { voltada para a rua } \\
\left({ }^{\circ} \mathrm{C}\right)\end{array}$ & \multicolumn{3}{|c|}{ Temp. Média das paredes $\left({ }^{\circ} \mathrm{C}\right)$} & Temp. Teto $\left({ }^{\circ} \mathrm{C}\right)$ & \\
\hline $12: 50$ & 32,6 & 32,5 & 27,8 & \multicolumn{3}{|c|}{27,2} & 28,2 & \\
\hline $16: 00$ & 31,2 & 29,3 & 27,6 & \multicolumn{3}{|c|}{26,6} & 26,8 & \\
\hline
\end{tabular}

Tabela 93: Resultados coletados in loco no quarto do Apartamento D no mês de Novembro de 2013. 


\begin{tabular}{|c|c|c|c|c|c|c|c|c|}
\hline \multicolumn{2}{|l|}{ Apartamento D } & \multicolumn{4}{|c|}{ Dados coletados CONFORTÍM ETRO Dezembro 2013 - QUARTO } & \multicolumn{3}{|c|}{$\begin{array}{c}\text { Parcialmente } \\
\text { nublado }\end{array}$} \\
\hline Intervalo & $\begin{array}{l}\text { Temperatura de } \\
\text { bulbo úmido }\left({ }^{\circ} \mathrm{C}\right)\end{array}$ & $\begin{array}{c}\text { Temperatura de } \\
\text { globo }\left({ }^{\circ} \mathrm{C}\right)\end{array}$ & $\begin{array}{c}\text { Temperatura do ar } \\
\left({ }^{\circ} \mathrm{C}\right)\end{array}$ & $\begin{array}{c}\text { Pressão } \\
\text { Atmosférica (atm) }\end{array}$ & $\begin{array}{l}\text { Umidade relativa } \\
\text { do ar (\%) }\end{array}$ & $\begin{array}{l}\text { Velocidade do ar } \\
\qquad(\mathrm{m} / \mathrm{s})\end{array}$ & $\begin{array}{l}\text { Temperatura } \\
\text { radiante }\left({ }^{\circ} \mathrm{C}\right)\end{array}$ & $\begin{array}{l}\text { Temperatura } \\
\text { Operativa }\left({ }^{\circ} \mathrm{C}\right)\end{array}$ \\
\hline $12: 50$ as $13: 20$ & 25,3 & 28,0 & 27,9 & 1008,6 & 73,3 & 0,0 & 28,0 & 28,0 \\
\hline $13: 20$ as $13: 50$ & 25,0 & 27,9 & 27,9 & 1008,3 & 72,3 & 0,0 & 28,0 & 27,9 \\
\hline $13: 50$ as $14: 20$ & 25,0 & 27,9 & 27,8 & 1007,9 & 72,6 & 0,0 & 27,9 & 27,9 \\
\hline $14: 20$ as $14: 50$ & 24,9 & 28,0 & 27,9 & 1007,3 & 71,9 & 0,0 & 28,1 & 28,0 \\
\hline $14: 50$ as $15: 20$ & 25,0 & 28,1 & 28,0 & 1006,9 & 71,8 & 0,0 & 28,1 & 28,1 \\
\hline $15: 20$ as $15: 50$ & 25,1 & 28,1 & 28,0 & 1006,5 & 72,7 & 0,0 & 28,1 & 28,1 \\
\hline Desvio Padrão & 0,14 & 0,12 & 0,09 & 0,77 & 0,66 & 0,01 & 0,13 & 1,63 \\
\hline Média & 25,1 & 28,0 & 27,9 & 1007,7 & 72,5 & 0,0 & 28,0 & 28,0 \\
\hline \multicolumn{8}{|c|}{ Dados coletados Termômetro de fluxo de laser } & \\
\hline Horário/Quarto & $\begin{array}{l}\text { Temp. Externa do ar } \\
\left({ }^{\circ} \mathrm{C}\right)\end{array}$ & $\begin{array}{l}\text { Temp. Paredes } \\
\text { externas }\left({ }^{\circ} \mathrm{C}\right)\end{array}$ & $\begin{array}{c}\text { Temp. Paredes } \\
\text { voltada para a rua } \\
\left({ }^{\circ} \mathrm{C}\right)\end{array}$ & \multicolumn{3}{|c|}{ Temp. Média das paredes $\left({ }^{\circ} \mathrm{C}\right)$} & Temp. Teto $\left({ }^{\circ} \mathrm{C}\right)$ & \\
\hline $12: 50$ & 31 & 31,8 & 27,7 & \multicolumn{3}{|c|}{27,1} & 27,6 & \\
\hline $16: 00$ & 36,7 & 37,9 & 29,1 & \multicolumn{3}{|c|}{27,2} & 28,2 & \\
\hline
\end{tabular}

Tabela 94: Resultados coletados in loco no quarto do Apartamento D no mês de Dezembro de 2013.

\begin{tabular}{|c|c|c|c|c|c|c|c|c|}
\hline \multicolumn{2}{|l|}{ Apartamento D } & \multicolumn{4}{|c|}{ Dados coletados CONFORTÍMETRO J aneiro 2014 - QUARTO } & \multicolumn{3}{|c|}{ céu claro } \\
\hline Intervalo & $\begin{array}{l}\text { Temperatura de } \\
\text { bulbo úmido }\left({ }^{\circ} \mathrm{C}\right)\end{array}$ & $\begin{array}{c}\text { Temperatura de } \\
\text { globo }\left({ }^{\circ} \mathrm{C}\right)\end{array}$ & $\begin{array}{c}\text { Temperatura do ar } \\
\left({ }^{\circ} \mathrm{C}\right)\end{array}$ & $\begin{array}{c}\text { Pressão } \\
\text { Atmosférica (atm) }\end{array}$ & $\begin{array}{c}\text { Umidade relativa } \\
\text { do ar (\%) }\end{array}$ & $\begin{array}{c}\text { Velocidade do ar } \\
(\mathrm{m} / \mathrm{s})\end{array}$ & $\begin{array}{l}\text { Temperatura } \\
\text { radiante }\left({ }^{\circ} \mathrm{C}\right)\end{array}$ & $\begin{array}{l}\text { Temperatura } \\
\text { Operativa }\left({ }^{\circ} \mathrm{C}\right)\end{array}$ \\
\hline $12: 50$ as $13: 20$ & 24,6 & 28,8 & 28,8 & 1011,9 & 64,8 & 0,0 & 28,9 & 28,8 \\
\hline $13: 20$ as $13: 50$ & 24,4 & 28,9 & 29,0 & 1011,7 & 62,8 & 0,1 & 28,9 & 29,0 \\
\hline $13: 50$ as $14: 20$ & 24,4 & 29,2 & 29,2 & 1011,4 & 61,2 & 0,1 & 29,2 & 29,2 \\
\hline $14: 20$ as $14: 50$ & 24,5 & 29,3 & 29,3 & 1011,3 & 60,4 & 0,0 & 29,3 & 29,3 \\
\hline $14: 50$ as $15: 20$ & 24,6 & 29,3 & 29,2 & 1011,3 & 61,5 & 0,0 & 29,4 & 29,3 \\
\hline $15: 20$ as $15: 50$ & 24,5 & 29,5 & 29,5 & 1011,0 & 60,0 & 0,1 & 29,6 & 29,5 \\
\hline Desvio Padrão & 0,15 & 0,27 & 0,28 & 0,32 & 1,97 & 0,08 & 0,27 & 1,63 \\
\hline Média & 24,5 & 29,1 & 29,1 & 1011,5 & 62,2 & 0,1 & 29,1 & 29,1 \\
\hline \multicolumn{9}{|c|}{ Dados coletados Termômetro de fluxo de laser } \\
\hline Horário/Quarto & $\begin{array}{l}\text { Temp. Externa do ar } \\
\qquad\left({ }^{\circ} \mathrm{C}\right)\end{array}$ & $\begin{array}{l}\text { Temp. Paredes } \\
\text { externas }\left({ }^{\circ} \mathrm{C}\right)\end{array}$ & $\begin{array}{c}\text { Temp. Paredes } \\
\text { voltada para a rua } \\
\left({ }^{\circ} \mathrm{C}\right)\end{array}$ & \multicolumn{3}{|c|}{ Temp. Média das paredes $\left({ }^{\circ} \mathrm{C}\right)$} & Temp. Teto $\left({ }^{\circ} \mathrm{C}\right)$ & \\
\hline $12: 50$ & 31,7 & 30,4 & 28,1 & \multicolumn{3}{|c|}{28,3} & 29,4 & \\
\hline 16:00 & 37,7 & 40,2 & 30,8 & \multicolumn{3}{|c|}{28,3} & 28,8 & \\
\hline
\end{tabular}

Tabela 95: Resultados coletados in loco no quarto do Apartamento D no mês de Janeiro de 2014.

\begin{tabular}{|c|c|c|c|c|c|c|c|c|}
\hline \multicolumn{2}{|l|}{ Apartamento D } & \multicolumn{4}{|c|}{ Dados coletados CONFORTÍMETRO Fevereiro 2014 - QUARTO } & \multicolumn{3}{|c|}{ céu claro } \\
\hline Intervalo & $\begin{array}{l}\text { Temperatura de } \\
\text { bulbo úmido }\left({ }^{\circ} \mathrm{C}\right)\end{array}$ & $\begin{array}{l}\text { Temperatura de } \\
\text { globo }\left({ }^{\circ} \mathrm{C}\right)\end{array}$ & $\begin{array}{l}\text { Temperatura do ar } \\
\left({ }^{\circ} \mathrm{C}\right)\end{array}$ & $\begin{array}{c}\text { Pressão } \\
\text { Atmosférica (atm) }\end{array}$ & $\begin{array}{l}\text { Umidade relativa } \\
\text { do } \operatorname{ar}(\%)\end{array}$ & $\begin{array}{l}\text { Velocidade do ar } \\
\qquad(\mathrm{m} / \mathrm{s})\end{array}$ & $\begin{array}{l}\text { Temperatura } \\
\text { radiante }\left({ }^{\circ} \mathrm{C}\right)\end{array}$ & $\begin{array}{l}\text { Temperatura } \\
\text { Operativa }\left({ }^{\circ} \mathrm{C}\right)\end{array}$ \\
\hline $11: 50$ as $12: 20$ & 23,6 & 28,4 & 28,4 & 1011,8 & 60,4 & 0,1 & 28,4 & 28,4 \\
\hline $12: 20$ as $12: 50$ & 23,4 & 28,5 & 28,6 & 1011,6 & 58,7 & 0,1 & 28,5 & 28,5 \\
\hline $12: 50$ as $13: 20$ & 23,6 & 28,8 & 28,9 & 1011,4 & 58,1 & 0,1 & 28,7 & 28,8 \\
\hline $13: 20$ as $13: 50$ & 23,8 & 28,8 & 28,8 & 1011,1 & 59,1 & 0,0 & 28,8 & 28,8 \\
\hline $13: 50$ as $14: 20$ & 24,0 & 28,5 & 28,5 & 1010,8 & 61,6 & 0,0 & 28,5 & 28,5 \\
\hline $14: 20$ as $14: 50$ & 24,1 & 28,5 & 28,4 & 1010,6 & 62,2 & 0,0 & 28,6 & 28,5 \\
\hline Desvio Padrão & 0,26 & 0,17 & 0,23 & 0,44 & 1,66 & 0,06 & 0,18 & 1,63 \\
\hline Média & 23,7 & 28,6 & 28,6 & 1011,2 & 60,0 & 0,0 & 28,6 & 28,6 \\
\hline \multicolumn{9}{|c|}{ Dados coletados Termômetro de fluxo de laser } \\
\hline Horário/Quarto & $\begin{array}{l}\text { Temp. Externa do ar } \\
\left({ }^{\circ} \mathrm{C}\right)\end{array}$ & $\begin{array}{l}\text { Temp. Paredes } \\
\text { externas }\left({ }^{\circ} \mathrm{C}\right)\end{array}$ & $\begin{array}{c}\text { Temp. Paredes } \\
\text { voltada para a rua } \\
\left({ }^{\circ} \mathrm{C}\right)\end{array}$ & \multicolumn{3}{|c|}{ Temp. Média das paredes $\left({ }^{\circ} \mathrm{C}\right)$} & Temp. Teto $\left({ }^{\circ} \mathrm{C}\right)$ & \\
\hline $11: 50$ & 33,3 & 31,2 & 27 & \multicolumn{3}{|c|}{28} & 28 & \\
\hline $15: 00$ & 31 & 41,6 & 29,4 & \multicolumn{3}{|c|}{28} & 28,8 & \\
\hline
\end{tabular}

Tabela 96: Resultados coletados in loco no quarto do Apartamento D no mês de Fevereiro de 2014.

\begin{tabular}{|c|c|c|c|c|c|c|c|c|}
\hline \multicolumn{2}{|l|}{ Apartamento D } & \multicolumn{4}{|c|}{ Dados coletados CONFORTÍMETRO Março 2014 - QUARTO } & \multicolumn{3}{|c|}{ céu claro } \\
\hline Intervalo & $\begin{array}{l}\text { Temperatura de } \\
\text { bulbo úmido }\left({ }^{\circ} \mathrm{C}\right)\end{array}$ & $\begin{array}{c}\text { Temperatura de } \\
\text { globo }\left({ }^{\circ} \mathrm{C}\right)\end{array}$ & $\begin{array}{l}\text { Temperatura do ar } \\
\left({ }^{\circ} \mathrm{C}\right)\end{array}$ & $\begin{array}{c}\text { Pressão } \\
\text { Atmosférica (atm) }\end{array}$ & $\begin{array}{c}\text { Umidade relativa } \\
\text { do } \operatorname{ar}(\%)\end{array}$ & $\begin{array}{l}\text { Velocidade do ar } \\
\qquad(\mathrm{m} / \mathrm{s})\end{array}$ & $\begin{array}{l}\text { Temperatura } \\
\text { radiante }\left({ }^{\circ} \mathrm{C}\right)\end{array}$ & $\begin{array}{c}\text { Temperatura } \\
\text { Operativa }\left({ }^{\circ} \mathrm{C}\right)\end{array}$ \\
\hline $11: 50$ as $12: 20$ & 26,3 & 31,2 & 31,1 & 1003,8 & 62,5 & 0,0 & 31,2 & 31,2 \\
\hline $12: 20$ as $12: 50$ & 26,5 & 31,0 & 31,0 & 1003,8 & 64,8 & 0,0 & 31,0 & 31,0 \\
\hline $12: 50$ as $13: 20$ & 26,9 & 31,0 & 30,9 & 1003,7 & 67,8 & 0,0 & 31,0 & 31,0 \\
\hline $13: 20$ as $13: 50$ & 27,2 & 30,9 & 30,9 & 1004,1 & 70,1 & 0,0 & 30,9 & 30,9 \\
\hline $13: 50$ as $14: 20$ & 27,2 & 30,9 & 30,8 & 1004,3 & 70,6 & 0,0 & 30,9 & 30,9 \\
\hline $14: 20$ as $14: 50$ & 27,1 & 30,9 & 30,8 & 1004,4 & 69,9 & 0,0 & 30,9 & 30,8 \\
\hline Desvio Padrão & 0,33 & 0,14 & 0,16 & 0,27 & 2,80 & 0,06 & 0,15 & 1,63 \\
\hline Média & 26,9 & 31,0 & 30,9 & 1004,0 & 68,1 & 0,0 & 31,0 & 30,9 \\
\hline \multicolumn{8}{|c|}{ Dados coletados Termômetro de fluxo de laser } & \\
\hline Horário/Quarto & $\begin{array}{l}\text { Temp. Externa do ar } \\
\qquad\left({ }^{\circ} \mathrm{C}\right)\end{array}$ & $\begin{array}{c}\text { Temp. Paredes } \\
\text { externas }\left({ }^{\circ} \mathrm{C}\right)\end{array}$ & $\begin{array}{c}\text { Temp. Paredes } \\
\text { voltada para a rua } \\
\left({ }^{\circ} \mathrm{C}\right)\end{array}$ & \multicolumn{3}{|c|}{ Temp. Média das paredes $\left({ }^{\circ} \mathrm{C}\right)$} & Temp. Teto $\left({ }^{\circ} \mathrm{C}\right)$ & \\
\hline $11: 50$ & 39,5 & 38,8 & 30,4 & \multicolumn{3}{|c|}{31,3} & 31,6 & \\
\hline $15: 00$ & 32,7 & 36 & 32,5 & \multicolumn{3}{|c|}{30,7} & 31,1 & \\
\hline
\end{tabular}

Tabela 97: Resultados coletados in loco no quarto do Apartamento D no mês de Março de 2014. 


\begin{tabular}{|c|c|c|c|c|c|c|c|c|}
\hline \multicolumn{2}{|l|}{ Apartamento D } & \multicolumn{4}{|c|}{ Dados coletados CON FORTÍM ETRO Abril 2014 - QUARTO } & \multicolumn{3}{|c|}{$\begin{array}{l}\text { Parcialmente } \\
\text { claro }\end{array}$} \\
\hline Intervalo & $\begin{array}{l}\text { Temperatura de } \\
\text { bulbo úmido }\left({ }^{\circ} \mathrm{C}\right)\end{array}$ & $\begin{array}{l}\text { Temperatura de } \\
\text { globo }\left({ }^{\circ} \mathrm{C}\right)\end{array}$ & $\begin{array}{c}\text { Temperatura do ar } \\
\left({ }^{\circ} \mathrm{C}\right)\end{array}$ & $\begin{array}{c}\text { Pressão } \\
\text { Atmosférica (atm) }\end{array}$ & $\begin{array}{l}\text { Umidade relativa } \\
\qquad \text { do } \operatorname{ar}(\%)\end{array}$ & $\begin{array}{l}\text { Velocidade do ar } \\
(\mathrm{m} / \mathrm{s})\end{array}$ & $\begin{array}{l}\text { Temperatura } \\
\text { radiante }\left({ }^{\circ} \mathrm{C}\right)\end{array}$ & $\begin{array}{l}\text { Temperatura } \\
\text { Operativa }\left({ }^{\circ} \mathrm{C}\right)\end{array}$ \\
\hline $11: 50$ as $12: 20$ & 18,0 & 24,4 & 24,2 & 1017,8 & 46,4 & 0,0 & 24,4 & 24,3 \\
\hline $12: 20$ as $12: 50$ & 18,0 & 24,2 & 24,1 & 1017,4 & 46,4 & 0,0 & 24,2 & 24,1 \\
\hline $12: 50$ as $13: 20$ & 18,2 & 24,3 & 24,1 & 1016,9 & 48,3 & 0,0 & 24,3 & 24,2 \\
\hline $13: 20$ as $13: 50$ & 18,1 & 24,2 & 24,0 & 1016,4 & 47,7 & 0,0 & 24,2 & 24,1 \\
\hline $13: 50$ as $14: 20$ & 18,2 & 24,2 & 24,1 & 1016,1 & 47,4 & 0,0 & 24,3 & 24,2 \\
\hline $14: 20$ as $14: 50$ & 18,2 & 24,2 & 24,1 & 1015,8 & 47,1 & 0,0 & 24,2 & 24,1 \\
\hline Desvio Padrão & 0,15 & 0,09 & 0,11 & 0,73 & 1,23 & 0,01 & 0,11 & 1,63 \\
\hline Média & 18,1 & 24,2 & 24,1 & 1016,8 & 47,2 & 0,0 & 24,3 & 24,2 \\
\hline \multicolumn{8}{|c|}{ Dados coletados Termômetro de fluxo de laser } & \\
\hline Horário/Quarto & $\begin{array}{l}\text { Temp. Externa do ar } \\
\left({ }^{\circ} \mathrm{C}\right)\end{array}$ & $\begin{array}{l}\text { Temp. Paredes } \\
\text { externas }\left({ }^{\circ} \mathrm{C}\right)\end{array}$ & $\begin{array}{c}\text { Temp. Paredes } \\
\text { voltada para a rua } \\
\left({ }^{\circ} \mathrm{C}\right)\end{array}$ & \multicolumn{3}{|c|}{ Temp. Média das paredes $\left({ }^{\circ} \mathrm{C}\right)$} & Temp. Teto $\left({ }^{\circ} \mathrm{C}\right)$ & \\
\hline $11: 50$ & 25,4 & 29,7 & 23,1 & \multicolumn{3}{|c|}{23,9} & 24,3 & \\
\hline 15:00 & 28,9 & 26,4 & 24,7 & \multicolumn{3}{|c|}{23,5} & 23,9 & \\
\hline
\end{tabular}

Tabela 98: Resultados coletados in loco no quarto do Apartamento D no mês de Abril de 2014.

\begin{tabular}{|c|c|c|c|c|c|c|c|c|}
\hline \multicolumn{2}{|l|}{ Apartamento D } & \multicolumn{4}{|c|}{ Dados coletados CONFORTÍM ETRO M aio 2014 - QUARTO } & \multicolumn{3}{|c|}{ céu claro } \\
\hline Intervalo & $\begin{array}{l}\text { Temperatura de } \\
\text { bulbo úmido }\left({ }^{\circ} \mathrm{C}\right)\end{array}$ & $\begin{array}{l}\text { Temperatura de } \\
\text { globo }\left({ }^{\circ} \mathrm{C}\right)\end{array}$ & $\begin{array}{l}\text { Temperatura do ar } \\
\left({ }^{\circ} \mathrm{C}\right)\end{array}$ & $\begin{array}{c}\text { Pressão } \\
\text { Atmosférica (atm) }\end{array}$ & $\begin{array}{l}\text { Umidade relativa } \\
\text { do ar (\%) }\end{array}$ & $\begin{array}{l}\text { Velocidade do ar } \\
\qquad(\mathrm{m} / \mathrm{s})\end{array}$ & $\begin{array}{l}\text { Temperatura } \\
\text { radiante }\left({ }^{\circ} \mathrm{C}\right)\end{array}$ & $\begin{array}{l}\text { Temperatura } \\
\text { Operativa }\left({ }^{\circ} \mathrm{C}\right)\end{array}$ \\
\hline $11: 50$ as $12: 20$ & 19,4 & 24,6 & 24,5 & 1016,1 & 53,3 & 0,1 & 24,7 & 24,6 \\
\hline $12: 20$ as $12: 50$ & 19,3 & 24,7 & 24,5 & 1016,1 & 52,6 & 0,0 & 24,7 & 24,6 \\
\hline $12: 50$ as $13: 20$ & 19,1 & 24,6 & 24,4 & 1016,0 & 51,9 & 0,0 & 24,7 & 24,6 \\
\hline $13: 20$ as $13: 50$ & 19,2 & 24,5 & 24,3 & 1015,7 & 52,7 & 0,0 & 24,5 & 24,4 \\
\hline $13: 50$ as $14: 20$ & 19,1 & 24,5 & 24,4 & 1015,2 & 52,2 & 0,0 & 24,5 & 24,5 \\
\hline $14: 20$ as $14: 50$ & 18,6 & 24,5 & 24,5 & 1014,9 & 48,6 & 0,1 & 24,6 & 24,5 \\
\hline Desvio Padrão & 0,31 & 0,07 & 0,07 & 0,42 & 1,93 & 0,07 & 0,09 & 1,63 \\
\hline Média & 19,0 & 24,5 & 24,4 & 1015,4 & 51,2 & 0,0 & 24,6 & 24,5 \\
\hline \multicolumn{9}{|c|}{ Dados coletados Termômetro de fluxo de laser } \\
\hline Horário/Quarto & $\begin{array}{l}\text { Temp. Externa do ar } \\
\left({ }^{\circ} \mathrm{C}\right)\end{array}$ & $\begin{array}{l}\text { Temp. Paredes } \\
\text { externas }\left({ }^{\circ} \mathrm{C}\right)\end{array}$ & $\begin{array}{c}\text { Temp.Paredes } \\
\text { voltada para a rua } \\
\left({ }^{\circ} \mathrm{C}\right)\end{array}$ & \multicolumn{3}{|c|}{ Temp. Média das paredes $\left({ }^{\circ} \mathrm{C}\right)$} & Temp. Teto $\left({ }^{\circ} \mathrm{C}\right)$ & \\
\hline $11: 50$ & 25,3 & 27,2 & 24 & \multirow{2}{*}{\multicolumn{3}{|c|}{24,1}} & 24,1 & \\
\hline $15: 00$ & 28,5 & 25,9 & 25,2 & & & & 23,8 & \\
\hline
\end{tabular}

Tabela 99: Resultados coletados in loco no quarto do Apartamento D no mês de Maio de 2014.

\begin{tabular}{|c|c|c|c|c|c|c|c|c|}
\hline \multicolumn{2}{|l|}{ Apartamento D } & \multicolumn{4}{|c|}{ Dados coletados CONFORTÍM ETRO Junho 2014 - QUARTO } & \multicolumn{3}{|c|}{$\begin{array}{c}\text { Parcialmente } \\
\text { nublado }\end{array}$} \\
\hline Intervalo & $\begin{array}{l}\text { Temperatura de } \\
\text { bulbo úmido }\left({ }^{\circ} \mathrm{C}\right)\end{array}$ & $\begin{array}{l}\text { Temperatura de } \\
\text { globo }\left({ }^{\circ} \mathrm{C}\right)\end{array}$ & $\begin{array}{l}\text { Temperatura do ar } \\
\left({ }^{\circ} \mathrm{C}\right)\end{array}$ & $\begin{array}{c}\text { Pressão } \\
\text { Atmosférica (atm) }\end{array}$ & $\begin{array}{l}\text { Umidade relativa } \\
\text { do } \operatorname{ar}(\%)\end{array}$ & $\begin{array}{c}\text { Velocidade do ar } \\
(\mathrm{m} / \mathrm{s})\end{array}$ & $\begin{array}{l}\text { Temperatura } \\
\text { radiante }\left({ }^{\circ} \mathrm{C}\right)\end{array}$ & $\begin{array}{l}\text { Temperatura } \\
\text { Operativa }\left({ }^{\circ} \mathrm{C}\right)\end{array}$ \\
\hline $11: 50$ as $12: 20$ & 21,5 & 24,1 & 23,9 & 1019,1 & 75,7 & 0,0 & 24,3 & 24,1 \\
\hline $12: 20$ as $12: 50$ & 21,7 & 24,2 & 24,0 & 1018,7 & 77,0 & 0,0 & 24,4 & 24,2 \\
\hline $12: 50$ as $13: 20$ & 21,8 & 24,1 & 24,0 & 1018,5 & 78,0 & 0,0 & 24,2 & 24,1 \\
\hline $13: 20$ as $13: 50$ & 21,9 & 23,9 & 23,8 & 1018,9 & 79,8 & 0,0 & 24,1 & 23,9 \\
\hline $13: 50$ as $14: 20$ & 21,2 & 23,4 & 23,2 & 1019,3 & 77,8 & 0,0 & 23,6 & 23,4 \\
\hline $14: 20$ as $14: 50$ & 20,9 & 23,4 & 23,2 & 1019,4 & 74,2 & 0,0 & 23,5 & 23,4 \\
\hline Desvio Padrão & 0,36 & 0,34 & 0,35 & 0,33 & 1,91 & 0,07 & 0,38 & 1,63 \\
\hline Média & 21,5 & 23,9 & 23,7 & 1019,0 & 77,0 & 0,0 & 24,0 & 23,9 \\
\hline \multicolumn{9}{|c|}{ Dados coletados Termômetro de fluxo de laser } \\
\hline Horário/Quarto & $\begin{array}{l}\text { Temp. Externa do ar } \\
\left({ }^{\circ} \mathrm{C}\right)\end{array}$ & $\begin{array}{l}\text { Temp. Paredes } \\
\text { externas }\left({ }^{\circ} \mathrm{C}\right)\end{array}$ & $\begin{array}{c}\text { Temp. Paredes } \\
\text { voltada para a rua } \\
\left({ }^{\circ} \mathrm{C}\right)\end{array}$ & \multicolumn{3}{|c|}{ Temp. Média das paredes $\left({ }^{\circ} \mathrm{C}\right)$} & Temp. Teto $\left({ }^{\circ} \mathrm{C}\right)$ & \\
\hline $11: 50$ & 24,6 & 23,5 & 22,8 & \multicolumn{3}{|c|}{23,7} & 23,5 & \\
\hline $14: 50$ & 25,2 & 22,3 & 23,8 & \multicolumn{3}{|c|}{23,9} & 24,1 & \\
\hline
\end{tabular}

Tabela 100: Resultados coletados in loco no quarto do Apartamento D no mês de Junho de 2014.

\begin{tabular}{|c|c|c|c|c|c|c|c|c|}
\hline \multicolumn{2}{|l|}{ Apartamento D } & \multicolumn{4}{|c|}{ Dados coletados CONFORTÍM ETRO Julho 2013 - SALA } & \multicolumn{3}{|c|}{ Chuva } \\
\hline Intervalo & $\begin{array}{l}\text { Temperatura de } \\
\text { bulbo úmido }\left({ }^{\circ} \mathrm{C}\right)\end{array}$ & $\begin{array}{c}\text { Temperatura de } \\
\text { globo }\left({ }^{\circ} \mathrm{C}\right)\end{array}$ & $\begin{array}{c}\text { Temperatura do ar } \\
\left({ }^{\circ} \mathrm{C}\right)\end{array}$ & $\begin{array}{c}\text { Pressão } \\
\text { Atmosférica }\end{array}$ & $\begin{array}{c}\text { Umidade relativa } \\
\text { do ar (\%) }\end{array}$ & $\begin{array}{c}\text { Velocidade do ar } \\
(\mathrm{m} / \mathrm{s})\end{array}$ & $\begin{array}{l}\text { Temperatura } \\
\text { radiante }\left({ }^{\circ} \mathrm{C}\right)\end{array}$ & $\begin{array}{c}\text { Temperatura } \\
\text { Operativa }\left({ }^{\circ} \mathrm{C}\right)\end{array}$ \\
\hline $15: 00$ as $15: 30$ & 18,6 & 21,7 & 21,4 & 1017,0 & 69,7 & 0,0 & 21,8 & 21,6 \\
\hline $15: 30$ as $16: 00$ & 18,8 & 21,7 & 21,4 & 1017,0 & 71,3 & 0,0 & 21,8 & 21,6 \\
\hline $15: 30$ as $16: 00$ & 19,0 & 21,7 & 21,4 & 1017,1 & 73,3 & 0,0 & 21,8 & 21,6 \\
\hline $16: 30$ as $17: 00$ & 18,8 & 21,7 & 21,4 & 1017,3 & 71,5 & 0,0 & 21,8 & 21,6 \\
\hline Desvio Padrão & 0,20 & 0,06 & 0,04 & 0,14 & 1,82 & 0,03 & 0,09 & 0,1 \\
\hline Média & 18,8 & 21,7 & 21,4 & 1017,1 & 71,4 & 0,0 & 21,8 & 21,6 \\
\hline \multicolumn{9}{|c|}{ Dados coletados Termômetro de fluxo de laser } \\
\hline Horário/Quarto & $\begin{array}{l}\text { Temp. Externa do ar } \\
\left({ }^{\circ} \mathrm{C}\right)\end{array}$ & $\begin{array}{l}\text { Temp. Paredes } \\
\text { externas }\left({ }^{\circ} \mathrm{C}\right)\end{array}$ & $\begin{array}{c}\text { Temp.Paredes } \\
\text { voltada para a rua } \\
\left({ }^{\circ} \mathrm{C}\right)\end{array}$ & \multicolumn{3}{|c|}{ Temp. M édia das paredes $\left({ }^{\circ} \mathrm{C}\right)$} & Temp. Teto $\left({ }^{\circ} \mathrm{C}\right)$ & \\
\hline $15: 00$ & 21 & 19 & 21 & \multicolumn{3}{|c|}{21} & 23 & \\
\hline $17: 00$ & 19 & 18,5 & 21 & \multicolumn{3}{|c|}{21,2} & 23 & \\
\hline
\end{tabular}

Tabela 101: Resultados coletados in loco na sala do Apartamento D no mês de Julho de 2013. 


\begin{tabular}{|c|c|c|c|c|c|c|c|c|}
\hline \multicolumn{2}{|l|}{ Apartamento D } & \multicolumn{4}{|c|}{ Dados coletados CONFORTíMETRO Agosto 2013 - SALA } & \multicolumn{3}{|c|}{ Chuva } \\
\hline Intervalo & $\begin{array}{l}\text { Temperatura de } \\
\text { bulbo úmido }\left({ }^{\circ} \mathrm{C}\right)\end{array}$ & $\begin{array}{l}\text { Temperatura de } \\
\text { globo }\left({ }^{\circ} \mathrm{C}\right)\end{array}$ & $\begin{array}{c}\text { Temperatura do ar } \\
\left({ }^{\circ} \mathrm{C}\right)\end{array}$ & $\begin{array}{l}\text { Pressão } \\
\text { Atmosférica } \\
\text { (atm) }\end{array}$ & $\begin{array}{l}\text { Umidade relativa } \\
\text { do ar (\%) }\end{array}$ & $\begin{array}{l}\text { Velocidade do ar } \\
\qquad(\mathrm{m} / \mathrm{s})\end{array}$ & $\begin{array}{l}\text { Temperatura } \\
\text { radiante }\left({ }^{\circ} \mathrm{C}\right)\end{array}$ & $\begin{array}{c}\text { Temperatura } \\
\text { Operativa }\left({ }^{\circ} \mathrm{C}\right)\end{array}$ \\
\hline $15: 00$ as $15: 30$ & 20,7 & 22,4 & 22,4 & 1010,2 & 79,9 & 0,0 & 22,5 & 22,4 \\
\hline $15: 30$ as $16: 00$ & 20,7 & 22,3 & 22,3 & 1010,3 & 79,9 & 0,0 & 22,3 & 22,3 \\
\hline $15: 30$ as $16: 00$ & 20,6 & 22,3 & 22,3 & 1010,4 & 79,9 & 0,0 & 22,3 & 22,3 \\
\hline $16: 30$ as $17: 00$ & 20,5 & 22,7 & 22,4 & 1010,5 & 79,0 & 0,0 & 22,8 & 22,6 \\
\hline Desvio Padrão & 0,05 & 0,05 & 0,04 & 0,05 & 0,14 & 0,04 & 0,05 & 0,0 \\
\hline Média & 20,6 & 22,4 & 22,4 & 1010,3 & 79,7 & 0,0 & 22,5 & 22,4 \\
\hline \multicolumn{8}{|c|}{ Dados coletados Termômetro de fluxo de laser } & \\
\hline Horário/Quarto & $\begin{array}{l}\text { Temp. Externa do ar } \\
\left({ }^{\circ} \mathrm{C}\right)\end{array}$ & $\begin{array}{l}\text { Temp. Paredes } \\
\text { externas }\left({ }^{\circ} \mathrm{C}\right)\end{array}$ & $\begin{array}{c}\text { Temp.Paredes } \\
\text { voltada para a rua } \\
\left({ }^{\circ} \mathrm{C}\right)\end{array}$ & \multicolumn{3}{|c|}{ Temp. Média das paredes $\left({ }^{\circ} \mathrm{C}\right)$} & Temp. Teto $\left({ }^{\circ} \mathrm{C}\right)$ & \\
\hline $15: 00$ & 22 & 22 & 22,5 & \multicolumn{3}{|c|}{22} & 24 & \\
\hline $17: 00$ & 23,1 & 23 & 22 & \multicolumn{3}{|c|}{21,9} & 22,2 & \\
\hline
\end{tabular}

Tabela 102: Resultados coletados in loco na sala do Apartamento D no mês de Agosto de 2013.

\begin{tabular}{|c|c|c|c|c|c|c|c|c|}
\hline \multicolumn{2}{|l|}{ Apartamento D } & \multicolumn{4}{|c|}{ Dados coletados CONFORTím ETRO Setembro 2013 - SALA } & \multicolumn{3}{|c|}{ Chuva } \\
\hline Intervalo & $\begin{array}{l}\text { Temperatura de } \\
\text { bulbo úmido }\left({ }^{\circ} \mathrm{C}\right)\end{array}$ & $\begin{array}{c}\text { Temperatura de } \\
\text { globo }\left({ }^{\circ} \mathrm{C}\right)\end{array}$ & $\begin{array}{l}\text { Temperatura do ar } \\
\left({ }^{\circ} \mathrm{C}\right)\end{array}$ & $\begin{array}{l}\text { Pressão } \\
\text { Atmosférica } \\
\text { (atm) }\end{array}$ & $\begin{array}{c}\text { Umidade relativa } \\
\text { do ar (\%) }\end{array}$ & $\begin{array}{l}\text { Velocidade do ar } \\
\qquad(\mathrm{m} / \mathrm{s})\end{array}$ & $\begin{array}{l}\text { Temperatura } \\
\text { radiante }\left({ }^{\circ} \mathrm{C}\right)\end{array}$ & $\begin{array}{l}\text { Temperatura } \\
\text { Operativa }\left({ }^{\circ} \mathrm{C}\right)\end{array}$ \\
\hline $15: 00$ as $15: 30$ & 21,3 & 23,4 & 23,2 & 1010,3 & 79,0 & 0,0 & 23,6 & 23,4 \\
\hline $15: 30$ as $16: 00$ & 21,5 & 23,6 & 23,4 & 1009,6 & 79,5 & 0,0 & 23,7 & 23,6 \\
\hline $15: 30$ as $16: 00$ & 21,7 & 23,6 & 23,4 & 1009,2 & 80,1 & 0,0 & 23,7 & 23,6 \\
\hline $16: 30$ as $17: 00$ & 21,6 & 23,5 & 23,3 & 1009,9 & 80,9 & 0,1 & 23,7 & 23,5 \\
\hline Desvio Padrão & 0,19 & 0,09 & 0,13 & 0,53 & 0,78 & 0,08 & 0,18 & 0,2 \\
\hline Média & 21,5 & 23,5 & 23,3 & 1009,7 & 79,8 & 0,0 & 23,7 & 23,5 \\
\hline \multicolumn{9}{|c|}{ Dados coletados Termômetro de fluxo de laser } \\
\hline Horário/Quarto & $\begin{array}{l}\text { Temp. Externa do ar } \\
\left({ }^{\circ} \mathrm{C}\right)\end{array}$ & $\begin{array}{l}\text { Temp. Paredes } \\
\text { externas }\left({ }^{\circ} \mathrm{C}\right)\end{array}$ & $\begin{array}{c}\text { Temp.Paredes } \\
\text { voltada para a rua } \\
\left({ }^{\circ} \mathrm{C}\right)\end{array}$ & \multicolumn{3}{|c|}{ Temp. Média das paredes $\left({ }^{\circ} \mathrm{C}\right)$} & Temp. Teto $\left({ }^{\circ} \mathrm{C}\right)$ & \\
\hline $15: 00$ & 22,3 & 21,3 & 23,7 & \multicolumn{3}{|c|}{24,1} & 24,1 & \\
\hline $17: 00$ & 23 & 22,2 & 23,3 & \multicolumn{3}{|c|}{23,6} & 24,2 & \\
\hline
\end{tabular}

Tabela 103: Resultados coletados in loco na sala do Apartamento D no mês de Setembro de 2013.

\begin{tabular}{|c|c|c|c|c|c|c|c|c|}
\hline \multicolumn{2}{|l|}{ Apartamento D } & \multicolumn{4}{|c|}{ Dados coletados CONFORTÍMETRO Outubro 2013 - SALA } & \multicolumn{3}{|c|}{ Nublado } \\
\hline Intervalo & $\begin{array}{l}\text { Temperatura de } \\
\text { bulbo úmido }\left({ }^{\circ} \mathrm{C}\right)\end{array}$ & $\begin{array}{c}\text { Temperatura de } \\
\text { globo }\left({ }^{\circ} \mathrm{C}\right)\end{array}$ & $\begin{array}{c}\text { Temperatura do ar } \\
\left({ }^{\circ} \mathrm{C}\right)\end{array}$ & $\begin{array}{l}\text { Pressão } \\
\text { Atmosférica } \\
\text { (atm) }\end{array}$ & $\begin{array}{l}\text { Umidade relativa } \\
\text { do ar (\%) }\end{array}$ & $\begin{array}{l}\text { Velocidade do ar } \\
\qquad(\mathrm{m} / \mathrm{s})\end{array}$ & $\begin{array}{l}\text { Temperatura } \\
\text { radiante }\left({ }^{\circ} \mathrm{C}\right)\end{array}$ & $\begin{array}{l}\text { Temperatura } \\
\text { Operativa }\left({ }^{\circ} \mathrm{C}\right)\end{array}$ \\
\hline $15: 00$ as $15: 30$ & 20,9 & 23,0 & 22,7 & 1005,6 & 81,1 & 0,2 & 23,5 & 23,1 \\
\hline $15: 30$ as $16: 00$ & 21,0 & 22,9 & 22,7 & 1006,2 & 81,5 & 0,1 & 23,2 & 22,9 \\
\hline $15: 30$ as $16: 00$ & 21,4 & 23,2 & 23,0 & 1005,5 & 80,6 & 0,0 & 23,2 & 23,1 \\
\hline $16: 30$ as $17: 00$ & 21,4 & 23,3 & 23,1 & 1005,2 & 80,0 & 0,0 & 23,3 & 23,2 \\
\hline Desvio Padrão & 0,25 & 0,17 & 0,20 & 0,41 & 0,68 & 0,13 & 0,24 & 0,2 \\
\hline Média & 21,2 & 23,1 & 22,9 & 1005,6 & 80,8 & 0,1 & 23,3 & 23,1 \\
\hline \multicolumn{9}{|c|}{ Dados coletados Termômetro de fluxo de laser } \\
\hline Horário/Quarto & $\begin{array}{l}\text { Temp. Externa do ar } \\
\left({ }^{\circ} \mathrm{C}\right)\end{array}$ & $\begin{array}{l}\text { Temp. Paredes } \\
\text { externas }\left({ }^{\circ} \mathrm{C}\right)\end{array}$ & $\begin{array}{c}\text { Temp.Paredes } \\
\text { voltada para a rua } \\
\left({ }^{\circ} \mathrm{C}\right)\end{array}$ & \multicolumn{3}{|c|}{ Temp. Média das paredes $\left({ }^{\circ} \mathrm{C}\right)$} & Temp. Teto $\left({ }^{\circ} \mathrm{C}\right)$ & \\
\hline $15: 00$ & 18,9 & 21,9 & 22,7 & \multicolumn{3}{|c|}{23,4} & 23,2 & \\
\hline $17: 00$ & 23 & 21,9 & 22,6 & \multicolumn{3}{|c|}{22,9} & 23 & \\
\hline
\end{tabular}

Tabela 104: Resultados coletados in loco na sala do Apartamento D no mês de Outubro de 2013.

\begin{tabular}{|c|c|c|c|c|c|c|c|c|}
\hline \multicolumn{2}{|l|}{ Apartamento D } & \multicolumn{4}{|c|}{ Dados coletados CONFORTíMETRO Novembro 2013 - SALA } & \multicolumn{3}{|c|}{ Chuva } \\
\hline Intervalo & $\begin{array}{l}\text { Temperatura de } \\
\text { bulbo úmido }\left({ }^{\circ} \mathrm{C}\right)\end{array}$ & $\begin{array}{c}\text { Temperatura de } \\
\text { globo }\left({ }^{\circ} \mathrm{C}\right)\end{array}$ & $\begin{array}{c}\text { Temperatura do ar } \\
\left({ }^{\circ} \mathrm{C}\right)\end{array}$ & $\begin{array}{l}\text { Pressão } \\
\text { Atmosférica } \\
\text { (atm) }\end{array}$ & $\begin{array}{c}\text { Umidade relativa } \\
\text { do ar (\%) }\end{array}$ & $\begin{array}{l}\text { Velocidade do ar } \\
\qquad(\mathrm{m} / \mathrm{s})\end{array}$ & $\begin{array}{l}\text { Temperatura } \\
\text { radiante }\left({ }^{\circ} \mathrm{C}\right)\end{array}$ & $\begin{array}{l}\text { Temperatura } \\
\text { Operativa }\left({ }^{\circ} \mathrm{C}\right)\end{array}$ \\
\hline $16: 00$ as $16: 30$ & 25,1 & 28,0 & 28,0 & 1004,7 & 73,8 & 0,1 & 28,1 & 28,0 \\
\hline $16: 30$ as $17: 00$ & 25,2 & 27,9 & 27,8 & 1005,8 & 75,3 & 0,0 & 27,9 & 27,9 \\
\hline $17: 00$ as $17: 30$ & 25,1 & 27,7 & 27,6 & 1006,7 & 75,9 & 0,0 & 27,7 & 27,7 \\
\hline $17: 30$ as $18: 00$ & 24,9 & 27,4 & 27,3 & 1006,5 & 77,7 & 0,0 & 27,5 & 27,4 \\
\hline Desvio Padrão & 0,21 & 0,25 & 0,32 & 0,83 & 1,84 & 0,08 & 0,24 & 0,3 \\
\hline Média & 25,1 & 27,8 & 27,7 & 1005,8 & 75,5 & 0,0 & 27,8 & 27,8 \\
\hline \multicolumn{9}{|c|}{ Dados coletados Termômetro de fluxo de laser } \\
\hline Horário/Quarto & $\begin{array}{c}\text { Temp. Externa do ar } \\
\left({ }^{\circ} \mathrm{C}\right)\end{array}$ & $\begin{array}{l}\text { Temp. Paredes } \\
\text { externas }\left({ }^{\circ} \mathrm{C}\right)\end{array}$ & $\begin{array}{c}\text { Temp.Paredes } \\
\text { voltada para a rua } \\
\left({ }^{\circ} \mathrm{C}\right)\end{array}$ & \multicolumn{3}{|c|}{ Temp. Média das paredes $\left({ }^{\circ} \mathrm{C}\right)$} & Temp. Teto $\left({ }^{\circ} \mathrm{C}\right)$ & \\
\hline $16: 00$ & 31,2 & 29,4 & 28,1 & \multicolumn{3}{|c|}{27,1} & 27,1 & \\
\hline $18: 00$ & 26,9 & 27,2 & 28,3 & \multicolumn{3}{|c|}{27,2} & 27,3 & \\
\hline
\end{tabular}

Tabela 105: Resultados coletados in loco na sala do Apartamento D no mês de Novembro de 2013. 


\begin{tabular}{|c|c|c|c|c|c|c|c|c|}
\hline \multicolumn{2}{|l|}{ Apartamento D } & \multicolumn{4}{|c|}{ Dados coletados CONFORTím ETRO Dezembro 2013 - SALA } & \multicolumn{3}{|c|}{$\begin{array}{l}\text { Parcialmente } \\
\text { nublado }\end{array}$} \\
\hline Intervalo & $\begin{array}{l}\text { Temperatura de } \\
\text { bulbo úmido }\left({ }^{\circ} \mathrm{C}\right)\end{array}$ & $\begin{array}{l}\text { Temperatura de } \\
\text { globo }\left({ }^{\circ} \mathrm{C}\right)\end{array}$ & $\begin{array}{c}\text { Temperatura do ar } \\
\left({ }^{\circ} \mathrm{C}\right)\end{array}$ & $\begin{array}{l}\text { Pressão } \\
\text { Atmosférica } \\
\text { (atm) }\end{array}$ & $\begin{array}{c}\text { Umidade relativa } \\
\text { do ar (\%) }\end{array}$ & $\begin{array}{l}\text { Velocidade do ar } \\
\qquad(\mathrm{m} / \mathrm{s})\end{array}$ & $\begin{array}{l}\text { Temperatura } \\
\text { radiante }\left({ }^{\circ} \mathrm{C}\right)\end{array}$ & $\begin{array}{l}\text { Temperatura } \\
\text { Operativa }\left({ }^{\circ} \mathrm{C}\right)\end{array}$ \\
\hline $16: 00$ as $16: 30$ & 25,1 & 28,7 & 28,6 & 1006,2 & 70,4 & 0,0 & 28,7 & 28,7 \\
\hline $16: 30$ as $17: 00$ & 25,2 & 28,7 & 28,7 & 1006,0 & 70,4 & 0,1 & 28,7 & 28,7 \\
\hline $17: 00$ as $17: 30$ & 25,2 & 28,7 & 28,7 & 1005,7 & 71,1 & 0,2 & 28,6 & 28,7 \\
\hline $17: 30$ as $18: 00$ & 25,2 & 28,6 & 28,6 & 1005,5 & 70,9 & 0,0 & 28,6 & 28,6 \\
\hline Desvio Padrão & 0,08 & 0,11 & 0,10 & 0,28 & 0,56 & 0,11 & 0,12 & 0,1 \\
\hline Média & 25,2 & 28,7 & 28,7 & 1005,9 & 70,7 & 0,1 & 28,7 & 28,7 \\
\hline \multicolumn{8}{|c|}{ Dados coletados Termômetro de fluxo de laser } & \\
\hline Horário/Quarto & $\begin{array}{l}\text { Temp. Externa do ar } \\
\left({ }^{\circ} \mathrm{C}\right)\end{array}$ & $\begin{array}{l}\text { Temp. Paredes } \\
\text { externas }\left({ }^{\circ} \mathrm{C}\right)\end{array}$ & $\begin{array}{c}\text { Temp.Paredes } \\
\text { voltada para a rua } \\
\left({ }^{\circ} \mathrm{C}\right)\end{array}$ & \multicolumn{3}{|c|}{ Temp. Média das paredes $\left({ }^{\circ} \mathrm{C}\right)$} & Temp. Teto $\left({ }^{\circ} \mathrm{C}\right)$ & \\
\hline $16: 00$ & 36,7 & 39,9 & 28,8 & \multicolumn{3}{|c|}{27,3} & 28,1 & \\
\hline $18: 00$ & 31,7 & 34,6 & 30,3 & \multicolumn{3}{|c|}{28,2} & 28,2 & \\
\hline
\end{tabular}

Tabela 106: Resultados coletados in loco na sala do Apartamento D no mês de Dezembro de 2013.

\begin{tabular}{|c|c|c|c|c|c|c|c|c|}
\hline \multicolumn{2}{|l|}{ Apartamento D } & \multicolumn{4}{|c|}{ Dados coletados CONFORTÍM ETRO Janeiro 2014 - SALA } & \multicolumn{3}{|c|}{ Céu claro } \\
\hline Intervalo & $\begin{array}{l}\text { Temperatura de } \\
\text { bulbo úmido }\left({ }^{\circ} \mathrm{C}\right)\end{array}$ & $\begin{array}{c}\text { Temperatura de } \\
\text { globo }\left({ }^{\circ} \mathrm{C}\right)\end{array}$ & $\begin{array}{c}\text { Temperatura do ar } \\
\left({ }^{\circ} \mathrm{C}\right)\end{array}$ & $\begin{array}{c}\text { Pressão } \\
\text { Atmosférica } \\
\text { (atm) }\end{array}$ & $\begin{array}{l}\text { Umidade relativa } \\
\text { do ar (\%) }\end{array}$ & $\begin{array}{l}\text { Velocidade do ar } \\
\qquad(\mathrm{m} / \mathrm{s})\end{array}$ & $\begin{array}{l}\text { Temperatura } \\
\text { radiante }\left({ }^{\circ} \mathrm{C}\right)\end{array}$ & $\begin{array}{l}\text { Temperatura } \\
\text { Operativa }\left({ }^{\circ} \mathrm{C}\right)\end{array}$ \\
\hline $16: 00$ as $16: 30$ & 24,7 & 29,4 & 29,3 & 1010,7 & 60,6 & 0,0 & 29,5 & 29,4 \\
\hline $16: 30$ as $17: 00$ & 24,5 & 29,5 & 29,3 & 1010,2 & 60,0 & 0,0 & 29,5 & 29,4 \\
\hline $17: 00$ as $17: 30$ & 24,1 & 29,3 & 29,2 & 1009,9 & 59,9 & 0,1 & 29,3 & 29,2 \\
\hline $17: 30$ as $18: 00$ & 24,1 & 29,2 & 29,1 & 1009,7 & 60,9 & 0,2 & 29,3 & 29,2 \\
\hline Desvio Padrão & 0,30 & 0,13 & 0,11 & 0,39 & 0,68 & 0,12 & 0,14 & 0,1 \\
\hline Média & 24,4 & 29,3 & 29,2 & 1010,1 & 60,4 & 0,1 & 29,4 & 29,3 \\
\hline \multicolumn{9}{|c|}{ Dados coletados Termômetro de fluxo de laser } \\
\hline Horário/Quarto & $\begin{array}{c}\text { Temp. Externa do ar } \\
\left({ }^{\circ} \mathrm{C}\right)\end{array}$ & $\begin{array}{l}\text { Temp. Paredes } \\
\text { externas }\left({ }^{\circ} \mathrm{C}\right)\end{array}$ & $\begin{array}{c}\text { Temp. Paredes } \\
\text { voltada para a rua } \\
\left({ }^{\circ} \mathrm{C}\right)\end{array}$ & \multicolumn{3}{|c|}{ Temp. Média das paredes $\left({ }^{\circ} \mathrm{C}\right)$} & Temp. Teto $\left({ }^{\circ} \mathrm{C}\right)$ & \\
\hline $16: 00$ & 37,7 & 39,8 & 31,8 & \multicolumn{3}{|c|}{28,3} & 29,2 & \\
\hline 18:00 & 30 & 34,8 & 33,6 & \multicolumn{3}{|c|}{29,1} & 29,7 & \\
\hline
\end{tabular}

Tabela 107: Resultados coletados in loco na sala do Apartamento D no mês de Janeiro de 2014.

\begin{tabular}{|c|c|c|c|c|c|c|c|c|}
\hline \multicolumn{2}{|l|}{ Apartamento D } & \multicolumn{4}{|c|}{ Dados coletados CONFORTÍM ETRO Fevereiro 2014 - SALA } & \multicolumn{3}{|c|}{ Céu claro } \\
\hline Intervalo & $\begin{array}{l}\text { Temperatura de } \\
\text { bulbo úmido }\left({ }^{\circ} \mathrm{C}\right)\end{array}$ & $\begin{array}{l}\text { Temperatura de } \\
\text { globo }\left({ }^{\circ} \mathrm{C}\right)\end{array}$ & $\begin{array}{c}\text { Temperatura do ar } \\
\left({ }^{\circ} \mathrm{C}\right)\end{array}$ & $\begin{array}{l}\text { Pressão } \\
\text { Atmosférica } \\
\text { (atm) }\end{array}$ & $\begin{array}{l}\text { Umidade relativa } \\
\text { do ar (\%) }\end{array}$ & $\begin{array}{l}\text { Velocidade do ar } \\
\qquad(\mathrm{m} / \mathrm{s})\end{array}$ & $\begin{array}{l}\text { Temperatura } \\
\text { radiante }\left({ }^{\circ} \mathrm{C}\right)\end{array}$ & $\begin{array}{l}\text { Temperatura } \\
\text { Operativa }\left({ }^{\circ} \mathrm{C}\right)\end{array}$ \\
\hline $15: 00$ as $15: 30$ & 24,3 & 28,9 & 28,6 & 1010,2 & 62,4 & 0,0 & 29,0 & 28,8 \\
\hline $15: 30$ as $16: 00$ & 24,2 & 28,5 & 28,4 & 1010,0 & 63,3 & 0,0 & 28,6 & 28,5 \\
\hline $15: 30$ as $16: 00$ & 23,6 & 28,6 & 28,6 & 1010,0 & 61,1 & 0,2 & 28,8 & 28,7 \\
\hline $16: 30$ as $17: 00$ & 23,4 & 28,6 & 28,5 & 1010,0 & 60,9 & 0,1 & 28,7 & 28,6 \\
\hline Desvio Padrão & 0,41 & 0,17 & 0,11 & 0,12 & 1,05 & 0,13 & 0,18 & 0,1 \\
\hline Média & 23,9 & 28,7 & 28,5 & 1010,1 & 61,9 & 0,1 & 28,8 & 28,6 \\
\hline \multicolumn{9}{|c|}{ Dados coletados Termômetro de fluxo de laser } \\
\hline Horário/Quarto & $\begin{array}{l}\text { Temp. Externa do ar } \\
\left({ }^{\circ} \mathrm{C}\right)\end{array}$ & $\begin{array}{l}\text { Temp. Paredes } \\
\text { externas }\left({ }^{\circ} \mathrm{C}\right)\end{array}$ & $\begin{array}{c}\text { Temp.Paredes } \\
\text { voltada para a rua } \\
\left({ }^{\circ} \mathrm{C}\right)\end{array}$ & \multicolumn{3}{|c|}{ Temp. Média das paredes $\left({ }^{\circ} \mathrm{C}\right)$} & Temp. Teto $\left({ }^{\circ} \mathrm{C}\right)$ & \\
\hline 15:00 & 31 & 41,8 & 28,4 & \multicolumn{3}{|c|}{28,3} & 28,4 & \\
\hline $17: 00$ & 31 & 33,2 & 29 & \multicolumn{3}{|c|}{27,4} & 28,1 & \\
\hline
\end{tabular}

Tabela 108: Resultados coletados in loco na sala do Apartamento D no mês de Fevereiro de 2014.

\begin{tabular}{|c|c|c|c|c|c|c|c|c|}
\hline \multicolumn{2}{|l|}{ Apartamento D } & \multicolumn{4}{|c|}{ Dados coletados CONFORTÍM ETRO M arço 2014 - SALA } & \multicolumn{3}{|c|}{ Nublado } \\
\hline Intervalo & $\begin{array}{l}\text { Temperatura de } \\
\text { bulbo úmido }\left({ }^{\circ} \mathrm{C}\right)\end{array}$ & $\begin{array}{l}\text { Temperatura de } \\
\text { globo }\left({ }^{\circ} \mathrm{C}\right)\end{array}$ & $\begin{array}{c}\text { Temperatura do ar } \\
\left({ }^{\circ} \mathrm{C}\right)\end{array}$ & $\begin{array}{l}\text { Pressão } \\
\text { Atmosférica } \\
\text { (atm) }\end{array}$ & $\begin{array}{l}\text { Umidade relativa } \\
\text { do ar (\%) }\end{array}$ & $\begin{array}{l}\text { Velocidade do ar } \\
\qquad(\mathrm{m} / \mathrm{s})\end{array}$ & $\begin{array}{l}\text { Temperatura } \\
\text { radiante }\left({ }^{\circ} \mathrm{C}\right)\end{array}$ & $\begin{array}{l}\text { Temperatura } \\
\text { Operativa }\left({ }^{\circ} \mathrm{C}\right)\end{array}$ \\
\hline $15: 00$ as $15: 30$ & 26,7 & 30,8 & 30,8 & 1004,5 & 67,1 & 0,0 & 30,9 & 30,8 \\
\hline $15: 30$ as $16: 00$ & 26,5 & 31,0 & 30,9 & 1004,2 & 65,4 & 0,0 & 31,0 & 31,0 \\
\hline $15: 30$ as $16: 00$ & 26,2 & 31,0 & 31,0 & 1004,1 & 63,1 & 0,0 & 31,0 & 31,0 \\
\hline $16: 30$ as $17: 00$ & 26,1 & 30,9 & 30,9 & 1004,4 & 62,5 & 0,0 & 30,9 & 30,9 \\
\hline Desvio Padrão & 0,28 & 0,08 & 0,08 & 0,17 & 2,04 & 0,05 & 0,08 & 0,1 \\
\hline Média & 26,4 & 30,9 & 30,9 & 1004,3 & 64,6 & 0,0 & 30,9 & 30,9 \\
\hline \multicolumn{8}{|c|}{ Dados coletados Termômetro de fluxo de laser } & \\
\hline Horário/Quarto & $\begin{array}{l}\text { Temp. Externa do ar } \\
\left({ }^{\circ} \mathrm{C}\right)\end{array}$ & $\begin{array}{l}\text { Temp. Paredes } \\
\text { externas }\left({ }^{\circ} \mathrm{C}\right)\end{array}$ & $\begin{array}{c}\text { Temp.Paredes } \\
\text { voltada para a rua } \\
\left({ }^{\circ} \mathrm{C}\right)\end{array}$ & \multicolumn{3}{|c|}{ Temp. Média das paredes $\left({ }^{\circ} \mathrm{C}\right)$} & Temp. Teto $\left({ }^{\circ} \mathrm{C}\right)$ & \\
\hline $15: 00$ & 32,7 & 36,7 & 31,2 & \multicolumn{3}{|c|}{30,8} & 31,6 & \\
\hline $17: 00$ & 30,7 & 34,8 & 32,5 & \multicolumn{3}{|c|}{31,3} & 31,9 & \\
\hline
\end{tabular}

Tabela 109: Resultados coletados in loco na sala do Apartamento D no mês de Março de 2014. 


\begin{tabular}{|c|c|c|c|c|c|c|c|c|}
\hline \multicolumn{2}{|l|}{ Apartamento D } & \multicolumn{5}{|c|}{ Dados coletados CONFORTÍM ETRO Abril 2014 - SALA } & \multicolumn{2}{|l|}{ Parcialmente claro } \\
\hline Intervalo & $\begin{array}{l}\text { Temperatura de } \\
\text { bulbo úmido }\left({ }^{\circ} \mathrm{C}\right)\end{array}$ & $\begin{array}{l}\text { Temperatura de } \\
\text { globo }\left({ }^{\circ} \mathrm{C}\right)\end{array}$ & $\begin{array}{c}\text { Temperatura do ar } \\
\left({ }^{\circ} \mathrm{C}\right)\end{array}$ & $\begin{array}{c}\text { Pressão } \\
\text { Atmosférica } \\
\text { (atm) }\end{array}$ & $\begin{array}{l}\text { Umidade relativa } \\
\text { do ar (\%) }\end{array}$ & $\begin{array}{l}\text { Velocidade do ar } \\
\qquad(\mathrm{m} / \mathrm{s})\end{array}$ & $\begin{array}{l}\text { Temperatura } \\
\text { radiante }\left({ }^{\circ} \mathrm{C}\right)\end{array}$ & $\begin{array}{l}\text { Temperatura } \\
\text { Operativa }\left({ }^{\circ} \mathrm{C}\right)\end{array}$ \\
\hline $15: 00$ as $15: 30$ & 17,8 & 24,5 & 24,5 & 1015,4 & 44,2 & 0,3 & 24,5 & 24,5 \\
\hline $15: 30$ as $16: 00$ & 18,5 & 24,4 & 24,3 & 1015,5 & 47,5 & 0,1 & 24,4 & 24,4 \\
\hline $15: 30$ as $16: 00$ & 19,0 & 24,2 & 24,1 & 1015,4 & 50,6 & 0,0 & 24,2 & 24,1 \\
\hline $16: 30$ as $17: 00$ & 18,9 & 24,1 & 24,0 & 1015,3 & 51,0 & 0,1 & 24,1 & 24,1 \\
\hline Desvio Padrão & 0,54 & 0,18 & 0,21 & 0,09 & 3,02 & 0,37 & 0,17 & 0,2 \\
\hline Média & 18,6 & 24,3 & 24,2 & 1015,4 & 48,6 & 0,1 & 24,3 & 24,2 \\
\hline \multicolumn{9}{|c|}{ Dados coletados Termômetro de fluxo de laser } \\
\hline Horário/Quarto & $\begin{array}{l}\text { Temp. Externa do ar } \\
\left({ }^{\circ} \mathrm{C}\right)\end{array}$ & $\begin{array}{l}\text { Temp. Paredes } \\
\text { externas }\left({ }^{\circ} \mathrm{C}\right)\end{array}$ & $\begin{array}{c}\text { Temp. Paredes } \\
\text { voltada para a rua } \\
\left({ }^{\circ} \mathrm{C}\right)\end{array}$ & \multicolumn{3}{|c|}{ Temp. Média das paredes $\left({ }^{\circ} \mathrm{C}\right)$} & Temp. Teto $\left({ }^{\circ} \mathrm{C}\right)$ & \\
\hline 15:00 & 28,9 & 26,7 & 24 & \multicolumn{3}{|c|}{23,5} & 23,7 & \\
\hline $17: 00$ & 28,3 & 25,1 & 25,4 & \multicolumn{3}{|c|}{23,6} & 24,4 & \\
\hline
\end{tabular}

Tabela 110: Resultados coletados in loco na sala do Apartamento D no mês de Abril de 2014.

\begin{tabular}{|c|c|c|c|c|c|c|c|c|}
\hline \multicolumn{2}{|l|}{ Apartamento D } & \multicolumn{4}{|c|}{ Dados coletados CONFORTÍM ETRO M aio 2014 - SALA } & \multicolumn{3}{|c|}{ Céu claro } \\
\hline Intervalo & $\begin{array}{l}\text { Temperatura de } \\
\text { bulbo úmido }\left({ }^{\circ} \mathrm{C}\right)\end{array}$ & $\begin{array}{c}\text { Temperatura de } \\
\text { globo }\left({ }^{\circ} \mathrm{C}\right)\end{array}$ & $\begin{array}{c}\text { Temperatura do ar } \\
\left({ }^{\circ} \mathrm{C}\right)\end{array}$ & $\begin{array}{c}\text { Pressão } \\
\text { Atmosférica } \\
\text { (atm) }\end{array}$ & $\begin{array}{l}\text { Umidade relativa } \\
\qquad \text { do ar (\%) }\end{array}$ & $\begin{array}{l}\text { Velocidade do ar } \\
\qquad(\mathrm{m} / \mathrm{s})\end{array}$ & $\begin{array}{l}\text { Temperatura } \\
\text { radiante }\left({ }^{\circ} \mathrm{C}\right)\end{array}$ & $\begin{array}{l}\text { Temperatura } \\
\text { Operativa }\left({ }^{\circ} \mathrm{C}\right)\end{array}$ \\
\hline $15: 00$ as $15: 30$ & 19,5 & 24,8 & 24,8 & 1014,9 & 52,6 & 0,0 & 24,9 & 24,8 \\
\hline $15: 30$ as $16: 00$ & 20,1 & 24,7 & 24,6 & 1015,1 & 56,1 & 0,0 & 24,8 & 24,7 \\
\hline $15: 30$ as $16: 00$ & 20,1 & 24,6 & 24,5 & 1015,0 & 56,9 & 0,0 & 24,6 & 24,6 \\
\hline $16: 30$ as $17: 00$ & 20,1 & 24,5 & 24,4 & 1015,2 & 57,5 & 0,0 & 24,6 & 24,5 \\
\hline Desvio Padrão & 0,34 & 0,13 & 0,14 & 0,11 & 2,22 & 0,02 & 0,13 & 0,1 \\
\hline Média & 19,9 & 24,7 & 24,6 & 1015,1 & 55,7 & 0,0 & 24,7 & 24,6 \\
\hline \multicolumn{9}{|c|}{ Dados coletados Termômetro de fluxo de laser } \\
\hline Horário/Quarto & $\begin{array}{l}\text { Temp. Externa do ar } \\
\left({ }^{\circ} \mathrm{C}\right)\end{array}$ & $\begin{array}{l}\text { Temp. Paredes } \\
\text { externas }\left({ }^{\circ} \mathrm{C}\right)\end{array}$ & $\begin{array}{c}\text { Temp.Paredes } \\
\text { voltada para a rua } \\
\left({ }^{\circ} \mathrm{C}\right)\end{array}$ & \multicolumn{3}{|c|}{ Temp. M édia das paredes $\left({ }^{\circ} \mathrm{C}\right)$} & Temp. Teto $\left({ }^{\circ} \mathrm{C}\right)$ & \\
\hline 15:00 & 28,5 & 25,7 & 25,3 & \multicolumn{3}{|c|}{23,7} & 24 & \\
\hline $17: 00$ & 26,8 & 24,6 & 24,8 & \multicolumn{3}{|c|}{24,4} & 24,6 & \\
\hline
\end{tabular}

Tabela 111: Resultados coletados in loco na sala do Apartamento D no mês de Maio de 2014.

\begin{tabular}{|c|c|c|c|c|c|c|c|c|}
\hline \multicolumn{2}{|l|}{ Apartamento D } & \multicolumn{4}{|c|}{ Dados coletados CONFORTÍM ETRO Junho 2014 - SALA } & \multicolumn{3}{|c|}{ Nublado } \\
\hline Intervalo & $\begin{array}{l}\text { Temperatura de } \\
\text { bulbo úmido }\left({ }^{\circ} \mathrm{C}\right)\end{array}$ & $\begin{array}{l}\text { Temperatura de } \\
\text { globo }\left({ }^{\circ} \mathrm{C}\right)\end{array}$ & $\begin{array}{c}\text { Temperatura do ar } \\
\left({ }^{\circ} \mathrm{C}\right)\end{array}$ & $\begin{array}{l}\text { Pressão } \\
\text { Atmosférica } \\
\text { (atm) }\end{array}$ & $\begin{array}{l}\text { Umidade relativa } \\
\text { do ar (\%) }\end{array}$ & $\begin{array}{l}\text { Velocidade do ar } \\
\qquad(\mathrm{m} / \mathrm{s})\end{array}$ & $\begin{array}{l}\text { Temperatura } \\
\text { radiante }\left({ }^{\circ} \mathrm{C}\right)\end{array}$ & $\begin{array}{l}\text { Temperatura } \\
\text { Operativa }\left({ }^{\circ} \mathrm{C}\right)\end{array}$ \\
\hline $15: 00$ as $15: 30$ & 20,8 & 23,6 & 23,3 & 1019,8 & 74,0 & 0,0 & 23,7 & 23,5 \\
\hline $15: 30$ as $16: 00$ & 20,8 & 23,6 & 23,3 & 1019,8 & 73,6 & 0,0 & 23,6 & 23,5 \\
\hline $15: 30$ as $16: 00$ & 20,7 & 23,6 & 23,4 & 1020,0 & 72,9 & 0,0 & 23,7 & 23,6 \\
\hline $16: 30$ as $17: 00$ & 20,6 & 23,6 & 23,4 & 1020,3 & 71,5 & 0,0 & 23,8 & 23,6 \\
\hline Desvio Padrão & 0,12 & 0,03 & 0,05 & 0,20 & 1,00 & 0,04 & 0,10 & 0,1 \\
\hline Média & 20,7 & 23,6 & 23,4 & 1020,0 & 73,0 & 0,0 & 23,7 & 23,5 \\
\hline \multicolumn{8}{|c|}{ Dados coletados Termômetro de fluxo de laser } & \\
\hline Horário/Quarto & $\begin{array}{l}\text { Temp. Externa do ar } \\
\left({ }^{\circ} \mathrm{C}\right)\end{array}$ & $\begin{array}{l}\text { Temp. Paredes } \\
\text { externas }\left({ }^{\circ} \mathrm{C}\right)\end{array}$ & $\begin{array}{c}\text { Temp.Paredes } \\
\text { voltada para a rua } \\
\left({ }^{\circ} \mathrm{C}\right)\end{array}$ & \multicolumn{3}{|c|}{ Temp. M édia das paredes $\left({ }^{\circ} \mathrm{C}\right)$} & Temp. Teto $\left({ }^{\circ} \mathrm{C}\right)$ & \\
\hline 15:00 & 25,2 & 22,8 & 23,6 & \multicolumn{3}{|c|}{23,8} & 24 & \\
\hline $17: 00$ & 25,4 & 21,9 & 23,5 & \multicolumn{3}{|c|}{23,8} & 24,3 & \\
\hline
\end{tabular}

Tabela 112: Resultados coletados in loco na sala do Apartamento D no mês de Junho de 2014.

\begin{tabular}{|c|c|c|c|c|c|c|c|c|}
\hline \multicolumn{2}{|l|}{ Apartamento $\mathrm{E}$} & \multicolumn{4}{|c|}{ Dados coletados CONFORTIM ETRO Julho 2013 - QUARTO } & \multicolumn{3}{|c|}{ céu claro } \\
\hline Intervalo & $\begin{array}{l}\text { Temperatura de } \\
\text { bulbo úmido }\end{array}$ & $\begin{array}{l}\text { Temperatura de } \\
\text { globo }\end{array}$ & Temperatura do ar & Pressão Atmosférica & $\begin{array}{l}\text { Umidade } \\
\text { relativa do ar }\end{array}$ & Velocidade do ar & $\begin{array}{l}\text { Temperatura } \\
\text { radiante }\end{array}$ & $\begin{array}{l}\text { Temperatura } \\
\text { Operativa }\left({ }^{\circ} \mathrm{C}\right)\end{array}$ \\
\hline $11: 50$ as $12: 20$ & 19,4 & 22,9 & 22,7 & 1020,9 & 67,4 & 0,0 & 23,0 & 22,8 \\
\hline $12: 20$ as $12: 50$ & 19,4 & 22,9 & 22,7 & 1020,6 & 67,4 & 0,0 & 22,9 & 22,8 \\
\hline $12: 50$ as $13: 20$ & 19,4 & 22,8 & 22,7 & 1020,3 & 67,2 & 0,0 & 22,9 & 22,8 \\
\hline $13: 20$ as $13: 50$ & 19,5 & 22,8 & 22,7 & 1020,0 & 67,8 & 0,0 & 22,8 & 22,7 \\
\hline $13: 50$ as $14: 20$ & 19,4 & 22,9 & 22,8 & 1019,6 & 66,8 & 0,0 & 22,9 & 22,8 \\
\hline $14: 20$ as $14: 50$ & 19,3 & 23,0 & 22,8 & 1019,5 & 65,9 & 0,0 & 23,0 & 22,9 \\
\hline Desvio Padrão & 0,09 & 0,08 & 0,07 & 0,50 & 0,82 & 0,02 & 0,11 & 1,63 \\
\hline Média & 19,4 & 22,9 & 22,7 & 1020,2 & 67,1 & 0,0 & 22,9 & 22,8 \\
\hline \multicolumn{9}{|c|}{ Dados coletados Termômetro de fluxo de laser } \\
\hline Horário/Quarto & $\begin{array}{l}\text { Temp. Externa do ar } \\
\left({ }^{\circ} \mathrm{C}\right)\end{array}$ & $\begin{array}{l}\text { Temp. Paredes } \\
\text { externas }\left({ }^{\circ} \mathrm{C}\right)\end{array}$ & $\begin{array}{c}\text { Temp.Paredes } \\
\text { voltada para a rua } \\
\left({ }^{\circ} \mathrm{C}\right)\end{array}$ & \multicolumn{3}{|c|}{ Temp. Média das paredes $\left({ }^{\circ} \mathrm{C}\right)$} & Temp. Teto $\left({ }^{\circ} \mathrm{C}\right)$ & \\
\hline $11: 50$ & 21 & 20 & 19,7 & \multicolumn{3}{|c|}{20,3} & 20,8 & \\
\hline $15: 00$ & 21,5 & 21 & 22 & \multicolumn{3}{|c|}{22} & 22,7 & \\
\hline
\end{tabular}

Tabela 113: Resultados coletados in loco no quarto do Apartamento E no mês de Julho de 2013. 


\begin{tabular}{|c|c|c|c|c|c|c|c|c|}
\hline \multicolumn{2}{|l|}{ Apartamento $\mathrm{E}$} & \multicolumn{4}{|c|}{ Dados coletados CONFORTÍMETRO Agosto 2013 - QUARTO } & \multicolumn{3}{|c|}{ céu claro } \\
\hline Intervalo & $\begin{array}{l}\text { Temperatura de } \\
\text { bulbo úmido }\left({ }^{\circ} \mathrm{C}\right)\end{array}$ & $\begin{array}{c}\text { Temperatura de } \\
\text { globo }\left({ }^{\circ} \mathrm{C}\right)\end{array}$ & $\begin{array}{c}\text { Temperatura do ar } \\
\left({ }^{\circ} \mathrm{C}\right)\end{array}$ & $\begin{array}{l}\text { Pressão Atmosférica } \\
\text { (atm) }\end{array}$ & $\begin{array}{c}\text { Umidade } \\
\text { relativa do ar } \\
\text { (\%) }\end{array}$ & $\begin{array}{l}\text { Velocidade do ar } \\
\qquad(\mathrm{m} / \mathrm{s})\end{array}$ & $\begin{array}{l}\text { Temperatura } \\
\text { radiante }\left({ }^{\circ} \mathrm{C}\right)\end{array}$ & $\begin{array}{l}\text { Temperatura } \\
\text { Operativa }\left({ }^{\circ} \mathrm{C}\right)\end{array}$ \\
\hline $11: 50$ as $12: 20$ & 17,6 & 20,1 & 19,9 & 1022,3 & 71,8 & 0,0 & 20,2 & 20,1 \\
\hline $12: 20$ as $12: 50$ & 17,2 & 19,8 & 19,7 & 1022,5 & 70,8 & 0,0 & 19,9 & 19,8 \\
\hline $12: 50$ as $13: 20$ & 17,3 & 19,7 & 19,6 & 1022,5 & 73,5 & 0,1 & 19,9 & 19,8 \\
\hline $13: 20$ as $13: 50$ & 17,4 & 19,7 & 19,5 & 1022,4 & 76,5 & 0,1 & 19,9 & 19,7 \\
\hline $13: 50$ as $14: 20$ & 17,9 & 20,0 & 20,0 & 1022,2 & 77,0 & 0,1 & 20,1 & 20,0 \\
\hline $14: 20$ as $14: 50$ & 18,1 & 20,3 & 20,3 & 1021,8 & 76,1 & 0,1 & 20,4 & 20,3 \\
\hline Desvio Padrão & 0,36 & 0,26 & 0,29 & 0,26 & 2,54 & 0,09 & 0,24 & 1,63 \\
\hline Média & 17,6 & 20,0 & 19,8 & 1022,3 & 74,3 & 0,1 & 20,0 & 19,9 \\
\hline \multicolumn{8}{|c|}{ Dados coletados Termômetro de fluxo de laser } & \\
\hline Horário/Quarto & $\begin{array}{l}\text { Temp. Externa do ar } \\
\qquad\left({ }^{\circ} \mathrm{C}\right)\end{array}$ & $\begin{array}{l}\text { Temp. Paredes } \\
\text { externas }\left({ }^{\circ} \mathrm{C}\right)\end{array}$ & $\begin{array}{c}\text { Temp.Paredes } \\
\text { voltada para a rua } \\
\left({ }^{\circ} \mathrm{C}\right)\end{array}$ & \multicolumn{3}{|c|}{ Temp. Média das paredes $\left({ }^{\circ} \mathrm{C}\right)$} & Temp. Teto $\left({ }^{\circ} \mathrm{C}\right)$ & \\
\hline 11:50 & 17 & 18 & 20,4 & \multicolumn{3}{|c|}{20,4} & 20,6 & \\
\hline 15:00 & 20,6 & 21 & 21 & \multicolumn{3}{|c|}{21} & 21,2 & \\
\hline
\end{tabular}

Tabela 114: Resultados coletados in loco no quarto do Apartamento E no mês de Agosto de 2013.

\begin{tabular}{|c|c|c|c|c|c|c|c|c|}
\hline \multicolumn{2}{|l|}{ Apartamento $\mathrm{E}$} & \multicolumn{4}{|c|}{ Dados coletados CONFORTIM ETRO Setembro 2013 - QUARTO } & \multicolumn{3}{|c|}{ céu claro } \\
\hline Intervalo & $\begin{array}{l}\text { Temperatura de } \\
\text { bulbo úmido }\left({ }^{\circ} \mathrm{C}\right)\end{array}$ & $\begin{array}{l}\text { Temperatura de } \\
\text { globo }\left({ }^{\circ} \mathrm{C}\right)\end{array}$ & $\begin{array}{c}\text { Temperatura do ar } \\
\left({ }^{\circ} \mathrm{C}\right)\end{array}$ & $\begin{array}{l}\text { Pressão Atmosférica } \\
\text { (atm) }\end{array}$ & $\begin{array}{c}\text { Umidade } \\
\text { relativa do ar } \\
(\%)\end{array}$ & $\begin{array}{l}\text { Velocidade do ar } \\
\qquad(\mathrm{m} / \mathrm{s})\end{array}$ & $\begin{array}{l}\text { Temperatura } \\
\text { radiante }\left({ }^{\circ} \mathrm{C}\right)\end{array}$ & $\begin{array}{l}\text { Temperatura } \\
\text { Operativa }\left({ }^{\circ} \mathrm{C}\right)\end{array}$ \\
\hline $11: 50$ as $12: 20$ & 22,2 & 26,4 & 26,0 & 1009,6 & 65,5 & 0,2 & 27,1 & 26,5 \\
\hline $12: 20$ as $12: 50$ & 22,0 & 26,4 & 26,1 & 1009,5 & 63,0 & 0,1 & 26,8 & 26,5 \\
\hline $12: 50$ as $13: 20$ & 21,9 & 26,5 & 26,3 & 1009,4 & 61,3 & 0,1 & 26,7 & 26,5 \\
\hline $13: 20$ as $13: 50$ & 22,0 & 26,5 & 26,2 & 1008,8 & 62,7 & 0,0 & 26,7 & 26,4 \\
\hline $13: 50$ as $14: 20$ & 22,0 & 26,5 & 26,3 & 1008,3 & 61,8 & 0,0 & 26,7 & 26,5 \\
\hline $14: 20$ as $14: 50$ & 22,3 & 26,6 & 26,4 & 1007,9 & 62,9 & 0,0 & 26,7 & 26,5 \\
\hline Desvio Padrão & 0,21 & 0,07 & 0,10 & 0,58 & 0,81 & 0,05 & 0,13 & 1,63 \\
\hline Média & 22,1 & 26,5 & 26,3 & 1008,6 & 62,2 & 0,0 & 26,7 & 26,5 \\
\hline \multicolumn{9}{|c|}{ Dados coletados Termômetro de fluxo de laser } \\
\hline Horário/Quarto & $\begin{array}{l}\text { Temp. Externa do ar } \\
\left({ }^{\circ} \mathrm{C}\right)\end{array}$ & $\begin{array}{l}\text { Temp. Paredes } \\
\text { externas }\left({ }^{\circ} \mathrm{C}\right)\end{array}$ & $\begin{array}{c}\text { Temp.Paredes } \\
\text { voltada para a rua } \\
\left({ }^{\circ} \mathrm{C}\right)\end{array}$ & \multicolumn{3}{|c|}{ Temp. Média das paredes $\left({ }^{\circ} \mathrm{C}\right)$} & Temp. Teto $\left({ }^{\circ} \mathrm{C}\right)$ & \\
\hline $11: 50$ & 21,2 & 20,1 & 23,1 & \multicolumn{3}{|c|}{25,1} & 24,3 & \\
\hline $15: 00$ & 21,7 & 19,9 & 23,4 & \multicolumn{3}{|c|}{25,2} & 24,6 & \\
\hline
\end{tabular}

Tabela 115: Resultados coletados in loco no quarto do Apartamento E no mês de Setembro de 2013.

\begin{tabular}{|c|c|c|c|c|c|c|c|c|}
\hline \multicolumn{2}{|l|}{ Apartamento $\mathrm{E}$} & \multicolumn{4}{|c|}{ Dados coletados CONFORTÍMETRO Outubro 2013 - QUARTO } & \multicolumn{3}{|c|}{ céu claro } \\
\hline Intervalo & $\begin{array}{l}\text { Temperatura de } \\
\text { bulbo úmido }\left({ }^{\circ} \mathrm{C}\right)\end{array}$ & $\begin{array}{l}\text { Temperatura de } \\
\text { globo }\left({ }^{\circ} \mathrm{C}\right)\end{array}$ & $\begin{array}{c}\text { Temperatura do ar } \\
\left({ }^{\circ} \mathrm{C}\right)\end{array}$ & $\begin{array}{l}\text { Pressão Atmosférica } \\
\text { (atm) }\end{array}$ & $\begin{array}{l}\text { Umidade } \\
\text { relativa do ar } \\
(\%)\end{array}$ & $\begin{array}{l}\text { Velocidade do ar } \\
\qquad(\mathrm{m} / \mathrm{s})\end{array}$ & $\begin{array}{l}\text { Temperatura } \\
\text { radiante }\left({ }^{\circ} \mathrm{C}\right)\end{array}$ & $\begin{array}{l}\text { Temperatura } \\
\text { Operativa }\left({ }^{\circ} \mathrm{C}\right)\end{array}$ \\
\hline $12: 50$ as $13: 20$ & 23,9 & 27,9 & 27,6 & 1012,4 & 69,8 & 0,3 & 28,5 & 28,0 \\
\hline $13: 20$ as $13: 50$ & 23,6 & 27,8 & 27,5 & 1011,8 & 68,8 & 0,3 & 28,4 & 27,9 \\
\hline $13: 50$ as $14: 20$ & 24,2 & 27,7 & 27,5 & 1011,5 & 69,2 & 0,0 & 27,7 & 27,6 \\
\hline $14: 20$ as $14: 50$ & 24,3 & 27,6 & 27,5 & 1011,4 & 69,6 & 0,0 & 27,6 & 27,5 \\
\hline $14: 50$ as $15: 20$ & 24,2 & 27,6 & 27,5 & 1011,1 & 69,0 & 0,0 & 27,6 & 27,5 \\
\hline $15: 20$ as $15: 50$ & 24,2 & 27,7 & 27,6 & 1010,9 & 68,9 & 0,0 & 27,8 & 27,7 \\
\hline Desvio Padrão & 0,15 & 0,09 & 0,06 & 0,29 & 0,45 & 0,06 & 0,20 & 1,63 \\
\hline Média & 24,2 & 27,7 & 27,5 & 1011,2 & 69,2 & 0,0 & 27,7 & 27,6 \\
\hline \multicolumn{9}{|c|}{ Dados coletados Termômetro de fluxo de laser } \\
\hline Horário/Quarto & $\begin{array}{l}\text { Temp. Externa do ar } \\
\left({ }^{\circ} \mathrm{C}\right)\end{array}$ & $\begin{array}{l}\text { Temp. Paredes } \\
\text { externas }\left({ }^{\circ} \mathrm{C}\right)\end{array}$ & $\begin{array}{c}\text { Temp.Paredes } \\
\text { voltada para a rua } \\
\left({ }^{\circ} \mathrm{C}\right)\end{array}$ & \multicolumn{3}{|c|}{ Temp. Média das paredes $\left({ }^{\circ} \mathrm{C}\right)$} & Temp. Teto $\left({ }^{\circ} \mathrm{C}\right)$ & \\
\hline $12: 50$ & 29,8 & 31,3 & 26,8 & \multicolumn{3}{|c|}{27,1} & 27,7 & \\
\hline 16:00 & 28,6 & 31,4 & 27,8 & \multicolumn{3}{|c|}{27,7} & 28,2 & \\
\hline
\end{tabular}

Tabela 116: Resultados coletados in loco no quarto do Apartamento E no mês de Outubro de 2013.

\begin{tabular}{|c|c|c|c|c|c|c|c|c|}
\hline \multicolumn{2}{|l|}{ Apartamento $\mathrm{E}$} & \multicolumn{4}{|c|}{ Dados coletados CONFORTIMETRO Novembro 2013 - QUARTO } & \multicolumn{3}{|c|}{ Chuva } \\
\hline Intervalo & $\begin{array}{l}\text { Temperatura de } \\
\text { bulbo úmido }\left({ }^{\circ} \mathrm{C}\right)\end{array}$ & $\begin{array}{c}\text { Temperatura de } \\
\text { globo }\left({ }^{\circ} \mathrm{C}\right)\end{array}$ & $\begin{array}{c}\text { Temperatura do ar } \\
\left({ }^{\circ} \mathrm{C}\right)\end{array}$ & $\begin{array}{l}\text { Pressão Atmosférica } \\
\text { (atm) }\end{array}$ & $\begin{array}{c}\text { Umidade } \\
\text { relativa do ar } \\
(\%)\end{array}$ & $\begin{array}{c}\text { Velocidade do ar } \\
(\mathrm{m} / \mathrm{s})\end{array}$ & $\begin{array}{l}\text { Temperatura } \\
\text { radiante }\left({ }^{\circ} \mathrm{C}\right)\end{array}$ & $\begin{array}{l}\text { Temperatura } \\
\text { Operativa }\left({ }^{\circ} \mathrm{C}\right)\end{array}$ \\
\hline $12: 50$ as $13: 20$ & 24,7 & 28,0 & 27,9 & 1008,2 & 70,4 & 0,0 & 28,0 & 27,9 \\
\hline $13: 20$ as $13: 50$ & 24,3 & 27,8 & 27,7 & 1008,1 & 68,9 & 0,0 & 27,8 & 27,8 \\
\hline $13: 50$ as $14: 20$ & 24,4 & 27,7 & 27,6 & 1007,9 & 69,6 & 0,0 & 27,8 & 27,7 \\
\hline $14: 20$ as $14: 50$ & 24,3 & 27,7 & 27,6 & 1007,8 & 70,2 & 0,0 & 27,7 & 27,6 \\
\hline $14: 50$ as $15: 20$ & 24,3 & 27,6 & 27,5 & 1007,7 & 70,8 & 0,0 & 27,7 & 27,6 \\
\hline $15: 20$ as $15: 50$ & 24,4 & 27,6 & 27,4 & 1007,4 & 71,6 & 0,0 & 27,6 & 27,5 \\
\hline Desvio Padrão & 0,19 & 0,14 & 0,17 & 0,27 & 0,99 & 0,01 & 0,14 & 1,63 \\
\hline Média & 24,4 & 27,7 & 27,6 & 1007,9 & 70,2 & 0,0 & 27,8 & 27,7 \\
\hline \multicolumn{9}{|c|}{ Dados coletados Termômetro de fluxo de laser } \\
\hline Horário/Quarto & $\begin{array}{l}\text { Temp. Externa do ar } \\
\left({ }^{\circ} \mathrm{C}\right)\end{array}$ & $\begin{array}{c}\text { Temp. Paredes } \\
\text { externas }\left({ }^{\circ} \mathrm{C}\right)\end{array}$ & $\begin{array}{c}\text { Temp.Paredes } \\
\text { voltada para a rua } \\
\left({ }^{\circ} \mathrm{C}\right)\end{array}$ & \multicolumn{3}{|c|}{ Temp. Média das paredes $\left({ }^{\circ} \mathrm{C}\right)$} & Temp. Teto $\left({ }^{\circ} \mathrm{C}\right)$ & \\
\hline $12: 50$ & 27,4 & 27,2 & 27,8 & \multicolumn{3}{|c|}{28,4} & 28,9 & \\
\hline $16: 00$ & 25 & 26 & 27,1 & \multicolumn{3}{|c|}{28,2} & 27,7 & \\
\hline
\end{tabular}

Tabela 117: Resultados coletados in loco no quarto do Apartamento E no mês de Novembro de 2013. 


\begin{tabular}{|c|c|c|c|c|c|c|c|c|}
\hline \multicolumn{2}{|l|}{ Apartamento $\mathrm{E}$} & \multicolumn{4}{|c|}{ Dados coletados CONFORTÍM ETRO Dezembro 2013 - QUARTO } & \multicolumn{3}{|c|}{ Nublado } \\
\hline Intervalo & $\begin{array}{l}\text { Temperatura de } \\
\text { bulbo úmido }\left({ }^{\circ} \mathrm{C}\right)\end{array}$ & $\begin{array}{c}\text { Temperatura de } \\
\text { globo }\left({ }^{\circ} \mathrm{C}\right)\end{array}$ & $\begin{array}{c}\text { Temperatura do ar } \\
\left({ }^{\circ} \mathrm{C}\right)\end{array}$ & $\begin{array}{l}\text { Pressão Atmosférica } \\
\text { (atm) }\end{array}$ & $\begin{array}{c}\text { Umidade } \\
\text { relativa do ar } \\
\text { (\%) }\end{array}$ & $\begin{array}{l}\text { Velocidade do ar } \\
\qquad(\mathrm{m} / \mathrm{s})\end{array}$ & $\begin{array}{l}\text { Temperatura } \\
\text { radiante }\left({ }^{\circ} \mathrm{C}\right)\end{array}$ & $\begin{array}{l}\text { Temperatura } \\
\text { Operativa }\left({ }^{\circ} \mathrm{C}\right)\end{array}$ \\
\hline $12: 50$ as $13: 20$ & 23,9 & 28,6 & 28,6 & 1010,8 & 64,4 & 0,2 & 28,7 & 28,6 \\
\hline $13: 20$ as $13: 50$ & 24,3 & 28,5 & 28,4 & 1010,8 & 64,0 & 0,0 & 28,5 & 28,4 \\
\hline $13: 50$ as $14: 20$ & 24,3 & 28,4 & 28,3 & 1010,8 & 65,1 & 0,0 & 28,4 & 28,3 \\
\hline $14: 20$ as $14: 50$ & 24,4 & 28,3 & 28,3 & 1010,5 & 65,7 & 0,0 & 28,4 & 28,3 \\
\hline $14: 50$ as $15: 20$ & 24,4 & 28,4 & 28,3 & 1010,2 & 65,6 & 0,0 & 28,4 & 28,4 \\
\hline $15: 20$ as $15: 50$ & 24,3 & 28,4 & 28,4 & 1010,2 & 65,1 & 0,0 & 28,4 & 28,4 \\
\hline Desvio Padrão & 0,23 & 0,11 & 0,13 & 0,30 & 0,75 & 0,09 & 0,15 & 1,63 \\
\hline Média & 24,2 & 28,5 & 28,4 & 1010,6 & 64,9 & 0,1 & 28,5 & 28,4 \\
\hline \multicolumn{8}{|c|}{ Dados coletados Termômetro de fluxo de laser } & \\
\hline Horário/Quarto & $\begin{array}{l}\text { Temp. Externa do ar } \\
\qquad\left({ }^{\circ} \mathrm{C}\right)\end{array}$ & $\begin{array}{l}\text { Temp. Paredes } \\
\text { externas }\left({ }^{\circ} \mathrm{C}\right)\end{array}$ & $\begin{array}{c}\text { Temp.Paredes } \\
\text { voltada para a rua } \\
\left({ }^{\circ} \mathrm{C}\right)\end{array}$ & \multicolumn{3}{|c|}{ Temp. Média das paredes $\left({ }^{\circ} \mathrm{C}\right)$} & Temp. Teto $\left({ }^{\circ} \mathrm{C}\right)$ & \\
\hline $12: 50$ & 29 & 26,7 & 27,4 & \multicolumn{3}{|c|}{27,8} & 28,2 & \\
\hline $16: 00$ & 31,2 & 29,4 & 27,5 & \multicolumn{3}{|c|}{28,2} & 28,1 & \\
\hline
\end{tabular}

Tabela 118: Resultados coletados in loco no quarto do Apartamento E no mês de Dezembro de 2013.

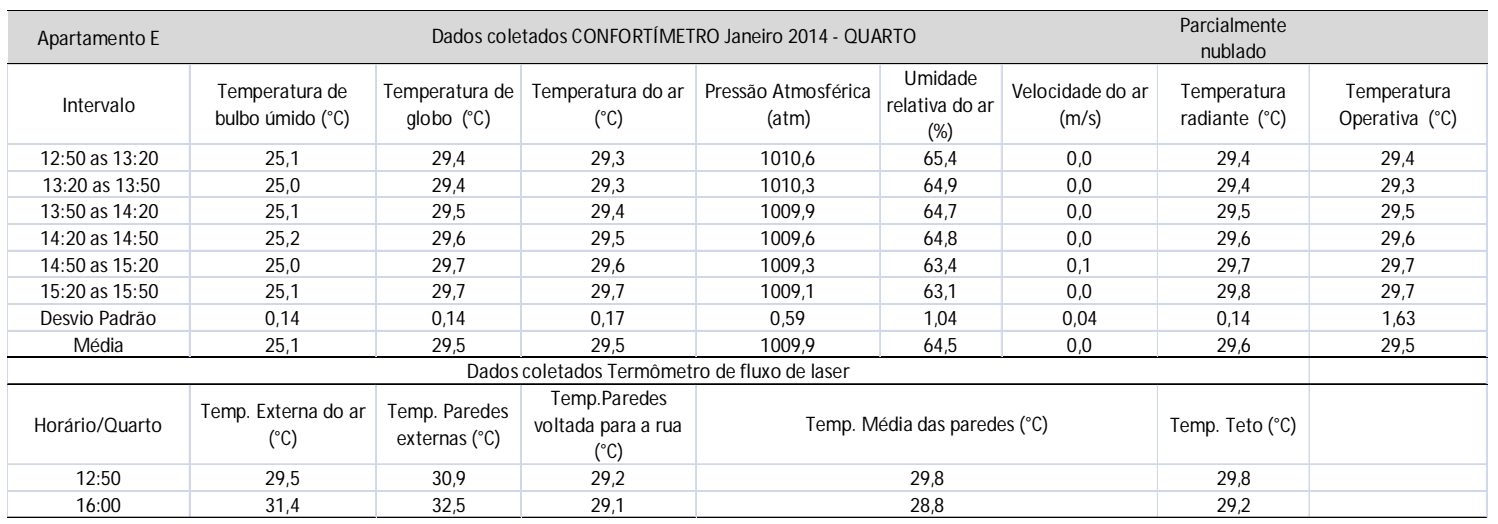

Tabela 119: Resultados coletados in loco no quarto do Apartamento E no mês de Janeiro de 2014.

\begin{tabular}{|c|c|c|c|c|c|c|c|c|}
\hline \multicolumn{2}{|l|}{ Apartamento $\mathrm{E}$} & \multicolumn{4}{|c|}{ Dados coletados CONFORTIM ETRO Fevereiro 2014 - QUARTO } & \multicolumn{3}{|c|}{$\begin{array}{l}\text { Parcialmente } \\
\text { aberto }\end{array}$} \\
\hline Intervalo & $\begin{array}{l}\text { Temperatura de } \\
\text { bulbo úmido }\left({ }^{\circ} \mathrm{C}\right)\end{array}$ & $\begin{array}{l}\text { Temperatura de } \\
\text { globo }\left({ }^{\circ} \mathrm{C}\right)\end{array}$ & $\begin{array}{l}\text { Temperatura do ar } \\
\left({ }^{\circ} \mathrm{C}\right)\end{array}$ & $\begin{array}{l}\text { Pressão Atmosférica } \\
\text { (atm) }\end{array}$ & $\begin{array}{c}\text { Umidade } \\
\text { relativa do ar } \\
(\%)\end{array}$ & $\begin{array}{l}\text { Velocidade do ar } \\
(\mathrm{m} / \mathrm{s})\end{array}$ & $\begin{array}{l}\text { Temperatura } \\
\text { radiante }\left({ }^{\circ} \mathrm{C}\right)\end{array}$ & $\begin{array}{l}\text { Temperatura } \\
\text { Operativa }\left({ }^{\circ} \mathrm{C}\right)\end{array}$ \\
\hline $11: 50$ as $12: 20$ & 23,3 & 28,5 & 28,4 & 1013,6 & 59,1 & 0,0 & 28,5 & 28,5 \\
\hline $12: 20$ as $12: 50$ & 23,6 & 28,6 & 28,5 & 1013,3 & 60,7 & 0,1 & 28,7 & 28,6 \\
\hline $12: 50$ as $13: 20$ & 24,0 & 28,6 & 28,6 & 1013,0 & 61,9 & 0,0 & 28,7 & 28,6 \\
\hline $13: 20$ as $13: 50$ & 23,9 & 28,7 & 28,6 & 1012,8 & 61,3 & 0,0 & 28,7 & 28,7 \\
\hline $13: 50$ as $14: 20$ & 23,8 & 28,7 & 28,5 & 1012,6 & 60,7 & 0,0 & 28,7 & 28,6 \\
\hline $14: 20$ as $14: 50$ & 23,8 & 28,7 & 28,5 & 1012,4 & 61,0 & 0,0 & 28,8 & 28,6 \\
\hline Desvio Padrão & 0,26 & 0,09 & 0,09 & 0,44 & 1,17 & 0,04 & 0,09 & 1,63 \\
\hline Média & 23,7 & 28,6 & 28,5 & 1013,0 & 60,7 & 0,0 & 28,7 & 28,6 \\
\hline \multicolumn{8}{|c|}{ Dados coletados Termômetro de fluxo de laser } & \\
\hline Horário/Quarto & $\begin{array}{l}\text { Temp. Externa do ar } \\
\left({ }^{\circ} \mathrm{C}\right)\end{array}$ & $\begin{array}{l}\text { Temp. Paredes } \\
\text { externas }\left({ }^{\circ} \mathrm{C}\right)\end{array}$ & $\begin{array}{c}\text { Temp.Paredes } \\
\text { voltada para a rua } \\
\left({ }^{\circ} \mathrm{C}\right)\end{array}$ & \multicolumn{3}{|c|}{ Temp. Média das paredes $\left({ }^{\circ} \mathrm{C}\right)$} & Temp. Teto $\left({ }^{\circ} \mathrm{C}\right)$ & \\
\hline 11:50 & 30 & 32,9 & 28,3 & \multicolumn{3}{|c|}{28,6} & 28,8 & \\
\hline $15: 00$ & 29,5 & 32,3 & 29,3 & \multicolumn{3}{|c|}{29,2} & 28,6 & \\
\hline
\end{tabular}

Tabela 120: Resultados coletados in loco no quarto do Apartamento E no mês de Fevereiro de 2014.

\begin{tabular}{|c|c|c|c|c|c|c|c|c|}
\hline \multicolumn{2}{|l|}{ Apartamento $\mathrm{E}$} & \multicolumn{4}{|c|}{ Dados coletados CONFORTIM ETRO Março 2014 - QUARTO } & \multicolumn{3}{|c|}{ Nublado } \\
\hline Intervalo & $\begin{array}{l}\text { Temperatura de } \\
\text { bulbo úmido }\left({ }^{\circ} \mathrm{C}\right)\end{array}$ & $\begin{array}{c}\text { Temperatura de } \\
\text { globo }\left({ }^{\circ} \mathrm{C}\right)\end{array}$ & $\begin{array}{c}\text { Temperatura do ar } \\
\left({ }^{\circ} \mathrm{C}\right)\end{array}$ & $\begin{array}{l}\text { Pressão Atmosférica } \\
\text { (atm) }\end{array}$ & \begin{tabular}{|c|} 
Umidade \\
relativa do ar \\
$(\%)$
\end{tabular} & $\begin{array}{l}\text { Velocidade do ar } \\
\qquad(\mathrm{m} / \mathrm{s})\end{array}$ & $\begin{array}{l}\text { Temperatura } \\
\text { radiante }\left({ }^{\circ} \mathrm{C}\right)\end{array}$ & $\begin{array}{l}\text { Temperatura } \\
\text { Operativa }\left({ }^{\circ} \mathrm{C}\right)\end{array}$ \\
\hline $11: 50$ as $12: 20$ & 22,5 & 27,3 & 27,1 & 1016,8 & 60,7 & 0,0 & 27,4 & 27,2 \\
\hline $12: 20$ as $12: 50$ & 22,4 & 27,4 & 27,2 & 1016,7 & 59,4 & 0,0 & 27,4 & 27,3 \\
\hline $12: 50$ as $13: 20$ & 22,5 & 27,4 & 27,3 & 1016,5 & 59,3 & 0,0 & 27,5 & 27,4 \\
\hline $13: 20$ as $13: 50$ & 22,2 & 27,4 & 27,2 & 1016,3 & 57,8 & 0,0 & 27,4 & 27,3 \\
\hline $13: 50$ as $14: 20$ & 22,4 & 27,5 & 27,3 & 1016,1 & 58,5 & 0,0 & 27,5 & 27,4 \\
\hline $14: 20$ as $14: 50$ & 22,3 & 27,4 & 27,2 & 1016,0 & 58,1 & 0,0 & 27,4 & 27,3 \\
\hline Desvio Padrão & 0,18 & 0,07 & 0,11 & 0,32 & 1,25 & 0,00 & 0,06 & 1,63 \\
\hline Média & 22,4 & 27,4 & 27,2 & 1016,4 & 59,0 & 0,0 & 27,4 & 27,3 \\
\hline \multicolumn{9}{|c|}{ Dados coletados Termômetro de fluxo de laser } \\
\hline Horário/Quarto & $\begin{array}{l}\text { Temp. Externa do ar } \\
\left({ }^{\circ} \mathrm{C}\right)\end{array}$ & $\begin{array}{l}\text { Temp. Paredes } \\
\text { externas }\left({ }^{\circ} \mathrm{C}\right)\end{array}$ & $\begin{array}{c}\text { Temp.Paredes } \\
\text { voltada para a rua } \\
\left({ }^{\circ} \mathrm{C}\right)\end{array}$ & \multicolumn{3}{|c|}{ Temp. Média das paredes $\left({ }^{\circ} \mathrm{C}\right)$} & Temp. Teto $\left({ }^{\circ} \mathrm{C}\right)$ & \\
\hline 11:50 & 27,4 & 26,8 & 26,9 & \multicolumn{3}{|c|}{27,9} & 28,1 & \\
\hline $15: 00$ & 27,5 & 27,8 & 27,6 & \multicolumn{3}{|c|}{27,7} & 27,7 & \\
\hline
\end{tabular}

Tabela 121: Resultados coletados in loco no quarto do Apartamento E no mês de Março de 2014. 


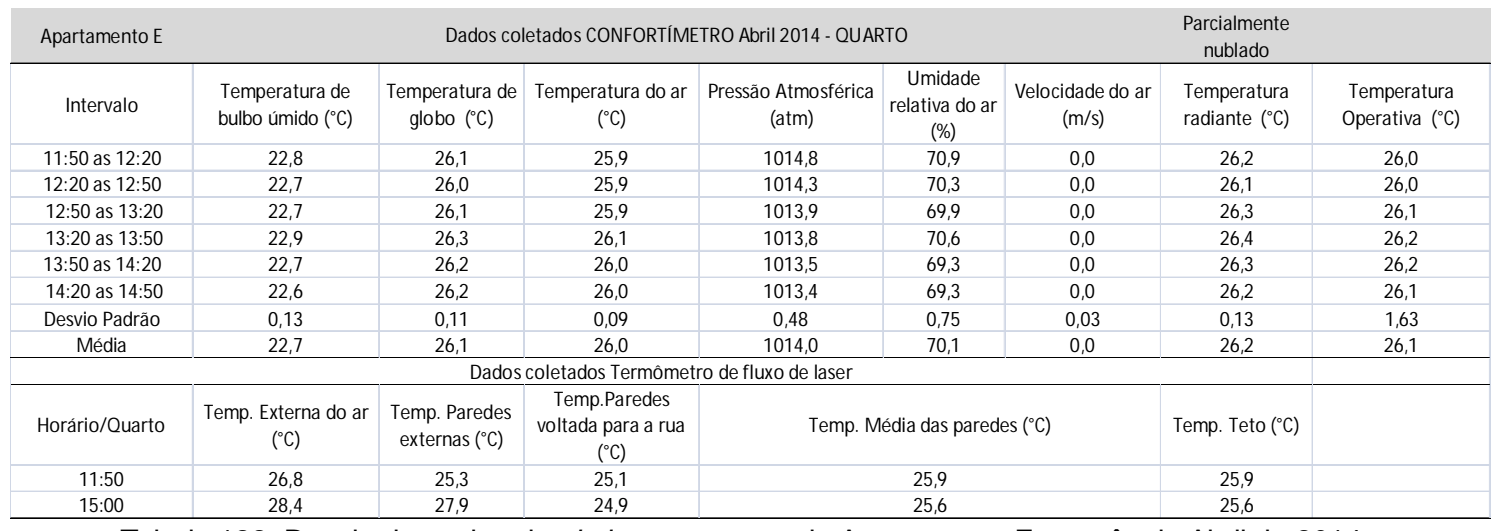

Tabela 122: Resultados coletados in loco no quarto do Apartamento E no mês de Abril de 2014.

\begin{tabular}{|c|c|c|c|c|c|c|c|c|}
\hline \multicolumn{2}{|l|}{ Apartamento $\mathrm{E}$} & \multicolumn{4}{|c|}{ Dados coletados CONFORTÍM ETRO Maio 2014 - QUARTO } & \multicolumn{3}{|c|}{$\begin{array}{l}\text { Parcialmente } \\
\text { aberto }\end{array}$} \\
\hline Intervalo & $\begin{array}{l}\text { Temperatura de } \\
\text { bulbo úmido }\left({ }^{\circ} \mathrm{C}\right)\end{array}$ & $\begin{array}{l}\text { Temperatura de } \\
\text { globo }\left({ }^{\circ} \mathrm{C}\right)\end{array}$ & $\begin{array}{l}\text { Temperatura do ar } \\
\left({ }^{\circ} \mathrm{C}\right)\end{array}$ & $\begin{array}{l}\text { Pressão Atmosférica } \\
\text { (atm) }\end{array}$ & $\begin{array}{c}\text { Umidade } \\
\text { relativa do ar } \\
(\%)\end{array}$ & $\begin{array}{l}\text { Velocidade do ar } \\
\qquad(\mathrm{m} / \mathrm{s})\end{array}$ & $\begin{array}{l}\text { Temperatura } \\
\text { radiante }\left({ }^{\circ} \mathrm{C}\right)\end{array}$ & $\begin{array}{l}\text { Temperatura } \\
\text { Operativa }\left({ }^{\circ} \mathrm{C}\right)\end{array}$ \\
\hline $11: 50$ as $12: 20$ & 23,6 & 27,0 & 26,8 & 1014,9 & 72,0 & 0,0 & 27,0 & 26,9 \\
\hline $12: 20$ as $12: 50$ & 23,8 & 27,1 & 27,0 & 1014,4 & 72,0 & 0,0 & 27,2 & 27,1 \\
\hline $12: 50$ as $13: 20$ & 23,9 & 27,3 & 27,2 & 1014,0 & 71,2 & 0,0 & 27,4 & 27,3 \\
\hline $13: 20$ as $13: 50$ & 24,0 & 27,5 & 27,3 & 1013,7 & 71,3 & 0,0 & 27,5 & 27,4 \\
\hline $13: 50$ as $14: 20$ & 24,0 & 27,5 & 27,3 & 1013,4 & 71,6 & 0,0 & 27,6 & 27,5 \\
\hline $14: 20$ as $14: 50$ & 24,2 & 27,6 & 27,3 & 1013,1 & 72,5 & 0,0 & 27,7 & 27,5 \\
\hline Desvio Padrão & 0,19 & 0,23 & 0,19 & 0,61 & 0,58 & 0,0 & 0,25 & 1,63 \\
\hline Média & 23,9 & 27,3 & 27,1 & 1013,9 & 71,8 & 0,0 & 27,4 & 27,3 \\
\hline \multicolumn{9}{|c|}{ Dados coletados Termômetro de fluxo de laser } \\
\hline Horário/Quarto & $\begin{array}{l}\text { Temp. Externa do ar } \\
\qquad\left({ }^{\circ} \mathrm{C}\right)\end{array}$ & $\begin{array}{l}\text { Temp. Paredes } \\
\text { externas }\left({ }^{\circ} \mathrm{C}\right)\end{array}$ & $\begin{array}{c}\text { Temp.Paredes } \\
\text { voltada para a rua } \\
\left({ }^{\circ} \mathrm{C}\right)\end{array}$ & \multicolumn{3}{|c|}{ Temp. Média das paredes $\left({ }^{\circ} \mathrm{C}\right)$} & Temp. Teto $\left({ }^{\circ} \mathrm{C}\right)$ & \\
\hline 11:50 & 27 & 28,6 & 26,4 & \multicolumn{3}{|c|}{27,3} & 27,4 & \\
\hline $15: 00$ & 29,5 & 28,4 & 26,8 & \multicolumn{3}{|c|}{27,1} & 27,4 & \\
\hline
\end{tabular}

Tabela 123:Resultados coletados in loco no quarto do Apartamento E no mês de Maio de 2014.

\begin{tabular}{|c|c|c|c|c|c|c|c|c|}
\hline \multicolumn{2}{|l|}{ Apartamento $\mathrm{E}$} & \multicolumn{4}{|c|}{ Dados coletados CONFORTIM ETRO Junho 2014 - QUARTO } & \multicolumn{3}{|c|}{ céu claro } \\
\hline Intervalo & $\begin{array}{l}\text { Temperatura de } \\
\text { bulbo úmido }\left({ }^{\circ} \mathrm{C}\right)\end{array}$ & $\begin{array}{l}\text { Temperatura de } \\
\text { globo }\left({ }^{\circ} \mathrm{C}\right)\end{array}$ & $\begin{array}{c}\text { Temperatura do ar } \\
\left({ }^{\circ} \mathrm{C}\right)\end{array}$ & $\begin{array}{c}\text { Pressão Atmosférica } \\
\text { (atm) }\end{array}$ & $\begin{array}{l}\text { Umidade } \\
\text { relativa do ar }\end{array}$ & $\begin{array}{l}\text { Velo cidade do ar } \\
\qquad(\mathrm{m} / \mathrm{s})\end{array}$ & $\begin{array}{l}\text { Temperatura } \\
\text { radiante }\left({ }^{\circ} \mathrm{C}\right)\end{array}$ & $\begin{array}{l}\text { Temperatura } \\
\text { Operativa }\left({ }^{\circ} \mathrm{C}\right)\end{array}$ \\
\hline $11: 50$ as $12: 20$ & 20,2 & 23,9 & 23,8 & 1015,8 & 65,1 & 0,0 & 23,9 & 23,9 \\
\hline $12: 20$ as $12: 50$ & 20,4 & 23,9 & 23,8 & 1015,2 & 65,9 & 0,0 & 23,9 & 23,9 \\
\hline $12: 50$ as $13: 20$ & 20,4 & 23,9 & 23,8 & 1014,7 & 65,6 & 0,0 & 23,9 & 23,9 \\
\hline $13: 20$ as $13: 50$ & 20,4 & 23,9 & 23,9 & 1014,3 & 65,5 & 0,0 & 24,0 & 23,9 \\
\hline $13: 50$ as $14: 20$ & 20,5 & 23,9 & 23,9 & 1014,2 & 66,7 & 0,0 & 24,0 & 23,9 \\
\hline $14: 20$ as $14: 50$ & 21,0 & 24,0 & 24,0 & 1013,9 & 69,9 & 0,0 & 24,0 & 24,0 \\
\hline Desvio Padrão & 0,27 & 0,08 & 0,08 & 0,70 & 1,87 & 0,01 & 0,08 & 1,63 \\
\hline Média & 20,5 & 23,9 & 23,9 & 1014,7 & 66,6 & 0,0 & 23,9 & 23,9 \\
\hline \multicolumn{9}{|c|}{ Dados coletados Termômetro de fluxo de laser } \\
\hline Horário/Quarto & $\begin{array}{l}\text { Temp. Externa do ar } \\
\left({ }^{\circ} \mathrm{C}\right)\end{array}$ & $\begin{array}{l}\text { Temp. Paredes } \\
\text { externas }\left({ }^{\circ} \mathrm{C}\right)\end{array}$ & $\begin{array}{c}\text { Temp.Paredes } \\
\text { voltada para a rua } \\
\left({ }^{\circ} \mathrm{C}\right)\end{array}$ & \multicolumn{3}{|c|}{ Temp. Média das paredes $\left({ }^{\circ} \mathrm{C}\right)$} & Temp. Teto $\left({ }^{\circ} \mathrm{C}\right)$ & \\
\hline 11:50 & 23,3 & 26,1 & 22,9 & \multicolumn{3}{|c|}{23,5} & 23,1 & \\
\hline $15: 00$ & 28,1 & 27,2 & 23,1 & \multicolumn{3}{|c|}{23,2} & 23,1 & \\
\hline
\end{tabular}

Tabela 124Resultados coletados in loco no quarto do Apartamento E no mês de Junho de 2014.

\begin{tabular}{|c|c|c|c|c|c|c|c|c|}
\hline \multicolumn{2}{|l|}{ Apartamento $\mathrm{E}$} & \multicolumn{4}{|c|}{ Dados coletados CONFORTímETRO Julho 2013 - SALA } & \multicolumn{3}{|c|}{ Céu claro } \\
\hline Intervalo & $\begin{array}{l}\text { Temperatura de } \\
\text { bulbo úmido }\left({ }^{\circ} \mathrm{C}\right)\end{array}$ & $\begin{array}{c}\text { Temperatura de } \\
\text { glo bo }\left({ }^{\circ} \mathrm{C}\right)\end{array}$ & $\begin{array}{c}\text { Temperatura do ar } \\
\left({ }^{\circ} \mathrm{C}\right)\end{array}$ & $\begin{array}{c}\text { Pressão } \\
\text { Atmosférica }\end{array}$ & $\begin{array}{c}\text { Umidade relativa } \\
\text { do ar (\%) }\end{array}$ & $\begin{array}{l}\text { Velocidade do ar } \\
\qquad(\mathrm{m} / \mathrm{s})\end{array}$ & $\begin{array}{l}\text { Temperatura } \\
\text { radiante }\left({ }^{\circ} \mathrm{C}\right)\end{array}$ & $\begin{array}{c}\text { Temperatura } \\
\text { Operativa }\left({ }^{\circ} \mathrm{C}\right)\end{array}$ \\
\hline $15: 00$ as $15: 30$ & 19,6 & 22,9 & 22,9 & 1019,5 & 67,2 & 0,0 & 23,0 & 22,9 \\
\hline $15: 30$ as $16: 00$ & 19,7 & 22,9 & 22,8 & 1019,5 & 69,0 & 0,0 & 22,9 & 22,9 \\
\hline $15: 30$ as $16: 00$ & 19,6 & 22,6 & 22,5 & 1019,7 & 69,4 & 0,0 & 22,7 & 22,6 \\
\hline $16: 30$ as $17: 00$ & 19,7 & 22,5 & 22,4 & 1019,7 & 71,3 & 0,0 & 22,6 & 22,5 \\
\hline Desvio Padrão & 0,13 & 0,20 & 0,19 & 0,10 & 1,62 & 0,03 & 0,21 & 0,2 \\
\hline Média & 19,6 & 22,7 & 22,7 & 1019,6 & 69,2 & 0,0 & 22,8 & 22,7 \\
\hline \multicolumn{8}{|c|}{ Dados coletados Termômetro de fluxo de laser } & \\
\hline Horário/Quarto & $\begin{array}{l}\text { Temp. Externa do ar } \\
\left({ }^{\circ} \mathrm{C}\right)\end{array}$ & $\begin{array}{c}\text { Temp. Paredes } \\
\text { externas }\left({ }^{\circ} \mathrm{C}\right)\end{array}$ & $\begin{array}{c}\text { Temp.Paredes } \\
\text { voltada para a rua } \\
\left({ }^{\circ} \mathrm{C}\right)\end{array}$ & \multicolumn{3}{|c|}{ Temp. Média das paredes $\left({ }^{\circ} \mathrm{C}\right)$} & Temp. Teto $\left({ }^{\circ} \mathrm{C}\right)$ & \\
\hline 15:00 & 21,5 & 22,5 & 22,6 & \multicolumn{3}{|c|}{22,6} & 22,9 & \\
\hline $17: 00$ & 20,8 & 21,5 & 21,9 & \multicolumn{3}{|c|}{21,9} & 22,7 & \\
\hline
\end{tabular}

Tabela 125: Resultados coletados in loco na sala do Apartamento E no mês de Julho de 2013. 


\begin{tabular}{|c|c|c|c|c|c|c|c|c|}
\hline \multicolumn{2}{|l|}{ Apartamento $\mathrm{E}$} & \multicolumn{4}{|c|}{ Dados coletados CONFORTÍM ETRO Agosto 2013 - SALA } & \multicolumn{3}{|c|}{ Céu claro } \\
\hline Intervalo & $\begin{array}{l}\text { Temperatura de } \\
\text { bulbo úmido }\left({ }^{\circ} \mathrm{C}\right)\end{array}$ & $\begin{array}{c}\text { Temperatura de } \\
\text { glo bo }\left({ }^{\circ} \mathrm{C}\right)\end{array}$ & $\begin{array}{c}\text { Temperatura do ar } \\
\left({ }^{\circ} \mathrm{C}\right)\end{array}$ & $\begin{array}{l}\text { Pressão } \\
\text { Atmosférica } \\
\text { (atm) }\end{array}$ & $\begin{array}{l}\text { Umidade relativa } \\
\text { do ar (\%) }\end{array}$ & $\begin{array}{l}\text { Velocidade do ar } \\
\qquad(\mathrm{m} / \mathrm{s})\end{array}$ & $\begin{array}{l}\text { Temperatura } \\
\text { radiante }\left({ }^{\circ} \mathrm{C}\right)\end{array}$ & $\begin{array}{l}\text { Temperatura } \\
\text { Operativa }\left({ }^{\circ} \mathrm{C}\right)\end{array}$ \\
\hline $15: 00$ as $15: 30$ & 18,3 & 20,7 & 20,6 & 1021,2 & 74,1 & 0,0 & 20,7 & 20,7 \\
\hline $15: 30$ as $16: 00$ & 18,2 & 20,6 & 20,6 & 1020,7 & 72,9 & 0,0 & 20,7 & 20,6 \\
\hline $15: 30$ as $16: 00$ & 18,0 & 20,5 & 20,4 & 1020,1 & 72,5 & 0,0 & 20,5 & 20,5 \\
\hline $16: 30$ as $17: 00$ & 18,1 & 20,6 & 20,6 & 1019,8 & 71,8 & 0,0 & 20,6 & 20,6 \\
\hline Desvio Padrão & 0,15 & 0,13 & 0,13 & 0,56 & 1,00 & 0,04 & 0,15 & 0,1 \\
\hline Média & 18,1 & 20,6 & 20,6 & 1020,5 & 72,8 & 0,0 & 20,6 & 20,6 \\
\hline \multicolumn{8}{|c|}{ Dados coletados Termômetro de fluxo de laser } & \\
\hline Horário/Quarto & $\begin{array}{l}\text { Temp. Externa do ar } \\
\left({ }^{\circ} \mathrm{C}\right)\end{array}$ & $\begin{array}{l}\text { Temp. Paredes } \\
\text { externas }\left({ }^{\circ} \mathrm{C}\right)\end{array}$ & $\begin{array}{c}\text { Temp.Paredes } \\
\text { voltada para a rua } \\
\left({ }^{\circ} \mathrm{C}\right)\end{array}$ & \multicolumn{3}{|c|}{ Temp. Média das paredes $\left({ }^{\circ} \mathrm{C}\right)$} & Temp. Teto $\left({ }^{\circ} \mathrm{C}\right)$ & \\
\hline $15: 00$ & 20,6 & 20,6 & 21,5 & \multicolumn{3}{|c|}{21,2} & 21,2 & \\
\hline $17: 00$ & 21,3 & 21,3 & 21,9 & \multicolumn{3}{|c|}{21,9} & 22,3 & \\
\hline
\end{tabular}

Tabela 126: Resultados coletados in loco na sala do Apartamento E no mês de Agosto de 2013.

\begin{tabular}{|c|c|c|c|c|c|c|c|c|}
\hline \multicolumn{2}{|l|}{ Apartamento $\mathrm{E}$} & \multicolumn{4}{|c|}{ Dados coletados CONFORTIMETRO Setembro 2013 - SALA } & \multicolumn{3}{|c|}{ Céu claro } \\
\hline Intervalo & $\begin{array}{l}\text { Temperatura de } \\
\text { bulbo úmido }\left({ }^{\circ} \mathrm{C}\right)\end{array}$ & $\begin{array}{c}\text { Temperatura de } \\
\text { glo bo }\left({ }^{\circ} \mathrm{C}\right)\end{array}$ & $\begin{array}{c}\text { Temperatura do ar } \\
\left({ }^{\circ} \mathrm{C}\right)\end{array}$ & $\begin{array}{l}\text { Pressão } \\
\text { Atmosférica } \\
\text { (atm) }\end{array}$ & $\begin{array}{l}\text { Umidade relativa } \\
\text { do ar (\%) }\end{array}$ & $\begin{array}{l}\text { Velocidade do ar } \\
\qquad(\mathrm{m} / \mathrm{s})\end{array}$ & $\begin{array}{l}\text { Temperatura } \\
\text { radiante }\left({ }^{\circ} \mathrm{C}\right)\end{array}$ & $\begin{array}{l}\text { Temperatura } \\
\text { Operativa }\left({ }^{\circ} \mathrm{C}\right)\end{array}$ \\
\hline $15: 00$ as $15: 30$ & 22,2 & 26,4 & 26,1 & 1007,5 & 65,5 & 0,1 & 26,6 & 26,4 \\
\hline $15: 30$ as $16: 00$ & 22,4 & 26,4 & 26,2 & 1007,2 & 66,0 & 0,0 & 26,5 & 26,4 \\
\hline $15: 30$ as $16: 00$ & 22,4 & 26,4 & 26,2 & 1007,1 & 66,5 & 0,0 & 26,4 & 26,3 \\
\hline $16: 30$ as $17: 00$ & 22,6 & 26,5 & 26,3 & 1007,1 & 66,6 & 0,0 & 26,5 & 26,4 \\
\hline Desvio Padrão & 0,17 & 0,07 & 0,11 & 0,18 & 0,56 & 0,07 & 0,12 & 0,1 \\
\hline Média & 22,4 & 26,4 & 26,2 & 1007,2 & 66,2 & 0,0 & 26,5 & 26,4 \\
\hline \multicolumn{9}{|c|}{ Dados coletados Termômetro de fluxo de laser } \\
\hline Horário/Quarto & $\begin{array}{l}\text { Temp. Externa do ar } \\
\left({ }^{\circ} \mathrm{C}\right)\end{array}$ & $\begin{array}{c}\text { Temp. Paredes } \\
\text { externas }\left({ }^{\circ} \mathrm{C}\right)\end{array}$ & $\begin{array}{c}\text { Temp.Paredes } \\
\text { voltada para a rua } \\
\left({ }^{\circ} \mathrm{C}\right)\end{array}$ & \multicolumn{3}{|c|}{ Temp. Média das paredes $\left({ }^{\circ} \mathrm{C}\right)$} & Temp. Teto $\left({ }^{\circ} \mathrm{C}\right)$ & \\
\hline $15: 00$ & 26,6 & 27,9 & 26,8 & \multicolumn{3}{|c|}{27,1} & 27,1 & \\
\hline $17: 00$ & 24,9 & 25,1 & 26,8 & \multicolumn{3}{|c|}{26,9} & 26,9 & \\
\hline
\end{tabular}

Tabela 127: Resultados coletados in loco na sala do Apartamento E no mês de Setembro de 2013.

\begin{tabular}{|c|c|c|c|c|c|c|c|c|}
\hline \multicolumn{2}{|l|}{ Apartamento $\mathrm{E}$} & \multicolumn{4}{|c|}{ Dados coletados CONFORTÍM ETRO Outubro 2013 - SALA } & \multicolumn{3}{|c|}{ Céu claro } \\
\hline Intervalo & $\begin{array}{l}\text { Temperatura de } \\
\text { bulbo úmido }\left({ }^{\circ} \mathrm{C}\right)\end{array}$ & $\begin{array}{c}\text { Temperatura de } \\
\text { glo bo }\left({ }^{\circ} \mathrm{C}\right)\end{array}$ & $\begin{array}{c}\text { Temperatura do ar } \\
\left({ }^{\circ} \mathrm{C}\right)\end{array}$ & $\begin{array}{c}\text { Pressão } \\
\text { Atmosférica } \\
\text { (atm) }\end{array}$ & $\begin{array}{l}\text { Umidade relativa } \\
\text { do ar (\%) }\end{array}$ & $\begin{array}{l}\text { Velocidade do ar } \\
\qquad(\mathrm{m} / \mathrm{s})\end{array}$ & $\begin{array}{l}\text { Temperatura } \\
\text { radiante }\left({ }^{\circ} \mathrm{C}\right)\end{array}$ & $\begin{array}{l}\text { Temperatura } \\
\text { Operativa }\left({ }^{\circ} \mathrm{C}\right)\end{array}$ \\
\hline $16: 00$ as $16: 30$ & 23,7 & 27,4 & 27,3 & 1011,3 & 69,6 & 0,1 & 27,6 & 27,5 \\
\hline $16: 30$ as $17: 00$ & 23,6 & 27,0 & 26,8 & 1011,3 & 72,1 & 0,1 & 27,1 & 27,0 \\
\hline $17: 00$ as $17: 30$ & 23,8 & 27,0 & 26,9 & 1010,5 & 72,4 & 0,1 & 27,1 & 27,0 \\
\hline $17: 30$ as $18: 00$ & 23,9 & 27,1 & 27,0 & 1010,1 & 72,0 & 0,0 & 27,2 & 27,1 \\
\hline Desvio Padrão & 0,13 & 0,23 & 0,22 & 0,57 & 1,31 & 0,07 & 0,28 & 0,3 \\
\hline Média & 23,7 & 27,1 & 27,0 & 1010,8 & 71,5 & 0,1 & 27,3 & 27,1 \\
\hline \multicolumn{8}{|c|}{ Dados coletados Termômetro de fluxo de laser } & \\
\hline Horário/Quarto & $\begin{array}{l}\text { Temp. Externa do ar } \\
\left({ }^{\circ} \mathrm{C}\right)\end{array}$ & $\begin{array}{c}\text { Temp. Paredes } \\
\text { externas }\left({ }^{\circ} \mathrm{C}\right)\end{array}$ & $\begin{array}{c}\text { Temp.Paredes } \\
\text { voltada para a rua } \\
\left({ }^{\circ} \mathrm{C}\right)\end{array}$ & Tem & p. Média das pared & $\mathrm{S}\left({ }^{\circ} \mathrm{C}\right)$ & Temp. Teto $\left({ }^{\circ} \mathrm{C}\right)$ & \\
\hline $16: 00$ & 28,6 & 29,9 & 27,2 & & 27,4 & & 27,4 & \\
\hline $18: 00$ & 29 & 27,6 & 27,9 & & 26,7 & & 27,2 & \\
\hline
\end{tabular}

Tabela 128: Resultados coletados in loco na sala do Apartamento E no mês de Outubro de 2013.

\begin{tabular}{|c|c|c|c|c|c|c|c|c|}
\hline \multicolumn{2}{|l|}{ Apartamento $\mathrm{E}$} & \multicolumn{4}{|c|}{ Dados coletados CONFORTÍM ETRO Novembro 2013 - SALA } & \multicolumn{3}{|c|}{ Chuva } \\
\hline Intervalo & $\begin{array}{l}\text { Temperatura de } \\
\text { bulbo úmido }\left({ }^{\circ} \mathrm{C}\right)\end{array}$ & $\begin{array}{c}\text { Temperatura de } \\
\text { globo }\left({ }^{\circ} \mathrm{C}\right)\end{array}$ & $\begin{array}{c}\text { Temperatura do ar } \\
\left({ }^{\circ} \mathrm{C}\right)\end{array}$ & $\begin{array}{l}\text { Pressão } \\
\text { Atmosférica } \\
\text { (atm) }\end{array}$ & $\begin{array}{l}\text { Umidade relativa } \\
\text { do ar (\%) }\end{array}$ & $\begin{array}{l}\text { Velocidade do ar } \\
\qquad(\mathrm{m} / \mathrm{s})\end{array}$ & $\begin{array}{l}\text { Temperatura } \\
\text { radiante }\left({ }^{\circ} \mathrm{C}\right)\end{array}$ & $\begin{array}{l}\text { Temperatura } \\
\text { Operativa }\left({ }^{\circ} \mathrm{C}\right)\end{array}$ \\
\hline $16: 00$ as $16: 30$ & 24,5 & 27,3 & 27,2 & 1007,3 & 74,4 & 0,0 & 27,4 & 27,3 \\
\hline $16: 30$ as $17: 00$ & 24,5 & 27,3 & 27,1 & 1007,2 & 75,7 & 0,0 & 27,3 & 27,2 \\
\hline $17: 00$ as $17: 30$ & 24,5 & 27,1 & 26,8 & 1007,3 & 76,9 & 0,0 & 27,2 & 27,0 \\
\hline $17: 30$ as $18: 00$ & 24,2 & 27,0 & 26,7 & 1007,4 & 76,9 & 0,0 & 27,1 & 26,9 \\
\hline Desvio Padrão & 0,15 & 0,17 & 0,23 & 0,09 & 1,22 & 0,03 & 0,16 & 0,2 \\
\hline Média & 24,4 & 27,2 & 27,0 & 1007,3 & 75,8 & 0,0 & 27,3 & 27,1 \\
\hline \multicolumn{8}{|c|}{ Dados coletados Termômetro de fluxo de laser } & \\
\hline Horário/Quarto & $\begin{array}{c}\text { Temp. Externa do ar } \\
\left({ }^{\circ} \mathrm{C}\right)\end{array}$ & $\begin{array}{l}\text { Temp. Paredes } \\
\text { externas }\left({ }^{\circ} \mathrm{C}\right)\end{array}$ & $\begin{array}{c}\text { Temp.Paredes } \\
\text { voltada para a rua } \\
\left({ }^{\circ} \mathrm{C}\right)\end{array}$ & \multicolumn{3}{|c|}{ Temp. Média das paredes $\left({ }^{\circ} \mathrm{C}\right)$} & Temp. Teto $\left({ }^{\circ} \mathrm{C}\right)$ & \\
\hline $16: 00$ & 25 & 26,1 & 27,3 & \multicolumn{3}{|c|}{27,8} & 27,8 & \\
\hline 18:00 & 24,5 & 24,5 & 27,7 & \multicolumn{3}{|c|}{27,6} & 27,8 & \\
\hline
\end{tabular}

Tabela 129: Resultados coletados in loco na sala do Apartamento E no mês de Novembro de 2013. 


\begin{tabular}{|c|c|c|c|c|c|c|c|c|}
\hline \multicolumn{6}{|c|}{ Dados coletados CONFORTÍMETRO Dezembro 2013 - SALA } & \multicolumn{3}{|c|}{ Nublado } \\
\hline Intervalo & $\begin{array}{l}\text { Temperatura de } \\
\text { bulbo úmido }\left({ }^{\circ} \mathrm{C}\right)\end{array}$ & $\begin{array}{l}\text { Temperatura de } \\
\text { glo bo }\left({ }^{\circ} \mathrm{C}\right)\end{array}$ & $\begin{array}{c}\text { Temperatura do ar } \\
\left({ }^{\circ} \mathrm{C}\right)\end{array}$ & $\begin{array}{l}\text { Pressão } \\
\text { Atmosférica } \\
\text { (atm) }\end{array}$ & $\begin{array}{l}\text { Umidade relativa } \\
\text { do ar (\%) }\end{array}$ & $\begin{array}{l}\text { Velocidade do ar } \\
\qquad(\mathrm{m} / \mathrm{s})\end{array}$ & $\begin{array}{l}\text { Temperatura } \\
\text { radiante }\left({ }^{\circ} \mathrm{C}\right)\end{array}$ & $\begin{array}{l}\text { Temperatura } \\
\text { Operativa }\left({ }^{\circ} \mathrm{C}\right)\end{array}$ \\
\hline $16: 00$ as $16: 30$ & 23,8 & 28,4 & 28,3 & 1010,1 & 65,9 & 0,0 & 28,5 & 28,4 \\
\hline $16: 30$ as $17: 00$ & 23,8 & 28,2 & 28,1 & 1009,6 & 67,1 & 0,1 & 28,5 & 28,3 \\
\hline $17: 00$ as $17: 30$ & 24,0 & 28,2 & 28,1 & 1009,5 & 68,1 & 0,1 & 28,3 & 28,2 \\
\hline $17: 30$ as $18: 00$ & 24,0 & 28,2 & 28,1 & 1009,4 & 68,4 & 0,0 & 28,5 & 28,3 \\
\hline Desvio Padrão & 0,12 & 0,10 & 0,12 & 0,31 & 1,08 & 0,08 & 0,11 & 0,1 \\
\hline Média & 23,9 & 28,3 & 28,2 & 1009,7 & 67,4 & 0,0 & 28,4 & 28,3 \\
\hline \multicolumn{8}{|c|}{ Dados coletados Termômetro de fluxo de laser } & \\
\hline Horário/Quarto & $\begin{array}{l}\text { Temp. Externa do ar } \\
\left({ }^{\circ} \mathrm{C}\right)\end{array}$ & $\begin{array}{c}\text { Temp. Paredes } \\
\text { externas }\left({ }^{\circ} \mathrm{C}\right)\end{array}$ & $\begin{array}{c}\text { Temp.Paredes } \\
\text { voltada para a rua } \\
\left({ }^{\circ} \mathrm{C}\right)\end{array}$ & \multicolumn{3}{|c|}{ Temp. Média das paredes $\left({ }^{\circ} \mathrm{C}\right)$} & Temp. Teto $\left({ }^{\circ} \mathrm{C}\right)$ & \\
\hline $16: 00$ & 31,2 & 30,1 & 27,6 & \multicolumn{3}{|c|}{28,1} & 27,7 & \\
\hline $18: 00$ & 29,6 & 29 & 27,6 & \multicolumn{3}{|c|}{28,1} & 27,8 & \\
\hline
\end{tabular}

Tabela 130: Resultados coletados in loco na sala do Apartamento E no mês de Dezembro de 2013.

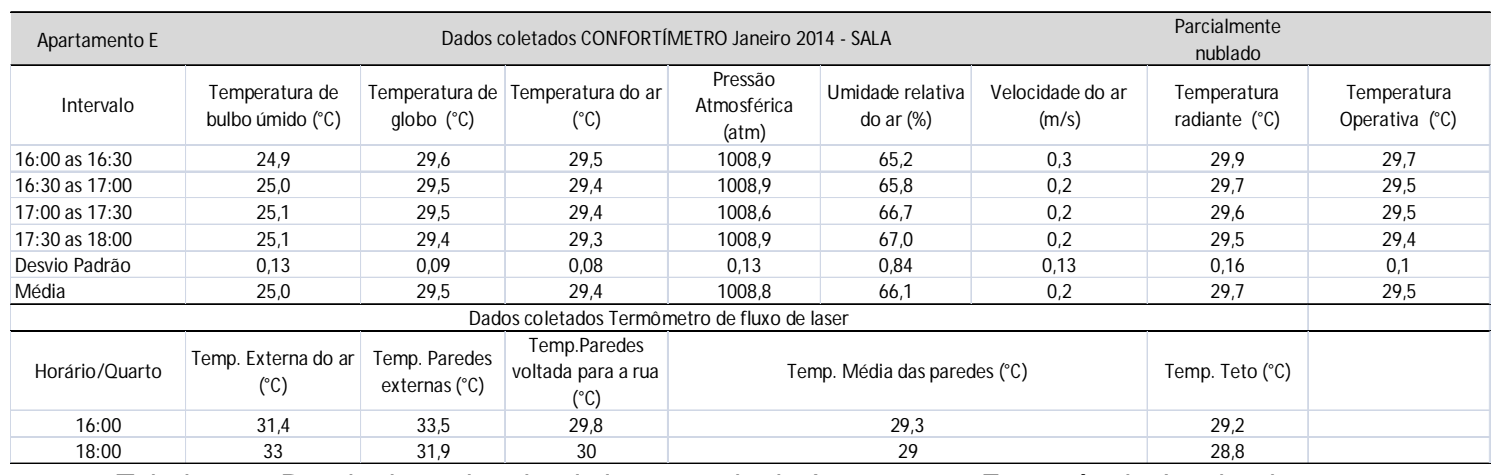

Tabela 131: Resultados coletados in loco na sala do Apartamento E no mês de Janeiro de 2014.

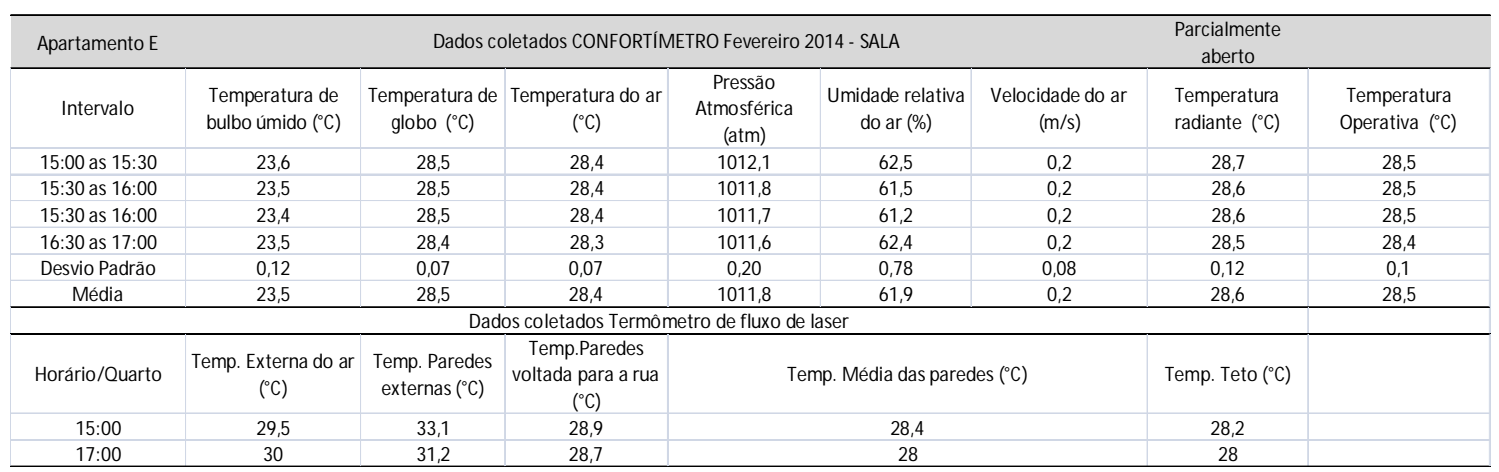

Tabela 132: Resultados coletados in loco na sala do Apartamento E no mês de Fevereiro de 2014.

\begin{tabular}{|c|c|c|c|c|c|c|c|c|}
\hline \multicolumn{2}{|l|}{ Apartamento $\mathrm{E}$} & \multicolumn{4}{|c|}{ Dados coletados CONFORTÍM ETRO M arço 2014 - SALA } & \multicolumn{3}{|c|}{ Nublado } \\
\hline Intervalo & $\begin{array}{l}\text { Temperatura de } \\
\text { bulbo úmido }\left({ }^{\circ} \mathrm{C}\right)\end{array}$ & $\begin{array}{c}\text { Temperatura de } \\
\text { glo bo }\left({ }^{\circ} \mathrm{C}\right)\end{array}$ & $\begin{array}{c}\text { Temperatura do ar } \\
\left({ }^{\circ} \mathrm{C}\right)\end{array}$ & $\begin{array}{l}\text { Pressão } \\
\text { Atmosférica } \\
\text { (atm) }\end{array}$ & $\begin{array}{l}\text { Umidade relativa } \\
\text { do ar (\%) }\end{array}$ & $\begin{array}{l}\text { Velocidade do ar } \\
\qquad(\mathrm{m} / \mathrm{s})\end{array}$ & $\begin{array}{l}\text { Temperatura } \\
\text { radiante }\left({ }^{\circ} \mathrm{C}\right)\end{array}$ & $\begin{array}{l}\text { Temperatura } \\
\text { Operativa }\left({ }^{\circ} \mathrm{C}\right)\end{array}$ \\
\hline $15: 00$ as $15: 30$ & 22,1 & 27,1 & 27,0 & 1015,9 & 59,9 & 0,0 & 27,1 & 27,0 \\
\hline $15: 30$ as 16:00 & 22,1 & 27,0 & 26,9 & 1015,8 & 61,0 & 0,0 & 27,1 & 27,0 \\
\hline $15: 30$ as $16: 00$ & 22,3 & 27,0 & 26,9 & 1015,9 & 61,2 & 0,0 & 27,1 & 27,0 \\
\hline $16: 30$ as $17: 00$ & 22,1 & 27,0 & 26,9 & 1015,9 & 60,3 & 0,0 & 27,0 & 26,9 \\
\hline Desvio Padrão & 0,16 & 0,06 & 0,05 & 0,06 & 0,78 & 0,04 & 0,08 & 0,1 \\
\hline Média & 22,2 & 27,0 & 26,9 & 1015,9 & 60,6 & 0,0 & 27,1 & 27,0 \\
\hline \multicolumn{8}{|c|}{ Dados coletados Termô metro de fluxo de laser } & \\
\hline Horário/Quarto & $\begin{array}{l}\text { Temp. Externa do ar } \\
\left({ }^{\circ} \mathrm{C}\right)\end{array}$ & $\begin{array}{c}\text { Temp. Paredes } \\
\text { externas }\left({ }^{\circ} \mathrm{C}\right)\end{array}$ & $\begin{array}{c}\text { Temp.Paredes } \\
\text { voltada para a rua } \\
\left({ }^{\circ} \mathrm{C}\right)\end{array}$ & \multicolumn{3}{|c|}{ Temp. Média das paredes $\left({ }^{\circ} \mathrm{C}\right)$} & Temp. Teto $\left({ }^{\circ} \mathrm{C}\right)$ & \\
\hline 15:00 & 27,5 & 28,4 & 27,2 & \multicolumn{3}{|c|}{27,3} & 27,7 & \\
\hline $17: 00$ & 28,8 & 27,7 & 27,4 & \multicolumn{3}{|c|}{27,2} & 27,4 & \\
\hline
\end{tabular}

Tabela 133: Resultados coletados in loco na sala do Apartamento E no mês de Março de 2014. 


\begin{tabular}{|c|c|c|c|c|c|c|c|c|}
\hline Apartamento $\mathrm{E}$ & & \multicolumn{4}{|c|}{ Dados coletados CONFORTÍM ETRO Abril 2014 - SALA } & \multicolumn{3}{|c|}{$\begin{array}{l}\text { Parcialmente } \\
\text { nublado }\end{array}$} \\
\hline Intervalo & $\begin{array}{l}\text { Temperatura de } \\
\text { bulbo úmido }\left({ }^{\circ} \mathrm{C}\right)\end{array}$ & $\begin{array}{c}\text { Temperatura de } \\
\text { glo bo }\left({ }^{\circ} \mathrm{C}\right)\end{array}$ & $\begin{array}{c}\text { Temperatura do ar } \\
\left({ }^{\circ} \mathrm{C}\right)\end{array}$ & $\begin{array}{c}\text { Pressão } \\
\text { Atmosférica } \\
\text { (atm) }\end{array}$ & $\begin{array}{l}\text { Umidade relativa } \\
\text { do ar (\%) }\end{array}$ & $\begin{array}{l}\text { Velocidade do ar } \\
\qquad(\mathrm{m} / \mathrm{s})\end{array}$ & $\begin{array}{l}\text { Temperatura } \\
\text { radiante }\left({ }^{\circ} \mathrm{C}\right)\end{array}$ & $\begin{array}{l}\text { Temperatura } \\
\text { Operativa }\left({ }^{\circ} \mathrm{C}\right)\end{array}$ \\
\hline $15: 00$ as $15: 30$ & 22,6 & 25,8 & 25,7 & 1013,5 & 72,1 & 0,1 & 25,9 & 25,8 \\
\hline $15: 30$ as $16: 00$ & 22,7 & 25,8 & 25,7 & 1013,5 & 72,9 & 0,1 & 25,9 & 25,8 \\
\hline $15: 30$ as $16: 00$ & 23,0 & 25,8 & 25,7 & 1013,6 & 74,8 & 0,0 & 25,8 & 25,8 \\
\hline $16: 30$ as $17: 00$ & 23,0 & 25,8 & 25,7 & 1013,8 & 74,5 & 0,1 & 25,9 & 25,8 \\
\hline Desvio Padrão & 0,18 & 0,08 & 0,07 & 0,13 & 1,22 & 0,07 & 0,10 & 0,1 \\
\hline Média & 22,8 & 25,8 & 25,7 & 1013,6 & 73,5 & 0,1 & 25,9 & 25,8 \\
\hline \multicolumn{8}{|c|}{ Dados coletados Termômetro de fluxo de laser } & \\
\hline Horário/Quarto & $\begin{array}{l}\text { Temp. Externa do ar } \\
\left({ }^{\circ} \mathrm{C}\right)\end{array}$ & $\begin{array}{l}\text { Temp. Paredes } \\
\text { externas }\left({ }^{\circ} \mathrm{C}\right)\end{array}$ & $\begin{array}{c}\text { Temp.Paredes } \\
\text { voltada para a rua } \\
\left({ }^{\circ} \mathrm{C}\right)\end{array}$ & \multicolumn{3}{|c|}{ Temp. Média das paredes $\left({ }^{\circ} \mathrm{C}\right)$} & Temp. Teto $\left({ }^{\circ} \mathrm{C}\right)$ & \\
\hline $15: 00$ & 28,4 & 28,1 & 25,6 & \multicolumn{3}{|c|}{25,1} & 25,3 & \\
\hline $17: 00$ & 28,3 & 25,8 & 25,6 & \multicolumn{3}{|c|}{25,1} & 25,5 & \\
\hline
\end{tabular}

Tabela 134: Resultados coletados in loco na sala do Apartamento E no mês de Abril de 2014.

\begin{tabular}{|c|c|c|c|c|c|c|c|c|}
\hline \multicolumn{2}{|l|}{ Apartamento $\mathrm{E}$} & \multicolumn{4}{|c|}{ Dados coletados CONFORTÍM ETRO M aio 2014 - SALA } & \multicolumn{3}{|c|}{$\begin{array}{c}\text { Parcialmente } \\
\text { aberto }\end{array}$} \\
\hline Intervalo & $\begin{array}{l}\text { Temperatura de } \\
\text { bulbo úmido }\left({ }^{\circ} \mathrm{C}\right)\end{array}$ & $\begin{array}{c}\text { Temperatura de } \\
\text { globo }\left({ }^{\circ} \mathrm{C}\right)\end{array}$ & $\begin{array}{c}\text { Temperatura do ar } \\
\left({ }^{\circ} \mathrm{C}\right)\end{array}$ & $\begin{array}{l}\text { Pressão } \\
\text { Atmosférica } \\
\text { (atm) }\end{array}$ & $\begin{array}{l}\text { Umidade relativa } \\
\text { do ar (\%) }\end{array}$ & $\begin{array}{l}\text { Velocidade do ar } \\
\qquad(\mathrm{m} / \mathrm{s})\end{array}$ & $\begin{array}{l}\text { Temperatura } \\
\text { radiante }\left({ }^{\circ} \mathrm{C}\right)\end{array}$ & $\begin{array}{l}\text { Temperatura } \\
\text { Operativa }\left({ }^{\circ} \mathrm{C}\right)\end{array}$ \\
\hline $15: 00$ as $15: 30$ & 24,1 & 27,1 & 27,0 & 1013,0 & 75,6 & 0,2 & 27,3 & 27,1 \\
\hline $15: 30$ as $16: 00$ & 23,9 & 27,0 & 26,9 & 1013,0 & 74,9 & 0,2 & 27,1 & 27,0 \\
\hline $15: 30$ as $16: 00$ & 23,8 & 26,9 & 26,8 & 1013,1 & 74,5 & 0,2 & 27,1 & 27,0 \\
\hline $16: 30$ as $17: 00$ & 23,7 & 26,9 & 26,8 & 1013,3 & 74,0 & 0,2 & 27,1 & 26,9 \\
\hline Desvio Padrão & 0,15 & 0,11 & 0,08 & 0,13 & 0,62 & 0,09 & 0,19 & 0,1 \\
\hline Média & 23,9 & 27,0 & 26,9 & 1013,1 & 74,8 & 0,2 & 27,1 & 27,0 \\
\hline \multicolumn{8}{|c|}{ Dados coletados Termômetro de fluxo de laser } & \\
\hline Horário/Quarto & $\begin{array}{l}\text { Temp. Externa do ar } \\
\left({ }^{\circ} \mathrm{C}\right)\end{array}$ & $\begin{array}{c}\text { Temp. Paredes } \\
\text { externas }\left({ }^{\circ} \mathrm{C}\right)\end{array}$ & $\begin{array}{c}\text { Temp.Paredes } \\
\text { voltada para a rua } \\
\left({ }^{\circ} \mathrm{C}\right)\end{array}$ & \multicolumn{3}{|c|}{ Temp. Média das paredes $\left({ }^{\circ} \mathrm{C}\right)$} & Temp. Teto $\left({ }^{\circ} \mathrm{C}\right)$ & \\
\hline 15:00 & 29,5 & 28,3 & 26,7 & \multicolumn{3}{|c|}{26,5} & 26,9 & \\
\hline $17: 00$ & 29,5 & 27,2 & 26,7 & \multicolumn{3}{|c|}{27,2} & 27,1 & \\
\hline
\end{tabular}

Tabela 135: Resultados coletados in loco na sala do Apartamento E no mês de Maio de 2014.

\begin{tabular}{|c|c|c|c|c|c|c|c|c|}
\hline \multicolumn{2}{|l|}{ Apartamento $\mathrm{E}$} & \multicolumn{4}{|c|}{ Dados coletados CONFORTÍM ETRO Junho 2014 - SALA } & \multicolumn{3}{|c|}{ Céu claro } \\
\hline Intervalo & $\begin{array}{l}\text { Temperatura de } \\
\text { bulbo úmido }\left({ }^{\circ} \mathrm{C}\right)\end{array}$ & $\begin{array}{c}\text { Temperatura de } \\
\text { glo bo }\left({ }^{\circ} \mathrm{C}\right)\end{array}$ & $\begin{array}{c}\text { Temperatura do ar } \\
\left({ }^{\circ} \mathrm{C}\right)\end{array}$ & $\begin{array}{l}\text { Pressão } \\
\text { Atmosférica } \\
\text { (atm) }\end{array}$ & $\begin{array}{l}\text { Umidade relativa } \\
\text { do ar (\%) }\end{array}$ & $\begin{array}{l}\text { Velocidade do ar } \\
\qquad(\mathrm{m} / \mathrm{s})\end{array}$ & $\begin{array}{l}\text { Temperatura } \\
\text { radiante }\left({ }^{\circ} \mathrm{C}\right)\end{array}$ & $\begin{array}{l}\text { Temperatura } \\
\text { Operativa }\left({ }^{\circ} \mathrm{C}\right)\end{array}$ \\
\hline $15: 00$ as $15: 30$ & 21,4 & 24,8 & 24,7 & 1013,5 & 69,5 & 0,0 & 24,9 & 24,8 \\
\hline $15: 30$ as $16: 00$ & 21,5 & 24,7 & 24,6 & 1013,5 & 70,8 & 0,0 & 24,8 & 24,7 \\
\hline $15: 30$ as $16: 00$ & 21,6 & 24,6 & 24,4 & 1013,5 & 72,6 & 0,0 & 24,6 & 24,5 \\
\hline $16: 30$ as $17: 00$ & 21,5 & 24,4 & 24,3 & 1013,7 & 72,5 & 0,0 & 24,5 & 24,4 \\
\hline Desvio Padrão & 0,10 & 0,16 & 0,18 & 0,10 & 1,42 & 0,03 & 0,17 & 0,2 \\
\hline Média & 21,5 & 24,6 & 24,5 & 1013,6 & 71,3 & 0,0 & 24,7 & 24,6 \\
\hline \multicolumn{8}{|c|}{ Dados coletados Termômetro de fluxo de laser } & \\
\hline Horário/Quarto & $\begin{array}{l}\text { Temp. Externa do ar } \\
\left({ }^{\circ} \mathrm{C}\right)\end{array}$ & $\begin{array}{c}\text { Temp. Paredes } \\
\text { externas }\left({ }^{\circ} \mathrm{C}\right)\end{array}$ & $\begin{array}{c}\text { Temp.Paredes } \\
\text { voltada para a rua } \\
\left({ }^{\circ} \mathrm{C}\right)\end{array}$ & \multicolumn{3}{|c|}{ Temp. Média das paredes $\left({ }^{\circ} \mathrm{C}\right)$} & Temp. Teto $\left({ }^{\circ} \mathrm{C}\right)$ & \\
\hline 15:00 & 28,1 & 27,1 & 23,1 & \multicolumn{3}{|c|}{23,4} & 23,1 & \\
\hline $17: 00$ & 26,4 & 25,2 & 24,2 & \multicolumn{3}{|c|}{23,9} & 23,6 & \\
\hline
\end{tabular}

Tabela 136: Resultados coletados in loco na sala do Apartamento E no mês de Junho de 2014.

\begin{tabular}{|c|c|c|c|c|c|c|c|c|}
\hline \multicolumn{2}{|l|}{ Apartamento $\mathrm{F}$} & \multicolumn{4}{|c|}{ Dados coletados CONFORTÍMETRO Julho 2013 - QUARTO } & \multicolumn{3}{|c|}{ Nublado } \\
\hline Intervalo & $\begin{array}{l}\text { Temperatura de } \\
\text { bulbo úmido }\left({ }^{\circ} \mathrm{C}\right)\end{array}$ & $\begin{array}{c}\text { Temperatura de } \\
\text { globo }\left({ }^{\circ} \mathrm{C}\right)\end{array}$ & $\begin{array}{c}\text { Temperatura do ar } \\
\left({ }^{\circ} \mathrm{C}\right)\end{array}$ & $\begin{array}{c}\text { Pressão Atmosférica } \\
\text { (atm) }\end{array}$ & $\begin{array}{c}\text { Umidade relativa do } \\
\text { ar (\%) }\end{array}$ & $\begin{array}{l}\text { Velocidade do ar } \\
\qquad(\mathrm{m} / \mathrm{s})\end{array}$ & $\begin{array}{l}\text { Temperatura } \\
\text { radiante }\left({ }^{\circ} \mathrm{C}\right)\end{array}$ & $\begin{array}{l}\text { Temperatura } \\
\text { Operativa }\left({ }^{\circ} \mathrm{C}\right)\end{array}$ \\
\hline $11: 50$ as $12: 20$ & 19,3 & 22,2 & 22,0 & 1023,7 & 72,1 & 0,0 & 22,3 & 22,1 \\
\hline $12: 20$ as $12: 50$ & 19,1 & 22,1 & 22,0 & 1023,0 & 70,4 & 0,0 & 22,2 & 22,1 \\
\hline $12: 50$ as $13: 20$ & 18,9 & 22,0 & 21,9 & 1022,7 & 70,1 & 0,0 & 22,2 & 22,0 \\
\hline $13: 20$ as $13: 50$ & 18,9 & 22,0 & 21,8 & 1022,5 & 69,6 & 0,0 & 22,1 & 22,0 \\
\hline $13: 50$ as $14: 20$ & 18,9 & 22,0 & 21,9 & 1022,3 & 69,8 & 0,0 & 22,1 & 22,0 \\
\hline $14: 20$ as $14: 50$ & 18,9 & 22,0 & 21,9 & 1022,3 & 69,8 & 0,0 & 22,1 & 22,0 \\
\hline Desvio Padrão & 0,23 & 0,14 & 0,07 & 0,59 & 1,26 & 0,05 & 0,23 & 1,63 \\
\hline Média & 19,1 & 22,1 & 21,9 & 1023,0 & 70,8 & 0,0 & 22,2 & 22,1 \\
\hline \multicolumn{8}{|c|}{ Dados coletados Termômetro de fluxo de laser } & \\
\hline Horário/Quarto & $\begin{array}{l}\text { Temp. Externa do ar } \\
\left({ }^{\circ} \mathrm{C}\right)\end{array}$ & $\begin{array}{l}\text { Temp. Paredes } \\
\text { externas }\left({ }^{\circ} \mathrm{C}\right)\end{array}$ & $\begin{array}{c}\text { Temp.Paredes voltada } \\
\text { para a rua }\left({ }^{\circ} \mathrm{C}\right)\end{array}$ & \multicolumn{3}{|c|}{ Temp. Média das paredes $\left({ }^{\circ} \mathrm{C}\right)$} & Temp. Teto $\left({ }^{\circ} \mathrm{C}\right)$ & \\
\hline 11:50 & 20 & 20 & 21 & \multicolumn{3}{|c|}{20,7} & 21,2 & \\
\hline 15:00 & 20 & 20 & 19,7 & \multicolumn{3}{|c|}{19,6} & 19,7 & \\
\hline
\end{tabular}

Tabela 137: Resultados coletados in loco no quarto do Apartamento F no mês de Julho de 2013. 


\begin{tabular}{|c|c|c|c|c|c|c|c|c|}
\hline \multicolumn{2}{|l|}{ Apartamento $\mathrm{F}$} & \multicolumn{4}{|c|}{ Dados coletados CONFORTÍMETRO Agosto 2013 - QUARTO } & \multicolumn{3}{|c|}{ Nublado } \\
\hline Intervalo & $\begin{array}{l}\text { Temperatura de } \\
\text { bulbo úmido }\left({ }^{\circ} \mathrm{C}\right)\end{array}$ & $\begin{array}{l}\text { Temperatura de } \\
\text { globo }\left({ }^{\circ} \mathrm{C}\right)\end{array}$ & $\begin{array}{c}\text { Temperatura do ar } \\
\left({ }^{\circ} \mathrm{C}\right)\end{array}$ & $\begin{array}{c}\text { Pressão Atmosférica } \\
\text { (atm) }\end{array}$ & $\begin{array}{c}\text { Umidade relativa do } \\
\text { ar (\%) }\end{array}$ & $\begin{array}{l}\text { Velocidade do ar } \\
\qquad(\mathrm{m} / \mathrm{s})\end{array}$ & $\begin{array}{l}\text { Temperatura } \\
\text { radiante }\left({ }^{\circ} \mathrm{C}\right)\end{array}$ & $\begin{array}{l}\text { Temperatura } \\
\text { Operativa }\left({ }^{\circ} \mathrm{C}\right)\end{array}$ \\
\hline $11: 50$ as $12: 20$ & 18,3 & 19,8 & 19,7 & 1020,3 & 80,8 & 0,0 & 19,9 & 19,8 \\
\hline $12: 20$ as $12: 50$ & 18,3 & 19,9 & 19,8 & 1020,1 & 81,9 & 0,0 & 19,9 & 19,8 \\
\hline $12: 50$ as $13: 20$ & 18,5 & 20,2 & 20,1 & 1019,8 & 81,1 & 0,0 & 20,2 & 20,2 \\
\hline $13: 20$ as $13: 50$ & 18,6 & 20,2 & 20,2 & 1019,6 & 81,3 & 0,0 & 20,3 & 20,2 \\
\hline $13: 50$ as $14: 20$ & 18,8 & 20,5 & 20,4 & 1019,3 & 80,5 & 0,0 & 20,5 & 20,4 \\
\hline $14: 20$ as $14: 50$ & 19,1 & 20,7 & 20,6 & 1019,2 & 80,8 & 0,0 & 20,8 & 20,7 \\
\hline Desvio Padrão & 0,28 & 0,33 & 0,35 & 0,39 & 0,62 & 0,03 & 0,33 & 1,63 \\
\hline Média & 18,6 & 20,2 & 20,1 & 1019,8 & 81,0 & 0,0 & 20,2 & 20,2 \\
\hline \multicolumn{8}{|c|}{ Dados coletados Termômetro de fluxo de laser } & \\
\hline Horário/Quarto & $\begin{array}{l}\text { Temp. Externa do ar } \\
\left({ }^{\circ} \mathrm{C}\right)\end{array}$ & $\begin{array}{l}\text { Temp. Paredes } \\
\text { externas }\left({ }^{\circ} \mathrm{C}\right)\end{array}$ & $\begin{array}{c}\text { Temp.Paredes voltada } \\
\text { para a rua }\left({ }^{\circ} \mathrm{C}\right)\end{array}$ & Temp & Média das paredes ( & & Temp. Teto $\left({ }^{\circ} \mathrm{C}\right)$ & \\
\hline 11:50 & 19,5 & 19 & 19,5 & & 19,6 & & 19,7 & \\
\hline 15:00 & 21,6 & 21,5 & 21,6 & & 20,9 & & 21,1 & \\
\hline
\end{tabular}

Tabela 138: Resultados coletados in loco no quarto do Apartamento F no mês de Agosto de 2013.

\begin{tabular}{|c|c|c|c|c|c|c|c|c|}
\hline \multicolumn{2}{|l|}{ Apartamento F } & \multicolumn{4}{|c|}{ Dados coletados CONFORTÍMETRO Setembro 2013 - QUARTO } & \multicolumn{3}{|c|}{ Céu claro } \\
\hline Intervalo & $\begin{array}{l}\text { Temperatura de } \\
\text { bulbo úmido }\left({ }^{\circ} \mathrm{C}\right)\end{array}$ & $\begin{array}{c}\text { Temperatura de } \\
\text { globo }\left({ }^{\circ} \mathrm{C}\right)\end{array}$ & $\begin{array}{c}\text { Temperatura do ar } \\
\left({ }^{\circ} \mathrm{C}\right)\end{array}$ & $\begin{array}{c}\text { Pressão Atmosférica } \\
\text { (atm) }\end{array}$ & $\begin{array}{l}\text { Umidade relativa do } \\
\text { ar (\%) }\end{array}$ & $\begin{array}{l}\text { Velocidade do ar } \\
(\mathrm{m} / \mathrm{s})\end{array}$ & $\begin{array}{l}\text { Temperatura } \\
\text { radiante }\left({ }^{\circ} \mathrm{C}\right)\end{array}$ & $\begin{array}{l}\text { Temperatura } \\
\text { Operativa }\left({ }^{\circ} \mathrm{C}\right)\end{array}$ \\
\hline $11: 50$ as $12: 20$ & 22,0 & 24,8 & 24,5 & 1008,9 & 74,9 & 0,1 & 25,1 & 24,8 \\
\hline $12: 20$ as $12: 50$ & 22,1 & 24,9 & 24,6 & 1009,4 & 75,0 & 0,0 & 25,1 & 24,8 \\
\hline $12: 50$ as $13: 20$ & 22,0 & 24,8 & 24,5 & 1010,1 & 75,8 & 0,0 & 24,9 & 24,7 \\
\hline $13: 20$ as $13: 50$ & 22,1 & 24,6 & 24,3 & 1011,4 & 77,6 & 0,1 & 24,8 & 24,6 \\
\hline $13: 50$ as $14: 20$ & 22,0 & 24,7 & 24,5 & 1011,7 & 75,5 & 0,0 & 24,8 & 24,6 \\
\hline $14: 20$ as $14: 50$ & 22,0 & 24,8 & 24,5 & 1011,4 & 74,2 & 0,0 & 25,0 & 24,7 \\
\hline Desvio Padrão & 0,12 & 0,12 & 0,15 & 1,12 & 1,20 & 0,06 & 0,19 & 1,63 \\
\hline Média & 22,0 & 24,8 & 24,5 & 1010,5 & 75,5 & 0,0 & 24,9 & 24,7 \\
\hline \multicolumn{8}{|c|}{ Dados coletados Termômetro de fluxo de laser } & \\
\hline Horário/Quarto & $\begin{array}{l}\text { Temp. Externa do ar } \\
\left({ }^{\circ} \mathrm{C}\right)\end{array}$ & $\begin{array}{l}\text { Temp. Paredes } \\
\text { externas }\left({ }^{\circ} \mathrm{C}\right)\end{array}$ & $\begin{array}{c}\text { Temp.Paredes voltada } \\
\text { para a rua }\left({ }^{\circ} \mathrm{C}\right)\end{array}$ & \multicolumn{3}{|c|}{ Temp. Média das paredes $\left({ }^{\circ} \mathrm{C}\right)$} & Temp. Teto $\left({ }^{\circ} \mathrm{C}\right)$ & \\
\hline 11:50 & 23,3 & 22,9 & 25,8 & \multicolumn{3}{|c|}{25,4} & 26 & \\
\hline $15: 00$ & 28,8 & 22,1 & 24,8 & \multicolumn{3}{|c|}{24,9} & 25,9 & \\
\hline
\end{tabular}

Tabela 139: Resultados coletados in loco no quarto do Apartamento F no mês de Setembro de 2013.

\begin{tabular}{|c|c|c|c|c|c|c|c|c|}
\hline \multicolumn{2}{|l|}{ Apartamento $\mathrm{F}$} & \multicolumn{4}{|c|}{ Dados coletados CONFORTÍM ETRO Outubro 2013 - QUARTO } & \multicolumn{3}{|c|}{ Nublado } \\
\hline Intervalo & $\begin{array}{l}\text { Temperatura de } \\
\text { bulbo úmido }\left({ }^{\circ} \mathrm{C}\right)\end{array}$ & $\begin{array}{c}\text { Temperatura de } \\
\text { globo }\left({ }^{\circ} \mathrm{C}\right)\end{array}$ & $\begin{array}{c}\text { Temperatura do ar } \\
\left({ }^{\circ} \mathrm{C}\right)\end{array}$ & $\begin{array}{c}\text { Pressão Atmosférica } \\
\text { (atm) }\end{array}$ & $\begin{array}{c}\text { Umidade relativa do } \\
\text { ar (\%) }\end{array}$ & $\begin{array}{l}\text { Velocidade do ar } \\
(\mathrm{m} / \mathrm{s})\end{array}$ & $\begin{array}{l}\text { Temperatura } \\
\text { radiante }\left({ }^{\circ} \mathrm{C}\right)\end{array}$ & $\begin{array}{l}\text { Temperatura } \\
\text { Operativa }\left({ }^{\circ} \mathrm{C}\right)\end{array}$ \\
\hline $11: 50$ as $12: 20$ & 21,8 & 24,7 & 24,7 & 1009,0 & 71,4 & 0,0 & 24,8 & 24,7 \\
\hline $12: 20$ as $12: 50$ & 21,8 & 24,7 & 24,6 & 1008,7 & 70,5 & 0,0 & 24,7 & 24,6 \\
\hline $12: 50$ as $13: 20$ & 21,7 & 24,7 & 24,7 & 1008,5 & 69,1 & 0,0 & 24,7 & 24,7 \\
\hline $13: 20$ as $13: 50$ & 21,9 & 25,0 & 24,9 & 1008,2 & 70,1 & 0,0 & 25,0 & 24,9 \\
\hline $13: 50$ as $14: 20$ & 22,1 & 25,1 & 25,1 & 1007,9 & 69,6 & 0,0 & 25,1 & 25,1 \\
\hline $14: 20$ as $14: 50$ & 22,3 & 25,3 & 25,2 & 1007,8 & 70,4 & 0,0 & 25,3 & 25,2 \\
\hline Desvio Padrão & 0,25 & 0,27 & 0,27 & 0,44 & 0,93 & 0,01 & 0,28 & 1,63 \\
\hline Média & 21,9 & 24,9 & 24,9 & 1008,4 & 70,2 & 0,0 & 24,9 & 24,9 \\
\hline \multicolumn{8}{|c|}{ Dados coletados Termômetro de fluxo de laser } & \\
\hline Horário/Quarto & $\begin{array}{l}\text { Temp. Externa do ar } \\
\left({ }^{\circ} \mathrm{C}\right)\end{array}$ & $\begin{array}{l}\text { Temp. Paredes } \\
\text { externas }\left({ }^{\circ} \mathrm{C}\right)\end{array}$ & $\begin{array}{c}\text { Temp.Paredes voltada } \\
\text { para a rua }\left({ }^{\circ} \mathrm{C}\right)\end{array}$ & \multicolumn{3}{|c|}{ Temp. M édia das paredes $\left({ }^{\circ} \mathrm{C}\right)$} & Temp. Teto $\left({ }^{\circ} \mathrm{C}\right)$ & \\
\hline 11:50 & 25,7 & 27,9 & 24,4 & \multicolumn{3}{|c|}{23,5} & 25,2 & \\
\hline $15: 00$ & 24,8 & 27,7 & 26,2 & \multicolumn{3}{|c|}{24,5} & 28,4 & \\
\hline
\end{tabular}

Tabela 140: Resultados coletados in loco no quarto do Apartamento F no mês de Outubro de 2013.

\begin{tabular}{|c|c|c|c|c|c|c|c|c|}
\hline \multicolumn{2}{|l|}{ Apartamento $\mathrm{F}$} & \multicolumn{4}{|c|}{ Dados coletados CONFORTÍMETRO Novembro 2013 - QUARTO } & \multicolumn{3}{|c|}{ Chuva } \\
\hline Intervalo & $\begin{array}{l}\text { Temperatura de } \\
\text { bulbo úmido }\left({ }^{\circ} \mathrm{C}\right)\end{array}$ & $\begin{array}{c}\text { Temperatura de } \\
\text { globo }\left({ }^{\circ} \mathrm{C}\right)\end{array}$ & $\begin{array}{c}\text { Temperatura do ar } \\
\left({ }^{\circ} \mathrm{C}\right)\end{array}$ & $\begin{array}{c}\text { Pressão Atmosférica } \\
\text { (atm) }\end{array}$ & $\begin{array}{l}\text { Umidade relativa do } \\
\text { ar (\%) }\end{array}$ & $\begin{array}{l}\text { Velocidade do ar } \\
(\mathrm{m} / \mathrm{s})\end{array}$ & $\begin{array}{l}\text { Temperatura } \\
\text { radiante }\left({ }^{\circ} \mathrm{C}\right)\end{array}$ & $\begin{array}{l}\text { Temperatura } \\
\text { Operativa }\left({ }^{\circ} \mathrm{C}\right)\end{array}$ \\
\hline $12: 50$ as $13: 20$ & 25,0 & 27,6 & 27,4 & 1012,7 & 78,5 & 0,1 & 27,9 & 27,6 \\
\hline $13: 20$ as $13: 50$ & 24,9 & 27,7 & 27,5 & 1012,6 & 77,3 & 0,1 & 27,9 & 27,7 \\
\hline $13: 50$ as $14: 20$ & 24,8 & 27,9 & 27,7 & 1012,3 & 75,6 & 0,1 & 28,0 & 27,9 \\
\hline $14: 20$ as $14: 50$ & 24,8 & 28,0 & 27,9 & 1012,0 & 74,5 & 0,0 & 28,1 & 28,0 \\
\hline $14: 50$ as $15: 20$ & 24,6 & 27,9 & 27,8 & 1011,8 & 73,6 & 0,0 & 28,0 & 27,9 \\
\hline 14:50 as $15: 20$ & 24,5 & 27,8 & 27,7 & 1011,6 & 73,1 & 0,0 & 27,9 & 27,8 \\
\hline Desvio Padrão & 0,20 & 0,14 & 0,19 & 0,42 & 2,03 & 0,04 & 0,14 & 1,63 \\
\hline Média & 24,8 & 27,8 & 27,7 & 1012,2 & 75,5 & 0,1 & 28,0 & 27,8 \\
\hline \multicolumn{8}{|c|}{ Dados coletados Termômetro de fluxo de laser } & \\
\hline Horário/Quarto & $\begin{array}{l}\text { Temp. Externa do ar } \\
\left({ }^{\circ} \mathrm{C}\right)\end{array}$ & $\begin{array}{l}\text { Temp. Paredes } \\
\text { externas }\left({ }^{\circ} \mathrm{C}\right)\end{array}$ & $\begin{array}{c}\text { Temp.Paredes voltada } \\
\text { para a rua }\left({ }^{\circ} \mathrm{C}\right)\end{array}$ & \multicolumn{3}{|c|}{ Temp. M édia das paredes $\left({ }^{\circ} \mathrm{C}\right)$} & Temp. Teto $\left({ }^{\circ} \mathrm{C}\right)$ & \\
\hline $12: 50$ & 25,9 & 25,6 & 27,2 & \multicolumn{3}{|c|}{28,4} & 27,7 & \\
\hline $16: 00$ & 28,8 & 28 & 26,8 & \multicolumn{3}{|c|}{27,4} & 27,6 & \\
\hline
\end{tabular}

Tabela 141: Resultados coletados in loco no quarto do Apartamento F no mês de Novembro de 2013. 


\begin{tabular}{|c|c|c|c|c|c|c|c|c|}
\hline \multicolumn{2}{|l|}{ Apartamento $\mathrm{F}$} & \multicolumn{4}{|c|}{ Dados coletados CONFORTÍM ETRO Dezembro 2013 - QUARTO } & \multicolumn{3}{|c|}{ Nublado } \\
\hline Intervalo & $\begin{array}{l}\text { Temperatura de } \\
\text { bulbo úmido }\left({ }^{\circ} \mathrm{C}\right)\end{array}$ & $\begin{array}{c}\text { Temperatura de } \\
\text { globo }\left({ }^{\circ} \mathrm{C}\right)\end{array}$ & $\begin{array}{c}\text { Temperatura do ar } \\
\left({ }^{\circ} \mathrm{C}\right)\end{array}$ & $\begin{array}{c}\text { Pressão Atmosférica } \\
\text { (atm) }\end{array}$ & $\begin{array}{c}\text { Umidade relativa do } \\
\text { ar (\%) }\end{array}$ & $\begin{array}{l}\text { Velocidade do ar } \\
(\mathrm{m} / \mathrm{s})\end{array}$ & $\begin{array}{l}\text { Temperatura } \\
\text { radiante }\left({ }^{\circ} \mathrm{C}\right)\end{array}$ & $\begin{array}{l}\text { Temperatura } \\
\text { Operativa }\left({ }^{\circ} \mathrm{C}\right)\end{array}$ \\
\hline $12: 50$ as $13: 20$ & 24,3 & 26,6 & 26,5 & 1012,7 & 79,0 & 0,1 & 26,7 & 26,6 \\
\hline $13: 20$ as $13: 50$ & 24,3 & 26,7 & 26,6 & 1012,4 & 78,2 & 0,1 & 26,7 & 26,6 \\
\hline $13: 50$ as $14: 20$ & 24,2 & 26,8 & 26,7 & 1012,1 & 76,9 & 0,1 & 26,9 & 26,8 \\
\hline $14: 20$ as $14: 50$ & 24,2 & 26,8 & 26,7 & 1011,8 & 76,5 & 0,1 & 26,9 & 26,8 \\
\hline $14: 50$ as $15: 20$ & 24,2 & 26,9 & 26,7 & 1011,5 & 75,9 & 0,1 & 27,0 & 26,9 \\
\hline $14: 50$ as $15: 20$ & 24,2 & 26,9 & 26,8 & 1011,2 & 75,7 & 0,1 & 27,0 & 26,9 \\
\hline Desvio Padrão & 0,08 & 0,13 & 0,13 & 0,54 & 1,30 & 0,10 & 0,16 & 1,63 \\
\hline Média & 24,3 & 26,8 & 26,6 & 1012,0 & 77,1 & 0,1 & 26,9 & 26,8 \\
\hline \multicolumn{8}{|c|}{ Dados coletados Termômetro de fluxo de laser } & \\
\hline Horário/Quarto & $\begin{array}{l}\text { Temp. Externa do ar } \\
\left({ }^{\circ} \mathrm{C}\right)\end{array}$ & $\begin{array}{l}\text { Temp. Paredes } \\
\text { externas }\left({ }^{\circ} \mathrm{C}\right)\end{array}$ & $\begin{array}{c}\text { Temp.Paredes voltada } \\
\text { para a rua }\left({ }^{\circ} \mathrm{C}\right)\end{array}$ & \multicolumn{3}{|c|}{ Temp. Média das paredes $\left({ }^{\circ} \mathrm{C}\right)$} & Temp. Teto $\left({ }^{\circ} \mathrm{C}\right)$ & \\
\hline 12:50 & 26,6 & 25,6 & 25,7 & \multicolumn{3}{|c|}{26,8} & 26,8 & \\
\hline $16: 00$ & 25,9 & 25,8 & 27,1 & \multicolumn{3}{|c|}{27,6} & 27 & \\
\hline
\end{tabular}

Tabela 142: Resultados coletados in loco no quarto do Apartamento F no mês de Dezembro de 2013.

\begin{tabular}{|c|c|c|c|c|c|c|c|c|}
\hline \multicolumn{2}{|l|}{ Apartamento $\mathrm{F}$} & \multicolumn{4}{|c|}{ Dados coletados CONFORTIMMETRO Janeiro 2014 - QUARTO } & \multicolumn{3}{|c|}{$\begin{array}{l}\text { Parcialmente } \\
\text { nublado }\end{array}$} \\
\hline Intervalo & $\begin{array}{l}\text { Temperatura de } \\
\text { bulbo úmido }\left({ }^{\circ} \mathrm{C}\right)\end{array}$ & $\begin{array}{l}\text { Temperatura de } \\
\text { globo }\left({ }^{\circ} \mathrm{C}\right)\end{array}$ & $\begin{array}{l}\text { Temperatura do ar } \\
\left({ }^{\circ} \mathrm{C}\right)\end{array}$ & $\begin{array}{l}\text { Pressão Atmosférica } \\
\text { (atm) }\end{array}$ & $\begin{array}{l}\text { Umidade relativa do } \\
\text { ar (\%) }\end{array}$ & $\begin{array}{l}\text { Velocidade do ar } \\
\qquad(\mathrm{m} / \mathrm{s})\end{array}$ & $\begin{array}{l}\text { Temperatura } \\
\text { radiante }\left({ }^{\circ} \mathrm{C}\right)\end{array}$ & $\begin{array}{l}\text { Temperatura } \\
\text { Operativa }\left({ }^{\circ} \mathrm{C}\right)\end{array}$ \\
\hline $12: 50$ as $13: 20$ & 24,6 & 28,6 & 28,5 & 1012,8 & 67,7 & 0,1 & 28,7 & 28,6 \\
\hline $13: 20$ as $13: 50$ & 24,6 & 28,8 & 28,6 & 1012,6 & 66,6 & 0,0 & 28,9 & 28,8 \\
\hline $13: 50$ as $14: 20$ & 24,5 & 29,0 & 28,8 & 1012,5 & 64,5 & 0,1 & 29,1 & 29,0 \\
\hline $14: 20$ as $14: 50$ & 24,6 & 29,3 & 29,1 & 1012,4 & 63,8 & 0,1 & 29,4 & 29,2 \\
\hline $14: 50$ as $15: 20$ & 24,7 & 29,5 & 29,3 & 1012,2 & 63,1 & 0,0 & 29,7 & 29,5 \\
\hline $14: 50$ as $15: 20$ & 24,8 & 29,7 & 29,5 & 1012,0 & 62,6 & 0,1 & 29,9 & 29,7 \\
\hline Desvio Padrão & 0,14 & 0,42 & 0,37 & 0,26 & 2,16 & 0,05 & 0,45 & 1,63 \\
\hline Média & 24,6 & 29,1 & 28,9 & 1012,5 & 65,1 & 0,1 & 29,2 & 29,1 \\
\hline \multicolumn{8}{|c|}{ Dados coletados Termômetro de fluxo de laser } & \\
\hline Horário/Quarto & $\begin{array}{l}\text { Temp. Externa do ar } \\
\left({ }^{\circ} \mathrm{C}\right)\end{array}$ & $\begin{array}{l}\text { Temp. Paredes } \\
\text { externas }\left({ }^{\circ} \mathrm{C}\right)\end{array}$ & $\begin{array}{c}\text { Temp.Paredes voltada } \\
\text { para a rua }\left({ }^{\circ} \mathrm{C}\right)\end{array}$ & \multicolumn{3}{|c|}{ Temp. M édia das paredes $\left({ }^{\circ} \mathrm{C}\right)$} & Temp. Teto $\left({ }^{\circ} \mathrm{C}\right)$ & \\
\hline $12: 50$ & 30,4 & 32,4 & 28,2 & \multicolumn{3}{|c|}{28,8} & 28,2 & \\
\hline $16: 00$ & 31,8 & 31,8 & 29,3 & \multicolumn{3}{|c|}{29,1} & 32,8 & \\
\hline
\end{tabular}

Tabela 143: Resultados coletados in loco no quarto do Apartamento F no mês de Janeiro de 2014.

\begin{tabular}{|c|c|c|c|c|c|c|c|c|}
\hline \multicolumn{2}{|l|}{ Apartamento $\mathrm{F}$} & \multicolumn{4}{|c|}{ Dados coletados CONFORTÍM ETRO Fevereiro 2014 - QUARTO } & \multicolumn{3}{|c|}{ Nublado } \\
\hline Intervalo & $\begin{array}{l}\text { Temperatura de } \\
\text { bulbo úmido }\left({ }^{\circ} \mathrm{C}\right)\end{array}$ & $\begin{array}{c}\text { Temperatura de } \\
\text { globo }\left({ }^{\circ} \mathrm{C}\right)\end{array}$ & $\begin{array}{c}\text { Temperatura do ar } \\
\left({ }^{\circ} \mathrm{C}\right)\end{array}$ & $\begin{array}{c}\text { Pressão Atmosférica } \\
\text { (atm) }\end{array}$ & $\begin{array}{l}\text { Umidade relativa do } \\
\text { ar (\%) }\end{array}$ & $\begin{array}{l}\text { Velocidade do ar } \\
\qquad(\mathrm{m} / \mathrm{s})\end{array}$ & $\begin{array}{l}\text { Temperatura } \\
\text { radiante }\left({ }^{\circ} \mathrm{C}\right)\end{array}$ & $\begin{array}{l}\text { Temperatura } \\
\text { Operativa }\left({ }^{\circ} \mathrm{C}\right)\end{array}$ \\
\hline $11: 50$ as $12: 20$ & 26,0 & 29,7 & 29,5 & 1010,8 & 70,5 & 0,1 & 29,9 & 29,7 \\
\hline $12: 20$ as $12: 50$ & 26,0 & 29,7 & 29,5 & 1010,4 & 70,7 & 0,1 & 29,9 & 29,7 \\
\hline $12: 50$ as $13: 20$ & 26,1 & 29,9 & 29,8 & 1010,3 & 70,4 & 0,1 & 30,1 & 29,9 \\
\hline $13: 20$ as $13: 50$ & 26,3 & 30,1 & 29,9 & 1010,2 & 70,9 & 0,1 & 30,2 & 30,0 \\
\hline $13: 50$ as $14: 20$ & 26,5 & 30,3 & 30,0 & 1010,1 & 70,8 & 0,0 & 30,3 & 30,2 \\
\hline $14: 20$ as $14: 50$ & 26,5 & 30,3 & 30,1 & 1009,8 & 70,2 & 0,0 & 30,4 & 30,3 \\
\hline Desvio Padrão & 0,24 & 0,27 & 0,24 & 0,33 & 0,49 & 0,05 & 0,26 & 1,63 \\
\hline Média & 26,2 & 30,0 & 29,8 & 1010,3 & 70,6 & 0,0 & 30,1 & 29,9 \\
\hline \multicolumn{8}{|c|}{ Dados coletados Termômetro de fluxo de laser } & \\
\hline Horário/Quarto & $\begin{array}{c}\text { Temp. Externa do ar } \\
\left({ }^{\circ} \mathrm{C}\right)\end{array}$ & $\begin{array}{l}\text { Temp. Paredes } \\
\text { externas }\left({ }^{\circ} \mathrm{C}\right)\end{array}$ & $\begin{array}{c}\text { Temp.Paredes voltada } \\
\text { para a rua }\left({ }^{\circ} \mathrm{C}\right)\end{array}$ & \multicolumn{3}{|c|}{ Temp. M édia das paredes $\left({ }^{\circ} \mathrm{C}\right)$} & Temp. Teto $\left({ }^{\circ} \mathrm{C}\right)$ & \\
\hline 11:50 & 29 & 37,4 & 28,4 & \multicolumn{3}{|c|}{28,3} & 30 & \\
\hline 15:00 & 30 & 31,8 & 31 & \multicolumn{3}{|c|}{31,1} & 34,6 & \\
\hline
\end{tabular}

Tabela 144: Resultados coletados in loco no quarto do Apartamento F no mês de Fevereiro de 2014.

\begin{tabular}{|c|c|c|c|c|c|c|c|c|}
\hline \multicolumn{2}{|l|}{ Apartamento $\mathrm{F}$} & \multicolumn{4}{|c|}{ Dados coletados CONFORTÍM ETRO M arço 2014 - QUARTO } & \multicolumn{3}{|c|}{ Nublado } \\
\hline Intervalo & $\begin{array}{l}\text { Temperatura de } \\
\text { bulbo úmido }\left({ }^{\circ} \mathrm{C}\right)\end{array}$ & $\begin{array}{c}\text { Temperatura de } \\
\text { globo }\left({ }^{\circ} \mathrm{C}\right)\end{array}$ & $\begin{array}{c}\text { Temperatura do ar } \\
\left({ }^{\circ} \mathrm{C}\right)\end{array}$ & $\begin{array}{c}\text { Pressão Atmosférica } \\
\text { (atm) }\end{array}$ & $\begin{array}{c}\text { Umidade relativa do } \\
\text { ar (\%) }\end{array}$ & $\begin{array}{c}\text { Velocidade do ar } \\
(\mathrm{m} / \mathrm{s})\end{array}$ & $\begin{array}{l}\text { Temperatura } \\
\text { radiante }\left({ }^{\circ} \mathrm{C}\right)\end{array}$ & $\begin{array}{l}\text { Temperatura } \\
\text { Operativa }\left({ }^{\circ} \mathrm{C}\right)\end{array}$ \\
\hline $11: 50$ as $12: 20$ & 25,5 & 29,2 & 28,8 & 1011,0 & 72,8 & 0,1 & 29,6 & 29,2 \\
\hline $12: 20$ as $12: 50$ & 25,6 & 29,5 & 29,2 & 1010,9 & 70,9 & 0,1 & 29,8 & 29,5 \\
\hline $12: 50$ as $13: 20$ & 25,8 & 29,6 & 29,2 & 1010,8 & 72,8 & 0,1 & 30,1 & 29,6 \\
\hline $13: 20$ as $13: 50$ & 25,7 & 30,0 & 29,6 & 1010,7 & 69,4 & 0,1 & 30,4 & 30,0 \\
\hline $13: 50$ as $14: 20$ & 25,4 & 30,0 & 29,4 & 1010,6 & 68,7 & 0,1 & 30,5 & 30,0 \\
\hline $14: 20$ as $14: 50$ & 25,3 & 29,9 & 29,4 & 1010,8 & 68,2 & 0,1 & 30,5 & 29,9 \\
\hline Desvio Padrão & 0,21 & 0,31 & 0,28 & 0,14 & 2,03 & 0,07 & 0,47 & 1,63 \\
\hline Média & 25,6 & 29,7 & 29,3 & 1010,8 & 70,5 & 0,1 & 30,2 & 29,7 \\
\hline \multicolumn{8}{|c|}{ Dados coletados Termômetro de fluxo de laser } & \\
\hline Horário/Quarto & $\begin{array}{c}\text { Temp. Externa do ar } \\
\left({ }^{\circ} \mathrm{C}\right)\end{array}$ & $\begin{array}{l}\text { Temp. Paredes } \\
\text { externas }\left({ }^{\circ} \mathrm{C}\right)\end{array}$ & $\begin{array}{c}\text { Temp.Paredes voltada } \\
\text { para a rua }\left({ }^{\circ} \mathrm{C}\right)\end{array}$ & \multicolumn{3}{|c|}{ Temp. Média das paredes $\left({ }^{\circ} \mathrm{C}\right)$} & Temp. Teto $\left({ }^{\circ} \mathrm{C}\right)$ & \\
\hline $11: 50$ & 30 & 31,2 & 29,3 & \multirow{2}{*}{\multicolumn{3}{|c|}{29,3}} & 29,8 & \\
\hline $15: 00$ & 31,5 & 29,2 & 29,8 & & & & 31,2 & \\
\hline
\end{tabular}

Tabela 145: Resultados coletados in loco no quarto do Apartamento F no mês de Março de 2014. 


\begin{tabular}{|c|c|c|c|c|c|c|c|c|}
\hline \multicolumn{2}{|l|}{ Apartamento $\mathrm{F}$} & \multicolumn{4}{|c|}{ Dados coletados CONFORTÍMETRO Abril 2014 - QUARTO } & \multicolumn{3}{|c|}{ Chuva } \\
\hline Intervalo & $\begin{array}{l}\text { Temperatura de } \\
\text { bulbo úmido }\left({ }^{\circ} \mathrm{C}\right)\end{array}$ & $\begin{array}{c}\text { Temperatura de } \\
\text { globo }\left({ }^{\circ} \mathrm{C}\right)\end{array}$ & $\begin{array}{c}\text { Temperatura do ar } \\
\left({ }^{\circ} \mathrm{C}\right)\end{array}$ & $\begin{array}{c}\text { Pressão Atmosférica } \\
\text { (atm) }\end{array}$ & $\begin{array}{c}\text { Umidade relativa do } \\
\text { ar (\%) }\end{array}$ & $\begin{array}{l}\text { Velocidade do ar } \\
(\mathrm{m} / \mathrm{s})\end{array}$ & $\begin{array}{l}\text { Temperatura } \\
\text { radiante }\left({ }^{\circ} \mathrm{C}\right)\end{array}$ & $\begin{array}{c}\text { Temperatura } \\
\text { Operativa }\left({ }^{\circ} \mathrm{C}\right)\end{array}$ \\
\hline $11: 50$ as $12: 20$ & 22,0 & 24,7 & 24,4 & 1013,6 & 77,2 & 0,1 & 25,2 & 24,8 \\
\hline $12: 20$ as $12: 50$ & 22,5 & 24,9 & 24,9 & 1013,6 & 75,9 & 0,1 & 24,8 & 24,9 \\
\hline $12: 50$ as $13: 20$ & 22,4 & 24,8 & 24,8 & 1013,7 & 76,9 & 0,1 & 24,8 & 24,8 \\
\hline $13: 20$ as $13: 50$ & 22,4 & 24,8 & 24,7 & 1013,8 & 77,3 & 0,1 & 24,8 & 24,7 \\
\hline $13: 50$ as $14: 20$ & 22,3 & 24,7 & 24,5 & 1013,7 & 78,1 & 0,1 & 24,8 & 24,7 \\
\hline $14: 20$ as $14: 50$ & 22,4 & 24,7 & 24,7 & 1013,9 & 77,7 & 0,1 & 24,8 & 24,7 \\
\hline Desvio Padrão & 0,19 & 0,10 & 0,21 & 0,10 & 0,94 & 0,07 & 0,21 & 1,63 \\
\hline Média & 22,3 & 24,8 & 24,7 & 1013,7 & 77,2 & 0,1 & 24,9 & 24,8 \\
\hline \multicolumn{8}{|c|}{ Dados coletados Termômetro de fluxo de laser } & \\
\hline Horário/Quarto & $\begin{array}{l}\text { Temp. Externa do ar } \\
\left({ }^{\circ} \mathrm{C}\right)\end{array}$ & $\begin{array}{l}\text { Temp. Paredes } \\
\text { externas }\left({ }^{\circ} \mathrm{C}\right)\end{array}$ & $\begin{array}{c}\text { Temp.Paredes voltada } \\
\text { para a rua }\left({ }^{\circ} \mathrm{C}\right)\end{array}$ & \multicolumn{3}{|c|}{ Temp. M édia das paredes $\left({ }^{\circ} \mathrm{C}\right)$} & Temp. Teto $\left({ }^{\circ} \mathrm{C}\right)$ & \\
\hline 11:50 & 25,6 & 21,8 & 24,2 & \multicolumn{3}{|c|}{25,2} & 25,3 & \\
\hline 15:00 & 25,7 & 21,8 & 24,3 & \multicolumn{3}{|c|}{25,4} & 25,4 & \\
\hline
\end{tabular}

Tabela 146: Resultados coletados in loco no quarto do Apartamento F no mês de Abril de 2014.

\begin{tabular}{|c|c|c|c|c|c|c|c|c|}
\hline \multicolumn{2}{|l|}{ Apartamento $\mathrm{F}$} & \multicolumn{4}{|c|}{ Dados coletados CONFORTÍMETRO Maio 2014 - QUARTO } & \multicolumn{3}{|c|}{ Nublado } \\
\hline Intervalo & $\begin{array}{l}\text { Temperatura de } \\
\text { bulbo úmido }\left({ }^{\circ} \mathrm{C}\right)\end{array}$ & $\begin{array}{c}\text { Temperatura de } \\
\text { globo }\left({ }^{\circ} \mathrm{C}\right)\end{array}$ & $\begin{array}{c}\text { Temperatura do ar } \\
\left({ }^{\circ} \mathrm{C}\right)\end{array}$ & $\begin{array}{c}\text { Pressão Atmosférica } \\
\text { (atm) }\end{array}$ & $\begin{array}{c}\text { Umidade relativa do } \\
\text { ar (\%) }\end{array}$ & $\begin{array}{l}\text { Velocidade do ar } \\
(\mathrm{m} / \mathrm{s})\end{array}$ & $\begin{array}{l}\text { Temperatura } \\
\text { radiante }\left({ }^{\circ} \mathrm{C}\right)\end{array}$ & $\begin{array}{l}\text { Temperatura } \\
\text { Operativa }\left({ }^{\circ} \mathrm{C}\right)\end{array}$ \\
\hline $11: 50$ as $12: 20$ & 19,0 & 26,5 & 26,6 & 1004,2 & 41,6 & 0,0 & 26,4 & 26,5 \\
\hline $12: 20$ as $12: 50$ & 19,5 & 26,2 & 26,3 & 1003,8 & 43,8 & 0,0 & 26,2 & 26,2 \\
\hline $12: 50$ as $13: 20$ & 19,5 & 26,1 & 26,2 & 1003,6 & 44,1 & 0,0 & 26,1 & 26,2 \\
\hline $13: 20$ as $13: 50$ & 19,6 & 26,8 & 26,9 & 1003,8 & 42,1 & 0,0 & 26,7 & 26,8 \\
\hline $13: 50$ as $14: 20$ & 19,8 & 27,3 & 27,4 & 1003,6 & 41,1 & 0,0 & 27,2 & 27,3 \\
\hline $14: 20$ as $14: 50$ & 20,1 & 27,2 & 27,2 & 1004,7 & 43,9 & 0,0 & 27,2 & 27,2 \\
\hline Desvio Padrão & 0,35 & 0,48 & 0,46 & 0,45 & 1,38 & 0,04 & 0,48 & 1,63 \\
\hline Média & 19,6 & 26,7 & 26,8 & 1003,9 & 42,8 & 0,0 & 26,6 & 26,7 \\
\hline \multicolumn{8}{|c|}{ Dados coletados Termômetro de fluxo de laser } & \\
\hline Horário/Quarto & $\begin{array}{l}\text { Temp. Externa do ar } \\
\left({ }^{\circ} \mathrm{C}\right)\end{array}$ & $\begin{array}{l}\text { Temp. Paredes } \\
\text { externas }\left({ }^{\circ} \mathrm{C}\right)\end{array}$ & $\begin{array}{c}\text { Temp.Paredes voltada } \\
\text { para a rua }\left({ }^{\circ} \mathrm{C}\right)\end{array}$ & \multicolumn{3}{|c|}{ Temp. M édia das paredes $\left({ }^{\circ} \mathrm{C}\right)$} & Temp. Teto $\left({ }^{\circ} \mathrm{C}\right)$ & \\
\hline 11:50 & 25,2 & 26,8 & 25 & \multicolumn{3}{|c|}{25,8} & 25,6 & \\
\hline 15:00 & 28,1 & 27,4 & 26 & \multicolumn{3}{|c|}{26,6} & 26,7 & \\
\hline
\end{tabular}

Tabela 147: Resultados coletados in loco no quarto do Apartamento F no mês de Maio de 2014.

\begin{tabular}{|c|c|c|c|c|c|c|c|c|}
\hline \multicolumn{2}{|l|}{ Apartamento $\mathrm{F}$} & \multicolumn{4}{|c|}{ Dados coletados CONFORTÍM ETRO J unho 2014 - QUARTO } & \multicolumn{3}{|c|}{ Nublado } \\
\hline Intervalo & $\begin{array}{l}\text { Temperatura de } \\
\text { bulbo úmido }\left({ }^{\circ} \mathrm{C}\right)\end{array}$ & $\begin{array}{c}\text { Temperatura de } \\
\text { globo }\left({ }^{\circ} \mathrm{C}\right)\end{array}$ & $\begin{array}{c}\text { Temperatura do ar } \\
\left({ }^{\circ} \mathrm{C}\right)\end{array}$ & $\begin{array}{c}\text { Pressão Atmosférica } \\
\text { (atm) }\end{array}$ & $\begin{array}{c}\text { Umidade relativa do } \\
\text { ar (\%) }\end{array}$ & $\begin{array}{l}\text { Velocidade do ar } \\
(\mathrm{m} / \mathrm{s})\end{array}$ & $\begin{array}{l}\text { Temperatura } \\
\text { radiante }\left({ }^{\circ} \mathrm{C}\right)\end{array}$ & $\begin{array}{l}\text { Temperatura } \\
\text { Operativa }\left({ }^{\circ} \mathrm{C}\right)\end{array}$ \\
\hline $11: 50$ as $12: 20$ & 22,0 & 24,4 & 24,2 & 1011,6 & 76,7 & 0,0 & 24,5 & 24,3 \\
\hline $12: 20$ as $12: 50$ & 22,1 & 24,6 & 24,4 & 1011,2 & 76,3 & 0,0 & 24,7 & 24,5 \\
\hline $12: 50$ as $13: 20$ & 22,3 & 24,9 & 24,7 & 1010,7 & 74,4 & 0,0 & 25,0 & 24,8 \\
\hline $13: 20$ as $13: 50$ & 22,3 & 24,9 & 24,7 & 1010,7 & 74,4 & 0,0 & 25,0 & 24,9 \\
\hline $13: 50$ as $14: 20$ & 22,3 & 25,0 & 24,7 & 1010,4 & 74,0 & 0,0 & 25,0 & 24,9 \\
\hline $14: 20$ as $14: 50$ & 22,4 & 25,1 & 24,8 & 1010,5 & 74,2 & 0,0 & 25,1 & 25,0 \\
\hline Desvio Padrão & 0,15 & 0,24 & 0,24 & 0,45 & 1,17 & 0,01 & 0,23 & 1,63 \\
\hline Média & 22,2 & 24,8 & 24,6 & 1010,9 & 75,0 & 0,0 & 24,9 & 24,7 \\
\hline \multicolumn{8}{|c|}{ Dados coletados Termômetro de fluxo de laser } & \\
\hline Horário/Quarto & $\begin{array}{l}\text { Temp. Externa do ar } \\
\left({ }^{\circ} \mathrm{C}\right)\end{array}$ & $\begin{array}{l}\text { Temp. Paredes } \\
\text { externas }\left({ }^{\circ} \mathrm{C}\right)\end{array}$ & $\begin{array}{c}\text { Temp.Paredes voltada } \\
\text { para a rua }\left({ }^{\circ} \mathrm{C}\right)\end{array}$ & \multicolumn{3}{|c|}{ Temp. M édia das paredes $\left({ }^{\circ} \mathrm{C}\right)$} & Temp. Teto $\left({ }^{\circ} \mathrm{C}\right)$ & \\
\hline 11:50 & 24,6 & 23,1 & 23,1 & \multicolumn{3}{|c|}{23,5} & 23,4 & \\
\hline 15:00 & 24,9 & 25,6 & 24,6 & \multicolumn{3}{|c|}{25,3} & 26,3 & \\
\hline
\end{tabular}

Tabela 148: Resultados coletados in loco no quarto do Apartamento F no mês de Junho de 2014.

\begin{tabular}{|c|c|c|c|c|c|c|c|c|}
\hline \multicolumn{2}{|l|}{ Apartamento $\mathrm{F}$} & \multicolumn{4}{|c|}{ Dados coletados CONFORTIMETRO Julho 2013 - SALA } & \multicolumn{3}{|c|}{ Nublado } \\
\hline Intervalo & $\begin{array}{l}\text { Temperatura de } \\
\text { bulbo úmido }\left({ }^{\circ} \mathrm{C}\right)\end{array}$ & $\begin{array}{c}\text { Temperatura de } \\
\text { globo }\left({ }^{\circ} \mathrm{C}\right)\end{array}$ & $\begin{array}{c}\text { Temperatura do ar } \\
\left({ }^{\circ} \mathrm{C}\right)\end{array}$ & $\begin{array}{c}\text { Pressão } \\
\text { Atmosférica }\end{array}$ & $\begin{array}{c}\text { Umidade relativa } \\
\text { do ar (\%) }\end{array}$ & $\begin{array}{l}\text { Velocidade do ar } \\
(\mathrm{m} / \mathrm{s})\end{array}$ & $\begin{array}{l}\text { Temperatura } \\
\text { radiante }\left({ }^{\circ} \mathrm{C}\right)\end{array}$ & $\begin{array}{l}\text { Temperatura } \\
\text { Operativa }\left({ }^{\circ} \mathrm{C}\right)\end{array}$ \\
\hline $15: 00$ as $15: 30$ & 19,3 & 22,5 & 22,1 & 1022,2 & 70,5 & 0,0 & 22,7 & 22,4 \\
\hline $15: 30$ as $16: 00$ & 19,4 & 22,6 & 22,1 & 1022,1 & 70,4 & 0,0 & 22,7 & 22,4 \\
\hline $15: 30$ as $16: 00$ & 19,3 & 22,3 & 22,0 & 1022,2 & 70,9 & 0,0 & 22,3 & 22,2 \\
\hline $16: 30$ as $17: 00$ & 0,08 & 0,20 & 22,1 & 0,08 & 0,50 & 0,02 & 22,6 & 22,4 \\
\hline Desvio Padrão & 19,4 & 22,5 & 0,1 & 1022,2 & 70,6 & 0,0 & 0,3 & 0,2 \\
\hline Média & 22,4 & 25,1 & 24,9 & 1010,9 & 73,7 & 0,0 & 25,2 & 25,0 \\
\hline \multicolumn{8}{|c|}{ Dados coletados Termômetro de fluxo de laser } & \\
\hline Horário/Quarto & Temp. Externa do ar & $\begin{array}{c}\text { Temp. Paredes } \\
\text { externas }\end{array}$ & $\begin{array}{c}\text { Temp.Paredes } \\
\text { voltada para a rua }\end{array}$ & \multicolumn{3}{|c|}{ Temp. Média das paredes } & Temp. Teto & \\
\hline 15:00 & 20 & 20 & 20,3 & \multicolumn{3}{|c|}{20,4} & 20,5 & \\
\hline $17: 00$ & 20,4 & 20,1 & 21 & \multicolumn{3}{|c|}{20,9} & 21,2 & \\
\hline
\end{tabular}

Tabela 149: Resultados coletados in loco na sala do Apartamento F no mês de Julho de 2013. 


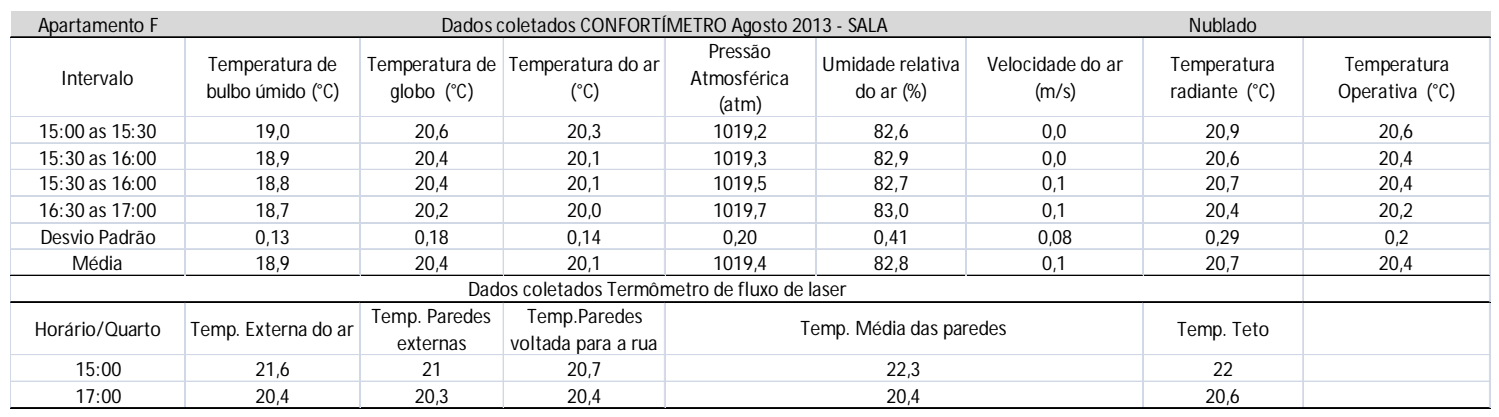

Tabela 150: Resultados coletados in loco na sala do Apartamento F no mês de Agosto de 2013.

\begin{tabular}{|c|c|c|c|c|c|c|c|c|}
\hline \multicolumn{6}{|c|}{ Dados coletados CONFORTÍM ETRO Setembro 2013 - SALA } & \multicolumn{3}{|c|}{ Céu limpo } \\
\hline Intervalo & $\begin{array}{l}\text { Temperatura de } \\
\text { bulbo úmido }\left({ }^{\circ} \mathrm{C}\right)\end{array}$ & $\begin{array}{c}\text { Temperatura de } \\
\text { globo }\left({ }^{\circ} \mathrm{C}\right)\end{array}$ & $\begin{array}{c}\text { Temperatura do ar } \\
\left({ }^{\circ} \mathrm{C}\right)\end{array}$ & $\begin{array}{l}\text { Pressão } \\
\text { Atmosférica } \\
\text { (atm) }\end{array}$ & $\begin{array}{l}\text { Umidade relativa } \\
\text { do ar (\%) }\end{array}$ & $\begin{array}{l}\text { Velocidade do ar } \\
\qquad(\mathrm{m} / \mathrm{s})\end{array}$ & $\begin{array}{l}\text { Temperatura } \\
\text { radiante }\left({ }^{\circ} \mathrm{C}\right)\end{array}$ & $\begin{array}{c}\text { Temperatura } \\
\text { Operativa }\left({ }^{\circ} \mathrm{C}\right)\end{array}$ \\
\hline $15: 00$ as $15: 30$ & 21,5 & 24,5 & 24,0 & 1011,1 & 73,8 & 0,1 & 24,9 & 24,4 \\
\hline $15: 30$ as $16: 00$ & 21,3 & 24,3 & 23,7 & 1010,8 & 73,6 & 0,0 & 24,7 & 24,2 \\
\hline $15: 30$ as $16: 00$ & 21,2 & 24,4 & 24,0 & 1010,5 & 71,3 & 0,1 & 24,6 & 24,3 \\
\hline $16: 30$ as $17: 00$ & 21,1 & 24,1 & 23,7 & 1009,5 & 73,9 & 0,1 & 24,5 & 24,1 \\
\hline Desvio Padrão & 0,26 & 0,20 & 0,33 & 0,71 & 1,67 & 0,10 & 0,49 & 0,4 \\
\hline Média & 21,2 & 24,3 & 23,8 & 1010,2 & 73,4 & 0,1 & 24,6 & 24,2 \\
\hline \multicolumn{8}{|c|}{ Dados coletados Termômetro de fluxo de laser } & \\
\hline Horário/ Quarto & Temp. Externa do ar & $\begin{array}{c}\text { Temp. Paredes } \\
\text { externas }\end{array}$ & $\begin{array}{c}\text { Temp.Paredes } \\
\text { voltada para a rua }\end{array}$ & \multicolumn{3}{|c|}{ Temp. Média das paredes } & Temp. Teto & \\
\hline 15:00 & 28,8 & 22,5 & 25,3 & \multirow{2}{*}{\multicolumn{3}{|c|}{$\begin{array}{c}25 \\
24,7\end{array}$}} & 26,2 & \\
\hline $17: 00$ & 22,5 & 24,4 & 24,4 & & & & 25,8 & \\
\hline
\end{tabular}

Tabela 151: Resultados coletados in loco na sala do Apartamento F no mês de Setembro de 2013.

\begin{tabular}{|c|c|c|c|c|c|c|c|c|}
\hline \multicolumn{2}{|l|}{ Apartamento F } & \multicolumn{4}{|c|}{ Dados coletados CONFORTÍMETRO Outubro 2013 - SALA } & \multicolumn{3}{|c|}{ Nublado } \\
\hline Intervalo & $\begin{array}{l}\text { Temperatura de } \\
\text { bulbo úmido }\left({ }^{\circ} \mathrm{C}\right)\end{array}$ & $\begin{array}{c}\text { Temperatura de } \\
\text { globo }\left({ }^{\circ} \mathrm{C}\right)\end{array}$ & $\begin{array}{c}\text { Temperatura do ar } \\
\left({ }^{\circ} \mathrm{C}\right)\end{array}$ & $\begin{array}{c}\text { Pressão } \\
\text { Atmosférica } \\
\text { (atm) }\end{array}$ & $\begin{array}{c}\text { Umidade relativa } \\
\text { do ar (\%) }\end{array}$ & $\begin{array}{l}\text { Velocidade do ar } \\
\qquad(\mathrm{m} / \mathrm{s})\end{array}$ & $\begin{array}{l}\text { Temperatura } \\
\text { radiante }\left({ }^{\circ} \mathrm{C}\right)\end{array}$ & $\begin{array}{l}\text { Temperatura } \\
\text { Operativa }\left({ }^{\circ} \mathrm{C}\right)\end{array}$ \\
\hline $15: 00$ as $15: 30$ & 21,7 & 25,1 & 24,8 & 1007,5 & 70,0 & 0,0 & 25,3 & 25,1 \\
\hline $15: 30$ as $16: 00$ & 21,7 & 25,0 & 24,7 & 1007,3 & 70,7 & 0,0 & 25,2 & 24,9 \\
\hline $15: 30$ as $16: 00$ & 21,7 & 25,2 & 24,9 & 1007,3 & 70,1 & 0,0 & 25,4 & 25,1 \\
\hline $16: 30$ as $17: 00$ & 21,6 & 25,1 & 24,8 & 1007,5 & 69,9 & 0,0 & 25,2 & 25,0 \\
\hline Desvio Padrão & 0,11 & 0,10 & 0,09 & 0,12 & 0,55 & 0,05 & 0,18 & 0,1 \\
\hline Média & 21,7 & 25,1 & 24,8 & 1007,4 & 70,2 & 0,0 & 25,3 & 25,0 \\
\hline \multicolumn{8}{|c|}{ Dados coletados Termômetro de fluxo de laser } & \\
\hline Horário/Quarto & Temp. Externa do ar & $\begin{array}{c}\text { Temp. Paredes } \\
\text { externas }\end{array}$ & $\begin{array}{c}\text { Temp.Paredes } \\
\text { voltada para a rua }\end{array}$ & \multicolumn{3}{|c|}{ Temp. Média das paredes } & Temp. Teto & \\
\hline 15:00 & 24,8 & 27,7 & 25,2 & \multicolumn{3}{|c|}{24} & 26,1 & \\
\hline $17: 00$ & 27,7 & 26 & 25,4 & \multicolumn{3}{|c|}{24,2} & 27,4 & \\
\hline
\end{tabular}

Tabela 152: Resultados coletados in loco na sala do Apartamento F no mês de Outubro de 2013.

\begin{tabular}{|c|c|c|c|c|c|c|c|c|}
\hline \multicolumn{6}{|c|}{ Dados coletados CONFORTÍMETRO Novembro 2013 - SALA } & \multicolumn{3}{|c|}{ Chuva } \\
\hline Intervalo & $\begin{array}{l}\text { Temperatura de } \\
\text { bulbo úmido }\left({ }^{\circ} \mathrm{C}\right)\end{array}$ & $\begin{array}{c}\text { Temperatura de } \\
\text { globo }\left({ }^{\circ} \mathrm{C}\right)\end{array}$ & $\begin{array}{l}\text { Temperatura do ar } \\
\left({ }^{\circ} \mathrm{C}\right)\end{array}$ & $\begin{array}{c}\text { Pressão } \\
\text { Atmosférica } \\
\text { (atm) }\end{array}$ & $\begin{array}{l}\text { Umidade relativa } \\
\text { do ar (\%) }\end{array}$ & $\begin{array}{l}\text { Velocidade do ar } \\
\qquad(\mathrm{m} / \mathrm{s})\end{array}$ & $\begin{array}{l}\text { Temperatura } \\
\text { radiante }\left({ }^{\circ} \mathrm{C}\right)\end{array}$ & $\begin{array}{l}\text { Temperatura } \\
\text { Operativa }\left({ }^{\circ} \mathrm{C}\right)\end{array}$ \\
\hline $16: 00$ as16:30 & 24,5 & 27,4 & 27,2 & 1011,5 & 75,2 & 0,0 & 27,6 & 27,4 \\
\hline $16: 30$ as $17: 00$ & 24,3 & 27,2 & 26,9 & 1011,4 & 76,1 & 0,0 & 27,4 & 27,2 \\
\hline $17: 00$ as $17: 30$ & 24,1 & 27,2 & 26,9 & 1011,2 & 74,6 & 0,0 & 27,4 & 27,1 \\
\hline $17: 30$ as $18: 00$ & 24,3 & 27,1 & 26,8 & 1011,0 & 76,6 & 0,0 & 27,3 & 27,0 \\
\hline Desvio Padrão & 0,16 & 0,16 & 0,20 & 0,21 & 0,88 & 0,03 & 0,16 & 0,2 \\
\hline Média & 24,3 & 27,2 & 26,9 & 1011,3 & 75,6 & 0,0 & 27,4 & 27,2 \\
\hline \multicolumn{8}{|c|}{ Dados coletados Termômetro de fluxo de laser } & \\
\hline Horário/Quarto & Temp. Externa do ar & $\begin{array}{c}\text { Temp. Paredes } \\
\text { externas }\end{array}$ & $\begin{array}{c}\text { Temp.Paredes } \\
\text { voltada para a rua }\end{array}$ & \multicolumn{3}{|c|}{ Temp. Média das paredes } & Temp. Teto & \\
\hline $16: 00$ & 28,8 & 28,5 & 26,7 & \multicolumn{3}{|c|}{26,8} & 27,5 & \\
\hline $18: 00$ & 26,6 & 26,7 & 26 & \multicolumn{3}{|c|}{27,3} & 27,3 & \\
\hline
\end{tabular}

Tabela 153: Resultados coletados in loco na sala do Apartamento F no mês de Novembro de 2013. 


\begin{tabular}{|c|c|c|c|c|c|c|c|c|}
\hline \multicolumn{6}{|c|}{ Dados coletados CONFORTÍM ETRO Dezembro 2013 - SALA } & \multicolumn{3}{|c|}{ Nublado } \\
\hline Intervalo & $\begin{array}{l}\text { Temperatura de } \\
\text { bulbo úmido }\left({ }^{\circ} \mathrm{C}\right)\end{array}$ & $\begin{array}{c}\text { Temperatura de } \\
\text { globo }\left({ }^{\circ} \mathrm{C}\right)\end{array}$ & $\begin{array}{c}\text { Temperatura do ar } \\
\left({ }^{\circ} \mathrm{C}\right)\end{array}$ & $\begin{array}{c}\text { Pressão } \\
\text { Atmosférica } \\
\text { (atm) }\end{array}$ & $\begin{array}{c}\text { Umidade relativa } \\
\text { do ar (\%) }\end{array}$ & $\begin{array}{l}\text { Velocidade do ar } \\
\qquad(\mathrm{m} / \mathrm{s})\end{array}$ & $\begin{array}{l}\text { Temperatura } \\
\text { radiante }\left({ }^{\circ} \mathrm{C}\right)\end{array}$ & $\begin{array}{l}\text { Temperatura } \\
\text { Operativa }\left({ }^{\circ} \mathrm{C}\right)\end{array}$ \\
\hline $16: 00$ as16:30 & 24,3 & 26,6 & 26,4 & 1011,1 & 78,2 & 0,0 & 26,7 & 26,6 \\
\hline $16: 30$ as $17: 00$ & 24,2 & 26,6 & 26,3 & 1010,9 & 78,4 & 0,0 & 26,7 & 26,5 \\
\hline $17: 00$ as $17: 30$ & 24,1 & 26,5 & 26,2 & 1010,9 & 78,0 & 0,0 & 26,6 & 26,4 \\
\hline $17: 30$ as $18: 00$ & 24,1 & 26,4 & 26,1 & 1010,8 & 78,5 & 0,0 & 26,5 & 26,3 \\
\hline Desvio Padrão & 0,10 & 0,10 & 0,11 & 0,12 & 0,31 & 0,01 & 0,11 & 0,1 \\
\hline Média & 24,2 & 26,5 & 26,3 & 1010,9 & 78,3 & 0,0 & 26,7 & 26,5 \\
\hline \multicolumn{8}{|c|}{ Dados coletados Termômetro de fluxo de laser } & \\
\hline Horário/Quarto & Temp. Externa do ar & $\begin{array}{c}\text { Temp. Paredes } \\
\text { externas }\end{array}$ & $\begin{array}{c}\text { Temp.Paredes } \\
\text { voltada para a rua }\end{array}$ & \multicolumn{3}{|c|}{ Temp. Média das paredes } & Temp. Teto & \\
\hline $16: 00$ & 25,9 & 25,1 & 25,7 & \multicolumn{3}{|c|}{26,2} & 26,2 & \\
\hline $18: 00$ & 26 & 25,1 & 26,1 & \multicolumn{3}{|c|}{26,6} & 27,1 & \\
\hline
\end{tabular}

Tabela 154: Resultados coletados in loco na sala do Apartamento F no mês de Dezembro de 2013.

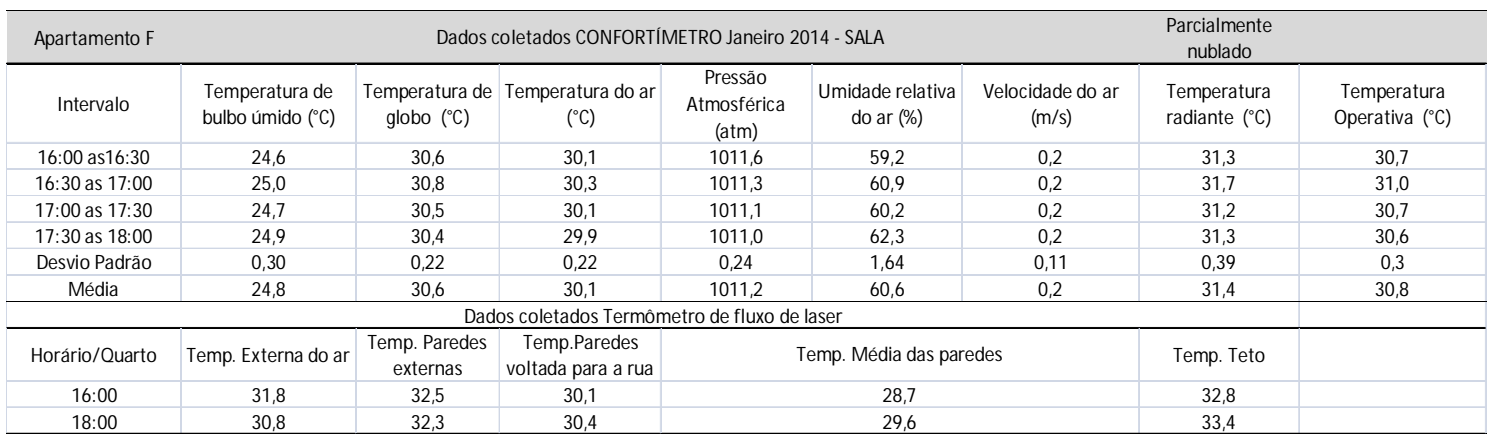

Tabela 155: Resultados coletados in loco na sala do Apartamento F no mês de Janeiro de 2014.

\begin{tabular}{|c|c|c|c|c|c|c|c|c|}
\hline Apartamento $\mathrm{F}$ & \multicolumn{5}{|c|}{ Dados coletados CONFORTIMMETRO Fevereiro 2014 - SALA } & \multicolumn{3}{|c|}{ Nublado } \\
\hline Intervalo & $\begin{array}{l}\text { Temperatura de } \\
\text { bulbo úmido }\left({ }^{\circ} \mathrm{C}\right)\end{array}$ & $\begin{array}{c}\text { Temperatura de } \\
\text { globo }\left({ }^{\circ} \mathrm{C}\right)\end{array}$ & $\begin{array}{c}\text { Temperatura do ar } \\
\left({ }^{\circ} \mathrm{C}\right)\end{array}$ & $\begin{array}{c}\text { Pressão } \\
\text { Atmosférica } \\
\text { (atm) }\end{array}$ & $\begin{array}{c}\text { Umidade relativa } \\
\text { do ar (\%) }\end{array}$ & $\begin{array}{l}\text { Velocidade do ar } \\
\qquad(\mathrm{m} / \mathrm{s})\end{array}$ & $\begin{array}{l}\text { Temperatura } \\
\text { radiante }\left({ }^{\circ} \mathrm{C}\right)\end{array}$ & $\begin{array}{l}\text { Temperatura } \\
\text { Operativa }\left({ }^{\circ} \mathrm{C}\right)\end{array}$ \\
\hline $15: 00$ as $15: 30$ & 26,2 & 30,9 & 30,7 & 1009,6 & 67,7 & 0,7 & 31,7 & 31,2 \\
\hline $15: 30$ as $16: 00$ & 26,3 & 30,9 & 30,7 & 1009,5 & 68,0 & 0,7 & 31,8 & 31,2 \\
\hline $15: 30$ as $16: 00$ & 26,2 & 30,8 & 30,6 & 1009,6 & 67,8 & 0,7 & 31,7 & 31,2 \\
\hline $16: 30$ as $17: 00$ & 25,9 & 30,6 & 30,4 & 1009,6 & 67,3 & 0,7 & 31,3 & 30,9 \\
\hline Desvio Padrão & 0,16 & 0,12 & 0,12 & 0,08 & 0,48 & 0,24 & 0,30 & 0,2 \\
\hline Média & 26,2 & 30,8 & 30,6 & 1009,6 & 67,7 & 0,7 & 31,6 & 31,1 \\
\hline \multicolumn{8}{|c|}{ Dados coletados Termômetro de fluxo de laser } & \\
\hline Horário/Quarto & Temp. Externa do ar & $\begin{array}{c}\text { Temp. Paredes } \\
\text { externas }\end{array}$ & $\begin{array}{c}\text { Temp.Paredes } \\
\text { voltada para a rua }\end{array}$ & \multicolumn{3}{|c|}{ Temp. Média das paredes } & Temp. Teto & \\
\hline 15:00 & 30 & 32,5 & 31 & \multicolumn{3}{|c|}{30,4} & 33,8 & \\
\hline $17: 00$ & 30 & 31 & 30 & \multicolumn{3}{|c|}{29,2} & 31,2 & \\
\hline
\end{tabular}

Tabela 156: Resultados coletados in loco na sala do Apartamento F no mês de Fevereiro de 2014.

\begin{tabular}{|c|c|c|c|c|c|c|c|c|}
\hline \multicolumn{2}{|l|}{ Apartamento $\mathrm{F}$} & \multicolumn{4}{|c|}{ Dados coletados CONFORTÍMETRO Março 2014 - SALA } & \multicolumn{3}{|c|}{ Nublado } \\
\hline Intervalo & $\begin{array}{l}\text { Temperatura de } \\
\text { bulbo úmido }\left({ }^{\circ} \mathrm{C}\right)\end{array}$ & $\begin{array}{c}\text { Temperatura de } \\
\text { globo }\left({ }^{\circ} \mathrm{C}\right)\end{array}$ & $\begin{array}{c}\text { Temperatura do ar } \\
\left({ }^{\circ} \mathrm{C}\right)\end{array}$ & $\begin{array}{c}\text { Pressão } \\
\text { Atmosférica } \\
\text { (atm) }\end{array}$ & $\begin{array}{l}\text { Umidade relativa } \\
\text { do ar (\%) }\end{array}$ & $\begin{array}{l}\text { Velocidade do ar } \\
\qquad(\mathrm{m} / \mathrm{s})\end{array}$ & $\begin{array}{l}\text { Temperatura } \\
\text { radiante }\left({ }^{\circ} \mathrm{C}\right)\end{array}$ & $\begin{array}{l}\text { Temperatura } \\
\text { Operativa }\left({ }^{\circ} \mathrm{C}\right)\end{array}$ \\
\hline $15: 00$ as $15: 30$ & 25,2 & 29,3 & 28,6 & 1010,7 & 72,5 & 0,1 & 29,8 & 29,2 \\
\hline $15: 30$ as $16: 00$ & 25,2 & 29,3 & 28,6 & 1010,7 & 71,8 & 0 & 29,7 & 29,2 \\
\hline $15: 30$ as $16: 00$ & 25,2 & 29,2 & 28,6 & 1010,8 & 71,8 & 0 & 29,6 & 29,1 \\
\hline $16: 30$ as $17: 00$ & 25 & 29,3 & 28,7 & 1010,9 & 69,6 & 0 & 29,6 & 29,2 \\
\hline Desvio Padrão & 0,18 & 0,07 & 0,10 & 0,10 & 1,28 & 0,04 & 0,29 & 0,2 \\
\hline Média & 25,1 & 29,3 & 28,6 & 1010,8 & 71,4 & 0,0 & 29,7 & 29,1 \\
\hline \multicolumn{8}{|c|}{ Dados coletados Termômetro de fluxo de laser } & \\
\hline Horário/Quarto & Temp. Externa do ar & $\begin{array}{c}\text { Temp. Paredes } \\
\text { externas }\end{array}$ & $\begin{array}{c}\text { Temp.Paredes } \\
\text { voltada para a rua }\end{array}$ & \multicolumn{3}{|c|}{ Temp. Média das paredes } & Temp. Teto & \\
\hline 15:00 & 31,5 & 29,2 & 30,3 & \multicolumn{3}{|c|}{29,6} & 31,3 & \\
\hline $17: 00$ & 30,9 & 29 & 29,2 & \multicolumn{3}{|c|}{29,2} & 29,3 & \\
\hline
\end{tabular}

Tabela 157: Resultados coletados in loco na sala do Apartamento F no mês de Março de 2014. 


\begin{tabular}{|c|c|c|c|c|c|c|c|c|}
\hline \multicolumn{6}{|c|}{ Dados coletados CONFORTÍM ETRO Abril 2014 - SALA } & \multicolumn{3}{|c|}{ Chuva } \\
\hline Intervalo & $\begin{array}{l}\text { Temperatura de } \\
\text { bulbo úmido }\left({ }^{\circ} \mathrm{C}\right)\end{array}$ & $\begin{array}{c}\text { Temperatura de } \\
\text { globo }\left({ }^{\circ} \mathrm{C}\right)\end{array}$ & $\begin{array}{c}\text { Temperatura do ar } \\
\left({ }^{\circ} \mathrm{C}\right)\end{array}$ & $\begin{array}{c}\text { Pressão } \\
\text { Atmosférica } \\
\text { (atm) }\end{array}$ & $\begin{array}{l}\text { Umidade relativa } \\
\text { do ar (\%) }\end{array}$ & $\begin{array}{l}\text { Velocidade do ar } \\
\qquad(\mathrm{m} / \mathrm{s})\end{array}$ & $\begin{array}{l}\text { Temperatura } \\
\text { radiante }\left({ }^{\circ} \mathrm{C}\right)\end{array}$ & $\begin{array}{l}\text { Temperatura } \\
\text { Operativa }\left({ }^{\circ} \mathrm{C}\right)\end{array}$ \\
\hline $15: 00$ as $15: 30$ & 22,1 & 24,6 & 24,3 & 1013,9 & 78,8 & 0,1 & 24,8 & 24,5 \\
\hline $15: 30$ as $16: 00$ & 22,1 & 24,4 & 24,1 & 1014,0 & 79,9 & 0,1 & 24,9 & 24,5 \\
\hline $15: 30$ as $16: 00$ & 22,1 & 24,4 & 24,0 & 1014,2 & 80,9 & 0,1 & 24,9 & 24,4 \\
\hline $16: 30$ as $17: 00$ & 22,0 & 24,3 & 23,9 & 1014,3 & 79,8 & 0,1 & 24,7 & 24,3 \\
\hline Desvio Padrão & 0,09 & 0,11 & 0,16 & 0,17 & 0,90 & 0,06 & 0,22 & 0,2 \\
\hline Média & 22,1 & 24,4 & 24,1 & 1014,1 & 79,8 & 0,1 & 24,8 & 24,5 \\
\hline \multicolumn{9}{|c|}{ Dados coletados Termômetro de fluxo de laser } \\
\hline Horário/Quarto & Temp. Externa do ar & $\begin{array}{l}\text { Temp. Paredes } \\
\text { externas }\end{array}$ & $\begin{array}{c}\text { Temp.Paredes } \\
\text { voltada para a rua }\end{array}$ & \multicolumn{3}{|c|}{ Temp. Média das paredes } & Temp. Teto & \\
\hline 15:00 & 25,7 & 21,7 & 24,3 & \multicolumn{3}{|c|}{25,5} & 25,6 & \\
\hline $17: 00$ & 25,6 & 22 & 24,3 & \multicolumn{3}{|c|}{24,9} & 25,3 & \\
\hline
\end{tabular}

Tabela 158: Resultados coletados in loco na sala do Apartamento F no mês de Abril de 2014.

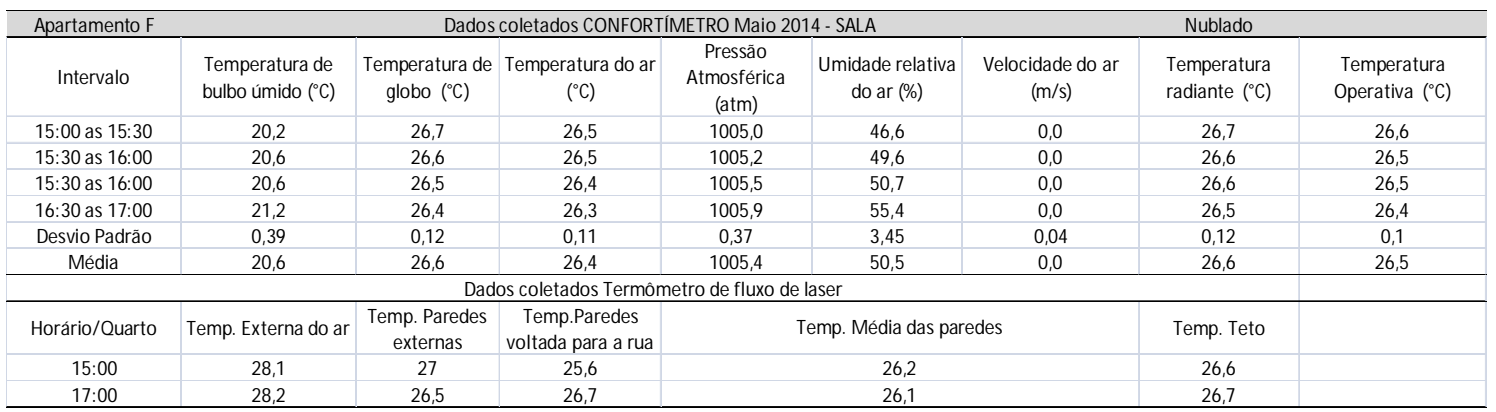

Tabela 159: Resultados coletados in loco na sala do Apartamento F no mês de Maio de 2014.

\begin{tabular}{|c|c|c|c|c|c|c|c|c|}
\hline \multicolumn{2}{|l|}{ Apartamento $\mathrm{F}$} & \multicolumn{4}{|c|}{ Dados coletados CONFORTIMMETRO Junho 2014 - SALA } & \multicolumn{3}{|c|}{ Nublado } \\
\hline Intervalo & $\begin{array}{l}\text { Temperatura de } \\
\text { bulbo úmido }\left({ }^{\circ} \mathrm{C}\right)\end{array}$ & $\begin{array}{c}\text { Temperatura de } \\
\text { globo }\left({ }^{\circ} \mathrm{C}\right)\end{array}$ & $\begin{array}{c}\text { Temperatura do ar } \\
\left({ }^{\circ} \mathrm{C}\right)\end{array}$ & $\begin{array}{l}\text { Pressão } \\
\text { Atmosférica } \\
\text { (atm) }\end{array}$ & $\begin{array}{l}\text { Umidade relativa } \\
\text { do ar (\%) }\end{array}$ & $\begin{array}{l}\text { Velocidade do ar } \\
\qquad(\mathrm{m} / \mathrm{s})\end{array}$ & $\begin{array}{l}\text { Temperatura } \\
\text { radiante }\left({ }^{\circ} \mathrm{C}\right)\end{array}$ & $\begin{array}{l}\text { Temperatura } \\
\text { Operativa }\left({ }^{\circ} \mathrm{C}\right)\end{array}$ \\
\hline $15: 00$ as $15: 30$ & 22,4 & 25,2 & 25,0 & 1010,6 & 73,4 & 0,0 & 25,3 & 25,1 \\
\hline $15: 30$ as $16: 00$ & 22,5 & 25,1 & 24,9 & 1010,7 & 73,8 & 0,0 & 25,2 & 25,0 \\
\hline $15: 30$ as $16: 00$ & 22,4 & 25,0 & 24,8 & 1011,0 & 74,0 & 0,0 & 25,1 & 25,0 \\
\hline $16: 30$ as $17: 00$ & 22,3 & 25,0 & 24,8 & 1011,3 & 73,6 & 0,0 & 25,1 & 24,9 \\
\hline Desvio Padrão & 0,09 & 0,09 & 0,08 & 0,28 & 0,58 & 0,05 & 0,08 & 0,1 \\
\hline Média & 22,4 & 25,1 & 24,9 & 1010,9 & 73,7 & 0,0 & 25,2 & 25,0 \\
\hline \multicolumn{8}{|c|}{ Dados coletados Termômetro de fluxo de laser } & \\
\hline Horário/Quarto & Temp. Externa do ar & $\begin{array}{c}\text { Temp. Paredes } \\
\text { externas }\end{array}$ & $\begin{array}{c}\text { Temp.Paredes } \\
\text { voltada para a rua }\end{array}$ & \multicolumn{3}{|c|}{ Temp. Média das paredes } & Temp. Teto & \\
\hline 15:00 & 24,9 & 24,7 & 24,1 & \multicolumn{3}{|c|}{24,9} & 25 & \\
\hline $17: 00$ & 27,6 & 23,9 & 24,3 & \multicolumn{3}{|c|}{25} & 26,2 & \\
\hline
\end{tabular}

Tabela 160: Resultados coletados in loco na sala do Apartamento F no mês de Junho de 2014.

\begin{tabular}{|c|c|c|c|c|c|c|c|c|}
\hline \multicolumn{2}{|l|}{ Apartamento G } & \multicolumn{4}{|c|}{ Dados coletados CONFORTÍMETRO Julho 2013 - QUARTO } & \multicolumn{3}{|c|}{ céu claro } \\
\hline Intervalo & $\begin{array}{l}\text { Temperatura de } \\
\text { bulbo úmido }\left({ }^{\circ} \mathrm{C}\right)\end{array}$ & $\begin{array}{c}\text { Temperatura de } \\
\text { globo }\left({ }^{\circ} \mathrm{C}\right)\end{array}$ & $\begin{array}{c}\text { Temperatura do ar } \\
\left({ }^{\circ} \mathrm{C}\right)\end{array}$ & $\begin{array}{c}\text { Pressão Atmosférica } \\
\text { (atm) }\end{array}$ & $\begin{array}{c}\text { Umidade relativa do } \\
\operatorname{ar}(\%)\end{array}$ & $\begin{array}{l}\text { Velocidade do ar } \\
\qquad(\mathrm{m} / \mathrm{s})\end{array}$ & $\begin{array}{l}\text { Temperatura } \\
\text { radiante }\left({ }^{\circ} \mathrm{C}\right)\end{array}$ & $\begin{array}{l}\text { Temperatura } \\
\text { Operativa }\left({ }^{\circ} \mathrm{C}\right)\end{array}$ \\
\hline $11: 50$ as $12: 20$ & 18,4 & 22,2 & 22,2 & 1021,6 & 62,6 & 0,1 & 22,0 & 22,1 \\
\hline $12: 20$ as $12: 50$ & 18,9 & 22,7 & 22,6 & 1021,2 & 63,7 & 0,1 & 22,7 & 22,7 \\
\hline $12: 50$ as $13: 20$ & 21,2 & 23,0 & 22,9 & 1020,9 & 63,0 & 0,1 & 23,0 & 23,0 \\
\hline $13: 20$ as $13: 50$ & 22,0 & 23,7 & 23,4 & 1020,7 & 61,7 & 0,1 & 24,0 & 23,7 \\
\hline $13: 50$ as $14: 20$ & 20,5 & 25,8 & 24,1 & 1020,5 & 60,0 & 0,1 & 27,7 & 25,9 \\
\hline $14: 20$ as $14: 50$ & 19,7 & 23,8 & 23,5 & 1020,5 & 62,2 & 0,1 & 24,0 & 23,8 \\
\hline Desvio Padrão & 1,32 & 1,24 & 0,64 & 0,40 & 1,38 & 0,11 & 2,02 & 1,63 \\
\hline Média & 20,1 & 23,5 & 23,1 & 1020,9 & 62,2 & 0,1 & 23,9 & 23,5 \\
\hline \multicolumn{8}{|c|}{ Dados coletados Termômetro de fluxo de laser } & \\
\hline Horário/Quarto & $\begin{array}{l}\text { Temp. Externa do ar } \\
\left({ }^{\circ} \mathrm{C}\right)\end{array}$ & $\begin{array}{l}\text { Temp. Paredes } \\
\text { externas }\left({ }^{\circ} \mathrm{C}\right)\end{array}$ & $\begin{array}{c}\text { Temp. Paredes voltada } \\
\text { para a rua }\left({ }^{\circ} \mathrm{C}\right)\end{array}$ & \multicolumn{3}{|c|}{ Temp. Média das paredes $\left({ }^{\circ} \mathrm{C}\right)$} & Temp. Teto $\left({ }^{\circ} \mathrm{C}\right)$ & \\
\hline 11:50 & 21 & 22 & 22 & \multicolumn{3}{|c|}{22} & 22,3 & \\
\hline 15:00 & 22 & 23 & 24 & \multicolumn{3}{|c|}{23,3} & 24 & \\
\hline
\end{tabular}

Tabela 161: Resultados coletados in loco no quarto do Apartamento G no mês de Julho de 2013. 


\begin{tabular}{|c|c|c|c|c|c|c|c|c|}
\hline \multicolumn{2}{|l|}{ Apartamento G } & \multicolumn{4}{|c|}{ Dados coletados CONFORTÍMETRO Agosto 2013 - QUARTO } & \multicolumn{3}{|c|}{ céu claro } \\
\hline Intervalo & $\begin{array}{l}\text { Temperatura de } \\
\text { bulbo úmido }\left({ }^{\circ} \mathrm{C}\right)\end{array}$ & $\begin{array}{l}\text { Temperatura de } \\
\text { globo }\left({ }^{\circ} \mathrm{C}\right)\end{array}$ & $\begin{array}{c}\text { Temperatura do ar } \\
\left({ }^{\circ} \mathrm{C}\right)\end{array}$ & $\begin{array}{c}\text { Pressão Atmosférica } \\
\text { (atm) }\end{array}$ & $\begin{array}{c}\text { Umidade relativa do } \\
\operatorname{ar}(\%)\end{array}$ & $\begin{array}{l}\text { Velocidade do ar } \\
\qquad(\mathrm{m} / \mathrm{s})\end{array}$ & $\begin{array}{l}\text { Temperatura } \\
\text { radiante }\left({ }^{\circ} \mathrm{C}\right)\end{array}$ & $\begin{array}{l}\text { Temperatura } \\
\text { Operativa }\left({ }^{\circ} \mathrm{C}\right)\end{array}$ \\
\hline $11: 50$ as $12: 20$ & 15,5 & 18,1 & 18,1 & 1022,4 & 70,4 & 0,1 & 18,2 & 18,1 \\
\hline $12: 20$ as $12: 50$ & 15,5 & 17,8 & 17,8 & 1022,1 & 71,6 & 0,1 & 17,7 & 17,8 \\
\hline $12: 50$ as $13: 20$ & 15,4 & 17,8 & 17,8 & 1021,7 & 71,9 & 0,1 & 17,8 & 17,8 \\
\hline $13: 20$ as $13: 50$ & 15,6 & 18,0 & 17,9 & 1021,4 & 72,3 & 0,0 & 18,2 & 18,0 \\
\hline $13: 50$ as $14: 20$ & 15,6 & 18,5 & 18,0 & 1021,2 & 71,9 & 0,1 & 18,9 & 18,5 \\
\hline $14: 20$ as $14: 50$ & 15,7 & 18,1 & 18,0 & 1020,9 & 72,3 & 0,0 & 18,3 & 18,1 \\
\hline Desvio Padrão & 0,12 & 0,41 & 0,17 & 0,52 & 0,86 & 0,06 & 0,71 & 1,63 \\
\hline Média & 15,5 & 18,1 & 17,9 & 1021,6 & 71,7 & 0,1 & 18,2 & 18,0 \\
\hline \multicolumn{8}{|c|}{ Dados coletados Termômetro de fluxo de laser } & \\
\hline Horário/Quarto & $\begin{array}{l}\text { Temp. Externa do ar } \\
\left({ }^{\circ} \mathrm{C}\right)\end{array}$ & $\begin{array}{l}\text { Temp. Paredes } \\
\text { externas }\left({ }^{\circ} \mathrm{C}\right)\end{array}$ & $\begin{array}{c}\text { Temp. Paredes voltada } \\
\text { para a rua }\left({ }^{\circ} \mathrm{C}\right)\end{array}$ & \multicolumn{3}{|c|}{ Temp. Média das paredes $\left({ }^{\circ} \mathrm{C}\right)$} & Temp. Teto $\left({ }^{\circ} \mathrm{C}\right)$ & \\
\hline 11:50 & 19 & 19 & 18,8 & \multicolumn{3}{|c|}{19,1} & 19,5 & \\
\hline $15: 00$ & 20 & 20 & 19,7 & \multicolumn{3}{|c|}{19,6} & 19,7 & \\
\hline
\end{tabular}

Tabela 162: Resultados coletados in loco no quarto do Apartamento G no mês de Agosto de 2013.

\begin{tabular}{|c|c|c|c|c|c|c|c|c|}
\hline \multicolumn{2}{|l|}{ Apartamento G } & \multicolumn{4}{|c|}{ Dados coletados CONFORTÍMETRO Setembro 2013 - QUARTO } & \multicolumn{3}{|c|}{ Chuva } \\
\hline Intervalo & $\begin{array}{l}\text { Temperatura de } \\
\text { bulbo úmido }\left({ }^{\circ} \mathrm{C}\right)\end{array}$ & $\begin{array}{l}\text { Temperatura de } \\
\text { globo }\left({ }^{\circ} \mathrm{C}\right)\end{array}$ & $\begin{array}{c}\text { Temperatura do ar } \\
\left({ }^{\circ} \mathrm{C}\right)\end{array}$ & $\begin{array}{c}\text { Pressão Atmosférica } \\
\text { (atm) }\end{array}$ & $\begin{array}{c}\text { Umidade relativa do } \\
\text { ar (\%) }\end{array}$ & $\begin{array}{l}\text { Velocidade do ar } \\
(\mathrm{m} / \mathrm{s})\end{array}$ & $\begin{array}{l}\text { Temperatura } \\
\text { radiante }\left({ }^{\circ} \mathrm{C}\right)\end{array}$ & $\begin{array}{l}\text { Temperatura } \\
\text { Operativa }\left({ }^{\circ} \mathrm{C}\right)\end{array}$ \\
\hline $11: 50$ as $12: 20$ & 19,5 & 22,0 & 21,8 & 1019,9 & 77,0 & 0,1 & 22,4 & 22,1 \\
\hline $12: 20$ as $12: 50$ & 19,4 & 21,8 & 21,5 & 1019,3 & 79,1 & 0,2 & 22,2 & 21,9 \\
\hline $12: 50$ as $13: 20$ & 19,5 & 21,8 & 21,5 & 1018,8 & 79,7 & 0,2 & 22,3 & 21,9 \\
\hline $13: 20$ as $13: 50$ & 19,5 & 21,8 & 21,5 & 1018,5 & 80,2 & 0,2 & 22,3 & 21,9 \\
\hline $13: 50$ as $14: 20$ & 19,5 & 21,8 & 21,5 & 1018,1 & 79,8 & 0,2 & 22,3 & 21,9 \\
\hline $14: 20$ as $14: 50$ & 19,5 & 21,8 & 21,6 & 1017,9 & 79,7 & 0,2 & 22,3 & 21,9 \\
\hline Desvio Padrão & 0,11 & 0,17 & 0,17 & 0,73 & 1,37 & 0,11 & 0,25 & 1,63 \\
\hline Média & 19,5 & 21,9 & 21,6 & 1018,8 & 79,1 & 0,2 & 22,3 & 21,9 \\
\hline \multicolumn{8}{|c|}{ Dados coletados Termômetro de fluxo de laser } & \\
\hline Horário/Quarto & $\begin{array}{l}\text { Temp. Externa do ar } \\
\left({ }^{\circ} \mathrm{C}\right)\end{array}$ & $\begin{array}{l}\text { Temp. Paredes } \\
\text { externas }\left({ }^{\circ} \mathrm{C}\right)\end{array}$ & $\begin{array}{c}\text { Temp. Paredes voltada } \\
\text { para a rua }\left({ }^{\circ} \mathrm{C}\right)\end{array}$ & \multicolumn{3}{|c|}{ Temp. Média das paredes $\left({ }^{\circ} \mathrm{C}\right)$} & Temp. Teto $\left({ }^{\circ} \mathrm{C}\right)$ & \\
\hline 11:50 & 20,7 & 19,6 & 21,1 & \multicolumn{3}{|c|}{22,3} & 21,7 & \\
\hline 15:00 & 21,1 & 20,1 & 21,2 & \multicolumn{3}{|c|}{21,8} & 21,4 & \\
\hline
\end{tabular}

Tabela 163: Resultados coletados in loco no quarto do Apartamento G no mês de Setembro de 2013.

\begin{tabular}{|c|c|c|c|c|c|c|c|c|}
\hline \multicolumn{2}{|l|}{ Apartamento G } & \multicolumn{4}{|c|}{ Dados coletados CONFORTÍM ETRO Outubro 2013 - QUARTO } & \multicolumn{3}{|c|}{ Céu claro } \\
\hline Intervalo & $\begin{array}{l}\text { Temperatura de } \\
\text { bulbo úmido }\left({ }^{\circ} \mathrm{C}\right)\end{array}$ & $\begin{array}{c}\text { Temperatura de } \\
\text { globo }\left({ }^{\circ} \mathrm{C}\right)\end{array}$ & $\begin{array}{c}\text { Temperatura do ar } \\
\left({ }^{\circ} \mathrm{C}\right)\end{array}$ & $\begin{array}{c}\text { Pressão Atmosférica } \\
\text { (atm) }\end{array}$ & $\begin{array}{c}\text { Umidade relativa do } \\
\text { ar (\%) }\end{array}$ & $\begin{array}{l}\text { Velocidade do ar } \\
(\mathrm{m} / \mathrm{s})\end{array}$ & $\begin{array}{l}\text { Temperatura } \\
\text { radiante }\left({ }^{\circ} \mathrm{C}\right)\end{array}$ & $\begin{array}{l}\text { Temperatura } \\
\text { Operativa }\left({ }^{\circ} \mathrm{C}\right)\end{array}$ \\
\hline $12: 50$ as $13: 20$ & 19,6 & 25,2 & 24,8 & 1015,1 & 53,7 & 0,1 & 25,5 & 25,1 \\
\hline $13: 20$ as $13: 50$ & 19,4 & 25,4 & 24,9 & 1014,9 & 51,9 & 0,0 & 25,8 & 25,3 \\
\hline $13: 50$ as $14: 20$ & 19,8 & 25,9 & 25,2 & 1014,8 & 52,2 & 0,0 & 26,4 & 25,8 \\
\hline $14: 20$ as $14: 50$ & 19,8 & 26,7 & 25,8 & 1014,7 & 49,1 & 0,1 & 27,4 & 26,6 \\
\hline $14: 50$ as $15: 20$ & 19,5 & 27,0 & 26,0 & 1014,6 & 46,3 & 0,1 & 28,0 & 27,0 \\
\hline $15: 20$ as $15: 50$ & 19,5 & 26,8 & 25,9 & 1014,5 & 45,8 & 0,0 & 27,4 & 26,7 \\
\hline Desvio Padrão & 0,25 & 0,75 & 0,51 & 0,22 & 3,19 & 0,07 & 1,01 & 1,63 \\
\hline Média & 19,6 & 26,1 & 25,4 & 1014,8 & 50,3 & 0,1 & 26,6 & 26,0 \\
\hline \multicolumn{8}{|c|}{ Dados coletados Termômetro de fluxo de laser } & \\
\hline Horário/Quarto & $\begin{array}{l}\text { Temp. Externa do ar } \\
\left({ }^{\circ} \mathrm{C}\right)\end{array}$ & $\begin{array}{l}\text { Temp. Paredes } \\
\text { externas }\left({ }^{\circ} \mathrm{C}\right)\end{array}$ & $\begin{array}{c}\text { Temp. Paredes voltada } \\
\text { para a rua }\left({ }^{\circ} \mathrm{C}\right)\end{array}$ & \multicolumn{3}{|c|}{ Temp. Média das paredes $\left({ }^{\circ} \mathrm{C}\right)$} & Temp. Teto $\left({ }^{\circ} \mathrm{C}\right)$ & \\
\hline $12: 50$ & 25,6 & 26,3 & 24,3 & \multicolumn{3}{|c|}{24,9} & 25 & \\
\hline $16: 00$ & 26,2 & 30,1 & 25,5 & \multicolumn{3}{|c|}{25,5} & 27,2 & \\
\hline
\end{tabular}

Tabela 164: Resultados coletados in loco no quarto do Apartamento G no mês de Outubro de 2013.

\begin{tabular}{|c|c|c|c|c|c|c|c|c|}
\hline \multicolumn{2}{|l|}{ Apartamento G } & \multicolumn{4}{|c|}{ Dados coletados CONFORTÍMETRO Novembro 2013 - QUARTO } & \multicolumn{3}{|c|}{ Nublado } \\
\hline Intervalo & $\begin{array}{l}\text { Temperatura de } \\
\text { bulbo úmido }\left({ }^{\circ} \mathrm{C}\right)\end{array}$ & $\begin{array}{c}\text { Temperatura de } \\
\text { globo }\left({ }^{\circ} \mathrm{C}\right)\end{array}$ & $\begin{array}{c}\text { Temperatura do ar } \\
\left({ }^{\circ} \mathrm{C}\right)\end{array}$ & $\begin{array}{c}\text { Pressão Atmosférica } \\
\text { (atm) }\end{array}$ & $\begin{array}{c}\text { Umidade relativa do } \\
\text { ar (\%) }\end{array}$ & $\begin{array}{l}\text { Velocidade do ar } \\
(\mathrm{m} / \mathrm{s})\end{array}$ & $\begin{array}{l}\text { Temperatura } \\
\text { radiante }\left({ }^{\circ} \mathrm{C}\right)\end{array}$ & $\begin{array}{c}\text { Temperatura } \\
\text { Operativa }\left({ }^{\circ} \mathrm{C}\right)\end{array}$ \\
\hline $12: 50$ as $13: 20$ & 22,4 & 25,1 & 25,0 & 1009,2 & 74,9 & 0,1 & 25,1 & 25,1 \\
\hline $13: 20$ as $13: 50$ & 22,3 & 25,1 & 25,4 & 1008,9 & 72,2 & 0,0 & 25,0 & 25,2 \\
\hline $13: 50$ as $14: 20$ & 22,6 & 25,0 & 25,0 & 1008,6 & 74,4 & 0,0 & 25,0 & 25,0 \\
\hline $14: 20$ as $14: 50$ & 22,6 & 24,9 & 24,8 & 1008,2 & 76,3 & 0,0 & 25,0 & 24,9 \\
\hline $14: 50$ as $15: 20$ & 22,3 & 24,8 & 24,6 & 1007,9 & 77,3 & 0,1 & 25,0 & 24,8 \\
\hline $15: 20$ as $15: 50$ & 22,3 & 24,6 & 24,5 & 1007,6 & 77,2 & 0,1 & 24,7 & 24,6 \\
\hline Desvio Padrão & 0,23 & 0,19 & 0,35 & 0,56 & 1,98 & 0,16 & 0,20 & 1,63 \\
\hline Média & 22,4 & 24,9 & 24,9 & 1008,4 & 75,4 & 0,1 & 25,0 & 24,9 \\
\hline \multicolumn{8}{|c|}{ Dados coletados Termômetro de fluxo de laser } & \\
\hline Horário/Quarto & $\begin{array}{l}\text { Temp. Externa do ar } \\
\left({ }^{\circ} \mathrm{C}\right)\end{array}$ & $\begin{array}{l}\text { Temp. Paredes } \\
\text { externas }\left({ }^{\circ} \mathrm{C}\right)\end{array}$ & $\begin{array}{c}\text { Temp. Paredes voltada } \\
\text { para a rua }\left({ }^{\circ} \mathrm{C}\right)\end{array}$ & \multicolumn{3}{|c|}{ Temp. Média das paredes $\left({ }^{\circ} \mathrm{C}\right)$} & Temp. Teto $\left({ }^{\circ} \mathrm{C}\right)$ & \\
\hline $12: 50$ & 24,9 & 25,9 & 23,9 & \multirow{2}{*}{\multicolumn{3}{|c|}{$\begin{array}{l}24,1 \\
24,6\end{array}$}} & 24,1 & \\
\hline $16: 00$ & 24,7 & 24,2 & 24,6 & & & & 24,8 & \\
\hline
\end{tabular}

Tabela 165: Resultados coletados in loco no quarto do Apartamento G no mês de Novembro de 2013. 


\begin{tabular}{|c|c|c|c|c|c|c|c|c|}
\hline \multicolumn{2}{|l|}{ Apartamento G } & \multicolumn{4}{|c|}{ Dados coletados CONFORTÍM ETRO Dezembro 2013 - QUARTO } & \multicolumn{3}{|c|}{$\begin{array}{l}\text { Parcialmente } \\
\text { nublado }\end{array}$} \\
\hline Intervalo & $\begin{array}{l}\text { Temperatura de } \\
\text { bulbo úmido }\left({ }^{\circ} \mathrm{C}\right)\end{array}$ & $\begin{array}{l}\text { Temperatura de } \\
\text { globo }\left({ }^{\circ} \mathrm{C}\right)\end{array}$ & $\begin{array}{c}\text { Temperatura do ar } \\
\left({ }^{\circ} \mathrm{C}\right)\end{array}$ & $\begin{array}{l}\text { Pressão Atmosférica } \\
\text { (atm) }\end{array}$ & $\begin{array}{l}\text { Umidade relativa do } \\
\text { ar (\%) }\end{array}$ & $\begin{array}{l}\text { Velocidade do ar } \\
(\mathrm{m} / \mathrm{s})\end{array}$ & $\begin{array}{l}\text { Temperatura } \\
\text { radiante }\left({ }^{\circ} \mathrm{C}\right)\end{array}$ & $\begin{array}{l}\text { Temperatura } \\
\text { Operativa }\left({ }^{\circ} \mathrm{C}\right)\end{array}$ \\
\hline $12: 50$ as $13: 20$ & 25,1 & 29,3 & 28,8 & 1006,2 & 70,8 & 0,1 & 29,8 & 29,3 \\
\hline $13: 20$ as $13: 50$ & 25,2 & 29,6 & 28,8 & 1006,1 & 70,9 & 0,1 & 30,2 & 29,5 \\
\hline $13: 50$ as $14: 20$ & 25,4 & 29,8 & 29,2 & 1006,0 & 69,5 & 0,1 & 30,5 & 29,8 \\
\hline $14: 20$ as $14: 50$ & 25,7 & 30,4 & 30,0 & 1005,8 & 64,8 & 0,0 & 30,6 & 30,3 \\
\hline $14: 50$ as $15: 20$ & 26,0 & 31,1 & 30,5 & 1005,6 & 63,6 & 0,0 & 31,4 & 31,0 \\
\hline $15: 20$ as $15: 50$ & 25,9 & 31,2 & 30,5 & 1005,6 & 63,6 & 0,1 & 31,9 & 31,2 \\
\hline Desvio Padrão & 0,40 & 0,76 & 0,78 & 0,27 & 3,44 & 0,06 & 0,80 & 1,63 \\
\hline Média & 25,5 & 30,1 & 29,6 & 1005,9 & 67,5 & 0,1 & 30,7 & 30,1 \\
\hline \multicolumn{8}{|c|}{ Dados coletados Termômetro de fluxo de laser } & \\
\hline Horário/Quarto & $\begin{array}{l}\text { Temp. Externa do ar } \\
\left({ }^{\circ} \mathrm{C}\right)\end{array}$ & $\begin{array}{l}\text { Temp. Paredes } \\
\text { externas }\left({ }^{\circ} \mathrm{C}\right)\end{array}$ & $\begin{array}{c}\text { Temp. Paredes voltada } \\
\text { para a rua }\left({ }^{\circ} \mathrm{C}\right)\end{array}$ & \multicolumn{3}{|c|}{ Temp. Média das paredes $\left({ }^{\circ} \mathrm{C}\right)$} & Temp. Teto $\left({ }^{\circ} \mathrm{C}\right)$ & \\
\hline $12: 50$ & 30,3 & 30,4 & 27,5 & \multicolumn{3}{|c|}{27,9} & 30,8 & \\
\hline $16: 00$ & 36,6 & 34,8 & 27,2 & \multicolumn{3}{|c|}{26,6} & 31,4 & \\
\hline
\end{tabular}

Tabela 166: Resultados coletados in loco no quarto do Apartamento G no mês de Novembro de 2013.

\begin{tabular}{|c|c|c|c|c|c|c|c|c|}
\hline \multicolumn{2}{|l|}{ Apartamento G } & \multicolumn{4}{|c|}{ Dados coletados CONFORTÍMETRO Janeiro 2014 - QUARTO } & \multicolumn{3}{|c|}{ Céu claro } \\
\hline Intervalo & $\begin{array}{l}\text { Temperatura de } \\
\text { bulbo úmido }\left({ }^{\circ} \mathrm{C}\right)\end{array}$ & $\begin{array}{c}\text { Temperatura de } \\
\text { globo }\left({ }^{\circ} \mathrm{C}\right)\end{array}$ & $\begin{array}{c}\text { Temperatura do ar } \\
\left({ }^{\circ} \mathrm{C}\right)\end{array}$ & $\begin{array}{c}\text { Pressão Atmosférica } \\
\text { (atm) }\end{array}$ & $\begin{array}{c}\text { Umidade relativa do } \\
\text { ar (\%) }\end{array}$ & $\begin{array}{l}\text { Velocidade do ar } \\
(\mathrm{m} / \mathrm{s})\end{array}$ & $\begin{array}{l}\text { Temperatura } \\
\text { radiante }\left({ }^{\circ} \mathrm{C}\right)\end{array}$ & $\begin{array}{l}\text { Temperatura } \\
\text { Operativa }\left({ }^{\circ} \mathrm{C}\right)\end{array}$ \\
\hline $12: 50$ as $13: 20$ & 26,2 & 33,1 & 32,8 & 1007,7 & 54,7 & 0,0 & 33,3 & 33,0 \\
\hline $13: 20$ as $13: 50$ & 26,4 & 33,3 & 33,1 & 1007,3 & 54,4 & 0,0 & 33,5 & 33,3 \\
\hline $13: 50$ as $14: 20$ & 26,2 & 33,6 & 33,5 & 1007,0 & 52,4 & 0,1 & 33,8 & 33,6 \\
\hline $14: 20$ as $14: 50$ & 26,2 & 34,0 & 33,8 & 1006,9 & 50,4 & 0,1 & 34,2 & 34,0 \\
\hline $14: 50$ as $15: 20$ & 27,5 & 36,0 & 34,4 & 1006,7 & 53,2 & 0,1 & 34,5 & 34,5 \\
\hline $15: 20$ as $15: 50$ & 27,3 & 36,0 & 35,0 & 1006,2 & 50,3 & 0,2 & 35,0 & 35,0 \\
\hline Desvio Padrão & 0,60 & 5,66 & 0,78 & 0,49 & 1,94 & 0,11 & 0,42 & 1,63 \\
\hline Média & 26,7 & 37,3 & 33,8 & 1006,9 & 52,5 & 0,1 & 33,9 & 33,9 \\
\hline \multicolumn{8}{|c|}{ Dados coletados Termômetro de fluxo de laser } & \\
\hline Horário/Quarto & $\begin{array}{c}\text { Temp. Externa do ar } \\
\left({ }^{\circ} \mathrm{C}\right)\end{array}$ & $\begin{array}{l}\text { Temp. Paredes } \\
\text { externas }\left({ }^{\circ} \mathrm{C}\right)\end{array}$ & $\begin{array}{c}\text { Temp. Paredes voltada } \\
\text { para a rua }\left({ }^{\circ} \mathrm{C}\right)\end{array}$ & \multicolumn{3}{|c|}{ Temp. Média das paredes $\left({ }^{\circ} \mathrm{C}\right)$} & Temp. Teto $\left({ }^{\circ} \mathrm{C}\right)$ & \\
\hline $12: 50$ & 37,7 & 35,4 & 32,1 & \multicolumn{3}{|c|}{32,6} & 34 & \\
\hline $16: 00$ & 38 & 40,4 & 34,4 & \multicolumn{3}{|c|}{34,5} & 38,2 & \\
\hline
\end{tabular}

Tabela 167: Resultados coletados in loco no quarto do Apartamento G no mês de Janeiro de 2014.

\begin{tabular}{|c|c|c|c|c|c|c|c|c|}
\hline \multicolumn{2}{|l|}{ Apartamento $\mathrm{G}$} & \multicolumn{4}{|c|}{ Dados coletados CONFORTÍM ETRO Fevereiro 2014 - QUARTO } & \multicolumn{3}{|c|}{ Nublado } \\
\hline Intervalo & $\begin{array}{l}\text { Temperatura de } \\
\text { bulbo úmido }\left({ }^{\circ} \mathrm{C}\right)\end{array}$ & $\begin{array}{l}\text { Temperatura de } \\
\text { globo }\left({ }^{\circ} \mathrm{C}\right)\end{array}$ & $\begin{array}{c}\text { Temperatura do ar } \\
\left({ }^{\circ} \mathrm{C}\right)\end{array}$ & $\begin{array}{c}\text { Pressão Atmosférica } \\
\text { (atm) }\end{array}$ & $\begin{array}{c}\text { Umidade relativa do } \\
\text { ar (\%) }\end{array}$ & $\begin{array}{c}\text { Velocidade do ar } \\
(\mathrm{m} / \mathrm{s})\end{array}$ & $\begin{array}{l}\text { Temperatura } \\
\text { radiante }\left({ }^{\circ} \mathrm{C}\right)\end{array}$ & $\begin{array}{l}\text { Temperatura } \\
\text { Operativa }\left({ }^{\circ} \mathrm{C}\right)\end{array}$ \\
\hline $11: 50$ as $12: 20$ & 25,3 & 31,5 & 30,4 & 1009,3 & 60,3 & 0,0 & 31,8 & 31,1 \\
\hline $12: 20$ as $12: 50$ & 25,4 & 31,4 & 30,5 & 1009,3 & 60,0 & 0,0 & 31,9 & 31,2 \\
\hline $12: 50$ as $13: 20$ & 25,3 & 31,2 & 30,5 & 1009,3 & 59,9 & 0,0 & 31,4 & 31,0 \\
\hline $13: 20$ as $13: 50$ & 25,3 & 30,9 & 30,6 & 1009,2 & 59,4 & 0,0 & 31,0 & 30,8 \\
\hline $13: 50$ as $14: 20$ & 25,3 & 31,0 & 30,7 & 1009,2 & 59,4 & 0,0 & 31,1 & 30,9 \\
\hline $14: 20$ as $14: 50$ & 24,9 & 31,0 & 30,7 & 1008,9 & 56,5 & 0,0 & 31,1 & 30,9 \\
\hline Desvio Padrão & 0,26 & 0,10 & 0,07 & 0,17 & 1,56 & 0,04 & 0,15 & 1,63 \\
\hline Média & 25,2 & 31,0 & 30,7 & 1009,1 & 58,4 & 0,0 & 31,1 & 30,9 \\
\hline \multicolumn{8}{|c|}{ Dados coletados Termômetro de fluxo de laser } & \\
\hline Horário/Quarto & $\begin{array}{c}\text { Temp. Externa do ar } \\
\left({ }^{\circ} \mathrm{C}\right)\end{array}$ & $\begin{array}{l}\text { Temp. Paredes } \\
\text { externas }\left({ }^{\circ} \mathrm{C}\right)\end{array}$ & $\begin{array}{c}\text { Temp. Paredes voltada } \\
\text { para a rua }\left({ }^{\circ} \mathrm{C}\right)\end{array}$ & \multicolumn{3}{|c|}{ Temp. Média das paredes $\left({ }^{\circ} \mathrm{C}\right)$} & Temp. Teto $\left({ }^{\circ} \mathrm{C}\right)$ & \\
\hline $11: 50$ & 35,6 & 35,2 & 28,8 & \multicolumn{3}{|c|}{29,3} & 32,1 & \\
\hline $15: 00$ & 34,3 & 33 & 30,2 & \multicolumn{3}{|c|}{29,5} & 34 & \\
\hline
\end{tabular}

Tabela 168: Resultados coletados in loco no quarto do Apartamento G no mês de Fevereiro de 2014.

\begin{tabular}{|c|c|c|c|c|c|c|c|c|}
\hline \multicolumn{2}{|l|}{ Apartamento G } & \multicolumn{4}{|c|}{ Dados coletados CONFORTÍM ETRO M arço 2014 - QUARTO } & \multicolumn{3}{|c|}{$\begin{array}{l}\text { Parcialmente } \\
\text { aberto }\end{array}$} \\
\hline Intervalo & $\begin{array}{l}\text { Temperatura de } \\
\text { bulbo úmido }\left({ }^{\circ} \mathrm{C}\right)\end{array}$ & $\begin{array}{c}\text { Temperatura de } \\
\text { globo }\left({ }^{\circ} \mathrm{C}\right)\end{array}$ & $\begin{array}{c}\text { Temperatura do ar } \\
\left({ }^{\circ} \mathrm{C}\right)\end{array}$ & $\begin{array}{c}\text { Pressão Atmosférica } \\
\text { (atm) }\end{array}$ & $\begin{array}{l}\text { Umidade relativa do } \\
\operatorname{ar}(\%)\end{array}$ & $\begin{array}{l}\text { Velocidade do ar } \\
(\mathrm{m} / \mathrm{s})\end{array}$ & $\begin{array}{l}\text { Temperatura } \\
\text { radiante }\left({ }^{\circ} \mathrm{C}\right)\end{array}$ & $\begin{array}{l}\text { Temperatura } \\
\text { Operativa }\left({ }^{\circ} \mathrm{C}\right)\end{array}$ \\
\hline $11: 50$ as $12: 20$ & 24,1 & 28,6 & 28,5 & 1011,1 & 64,1 & 0,0 & 28,7 & 28,6 \\
\hline $12: 20$ as $12: 50$ & 24,3 & 28,8 & 28,6 & 1010,7 & 64,4 & 0,0 & 28,9 & 28,8 \\
\hline $12: 50$ as $13: 20$ & 24,6 & 29,1 & 28,9 & 1010,6 & 64,2 & 0,0 & 29,2 & 29,1 \\
\hline $13: 20$ as $13: 50$ & 24,8 & 29,5 & 29,2 & 1010,3 & 63,8 & 0,0 & 29,6 & 29,4 \\
\hline $13: 50$ as $14: 20$ & 25,0 & 29,7 & 29,4 & 1010,0 & 63,6 & 0,0 & 29,8 & 29,6 \\
\hline $14: 20$ as $14: 50$ & 25,2 & 30,0 & 29,7 & 1009,8 & 63,1 & 0,0 & 30,1 & 29,9 \\
\hline Desvio Padrão & 0,41 & 0,50 & 0,46 & 0,47 & 0,51 & 0,01 & 0,52 & 1,63 \\
\hline Média & 24,6 & 29,3 & 29,0 & 1010,4 & 63,9 & 0,0 & 29,3 & 29,2 \\
\hline \multicolumn{8}{|c|}{ Dados coletados Termômetro de fluxo de laser } & \\
\hline Horário/Quarto & $\begin{array}{l}\text { Temp. Externa do ar } \\
\left({ }^{\circ} \mathrm{C}\right)\end{array}$ & $\begin{array}{l}\text { Temp. Paredes } \\
\text { externas }\left({ }^{\circ} \mathrm{C}\right)\end{array}$ & $\begin{array}{c}\text { Temp. Paredes voltada } \\
\text { para a rua }\left({ }^{\circ} \mathrm{C}\right)\end{array}$ & \multicolumn{3}{|c|}{ Temp. Média das paredes $\left({ }^{\circ} \mathrm{C}\right)$} & Temp. Teto $\left({ }^{\circ} \mathrm{C}\right)$ & \\
\hline 11:50 & 28,3 & 31,4 & 27,5 & \multicolumn{3}{|c|}{28,8} & 29,4 & \\
\hline 15:00 & 31,3 & 39,3 & 30,4 & \multicolumn{3}{|c|}{29,3} & 32,1 & \\
\hline
\end{tabular}

Tabela 169: Resultados coletados in loco no quarto do Apartamento G no mês de Março de 2014. 


\begin{tabular}{|c|c|c|c|c|c|c|c|c|}
\hline \multicolumn{2}{|l|}{ Apartamento G } & \multicolumn{4}{|c|}{ Dados coletados CONFORTÍM ETRO Abril 2014 - QUARTO } & \multicolumn{3}{|c|}{ Chuva } \\
\hline Intervalo & $\begin{array}{l}\text { Temperatura de } \\
\text { bulbo úmido }\left({ }^{\circ} \mathrm{C}\right)\end{array}$ & $\begin{array}{l}\text { Temperatura de } \\
\text { globo }\left({ }^{\circ} \mathrm{C}\right)\end{array}$ & $\begin{array}{c}\text { Temperatura do ar } \\
\left({ }^{\circ} \mathrm{C}\right)\end{array}$ & $\begin{array}{c}\text { Pressão Atmosférica } \\
\text { (atm) }\end{array}$ & $\begin{array}{c}\text { Umidade relativa do } \\
\operatorname{ar}(\%)\end{array}$ & $\begin{array}{l}\text { Velocidade do ar } \\
\qquad(\mathrm{m} / \mathrm{s})\end{array}$ & $\begin{array}{l}\text { Temperatura } \\
\text { radiante }\left({ }^{\circ} \mathrm{C}\right)\end{array}$ & $\begin{array}{l}\text { Temperatura } \\
\text { Operativa }\left({ }^{\circ} \mathrm{C}\right)\end{array}$ \\
\hline $11: 50$ as $12: 20$ & 22,1 & 25,1 & 24,9 & 1014,1 & 76,5 & 0,0 & 25,3 & 25,1 \\
\hline $12: 20$ as $12: 50$ & 22,0 & 25,0 & 24,7 & 1013,7 & 76,2 & 0,0 & 25,1 & 24,9 \\
\hline $12: 50$ as $13: 20$ & 22,1 & 26,1 & 25,0 & 1013,4 & 75,3 & 0,1 & 27,1 & 26,1 \\
\hline $13: 20$ as $13: 50$ & 21,9 & 25,2 & 24,9 & 1013,3 & 75,2 & 0,0 & 25,4 & 25,1 \\
\hline $13: 50$ as $14: 20$ & 22,0 & 24,7 & 24,7 & 1013,1 & 77,4 & 0,0 & 24,7 & 24,7 \\
\hline $14: 20$ as $14: 50$ & 22,3 & 24,9 & 24,8 & 1012,9 & 77,0 & 0,0 & 24,9 & 24,8 \\
\hline Desvio Padrão & 0,16 & 0,57 & 0,13 & 0,41 & 1,00 & 0,04 & 1,03 & 1,63 \\
\hline Média & 22,1 & 25,2 & 24,8 & 1013,4 & 76,2 & 0,0 & 25,4 & 25,1 \\
\hline \multicolumn{8}{|c|}{ Dados coletados Termômetro de fluxo de laser } & \\
\hline Horário/Quarto & $\begin{array}{l}\text { Temp. Externa do ar } \\
\left({ }^{\circ} \mathrm{C}\right)\end{array}$ & $\begin{array}{l}\text { Temp. Paredes } \\
\text { externas }\left({ }^{\circ} \mathrm{C}\right)\end{array}$ & $\begin{array}{c}\text { Temp. Paredes voltada } \\
\text { para a rua }\left({ }^{\circ} \mathrm{C}\right)\end{array}$ & \multicolumn{3}{|c|}{ Temp. Média das paredes $\left({ }^{\circ} \mathrm{C}\right)$} & Temp. Teto $\left({ }^{\circ} \mathrm{C}\right)$ & \\
\hline 11:50 & 25,9 & 23 & 23,7 & \multicolumn{3}{|c|}{25,6} & 25 & \\
\hline 15:00 & 24,7 & 23,5 & 24,6 & \multicolumn{3}{|c|}{25,4} & 25,1 & \\
\hline
\end{tabular}

Tabela 170: Resultados coletados in loco no quarto do Apartamento G no mês de Abril de 2014.

\begin{tabular}{|c|c|c|c|c|c|c|c|c|}
\hline \multicolumn{2}{|l|}{ Apartamento G } & \multicolumn{4}{|c|}{ Dados coletados CONFORTÍMETRO Maio 2014 - QUARTO } & \multicolumn{3}{|c|}{ Céu claro } \\
\hline Intervalo & $\begin{array}{l}\text { Temperatura de } \\
\text { bulbo úmido }\left({ }^{\circ} \mathrm{C}\right)\end{array}$ & $\begin{array}{c}\text { Temperatura de } \\
\text { globo }\left({ }^{\circ} \mathrm{C}\right)\end{array}$ & $\begin{array}{c}\text { Temperatura do ar } \\
\left({ }^{\circ} \mathrm{C}\right)\end{array}$ & $\begin{array}{c}\text { Pressão Atmosférica } \\
\text { (atm) }\end{array}$ & $\begin{array}{l}\text { Umidade relativa do } \\
\operatorname{ar}(\%)\end{array}$ & $\begin{array}{l}\text { Velocidade do ar } \\
\qquad(\mathrm{m} / \mathrm{s})\end{array}$ & $\begin{array}{l}\text { Temperatura } \\
\text { radiante }\left({ }^{\circ} \mathrm{C}\right)\end{array}$ & $\begin{array}{l}\text { Temperatura } \\
\text { Operativa }\left({ }^{\circ} \mathrm{C}\right)\end{array}$ \\
\hline $11: 50$ as $12: 20$ & 22,8 & 26,7 & 26,6 & 1014,1 & 66,0 & 0,0 & 26,7 & 26,6 \\
\hline $12: 20$ as $12: 50$ & 22,8 & 26,9 & 26,9 & 1013,5 & 64,9 & 0,0 & 26,9 & 26,9 \\
\hline $12: 50$ as $13: 20$ & 23,1 & 27,2 & 27,1 & 1013,0 & 65,2 & 0,0 & 27,2 & 27,1 \\
\hline $13: 20$ as $13: 50$ & 23,3 & 27,4 & 27,2 & 1012,6 & 65,1 & 0,0 & 27,4 & 27,3 \\
\hline $13: 50$ as $14: 20$ & 23,2 & 27,5 & 27,4 & 1012,2 & 64,0 & 0,0 & 27,6 & 27,5 \\
\hline $14: 20$ as $14: 50$ & 23,4 & 27,7 & 27,5 & 1011,8 & 63,3 & 0,0 & 27,7 & 27,6 \\
\hline Desvio Padrão & 0,23 & 0,37 & 0,31 & 0,76 & 0,94 & 0,01 & 0,38 & 1,63 \\
\hline Média & 23,1 & 27,2 & 27,1 & 1012,8 & 64,8 & 0,0 & 27,2 & 27,2 \\
\hline \multicolumn{8}{|c|}{ Dados coletados Termômetro de fluxo de laser } & \\
\hline Horário/Quarto & $\begin{array}{l}\text { Temp. Externa do ar } \\
\left({ }^{\circ} \mathrm{C}\right)\end{array}$ & $\begin{array}{l}\text { Temp. Paredes } \\
\text { externas }\left({ }^{\circ} \mathrm{C}\right)\end{array}$ & $\begin{array}{c}\text { Temp. Paredes voltada } \\
\text { para a rua }\left({ }^{\circ} \mathrm{C}\right)\end{array}$ & \multicolumn{3}{|c|}{ Temp. Média das paredes $\left({ }^{\circ} \mathrm{C}\right)$} & Temp. Teto $\left({ }^{\circ} \mathrm{C}\right)$ & \\
\hline 11:50 & 27,3 & 29,3 & 25,1 & \multirow{2}{*}{\multicolumn{3}{|c|}{26,4}} & 26,6 & \\
\hline 15:00 & 33,3 & 35,5 & 28,3 & & & & 28,4 & \\
\hline
\end{tabular}

Tabela 171: Resultados coletados in loco no quarto do Apartamento G no mês de Maio de 2014.

\begin{tabular}{|c|c|c|c|c|c|c|c|c|}
\hline \multicolumn{2}{|l|}{ Apartamento G } & \multicolumn{4}{|c|}{ Dados coletados CONFORTÍM ETRO Junho 2014 - QUARTO } & \multicolumn{3}{|c|}{$\begin{array}{l}\text { Parcialmente } \\
\text { nublado }\end{array}$} \\
\hline Intervalo & $\begin{array}{l}\text { Temperatura de } \\
\text { bulbo úmido }\left({ }^{\circ} \mathrm{C}\right)\end{array}$ & $\begin{array}{c}\text { Temperatura de } \\
\text { globo }\left({ }^{\circ} \mathrm{C}\right)\end{array}$ & $\begin{array}{c}\text { Temperatura do ar } \\
\left({ }^{\circ} \mathrm{C}\right)\end{array}$ & $\begin{array}{c}\text { Pressão Atmosférica } \\
\text { (atm) }\end{array}$ & $\begin{array}{c}\text { Umidade relativa do } \\
\text { ar (\%) }\end{array}$ & $\begin{array}{l}\text { Velocidade do ar } \\
(\mathrm{m} / \mathrm{s})\end{array}$ & $\begin{array}{l}\text { Temperatura } \\
\text { radiante }\left({ }^{\circ} \mathrm{C}\right)\end{array}$ & $\begin{array}{l}\text { Temperatura } \\
\text { Operativa }\left({ }^{\circ} \mathrm{C}\right)\end{array}$ \\
\hline $11: 50$ as $12: 20$ & 21,1 & 24,7 & 24,4 & 1014,8 & 71,7 & 0,1 & 25,2 & 24,8 \\
\hline $12: 20$ as $12: 50$ & 21,2 & 24,6 & 24,4 & 1014,3 & 71,9 & 0,1 & 24,9 & 24,6 \\
\hline $12: 50$ as $13: 20$ & 21,3 & 24,6 & 24,3 & 1014,3 & 73,1 & 0,1 & 24,8 & 24,6 \\
\hline $13: 20$ as $13: 50$ & 21,3 & 24,5 & 24,3 & 1014,1 & 72,8 & 0,1 & 24,7 & 24,5 \\
\hline $13: 50$ as $14: 20$ & 21,3 & 24,6 & 24,3 & 1013,8 & 72,5 & 0,1 & 24,9 & 24,6 \\
\hline $14: 20$ as $14: 50$ & 21,2 & 24,5 & 24,2 & 1013,6 & 72,7 & 0,1 & 24,7 & 24,5 \\
\hline Desvio Padrão & 0,11 & 0,15 & 0,11 & 0,40 & 0,67 & 0,06 & 0,28 & 1,63 \\
\hline Média & 21,2 & 24,6 & 24,3 & 1014,2 & 72,5 & 0,1 & 24,9 & 24,6 \\
\hline \multicolumn{8}{|c|}{ Dados coletados Termômetro de fluxo de laser } & \\
\hline Horário/Quarto & $\begin{array}{l}\text { Temp. Externa do ar } \\
\left({ }^{\circ} \mathrm{C}\right)\end{array}$ & $\begin{array}{l}\text { Temp. Paredes } \\
\text { externas }\left({ }^{\circ} \mathrm{C}\right)\end{array}$ & $\begin{array}{c}\text { Temp. Paredes voltada } \\
\text { para a rua }\left({ }^{\circ} \mathrm{C}\right)\end{array}$ & \multicolumn{3}{|c|}{ Temp. Média das paredes $\left({ }^{\circ} \mathrm{C}\right)$} & Temp. Teto $\left({ }^{\circ} \mathrm{C}\right)$ & \\
\hline 11:50 & 24,8 & 25,8 & 23,9 & \multicolumn{3}{|c|}{24,6} & 24,2 & \\
\hline 15:00 & 26,1 & 23,8 & 24,3 & \multicolumn{3}{|c|}{24,7} & 25 & \\
\hline
\end{tabular}

Tabela 172: Resultados coletados in loco no quarto do Apartamento G no mês de Junho de 2014.

\begin{tabular}{|c|c|c|c|c|c|c|c|c|}
\hline \multicolumn{2}{|l|}{ Apartamento G } & \multicolumn{4}{|c|}{ Dados coletados CONFORTÍM ETRO Julho 2013 - SALA } & \multicolumn{3}{|c|}{ Céu claro } \\
\hline Intervalo & $\begin{array}{l}\text { Temperatura de } \\
\text { bulbo úmido }\left({ }^{\circ} \mathrm{C}\right)\end{array}$ & $\begin{array}{c}\text { Temperatura de } \\
\text { globo }\left({ }^{\circ} \mathrm{C}\right)\end{array}$ & $\begin{array}{c}\text { Temperatura do ar } \\
\left({ }^{\circ} \mathrm{C}\right)\end{array}$ & $\begin{array}{c}\text { Pressão Atmo sférica } \\
\text { (atm) }\end{array}$ & $\begin{array}{l}\text { Umidade relativa } \\
\text { do ar (\%) }\end{array}$ & $\begin{array}{l}\text { Velocidade do ar } \\
(\mathrm{m} / \mathrm{s})\end{array}$ & $\begin{array}{l}\text { Temperatura } \\
\text { radiante }\left({ }^{\circ} \mathrm{C}\right)\end{array}$ & $\begin{array}{l}\text { Temperatura } \\
\text { Operativa }\left({ }^{\circ} \mathrm{C}\right)\end{array}$ \\
\hline $15: 00$ as $15: 30$ & 19,25 & 23,56 & 23,5 & 1020,32 & 60,90 & 0,02 & 23,6 & 23,6 \\
\hline $15: 30$ as $16: 00$ & 19,34 & 23,62 & 23,6 & 1020,33 & 61,09 & 0,01 & 23,6 & 23,6 \\
\hline $15: 30$ as $16: 00$ & 19,27 & 23,45 & 23,4 & 1020,40 & 61,60 & 0,01 & 23,5 & 23,4 \\
\hline $16: 30$ as $17: 00$ & 19,37 & 23,62 & 23,4 & 1020,36 & 61,37 & 0,02 & 23,7 & 23,6 \\
\hline Desvio Padrão & 0,13 & 0,09 & 0,13 & 0,05 & 0,84 & 0,03 & 0,10 & 0,1 \\
\hline Média & 19,3 & 23,6 & 23,5 & 1020,4 & 61,2 & 0,0 & 23,6 & 23,5 \\
\hline \multicolumn{8}{|c|}{ Dados coletados Termômetro de fluxo de laser } & \\
\hline Horário/Quarto & Temp. Externa do ar & $\begin{array}{c}\text { Temp. Paredes } \\
\text { externas }\end{array}$ & $\begin{array}{c}\text { Temp.Paredes } \\
\text { voltada para a rua }\end{array}$ & \multicolumn{3}{|c|}{ Temp. M édia das paredes } & Temp. Teto & \\
\hline 15:00 & 22 & 22,1 & 24,7 & \multicolumn{3}{|c|}{23,7} & 25 & \\
\hline $17: 00$ & 21,8 & 22,2 & 24 & \multicolumn{3}{|c|}{23,7} & 24 & \\
\hline
\end{tabular}

Tabela 173: Resultados coletados in loco na sala do Apartamento G no mês de Julho de 2013. 


\begin{tabular}{|c|c|c|c|c|c|c|c|c|}
\hline \multicolumn{2}{|l|}{ Apartamento G } & \multicolumn{4}{|c|}{ Dados coletados CONFORTIM ETRO Agosto 2013 - SALA } & \multicolumn{3}{|c|}{ Céu claro } \\
\hline Intervalo & $\begin{array}{l}\text { Temperatura de } \\
\text { bulbo úmido }\left({ }^{\circ} \mathrm{C}\right)\end{array}$ & $\begin{array}{c}\text { Temperatura de } \\
\text { globo }\left({ }^{\circ} \mathrm{C}\right)\end{array}$ & $\begin{array}{c}\text { Temperatura do ar } \\
\left({ }^{\circ} \mathrm{C}\right)\end{array}$ & $\begin{array}{c}\text { Pressão Atmo sférica } \\
\text { (atm) }\end{array}$ & $\begin{array}{c}\text { Umidade relativa } \\
\text { do ar }(\%)\end{array}$ & $\begin{array}{l}\text { Velocidade do ar } \\
(\mathrm{m} / \mathrm{s})\end{array}$ & $\begin{array}{l}\text { Temperatura } \\
\text { radiante }\left({ }^{\circ} \mathrm{C}\right)\end{array}$ & $\begin{array}{c}\text { Temperatura } \\
\text { Operativa }\left({ }^{\circ} \mathrm{C}\right)\end{array}$ \\
\hline $15: 00$ as $15: 30$ & 16,5 & 19,9 & 19,6 & 1020,8 & 66,8 & 0,0 & 20,1 & 19,9 \\
\hline $15: 30$ as $16: 00$ & 16,7 & 20,2 & 19,8 & 1020,7 & 66,7 & 0,0 & 20,4 & 20,1 \\
\hline $15: 30$ as $16: 00$ & 16,5 & 19,4 & 19,2 & 1020,9 & 70,2 & 0,0 & 19,4 & 19,3 \\
\hline $16: 30$ as $17: 00$ & 16,5 & 19,2 & 19,0 & 1020,8 & 71,8 & 0,0 & 19,2 & 19,1 \\
\hline Desvio Padrão & 0,17 & 0,58 & 0,47 & 0,07 & 2,69 & 0,03 & 0,64 & 0,6 \\
\hline Média & 16,5 & 19,7 & 19,4 & 1020,8 & 68,8 & 0,0 & 19,8 & 19,6 \\
\hline \multicolumn{8}{|c|}{ Dados coletados Termômetro de fluxo de laser } & \\
\hline Horário/Quarto & Temp. Externa do ar & $\begin{array}{c}\text { Temp. Paredes } \\
\text { externas }\end{array}$ & $\begin{array}{c}\text { Temp. Paredes } \\
\text { voltada para a rua }\end{array}$ & \multicolumn{3}{|c|}{ Temp. M édia das paredes } & Temp. Teto & \\
\hline $15: 00$ & 20 & 20 & 20,3 & \multicolumn{3}{|c|}{20,3} & 20,5 & \\
\hline $17: 00$ & 19 & 19 & 20,4 & \multicolumn{3}{|c|}{20,4} & 20,3 & \\
\hline
\end{tabular}

Tabela 174: Resultados coletados in loco na sala do Apartamento G no mês de Agosto de 2013.

\begin{tabular}{|c|c|c|c|c|c|c|c|c|}
\hline \multicolumn{2}{|l|}{ Apartamento G } & \multicolumn{4}{|c|}{ Dados coletados CONFORTÍMETRO Setembro 2013 - SALA } & \multicolumn{3}{|c|}{ Chuva } \\
\hline Intervalo & $\begin{array}{l}\text { Temperatura de } \\
\text { bulbo úmido }\left({ }^{\circ} \mathrm{C}\right)\end{array}$ & $\begin{array}{c}\text { Temperatura de } \\
\text { globo }\left({ }^{\circ} \mathrm{C}\right)\end{array}$ & $\begin{array}{c}\text { Temperatura do ar } \\
\left({ }^{\circ} \mathrm{C}\right)\end{array}$ & $\begin{array}{c}\text { Pressão Atmosférica } \\
\text { (atm) }\end{array}$ & $\begin{array}{c}\text { Umidade relativa } \\
\text { do ar (\%) }\end{array}$ & $\begin{array}{c}\text { Velocidade do ar } \\
(\mathrm{m} / \mathrm{s})\end{array}$ & $\begin{array}{l}\text { Temperatura } \\
\text { radiante }\left({ }^{\circ} \mathrm{C}\right)\end{array}$ & $\begin{array}{l}\text { Temperatura } \\
\text { Operativa }\left({ }^{\circ} \mathrm{C}\right)\end{array}$ \\
\hline $15: 00$ as $15: 30$ & 20,4 & 22,7 & 22,5 & 1017,8 & 77,3 & 0,0 & 22,7 & 22,6 \\
\hline $15: 30$ as $16: 00$ & 20,4 & 22,8 & 22,6 & 1017,8 & 76,8 & 0,0 & 22,9 & 22,7 \\
\hline $15: 30$ as $16: 00$ & 20,4 & 22,8 & 22,5 & 1017,7 & 77,3 & 0,0 & 22,8 & 22,7 \\
\hline $16: 30$ as $17: 00$ & 20,5 & 22,8 & 22,6 & 1017,9 & 77,6 & 0,0 & 22,8 & 22,7 \\
\hline Desvio Padrão & 0,07 & 0,14 & 0,10 & 0,09 & 0,66 & 0,02 & 0,15 & 0,1 \\
\hline Média & 20,4 & 22,8 & 22,5 & 1017,8 & 77,2 & 0,0 & 22,8 & 22,7 \\
\hline \multicolumn{8}{|c|}{ Dados coletados Termômetro de fluxo de laser } & \\
\hline Horário/Quarto & Temp. Externa do ar & $\begin{array}{c}\text { Temp. Paredes } \\
\text { externas }\end{array}$ & $\begin{array}{c}\text { Temp. Paredes } \\
\text { voltada para a rua }\end{array}$ & \multicolumn{3}{|c|}{ Temp. M édia das paredes } & Temp. Teto & \\
\hline $15: 00$ & 21,1 & 19,7 & 21,6 & \multicolumn{3}{|c|}{22,7} & 21,4 & \\
\hline $17: 00$ & 20,4 & 19,3 & 21,6 & \multicolumn{3}{|c|}{22,7} & 22,4 & \\
\hline
\end{tabular}

Tabela 175: Resultados coletados in loco na sala do Apartamento G no mês de Setembro de 2013.

\begin{tabular}{|c|c|c|c|c|c|c|c|c|}
\hline \multicolumn{2}{|l|}{ Apartamento G } & \multicolumn{4}{|c|}{ Dados coletados CONFORTIM ETRO Outubro 2013 - SALA } & \multicolumn{3}{|c|}{ Céu limpo } \\
\hline Intervalo & $\begin{array}{l}\text { Temperatura de } \\
\text { bulbo úmido }\left({ }^{\circ} \mathrm{C}\right)\end{array}$ & $\begin{array}{c}\text { Temperatura de } \\
\text { globo }\left({ }^{\circ} \mathrm{C}\right)\end{array}$ & $\begin{array}{c}\text { Temperatura do ar } \\
\left({ }^{\circ} \mathrm{C}\right)\end{array}$ & $\begin{array}{c}\text { Pressão Atmo sférica } \\
\text { (atm) }\end{array}$ & $\begin{array}{c}\text { Umidade relativa } \\
\text { do } \operatorname{ar}(\%)\end{array}$ & $\begin{array}{c}\text { Velocidade do ar } \\
(\mathrm{m} / \mathrm{s})\end{array}$ & $\begin{array}{l}\text { Temperatura } \\
\text { radiante }\left({ }^{\circ} \mathrm{C}\right)\end{array}$ & $\begin{array}{l}\text { Temperatura } \\
\text { Operativa }\left({ }^{\circ} \mathrm{C}\right)\end{array}$ \\
\hline $16: 00$ as $16: 30$ & 19,8 & 26,2 & 25,7 & 1014,3 & 50,2 & 0,0 & 26,6 & 26,2 \\
\hline $16: 30$ as $17: 00$ & 20,0 & 26,8 & 26,1 & 1014,2 & 49,9 & 0,0 & 27,3 & 26,7 \\
\hline $17: 00$ as $17: 30$ & 20,0 & 26,5 & 26,0 & 1014,4 & 49,7 & 0,0 & 26,9 & 26,5 \\
\hline $17: 30$ as $18: 00$ & 19,9 & 26,5 & 25,9 & 1014,5 & 49,3 & 0,0 & 26,8 & 26,4 \\
\hline Desvio Padrão & 0,18 & 0,22 & 0,16 & 0,09 & 0,59 & 0,04 & 0,37 & 0,3 \\
\hline Média & 19,9 & 26,5 & 25,9 & 1014,3 & 49,8 & 0,0 & 26,9 & 26,4 \\
\hline \multicolumn{8}{|c|}{ Dados coletados Termômetro de fluxo de laser } & \\
\hline Horário/Quarto & Temp. Externa do ar & $\begin{array}{c}\text { Temp. Paredes } \\
\text { externas }\end{array}$ & $\begin{array}{c}\text { Temp. Paredes } \\
\text { voltada para a rua }\end{array}$ & \multicolumn{3}{|c|}{ Temp. Média das paredes } & Temp. Teto & \\
\hline $16: 00$ & 26,2 & 30,6 & 25,3 & \multicolumn{3}{|c|}{25,7} & 27,2 & \\
\hline $18: 00$ & 24,3 & 28,8 & 26,9 & \multicolumn{3}{|c|}{28,4} & 29,1 & \\
\hline
\end{tabular}

Tabela 176: Resultados coletados in loco na sala do Apartamento G no mês de Outubro de 2013.

\begin{tabular}{|c|c|c|c|c|c|c|c|c|}
\hline \multicolumn{2}{|l|}{ Apartamento G } & \multicolumn{4}{|c|}{ Dados coletados CONFORTIM ETRO Novembro 2013 - SALA } & \multicolumn{3}{|c|}{ Nublado } \\
\hline Intervalo & $\begin{array}{l}\text { Temperatura de } \\
\text { bulbo úmido }\left({ }^{\circ} \mathrm{C}\right)\end{array}$ & $\begin{array}{c}\text { Temperatura de } \\
\text { globo }\left({ }^{\circ} \mathrm{C}\right)\end{array}$ & $\begin{array}{c}\text { Temperatura do ar } \\
\left({ }^{\circ} \mathrm{C}\right)\end{array}$ & $\begin{array}{c}\text { Pressão Atmo sférica } \\
\text { (atm) }\end{array}$ & $\begin{array}{c}\text { Umidade relativa } \\
\text { do ar (\%) }\end{array}$ & $\begin{array}{l}\text { Velocidade do ar } \\
(\mathrm{m} / \mathrm{s})\end{array}$ & $\begin{array}{l}\text { Temperatura } \\
\text { radiante }\left({ }^{\circ} \mathrm{C}\right)\end{array}$ & $\begin{array}{l}\text { Temperatura } \\
\text { Operativa }\left({ }^{\circ} \mathrm{C}\right)\end{array}$ \\
\hline $16: 00$ as $16: 30$ & 22,6 & 24,8 & 24,7 & 1007,2 & \begin{tabular}{|l|}
77,7 \\
\end{tabular} & 0,0 & 24,9 & 24,8 \\
\hline $16: 30$ as $17: 00$ & 22,6 & 24,8 & 24,7 & 1007,0 & 77,2 & 0,0 & 24,8 & 24,8 \\
\hline $17: 00$ as $17: 30$ & 22,3 & 24,7 & 24,6 & 1006,7 & 77,3 & 0,1 & 24,8 & 24,7 \\
\hline $17: 30$ as $18: 00$ & 22,5 & 24,7 & 24,6 & 1006,4 & 77,8 & 0,0 & 24,8 & 24,7 \\
\hline Desvio Padrão & 0,18 & 0,10 & 0,11 & 0,25 & 0,44 & 0,12 & 0,15 & 0,1 \\
\hline Média & 22,5 & 24,7 & 24,6 & 1006,7 & 77,5 & 0,0 & 24,8 & 24,7 \\
\hline \multicolumn{8}{|c|}{ Dados coletados Termômetro de fluxo de laser } & \\
\hline Horário/Quarto & Temp. Externa do ar & $\begin{array}{c}\text { Temp. Paredes } \\
\text { externas }\end{array}$ & $\begin{array}{c}\text { Temp.Paredes } \\
\text { voltada para a rua }\end{array}$ & \multicolumn{3}{|c|}{ Temp. Média das paredes } & Temp. Teto & \\
\hline $16: 00$ & 24,7 & 24,6 & 24,8 & \multicolumn{3}{|c|}{23,5} & 23,6 & \\
\hline 18:00 & 24 & 23,8 & 24,6 & \multicolumn{3}{|c|}{25,1} & 25,2 & \\
\hline
\end{tabular}

Tabela 177: Resultados coletados in loco na sala do Apartamento G no mês de Novembro de 2013.

\begin{tabular}{|c|c|c|c|c|c|c|c|c|}
\hline \multicolumn{2}{|l|}{ Apartamento G } & \multicolumn{4}{|c|}{ Dados coletados CONFORTÍMETRO Dezembro 2013 - SALA } & \multicolumn{3}{|c|}{ Céu limpo } \\
\hline Intervalo & $\begin{array}{l}\text { Temperatura de } \\
\text { bulbo úmido }\left({ }^{\circ} \mathrm{C}\right)\end{array}$ & $\begin{array}{c}\text { Temperatura de } \\
\text { globo }\left({ }^{\circ} \mathrm{C}\right)\end{array}$ & $\begin{array}{c}\text { Temperatura do ar } \\
\left({ }^{\circ} \mathrm{C}\right)\end{array}$ & $\begin{array}{c}\text { Pressão Atmo sférica } \\
\text { (atm) }\end{array}$ & $\begin{array}{c}\text { Umidade relativa } \\
\text { do ar (\%) }\end{array}$ & $\begin{array}{l}\text { Velocidade do ar } \\
(\mathrm{m} / \mathrm{s})\end{array}$ & $\begin{array}{l}\text { Temperatura } \\
\text { radiante }\left({ }^{\circ} \mathrm{C}\right)\end{array}$ & $\begin{array}{c}\text { Temperatura } \\
\text { Operativa }\left({ }^{\circ} \mathrm{C}\right)\end{array}$ \\
\hline $16: 00$ as $16: 30$ & 26,1 & 31,3 & 30,5 & 1005,7 & 63,5 & 0,0 & 31,6 & 31,1 \\
\hline $16: 30$ as $17: 00$ & 25,7 & 31,1 & 30,3 & 1005,8 & 63,9 & 0,0 & 31,4 & 30,8 \\
\hline $17: 00$ as $17: 30$ & 25,6 & 31,0 & 30,3 & 1005,7 & 62,8 & 0,0 & 31,3 & 30,8 \\
\hline $17: 30$ as $18: 00$ & 26,0 & 31,1 & 30,5 & 1005,7 & 63,8 & 0,0 & 31,4 & 30,9 \\
\hline Desvio Padrão & 0,29 & 0,17 & 0,16 & 0,06 & 0,63 & 0,02 & 0,23 & 0,2 \\
\hline Média & 25,9 & 31,1 & 30,4 & 1005,7 & 63,5 & 0,0 & 31,4 & 30,9 \\
\hline \multicolumn{8}{|c|}{ Dados coletados Termômetro de fluxo de laser } & \\
\hline Horário/Quarto & Temp. Externa do ar & $\begin{array}{c}\text { Temp. Paredes } \\
\text { externas }\end{array}$ & $\begin{array}{c}\text { Temp.Paredes } \\
\text { voltada para a rua }\end{array}$ & \multicolumn{3}{|c|}{ Temp. M édia das paredes } & Temp. Teto & \\
\hline $16: 00$ & 36,6 & 36,1 & 27,8 & \multicolumn{3}{|c|}{27,5} & 31,9 & \\
\hline $18: 00$ & 33,3 & 37 & 30,4 & \multicolumn{3}{|c|}{30} & 34,1 & \\
\hline
\end{tabular}

Tabela 178: Resultados coletados in loco na sala do Apartamento G no mês de Dezembro de 2013. 


\begin{tabular}{|c|c|c|c|c|c|c|c|c|}
\hline \multicolumn{2}{|l|}{ Apartamento G } & \multicolumn{4}{|c|}{ Dados coletados CONFORTIMMETRO Janeiro 2014 - SALA } & \multicolumn{3}{|c|}{ Céu limpo } \\
\hline Intervalo & $\begin{array}{l}\text { Temperatura de } \\
\text { bulbo úmido }\left({ }^{\circ} \mathrm{C}\right)\end{array}$ & $\begin{array}{c}\text { Temperatura de } \\
\text { globo }\left({ }^{\circ} \mathrm{C}\right)\end{array}$ & $\begin{array}{c}\text { Temperatura do ar } \\
\left({ }^{\circ} \mathrm{C}\right)\end{array}$ & $\begin{array}{c}\text { Pressão Atmo sférica } \\
\text { (atm) }\end{array}$ & $\begin{array}{c}\text { Umidade relativa } \\
\text { do ar }(\%)\end{array}$ & $\begin{array}{l}\text { Velocidade do ar } \\
(\mathrm{m} / \mathrm{s})\end{array}$ & $\begin{array}{l}\text { Temperatura } \\
\text { radiante }\left({ }^{\circ} \mathrm{C}\right)\end{array}$ & $\begin{array}{c}\text { Temperatura } \\
\text { Operativa }\left({ }^{\circ} \mathrm{C}\right)\end{array}$ \\
\hline $16: 00$ as $16: 30$ & 27,2 & 34,5 & 34,2 & 1010,4 & 54,1 & 0,1 & 34,9 & 34,6 \\
\hline $16: 30$ as $17: 00$ & 27,7 & 34,7 & 34,2 & 1010,4 & 55,2 & 0,0 & 35,0 & 34,6 \\
\hline $17: 00$ as $17: 30$ & 27,7 & 34,9 & 34,3 & 1010,1 & 54,1 & 0,0 & 35,3 & 34,8 \\
\hline $17: 30$ as $18: 00$ & 27,7 & 34,9 & 34,2 & 1009,9 & 54,7 & 0,0 & 35,4 & 34,8 \\
\hline Desvio Padrão & 0,15 & 0,19 & 0,17 & 0,31 & 0,74 & 0,09 & 0,25 & 0,2 \\
\hline Média & 27,6 & 34,8 & 34,2 & 1010,3 & 54,8 & 0,1 & 35,2 & 34,7 \\
\hline \multicolumn{8}{|c|}{ Dados coletados Termômetro de fluxo de laser } & \\
\hline Horário/Quarto & Temp. Externa do ar & $\begin{array}{c}\text { Temp. Paredes } \\
\text { externas }\end{array}$ & $\begin{array}{c}\text { Temp. Paredes } \\
\text { voltada para a rua }\end{array}$ & \multicolumn{3}{|c|}{ Temp. M édia das paredes } & Temp. Teto & \\
\hline $16: 00$ & 38 & 40 & 34,1 & \multicolumn{3}{|c|}{34,4} & 39,4 & \\
\hline $18: 00$ & 36,1 & 41,8 & 36 & \multicolumn{3}{|c|}{34,5} & 39,9 & \\
\hline
\end{tabular}

Tabela 179: Resultados coletados in loco na sala do Apartamento G no mês de Janeiro de 2014.

\begin{tabular}{|c|c|c|c|c|c|c|c|c|}
\hline \multicolumn{2}{|l|}{ Apartamento G } & \multicolumn{4}{|c|}{ Dados coletados CONFORTÍMETRO Fevereiro 2014 - SALA } & \multicolumn{3}{|c|}{ Nublado } \\
\hline Intervalo & $\begin{array}{l}\text { Temperatura de } \\
\text { bulbo úmido }\left({ }^{\circ} \mathrm{C}\right)\end{array}$ & $\begin{array}{c}\text { Temperatura de } \\
\text { globo }\left({ }^{\circ} \mathrm{C}\right)\end{array}$ & $\begin{array}{c}\text { Temperatura do ar } \\
\left({ }^{\circ} \mathrm{C}\right)\end{array}$ & $\begin{array}{c}\text { Pressão Atmo sférica } \\
\text { (atm) }\end{array}$ & $\begin{array}{c}\text { Umidade relativa } \\
\text { do ar (\%) }\end{array}$ & $\begin{array}{l}\text { Velocidade do ar } \\
(\mathrm{m} / \mathrm{s})\end{array}$ & $\begin{array}{l}\text { Temperatura } \\
\text { radiante }\left({ }^{\circ} \mathrm{C}\right)\end{array}$ & $\begin{array}{l}\text { Temperatura } \\
\text { Operativa }\left({ }^{\circ} \mathrm{C}\right)\end{array}$ \\
\hline $15: 00$ as $15: 30$ & 24,9 & 30,8 & 30,5 & 1008,6 & 57,8 & 0,0 & 30,8 & 30,7 \\
\hline $15: 30$ as $16: 00$ & 25,0 & 30,7 & 30,3 & 1008,4 & 58,8 & 0,0 & 30,8 & 30,6 \\
\hline $15: 30$ as $16: 00$ & 25,7 & 31,9 & 30,7 & 1008,2 & 59,0 & 0,0 & 32,3 & 31,5 \\
\hline $16: 30$ as $17: 00$ & 26,0 & 31,1 & 30,5 & 1008,1 & 62,1 & 0,0 & 31,3 & 30,9 \\
\hline Desvio Padrão & 0,49 & 0,52 & 0,18 & 0,23 & 1,94 & 0,02 & 0,69 & 0,4 \\
\hline Média & 25,5 & 31,1 & 30,5 & 1008,3 & 59,6 & 0,0 & 31,3 & 30,9 \\
\hline \multicolumn{8}{|c|}{ Dados coletados Termômetro de fluxo de laser } & \\
\hline Horário/Quarto & Temp. Externa do ar & $\begin{array}{c}\text { Temp. Paredes } \\
\text { externas }\end{array}$ & $\begin{array}{c}\text { Temp.Paredes } \\
\text { voltada para a rua }\end{array}$ & \multicolumn{3}{|c|}{ Temp. M édia das paredes } & Temp. Teto & \\
\hline 15:00 & 34,3 & 32,6 & 29,6 & \multicolumn{3}{|c|}{30,3} & 33,3 & \\
\hline $17: 00$ & 33 & 31 & 30 & \multicolumn{3}{|c|}{30,7} & 33 & \\
\hline
\end{tabular}

Tabela 180: Resultados coletados in loco na sala do Apartamento G no mês de Fevereiro de 2014.

\begin{tabular}{|c|c|c|c|c|c|c|c|c|}
\hline \multicolumn{2}{|l|}{ Apartamento G } & \multicolumn{4}{|c|}{ Dados coletados CONFORTÍMETRO MarçO 2014 - SALA } & \multicolumn{3}{|c|}{ Parcialmente claro } \\
\hline Intervalo & $\begin{array}{l}\text { Temperatura de } \\
\text { bulbo úmido }\left({ }^{\circ} \mathrm{C}\right)\end{array}$ & $\begin{array}{c}\text { Temperatura de } \\
\text { globo }\left({ }^{\circ} \mathrm{C}\right)\end{array}$ & $\begin{array}{c}\text { Temperatura do ar } \\
\left({ }^{\circ} \mathrm{C}\right)\end{array}$ & $\begin{array}{c}\text { Pressão Atmo sférica } \\
\text { (atm) }\end{array}$ & $\begin{array}{c}\text { Umidade relativa } \\
\text { do ar (\%) }\end{array}$ & $\begin{array}{l}\text { Velocidade do ar } \\
(\mathrm{m} / \mathrm{s})\end{array}$ & $\begin{array}{l}\text { Temperatura } \\
\text { radiante }\left({ }^{\circ} \mathrm{C}\right)\end{array}$ & $\begin{array}{c}\text { Temperatura } \\
\text { Operativa }\left({ }^{\circ} \mathrm{C}\right)\end{array}$ \\
\hline $15: 00$ as $15: 30$ & 25,2 & 30,2 & 30 & 1009,3 & 64,3 & 0,0 & 30,9 & 30,5 \\
\hline $15: 30$ as $16: 00$ & 25,3 & 30,5 & 30,2 & 1009,1 & 63,7 & 0,0 & 30,9 & 30,6 \\
\hline $15: 30$ as $16: 00$ & 25,4 & 30,6 & 30,3 & 1009,0 & 63,7 & 0,0 & 31,0 & 30,7 \\
\hline $16: 30$ as $17: 00$ & 25,3 & 30,6 & 30,3 & 1008,8 & 63,3 & 0,0 & 31,0 & 30,7 \\
\hline Desvio Padrão & 0,06 & 0,09 & 0,08 & 0,14 & 0,34 & 0,06 & 0,16 & 0,1 \\
\hline Média & 25,3 & 30,6 & 30,3 & 1009,0 & 63,5 & 0,0 & 31,0 & 30,6 \\
\hline \multicolumn{8}{|c|}{ Dados coletados Termômetro de fluxo de laser } & \\
\hline Horário/Quarto & Temp. Externa do ar & $\begin{array}{c}\text { Temp. Paredes } \\
\text { externas }\end{array}$ & $\begin{array}{c}\text { Temp.Paredes } \\
\text { voltada para a rua }\end{array}$ & \multicolumn{3}{|c|}{ Temp. Média das paredes } & Temp. Teto & \\
\hline 15:00 & 31,3 & 38,4 & 30,1 & \multicolumn{3}{|c|}{29,8} & 30,9 & \\
\hline $17: 00$ & 29 & 33,3 & 32,9 & \multicolumn{3}{|c|}{30,7} & 32,8 & \\
\hline
\end{tabular}

Tabela 181: Resultados coletados in loco na sala do Apartamento G no mês de Março de 2014.

\begin{tabular}{|c|c|c|c|c|c|c|c|c|}
\hline \multicolumn{2}{|l|}{ Apartamento G } & \multicolumn{4}{|c|}{ Dados coletados CONFORTÍM ETRO Abril 2014 - SALA } & \multicolumn{3}{|c|}{ Chuva } \\
\hline Intervalo & $\begin{array}{l}\text { Temperatura de } \\
\text { bulbo úmido }\left({ }^{\circ} \mathrm{C}\right)\end{array}$ & $\begin{array}{l}\text { Temperatura de } \\
\text { globo }\left({ }^{\circ} \mathrm{C}\right)\end{array}$ & $\begin{array}{c}\text { Temperatura do ar } \\
\left({ }^{\circ} \mathrm{C}\right)\end{array}$ & $\begin{array}{c}\text { Pressão Atmo sférica } \\
\text { (atm) }\end{array}$ & $\begin{array}{c}\text { Umidade relativa } \\
\text { do ar (\%) }\end{array}$ & $\begin{array}{l}\text { Velocidade do ar } \\
\qquad(\mathrm{m} / \mathrm{s})\end{array}$ & $\begin{array}{l}\text { Temperatura } \\
\text { radiante }\left({ }^{\circ} \mathrm{C}\right)\end{array}$ & $\begin{array}{l}\text { Temperatura } \\
\text { Operativa }\left({ }^{\circ} \mathrm{C}\right)\end{array}$ \\
\hline $15: 00$ as $15: 30$ & 22,9 & 25,4 & 25,3 & 1013,0 & 75,9 & 0,0 & 25,4 & 25,3 \\
\hline $15: 30$ as $16: 00$ & 22,8 & 25,5 & 25,4 & 1013,1 & 74,7 & 0,0 & 25,5 & 25,5 \\
\hline $15: 30$ as $16: 00$ & 22,9 & 25,5 & 25,3 & 1013,2 & 75,2 & 0,0 & 25,5 & 25,4 \\
\hline $16: 30$ as $17: 00$ & 22,9 & 25,3 & 25,1 & 1013,3 & 76,3 & 0,0 & 25,4 & 25,3 \\
\hline Desvio Padrão & 0,06 & 0,13 & 0,12 & 0,12 & 0,72 & 0,03 & 0,14 & 0,1 \\
\hline Média & 22,9 & 25,4 & 25,3 & \begin{tabular}{|r|}
1013,2 \\
\end{tabular} & 75,5 & 0,0 & 25,5 & 25,4 \\
\hline \multicolumn{8}{|c|}{ Dados coletados Termômetro de fluxo de laser } & \\
\hline Horário/Quarto & Temp. Externa do ar & $\begin{array}{c}\text { Temp. Paredes } \\
\text { externas }\end{array}$ & $\begin{array}{c}\text { Temp.Paredes } \\
\text { voltada para a rua }\end{array}$ & \multicolumn{3}{|c|}{ Temp. Média das paredes } & Temp. Teto & \\
\hline 15:00 & 24,7 & 23,4 & 24 & \multicolumn{3}{|c|}{25,2} & 25 & \\
\hline $17: 00$ & 24,6 & 25 & 24,7 & \multicolumn{3}{|c|}{25,8} & 25,8 & \\
\hline
\end{tabular}

Tabela 182: Resultados coletados in loco na sala do Apartamento G no mês de Abril de 2014.

\begin{tabular}{|c|c|c|c|c|c|c|c|c|}
\hline \multicolumn{2}{|l|}{ Apartamento G } & \multicolumn{4}{|c|}{ Dados coletados CONFORTÍM ETRO M aio 2014 - SALA } & \multicolumn{3}{|c|}{ Céu claro } \\
\hline Intervalo & $\begin{array}{l}\text { Temperatura de } \\
\text { bulbo úmido }\left({ }^{\circ} \mathrm{C}\right)\end{array}$ & $\begin{array}{c}\text { Temperatura de } \\
\text { globo }\left({ }^{\circ} \mathrm{C}\right)\end{array}$ & $\begin{array}{c}\text { Temperatura do ar } \\
\left({ }^{\circ} \mathrm{C}\right)\end{array}$ & $\begin{array}{c}\text { Pressão Atmo sférica } \\
\text { (atm) }\end{array}$ & $\begin{array}{l}\text { Umidade relativa } \\
\text { do ar (\%) }\end{array}$ & $\begin{array}{l}\text { Velocidade do ar } \\
\qquad(\mathrm{m} / \mathrm{s})\end{array}$ & $\begin{array}{l}\text { Temperatura } \\
\text { radiante }\left({ }^{\circ} \mathrm{C}\right)\end{array}$ & $\begin{array}{l}\text { Temperatura } \\
\text { Operativa }\left({ }^{\circ} \mathrm{C}\right)\end{array}$ \\
\hline $15: 00$ as $15: 30$ & 23,7 & 28,7 & 28,4 & 1011,6 & 61,2 & 0,0 & 28,9 & 28,6 \\
\hline $15: 30$ as $16: 00$ & 23,6 & 28,7 & 28,3 & 1011,6 & 60,7 & 0,0 & 28,8 & 28,6 \\
\hline $15: 30$ as $16: 00$ & 23,6 & 28,6 & 28,2 & 1011,9 & 61,0 & 0,0 & 28,7 & 28,4 \\
\hline $16: 30$ as $17: 00$ & 23,9 & 28,4 & 28,1 & 1012,1 & 63,7 & 0,0 & 28,6 & 28,3 \\
\hline Desvio Padrão & 0,15 & 0,18 & 0,16 & 0,22 & 1,31 & 0,02 & 0,22 & 0,2 \\
\hline Média & 23,7 & 28,6 & 28,2 & 1011,8 & 61,7 & 0,0 & 28,7 & 28,5 \\
\hline \multicolumn{8}{|c|}{ Dados coletados Termômetro de fluxo de laser } & \\
\hline Horário/Quarto & Temp. Externa do ar & $\begin{array}{c}\text { Temp. Paredes } \\
\text { externas }\end{array}$ & $\begin{array}{c}\text { Temp.Paredes } \\
\text { voltada para a rua }\end{array}$ & \multicolumn{3}{|c|}{ Temp. Média das paredes } & Temp. Teto & \\
\hline 15:00 & 33,3 & 37,8 & 30,4 & \multicolumn{3}{|c|}{27,1} & 29,3 & \\
\hline 17:00 & 27,8 & 30,4 & 29,7 & \multicolumn{3}{|c|}{29,2} & 31,7 & \\
\hline
\end{tabular}

Tabela 183: Resultados coletados in loco na sala do Apartamento G no mês de Maio de 2014. 


\begin{tabular}{|c|c|c|c|c|c|c|c|c|}
\hline \multicolumn{2}{|l|}{ Apartamento G } & \multicolumn{4}{|c|}{ Dados coletados CONFORTIMMETRO Junho 2014 - SALA } & \multicolumn{3}{|c|}{ Nublado } \\
\hline Intervalo & $\begin{array}{l}\text { Temperatura de } \\
\text { bulbo úmido }\left({ }^{\circ} \mathrm{C}\right)\end{array}$ & $\begin{array}{c}\text { Temperatura de } \\
\text { globo }\left({ }^{\circ} \mathrm{C}\right)\end{array}$ & $\begin{array}{c}\text { Temperatura do ar } \\
\left({ }^{\circ} \mathrm{C}\right)\end{array}$ & $\begin{array}{c}\text { Pressão Atmo sférica } \\
\text { (atm) }\end{array}$ & $\begin{array}{c}\text { Umidade relativa } \\
\text { do ar }(\%)\end{array}$ & $\begin{array}{l}\text { Velocidade do ar } \\
(\mathrm{m} / \mathrm{s})\end{array}$ & $\begin{array}{l}\text { Temperatura } \\
\text { radiante }\left({ }^{\circ} \mathrm{C}\right)\end{array}$ & $\begin{array}{c}\text { Temperatura } \\
\text { Operativa }\left({ }^{\circ} \mathrm{C}\right)\end{array}$ \\
\hline $15: 00$ as $15: 30$ & 21,7 & 24,8 & 24,4 & 1013,8 & 72,8 & 0,0 & 25,0 & 24,7 \\
\hline $15: 30$ as $16: 00$ & 21,7 & 24,8 & 24,4 & 1013,9 & 73,1 & 0,0 & 24,9 & 24,7 \\
\hline $15: 30$ as $16: 00$ & 21,7 & 24,7 & 24,4 & 1014,0 & 72,8 & 0,0 & 24,9 & 24,6 \\
\hline $16: 30$ as $17: 00$ & 21,6 & 24,8 & 24,4 & 1014,1 & 71,4 & 0,0 & 25,0 & 24,7 \\
\hline Desvio Padrão & 0,09 & 0,09 & 0,07 & 0,17 & 0,73 & 0,04 & 0,16 & 0,1 \\
\hline Média & 21,7 & 24,8 & 24,4 & 1014,0 & 72,5 & 0,0 & 25,0 & 24,7 \\
\hline \multicolumn{8}{|c|}{ Dados coletados Termômetro de fluxo de laser } & \\
\hline Horário/Quarto & Temp. Externa do ar & $\begin{array}{c}\text { Temp. Paredes } \\
\text { externas }\end{array}$ & $\begin{array}{c}\text { Temp. Paredes } \\
\text { voltada para a rua }\end{array}$ & \multicolumn{3}{|c|}{ Temp. M édia das paredes } & Temp. Teto & \\
\hline $15: 00$ & 26,1 & 23,9 & 24,4 & \multicolumn{3}{|c|}{25,1} & 25,8 & \\
\hline $17: 00$ & 26,4 & 23,2 & 24,3 & \multicolumn{3}{|c|}{25,2} & 25,6 & \\
\hline
\end{tabular}

Tabela 184: Resultados coletados in loco na sala do Apartamento G no mês de Junho de 2014.

\begin{tabular}{|c|c|c|c|c|c|c|c|c|}
\hline \multicolumn{2}{|l|}{ Apartamento $\mathrm{H}$} & \multicolumn{4}{|c|}{ Dados coletados CONFORTIM ETRO Julho 2013 - QUARTO } & \multicolumn{3}{|c|}{ Nublado } \\
\hline Intervalo & $\begin{array}{l}\text { Temperatura de } \\
\text { bulbo úmido }\left({ }^{\circ} \mathrm{C}\right)\end{array}$ & $\begin{array}{c}\text { Temperatura de } \\
\text { globo }\left({ }^{\circ} \mathrm{C}\right)\end{array}$ & $\begin{array}{c}\text { Temperatura do ar } \\
\left({ }^{\circ} \mathrm{C}\right)\end{array}$ & $\begin{array}{c}\text { Pressão Atmosférica } \\
\text { (atm) }\end{array}$ & $\begin{array}{c}\text { Umidade relativa do } \\
\text { ar (\%) }\end{array}$ & $\begin{array}{l}\text { Velocidade do } \\
\quad \operatorname{ar}(\mathrm{m} / \mathrm{s})\end{array}$ & $\begin{array}{l}\text { Temperatura } \\
\text { radiante }\left({ }^{\circ} \mathrm{C}\right)\end{array}$ & $\begin{array}{l}\text { Temperatura } \\
\text { Operativa }\left({ }^{\circ} \mathrm{C}\right)\end{array}$ \\
\hline $11: 50$ as $12: 20$ & 14,4 & 18,9 & 18,2 & 1023,8 & 57,6 & 0,0 & 19,4 & 18,8 \\
\hline $12: 20$ as $12: 50$ & 14,0 & 18,4 & 17,9 & 1023,4 & 56,4 & 0,0 & 18,8 & 18,3 \\
\hline $12: 50$ as $13: 20$ & 13,8 & 18,1 & 17,5 & 1023,1 & 57,9 & 0,0 & 18,5 & 18,0 \\
\hline $13: 20$ as $13: 50$ & 14,6 & 18,5 & 18,2 & 1022,8 & 57,1 & 0,0 & 18,7 & 18,4 \\
\hline $13: 50$ as $14: 20$ & 14,8 & 18,7 & 18,4 & 1022,7 & 57,4 & 0,0 & 18,8 & 18,6 \\
\hline $14: 20$ as $14: 50$ & 14,9 & 18,8 & 18,5 & 1022,7 & 57,6 & 0,0 & 18,8 & 18,7 \\
\hline Desvio Padrão & 0,48 & 0,33 & 0,41 & 0,44 & 0,61 & 0,05 & 0,40 & 1,63 \\
\hline Média & 14,4 & 18,6 & 18,1 & 1023,1 & 57,3 & 0,0 & 18,8 & 18,5 \\
\hline \multicolumn{9}{|c|}{ Dados coletados Termômetro de fluxo de laser } \\
\hline Horário/Quarto & $\begin{array}{l}\text { Temp. Externa do ar } \\
\left({ }^{\circ} \mathrm{C}\right)\end{array}$ & $\begin{array}{c}\text { Temp. Paredes } \\
\text { externas }\left({ }^{\circ} \mathrm{C}\right)\end{array}$ & $\begin{array}{c}\text { Temp.Paredes voltada } \\
\text { para a rua }\left({ }^{\circ} \mathrm{C}\right)\end{array}$ & \multicolumn{3}{|c|}{ Temp. Média das paredes $\left({ }^{\circ} \mathrm{C}\right)$} & Temp. Teto $\left({ }^{\circ} \mathrm{C}\right)$ & \\
\hline $11: 50$ & 16 & 17 & 17 & \multicolumn{3}{|c|}{16,6} & 17 & \\
\hline $15: 00$ & 16,5 & 17,4 & 17 & \multicolumn{3}{|c|}{16,6} & 17,1 & \\
\hline
\end{tabular}

Tabela 185: Resultados coletados in loco no quarto do Apartamento H no mês de Julho de 2013.

\begin{tabular}{|c|c|c|c|c|c|c|c|c|}
\hline \multicolumn{2}{|l|}{ Apartamento $\mathrm{H}$} & \multicolumn{4}{|c|}{ Dados coletados CONFORTIMETRO Agosto 2013 - QUARTO } & \multicolumn{3}{|c|}{ Céu claro } \\
\hline Intervalo & $\begin{array}{l}\text { Temperatura de } \\
\text { bulbo úmido }\left({ }^{\circ} \mathrm{C}\right)\end{array}$ & $\begin{array}{c}\text { Temperatura de } \\
\text { globo }\left({ }^{\circ} \mathrm{C}\right)\end{array}$ & $\begin{array}{c}\text { Temperatura do ar } \\
\left({ }^{\circ} \mathrm{C}\right)\end{array}$ & $\begin{array}{c}\text { Pressão Atmosférica } \\
\text { (atm) }\end{array}$ & $\begin{array}{c}\text { Umidade relativa do } \\
\text { ar (\%) }\end{array}$ & $\begin{array}{l}\text { Velocidade do } \\
\operatorname{ar}(\mathrm{m} / \mathrm{s})\end{array}$ & $\begin{array}{l}\text { Temperatura } \\
\text { radiante }\left({ }^{\circ} \mathrm{C}\right)\end{array}$ & $\begin{array}{l}\text { Temperatura } \\
\text { Operativa }\left({ }^{\circ} \mathrm{C}\right)\end{array}$ \\
\hline $11: 50$ as $12: 20$ & 18,8 & 21,7 & 21,4 & 1021,9 & 72,8 & 0,0 & 21,8 & 21,6 \\
\hline $12: 20$ as $12: 50$ & 18,7 & 21,4 & 21,2 & 1021,6 & 73,7 & 0,0 & 21,5 & 21,4 \\
\hline $12: 50$ as $13: 20$ & 19,0 & 21,6 & 21,4 & 1021,1 & 73,9 & 0,0 & 21,6 & 21,5 \\
\hline $13: 20$ as $13: 50$ & 19,1 & 21,7 & 21,6 & 1020,8 & 73,0 & 0,0 & 21,7 & 21,6 \\
\hline $13: 50$ as $14: 20$ & 19,2 & 21,9 & 21,8 & 1020,3 & 71,0 & 0,0 & 22,0 & 21,9 \\
\hline $14: 20$ as $14: 50$ & 19,2 & 22,3 & 22,2 & 1019,7 & 69,1 & 0,0 & 22,3 & 22,2 \\
\hline Desvio Padrão & 0,20 & 0,30 & 0,32 & 0,76 & 1,74 & 0,04 & 0,30 & 1,63 \\
\hline Média & 19,0 & 21,8 & 21,6 & 1020,9 & 72,3 & 0,0 & 21,8 & 21,7 \\
\hline \multicolumn{8}{|c|}{ Dados coletados Termômetro de fluxo de laser } & \\
\hline Horário/Quarto & $\begin{array}{l}\text { Temp. Externa do ar } \\
\left({ }^{\circ} \mathrm{C}\right)\end{array}$ & $\begin{array}{c}\text { Temp. Paredes } \\
\text { externas }\left({ }^{\circ} \mathrm{C}\right)\end{array}$ & $\begin{array}{c}\text { Temp.Paredes voltada } \\
\text { para a rua }\left({ }^{\circ} \mathrm{C}\right)\end{array}$ & \multicolumn{3}{|c|}{ Temp. Média das paredes $\left({ }^{\circ} \mathrm{C}\right)$} & Temp. Teto $\left({ }^{\circ} \mathrm{C}\right)$ & \\
\hline $11: 50$ & 21,9 & 21 & 21,3 & \multicolumn{3}{|c|}{22,4} & 21,5 & \\
\hline $15: 00$ & 26,2 & 26 & 23,2 & \multicolumn{3}{|c|}{23,2} & 23,3 & \\
\hline
\end{tabular}

Tabela 186: Resultados coletados in loco no quarto do Apartamento H no mês de Agosto de 2013.

\begin{tabular}{|c|c|c|c|c|c|c|c|c|}
\hline \multicolumn{2}{|l|}{ Apartamento $\mathrm{H}$} & \multicolumn{4}{|c|}{ Dados coletados CONFORTIMETRO Setembro 2013 - QUARTO } & \multicolumn{3}{|c|}{ Céu claro } \\
\hline Intervalo & $\begin{array}{l}\text { Temperatura de } \\
\text { bulbo úmido }\left({ }^{\circ} \mathrm{C}\right)\end{array}$ & $\begin{array}{c}\text { Temperatura de } \\
\text { globo }\left({ }^{\circ} \mathrm{C}\right)\end{array}$ & $\begin{array}{c}\text { Temperatura do ar } \\
\left({ }^{\circ} \mathrm{C}\right)\end{array}$ & $\begin{array}{c}\text { Pressão Atmosférica } \\
\text { (atm) }\end{array}$ & $\begin{array}{c}\text { Umidade relativa do } \\
\text { ar (\%) }\end{array}$ & $\begin{array}{l}\text { Velocidade do } \\
\text { ar }(\mathrm{m} / \mathrm{s})\end{array}$ & $\begin{array}{l}\text { Temperatura } \\
\text { radiante }\left({ }^{\circ} \mathrm{C}\right)\end{array}$ & $\begin{array}{l}\text { Temperatura } \\
\text { Operativa }\left({ }^{\circ} \mathrm{C}\right)\end{array}$ \\
\hline $11: 50$ as $12: 20$ & 20,7 & 25,1 & 25,2 & 1004,9 & 60,4 & 0,0 & 25,0 & 25,1 \\
\hline $12: 20$ as $12: 50$ & 20,9 & 25,6 & 26,0 & 1004,8 & 57,1 & 0,0 & 25,3 & 25,7 \\
\hline $12: 50$ as $13: 20$ & 21,3 & 25,9 & 26,3 & 1004,6 & 57,4 & 0,0 & 25,7 & 26,0 \\
\hline $13: 20$ as $13: 50$ & 21,5 & 26,2 & 26,6 & 1004,3 & 56,9 & 0,0 & 26,0 & 26,3 \\
\hline $13: 50$ as $14: 20$ & 21,4 & 26,6 & 26,9 & 1003,9 & 54,3 & 0,0 & 26,4 & 26,7 \\
\hline $14: 20$ as $14: 50$ & 21,3 & 26,9 & 27,3 & 1003,5 & 51,9 & 0,1 & 26,4 & 26,8 \\
\hline Desvio Padrão & 0,30 & 0,62 & 0,68 & 0,51 & 2,78 & 0,06 & 0,58 & 1,63 \\
\hline Média & 21,2 & 26,0 & 26,4 & 1004,3 & 56,4 & 0,0 & 25,8 & 26,1 \\
\hline \multicolumn{8}{|c|}{ Dados coletados Termômetro de fluxo de laser } & \\
\hline Horário/Quarto & $\begin{array}{l}\text { Temp. Externa do ar } \\
\left({ }^{\circ} \mathrm{C}\right)\end{array}$ & $\begin{array}{c}\text { Temp. Paredes } \\
\text { externas }\left({ }^{\circ} \mathrm{C}\right)\end{array}$ & $\begin{array}{c}\text { Temp.Paredes voltada } \\
\text { para a rua }\left({ }^{\circ} \mathrm{C}\right)\end{array}$ & \multicolumn{3}{|c|}{ Temp. Média das paredes $\left({ }^{\circ} \mathrm{C}\right)$} & Temp. Teto $\left({ }^{\circ} \mathrm{C}\right)$ & \\
\hline $11: 50$ & 27 & 27 & 22,7 & \multicolumn{3}{|c|}{23,8} & 24,1 & \\
\hline $15: 00$ & 29 & 27 & 27,6 & \multicolumn{3}{|c|}{25,7} & 25,2 & \\
\hline
\end{tabular}

Tabela 187: Resultados coletados in loco no quarto do Apartamento H no mês de Setembro de 2013. 


\begin{tabular}{|c|c|c|c|c|c|c|c|c|}
\hline \multicolumn{2}{|l|}{ Apartamento $\mathrm{H}$} & \multicolumn{4}{|c|}{ Dado s coletados CONFORTIM ETRO Outubro 2013 - QUARTO } & \multicolumn{3}{|c|}{ Nublado } \\
\hline Intervalo & $\begin{array}{l}\text { Temperatura de } \\
\text { bulbo úmido }\left({ }^{\circ} \mathrm{C}\right)\end{array}$ & $\begin{array}{c}\text { Temperatura de } \\
\text { globo }\left({ }^{\circ} \mathrm{C}\right)\end{array}$ & $\begin{array}{c}\text { Temperatura do ar } \\
\left({ }^{\circ} \mathrm{C}\right)\end{array}$ & $\begin{array}{c}\text { Pressão Atmosférica } \\
\text { (atm) }\end{array}$ & $\begin{array}{c}\text { Umidade relativa do } \\
\text { ar (\%) }\end{array}$ & $\begin{array}{l}\text { Velocidade do } \\
\text { ar (m/s) }\end{array}$ & $\begin{array}{l}\text { Temperatura } \\
\text { radiante }\left({ }^{\circ} \mathrm{C}\right)\end{array}$ & $\begin{array}{l}\text { Temperatura } \\
\text { Operativa }\left({ }^{\circ} \mathrm{C}\right)\end{array}$ \\
\hline $12: 50$ as $13: 20$ & 19,9 & 25,0 & 24,7 & 1016,1 & 52,5 & 0,0 & 25,1 & 24,9 \\
\hline $13: 20$ as $13: 50$ & 19,6 & 24,9 & 24,7 & 1015,8 & 51,8 & 0,0 & 24,9 & 24,8 \\
\hline $13: 50$ as $14: 20$ & 19,4 & 24,9 & 24,6 & 1015,5 & 50,9 & 0,0 & 24,9 & 24,8 \\
\hline $14: 20$ as $14: 50$ & 19,3 & 24,9 & 24,7 & 1015,2 & 50,2 & 0,0 & 25,0 & 24,8 \\
\hline $14: 50$ as $15: 20$ & 19,2 & 24,9 & 24,7 & 1015,1 & 50,0 & 0,0 & 25,0 & 24,8 \\
\hline $15: 20$ as $15: 50$ & 19,2 & 24,9 & 24,6 & 1014,9 & 50,3 & 0,0 & 24,9 & 24,8 \\
\hline Desvio Padrão & 0,28 & 0,07 & 0,07 & 0,44 & 0,99 & 0,01 & 0,09 & 1,63 \\
\hline Média & 19,5 & 24,9 & 24,7 & 1015,5 & 51,1 & 0,0 & 25,0 & 24,8 \\
\hline \multicolumn{8}{|c|}{ Dados coletados Termômetro de fluxo de laser } & \\
\hline Horário/Quarto & $\begin{array}{l}\text { Temp. Externa do ar } \\
\left({ }^{\circ} \mathrm{C}\right)\end{array}$ & $\begin{array}{c}\text { Temp. Paredes } \\
\text { externas }\left({ }^{\circ} \mathrm{C}\right)\end{array}$ & $\begin{array}{c}\text { Temp.Paredes voltada } \\
\text { para a rua }\left({ }^{\circ} \mathrm{C}\right)\end{array}$ & \multicolumn{3}{|c|}{ Temp. Média das paredes $\left({ }^{\circ} \mathrm{C}\right)$} & Temp. Teto $\left({ }^{\circ} \mathrm{C}\right)$ & \\
\hline 12:50 & 23,7 & 23,8 & 23,5 & \multicolumn{3}{|c|}{25} & 25,8 & \\
\hline $16: 00$ & 23,8 & 24,7 & 24,2 & \multicolumn{3}{|c|}{24,9} & 25,5 & \\
\hline
\end{tabular}

Tabela 188: Resultados coletados in loco no quarto do Apartamento H no mês de Outubro de 2013.

\begin{tabular}{|c|c|c|c|c|c|c|c|c|}
\hline \multicolumn{2}{|l|}{ Apartamento $\mathrm{H}$} & \multicolumn{4}{|c|}{ Dados coletados CONFORTIMMETRO Novembro 2013 - QUARTO } & \multicolumn{3}{|c|}{ Céu claro } \\
\hline Intervalo & $\begin{array}{l}\text { Temperatura de } \\
\text { bulbo úmido }\left({ }^{\circ} \mathrm{C}\right)\end{array}$ & $\begin{array}{c}\text { Temperatura de } \\
\text { globo }\left({ }^{\circ} \mathrm{C}\right)\end{array}$ & $\begin{array}{c}\text { Temperatura do ar } \\
\left({ }^{\circ} \mathrm{C}\right)\end{array}$ & $\begin{array}{c}\text { Pressão Atmosférica } \\
\text { (atm) }\end{array}$ & $\begin{array}{l}\text { Umidade relativa do } \\
\text { ar (\%) }\end{array}$ & $\begin{array}{l}\text { Velocidade do } \\
\quad \operatorname{ar}(\mathrm{m} / \mathrm{s})\end{array}$ & $\begin{array}{l}\text { Temperatura } \\
\text { radiante }\left({ }^{\circ} \mathrm{C}\right)\end{array}$ & $\begin{array}{l}\text { Temperatura } \\
\text { Operativa }\left({ }^{\circ} \mathrm{C}\right)\end{array}$ \\
\hline $12: 50$ as $13: 20$ & 22,5 & 26,4 & 26,2 & 1012,6 & 66,0 & 0,0 & 26,5 & 26,3 \\
\hline $13: 20$ as $13: 50$ & 22,5 & 26,4 & 26,3 & 1012,5 & 64,9 & 0,0 & 26,5 & 26,4 \\
\hline $13: 50$ as $14: 20$ & 22,5 & 26,6 & 26,4 & 1012,2 & 64,1 & 0,0 & 26,6 & 26,5 \\
\hline $14: 20$ as $14: 50$ & 22,4 & 26,6 & 26,4 & 1011,9 & 62,9 & 0,0 & 26,6 & 26,5 \\
\hline $14: 50$ as $15: 20$ & 22,3 & 26,6 & 26,4 & 1011,6 & 62,1 & 0,0 & 26,7 & 26,5 \\
\hline $15: 20$ as $15: 50$ & 22,4 & 26,7 & 26,4 & 1011,3 & 62,4 & 0,0 & 26,7 & 26,6 \\
\hline Desvio Padrão & 0,12 & 0,11 & 0,11 & 0,47 & 1,49 & 0,01 & 0,12 & 1,63 \\
\hline Média & 22,4 & 26,5 & 26,3 & 1012,1 & 63,8 & 0,0 & 26,6 & 26,5 \\
\hline \multicolumn{8}{|c|}{ Dados coletados Termômetro de fluxo de laser } & \\
\hline Horário/Quarto & $\begin{array}{l}\text { Temp. Externa do ar } \\
\left({ }^{\circ} \mathrm{C}\right)\end{array}$ & $\begin{array}{l}\text { Temp. Paredes } \\
\text { externas }\left({ }^{\circ} \mathrm{C}\right)\end{array}$ & $\begin{array}{c}\text { Temp.Paredes voltada } \\
\text { para a rua }\left({ }^{\circ} \mathrm{C}\right)\end{array}$ & \multicolumn{3}{|c|}{ Temp. Média das paredes $\left({ }^{\circ} \mathrm{C}\right)$} & Temp. Teto $\left({ }^{\circ} \mathrm{C}\right)$ & \\
\hline $12: 50$ & 26,5 & 26,4 & 25,3 & \multicolumn{3}{|c|}{26,6} & 26,1 & \\
\hline $16: 00$ & 32,3 & 31,2 & 25,4 & \multicolumn{3}{|c|}{26,4} & 26,1 & \\
\hline
\end{tabular}

Tabela 189: Resultados coletados in loco no quarto do Apartamento H no mês de Novembro de 2013.

\begin{tabular}{|c|c|c|c|c|c|c|c|c|}
\hline \multicolumn{2}{|l|}{ Apartamento $\mathrm{H}$} & \multicolumn{4}{|c|}{ Dados coletados CONFORTÍM ETRO Dezembro 2013 - QUARTO } & \multicolumn{3}{|c|}{$\begin{array}{l}\text { Parcialmente } \\
\text { nublado }\end{array}$} \\
\hline Intervalo & $\begin{array}{l}\text { Temperatura de } \\
\text { bulbo úmido }\left({ }^{\circ} \mathrm{C}\right)\end{array}$ & $\begin{array}{c}\text { Temperatura de } \\
\text { globo }\left({ }^{\circ} \mathrm{C}\right)\end{array}$ & $\begin{array}{c}\text { Temperatura do ar } \\
\left({ }^{\circ} \mathrm{C}\right)\end{array}$ & $\begin{array}{c}\text { Pressão Atmosférica } \\
\text { (atm) }\end{array}$ & $\begin{array}{c}\text { Umidade relativa do } \\
\text { ar (\%) }\end{array}$ & $\begin{array}{l}\text { Velocidade do } \\
\quad \operatorname{ar}(\mathrm{m} / \mathrm{s})\end{array}$ & $\begin{array}{l}\text { Temperatura } \\
\text { radiante }\left({ }^{\circ} \mathrm{C}\right)\end{array}$ & $\begin{array}{l}\text { Temperatura } \\
\text { Operativa }\left({ }^{\circ} \mathrm{C}\right)\end{array}$ \\
\hline $12: 50$ as $13: 20$ & 24,6 & 27,5 & 27,3 & 1006,5 & 74,1 & 0,0 & 27,6 & 27,4 \\
\hline $13: 20$ as $13: 50$ & 24,3 & 27,4 & 27,3 & 1006,4 & 72,9 & 0,0 & 27,4 & 27,4 \\
\hline $13: 50$ as $14: 20$ & 24,3 & 27,4 & 27,3 & 1005,9 & 72,4 & 0,0 & 27,4 & 27,4 \\
\hline $14: 20$ as $14: 50$ & 24,3 & 27,4 & 27,3 & 1005,8 & 72,4 & 0,0 & 27,4 & 27,4 \\
\hline $14: 50$ as $15: 20$ & 24,3 & 27,4 & 27,3 & 1005,6 & 72,6 & 0,0 & 27,4 & 27,3 \\
\hline $15: 20$ as $15: 50$ & 24,3 & 27,4 & 27,2 & 1005,3 & 72,8 & 0,0 & 27,4 & 27,3 \\
\hline Desvio Padrão & 0,14 & 0,09 & 0,04 & 0,45 & 0,70 & 0,01 & 0,12 & 1,63 \\
\hline Média & 24,4 & 27,4 & 27,3 & 1006,0 & 73,0 & 0,0 & 27,5 & 27,4 \\
\hline \multicolumn{8}{|c|}{ Dados coletados Termômetro de fluxo de laser } & \\
\hline Horário/Quarto & $\begin{array}{l}\text { Temp. Externa do ar } \\
\left({ }^{\circ} \mathrm{C}\right)\end{array}$ & $\begin{array}{c}\text { Temp. Paredes } \\
\text { externas }\left({ }^{\circ} \mathrm{C}\right)\end{array}$ & $\begin{array}{c}\text { Temp.Paredes voltada } \\
\text { para a rua }\left({ }^{\circ} \mathrm{C}\right)\end{array}$ & \multicolumn{3}{|c|}{ Temp. Média das paredes $\left({ }^{\circ} \mathrm{C}\right)$} & Temp. Teto $\left({ }^{\circ} \mathrm{C}\right)$ & \\
\hline $12: 50$ & 28,3 & 28,8 & 27,1 & \multicolumn{3}{|c|}{27,4} & 27,5 & \\
\hline $16: 00$ & 27,1 & 29,1 & 27,4 & \multicolumn{3}{|c|}{27,7} & 27,4 & \\
\hline
\end{tabular}

Tabela 190: Resultados coletados in loco no quarto do Apartamento H no mês de Dezembro de 2013.

\begin{tabular}{|c|c|c|c|c|c|c|c|c|}
\hline \multicolumn{2}{|l|}{ Apartamento $\mathrm{H}$} & \multicolumn{4}{|c|}{ Dados coletados CONFORTÍM ETRO Janeiro 2014 - QUARTO } & \multicolumn{3}{|c|}{ Céu claro } \\
\hline Intervalo & $\begin{array}{l}\text { Temperatura de } \\
\text { bulbo úmido }\left({ }^{\circ} \mathrm{C}\right)\end{array}$ & $\begin{array}{c}\text { Temperatura de } \\
\text { globo }\left({ }^{\circ} \mathrm{C}\right)\end{array}$ & $\begin{array}{c}\text { Temperatura do ar } \\
\left({ }^{\circ} \mathrm{C}\right)\end{array}$ & $\begin{array}{c}\text { Pressão Atmosférica } \\
\text { (atm) }\end{array}$ & $\begin{array}{c}\text { Umidade relativa do } \\
\text { ar (\%) }\end{array}$ & $\begin{array}{l}\text { Velocidade do } \\
\text { ar (m/s) }\end{array}$ & $\begin{array}{l}\text { Temperatura } \\
\text { radiante }\left({ }^{\circ} \mathrm{C}\right)\end{array}$ & $\begin{array}{l}\text { Temperatura } \\
\text { Operativa }\left({ }^{\circ} \mathrm{C}\right)\end{array}$ \\
\hline $12: 50$ as $13: 20$ & 26,9 & 33,0 & 32,8 & 1013,8 & 56,4 & 0,0 & 33,0 & 32,9 \\
\hline $13: 20$ as $13: 50$ & 27,0 & 33,0 & 32,9 & 1013,5 & 56,3 & 0,0 & 33,0 & 33,0 \\
\hline $13: 50$ as $14: 20$ & 27,0 & 33,0 & 32,9 & 1013,3 & 56,3 & 0,0 & 33,1 & 33,0 \\
\hline $14: 20$ as $14: 50$ & 26,9 & 33,0 & 32,8 & 1013,0 & 56,5 & 0,0 & 33,0 & 32,9 \\
\hline $14: 50$ as $15: 20$ & 27,0 & 33,0 & 32,8 & 1012,7 & 57,1 & 0,0 & 33,0 & 32,9 \\
\hline $15: 20$ as $15: 50$ & 27,1 & 33,0 & 32,9 & 1012,4 & 57,3 & 0,0 & 33,1 & 33,0 \\
\hline Desvio Padrão & 0,12 & 0,04 & 0,05 & 0,48 & 0,42 & 0,01 & 0,05 & 1,63 \\
\hline Média & 27,0 & 33,0 & 32,9 & 1013,2 & 56,6 & 0,0 & 33,0 & 33,0 \\
\hline \multicolumn{8}{|c|}{ Dados coletados Termômetro de fluxo de laser } & \\
\hline Horário/Quarto & $\begin{array}{l}\text { Temp. Externa do ar } \\
\left({ }^{\circ} \mathrm{C}\right)\end{array}$ & $\begin{array}{l}\text { Temp. Paredes } \\
\text { externas }\left({ }^{\circ} \mathrm{C}\right)\end{array}$ & $\begin{array}{c}\text { Temp.Paredes voltada } \\
\text { para a rua }\left({ }^{\circ} \mathrm{C}\right)\end{array}$ & \multicolumn{3}{|c|}{ Temp. Média das paredes $\left({ }^{\circ} \mathrm{C}\right)$} & Temp. Teto $\left({ }^{\circ} \mathrm{C}\right)$ & \\
\hline $12: 50$ & 30,1 & 36,1 & 33,5 & \multicolumn{3}{|c|}{34,1} & 34,1 & \\
\hline $16: 00$ & 33,1 & 38,6 & 33,4 & \multicolumn{3}{|c|}{33,7} & 33,4 & \\
\hline
\end{tabular}

Tabela 191: Resultados coletados in loco no quarto do Apartamento H no mês de Janeiro de 2014. 


\begin{tabular}{|c|c|c|c|c|c|c|c|c|}
\hline \multicolumn{2}{|l|}{ Apartamento $\mathrm{H}$} & \multicolumn{4}{|c|}{ Dados coletados CONFORTÍM ETRO Fevereiro 2014 - QUARTO } & \multicolumn{3}{|c|}{ Céu claro } \\
\hline Intervalo & $\begin{array}{l}\text { Temperatura de } \\
\text { bulbo úmido }\left({ }^{\circ} \mathrm{C}\right)\end{array}$ & $\begin{array}{c}\text { Temperatura de } \\
\text { globo }\left({ }^{\circ} \mathrm{C}\right)\end{array}$ & $\begin{array}{c}\text { Temperatura do ar } \\
\left({ }^{\circ} \mathrm{C}\right)\end{array}$ & $\begin{array}{c}\text { Pressão Atmosférica } \\
\text { (atm) }\end{array}$ & $\begin{array}{c}\text { Umidade relativa do } \\
\text { ar (\%) }\end{array}$ & $\begin{array}{l}\text { Velocidade do } \\
\text { ar (m/s) }\end{array}$ & $\begin{array}{l}\text { Temperatura } \\
\text { radiante }\left({ }^{\circ} \mathrm{C}\right)\end{array}$ & $\begin{array}{l}\text { Temperatura } \\
\text { Operativa }\left({ }^{\circ} \mathrm{C}\right)\end{array}$ \\
\hline $11: 50$ as $12: 20$ & 24,6 & 28,8 & 28,8 & 1011,9 & 64,8 & 0,0 & 28,9 & 28,8 \\
\hline $12: 20$ as $12: 50$ & 24,4 & 28,9 & 29,0 & 1011,7 & 62,8 & 0,1 & 28,9 & 29,0 \\
\hline $12: 50$ as $13: 20$ & 24,4 & 29,2 & 29,2 & 1011,4 & 61,2 & 0,1 & 29,2 & 29,2 \\
\hline $13: 20$ as $13: 50$ & 24,5 & 29,3 & 29,3 & 1011,3 & 60,4 & 0,0 & 29,3 & 29,3 \\
\hline $13: 50$ as $14: 20$ & 24,6 & 29,3 & 29,2 & 1011,3 & 61,5 & 0,0 & 29,4 & 29,3 \\
\hline $14: 20$ as $14: 50$ & 24,5 & 29,5 & 29,5 & 1011,0 & 60,0 & 0,1 & 29,6 & 29,5 \\
\hline Desvio Padrão & 0,15 & 0,27 & 0,28 & 0,32 & 1,97 & 0,08 & 0,27 & 1,63 \\
\hline Média & 24,5 & 29,1 & 29,1 & 1011,5 & 62,2 & 0,1 & 29,1 & 29,1 \\
\hline \multicolumn{8}{|c|}{ Dados coletados Termômetro de fluxo de laser } & \\
\hline Horário/Quarto & $\begin{array}{l}\text { Temp. Externa do ar } \\
\left({ }^{\circ} \mathrm{C}\right)\end{array}$ & $\begin{array}{c}\text { Temp. Paredes } \\
\text { externas }\left({ }^{\circ} \mathrm{C}\right)\end{array}$ & $\begin{array}{c}\text { Temp.Paredes voltada } \\
\text { para a rua }\left({ }^{\circ} \mathrm{C}\right)\end{array}$ & \multicolumn{3}{|c|}{ Temp. Média das paredes $\left({ }^{\circ} \mathrm{C}\right)$} & Temp. Teto $\left({ }^{\circ} \mathrm{C}\right)$ & \\
\hline 11:50 & 31,7 & 30,4 & 28,1 & \multicolumn{3}{|c|}{28,3} & 29,4 & \\
\hline $15: 00$ & 37,7 & 40,2 & 30,8 & \multicolumn{3}{|c|}{28,3} & 28,8 & \\
\hline
\end{tabular}

Tabela 192: Resultados coletados in loco no quarto do Apartamento H no mês de Fevereiro de 2014.

\begin{tabular}{|c|c|c|c|c|c|c|c|c|}
\hline \multicolumn{2}{|l|}{ Apartamento $\mathrm{H}$} & \multicolumn{4}{|c|}{ Dados coletados CONFORTÍM ETRO M arço 2014 - QUARTO } & \multicolumn{3}{|c|}{ Chuva } \\
\hline Intervalo & $\begin{array}{l}\text { Temperatura de } \\
\text { bulbo úmido }\left({ }^{\circ} \mathrm{C}\right)\end{array}$ & $\begin{array}{c}\text { Temperatura de } \\
\text { globo }\left({ }^{\circ} \mathrm{C}\right)\end{array}$ & $\begin{array}{c}\text { Temperatura do ar } \\
\left({ }^{\circ} \mathrm{C}\right)\end{array}$ & $\begin{array}{c}\text { Pressão Atmosférica } \\
\text { (atm) }\end{array}$ & $\begin{array}{c}\text { Umidade relativa do } \\
\text { ar (\%) }\end{array}$ & $\begin{array}{l}\text { Velocidade do } \\
\text { ar }(\mathrm{m} / \mathrm{s})\end{array}$ & $\begin{array}{l}\text { Temperatura } \\
\text { radiante }\left({ }^{\circ} \mathrm{C}\right)\end{array}$ & $\begin{array}{l}\text { Temperatura } \\
\text { Operativa }\left({ }^{\circ} \mathrm{C}\right)\end{array}$ \\
\hline $11: 50$ as $12: 20$ & 23,9 & 27,3 & 27,1 & 1017,6 & 71,8 & 0,0 & 27,5 & 27,3 \\
\hline $12: 20$ as $12: 50$ & 24,0 & 27,2 & 26,9 & 1017,4 & 74,6 & 0,0 & 27,3 & 27,1 \\
\hline $12: 50$ as $13: 20$ & 24,3 & 27,2 & 26,9 & 1017,2 & 75,9 & 0,0 & 27,3 & 27,1 \\
\hline $13: 20$ as $13: 50$ & 24,3 & 27,2 & 26,8 & 1016,8 & 75,9 & 0,0 & 27,3 & 27,1 \\
\hline $13: 50$ as $14: 20$ & 24,1 & 27,1 & 26,7 & 1016,5 & 76,0 & 0,0 & 27,3 & 27,0 \\
\hline $14: 20$ as $14: 50$ & 24,1 & 27,1 & 26,8 & 1016,3 & 75,3 & 0,0 & 27,2 & 27,0 \\
\hline Desvio Padrão & 0,16 & 0,10 & 0,12 & 0,50 & 1,50 & 0,03 & 0,12 & 1,63 \\
\hline Média & 24,1 & 27,2 & 26,9 & 1016,9 & 75,0 & 0,0 & 27,3 & 27,1 \\
\hline \multicolumn{8}{|c|}{ Dados coletados Termômetro de fluxo de laser } & \\
\hline Horário/Quarto & $\begin{array}{l}\text { Temp. Externa do ar } \\
\left({ }^{\circ} \mathrm{C}\right)\end{array}$ & $\begin{array}{l}\text { Temp. Paredes } \\
\text { externas }\left({ }^{\circ} \mathrm{C}\right)\end{array}$ & $\begin{array}{c}\text { Temp.Paredes voltada } \\
\text { para a rua }\left({ }^{\circ} \mathrm{C}\right)\end{array}$ & \multicolumn{3}{|c|}{ Temp. Média das paredes $\left({ }^{\circ} \mathrm{C}\right)$} & Temp. Teto $\left({ }^{\circ} \mathrm{C}\right)$ & \\
\hline 11:50 & 27,1 & 26,7 & 27,2 & \multicolumn{3}{|c|}{27,7} & 27,9 & \\
\hline $15: 00$ & 26,4 & 24,1 & 26,6 & \multicolumn{3}{|c|}{27,1} & 27,7 & \\
\hline
\end{tabular}

Tabela 193: Resultados coletados in loco no quarto do Apartamento H no mês de Março de 2014.

\begin{tabular}{|c|c|c|c|c|c|c|c|c|}
\hline \multicolumn{2}{|l|}{ Apartamento $\mathrm{H}$} & \multicolumn{4}{|c|}{ Dados coletados CONFORTIMETRO Abril 2014 - QUARTO } & \multicolumn{3}{|c|}{$\begin{array}{l}\text { Parcialmente } \\
\text { aberto }\end{array}$} \\
\hline Intervalo & $\begin{array}{l}\text { Temperatura de } \\
\text { bulbo úmido }\left({ }^{\circ} \mathrm{C}\right)\end{array}$ & $\begin{array}{c}\text { Temperatura de } \\
\text { globo }\left({ }^{\circ} \mathrm{C}\right)\end{array}$ & $\begin{array}{c}\text { Temperatura do ar } \\
\left({ }^{\circ} \mathrm{C}\right)\end{array}$ & $\begin{array}{l}\text { Pressão Atmosférica } \\
\text { (atm) }\end{array}$ & $\begin{array}{c}\text { Umidade relativa do } \\
\text { ar (\%) }\end{array}$ & $\begin{array}{l}\text { Velocidade do } \\
\operatorname{ar}(\mathrm{m} / \mathrm{s})\end{array}$ & $\begin{array}{l}\text { Temperatura } \\
\text { radiante }\left({ }^{\circ} \mathrm{C}\right)\end{array}$ & $\begin{array}{l}\text { Temperatura } \\
\text { Operativa }\left({ }^{\circ} \mathrm{C}\right)\end{array}$ \\
\hline $11: 50$ as $12: 20$ & 21,7 & 24,1 & 24,0 & 1014,0 & 76,6 & 0,0 & 24,2 & 24,1 \\
\hline $12: 20$ as $12: 50$ & 21,3 & 24,2 & 24,0 & 1013,7 & 73,0 & 0,0 & 24,2 & 24,1 \\
\hline $12: 50$ as $13: 20$ & 21,3 & 24,2 & 24,1 & 1013,4 & 72,3 & 0,0 & 24,2 & 24,2 \\
\hline $13: 20$ as $13: 50$ & 21,2 & 24,2 & 24,1 & 1013,0 & 72,0 & 0,0 & 24,3 & 24,2 \\
\hline $13: 50$ as $14: 20$ & 21,0 & 24,3 & 24,1 & 1012,7 & 70,4 & 0,0 & 24,4 & 24,2 \\
\hline $14: 20$ as $14: 50$ & 20,9 & 24,3 & 24,2 & 1012,6 & 70,6 & 0,1 & 24,5 & 24,3 \\
\hline Desvio Padrão & 0,26 & 0,06 & 0,08 & 0,51 & 2,18 & 0,06 & 0,13 & 1,63 \\
\hline Média & 21,2 & 24,2 & 24,1 & 1013,3 & 72,5 & 0,0 & 24,3 & 24,2 \\
\hline \multicolumn{8}{|c|}{ Dados coletados Termômetro de fluxo de laser } & \\
\hline Horário/Quarto & $\begin{array}{l}\text { Temp. Externa do ar } \\
\left({ }^{\circ} \mathrm{C}\right)\end{array}$ & $\begin{array}{c}\text { Temp. Paredes } \\
\text { externas }\left({ }^{\circ} \mathrm{C}\right)\end{array}$ & $\begin{array}{c}\text { Temp.Paredes voltada } \\
\text { para a rua }\left({ }^{\circ} \mathrm{C}\right)\end{array}$ & \multicolumn{3}{|c|}{ Temp. Média das paredes $\left({ }^{\circ} \mathrm{C}\right)$} & Temp. Teto $\left({ }^{\circ} \mathrm{C}\right)$ & \\
\hline $11: 50$ & 25,3 & 25 & 23,8 & \multicolumn{3}{|c|}{24,3} & 24,3 & \\
\hline 15:00 & 25,5 & 23,1 & 24 & \multicolumn{3}{|c|}{23,8} & 24,3 & \\
\hline
\end{tabular}

Tabela 194: Resultados coletados in loco no quarto do Apartamento H no mês de Abril de 2014.

\begin{tabular}{|c|c|c|c|c|c|c|c|c|}
\hline \multicolumn{2}{|l|}{ Apartamento $\mathrm{H}$} & \multicolumn{4}{|c|}{ Dados coletados CONFORTÍM ETRO M aio 2014 - QUARTO } & \multicolumn{3}{|c|}{$\begin{array}{l}\text { Parcialmente } \\
\text { aberto }\end{array}$} \\
\hline Intervalo & $\begin{array}{l}\text { Temperatura de } \\
\text { bulbo úmido }\left({ }^{\circ} \mathrm{C}\right)\end{array}$ & $\begin{array}{c}\text { Temperatura de } \\
\text { globo }\left({ }^{\circ} \mathrm{C}\right)\end{array}$ & $\begin{array}{c}\text { Temperatura do ar } \\
\left({ }^{\circ} \mathrm{C}\right)\end{array}$ & $\begin{array}{c}\text { Pressão Atmosférica } \\
\text { (atm) }\end{array}$ & $\begin{array}{c}\text { Umidade relativa do } \\
\text { ar (\%) }\end{array}$ & $\begin{array}{l}\text { Velocidade do } \\
\qquad \operatorname{ar}(\mathrm{m} / \mathrm{s})\end{array}$ & $\begin{array}{l}\text { Temperatura } \\
\text { radiante }\left({ }^{\circ} \mathrm{C}\right)\end{array}$ & $\begin{array}{l}\text { Temperatura } \\
\text { Operativa }\left({ }^{\circ} \mathrm{C}\right)\end{array}$ \\
\hline $11: 50$ as $12: 20$ & 21,7 & 24,1 & 23,9 & 1014,1 & 77,3 & 0,0 & 24,3 & 24,1 \\
\hline $12: 20$ as $12: 50$ & 21,5 & 24,2 & 24,0 & 1013,9 & 73,7 & 0,0 & 24,2 & 24,1 \\
\hline $12: 50$ as $13: 20$ & 21,3 & 24,2 & 24,1 & 1013,4 & 72,3 & 0,0 & 24,2 & 24,2 \\
\hline $13: 20$ as $13: 50$ & 21,2 & 24,2 & 24,1 & 1013,0 & 72,0 & 0,0 & 24,3 & 24,2 \\
\hline $13: 50$ as $14: 20$ & 21,0 & 24,3 & 24,1 & 1012,7 & 70,4 & 0,0 & 24,4 & 24,2 \\
\hline $14: 20$ as $14: 50$ & 21,0 & 24,3 & 24,2 & 1012,7 & 70,4 & 0,1 & 24,6 & 24,4 \\
\hline Desvio Padrão & 0,28 & 0,07 & 0,10 & 0,55 & 2,40 & 0,07 & 0,13 & 1,63 \\
\hline Média & 21,3 & 24,2 & 24,1 & 1013,3 & 72,7 & 0,0 & 24,3 & 24,2 \\
\hline \multicolumn{8}{|c|}{ Dados coletados Termômetro de fluxo de laser } & \\
\hline Horário/Quarto & $\begin{array}{l}\text { Temp. Externa do ar } \\
\left({ }^{\circ} \mathrm{C}\right)\end{array}$ & $\begin{array}{c}\text { Temp. Paredes } \\
\text { externas }\left({ }^{\circ} \mathrm{C}\right)\end{array}$ & $\begin{array}{c}\text { Temp.Paredes voltada } \\
\text { para a rua }\left({ }^{\circ} \mathrm{C}\right)\end{array}$ & \multicolumn{3}{|c|}{ Temp. Média das paredes $\left({ }^{\circ} \mathrm{C}\right)$} & Temp. Teto $\left({ }^{\circ} \mathrm{C}\right)$ & \\
\hline 11:50 & 25,2 & 24,8 & 23,6 & \multicolumn{3}{|c|}{24} & 24 & \\
\hline $15: 00$ & 25,4 & 23 & 23,9 & \multicolumn{3}{|c|}{23,9} & 24 & \\
\hline
\end{tabular}

Tabela 195: Resultados coletados in loco no quarto do Apartamento H no mês de Maio de 2014. 


\begin{tabular}{|c|c|c|c|c|c|c|c|c|}
\hline \multicolumn{2}{|l|}{ Apartamento $\mathrm{H}$} & \multicolumn{4}{|c|}{ Dados coletados CONFORTIM ETRO J unho 2014 - QUARTO } & \multicolumn{3}{|c|}{ Chuva } \\
\hline Intervalo & $\begin{array}{l}\text { Temperatura de } \\
\text { bulbo úmido }\left({ }^{\circ} \mathrm{C}\right)\end{array}$ & $\begin{array}{c}\text { Temperatura de } \\
\text { globo }\left({ }^{\circ} \mathrm{C}\right)\end{array}$ & $\begin{array}{c}\text { Temperatura do ar } \\
\left({ }^{\circ} \mathrm{C}\right)\end{array}$ & $\begin{array}{l}\text { Pressão Atmosférica } \\
\text { (atm) }\end{array}$ & $\begin{array}{c}\text { Umidade relativa do } \\
\text { ar (\%) }\end{array}$ & $\begin{array}{l}\text { Velocidade do } \\
\text { ar (m/s) }\end{array}$ & $\begin{array}{l}\text { Temperatura } \\
\text { radiante }\left({ }^{\circ} \mathrm{C}\right)\end{array}$ & $\begin{array}{l}\text { Temperatura } \\
\text { Operativa }\left({ }^{\circ} \mathrm{C}\right)\end{array}$ \\
\hline $11: 50$ as $12: 20$ & 18,6 & 21,1 & 20,4 & 1020,7 & 77,5 & 0,0 & 21,4 & 20,9 \\
\hline $12: 20$ as $12: 50$ & 18,6 & 21,0 & 20,4 & 1020,3 & 78,3 & 0,0 & 21,4 & 20,9 \\
\hline $12: 50$ as $13: 20$ & 18,6 & 20,9 & 20,2 & 1019,9 & 80,2 & 0,0 & 21,3 & 20,7 \\
\hline $13: 20$ as $13: 50$ & 18,7 & 21,0 & 20,4 & 1019,4 & 79,9 & 0,0 & 21,3 & 20,8 \\
\hline $13: 50$ as $14: 20$ & 18,7 & 21,1 & 20,4 & 1019,3 & 78,8 & 0,0 & 21,4 & 20,9 \\
\hline $14: 20$ as $14: 50$ & 18,5 & 20,9 & 20,3 & 1019,3 & 78,8 & 0,0 & 21,3 & 20,8 \\
\hline Desvio Padrão & 0,11 & 0,09 & 0,13 & 0,56 & 0,99 & 0,03 & 0,21 & 1,63 \\
\hline Média & 18,6 & 21,0 & 20,3 & 1019,8 & 78,9 & 0,0 & 21,3 & 20,8 \\
\hline \multicolumn{8}{|c|}{ Dados coletados Termômetro de fluxo de laser } & \\
\hline Horário/Quarto & $\begin{array}{l}\text { Temp. Externa do ar } \\
\left({ }^{\circ} \mathrm{C}\right)\end{array}$ & $\begin{array}{l}\text { Temp. Paredes } \\
\text { externas }\left({ }^{\circ} \mathrm{C}\right)\end{array}$ & $\begin{array}{c}\text { Temp.Paredes voltada } \\
\text { para a rua }\left({ }^{\circ} \mathrm{C}\right)\end{array}$ & \multicolumn{3}{|c|}{ Temp. Média das paredes $\left({ }^{\circ} \mathrm{C}\right)$} & Temp. Teto $\left({ }^{\circ} \mathrm{C}\right)$ & \\
\hline 11:50 & 22,1 & 18,1 & 20,1 & \multicolumn{3}{|c|}{21,8} & 22,3 & \\
\hline $15: 00$ & 22,1 & 17,4 & 18,2 & \multicolumn{3}{|c|}{21,8} & 21,9 & \\
\hline
\end{tabular}

Tabela 196: Resultados coletados in loco no quarto do Apartamento H no mês de Junho de 2014.

\begin{tabular}{|c|c|c|c|c|c|c|c|c|}
\hline \multicolumn{2}{|l|}{ Apartamento $\mathrm{H}$} & \multicolumn{4}{|c|}{ Dados coletados CONFORTIMMETRO Julho 2013 - SALA } & \multicolumn{3}{|c|}{ Nublado } \\
\hline Intervalo & $\begin{array}{l}\text { Temperatura de } \\
\text { bulbo úmido }\left({ }^{\circ} \mathrm{C}\right)\end{array}$ & $\begin{array}{c}\text { Temperatura de } \\
\text { globo }\left({ }^{\circ} \mathrm{C}\right)\end{array}$ & $\begin{array}{c}\text { Temperatura do ar } \\
\left({ }^{\circ} \mathrm{C}\right)\end{array}$ & $\begin{array}{c}\text { Pressão Atmosférica } \\
\text { (atm) }\end{array}$ & $\begin{array}{c}\text { Umidade relativa } \\
\text { do ar (\%) }\end{array}$ & $\begin{array}{l}\text { Velocidade do ar } \\
\qquad(\mathrm{m} / \mathrm{s})\end{array}$ & $\begin{array}{l}\text { Temperatura } \\
\text { radiante }\left({ }^{\circ} \mathrm{C}\right)\end{array}$ & $\begin{array}{l}\text { Temperatura } \\
\text { Operativa }\left({ }^{\circ} \mathrm{C}\right)\end{array}$ \\
\hline $15: 00$ as $15: 30$ & 14,7 & 18,9 & 18,5 & 1022,6 & 57,1 & 0,0 & 19,0 & 18,7 \\
\hline $15: 30$ as $16: 00$ & 15,1 & 19,0 & 18,7 & 1022,2 & 58,8 & 0,0 & 19,1 & 18,9 \\
\hline $15: 30$ as $16: 00$ & 15,3 & 19,1 & 18,8 & 1022,3 & 59,7 & 0,0 & 19,2 & 19,0 \\
\hline $16: 30$ as $17: 00$ & 15,4 & 19,2 & 18,9 & 1022,5 & 59,6 & 0,0 & 19,3 & 19,1 \\
\hline Desvio Padrão & 0,29 & 0,14 & 0,15 & 0,21 & 1,20 & 0,01 & 0,14 & 0,1 \\
\hline Média & 15,1 & 19,0 & 18,7 & 1022,4 & 58,7 & 0,0 & 19,1 & 18,9 \\
\hline \multicolumn{8}{|c|}{ Dados coletados Termômetro de fluxo de laser } & \\
\hline Horário/Quarto & Temp. Externa do ar & $\begin{array}{c}\text { Temp. Paredes } \\
\text { externas }\end{array}$ & $\begin{array}{c}\text { Temp.Paredes } \\
\text { voltada para a rua }\end{array}$ & \multicolumn{3}{|c|}{ Temp. Média das paredes } & Temp. Teto & \\
\hline $15: 00$ & 16,5 & 17,1 & 17 & \multicolumn{3}{|c|}{16,7} & 17,4 & \\
\hline $17: 00$ & 17 & 17,2 & 17,3 & \multicolumn{3}{|c|}{17} & 17,5 & \\
\hline
\end{tabular}

Tabela 197: Resultados coletados in loco na sala do Apartamento H no mês de Julho de 2013.

\begin{tabular}{|c|c|c|c|c|c|c|c|c|}
\hline \multicolumn{2}{|l|}{ Apartamento $\mathrm{H}$} & \multicolumn{4}{|c|}{ Dados coletados CONFORTÍMETRO Agosto 2013 - SALA } & \multicolumn{3}{|c|}{ Céu claro } \\
\hline Intervalo & $\begin{array}{l}\text { Temperatura de } \\
\text { bulbo úmido }\left({ }^{\circ} \mathrm{C}\right)\end{array}$ & $\begin{array}{c}\text { Temperatura de } \\
\text { globo }\left({ }^{\circ} \mathrm{C}\right)\end{array}$ & $\begin{array}{c}\text { Temperatura do ar } \\
\left({ }^{\circ} \mathrm{C}\right)\end{array}$ & $\begin{array}{c}\text { Pressão Atmosférica } \\
\text { (atm) }\end{array}$ & $\begin{array}{c}\text { Umidade relativa } \\
\text { do } \operatorname{ar}(\%)\end{array}$ & $\begin{array}{l}\text { Velocidade do ar } \\
(\mathrm{m} / \mathrm{s})\end{array}$ & $\begin{array}{l}\text { Temperatura } \\
\text { radiante }\left({ }^{\circ} \mathrm{C}\right)\end{array}$ & $\begin{array}{l}\text { Temperatura } \\
\text { Operativa }\left({ }^{\circ} \mathrm{C}\right)\end{array}$ \\
\hline $15: 00$ as $15: 30$ & 19,6 & 23,2 & 23,1 & 1019,3 & 65,2 & 0,0 & 23,3 & 23,2 \\
\hline $15: 30$ as $16: 00$ & 19,5 & 22,7 & 22,6 & 1019,0 & 66,6 & 0,0 & 22,8 & 22,7 \\
\hline $15: 30$ as $16: 00$ & 19,3 & 22,4 & 22,2 & 1018,7 & 68,0 & 0,0 & 22,4 & 22,3 \\
\hline $16: 30$ as $17: 00$ & 19,2 & 22,2 & 22,0 & 1018,5 & 68,3 & 0,0 & 22,3 & 22,2 \\
\hline Desvio Padrão & 0,14 & 0,39 & 0,41 & 0,29 & 1,27 & 0,02 & 0,39 & 0,4 \\
\hline Média & 19,4 & 22,6 & 22,4 & 1018,8 & 67,2 & 0,0 & 22,6 & 22,5 \\
\hline \multicolumn{8}{|c|}{ Dados coletados Termômetro de fluxo de laser } & \\
\hline Horário/Quarto & Temp. Externa do ar & $\begin{array}{c}\text { Temp. Paredes } \\
\text { externas }\end{array}$ & $\begin{array}{c}\text { Temp.Paredes } \\
\text { voltada para a rua }\end{array}$ & \multicolumn{3}{|c|}{ Temp. Média das paredes } & Temp. Teto & \\
\hline $15: 00$ & 26,2 & 23 & 23,2 & \multicolumn{3}{|c|}{23,1} & 23,3 & \\
\hline $17: 00$ & 23,6 & 23,5 & 23,8 & \multicolumn{3}{|c|}{23,7} & 23,8 & \\
\hline
\end{tabular}

Tabela 198: Resultados coletados in loco na sala do Apartamento H no mês de Agosto de 2013.

\begin{tabular}{|c|c|c|c|c|c|c|c|c|}
\hline \multicolumn{2}{|l|}{ Apartamento $\mathrm{H}$} & \multicolumn{4}{|c|}{ Dados coletados CONFORTÍM ETRO Setembro 2013 - SALA } & \multicolumn{3}{|c|}{ Céu claro } \\
\hline Intervalo & $\begin{array}{l}\text { Temperatura de } \\
\text { bulbo úmido }\left({ }^{\circ} \mathrm{C}\right)\end{array}$ & $\begin{array}{c}\text { Temperatura de } \\
\text { globo }\left({ }^{\circ} \mathrm{C}\right)\end{array}$ & $\begin{array}{c}\text { Temperatura do ar } \\
\left({ }^{\circ} \mathrm{C}\right)\end{array}$ & $\begin{array}{c}\text { Pressão Atmosférica } \\
\text { (atm) }\end{array}$ & $\begin{array}{c}\text { Umidade relativa } \\
\text { do } \operatorname{ar}(\%)\end{array}$ & $\begin{array}{l}\text { Velocidade do ar } \\
(\mathrm{m} / \mathrm{s})\end{array}$ & $\begin{array}{l}\text { Temperatura } \\
\text { radiante }\left({ }^{\circ} \mathrm{C}\right)\end{array}$ & $\begin{array}{l}\text { Temperatura } \\
\text { Operativa }\left({ }^{\circ} \mathrm{C}\right)\end{array}$ \\
\hline $15: 00$ as $15: 30$ & 21,4 & 26,9 & 27,3 & 1003,3 & 51,7 & 0,1 & 26,5 & 26,9 \\
\hline $15: 30$ as $16: 00$ & 21,3 & 26,9 & 27,3 & 1003,6 & 52,0 & 0,1 & 26,4 & 26,8 \\
\hline $15: 30$ as $16: 00$ & 21,5 & 26,4 & 26,8 & 1004,0 & 55,4 & 0,0 & 26,3 & 26,5 \\
\hline $16: 30$ as $17: 00$ & 21,1 & 25,6 & 26,0 & 1004,7 & 57,9 & 0,0 & 25,4 & 25,7 \\
\hline Desvio Padrão & 0,27 & 0,58 & 0,60 & 0,48 & 2,58 & 0,06 & 0,57 & 0,6 \\
\hline Média & 21,2 & 26,1 & 26,5 & 1004,3 & 56,0 & 0,0 & 25,8 & 26,2 \\
\hline \multicolumn{8}{|c|}{ Dados coletados Termômetro de fluxo de laser } & \\
\hline Horário/Quarto & Temp. Externa do ar & $\begin{array}{l}\text { Temp. Paredes } \\
\text { externas }\end{array}$ & $\begin{array}{c}\text { Temp. Paredes } \\
\text { voltada para a rua }\end{array}$ & \multicolumn{3}{|c|}{ Temp. Média das paredes } & Temp. Teto & \\
\hline 15:00 & 28 & 28 & 27 & \multicolumn{3}{|c|}{25,8} & 26,2 & \\
\hline $17: 00$ & 29 & 29 & 29,1 & \multicolumn{3}{|c|}{26,7} & 26,7 & \\
\hline
\end{tabular}

Tabela 199: Resultados coletados in loco na sala do Apartamento H no mês de Setembro de 2013.

\begin{tabular}{|c|c|c|c|c|c|c|c|c|}
\hline \multicolumn{2}{|l|}{ Apartamento H } & \multicolumn{4}{|c|}{ Dados coletados CONFORTímETRO Outubro 2013 - SALA } & \multicolumn{3}{|c|}{ Nublado } \\
\hline Intervalo & $\begin{array}{l}\text { Temperatura de } \\
\text { bulbo úmido }\left({ }^{\circ} \mathrm{C}\right)\end{array}$ & $\begin{array}{c}\text { Temperatura de } \\
\text { globo }\left({ }^{\circ} \mathrm{C}\right)\end{array}$ & $\begin{array}{c}\text { Temperatura do ar } \\
\left({ }^{\circ} \mathrm{C}\right)\end{array}$ & $\begin{array}{c}\text { Pressão Atmosférica } \\
\text { (atm) }\end{array}$ & $\begin{array}{c}\text { Umidade relativa } \\
\text { do ar (\%) }\end{array}$ & $\begin{array}{l}\text { Velocidade do ar } \\
\qquad(\mathrm{m} / \mathrm{s})\end{array}$ & $\begin{array}{l}\text { Temperatura } \\
\text { radiante }\left({ }^{\circ} \mathrm{C}\right)\end{array}$ & $\begin{array}{l}\text { Temperatura } \\
\text { Operativa }\left({ }^{\circ} \mathrm{C}\right)\end{array}$ \\
\hline $16: 00$ as $16: 30$ & 18,8 & 24,9 & 24,6 & 1014,6 & 49,5 & 0,1 & 25,1 & 24,9 \\
\hline $16: 30$ as $17: 00$ & 19,2 & 25,2 & 24,9 & 1014,3 & 50,5 & 0,0 & 25,2 & 25,1 \\
\hline $17: 00$ as $17: 30$ & 19,2 & 25,0 & 24,8 & 1014,1 & 50,6 & 0,0 & 25,1 & 24,9 \\
\hline $17: 30$ as $18: 00$ & 19,0 & 25,2 & 24,9 & 1014,2 & 50,6 & 0,0 & 25,4 & 25,1 \\
\hline Desvio Padrão & 0,32 & 0,16 & 0,16 & 0,20 & 0,57 & 0,06 & 0,20 & 0,2 \\
\hline Média & 19,1 & 25,1 & 24,8 & 1014,3 & 50,3 & 0,0 & 25,2 & 25,0 \\
\hline \multicolumn{8}{|c|}{ Dados coletados Termômetro de fluxo de laser } & \\
\hline Horário/Quarto & Temp. Externa do ar & $\begin{array}{c}\text { Temp. Paredes } \\
\text { externas }\end{array}$ & $\begin{array}{c}\text { Temp.Paredes } \\
\text { voltada para a rua }\end{array}$ & \multicolumn{3}{|c|}{ Temp. Média das paredes } & Temp. Teto & \\
\hline $16: 00$ & 23,8 & 24,9 & 23,9 & \multicolumn{3}{|c|}{24,6} & 25,3 & \\
\hline $18: 00$ & 23,5 & 23,7 & 25,1 & \multicolumn{3}{|c|}{25,2} & 26,1 & \\
\hline
\end{tabular}

Tabela 200: Resultados coletados in loco na sala do Apartamento H no mês de Outubro de 2013. 


\begin{tabular}{|c|c|c|c|c|c|c|c|c|}
\hline \multicolumn{2}{|l|}{ Apartamento $\mathrm{H}$} & \multicolumn{4}{|c|}{ Dados coletados CONFORTíMETRO Novembro 2013 - SALA } & \multicolumn{3}{|c|}{ Céu claro } \\
\hline Intervalo & $\begin{array}{l}\text { Temperatura de } \\
\text { bulbo úmido }\left({ }^{\circ} \mathrm{C}\right)\end{array}$ & $\begin{array}{c}\text { Temperatura de } \\
\text { globo }\left({ }^{\circ} \mathrm{C}\right)\end{array}$ & $\begin{array}{c}\text { Temperatura do ar } \\
\left({ }^{\circ} \mathrm{C}\right)\end{array}$ & $\begin{array}{c}\text { Pressão Atmosférica } \\
\text { (atm) }\end{array}$ & $\begin{array}{c}\text { Umidade relativa } \\
\text { do ar (\%) }\end{array}$ & $\begin{array}{l}\text { Velocidade do ar } \\
\qquad(\mathrm{m} / \mathrm{s})\end{array}$ & $\begin{array}{l}\text { Temperatura } \\
\text { radiante }\left({ }^{\circ} \mathrm{C}\right)\end{array}$ & $\begin{array}{l}\text { Temperatura } \\
\text { Operativa }\left({ }^{\circ} \mathrm{C}\right)\end{array}$ \\
\hline $16: 00$ as $16: 30$ & 22,6 & 27,1 & 26,9 & 1010,9 & 61,8 & 0,0 & 27,2 & 27,0 \\
\hline $16: 30$ as $17: 00$ & 22,2 & 26,7 & 26,5 & 1010,8 & 61,0 & 0,0 & 26,8 & 26,7 \\
\hline $17: 00$ as $17: 30$ & 22,2 & 26,5 & 26,4 & 1010,6 & 61,4 & 0,0 & 26,6 & 26,5 \\
\hline $17: 30$ as $18: 00$ & 22,3 & 26,5 & 26,3 & 1010,6 & 62,9 & 0,0 & 26,6 & 26,4 \\
\hline Desvio Padrão & 0,19 & 0,25 & 0,25 & 0,13 & 0,77 & 0,02 & 0,27 & 0,3 \\
\hline Média & 22,3 & 26,7 & 26,5 & 1010,7 & 61,8 & 0,0 & 26,8 & 26,7 \\
\hline \multicolumn{8}{|c|}{ Dados coletados Termômetro de fluxo de laser } & \\
\hline Horário/Quarto & Temp. Externa do ar & $\begin{array}{c}\text { Temp. Paredes } \\
\text { externas }\end{array}$ & $\begin{array}{c}\text { Temp.Paredes } \\
\text { voltada para a rua }\end{array}$ & \multicolumn{3}{|c|}{ Temp. Média das paredes } & Temp. Teto & \\
\hline $16: 00$ & 32,3 & 31,7 & 26,2 & \multicolumn{3}{|c|}{26,1} & 26,4 & \\
\hline $18: 00$ & 26 & 27,6 & 27,2 & \multicolumn{3}{|c|}{25,8} & 26,1 & \\
\hline
\end{tabular}

Tabela 201: Resultados coletados in loco na sala do Apartamento H no mês de Novembro de 2013.

\begin{tabular}{|c|c|c|c|c|c|c|c|c|}
\hline \multicolumn{2}{|l|}{ Apartamento $\mathrm{H}$} & \multicolumn{4}{|c|}{ Dados coletados CONFORTÍMETRO Dezembro 2013 - SALA } & \multicolumn{3}{|c|}{$\begin{array}{c}\text { Parcialmente } \\
\text { nublado }\end{array}$} \\
\hline Intervalo & $\begin{array}{l}\text { Temperatura de } \\
\text { bulbo úmido }\left({ }^{\circ} \mathrm{C}\right)\end{array}$ & $\begin{array}{c}\text { Temperatura de } \\
\text { globo }\left({ }^{\circ} \mathrm{C}\right)\end{array}$ & $\begin{array}{c}\text { Temperatura do ar } \\
\left({ }^{\circ} \mathrm{C}\right)\end{array}$ & $\begin{array}{c}\text { Pressão Atmosférica } \\
\text { (atm) }\end{array}$ & $\begin{array}{c}\text { Umidade relativa } \\
\text { do ar (\%) }\end{array}$ & $\begin{array}{l}\text { Velocidade do ar } \\
\qquad(\mathrm{m} / \mathrm{s})\end{array}$ & $\begin{array}{l}\text { Temperatura } \\
\text { radiante }\left({ }^{\circ} \mathrm{C}\right)\end{array}$ & $\begin{array}{l}\text { Temperatura } \\
\text { Operativa }\left({ }^{\circ} \mathrm{C}\right)\end{array}$ \\
\hline $16: 00$ as $16: 30$ & 24,2 & 27,3 & 27,2 & 1004,8 & 73,6 & 0,0 & 27,4 & 27,3 \\
\hline $16: 30$ as $17: 00$ & 24,4 & 27,4 & 27,2 & 1004,9 & 73,7 & 0,0 & 27,5 & 27,3 \\
\hline $17: 00$ as $17: 30$ & 24,2 & 27,4 & 27,2 & 1005,1 & 73,5 & 0,2 & 27,6 & 27,4 \\
\hline $17: 30$ as $18: 00$ & 24,2 & 27,5 & 27,3 & 1005,0 & 73,1 & 0,1 & 27,6 & 27,4 \\
\hline Desvio Padrão & 0,15 & 0,10 & 0,11 & 0,10 & 0,46 & 0,21 & 0,19 & 0,2 \\
\hline Média & 24,2 & 27,4 & 27,3 & 1005,0 & 73,2 & 0,1 & 27,6 & 27,4 \\
\hline \multicolumn{8}{|c|}{ Dados coletados Termômetro de fluxo de laser } & \\
\hline Horário/Quarto & Temp. Externa do ar & $\begin{array}{c}\text { Temp. Paredes } \\
\text { externas }\end{array}$ & $\begin{array}{c}\text { Temp.Paredes } \\
\text { voltada para a rua }\end{array}$ & \multicolumn{3}{|c|}{ Temp. Média das paredes } & Temp. Teto & \\
\hline $16: 00$ & 27,1 & 29,5 & 27,8 & \multicolumn{3}{|c|}{27,2} & 27,9 & \\
\hline $18: 00$ & 26,8 & 28,1 & 27,9 & \multicolumn{3}{|c|}{27,3} & 28,1 & \\
\hline
\end{tabular}

Tabela 202: Resultados coletados in loco na sala do Apartamento H no mês de Dezembro de 2013.

\begin{tabular}{|c|c|c|c|c|c|c|c|c|}
\hline \multicolumn{7}{|c|}{ Dados coletados CONFORTÍMETRO Janeiro 2014 - SALA } & \multicolumn{2}{|l|}{$\begin{array}{l}\text { Parcialmente } \\
\text { nublado }\end{array}$} \\
\hline Intervalo & $\begin{array}{l}\text { Temperatura de } \\
\text { bulbo úmido }\left({ }^{\circ} \mathrm{C}\right)\end{array}$ & $\begin{array}{c}\text { Temperatura de } \\
\text { globo }\left({ }^{\circ} \mathrm{C}\right)\end{array}$ & $\begin{array}{c}\text { Temperatura do ar } \\
\left({ }^{\circ} \mathrm{C}\right)\end{array}$ & $\begin{array}{c}\text { Pressão Atmosférica } \\
\text { (atm) }\end{array}$ & $\begin{array}{c}\text { Umidade relativa } \\
\text { do ar (\%) }\end{array}$ & $\begin{array}{l}\text { Velocidade do ar } \\
\qquad(\mathrm{m} / \mathrm{s})\end{array}$ & $\begin{array}{l}\text { Temperatura } \\
\text { radiante }\left({ }^{\circ} \mathrm{C}\right)\end{array}$ & $\begin{array}{l}\text { Temperatura } \\
\text { Operativa }\left({ }^{\circ} \mathrm{C}\right)\end{array}$ \\
\hline $16: 00$ as $16: 30$ & 26,9 & 32,8 & 32,5 & 1012,1 & 58,9 & 0,1 & 33,0 & 32,8 \\
\hline $16: 30$ as $17: 00$ & 27,0 & 32,7 & 32,5 & 1011,9 & 60,0 & 0,1 & 32,9 & 32,7 \\
\hline $17: 00$ as $17: 30$ & 26,9 & 32,5 & 32,3 & 1011,7 & 60,9 & 0,1 & 32,8 & 32,5 \\
\hline $17: 30$ as $18: 00$ & 26,8 & 32,4 & 32,1 & 1011,5 & 60,9 & 0,1 & 32,6 & 32,3 \\
\hline Desvio Padrão & 0,13 & 0,17 & 0,20 & 0,25 & 0,88 & 0,06 & 0,20 & 0,2 \\
\hline Média & 26,9 & 32,6 & 32,4 & 1011,8 & 60,1 & 0,1 & 32,8 & 32,6 \\
\hline \multicolumn{9}{|c|}{ Dados coletados Termômetro de fluxo de laser } \\
\hline Horário/Quarto & Temp. Externa do ar & $\begin{array}{l}\text { Temp. Paredes } \\
\text { externas }\end{array}$ & $\begin{array}{c}\text { Temp.Paredes } \\
\text { voltada para a rua }\end{array}$ & \multicolumn{3}{|c|}{ Temp. Média das paredes } & Temp. Teto & \\
\hline $16: 00$ & 34 & 41,9 & 33,4 & \multicolumn{3}{|c|}{33} & 33,2 & \\
\hline $18: 00$ & 32,2 & 34,2 & 33,8 & \multicolumn{3}{|c|}{33,1} & 33,6 & \\
\hline
\end{tabular}

Tabela 203: Resultados coletados in loco na sala do Apartamento H no mês de Janeiro de 2014.

\begin{tabular}{|c|c|c|c|c|c|c|c|c|}
\hline \multicolumn{2}{|l|}{ Apartamento $\mathrm{H}$} & \multicolumn{4}{|c|}{ Dados coletados CONFORTÍMETRO Fevereiro 2014 - SALA } & \multicolumn{3}{|c|}{ Céu claro } \\
\hline Intervalo & $\begin{array}{l}\text { Temperatura de } \\
\text { bulbo úmido }\left({ }^{\circ} \mathrm{C}\right)\end{array}$ & $\begin{array}{c}\text { Temperatura de } \\
\text { globo }\left({ }^{\circ} \mathrm{C}\right)\end{array}$ & $\begin{array}{c}\text { Temperatura do ar } \\
\left({ }^{\circ} \mathrm{C}\right)\end{array}$ & $\begin{array}{c}\text { Pressão Atmosférica } \\
\text { (atm) }\end{array}$ & $\begin{array}{c}\text { Umidade relativa } \\
\text { do } \operatorname{ar}(\%)\end{array}$ & $\begin{array}{l}\text { Velocidade do ar } \\
\qquad(\mathrm{m} / \mathrm{s})\end{array}$ & $\begin{array}{l}\text { Temperatura } \\
\text { radiante }\left({ }^{\circ} \mathrm{C}\right)\end{array}$ & $\begin{array}{l}\text { Temperatura } \\
\text { Operativa }\left({ }^{\circ} \mathrm{C}\right)\end{array}$ \\
\hline $15: 00$ as $15: 30$ & 24,7 & 29,4 & 29,3 & 1010,7 & 60,6 & 0,0 & 29,5 & 29,4 \\
\hline $15: 30$ as $16: 00$ & 24,5 & 29,5 & 29,3 & 1010,2 & 60,0 & 0,0 & 29,5 & 29,4 \\
\hline $15: 30$ as $16: 00$ & 24,1 & 29,3 & 29,2 & 1009,9 & 59,9 & 0,1 & 29,3 & 29,2 \\
\hline $16: 30$ as $17: 00$ & 24,1 & 29,2 & 29,1 & 1009,7 & 60,9 & 0,2 & 29,3 & 29,2 \\
\hline Desvio Padrão & 0,30 & 0,13 & 0,11 & 0,39 & 0,68 & 0,12 & 0,14 & 0,1 \\
\hline Média & 24,4 & 29,3 & 29,2 & 1010,1 & 60,4 & 0,1 & 29,4 & 29,3 \\
\hline \multicolumn{8}{|c|}{ Dados coletados Termômetro de fluxo de laser } & \\
\hline Horário/Quarto & Temp. Externa do ar & $\begin{array}{l}\text { Temp. Paredes } \\
\text { externas }\end{array}$ & $\begin{array}{c}\text { Temp.Paredes } \\
\text { voltada para a rua }\end{array}$ & \multicolumn{3}{|c|}{ Temp. Média das paredes } & Temp. Teto & \\
\hline $15: 00$ & 37,7 & 39,8 & 31,8 & \multicolumn{3}{|c|}{28,3} & 29,2 & \\
\hline $17: 00$ & 30 & 34,8 & 33,6 & \multicolumn{3}{|c|}{29,1} & 29,7 & \\
\hline
\end{tabular}

Tabela 204: Resultados coletados in loco na sala do Apartamento H no mês de Fevereiro de 2014. 


\begin{tabular}{|c|c|c|c|c|c|c|c|c|}
\hline \multicolumn{2}{|l|}{ Apartamento $\mathrm{H}$} & \multicolumn{4}{|c|}{ Dados coletados CONFORTIM ETRO Março 2014 - SALA } & \multicolumn{3}{|c|}{ Chuva } \\
\hline Intervalo & $\begin{array}{l}\text { Temperatura de } \\
\text { bulbo úmido }\left({ }^{\circ} \mathrm{C}\right)\end{array}$ & $\begin{array}{c}\text { Temperatura de } \\
\text { globo }\left({ }^{\circ} \mathrm{C}\right)\end{array}$ & $\begin{array}{c}\text { Temperatura do ar } \\
\left({ }^{\circ} \mathrm{C}\right)\end{array}$ & $\begin{array}{c}\text { Pressão Atmosférica } \\
\text { (atm) }\end{array}$ & $\begin{array}{c}\text { Umidade relativa } \\
\text { do ar (\%) }\end{array}$ & $\begin{array}{l}\text { Velocidade do ar } \\
(\mathrm{m} / \mathrm{s})\end{array}$ & $\begin{array}{l}\text { Temperatura } \\
\text { radiante }\left({ }^{\circ} \mathrm{C}\right)\end{array}$ & $\begin{array}{l}\text { Temperatura } \\
\text { Operativa }\left({ }^{\circ} \mathrm{C}\right)\end{array}$ \\
\hline $15: 00$ as $15: 30$ & 24,4 & 27,2 & 26,9 & 1016,5 & 75,3 & 0,0 & 27,2 & 27,1 \\
\hline $15: 30$ as $16: 00$ & 24,4 & 27,1 & 26,9 & 1016,4 & 74,8 & 0,0 & 27,2 & 27,1 \\
\hline $15: 30$ as $16: 00$ & 24,4 & 27,1 & 26,9 & 1016,5 & 75,4 & 0,0 & 27,2 & 27,1 \\
\hline $16: 30$ as $17: 00$ & 24,4 & 27,0 & 26,8 & 1016,5 & 75,6 & 0,0 & 27,1 & 27,0 \\
\hline Desvio Padrão & 0,06 & 0,06 & 0,05 & 0,06 & 0,51 & 0,01 & 0,06 & 0,1 \\
\hline Média & 24,4 & 27,1 & 26,9 & 1016,5 & 75,3 & 0,0 & 27,2 & 27,0 \\
\hline \multicolumn{8}{|c|}{ Dados coletados Termômetro de fluxo de laser } & \\
\hline Horário/Quarto & Temp. Externa do ar & $\begin{array}{c}\text { Temp. Paredes } \\
\text { externas }\end{array}$ & $\begin{array}{c}\text { Temp.Paredes } \\
\text { voltada para a rua }\end{array}$ & \multicolumn{3}{|c|}{ Temp. Média das paredes } & Temp. Teto & \\
\hline 15:00 & 26,4 & 24,6 & 26,7 & \multicolumn{3}{|c|}{27,4} & 27,6 & \\
\hline $17: 00$ & 24,8 & 23,6 & 23,6 & \multicolumn{3}{|c|}{28,1} & 28,6 & \\
\hline
\end{tabular}

Tabela 205: Resultados coletados in loco na sala do Apartamento H no mês de Março de 2014.

\begin{tabular}{|c|c|c|c|c|c|c|c|c|}
\hline \multicolumn{2}{|l|}{ Apartamento $\mathrm{H}$} & \multicolumn{4}{|c|}{ Dados coletados CONFORTím ETRO Abril 2014 - SALA } & \multicolumn{3}{|c|}{$\begin{array}{c}\text { Parcialmente } \\
\text { aberto }\end{array}$} \\
\hline Intervalo & $\begin{array}{l}\text { Temperatura de } \\
\text { bulbo úmido }\left({ }^{\circ} \mathrm{C}\right)\end{array}$ & $\begin{array}{c}\text { Temperatura de } \\
\text { globo }\left({ }^{\circ} \mathrm{C}\right)\end{array}$ & $\begin{array}{c}\text { Temperatura do ar } \\
\left({ }^{\circ} \mathrm{C}\right)\end{array}$ & $\begin{array}{c}\text { Pressão Atmosférica } \\
\text { (atm) }\end{array}$ & $\begin{array}{c}\text { Umidade relativa } \\
\text { do ar (\%) }\end{array}$ & $\begin{array}{l}\text { Velocidade do ar } \\
(\mathrm{m} / \mathrm{s})\end{array}$ & $\begin{array}{l}\text { Temperatura } \\
\text { radiante }\left({ }^{\circ} \mathrm{C}\right)\end{array}$ & $\begin{array}{l}\text { Temperatura } \\
\text { Operativa }\left({ }^{\circ} \mathrm{C}\right)\end{array}$ \\
\hline $15: 00$ as $15: 30$ & 21,0 & 24,4 & 24,2 & 1012,8 & 70,3 & 0,0 & 24,5 & 24,4 \\
\hline $15: 30$ as $16: 00$ & 21,0 & 24,3 & 24,1 & 1012,8 & 70,1 & 0,0 & 24,3 & 24,2 \\
\hline $15: 30$ as $16: 00$ & 20,9 & 24,2 & 24,0 & 1013,0 & 69,2 & 0,0 & 24,2 & 24,1 \\
\hline $16: 30$ as $17: 00$ & 20,8 & 24,2 & 24,0 & 1013,1 & 69,4 & 0,0 & 24,2 & 24,1 \\
\hline Desvio Padrão & 0,12 & 0,10 & 0,10 & 0,15 & 0,61 & 0,05 & 0,12 & 0,1 \\
\hline Média & 20,9 & 24,2 & 24,1 & 1012,9 & 69,8 & 0,0 & 24,3 & 24,2 \\
\hline \multicolumn{8}{|c|}{ Dados coletados Termômetro de fluxo de laser } & \\
\hline Horário/Quarto & Temp. Externa do ar & $\begin{array}{c}\text { Temp. Paredes } \\
\text { externas }\end{array}$ & $\begin{array}{c}\text { Temp.Paredes } \\
\text { voltada para a rua }\end{array}$ & \multicolumn{3}{|c|}{ Temp. Média das paredes } & Temp. Teto & \\
\hline 15:00 & 25,5 & 23,3 & 23,9 & \multicolumn{3}{|c|}{23,7} & 24,3 & \\
\hline $17: 00$ & 25,4 & 23 & 24,1 & \multicolumn{3}{|c|}{24,6} & 24,7 & \\
\hline
\end{tabular}

Tabela 206: Resultados coletados in loco na sala do Apartamento H no mês de Abril de 2014.

\begin{tabular}{|c|c|c|c|c|c|c|c|c|}
\hline \multicolumn{2}{|l|}{ Apartamento $\mathrm{H}$} & \multicolumn{4}{|c|}{ Dados coletados CONFORTíM ETRO Maio 2014 - SALA } & \multicolumn{3}{|c|}{$\begin{array}{l}\text { Parcialmente } \\
\text { aberto }\end{array}$} \\
\hline Intervalo & $\begin{array}{l}\text { Temperatura de } \\
\text { bulbo úmido }\left({ }^{\circ} \mathrm{C}\right)\end{array}$ & $\begin{array}{c}\text { Temperatura de } \\
\text { globo }\left({ }^{\circ} \mathrm{C}\right)\end{array}$ & $\begin{array}{c}\text { Temperatura do ar } \\
\left({ }^{\circ} \mathrm{C}\right)\end{array}$ & $\begin{array}{c}\text { Pressão Atmosférica } \\
\text { (atm) }\end{array}$ & $\begin{array}{c}\text { Umidade relativa } \\
\text { do } \operatorname{ar}(\%)\end{array}$ & $\begin{array}{l}\text { Velocidade do ar } \\
\qquad(\mathrm{m} / \mathrm{s})\end{array}$ & $\begin{array}{l}\text { Temperatura } \\
\text { radiante }\left({ }^{\circ} \mathrm{C}\right)\end{array}$ & $\begin{array}{l}\text { Temperatura } \\
\text { Operativa }\left({ }^{\circ} \mathrm{C}\right)\end{array}$ \\
\hline $15: 00$ as $15: 30$ & 21,0 & 24,4 & 24,2 & 1012,8 & 70,3 & 0,0 & 24,5 & 24,4 \\
\hline $15: 30$ as $16: 00$ & 21,0 & 24,3 & 24,1 & 1012,8 & 70,1 & 0,0 & 24,3 & 24,2 \\
\hline $15: 30$ as $16: 00$ & 21,0 & 24,2 & 24,1 & 1012,9 & 69,5 & 0,0 & 24,2 & 24,1 \\
\hline $16: 30$ as $17: 00$ & 21,0 & 24,3 & 24,1 & 1012,9 & 68,9 & 0,0 & 24,1 & 24,1 \\
\hline Desvio Padrão & 0,08 & 0,08 & 0,08 & 0,10 & 0,67 & 0,04 & 0,15 & 0,1 \\
\hline Média & 21,0 & 24,3 & 24,1 & 1012,8 & 69,7 & 0,0 & 24,3 & 24,2 \\
\hline \multicolumn{8}{|c|}{ Dados coletados Termômetro de fluxo de laser } & \\
\hline Horário/Quarto & Temp. Externa do ar & $\begin{array}{c}\text { Temp. Paredes } \\
\text { externas }\end{array}$ & $\begin{array}{c}\text { Temp.Paredes } \\
\text { voltada para a rua }\end{array}$ & \multicolumn{3}{|c|}{ Temp. Média das paredes } & Temp. Teto & \\
\hline 15:00 & 25,4 & 23,3 & 23,5 & \multicolumn{3}{|c|}{23,7} & 24,3 & \\
\hline $17: 00$ & 25,5 & 23,1 & 24,1 & \multicolumn{3}{|c|}{24,7} & 24,7 & \\
\hline
\end{tabular}

Tabela 207: Resultados coletados in loco na sala do Apartamento H no mês de Maio de 2014.

\begin{tabular}{|c|c|c|c|c|c|c|c|c|}
\hline \multicolumn{2}{|l|}{ Apartamento $\mathrm{H}$} & \multicolumn{4}{|c|}{ Dados coletados CONFORTIM ETRO J unho 2014 - SALA } & \multicolumn{3}{|c|}{ Chuva } \\
\hline Intervalo & $\begin{array}{l}\text { Temperatura de } \\
\text { bulbo úmido }\left({ }^{\circ} \mathrm{C}\right)\end{array}$ & $\begin{array}{c}\text { Temperatura de } \\
\text { globo }\left({ }^{\circ} \mathrm{C}\right)\end{array}$ & $\begin{array}{c}\text { Temperatura do ar } \\
\left({ }^{\circ} \mathrm{C}\right)\end{array}$ & $\begin{array}{c}\text { Pressão Atmosférica } \\
\text { (atm) }\end{array}$ & $\begin{array}{c}\text { Umidade relativa } \\
\text { do } \operatorname{ar}(\%)\end{array}$ & $\begin{array}{l}\text { Velocidade do ar } \\
(\mathrm{m} / \mathrm{s})\end{array}$ & $\begin{array}{l}\text { Temperatura } \\
\text { radiante }\left({ }^{\circ} \mathrm{C}\right)\end{array}$ & $\begin{array}{l}\text { Temperatura } \\
\text { Operativa }\left({ }^{\circ} \mathrm{C}\right)\end{array}$ \\
\hline $15: 00$ as $15: 30$ & 19,0 & 21,5 & 20,9 & 1019,2 & 76,7 & 0,0 & 21,6 & 21,3 \\
\hline $15: 30$ as $16: 00$ & 19,0 & 21,4 & 21,0 & 1019,2 & 76,3 & 0,0 & 21,5 & 21,2 \\
\hline $15: 30$ as $16: 00$ & 19,0 & 21,5 & 21,2 & 1019,1 & 75,3 & 0,0 & 21,6 & 21,4 \\
\hline $16: 30$ as $17: 00$ & 19,0 & 21,4 & 21,1 & 1019,2 & 75,7 & 0,0 & 21,5 & 21,3 \\
\hline Desvio Padrão & 0,06 & 0,08 & 0,11 & 0,06 & 0,59 & 0,01 & 0,10 & 0,1 \\
\hline Média & 19,0 & 21,4 & 21,0 & 1019,2 & 76,0 & 0,0 & 21,5 & 21,3 \\
\hline \multicolumn{8}{|c|}{ Dados coletados Termômetro de fluxo de laser } & \\
\hline Horário/Quarto & Temp. Externa do ar & $\begin{array}{c}\text { Temp. Paredes } \\
\text { externas }\end{array}$ & $\begin{array}{c}\text { Temp.Paredes } \\
\text { voltada para a rua }\end{array}$ & \multicolumn{3}{|c|}{ Temp. M édia das paredes } & Temp. Teto & \\
\hline 15:00 & 22,1 & 17,4 & 20,2 & \multicolumn{3}{|c|}{21,7} & 22,2 & \\
\hline 17:00 & 23 & 17,8 & 22,6 & \multicolumn{3}{|c|}{23} & 23,1 & \\
\hline
\end{tabular}

Tabela 208: Resultados coletados in loco na sala do Apartamento H no mês de Junho de 2014. 